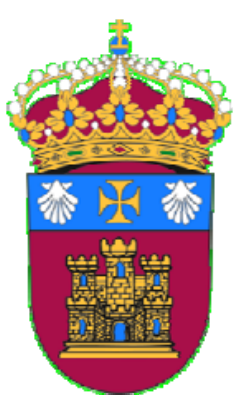

Universidad de Burgos

Departamento de Economía y Administración de Empresas

Área de Economía Financiera y Contabilidad

\title{
LA UTILIDAD DE LA INFORMACIÓN CONTABLE EN LA NEGOCIACION DE LOS CONVENIOS COLECTIVOS DE EMPRESA: APLICACIÓN A LAS EMPRESAS DE LA PROVINCIA DE BURGOS
}

por

Pablo Aguilar Conde

DIRECTORES: VALENTIN AZOFRA PALENZUELA BEGOÑA PRIETO MORENO 


\section{ÍNDICE GENERAL}

INTRODUCCIÓN .................................................................. 7

CAPÍTULO 1: MARCO TEÓRICO.......................................17

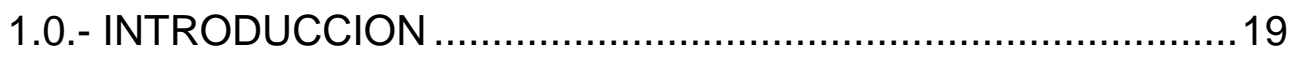

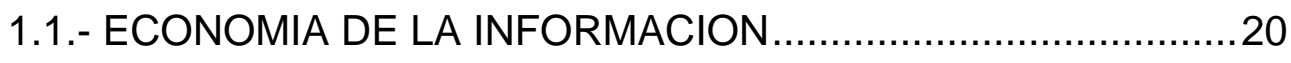

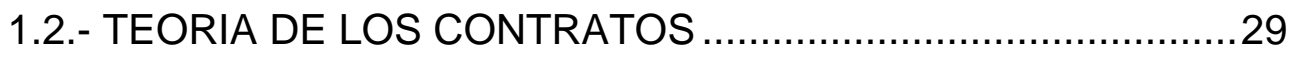

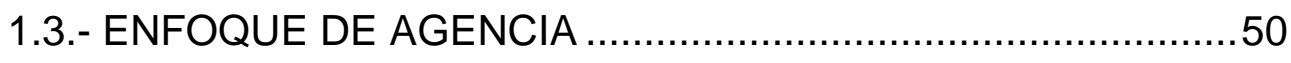

1.4.- LA ARQUITECTURA ORGANIZATIVA ................................ 72

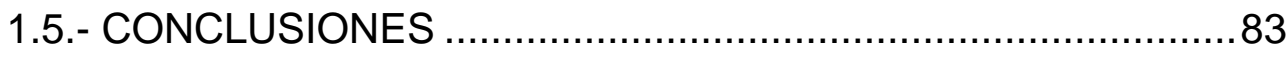

\section{CAPÍTULO 2: EL CONTRATO DE EMPLEO Y}

SUS GARANTÍAS EN EL DERECHO POSITIVO ....................87

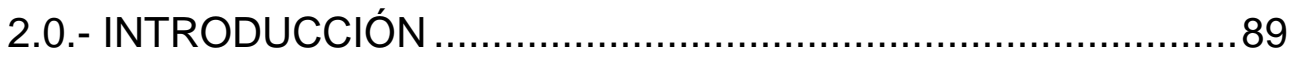

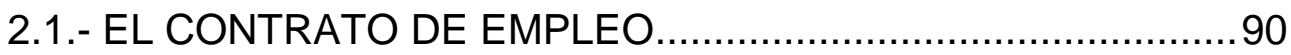

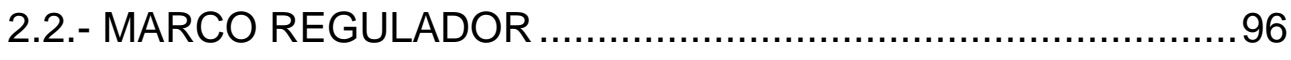

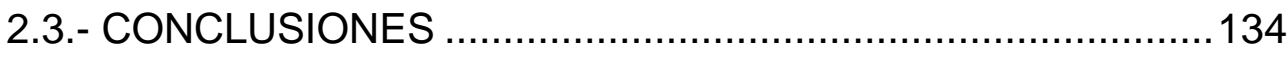




\section{CAPÍTULO 3: REVISIÓN DE LA LITERATURA TEÓRICA}

Y EMPÍRICA: ESTADO ACTUAL DE LA CUESTIÓN..........139

3.0.- INTRODUCCIÓN 141

3.1.- LA INFORMACIÓN CONTABLE COMO POSIBLE SOLUCIÓN EN LA RENEGOCIACIÓN DE LOS CONTRATOS: EVALUACIÓN DEL RENDIMIENTO Y MÉTODOS DE RECOMPENSA.

3.2.- LOS EMPLEADOS: USUARIOS DE LA INFORMACIÓN CONTABLE.

3.3.- QUE INFORMACIÓN CONTABLE SE SUMINISTRA A LOS EMPLEADOS

3.4.- CUANDO SE SUMINISTRA LA INFORMACIÓN CONTABLE A LOS EMPLEADOS

3.5.- REACCIÓN DE LOS EMPLEADOS ANTE LA INFORMACIÓN CONTABLE

3.6.- LA UTILIDAD DE LA INFORMACIÓN CONTABLE EN LAS RELACIONES LABORALES

3.7.- LA INFORMACION CONTABLE EN LAS RELACIONES INDUSTRIALES: CONOCIMIENTO MULTIDISCIPLINAR 183

3.8.- LA INFORMACION CONTABLE Y SU PAPEL

EN LA SOCIEDAD 185

3.9.- CONCLUSIONES 
CAPÍTULO 4: ANALÍSIS EXPLORATORIO

4.0.- INTRODUCCIÓN 197

4.1.- BREVE REVISIÓN EMPÍRICA 198

4.2.- MODELO PROPUESTO 204

4.3.- FUENTES DE INFORMACIÓN 206

4.4.- LA MUESTRA 208

4.5.- METODOLOGÍA 209

4.6.- RESULTADOS ANÁLISIS CONVENIOS Y ENCUESTAS (AÑO 2000) 211

4.7.- RESULTADOS ANÁLISIS CONVENIOS Y CUENTAS ANUALES (AÑOS 2002/2003 - 2013/2014).

CAPÍTULO 5: LA TEORÍA POSITIVA EN LAS RELACIONES

5.0.- INTRODUCCIÓN 235

5.1.- TEORÍA SUBYACENTE 236

5.2.- POSTULADOS GENERALES. 237

5.3.- METODOLOGÍA 239 


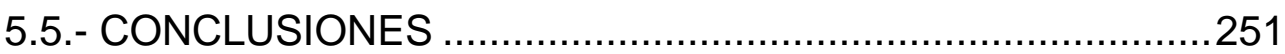

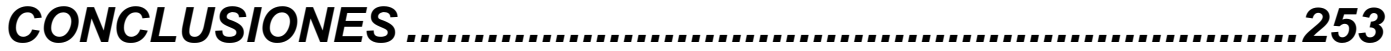

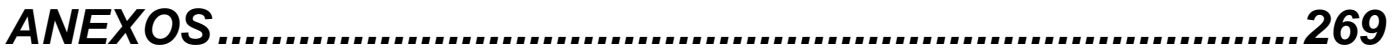

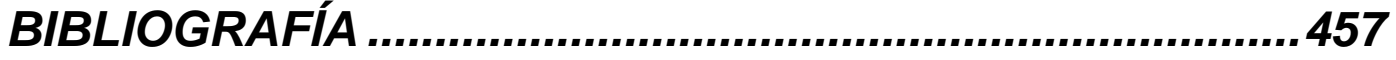




\section{INTRODUCCIÓN}


El propósito de este trabajo de investigación es valorar el uso que se hace de la información contable en la firma de los convenios colectivos de empresa; y, entre otros aspectos, verificar el papel que juega esta información contable, para establecer las subidas salariales y las remuneraciones variables pactadas en el convenio colectivo de empresa.

La realidad hasta ahora observada parece mostrarnos que hay una preponderancia a garantizar la recuperación del poder adquisitivo perdido por la inflación, con el establecimiento de unas cláusulas casi automáticas, que ajustan los salarios negociados en convenio colectivo con el IPC real. Sin embargo, si consideramos a los trabajadores como partícipes o stakeholders de la empresa, parecería más recomendable que se vinculara ese aumento/pérdida salarial con la situación económica de la empresa, lo que implicaría una vinculación entre cifras salariales y cifras económicas específicas; más si cabe en circunstancias como las actuales con inflación negativa.

Simultáneamente, intentamos verificar si las diferentes modalidades firmadas en convenio para cuantificar la revisión salarial, pueden tener un reflejo en la mejora o no de los datos económicos de las empresas y en los indicadores de generación de valor referentes a los recursos humanos.

Tomamos como hipótesis teóricas de partida la concepción de la empresa como un nexo de contratos y la divergencia de intereses a la hora de renegociar éstos -renegociación necesaria como consecuencia de la existencia de información incompleta y racionalidad limitada para determinar las cláusulas de los contratos -, la utilidad de la información contable como mecanismo capaz de reducir la asimetría de la información y la incertidumbre, que podría servir para fomentar la participación de los trabajadores y facilitar la negociación colectiva, disminuyendo los costes 
de agencia derivados de la misma. La información económica mejora claramente ese proceso de negociación.

En sintonía con el problema planteado, debemos considerar la importancia que adquieren en nuestro devenir profesional las reformas laborales habidas en nuestro país en los últimos años. Más concretamente, en la reforma laboral de Febrero de 2012, se plantea la necesidad de modernizar la negociación colectiva para acercarla a las necesidades específicas de empresas y trabajadores y fomentar el diálogo permanente en el seno de la empresa. La reforma laboral pretende facilitar la adaptación de los trabajadores y las empresas a la situación económica. Entre otros aspectos se quiere dar más importancia para regular la cuantificación y la distribución del salario, al convenio de empresa frente al convenio sectorial. Se pretende que las empresas puedan negociar aspectos salariales independientemente de lo que diga el acuerdo de ámbito superior; rompiendo así la jerarquía normativa del convenio sectorial sobre el de empresa.

Pues bien, en este contexto: negociación colectiva y participación de los trabajadores, es donde se plantea la idea fundamental de este trabajo. La negociación colectiva, representada en los convenios colectivos de empresa, adquiere tal protagonismo en el desarrollo económico que en su estudio debe dar cabida a otras disciplinas que puedan colaborar en el mismo. En este sentido, el presente estudio pretende contribuir, junto a otras ciencias sociales o jurídicas, a la identificación de cuantos elementos, desde el ámbito contable, puedan resultar útiles a la hora de facilitar la firma de los convenios colectivos de empresa.

Una primera aproximación para facilitar el conocimiento de los convenios colectivos de empresa la realizamos a través del análisis de estos convenios en el año 2000, apoyándonos en la cumplimentación de 
una encuesta dirigida a los responsables de recursos humanos de estas empresas, consiguiendo validar lo que realmente figura en los convenios y testando la opinión desde el punto de vista empresarial.

Esta primera aproximación, tuvo su primer reflejo en el Proyecto de Investigación "La utilidad de la información contable para la negociación de los convenios colectivos de empresa en la provincia de Burgos: su posible aplicación al campo de los recursos humanos y el empleo en las empresas castellano leonesas"; financiado por la Junta de Castilla y León, en virtud de convocatoria de 28 de Diciembre de 2000 de la Consejería de Economía y Hacienda, para la concesión de subvenciones destinadas a la realización de estudios y trabajos sobre materias socioeconómicas.

Posteriormente con los convenios firmados entre los años 2002 al 2014, volvemos a verificar el planteamiento teórico y analizamos el uso de la información contable en los mismos. Al no haber conseguido determinar un uso generalizado de la información contable, pero siendo conscientes de la importancia de la información económica de las empresas para el establecimiento de las diferentes condiciones económicas; unido al largo proceso llevado a cabo para firmar el nuevo acuerdo nacional para la negociación colectiva para el año 2015 y siguientes, nos lleva a plantearnos nuestra principal aportación: la búsqueda de un modelo que facilite la negociación de los convenios colectivos, para lo cual recurrimos al análisis de las respuestas dadas por los directores de recursos humanos de las empresas castellanoleonesas a las encuestas planteadas por un lado y por otro lado el estudio del planteamiento sugerido por los responsables sindicales de la provincia de Burgos a través de las entrevistas realizadas.

El trabajo germinal relacionado con este tema vio la luz en 1958, con la publicación de la investigación de Pillsbury "Organized labor`s view of corporate financial information", que sugería que los sindicatos usan los 
estados financieros en la misma medida que lo hacen los inversores y el resto de usuarios, es decir, para evaluar la actuación pasada y para tomar decisiones sobre el comportamiento futuro. Esta tesis supone una novedosa aportación al tema, ya que no se centra únicamente en los directivos, sino que se refiere a los trabajadores del convenio colectivo de empresa, en los cuales casi nunca se incluye al personal directivo o de alta dirección.

Nuestra investigación se plantea desde una perspectiva analítica, no meramente descriptiva, es decir, a través de la formulación de un modelo convergente con una teoría explícita y la observación simultánea de la realidad en la que opera, poder llegar a explicar la utilización real y potencial de la información contable en la negociación colectiva y el papel que en ella asume la misma.

Para conseguir el objetivo de la investigación propuesto, exponemos a grandes rasgos la estructura del trabajo, que presentamos. Implícitamente las partes de las que se compone son dos: una primera, en la que se examina el sustento teórico y la revisión de la literatura respecto a la relación convenio colectivo y uso de la información contable, y una segunda parte en la que, a partir de un análisis exploratorio inicial sobre la muestra de empresas, se aplica una metodología analítica con el fin de obtener resultados en torno al objetivo propuesto. Atendiendo a los atributos que, de acuerdo con nuestros planteamientos, deben caracterizar a la investigación científica, esta tesis doctoral se estructura formalmente mediante los siguientes capítulos.

En el capítulo 1 buscamos un enlace conceptual con el desarrollo empírico del trabajo. Después de un sucinto recorrido por los elementos fundamentales de la perspectiva teórica seleccionada, se intenta aplicar su esqueleto conceptual al estudio de unas relaciones contractuales de empleo en el seno de las organizaciones. El marco teórico, en el que 
desarrollaremos este estudio va incluido dentro de la economía de la información, para descender hasta el contrato de agencia entre empleador y empleados. La información imperfecta y la racionalidad limitada son el origen de estos contratos incompletos. Contratos incompletos de largo plazo que deberán renegociarse tratando de resolver el conflicto de intereses entre las partes con la menor pérdida residual para la empresa. En este proceso incorporamos, como elemento explicativo del mismo, el modelo del comportamiento humano de Jensen, que nos permita dar entrada al sistema de recompensas y sanciones.

El capítulo 2 lo dedicamos a situar el contrato de empleo dentro del marco legal, analizando a través de los diferentes textos legales, las garantías que se establecen para este contrato de empleo en el derecho positivo, prestando especial atención a la regulación de la negociación colectiva.

El capítulo 3 se completa con la revisión teórica y empírica del estado actual de la cuestión, en sus múltiples facetas, para luego decantarnos por un aspecto en concreto. El análisis se lleva a efecto desde un punto de vista cronológico.

En el capítulo 4, recorremos la cascada que va desde la construcción teórica al contraste empírico. Para ello, se plantea inicialmente un modelo inspirado en los postulados básicos del marco teórico elegido, la teoría de la agencia, y en la evidencia teórica y empírica revisada. A continuación se explora la realidad mediante las fuentes de datos que se han considerado necesarias y suficientes para este contenido: convenios colectivos, cuentas anuales y encuestas. Para la transformación de las fuentes de información mencionadas, obtenidas de la realidad, en datos y resultados concretos de la investigación que permitan posicionar los planteamientos del modelo propuesto, se han utilizado los siguientes métodos de observación y técnicas estadísticas: 
- Una encuesta inicial para describir el uso de la contabilidad dentro de la negociación colectiva (qué información se suministra, a quién, cuando, por qué, etc.).

- Todos los convenios colectivos de empresa depositados en la oficina territorial de empleo de la provincia de Burgos, de los que se han extraído las variables principales que se usan para la negociación.

- Todas las cuentas anuales de las empresas con convenio de la provincia de Burgos, intentando observar si hay diferencias en cuanto a creación de valor (rentabilidad, productividad, índices de valor agregado,...) entre las que usan más información contable en la negociación y las que no.

Con todo ello, en el capítulo 5, a modo de síntesis de los resultados obtenidos mediante las diferentes fuentes de observación, se formulan una serie de postulados con el fin de sugerir un modelo que, desde los planteamientos teóricos formulados y las observaciones realizadas, recoja los criterios que en nuestra opinión permitan alcanzar una negociación colectiva eficiente. Para facilitar este desarrollo se ha utilizado la siguiente metodología:

- Encuesta semiestructurada con los directores de recursos humanos incorporados a la red de directores de personal de Castilla y León para ver el modelo "deseable" a seguir.

- Tras la observación y los gaps señalados por los directivos, se realizaron entrevistas con los sindicatos más representativos de la provincia de Burgos, para confirmar la conformidad o no con el modelo inicialmente propuesto.

- Por último, se verifica la realidad de la negociación colectiva a nivel empresa aplicada a las empresas de Castilla y León 
y al periodo que abarca desde el 1 de enero hasta el 31 de mayo de 2015.

Al final, se incluye una reflexión final sobre el contenido del trabajo, induciendo futuras líneas de investigación, a partir del presente, que permitan resolver algunos interrogantes pendientes sobre el tema.

Destacar, finalmente, la idea de ampliar el camino iniciado en este Departamento de Economía y Administración de Empresas en investigaciones fructíferas desde el enfoque de agencia, en concreto en el área de economía financiera y contabilidad, cubriendo este trabajo una nueva vía de estudio que combina los ámbitos de la información económica-financiera y el de los recursos humanos, desde un enfoque de agencia. 
CAPÍTULO 1: MARCO TEÓRICO 


\section{0.- INTRODUCCIÓN}

"No hay nada tan práctico como una buena teoría", Josif Jungmann.

Antes de desarrollar las diferentes líneas de pensamiento, fruto de la revisión bibliográfica, y plantear la parte empírica, procede situar el tema dentro de un marco teórico capaz de proporcionar explicaciones sobre la posterior realidad observada.

Para conseguir este objetivo, dividimos el capítulo en cinco secciones. En la primera sección se incluyen, siquiera a grandes rasgos, algunos de los elementos conceptuales en los que se sustenta la economía de la información como marco de referencia que nos permita analizar la información contable en el ámbito de las relaciones laborales. En la segunda sección, llevadas las ideas subyacentes de la economía de la información al seno de las organizaciones, desarrollamos la teoría de los contratos en conexión con la renegociación de los mismos. En la tercera sección, tras haber desarrollado la renegociación de estos contratos incompletos, sugerimos el enfoque de agencia como marco conceptual óptimo en la explicación de las diferentes relaciones e incidencias producidas en el contrato de empleo. En la cuarta sección, con el fin de abordar la problemática de la renegociación en el marco del convenio colectivo de empresa y la utilidad de la información contable en la resolución del conflicto, introducimos las ideas propias de la arquitectura organizativa de Jensen y Meckling (1995). Por último, en la quinta sección, exponemos unos comentarios y conclusiones sobre el conjunto del capítulo. 


\section{1.- ECONOMÍA DE LA INFORMACIÓN}

"Aquel que no recuerde el pasado está condenado a repetirlo", Herbert L. Samuel.

Tradicionalmente los economistas han preferido elaborar modelos de mercado que, de forma abstracta y simple, describan el proceso de formación de los precios, relegando a un segundo plano el comportamiento de los agentes que intervienen en dicha institución.

El único agente que interesaba al economista ortodoxo del siglo XVIII y XIX era el mercado, y la decisión económica esencial se refería al intercambio comercial. En un contexto dominado por la confrontación de oferentes y demandantes en el mercado, no quedaba sitio para el análisis de un agente concreto como la empresa.

Aunque no existía una auténtica economía de la empresa, en el marco neoclásico se había gestado una teoría microeconómica de la empresa al estudiar el comportamiento de las unidades económicas productivas que operan bajo unas condiciones contextuales muy especiales que se conocen como economía de mercado.

El denominador común de todas las críticas del modelo neoclásico de empresa es la irrelevancia de las circunstancias específicas sobre propiedad, control y organización interna en lo que respecta a las decisiones que adoptan las empresas, resultando el beneficio el único que determina dichas decisiones.

Así, esta economía no da soluciones a problemas que superaban de forma importante la capacidad explicativa del modelo neoclásico de empresa; por lo cual surgen nuevas tendencias: la contractual y la 
evolucionista. La multiplicidad de teorías surgidas en el marco de una u otra de dichas tendencias parece haber propiciado el análisis de aspectos claramente diferentes acerca del comportamiento de la empresa.

La tendencia contractual, nos sitúa en un entorno en el cual se abandona la concepción de la empresa como función de producción y tomadora de decisiones perfectamente racional (Jensen, 1993), para reemplazarla por una visión muy alejada de los anteriores supuestos: un acuerdo contractual que busca una adaptación eficiente hacia el entorno. Se contempla a la empresa como alternativa al mercado (Coase, 1937).

En la literatura surgida en los últimos años se pone de manifiesto que las empresas son organizaciones complejas que operan en situación de incertidumbre o información limitada, suscitándose problemas como por ejemplo la pérdida de control en la renegociación de los contratos en ausencia de información perfecta.

La tendencia evolucionista va más enfocada al estudio de la empresa desde una óptica de proceso, lo que implica avanzar en un análisis de casos ideales y a defender la empresa como una unidad de acumulación de conocimiento.

Nos alejamos del modelo neoclásico, ya que entre otras razones, éste ignora la complejidad interna de las empresas en el mundo real. La introducción, por parte de las teorías gerenciales, de un eventual comportamiento discrecional de los directivos (empleados) ha favorecido la incorporación de conceptos claves en la teoría de los contratos como el de información asimétrica. Por parte de las teorías sobre el comportamiento de la empresa, la consideración de ésta como una coalición política proporciona la visión de la empresa como un complejo nexo de contratos, avanzando hacia la perspectiva contractual. 
El rasgo común a todas estas propuestas de revisión es el rechazo de la concepción neoclásica de la empresa como unidad elemental para el análisis del mercado y la pretensión de que dicho concepto sea el germen de una auténtica teoría de la empresa.

Enmarcamos el tema dentro de la nueva economía institucional, es decir, en un cuerpo de análisis económico moderno que emplea conceptos como información limitada, costes de transacción y oportunismo para explicar los fenómenos económicos observados (Simon, 1987). La nueva economía institucional se constituye en una corriente más amplia dentro del análisis económico, que engloba la teoría de los derechos de propiedad y la teoría de los costes de transacción, así como algunas derivaciones de éstas, en especial la teoría de la agencia.

Desde el enfoque de los derechos de propiedad, se enfatiza lo que cada persona física o jurídica puede hacer con los bienes, servicios o derechos disponibles en una sociedad. El sistema de derechos de propiedad imperante en la comunidad puede describirse como el conjunto de relaciones económicas y sociales que define la posición de cada individuo respecto a la utilización de recursos escasos. Se trata, en suma, de reforzar los derechos de propiedad, de arbitrar los mecanismos adecuados para hacer respetar las reglas establecidas, sancionando a quienes las vulneren y desincentivándoles a actuar en contra de los intereses de la colectividad. Así, la suposición central de la economía de los derechos de propiedad es que el contenido de tales derechos afecta a la asignación y al uso de recursos siguiendo unas pautas específicas y predecibles y que además, las diferentes asignaciones de derechos de propiedad conducen a distintas estructuras de recompensas y sanciones, que influyen sobre el comportamiento de los agentes económicos. Se plantea así la interconexión entre derechos de propiedad, incentivos y comportamiento económico. 
Sin embargo, muchos de los rasgos distintivos del enfoque de los derechos de propiedad, comportamiento maximizador y eficiencia económica, configuran el análisis de los derechos de propiedad como un intento de ampliación del marco del modelo económico neoclásico. No obstante, para que se ajuste el criterio de eficiencia que nuclea el modelo neoclásico y garantice el funcionamiento autónomo del mercado es necesario que los costes de transacción sean nulos o poco relevantes.

Los costes de definición, intercambio y exigencia del cumplimiento y vigilancia de los derechos de propiedad proporcionan contenido al concepto de costes de transacción. Estos costes aparecen vinculados al funcionamiento del sistema económico utilizado para organizar la producción y el intercambio. En los modelos organizativos basados en el mercado, el intercambio de bienes y servicios se produce sin coste alguno. Pero a partir de la reflexión de Coase, el análisis económico retornó la cuestión de los derechos de propiedad, al objeto de indagar en los efectos de la asignación de titularidades cuando los costes de transacción son relevantes.

El punto de partida es la sustitución de la maximización del beneficio por el postulado de que los individuos intentan maximizar su utilidad dentro de los límites establecidos por la estructura organizativa de la empresa. La empresa deja de ser la unidad básica del análisis, el individuo reemplaza a la organización como eje central del análisis y se tiende a explicar el comportamiento de la empresa y el de otras instituciones observando las acciones del individuo en el seno de la organización. Por lo tanto se acentúa la conexión entre la estructura institucional y los incentivos económicos.

Pero hoy por hoy, no existe una teoría generalmente aceptada de la formación y distribución inicial de los derechos de propiedad. La hipótesis básica es que los cambios de los derechos de propiedad son 
desencadenados por la búsqueda del ser humano de una mayor utilidad. Sin embargo, para Jensen y Meckling (1976), la especificación de los derechos de propiedad determina la forma en que costes y recompensas se asignan entre los agentes de una organización.

La economía de los costes de transacción es otra rama del análisis económico que enfatiza la importancia de los costes derivados de la realización de transacciones económicas, con el propósito de comparar los costes de transacción con que operan las distintas instituciones y explicar la prevalencia de unas instituciones sobre otras en contextos determinados.

Hacemos referencia a la fase contractual que se produce cuando dos o más agentes acuerdan contractualmente el lugar y la fecha en que va a producirse el intercambio de un bien o servicio, en los términos de la economía de los costes de transacción. El punto de partida es que los contratos económicos surgen para minimizar los costes de transacción entre los factores productivos.

Las aportaciones de Jensen y Meckling (1976) junto con los trabajos anteriores de Coase (1937) y Alchian y Demsetz (1972) constituyen el punto de partida para la elaboración de la teoría de la agencia. Así la teoría de la agencia es la rama de la nueva economía institucional que se ocupa del análisis de los contratos entre agentes económicos individuales, al objeto de minimizar los costes de agencia que se derivan de toda forma de cooperación entre dos o más personas.

Dentro de esta formulación teórica, destacamos el principio de racionalidad limitada, que supone que los individuos persiguen la maximización de su utilidad. En este proceso se hallan sometidos a una serie de restricciones, como por ejemplo, una limitación intelectual que impide a los agentes económicos evaluar todas las contingencias y 
condiciones contractuales, es decir, estamos ante la presencia de contratos incompletos.

Por otra parte, también conviene destacar la posibilidad de comportamientos oportunistas por parte de los agentes económicos. Tales comportamientos se manifiestan en la propensión de las partes contractuales a revelar falsa información o a incumplir los acuerdos contraídos cuando tales actuaciones les reportan un beneficio. Es por esta razón, por la que tiene importancia el estudio de la información, ya que si todos los agentes dispusieran de la misma información no existiría problema alguno (Douma y Schreuder, 1991).

Dentro de la nueva economía institucional, las respuestas que buscamos deben venir dadas en términos de información incompleta y/o asimétrica (Ross, 1973), lo que en términos de la teoría de la agencia, sugiere analizar aspectos tales como acuerdos contractuales que resuelven problemas de incumplimiento $u$ otros problemas de motivación.

La incertidumbre es el reflejo de la falta de información a que se enfrentan las partes involucradas en los diferentes concretos. Es de vital importancia, considerar a la información y la incertidumbre para la comprensión del comportamiento económico.

Dentro de la incertidumbre se puede distinguir entre incertidumbre exógena e incertidumbre endógena (Azofra, 1993). La incertidumbre endógena es la que prestaremos especial atención, al ser la debida a las decisiones de los agentes. El problema más importante que se plantea surge de la constatación del hecho de que el entorno en el que los agentes económicos individuales toman sus decisiones, no sólo viene determinado por la ocurrencia de un incierto estado de la naturaleza, sino también por la incertidumbre que, en un mundo de información imperfecta 
o incompleta, pudiera afectar a la renegociación de los contratos entre los diferentes agentes intervinientes.

Los problemas de información asimétrica se pueden manifestar de diversas formas, dependiendo de que los agentes dispongan de información diferente antes o después de llegar al acuerdo, problemas que se denominan respectivamente selección adversa y riesgo moral, y que a menudo provocan comportamientos oportunistas que a su vez conducen a asignaciones ineficientes.

Se establece así una estrecha interrelación entre la economía de la incertidumbre y la economía de la información, la falta de información, no es sino el reflejo de los problemas originados por la incertidumbre a que se enfrentan los agentes económicos, al verse imposibilitados de prever o enumerar exhaustivamente todas las posibles contingencias que el futuro incierto puede depararles.

Enfatizamos el hecho de que la información, incluida la contable, es imperfecta y costosa. Esto implica que los empleados y empleadores actúan con un elevado margen de discrecionalidad, disponen de informaciones privilegiadas que no conoce la otra parte. Además, tales informaciones son costosas de revelar (Hyafil, 1991) porque su formalización suele ser difícil por la existencia de racionalidad limitada; porque existen costes de comunicación; y porque su difusión podría beneficiar a la otra parte.

En una organización cierta, este problema de información o de agencia no existiría, pues, aún siendo divergentes los intereses del agente y del principal, los esfuerzos desplegados por el agente sería perfectamente observables y, en el supuesto de que no hubiese costes asociados a la formalización y el cumplimiento de los contratos, sería posible establecer un contrato que indujese al agente a comportarse 
conforme a los deseos del principal. La aparición del problema de agencia aparece así asociado a la incertidumbre y a la falta de información.

Enfatizamos el hecho de que la información es imperfecta y que el acceso a la misma comporta costes. Por lo tanto, es preciso tener en cuenta los problemas originados por la existencia de información asimétrica. Este problema de agencia se traduce en una serie de costes contractuales, que analizaremos posteriormente. Haremos especial hincapié en los costes de información en los que se incurre con objeto de reducir la desviación del comportamiento del agente respecto a los intereses del principal (Arruñada, 1990).

Se plantea, por tanto, la necesidad de resolver los problemas originados por la incertidumbre a que se enfrentan las partes implicadas en las relaciones de empresa, como reflejo de la falta de información sobre las circunstancias relevantes del futuro. Esta falta de información se traduce en contratos incompletos, contratos que, al no poder prever todas las contingencias posibles, tampoco pueden determinar las relaciones contractuales en cada momento y situación. Se constata, además que la incompleta redacción explícita de los contratos no sólo es debida al problema de incertidumbre, sino que a menudo, este problema lleva aparejado otro de observabilidad y asimetría informativa. La información asimétrica es también la razón principal por la que los individuos delegan responsabilidad, encontrándose ante el problema de agencia (Salas, 1989).

La incapacidad de observar el esfuerzo puesto por los miembros del equipo causa un problema de información. Por esta razón nace la figura del controlador. Sin embargo en la empresa clásica (Douma, 1992), el controlador es el propietario de la empresa: el recibe el resultado, tiene el derecho de vender la empresa, tiene el derecho de contratar o despedir a los miembros del equipo y ajustar individualmente sus sueldos. El 
controlador es el empleador o empresario: los otros miembros del equipo son los empleados. El empresario clásico surge como solución a un problema de elusión dentro de los equipos pero para realizar esta labor necesita de la información. Los actuales mecanismos de coordinación dependen fundamentalmente de los sistemas de información.

En síntesis, se trata de un problema de información imperfecta o, más precisamente, de información asimétrica. En palabras de la teoría del principal y el agente es el principal el que no tiene información sobre el comportamiento del agente y no puede observar su comportamiento directamente. La resolución de los problemas asociados a la información asimétrica requiere un análisis de los factores determinantes en la empresa, a fin de minimizar los costes de agencia.

Nos hemos separado del modelo neoclásico de competencia perfecta: existen costes de transacción y la información no es perfecta. Este problema de información imperfecta hace necesario el estudio detallado de las transacciones que tienen lugar dentro de la empresa. Así, nos encontramos con que no sólo existen costes de información sino que además existen limitaciones a la racionalidad. Las imperfecciones de información crean problemas a la hora de establecer relaciones o contratos (Cuervo, 1999), como discutiremos posteriormente en la teoría de la agencia.

En la medida en que los sistemas de información, de cualquier tipo, son un elemento fundamental para controlar y reducir el oportunismo (Eisenhart, 1989), los problemas pueden resolverse con la ayuda de las estructuras y los sistemas de recompensa adecuados. 


\section{2.- LA TEORÍA DE LOS CONTRATOS}

"La armonía total de este mundo está formada por una natural aglomeración de discordancias", Séneca.

Puesto que la realidad económica es sumamente compleja, resulta factible pensar que son muchas las razones que justifican el nacimiento y supervivencia de la empresa. Una vez admitido que el mercado no es el único mecanismo válido para realizar las transacciones, que la racionalidad limitada de los individuos es limitada, que no disponen de información perfecta, es decir que los supuestos sobre los que se basa la visión neoclásica o tradicional de la empresa es insostenible, y que la separación entre la propiedad y el control es un hecho; debemos orientar la economía de la información hacia las organizaciones avanzando sobre la anterior línea orientada hacia los mercados.

Según apuntamos anteriormente, la incertidumbre es el reflejo de la falta de información a que se enfrentan las partes involucradas en las relaciones contractuales. Esta falta de información hace que se intenten delimitar las estructuras de gobierno de las organizaciones.

Williamson (1979) distingue tres grandes tipos de relaciones contractuales: no específicas, semi-específicas y muy específicas. El mercado es la clásica estructura de gobierno no específica; por el contrario, las estructuras específicas son diseñadas para atender las necesidades especiales de la transacción.

Cuando Williamson recurre a literatura mercantilista americana para proponer una clasificación de las estructuras contractuales mucho más precisa y operativa que la anterior, vinculando las características de 
las transacciones a la estructura de gobierno, distingue: el contrato clásico, el contrato relacional y el contrato neoclásico.

El contrato clásico, asociado al mercado como estructura de gobierno, es aquel en el que las condiciones de intercambio están perfectamente definidas, como normalmente sucede en las transacciones mediante las cuales se intercambian activos estandarizados, cualquiera que sea la frecuencia con la que se realicen.

El contrato relacional, asociado al gobierno de transacciones específicas, es aquel que regula el intercambio repetido o transacciones recurrentes de activos no estandarizados, manteniendo unas veces la autonomía de las partes o substrayendo la transacción al mercado para integrar a las partes en una misma unidad de gestión y gobernar la transacción mediante una relación de autoridad.

El contrato neoclásico, asociado al gobierno de transacciones ocasionales de activos no estandarizados, es una forma institucional intermedia entre las anteriores que se caracteriza por contemplar el concurso de una tercera parte para resolver posibles disputas entre las dos partes implicadas en un intercambio. Se trata de una alternativa que evita una definición más exhaustiva de las condiciones del intercambio.

Salas $(1984,1987)$ identifica tres variables por las que se diferencian los contratos: el grado en el que el contrato esté cerrado, diferenciando contratos completos e incompletos; la estructura de la relación contractual resultante, distinguiendo contratos multilaterales y bilaterales; y la dependencia entre las partes contratos derivada del contrato, estableciendo una diferencia entre los contratos sin relación de autoridad y contratos con relación de autoridad. 
Mientras que en los contratos completos se especifican todas y cada una de las contraprestaciones que lleva consigo el acuerdo, el contrato incompleto condiciona determinadas contrapartidas a la ocurrencia futura de sucesos inciertos en el momento del acuerdo, o bien cede a una de las partes la iniciativa para que tome decisiones que afectarán a la otra parte, en función de este tipo de contingencias. Las razones de la existencia de los contratos incompletos parecen obvias, pues no existe capacidad para prever todas las contingencias y, aunque así fuera, puede resultar más económico tomar decisiones en el momento, en lugar de planificar todas las respuestas necesarias para todas las contingencias.

Los contratos multilaterales dan lugar a estructuras de relaciones multilaterales entre las partes involucradas, sin ningún tipo de restricción sobre quienes pueden contratar entre sí y sobre qué contenidos. Los contratos bilaterales motivan una estructura contractual bilateral en la que una de las partes actúa como nexo contractual entre múltiples agentes que se relacionan entre sí por el hecho de estar vinculados a un nexo contractual común, pero sin existir acuerdos o contratos explícitos entre ellos.

Los contratos sin relación de autoridad no crean dependencia adicional alguna entre las partes más allá del cumplimiento de lo acordado. Mientras que en los contratos con relación de autoridad, una de las partes acepta la posibilidad de recibir órdenes e instrucciones de la otra respecto a qué hacer y a cómo hacerlo en un ámbito determinado.

Klein (1983) distingue entre contratos reales e ideales. Frente a estos últimos, a los que identifica con los contratos de la teoría económica convencional, contrapone los contratos que se negocian en el mundo real, que no contemplan todos los estados posibles de la naturaleza, siendo por tanto incompletos, y cuyo seguimiento y cumplimiento es costoso. La 
incompletitud de los contratos reales se debe, según este autor, a problemas de incertidumbre, de observación imperfecta y de asimetría de información.

Para Williamson (1985) la perspectiva que proporcionan los contratos incompletos es esencial. Así, frente al contrato de mercado, en el que concurren las características de completo, multilateral y sin relación de autoridad, los contratos que gobiernan la relación de la empresa con sus empleados, proveedores, clientes, accionistas y prestamistas tiene un rasgo en común, el de ser contratos incompletos de diferentes tipos: contratos organizacionales, contratos contingentes y contratos de agencia.

Los contratos organizacionales se caracterizan por ser contratos incompletos, unilaterales y con relación de autoridad. Los contratos contingentes son contratos incompletos, multilaterales y sin autoridad, en los que parte de las contrapartidas se establecen como contingentes a la ocurrencia o no de un suceso a priori incierto. Por último, los contratos de agencia son contratos incompletos, multilaterales y con relación de autoridad, surgidos cuando una parte cede a la otra, poder e iniciativa para que actúe por delegación y en beneficio de aquella.

Mientras que el mercado aparece caracterizado por la libertad de relación entre las partes a través de contratos a corto plazo, y por el principio de maximización de la utilidad individual a partir de la información que proporcionan los precios; la organización viene definida por la existencia de contratos a largo plazo que regulan relaciones permanentes entre los miembros que se integran en la misma, y por la aceptación de una relación de autoridad que coordina comportamientos individuales y persigue objetivos comunes. 
En las relaciones contractuales, Williamson (1985) destaca los contratos incompletos como los que gobiernan la relación entre la empresa con sus empleados, refiriéndonos en nuestro estudio a los contratos de agencia: contratos incompletos, multilaterales y con relación de autoridad. Esta relación de agencia nos va a servir para plantear el diseño de sistemas de información.

Mientras los contratos normales facilitan la especialización eficiente según las ventajas comparativas, la producción en equipo suele emplear un tipo especial de contratos entre un grupo de factores para un proceso de producción conjunto. En lugar de contratos multilaterales entre todos los propietarios de factores, una parte central común a una serie de contratos bilaterales facilita la organización eficiente de los factores de producción en equipo. Los términos de los contratos forman la base de la entidad denominada empresa, especialmente apropiada para organizar procesos de producción en equipo (Alchian y Demsetz, 1972).

En la literatura se han identificado tres tipos generales de contratación relacional: relaciones bilaterales equilibradas, relaciones jerárquicas y relaciones trilaterales (Kreps, 1990). En la relación equilibrada, las dos partes mantienen un grado relativamente alto de autonomía y las contingencias se atienden a medida que se presentan. La relación jerárquica coincide con la relación de empleo en la empresa tradicional, con el empresario actuando de superior jerárquico y el trabajador de subordinado. Por último en la relación trilateral, un tercero decide cuando las partes no pueden llegar a tomar una decisión.

Hart (1995) insiste en la idea de que las empresas están inmersas en contextos donde los costes de transacción obligan a redactar contratos incompletos, ambiguos en los términos sobre cómo se desarrollarán las transacciones entre quienes contratan cuando en el futuro se prevén contingencias no previstas de antemano. En el momento en que 
determinadas contingencias se conozcan, previsiblemente las partes negociarán sobre las nuevas condiciones de los contratos. Adquiere importancia la noción de poder, que en la teoría del equilibrio general, es irrelevante, ya que se supone que el intercambio ocurre entre agentes anónimos mutuamente vinculados entre sí por contratos completos o con plena protección contra el oportunismo.

Concluimos, este análisis planteando a la empresa como una ficción legal (Jensen y Meckling, 1976), como un nexo de contratos (Coase, 1937; Alchian y Demsetz, 1972), entre los cuales vamos a plantear específicamente el que se establece entre el empleador y el empleado. También puede ser entendida como un proceso de especialización de funciones, que lleva aparejado el nacimiento de relaciones contractuales especiales, cuya razón de ser es limitar los conflictos de intereses inherentes a la especialización. Jensen y Meckling conciben la organización, una de cuyas formas es la empresa, como un artificio legal, que sirve como un nexo para un conjunto de relaciones contractuales entre individuos. En las relaciones con estos individuos, clientes, proveedores y acreedores se plantean problemas de control similares al que motiva a los empleados a negociar bilateralmente con el empresario, en lugar de hacerlo con el mercado. Podríamos decir que dentro del eje de las actividades de la empresa la fundamental es la contratación en lugar de la autoridad. Se puede estudiar el comportamiento de la empresa analizando las características de los contratos celebrados por la misma (Namazi, 1985).

Todos los intercambios requieren procesos contractuales para que puedan hacerse realidad. En ellos, cabe distinguir dos tipos esenciales de problemas, relacionados con el perfeccionamiento y la salvaguardia del intercambio (Arruñada, 1999). Los problemas relacionados con el perfeccionamiento vienen como consecuencia de la renegociación, al no ser los contratos perfectamente cerrados o explícitos. Los problemas del 
segundo tipo, vienen definidos por la proclividad de los individuos a anteponer el logro de sus propios intereses al cumplimiento de sus obligaciones. En la mayoría de los contratos se utiliza el perfeccionamiento diferido para resolver el primer problema; y la presencia de elementos institucionales, para el segundo problema. Así, por ejemplo el contrato de empleo, se redacta dentro de un marco legal, como analizaremos posteriormente, y que asigna al empresario cierta autoridad para completarlo en el futuro (remuneración por rendimiento), así como ciertos derechos para el empleado.

Dentro del nexo de contratos que constituyen la empresa, nos centraremos en el contrato de empleo, como aquel que se desarrolla entre los empleados y los empleadores. Aprovecharemos esta sección para concretar el tema de la negociación colectiva, generalmente tratado por psicólogos, sociólogos y abogados, ya que implícitamente subyace el problema al estar en presencia de contratos incompletos.

El papel que juega la contabilidad en la empresa como parte de la tecnología contractual eficiente de la empresa es muy importante, tanto en lo que se refiere a los términos del contrato como en el control de los mismos. Si la contabilidad es una parte integral de los contratos que conforman la empresa y los costes de agencia varían con los diferentes contratos, los procedimientos contables tienen el potencial de tener efectos en el valor de la empresa y en los sistemas de compensación que tienen lugar en el seno de la misma.

Existen diversas formas de gobernar las transacciones que se producen dentro de la empresa, nexo de contratos. Esto es conocido por los economistas como contratación relacional. Al formar parte los trabajadores de la empresa, se puede extender la contratación relacional a la relación de empleo, es decir, al contrato entre propietarios de los activos no humanos y propietarios del capital humano. La idea básica es 
mantener los activos en manos de diversas entidades, pero al mismo tiempo ahorrar en costes de transacción debido a las negociaciones y renegociaciones de los contratos, aprovechando las relaciones a largo plazo.

En un mundo en el que todas las decisiones relevantes pudieran ser tomadas ex ante, no habría lugar para la negociación; sin embargo en el mundo real, los contratos son incompletos y por esto, las organizaciones tienen que negociar continuadamente los derechos y obligaciones de las partes.

La negociación es una actividad en la cual intervienen dos o más actores que confrontan sus divergencias. La negociación es un método específico de decisión social, en el cual intervienen de una forma más o menos decisiva los comportamientos, las voluntades, los poderes, los factores afectivos e irracionales de los actores. La negociación es también una explicitación de las divergencias que implica un reconocimiento de una cierta solidaridad en la acción y de una cierta independencia de objetivos. La negociación implica un deseo de concluir, y este deseo es lo que la hace diferente del enfrentamiento o del conflicto abierto. Las características definitorias de una negociación son: la intervención de dos o más actores, la existencia de un método específico de decisión social, la explicitación de las divergencias de los actores, y un deseo de concluir (Laffarga, 1993).

Desde la psicología, la negociación se define estrictamente como la acción de tratar por vía diplomática un asunto con el objetivo de alcanzar un acuerdo. Esto implica, como es obvio, que existe de partida una diferencia de intereses (teoría de la agencia) entre los asistentes a una negociación. Por lo tanto, una negociación se dará cuando: se plantee un resultado incierto respecto a un determinado punto (por ejemplo, el incremento salarial); cuando exista cierto interés compartido (la 
maximización del beneficio); cuando haya una motivación por las partes implicadas para alcanzar un acuerdo (ambos son componentes del contrato de empresa); y cuando exista una capacidad y autoridad para negociar reconocida por las partes implicadas (representantes).

La negociación colectiva se ha convertido en el mecanismo más importante de regulación de las relaciones laborales. La negociación colectiva es el conjunto de normas legales, reglas de procedimiento y prácticas habituales que ordenan en un marco estable e institucionalizado las relaciones de trabajo entre empleados y empleadores. Es, al mismo tiempo, un instrumento jurídico cuyo resultado final es el convenio colectivo, documento que recoge el acuerdo entre las partes sobre un amplio abanico de aspectos de las relaciones laborales en un marco económico empresarial determinado (Miquélez y Prieto, 1992).

Así, en la negociación laboral se van a tratar tres puntos fundamentalmente: el poder, que es la capacidad para lograr un cambio (medidas de presión: cierre patronal o huelga); la información, que es el conjunto de datos sobre los que se justifican las necesidades y deseos de las partes en negociación (la información contable en nuestro caso); y la presión, que es la necesidad de supeditarse a factores 0 condicionamientos esenciales como es el tiempo, las expectativas, las alternativas y los antecedentes. La negociación colectiva está basada en un objetivo común: las plusvalías de la empresa; con intereses particulares: cómo se reparten esas plusvalías.

Según Foley y Maunders (1977) podemos clasificar diferentes modelos de negociación colectiva. Los modelos clasificados dentro de la teoría de juegos, que ponen su énfasis en predecir el resultado de la negociación dejando a un lado el proceso de la misma. Los modelos cuasi - temporales, donde se trata al tiempo como una variable importante. Los 
modelos denominados modelos de comportamiento suelen ser más descriptivos que los anteriores.

Los modelos basados en la teoría de juegos son fundamentalmente utilizados para información perfecta o completa. En estos modelos que emplean como supuestos previos la racionalidad, el comportamiento perfecto y el juego independiente del resultado, se incluye la posibilidad de que el suministro de información financiera por parte de las empresas tenga un papel importante y significativo. Sin embargo en las relaciones de agencia empleador - empleado la racionalidad es limitada, el comportamiento no es perfecto y las recompensas pueden depender del resultado.

Los modelos anteriores no consideran el efecto del paso del tiempo en la negociación, son modelos estáticos. Sin embargo, el proceso que se sigue en la elaboración de un convenio es dinámico, en el mismo aparecen constantemente cambios entre los que habrá que tomar una elección, elección de la que dependerá el resultado. Para explicar el posible impacto que tiene la información en el resultado de la negociación habrá que reconocerla tal y como es en la práctica: un proceso dinámico y adaptable, en el cual la incorporación de información en diferentes momentos del proceso podrá tener diferentes efectos. Este es el caso de los modelos cuasi - temporales.

Si queremos analizar el verdadero proceso de elaboración del convenio con mucho más detalle, deberíamos utilizar los modelos de comportamiento. El modelo de Walton y Mackersie (1974) es uno de los clásicos en psicología y es de los más representativos para el análisis de la relación empleador - empleado. Los autores distinguen en la negociación colectiva cuatro subprocesos que se denominan: negociación distributiva, negociación integrativa, estructuración de las actitudes, y negociación intraorganizativa. 
La negociación distributiva tiene como idea central el conflicto, ya que la misma se plantea respecto de la distribución o reparto de bienes limitados. En este sentido, las ventajas o beneficios de una de las partes del convenio, por ejemplo, mayores salarios, son, en un principio, desventajas o perjuicios para la parte contraria. En este caso, aparecen las tácticas de presión como normales y la huelga como una alternativa al acuerdo. Podríamos decir que en esta negociación se incluyen una serie de comportamientos competitivos que procuran influir sobre la división de unos recursos limitados. En nuestro caso, pretendemos que ganen ambas partes, y creemos que este tipo de negociación sería más apropiado desde la teoría de juegos y no para la teoría de la agencia.

La negociación integrativa que aparece cuando en los problemas que son comunes a las partes de la negociación, ocurre que una ventaja concreta para una de las partes no representa, en principio, una desventaja recíproca para la otra parte de la negociación. La negociación integrativa es la que juega con las motivaciones de los negociadores más que con las tácticas de presión. En definitiva, este sistema de negociación comprende actividades que incrementan la ganancia conjunta disponible para las partes negociadoras. Tales actividades incluyen comportamientos resolutorios de problemas y otras capaces de identificar, ampliar y actuar sobre los comunes intereses de las partes. La información, el sistema de información contable, se considera como una actividad fundamental.

La estructuración de las actitudes, se sitúa en una órbita socioemocional interpersonal, que se encamina a modificar actitudes y relaciones de una parte respecto de la otra. La negociación se entiende así como una ocasión óptima para reforzar o transformar las actitudes predominantes de una parte frente al antagonista, aunque la negociación no mejora de modo necesario las relaciones preexistentes. Este sistema 
comprende actividades que influyen sobre las actividades de las partes entre sí, mutuamente, y afecta a los lazos básicos de la relación entre las unidades sociales implicadas. La negociación distributiva, y la integrativa, corresponden a los problemas de índole económica, y a los derechos y obligaciones de las partes, que son el contenido, generalmente reconocido de las negociaciones laborales. Ahora bien, pretendemos que la información contable sirva para otra función adicional clave en las negociaciones, influir las relaciones entre bandos, en particular actitudes tales como hostilidad, amistad, confianza, respeto y la orientación motivadora de la cooperación pueden estar en esta línea.

La negociación intraorganizativa se plantea como un subproceso en el seno del sindicato; de hecho los negociadores que se sientan frente a frente son representantes de dos conjuntos de demandas, una la lógica de la contraparte y la otra la propia organización. Esta negociación está necesariamente en conflicto con la negociación distributiva, pues mientras que en ésta el negociador intenta modificar la posición del antagonista, llevándole al terreno en el que se mueven las expectativas del poder social que representa, en la negociación intraorganizativa el negociador se propone llevar las esperanzas de aquel poder social a alinearse con el oponente. Los tres procesos anteriores se relacionan con el proceso de conciliación entre el sindicato y la empresa, pero durante el curso de las negociaciones acontece otro sistema de actividades, diseñado para alcanzar un consenso dentro del sindicato, y en el interior, también de la propia compañía en sí.

La teoría del comportamiento de Walton y Mckersie avanza en el proceso de negociación, sobre las ideas originarias sólo económicas (Peterson y Tracy, 1977). No sólo se trata de optimizar el beneficio en todos los sentidos, sino que el objetivo dependerá del proceso negociador en el que tenga lugar. Así, para la negociación distributiva se intenta maximizar el beneficio para una parte dentro de unos beneficios fijos. 
Para la negociación integrativa se intentan solucionar problemas e incrementar el beneficio mutuo. Para la estructuración de las actitudes se busca obtener y mantener una relación de trabajo aceptable con la otra parte. $Y$ para la negociación intraorganizativa se intenta influir en sus propios representados y obtener negociaciones exitosas. Las bases teóricas de estos modelos de negociación son diferentes: el distributivo se centra en los costes de huelga, el integrativo en la resolución de problemas, el de las actitudes en los aspectos psicológicos y el intraorganizativo no es más que una aplicación de la teoría de juegos. Por todas estas razones, nuestro planteamiento va más inmerso dentro del proceso negociador integrativo, donde tratamos de resolver problemas de agencia.

El sindicato es una asociación continua de asalariados que tiene por objetivo mantener o mejorar las condiciones de su vida laboral. Los sindicatos intentan conseguir sus propósitos mediante la imposición a los empresarios de normas referentes a la forma de tratar a sus asalariados 0 a aquellas clases de trabajadores por las que se interesaban; pero elaboraban estas normas y las aplicaban de diversas maneras, según las circunstancias. En primer lugar, los sindicatos formulaban sus propias normas especificando los términos en los que sus afiliados podían aceptar un empleo, denominada regulación sindical unilateral. En segundo lugar, se reunían con los empresarios para acordar normas conjuntas utilizando el procedimiento conocido como negociación colectiva. En tercer lugar persuadían al parlamento para que decretase normas legales, es decir, mediante regulación legal. Nos referiremos exclusivamente al segundo método o la negociación colectiva.

En la negociación colectiva los trabajadores normalmente, si no invariablemente, se asocian en sindicatos para negociar con sus empleadores. No requiere la acción colectiva por parte de los empresarios, pues los sindicatos negocian tanto con las asociaciones 
patronales como con cada empresario o con sus representantes. En nuestro caso prestaremos atención a la negociación con cada empresario, es decir, la negociación a nivel de empresa. En muchas ocasiones la negociación lleva a un convenio firmado por ambas partes.

Suecia es el país que registra la mayor cobertura de la negociación colectiva; los sindicatos y las asociaciones patronales negocian a nivel de la industria. En Francia, la negociación colectiva a nivel de planta tardó en instaurarse. En Alemania, la negociación colectiva se realiza en su mayor parte a nivel regional, aunque en cierto número de industrias, los sindicatos y las asociaciones patronales negocian acuerdos marco nacionales que sirven de guía; casi todos los convenios de planta se refieren a pequeñas empresas no incluidas en las asociaciones patronales y, por lo tanto, sólo corresponden a una fracción minúscula de empleo total. Gran Bretaña ha sido un país de convenios industriales; de negociaciones de planta en su mayor parte por los "shop stewards" (delegados sindicales). En Estados Unidos se obliga a los empresarios a negociar con los sindicatos.

Existe una gran diversidad entre los cinco países en la amplitud del control legal de la negociación colectiva. En primer lugar, están los Estados Unidos con su regulación detallada de la unidad de negociación, la elección del sindicato y el alcance y contenido de los convenios colectivos y su aplicación. Francia tiene el volumen mayor de normas legales, pero dado que el desarrollo de la negociación colectiva no se ha aproximado en ningún momento al americano las normas tienen un efecto mucho menos práctico. Alemania ha legislado sobre todo acerca de comités de empresa y regulación de las huelgas y de los convenios colectivos. Suecia posee leyes relativas al cumplimiento de los convenios y al reconocimiento de los sindicatos. Finalmente, Gran Bretaña tiene el sistema en el que más interviene la voluntad. 
Como podemos comprobar por estos cinco países analizados, es en Estados Unidos y Gran Bretaña donde más se negocia a nivel de empresa, por lo que ésta podría ser una de las razones por las cuales en la revisión bibliográfica desarrollada en el capítulo referente al estado actual de la cuestión, la mayor parte de los trabajos corresponden a autores norteamericanos e ingleses. Además el sindicalismo británico es el más antiguo del mundo porque la Revolución Industrial se inició en Gran Bretaña. De igual manera la organización del centro de trabajo sólo es núcleo importante de poder sindical por derecho propio en Gran Bretaña. Por otra parte, la negociación en planta en Estados Unidos es el resultado de la escasa importancia de las asociaciones patronales en este país y permite explicar el alto grado de control ejercido por los convenios y procedimientos diseñados específicamente para aplicarse a las circunstancias de cada planta o empresa. Además de Gran Bretaña y Estados Unidos, en Japón también tiene una enorme importancia la negociación de convenios colectivos de empresa.

En la determinación de los salarios los diferentes países del entorno europeo presentan muchos rasgos comunes en lo que concierne a las estructuras habituales de negociación. El cuadro tradicional de negociación es en efecto la rama de industria. En sentido inverso, en muchos casos, la negociación se ha dirigido hacia la empresa. Las negociaciones suelen fijar mínimos, aunque no necesariamente, y en la empresa se fijan salarios efectivos. Es posible pues que las empresas individuales paguen más o menos si lo juzgan oportuno. La negociación de empresa existe en Dinamarca, sobre todo para las empresas que no pertenecen a las asociaciones de empleadores; en Inglaterra, como ya quedó mencionado, se produce el desarrollo más significativo. La tendencia al aumento de la negociación de empresa también se nota en Italia, Francia, Países Bajos, Alemania y Bélgica, entre otros. 
En definitiva, la negociación en la empresa constituye una de las tendencias más importantes de los últimos años, no sólo en España sino en el entorno europeo, hasta el punto de que los observadores han podido ver en esta tendencia una aproximación entre los sistemas europeos y los norteamericanos, más si cabe a raíz de la globalización de la economía. En muchos casos, habría que hablar, más que de negociación de empresa, de negociación de centro de trabajo.

Los objetivos globales de la negociación en la empresa han sido estrechar los vínculos de los trabajadores con la toma de decisiones en el lugar de trabajo, responder a las exigencias de mayor participación de los trabajadores en el control de las condiciones de trabajo, fomentar una mayor satisfacción en el puesto de trabajo y, por último, mejorar quizás la productividad y la eficacia.

Además de negociar con los empleados, el empleador tiene la obligación de proveer una información regular sobre las perspectivas de producción, económicas y de empleo de la empresa. En varios países, esta obligación ha sido desarrollada y precisada (en Francia por Ley en 1966, en Alemania por Ley en 1972, en Bélgica por convenio colectivo nacional en 1970, etc.). Dentro de esta información, se incluye la información de los estados financieros. Podríamos decir que los sindicatos o representantes de los trabajadores tienen tres derechos fundamentales en las relaciones laborales: consulta, participación y negociación.

Aunque una buena parte de los datos necesarios para que la negociación resulte eficaz son de dominio público, o al menos son accesibles, por lo general, a las partes, otra parte de la información objetiva está exclusivamente en posesión de los empleadores. Este es un factor importante en situaciones que se caracterizan por la celebración de negociaciones a nivel de empresa. Así, los comités de empresa tienen 
amplios derechos en lo que se refiere a la información relativa a la situación económica actual y prevista de la empresa. En Estados Unidos, la obligación del empleador de revelar información que el sindicato pueda demostrar que es pertinente y necesaria para preparar la negociación colectiva se deriva de la obligación legal de negociar de buena fe; por lo que se refiere a la información financiera, el sindicato tiene derecho a conocer datos relativos a los registros de producción y ventas, costes de las materias primas y cifras de gastos de explotación con el fin de verificar cualquier afirmación de un empleador en el sentido de que le es imposible desde un punto de vista económico satisfacer una demanda salarial. En igual sentido está regulado en el Reino Unido, Suecia (derecho de acceder a los libros de contabilidad del empleador y otros documentos pertinentes), Francia, etc.

La negociación distributiva resulta clave para las negociaciones laborales $\mathrm{y}$, normalmente suele ser considerada como la actividad dominante en la relación sindicato - empresa. Los sindicatos representan a los trabajadores para la determinación de unas materias que llevan consigo la distribución de unos recursos escasos, se entiende que va a existir cierto conflicto de intereses. Estos conflictos de intereses se pueden manifestar en costes huelguísticos, que se tratan de minimizar mediante la negociación. Estos costes son: pérdida de salarios para los trabajadores, pérdida de la seguridad institucional, pérdida de buena voluntad por parte de la gerencia, pérdidas de cara a la imagen pública, pérdida de beneficios en el funcionamiento, pérdida de buena voluntad ante los trabajadores (Walton y McKersie, 1974).

En la negociación distributiva, el suministro de información por parte de las empresas se considera, a menudo, como que oscurece más que clarifica el conocimiento. Así, en una negociación puramente distributiva, el suministro de información necesita ser analizado como un arma potencial para ser usada en una situación esencialmente 
competitiva. El suministro de información puede ser utilizado para operar en los componentes de los niveles de aspiraciones de los oponentes, tanto que puede modificar el rango del convenio $y$, por lo tanto, el resultado eventual. Por lo tanto, será muy importante para la dirección el control del acceso a la información interna de la empresa a los representantes de los trabajadores.

En la negociación distributiva, tienen gran importancia la influencia de los cambios en las utilidades percibidas y la evaluación de las probabilidades. El interesado está tratando de comunicar los parámetros básicos de utilidad en orden a dar forma a las esperanzas del oponente de una manera generalizada. Aquí, el interesado tratará de influir la visión que tenga el oponente sobre la naturaleza, acerca de la pujanza de sus necesidades y capacidad coercitiva de las mismas. También se trata de convencer al oponente de la fortaleza en la posición táctica del interesado. Podríamos decir que la posibilidad de impago es un aspecto importante de la negociación distributiva. La asignación táctica primordial, inicial, del interesado, consiste en evaluar las utilidades del oponente, sus costos huelguísticos, y, si le es posible, dilucidar también cuál sea su punto de resistencia.

El tema objeto de la negociación distributiva lo constituían los conflictos, el que corresponde a la negociación integrativa está constituido por problemas. Los problemas generalmente van asociados con recompensas. En el proceso integrativo se parte de que se hace un uso máximo de la voluntariedad de suministro de información, asegurando discusión en las áreas que afectan a ambos grupos e intentando evitar consecuencias que pudiesen presentar nuevas dificultades para los oponentes, justo al contrario del proceso distributivo, donde se parte del supuesto de conseguir la máxima información del oponente, pero suministrando la mínima ellos. 
En una negociación integrativa, la política de divulgar completamente la información financiera a los representantes de los trabajadores puede ser vista como una condición necesaria para incrementar los resultados de la dirección. La información es crucial en todas las partes del proceso. Así, si no hay una información detallada y completa, el resultado podría ser una definición menos adecuada del problema, donde se generarían menos alternativas. Para dar soluciones a los problemas y obtener el máximo beneficio de una forma integrativa, es esencial que la patronal adopte una política liberal con respecto al suministro de la información contable a los representantes de los trabajadores. Una política de incremento del suministro de la información supondrá un beneficio máximo a la dirección de las empresas a corto plazo cuando exista una atmósfera de confianza tal que la solución de un problema común pueda ser acometida inmediatamente, pero también puede traer beneficios a largo plazo en otras situaciones ayudando a fomentar la confianza, la cual pueda inducir a posibilidades de negociar integrativamente.

En el proceso integrativo se pueden encontrar tres etapas: la identificación del problema; la búsqueda de soluciones alternativas y sus consecuencias; y una ordenación de soluciones por preferente clasificación, y la posterior selección de la acción a emprender. La primera etapa implica un intercambio máximo de información en torno a los problemas percibidos por cada bando para identificarlos y definirlos en lo esencial. La etapa segunda implica una recogida a fondo, y con exactitud, de la información acerca de posibles alternativas y sus consecuencias varias. La tercera etapa lleva consigo la identificación de la suma más amplia de utilidades netas que sean posibles dada la situación, es decir la toma de decisiones. Se deben facilitar las condiciones para la resolución de los problemas. Pude ser la información contable la que apoye en la motivación, confianza e información de los interesados. El empleador podría facilitar la resolución de los problemas incrementado la motivación 
del empleado para resolver el problema, asegurando que la información relevante esté disponible, y facilitando la comunicación entre ellos, así como estructurar la situación de manera que permita confianza y apoyo emocional entre los empleadores y los empleados.

En la estructuración de las actitudes, el suministro directo de información para los trabajadores 0 sus representantes en las negociaciones puede, a menudo, ser un ejemplo de diferentes tácticas. Además existen diferentes factores que modifican las posturas en la negociación: la orientación motivacional; el nivel de confianza; la creencia en la legitimidad; y el grado de amistad. Asumimos que el interesado, después de considerar los diferentes factores, desea modificar las actitudes del oponente. El uso de los castigos y recompensas puede ayudar a cambiar el comportamiento en el sentido deseado.

Mientras que los procesos anteriormente discutidos se referían a la resolución de un conflicto entre organizaciones, el proceso al que se denomina negociación intraorganizativa trata del conflicto que se produce en el interior de cada organización. La información contable puede servir para argumentar a los propios representados porqué la petición salarial fue en tan sentido o porqué los empleadores, escudándose en la incapacidad de pago, sólo han concedido tal subida salarial.

Muchas de las veces, la conflictividad dentro del grupo de los empleados, (negociación intraorganizativa) viene como consecuencia de la disparidad en la cuantía de la información que los miembros de la organización poseen; este problema desaparecería si todos los empleados dispusieran de la misma información sobre la empresa, y en particular la información contable. Así, por ejemplo, cuando el grupo de representantes tiene información que no poseen los representados, estos últimos tienen unas expectativas que no son compatibles con las propias 
proyecciones del negociador acerca del resultado, y sus juicios sobre cuál sea el mejor método de negociar.

En síntesis, en la negociación distributiva, un negociador trata de usar un módulo de compromiso tan firme y tan temprano como le permita su conocimiento actual acerca del propio punto de resistencia, y el del antagonista, y como le permitan también los medios disponibles para comunicar y confirmar los compromisos tácticos, y su racionalización. En la negociación integrativa, una cuestión crítica para el negociador es el grado de apertura que deberá asumir en cuanto a las comunicaciones sobre toma de decisiones; no cabe duda de que fuera preferible que las partes compartieran toda su información. En la estructuración de las actitudes, el estado de la relación empleado - empleador implica multitud de dimensiones en las actitudes, pero una cuestión clave es la confianza en la información. En la negociación intraorganizativa, debe haber una escasa heterogeneidad dentro de cada grupo, lo que se consigue disponiendo de la misma información.

Existe un proceso de legislación sobre la divulgación de la información que nos puede llevar a formular las siguientes reflexiones. En primer lugar, la expectativa de que una base de datos común, creada, si es necesario, presionando sobre el empleador para que comparta la información pertinente, permitirá establecer unas estrategias de negociación más realistas y conducirá a unos resultados de negociación más responsables. En segundo lugar, la divulgación de información debe servir de medio para ensanchar el campo de cooperación en la toma de decisiones entre sindicatos y empleadores, al facilitar a los primeros acceso a la misma base de información de que disponen los segundos. Por último, la tendencia a establecer legislaciones que exijan mayor participación en la información se ha visto influida asimismo por las políticas oficiales que pretenden poner la negociación colectiva en más íntima relación con el lugar de trabajo reforzando el establecimiento de 
negociaciones a nivel de centro de trabajo y de empresa en detrimento de las negociaciones a nivel de industria.

La negociación colectiva es uno de los mecanismos más importantes de las relaciones laborales, que trata de alinear intereses contrapuestos entre el empleado y el empleador.

En el entorno de los países industrializados la negociación colectiva ha pasado de ser una negociación nacional, industrial o sectorial, a ser una negociación de empresa e incluso de planta, de tal manera que los problemas y las soluciones se plantean mucho más cercanos a los agentes implicados.

La información contable debe jugar un papel fundamental en la negociación colectiva de empresa, ya que como veremos en secciones y capítulos posteriores, puede servir como elemento para asignar derechos de decisión, como mecanismo de control, como instrumento que apoye la fijación de recompensas, etc.

\section{3.- ENFOQUE DE AGENCIA}

"El conocimiento teórico es un tesoro cuya llave es su práctica", Thomas Fuller.

Como comentamos en la sección primera, la teoría de la agencia surge en el enfoque de la nueva economía institucional, después de que la teoría de la empresa desarrollada en el análisis neoclásico adoptara una visión muy restrictiva de la naturaleza de la empresa. El mercado no 
es el único mecanismo válido para realizar transacciones, la racionalidad de los individuos es limitada, no disponen de información perfecta, es decir, que los supuestos sobre los que se basa la visión neoclásica o tradicional de la empresa son insostenibles.

Simon (1986), por ejemplo, criticó el modelo neoclásico de la empresa. Así para este autor muchas veces los individuos se conforman en conseguir resultados satisfactorios y renuncian a la consecución del óptimo. Se consideraba que las decisiones de la organización eran tomadas por los propietarios del capital, dada la coincidencia entre propiedad y dirección, y lo que es más importante, aceptadas por el resto de factores productivos. Sin embargo, las empresas se caracterizan por una separación entre la propiedad y el control de la empresa. Este hecho introduce la posibilidad de que exista un conflicto de intereses entre empleadores y empleados en el seno de la empresa. Además en el modelo neoclásico se parte de que existe un único agente con capacidad de decisión y en el caso de la empresa existen varios agentes. La empresa real es de considerable complejidad interna y el modelo neoclásico deja de ser el apropiado; la falta de información es la norma y no la excepción en las decisiones empresariales.

La teoría de la agencia proporciona el marco teórico ideal para analizar los problemas que surgen de la separación entre la propiedad y el control de las empresas, es decir, sirve para analizar la mayor parte de las organizaciones de nuestros días.

La teoría de la agencia es la rama de la nueva economía institucional que centra su interés en el análisis de los contratos entre los agentes económicos individuales, al objeto de minimizar los costes de agencia que se derivan de toda forma de cooperación entre dos o más personas. 
La relación de agencia se define como un contrato implícito o explícito entre dos partes, por el que una de ellas, agente, se compromete a realizar una actividad o prestar un servicio en nombre de la otra, principal; estos efectos, el principal que es quien dispone el derecho correspondiente, delega en el agente la autoridad para tomar decisiones.

En el desarrollo de la teoría de la agencia se han configurado dos enfoques o corrientes a las que Jensen (1983) denomina teoría positiva de la agencia y literatura principal-agente.

La literatura principal-agente o teoría económica de la agencia, que constituye la rama normativa de este enfoque, sigue una orientación fundamentalmente matemática y no empírica. A partir de modelos basados en hipótesis relativas a la estructura de preferencias de los agentes, a la estructura de la información y a la naturaleza de la incertidumbre, la teoría económica de la agencia estudia la asignación óptima del riesgo entre los agentes, las características de los contratos óptimos y las propiedades de las soluciones de equilibrio desde la óptica del análisis del bienestar.

El enfoque normativo de la teoría de la agencia afronta, pues, los problemas que plantea la incertidumbre para la asignación eficiente de recursos cuando se admite que la asignación de riesgos incide en el comportamiento de los agentes. En nuestro caso, el interés de esta corriente se centra en la especificación de aquellos sistemas de incentivos que incorporados a la relación contractual debieran incluir al agente a adoptar actitudes frente al riesgo similares a las del principal, de manera que la delegación de poder característica de la relación de agencia se produzca en términos óptimos.

En paralelo a la teoría económica de la agencia, y de forma independiente, se ha desarrollado otra corriente del análisis de clara 
orientación empírica y no matemática, a la que, habitualmente se denomina teoría positiva de la agencia. Es ésta una rama de la economía de la agencia más preocupada por explicar el comportamiento real de las organizaciones en general, y de las empresas en particular, que por el diseño de contratos óptimos.

En contraposición a la corriente normativa, la teoría positiva de la agencia apela en escasa medida a la formalización y supone implícitamente que las variables retenidas por el análisis económico para el tratamiento analítico de la relación de agencia no son suficientes para la comprensión de los fenómenos organizacionales y de importancia secundaria con respecto a variables tales como los costes de información, la estructura del entorno, la tecnología de los contratos y los métodos de supervisión. Charreaux (2000) señala que la teoría positiva de la agencia otorga especial importancia a las variables del mercado, principalmente el mercado financiero y el mercado de trabajo.

Metodológicamente hablando, la teoría positiva de la agencia se basa en el método hipotético-deductivo para partiendo, de un modelo simple de comportamiento y de la toma en consideración del entorno contractual, aventurar conjeturas susceptibles de contrastación con la realidad, al objeto de corroborarlas o refutarlas (Charreaux, 2000).

Podríamos decir que dentro de las teorías contables, se distingue entre teorías normativas y teorías positivas, entre lo que es y lo que debería ser. La investigación es positiva mientras que la metodología es normativa (Christenson, 1983). Por lo que nos centraremos en la teoría positiva, es decir, lo que se hace por parte de las empresas. El centro de atención del enfoque positivo, más que la producción de información contable, es su utilización. Además, según la Escuela de Rochester, la teoría positiva debería servir para predecir el comportamiento futuro de las empresas, por ejemplo el comportamiento de los empleados respecto 
a la información contable suministrada por los empleadores. De hecho, siempre se ha dicho que la teoría positiva es más realista (Tinker, Merino y Dale Neimark, 1982). En esta tendencia positiva, la teoría contable se generará únicamente a través de la observación de la realidad. La teoría contable positiva tiene como objetivo explicar y predecir la práctica contable en las empresas tal y como efectivamente es. Uno de los méritos innegables de la contabilidad positiva es concebir la disciplina como una parte integral de la economía, no como un cuerpo de conocimiento independiente y separado (Monterrey, 1998).

La teoría positiva de la contabilidad se encuadra dentro de la teoría positiva de la agencia (Jensen y Meckling, 1976; Azofra y Prieto, 1994) y representa, junto al modelo normativo de la agencia, una de las prometedoras ramificaciones del modelo de agencia, la cual se inserta dentro de una amplia corriente dentro del análisis económico, conocida como nueva economía institucional o contractual. La teoría positiva de la agencia se ha desarrollado en paralelo con la teoría normativa de la agencia, a diferencia de ésta, se encuentra mucho más preocupada por explicar el comportamiento real de las organizaciones que por el diseño de contratos óptimos.

El problema más importante de la relación de agencia es diseñar el contenido del contrato óptimo entre principal y agente, o lo que es igual una fórmula para compartir riesgos. En el diseño del contrato debe buscarse una motivación suficiente del agente, para que sus intereses sean lo más parecidos posibles a los del principal, con el fin de que las actuaciones que realicen no vayan en contra del cuadro de preferencias del principal.

Las variables contables son, por tanto, definitivas para el establecimiento de un contrato de agencia, por dos razones: miden la eficacia de la gestión, que depende de las acciones del agente y de 
sucesos externos incontrolables para él; y sirven para marcar el reparto del resultado entre los dos, sea cual sea la forma en que se comparta el riesgo y los beneficios (Cañibano y Gonzalo, 1997). Así, nosotros trataremos de minimizar los costes del contrato de agencia para el empleador, en especial, si se debe suministrar información contable a los empleados, cómo va a ser ésta utilizada y los efectos en la renegociación de los contratos.

Como ya comentamos en la sección primera, en la teoría de los costes de transacción, también enfatizamos el comportamiento oportunista de los agentes. Esta teoría no pretende formalizar los contratos y se dedica más a la asignación de los derechos de decisión que al sistema de control de la actuación del agente, por lo cual hemos rechazado esta teoría a la hora de analizar los contratos laborales. Es cierto que existen costes de transacción, que se tratan de economizar (Coase, 1937; Williamson, 1975, 1979), pero el hecho de trabajar en equipo conlleva la necesidad de organizar el trabajo y controlarlo (Alchian y Demsetz, 1972); para lo cual hay que determinar las reglas de reparto del excedente de la empresa entre los que en ella colaboran, así como el mecanismo de control del que actúa como empresario.

Cuando se presenta la relación de agencia entre empleadores y empleados, algunos autores tratan de ver esta relación únicamente dentro de la teoría de elección eficiente y elección oportunista de los métodos contables, entendiéndose, la elección no como un acto neutral sino una acción orientada con efectos sobre los individuos o agentes. Dentro de esta línea se desarrolla el procedimiento del alisamiento de beneficios (Barefield y Comiskey, 1972). De hecho, se plantea la hipótesis del alisamiento de beneficios al encontrarnos ante dos sujetos con distinta medida del riesgo, por un lado el principal es neutral al riesgo, mientras que los agentes son adversos al riesgo (Beidleman, 1973). Los directivos podrían alisar el beneficio si el sistema de remuneración estuviera 
relacionado con cifras de crecimiento (Watts y Zimmerman, 1978; Ronen y Sadan, 1981). Para Smith (1976) los empleadores podrían intentar alisar el beneficio para influir en las peticiones salariales de los representantes de los trabajadores. Para Gordon (1964) una de las motivaciones de la gerencia para alisar el beneficio es la búsqueda de seguridad en el trabajo. Se busca aquel resultado contable que haga posible una tendencia sin oscilaciones apreciables, ya que los aumentos notables de beneficios llevan al aumento de presiones que se ciernen sobre la empresa, procedentes principalmente de la fuerza de trabajo y de sus organizaciones representativas. Pero, esta teoría no deja sino de ser una simple operación de maquillaje contable y cómo los directivos buscan las cifras de beneficios que más favorecen a su retribución. En este caso, los directivos son también empleados o agentes dentro de la relación con el accionista o principal de la empresa. Rechazamos este marco conceptual por quedarse limitado a simple creatividad contable. Además el esquema de compensación no es sino una parte de la relación de agencia (Koch, 1981).

Los efectos que se persiguen no sólo pueden lograrse mediante la elección de métodos que alteren la cuantificación del resultado, bien mediante alisamiento o su amplificación, sino mediante lo que Gibbins, Richardson y Waterhouse (1990) denominan políticas de revelación. Así, las políticas de revelación de las empresas son el fruto de un calculado análisis coste-beneficio; las empresas sólo divulgarán información de modo voluntario cuando las consecuencias positivas de su diseminación sean superiores a los costes que origina. En nuestro caso, planteamos un estado más avanzado que la mera revelación, centrándonos en la utilización de la información contable.

La relación empleador - empleado también ha sido analizada en la teoría de juegos de Nash, como una solución al problema de la negociación. Sin embargo, en la mayoría de los casos se plantea la 
situación donde lo que uno gana lo pierde el otro, es decir, teoría de juegos de suma cero. En nuestro planteamiento rechazamos esta aplicación ya que buscamos un comportamiento cooperativo o teoría de juegos no de suma cero sino de suma variable. Además bajo esta teoría se supone que estamos en presencia de información perfecta y completa (Nash, 1950), cuando realmente esto nunca se da en el ámbito de las relaciones laborales.

El análisis de los contratos de trabajo se hace generalmente a través del concepto de óptimo de Pareto (Namazi, 1985). Se estudian los factores de la relación principal - agente y se analiza la selección de los sistemas de información. Los sistemas de información generalmente planteados hacen referencia a tres aspectos: información contable sobre resultados únicamente, información contable sobre esfuerzo y resultados; e información que incorpore además variables endógenas. Todos estos conceptos van a ser tratados desde la teoría de la agencia (Ross, 1973; Jensen y Meckling, 1976; Atkinson, 1978, 1979).

La teoría económica de la organización interna ha adoptado dos variables principales para caracterizar los grandes problemas objeto de investigación: los objetivos de los miembros y su grado de información (Marschak, 1974). La coincidencia o no en los objetivos a perseguir entre los miembros de la organización es más o menos relevante para superar los problemas de funcionamiento eficiente según cuál sea la situación de información en que se encuentran dichos miembros. Distinguiremos entre situaciones de información donde ésta es la misma para todos los miembros y situaciones donde la información es diferente, es decir existen asimetrías en la distribución de información. Si la información es la misma para todos, y especialmente si es completa, el conflicto de objetivos dentro de la organización tiene poca relevancia en cuanto que se superará a través de la negociación entre las partes enfrentadas; con información asimétrica, traducida, por ejemplo en la imposibilidad o coste 
excesivo para que cada agente negociador sepa si los demás cumplen o no lo acordado, la negociación pura no sirve para asegurar la eficiencia en el funcionamiento de la organización. Alcanzar la eficiencia requerirá en este caso del diseño de incentivos y mecanismos de supervisión que hagan compatibles intereses individuales y eficiencia colectiva. Por lo tanto, estamos en el centro de nuestro planteamiento: agencia e incentivos.

El problema de agencia no existiría en un universo cierto, pues aún siendo divergentes los intereses del agente y del principal, los esfuerzos desplegados por el primero serían perfectamente observables y, en el supuesto de que no hubiese costes asociados a la formalización y cumplimiento de los contratos, siempre sería posible establecer un contrato que indujese al agente a comportarse conforme a los deseos del principal. La aparición del problema de agencia aparece asociada a la incertidumbre, a la imposibilidad de observar perfectamente el comportamiento del agente, y a los costes de formalización y cumplimiento de los contratos.

La Teoría de la Agencia proporciona un marco teórico útil para analizar el proceso contractual en la empresa. Define una relación de agencia todo contrato en el que al menos una parte, el agente, se compromete a realizar algo para otra parte, el principal. La relación laboral es aquella en la cual el trabajador se compromete a cambio de un salario, que puede o no ser función de diversos indicadores de productividad, a proporcionar un esfuerzo, productividad o rendimiento al empleador. El empleado usa el contrato laboral para "controlar" a la empresa, de la misma manera que el empleador lo usa para controlar al empleado (Epstein, 1984). El enfoque positivo en esta relación de agencia considera que la información contable no es una variable exógena, sino que está en interacción con las decisiones operativas, de inversión y de financiación de las empresas, desempeñando un papel crucial en la asignación de 
recursos, en la compensación salarial y en multitud de procesos de negociación (Monterrey, 1998).

Dentro de la teoría contractual, intentaremos explicar la teoría de la agencia en las relaciones laborales, es decir, el principal será el empleador y el agente será el empleado; a pesar de que en la mayor parte de las ocasiones la teoría de la agencia se ha utilizado para la relación dirección - accionista. Como en la teoría de la agencia a un nivel general, partimos de tres asunciones básicas: el empleador y el empleado son individuos diferenciados que tienen su propia función de objetivos, no coincidente. Existen asimetrías en la información, lo que implica que el empleador no pueda conocer con exactitud el comportamiento del empleado. Mientras que el empleador es neutral al riesgo, el agente es adverso al riesgo. Bajo estas asunciones surge el problema de que el empleado realice su tarea en contra de los intereses del empleador.

En este sentido, los trabajadores son los agentes de las empresas, es decir, partes que son contratadas para promover los intereses de otras. Las empresas pueden concebirse como principales, es decir, partes que contratan a otras para ayudarlas a alcanzar sus objetivos. En este caso, el objetivo de las empresas o principales son los beneficios; los trabajadores están dispuestos a ayudarlas a obtener beneficios a cambio de pagar una renta salarial. Por tanto, la relación entre los principales y los agentes se basa en el interés mutuo; la relación de empleo beneficia tanto a las empresas como a los trabajadores. Pero decir que los principales y los agentes tienen intereses en común no equivale a decir que todos sus intereses son idénticos. El problema del principal y el agente se plantea cuando los agentes persiguen algunos de sus propios objetivos que están en conflicto con los de los principales (Campbell).

Intentaremos hacer frente a una de las críticas más reiteradas de la teoría de la agencia: su aparente vinculación con los intereses de los 
inversores en detrimento de otros grupos y, muy en particular de los trabajadores (Perrow, 1986).

El Código Civil español define la relación principal - agente como un mandato en la que el mandatario (el agente) se obliga a prestar algún servicio o hacer alguna cosa por cuenta o encargo del mandante (principal). La relación principal - agente puede dar lugar a un tipo de contrato más específico que el mandato; así la relación empleado empresario es un contrato laboral que se rige por el Estatuto de los Trabajadores.

La relación empleador - empleado no es más que un contrato de empleo, que surge entre el supervisor (empleador) y los trabajadores directos (empleados) (Salas, 1996). Ese contrato es incompleto y es la autoridad una de las características esenciales. La negociación del contrato exigiría que ambas partes enumeraran las posibles contingencias de formula exhaustiva y acordaran la fórmula de intercambio para cada una de ellas. El tiempo y recursos que puede suponer la negociación, y por tanto su coste, podrían hacer desistir a las partes. Además la información es asimétrica: existe una dispersión natural de información y las partes muestran un rechazo a transmitir la información. La relación de empleo surge cuando un agente, empleador, contrata los servicios de otro, empleado, para que bajo la dirección y supervisión del primero realice las tareas que se le asignan en el ámbito de un puesto de trabajo, percibiendo a cambio una determinada remuneración. Para Simon (1951) un contrato de empleo es aquel que se hace entre los dueños de un factor de producción (los empleados) y el empleador, donde ciertos aspectos del comportamiento del empleado quedan fijados en los términos del contrato, otros quedan bajo la autoridad del empleador y otros se dejan para la decisión del empleado. 
La teoría de la agencia no sólo analizará el proceso de toma de decisiones (Ross, 1973) a partir del sistema de información contable sino que examinará los aspectos motivacionales de la información contable en las decisiones tomadas en el campo de las relaciones laborales (Baiman, 1982). El modelo de la contratación laboral podrá ser analizado en tres momentos. En primer lugar, empleados y empleadores seleccionan el contrato y el sistema de información a utilizar. En segundo lugar, el empleado selecciona y realiza su acción o esfuerzo independientemente. Y en tercer lugar, se observa el resultado, se evalúa y se asignan las recompensas según el diseño de los contratos del primer momento.

Básicamente, la teoría de la agencia es una teoría de contratación con trabajadores de producción, no sólo con directivos (Kaplan, 1984). Esta teoría asume que los agentes prefieren no ejercer el máximo esfuerzo y realizan acciones no deseadas, por lo cual necesitan ser compensados para inducirles a llevar a cabo acciones que beneficien a la empresa. La teoría de la agencia puede ser estudiada como una teoría formal que desarrolla la necesidad de información dentro de la empresa (Kaplan, 1984). Se debe buscar un sistema de información (Feltham, 1968; Demski, 1970; Butterworth, 1972; Marshall, 1972; Demski y Feltham, 1976; Feltham, 1977; Hilton, 1980; Ahituv, 1981...). Se buscará información ex - ante para que el empleado tome una decisión óptima sobre su acción o esfuerzo; e información ex - post para evaluar la acción y fijar la recompensa de esos empleados.

Dentro de esta teoría, y los múltiples objetivos de los diferentes contratantes, no podemos encontrar un objetivo propio de las empresas (Arruñada). Sólo las partes contratantes tienen atributos individuales, como objetivos o responsabilidad. El comportamiento de la empresa resulta de estos objetivos individuales. En consecuencia, el problema está en verificar qué objetivos se deben maximizar. Los objetivos pueden resultar alterados ante la separación entre propiedad y dirección, surge 
así un problema de control dado que las funciones de utilidad entre la propiedad y la dirección tienden a diverger. Las posibilidades de conflicto se manifiestan de formas muy diversas. El trabajador intenta escamotear su esfuerzo e incurre en conductas expropiatorias aprovechando su actividad laboral. Por otro lado, el empleador puede imponer unas condiciones de trabajo inferiores a las pactadas, o no pagar los salarios convenidos. Es común también que surjan diferencias al evaluar la aportación del trabajador, cuyo esfuerzo no necesariamente se relaciona con la productividad. La escasa información del principal sobre el esfuerzo y los factores externos que intervienen en la decisión del agente confieren a éste una gran discrecionalidad para perseguir sus propios objetivos.

Cuando el empleado y el empleador tienen objetivos diferentes y el empleador no puede determinar con facilidad si los informes y las acciones del empleado persiguen sus objetivos 0 responden al comportamiento interesado de éste, nos encontramos con el problema del riesgo moral. En las relaciones laborales, los empleados pueden abandonar sus obligaciones. Taylor escribió una vez "Difícilmente puede encontrarse un trabajador competente que no haya dedicado un tiempo considerable a considerar cuán despacio podría trabajar manteniendo el convencimiento de su jefe de que lo hace a un ritmo adecuado". La frecuencia con que las empresas proveen a sus empleados con incentivos y contratos que tienen en cuenta su desempeño es una prueba evidente de la importancia del riesgo moral en la relación laboral. La cantidad y calidad de los esfuerzos de los empleados son difíciles de medir directamente, mientras que los resultados pueden ser más fácilmente observados. Según Milgrom y Roberts, para que aparezca un problema de riesgo moral deben cumplirse tres condiciones: Primero, debe haber una potencial divergencia de intereses entre la gente; Segundo, debe haber bases para intercambios provechosos u otra forma de cooperación entre los individuos que activen los intereses divergentes; Tercero, debe haber dificultades para determinar si, en la práctica, los términos del 
contrato han sido respetados y para exigir su cumplimiento. Estas dificultades aparecen con frecuencia, porque el seguimiento de las acciones o la verificación de la información transmitida es costosa o imposible. Existe pues divergencia de intereses, traducida en costes, que se intenta disminuir en los contratos entre empleador y empleados.

Las empresas incurren en costes a fin de coordinar tareas altamente interdependientes, para las cuales se requiere reunir, procesar y transmitir una gran cantidad de información, desde la alta dirección hasta los destinatarios de la misma (Cuervo). Los costes de negociación son los costes de transacción asociados a las negociaciones entre las partes; incluyen el tiempo empleado y los recursos gastados tanto en negociar como en mejorar la posición negociadora, así como las pérdidas soportadas por el fracaso o el retardo en conseguir un acuerdo eficiente. Además también se incurren en costes de supervisión y costes para motivar a los trabajadores en quienes se ha delegado capacidad de decisión, costes de agencia. Estos costes existentes en la relación de agencia, van dirigidos a reducir la desviación en el comportamiento del agente respecto a los intereses del principal, es decir, reducir las posibilidades de incumplimiento y hacer posible la transacción (Arruñada, 1990).

Entre ellos podemos citar los costes de formalización contractual, los de garantía, los de control y la pérdida residual. En general, son costes de las relaciones contractuales dirigidos a eliminar el conflicto entre las partes y reducir las posibilidades de incumplimiento. Particularizando estos costes en la relación empleador - empleado, estos quedan configurados de la siguiente manera.

Los costes de formalización contractual, las partes incurren en costes para diseñar y escribir los contratos (selección), en los cuales se detallan las obligaciones que asume cada uno dentro de un conjunto 
limitado de situaciones; es decir, aún detallando un conjunto de derechos y obligaciones estamos en presencia de contratos incompletos.

Los costes de control, pagados por el principal o empleador para vigilar o condicionar positivamente la actividad del agente o trabajador; el empleador incurre en costes de control para seleccionar a los trabajadores y, sobre todo, para vigilar su actividad. También llamados costes de supervisión, son los costes derivados de las acciones emprendidas por el principal para regular el comportamiento del agente. Para que éste actúe de forma óptima, aquél puede implantar sistemas de compensación con el fin de condicionar los incentivos del agente, imponer restricciones presupuestarias o establecer todo tipo de controles. Este tipo de acciones se traducen en costes efectivos que en ningún caso podrán rebasar la cifra para la que el coste marginal esperado sea igual a la reducción marginal esperada en la pérdida residual del principal.

Los costes de garantía, abonados generalmente por el agente o empleado, para garantizar al empleador que su comportamiento no se desviará de lo previamente pactado; el empleado proporciona garantías sobre su actividad futura (titulaciones académicas); el empleador propone planes de incentivos. El agente puede estar dispuesto a incurrir en costes al objeto de garantizar al principal que no actuará en su perjuicio o que le indemnizará en caso de que llegase a adoptar tal comportamiento. Así, para mejorar su salario, el agente puede aceptar voluntariamente que en su contrato aparezcan cláusulas restrictivas de su capacidad de decisión u otras similares.

Pérdida residual o pérdida de bienestar que ocasiona la desviación de conducta del empleado respecto a lo estipulado en el contrato, que es consecuencia de ser prohibitivos los costes de formalización, garantía y control que se requerirían para un cumplimiento perfecto del contrato (estándares). 
Los costes de supervisión y fianza son, por tanto, los costes efectivos ocasionados por la formalización, administración y cumplimiento de los contratos de agencia. Por una parte, dichos costes responden a la voluntad del principal y del agente de garantizarse mutuamente la adopción de decisiones óptimas desde el punto de vista del primero; por otra, son el reflejo del esfuerzo cooperativo del agente y del principal por eliminar la pérdida residual resultante de las divergencias existentes en sus respectivas funciones de preferencia. Sin embargo, aún incurriendo en estos costes, ambas partes no conseguirán, probablemente, reducir a cero la pérdida residual o coste de oportunidad que caracteriza su relación de agencia.

En definitiva, son costes de negociar y sacar adelante el convenio laboral; incluyendo los costes de coordinación y los costes de motivación, como los de medir la actuación, crear incentivos y exigir el cumplimiento de los acuerdos para asegurar que los empleados siguen las instrucciones, cumplen los compromisos y mantienen los acuerdos. Los costes de agencia en la relación con el personal, quizás los más importantes en cuantía, se manifiestan principalmente en el diseño y organización de los sistemas de control interno, ya que cuando una parte está implicada en relaciones durante un largo periodo, es probable que compense establecer mecanismos o procedimientos que reduzcan estos costes.

También en la teoría de los costes de transacción se pueden identificar estos costes de similar naturaleza. Williamson (1985), al analizar los costes de transacción examina los costes comparativos de planificar, adaptar y supervisar la realización de tareas bajo estructuras de gobierno alternativas. Introduce la distinción entre costes ex - ante y costes ex - post. Entre los primeros incluye los costes de redactar, negociar y salvaguardar el acuerdo, mientras que los costes ex - post 
comprenden los costes de cambiar los planes, renegociar los términos, resolver las disputas y los costes de asegurar que las partes contratantes, en este caso los empleados, cumplan con los compromisos previamente adquiridos.

En la relación de agencia, se incurren en costes, ocasionados la mayor parte de las veces por la existencia de información asimétrica (Dye, 1985). La información asimétrica es especialmente objeto de estudio cuando la información es relevante para determinar un plan eficiente o para evaluar el desempeño individual. Los directivos poseen información sobre el conjunto de cifras y datos de la empresa, que no es conocida con tanta profundidad ni incluso con absoluta certeza por parte de los empleados. Por otra parte, los empleados son los únicos que conocen cual ha sido su esfuerzo aplicado en el desarrollo de las tareas. Estamos en presencia de información imperfecta e incompleta (Akerloff's, 1970). Además, al negociar los salarios en el convenio colectivo de empresa, nos encontramos con información asimétrica: el empleado o su representante sindical tiene información sobre el salario aceptable mientras que el empleador sólo conoce lo que la compañía está dispuesto a afrontar como subida salarial (Brickley, Smith y Zimmerman, 1996). Por parte de los empleadores no existe una total disposición a revelar esa información a los empleados, más bien sólo se tiende a revelar esta información cuando es negativa para la empresa y puede evitar las demandas sindicales. Este hecho, contrasta evidentemente con lo expuesto en economía financiera, donde generalmente se procede a revelar esta información cuando es positiva e incide positivamente en la opinión de los mercados.

Cuando hablamos de información se suele distinguir entre información observable e información verificable. La relación entre un empresario y sus trabajadores genera información sobre el esfuerzo y motivación del trabajador, sobre los medios que le pone a su disposición 
el empresario, que es observable por ambos pero difícilmente verificable por terceros. La cláusula de revisión de costes en un contrato por la cual el coste se ajusta a la evolución de la inflación, incluiría información verificable. Sin embargo, el dato más significativo de la información en el campo de las relaciones laborales, es su carácter de asimetría, como quedó anteriormente mencionado. Esto genera incertidumbre, ya que los empleados y empleadores sólo disponen de información parcial. El trabajador y el empresario son conscientes que el valor de los servicios de trabajo dentro y fuera de la empresa puede variar a lo largo del tiempo que se desarrolla la relación de empleo. La falta de información, y más concretamente su distribución asimétrica entre ambos, da lugar a costes o ineficiencias, como resultado de las características del proceso negociador a que se ven forzados las partes. Existe información imperfecta, más bien información asimétrica, ya que todos los agentes no disponen de stocks informacionales idénticos.

La información contable debe servir para negociar los contratos antes de y después de. Esta información debe ayudar a minimizar el oportunismo precontractual y postcontractual. Estamos en presencia de mercados imperfectos, de información limitada y la contabilidad puede ayudar a completar esta ausencia de información. La información contable anterior a la negociación del contrato puede ayudar al empleado a examinar quien va a ser su empleador, es decir, el principal de la relación. Mientras que la información contable utilizada después de haber negociado el contrato inicial ayudará a determinar los términos de la renegociación (Beaver y Demski, 1979). En definitiva, puede servir para esclarecer las posiciones y reducir los costes de la renegociación, que sin duda serían más elevados si las partes, principal y agente, no utilizaran la información contable. A pesar de ser información asimétrica debe ser útil en la negociación de los convenios laborales dentro del ámbito de las empresas. 
Estamos en presencia de contratos incompletos, y es por esa razón por la que se procede a la renegociación de los mismos. De hecho, los contratos son más bien implícitos que explícitos y con no excesivo nivel de detalle. En muchas de las cláusulas y estipulaciones de los contratos laborales, se hace referencia al convenio colectivo, es decir, el convenio colectivo laboral, va a ser el instrumento que va a concretar las generalidades de los contratos de trabajo. Son contratos a largo plazo, donde las partes tienen racionalidad limitada, ya que estos no pueden tomar en consideración todas las eventualidades que pudieran ocurrir (Hart, 1983), es decir, existen ciertas limitaciones de la capacidad de raciocinio que impiden a los empleados y empleadores prever todas las contingencias posibles de las relaciones laborales para determinar su comportamiento óptimo. Estos contratos de trabajo son bastante imprecisos, incompletos, implícitos; la propia forma de estos contratos es una respuesta a la imposibilidad de la contratación completa. Los convenios intentan especificar los términos de forma explícita y detallada.

Además de racionalidad limitada, a los empleados les disgusta que sus ingresos dependan de factores aleatorios; tienen aversión al riesgo, y aceptarían antes un ingreso de menor cuantía determinada que otro, algo mayor en promedio, sujeto a variaciones imprevisibles e incontrolables. Los riesgos creados por los contratos de incentivos son costosos para esta gente, en consecuencia, se les deberá pagar más para que acepten el riesgo. Pensamos habitualmente en los incentivos como recompensas al incremento de los beneficios asociado al comportamiento deseado; por ejemplo, motivando el interés de los empleados en la persecución del beneficio al ligar sus salarios a la rentabilidad.

La contabilidad proporciona un instrumento de control que facilita la vigilancia y fiscalización de las relaciones de agencia, satisfaciendo parte de la demanda para el control del cumplimiento contractual. Sus cifras son 
empleadas para condicionar a los agentes, de tal modo que su conducta se mantenga dentro de los términos estipulados en los contratos.

La información contable, como parte de los contratos que dan forma a la empresa, actuará como árbitro entre los grupos que la componen, regulando su organigrama y permitiendo evaluar y remunerar a sus componentes, determinando las prestaciones económicas de cada contrato (Giner Inchausti, 1990); tratando de evitar la conflictividad, consecuencia de los conflictos de intereses.

La contabilidad debe usarse como elemento comunicador, sobretodo en un modelo de agencia, donde las partes contratantes poseen diferente información (Christensen, 1981). No sólo es importante suministrar información sino transmitir el tipo de información útil para cada parte, de tal manera que mediante su utilización se consigan efectos positivos para el conjunto de la empresa.

La contabilidad puede ayudar a solucionar el problema de la motivación, asegurando que los diferentes empleados involucrados realicen voluntariamente su parte, transmitiendo la información con precisión para permitir la elaboración del plan adecuado y actuando como se supone que deben hacerlo. En principio, un contrato completo perfectamente redactado podría resolver el problema de la motivación. Pero como los contratos no suelen ser completos es por lo que surge el problema de la motivación. Los contratos son incompletos porque estamos en presencia de racionalidad limitada; pueden aparecer circunstancias imprevistas y además aún cuando las contingencias fueran previstas, exigiría un cálculo excesivamente costoso. Los contratos laborales son contratos incompletos en los que más que describir el trabajo a realizar en cada contingencia delegan la autoridad en el empresario para dirigir la actividad de los empleados, son una respuesta a la necesidad de contratación incompleta e imperfecta. El empresario y el 
empleado no negocian todas las posibles situaciones, lo que se espera es que el empleado haga lo que ordene el empresario. La última defensa del empleado contra las exigencias irrazonables es la renuncia, y la del empresario contra la negación a cumplir las órdenes es el despido. Todo esto economiza costes de contratación.

La información contable da legitimidad a las posibles peticiones de las partes. Cuando hablamos de legitimación, se hace bajo tres perspectivas: funcional, social y hegemónica (Richardson, 1987). Entendemos que dentro del problema de agencia, el papel de la información contable es minimizar los conflictos, como aparece recogido bajo la perspectiva funcional (Gambling, 1977; Tiessen y Waterhouse, 1983). También las peticiones salariales reiteradas de los trabajadores legitiman a la empresa a pedir la elaboración de nuevas normas o "estándares" (Watts y Zimmerman, 1978), para minimizar los costes políticos o de petición de los trabajadores.

Los números contables desempeñan dos funciones principales, sirviendo como herramienta para la vigilancia del cumplimiento contractual y la determinación del precio de los títulos valores en el mercado de capitales (Arruñada, 1990). Es precisamente la primera función la que resulta de fundamental importancia en nuestro desarrollo del tema. La contabilidad es un instrumento de control que facilita la vigilancia y fiscalización de las relaciones de agencia. La contabilidad satisface así parte de la demanda para el cumplimiento contractual. Los números contables son empleados para condicionar a los agentes, de tal modo que su conducta se mantenga dentro de los términos estipulados en el contrato. Prueba adicional de esta función contractual de la contabilidad la proporcionan la explicación de pautas y principios contables por el papel que desempeñan en la solución de conflictos de intereses entre las partes. 
La contabilidad puede servir como instrumento legítimo para reducir los costes de la renegociación de los contratos, los costes debidos a la posible conflictividad social, ya que la información contable puede jugar un importante papel como elemento utilizado en la negociación colectiva. La información contable es útil para afrontar la negociación, útil para la toma de decisiones por diferentes usuarios, en definitiva, para el suministro de información útil para el usuario, según el paradigma de la utilidad propugnado por Túa. La contabilidad puede dar legitimidad a una serie de operaciones (Arnold y Hammond, 1994); así por ejemplo puede servir para justificar ante la empresa y los trabajadores, los términos del convenio colectivo alcanzado entre los representantes de la empresa y los de los trabajadores. La contabilidad ha roto el viejo enfoque o paradigma de la ganancia líquida realizada, proclamando que la información contable es útil para la toma de decisiones y no sólo sirve para evaluar el proceso de medición de la utilidad operacional (Araujo, 1994).

La información contable puede ayudar a explicar el comportamiento de la empresa. Comportamiento de la empresa bajo diferentes facetas: calidad de la información, elección contable... También puede ayudar a explicar el comportamiento de los individuos, fruto de la información contable suministrada por las empresas.

La contabilidad, incluida la contabilidad de gestión, puede desempeñar un papel importante para influir en el comportamiento e incrementar el conocimiento y la innovación (Prieto Moreno, 1997). Los sistemas de información contable, como instrumentos para la evaluación y el control del rendimiento global e individual, juegan un papel de fundamental importancia en la motivación de los integrantes de la empresa, induciendo determinadas conductas y penalizando otras.

La teoría de la agencia parte de la consideración de que los sistemas contables juegan un triple papel en la empresa: facilitar la 
comunicación, mejorar la toma de decisiones y servir como mecanismo para la motivación y evaluación del rendimiento de los agentes económicos, permitiendo entender cómo influyen las señales contables en la motivación de los individuos.

\section{4.- LA ARQUITECTURA ORGANIZATIVA}

"Lo que no es útil para la colmena no lo es tampoco para la abeja", Marco Aurelio.

El concepto de racionalidad limitada subyacente en el modelo de agencia constituye, a través de su influencia en el conocimiento, el cimiento de nuevas comprensiones de la existencia de empresas y de su arquitectura organizativa.

Por el término arquitectura organizativa nos referimos a tres aspectos de la organización de la empresa: la asignación de los derechos de decisión; la estructura de los sistemas para evaluar el rendimiento; y los métodos de recompensa. En las empresas exitosas se asignan los derechos de decisión de forma que se enlace la autoridad para la toma de decisiones con la información relevante para llevar a cabo las decisiones correctas. En el momento en que se asignan los derechos de decisión, la gerencia debe asegurarse que los sistemas de evaluación y recompensas en la empresa proporcionan a los tomadores de decisiones los incentivos apropiados para llevar a cabo las decisiones que aumenten el valor (Brickley, Smith y Zimmerman, 1995). En el campo de las relaciones laborales, de la relación empleador - empleado, consideramos de notable 
interés los dos últimos aspectos: la evaluación del rendimiento y los métodos de recompensa.

Un elemento que caracteriza los mercados es la enajenabilidad o alienabilidad, entendida como la combinación del derecho a vender o transferir un derecho y el derecho a percibir los resultados del citado intercambio. La enajenabilidad tiene gran importancia porque contribuye a la resolución de los problemas de la asignación de derechos y control. Respecto al primero de ellos, si los derechos son enajenables, estos derechos tenderán a dirigirse hacia aquellos individuos que, por su conocimiento, pueden hacer un uso más eficiente de los mismos. Igualmente al vincular los derechos de decisión con su valor económico, la enajenabilidad permite medir los resultados de las decisiones e implantar sistemas de recompensas y castigos.

En las empresas, por el contrario, no existen los mismos niveles de enajenabilidad, teniendo que conseguir más ventajas de tal situación lo suficientemente grandes como para compensar los costes asociados a dicha ausencia. Las consideraciones relativas al conocimiento son una de las razones que justifican la existencia de empresas. En este caso, cuando la producción, transferencia y aplicación del conocimiento es el bien que se ofrece, los intercambios tienden a tomar la forma de relaciones a largo plazo (contrato de empleo). Si no fuera así, las relaciones contractuales se establecerían caso por caso, con la correspondiente multiplicación de los costes de transacción.

La contabilidad no puede ir fuera del objeto de la economía, y por esa razón si la economía estudia dos grandes tipos de problemas: el problema de elegir entre alternativas excluyentes, y el problema de organizar las relaciones entre agentes que cooperan en actividades de producción y de intercambio (Salas, 1996); el sistema de información contable puede facilitar los instrumentos para solucionar estos problemas. 
Nelson (1981) propone un modo de producción en términos de cuál es el tratamiento que se da dentro de él a tres funciones: regímenes de responsabilidad y autoridad, naturaleza de los flujos de información relevantes para la coordinación y los controles e incentivos que determinan cómo se toman y se ejecutan las decisiones.

Puede que los tomadores de decisiones, por ejemplo los trabajadores, incluso teniendo la información relevante que necesitan, no tengan los incentivos necesarios y apropiados para tomar estas decisiones que incrementan el valor. A los empleados se les dota de autoridad para usar los recursos de la empresa, pero ellos no son los dueños, por ello puede que tengan menos incentivos para preocuparse por el uso eficiente de los recursos que los empleadores. Para controlar este problema de agencia, es necesario desarrollar un sistema de control que sea consistente con la asignación de los derechos de decisión. Este sistema de control estará formado por un sistema de evaluación del rendimiento de los trabajadores. Además se necesita un sistema de recompensas que alinee los intereses de los empleados con los de los empleadores.

El empleador está continuamente implicado en la renegociación de los contratos, en términos tales que deben ser aceptados por ambas partes (Alchian y Demsetz, 1972). Esta aceptación por ambas partes, convierte el problema en uno de reparto, donde deberemos plantear las medidas de evaluación del rendimiento y los sistemas de remuneración de ese rendimiento.

Para evaluar el rendimiento tendríamos que ser capaces de observar el resultado o el esfuerzo de los empleados. Si la observación del esfuerzo o comportamiento del empleado no fuera costosa, en ese caso ningún empleado podría ocultar su actitud, y por lo tanto lo más lógico parece que sería que su comportamiento fuera el deseado por su 
superior, su empleador, y así evitaría la reprimenda, castigo, mejor dicho, la no recompensa por parte de éste. Pero si la observación de ese comportamiento además de costosa fuera difícil, el empleador podría replantearse la no observación, con lo que en este caso el empleado no actuaría según lo deseado por el empleador, al observarse una divergencia importante de intereses entre las dos partes en conflicto: empleador y empleado; el empleador intentaría optimizar su propio beneficio, el cual vendría relacionado con el máximo esfuerzo por parte del empleado, mientras que el empleado al buscar su propio beneficio intentaría reducir su esfuerzo al mínimo nivel. Por lo tanto habría que encontrar algún mecanismo que facilitara, aunque sea indirectamente, la observación del rendimiento del empleado, ante la imposibilidad o excesivo coste de su observación directa y de esta manera minimizar la divergencia de intereses entre el principal o empleador y los agentes o empleados. Planteamos al sistema de información contable como instrumento que sirva para facilitar la evaluación del rendimiento, de una manera no excesivamente costosa ni difícil y que evite el comportamiento oportunista de los agentes, consecuencia de esa divergencia de intereses. Si existen costes de transacción (Coase, 1937) y la empresa tiene costes menores que el mercado, quizás el sistema de información contable puede facilitar la reducción de estos costes.

Para evaluar el rendimiento de la empresa, y dentro de la empresa, los empleados que forman parte de ella, podemos utilizar la información contable financiera como sistema de evaluación de resultados generales de la misma o la contabilidad analítica, para conocer el grado de cumplimiento de los objetivos por parte de los empleados, secciones departamentos, divisiones, en definitiva de las diferentes áreas de responsabilidad dentro de la empresa. Así, por ejemplo los centros de coste y los presupuestos pueden facilitar la medición del rendimiento de cada grupo. La contabilidad de gestión sirve como instrumento de control y de influencia para conducir el comportamiento de los individuos, que 
integran la organización. Según la Teoría Positiva de la Contabilidad, la importancia de la información contable interna es parte de la tecnología contractual eficiente de la empresa, que regula no sólo el organigrama de la misma, sino también la evaluación y remuneración de los diferentes agentes.

En cuanto al esfuerzo o rendimiento, hay que tener en cuenta que en la función de utilidad de una persona, empleado, se considera además de la renta, el ocio o tiempo libre y cualquier otra ventaja no pecuniaria, por lo que la decisión entre trabajar más o menos, dependerá de la valoración que haga de estos bienes, y puede aumentarse la utilidad traspasando los costes derivados del menor esfuerzo de los demás. Así, pues se plantea la necesidad de motivar al agente para que actúe en defensa de los intereses del principal, se hace necesario la inclusión y estudio de los incentivos.

Respecto al problema de incentivos, es una consecuencia fundamental del problema de agencia que se plantea cuando las acciones que el agente realiza o debiera realizar no pueden ser observadas ni tampoco ser interferidas directamente a partir de variables observables (Azofra y De Miguel, 1992). Es un problema de información imperfecta o, más precisamente de información asimétrica entre el empleador y los empleados. Las actividades de los empleados, su esfuerzo y dedicación, sólo son conocidas por éstos y no tienen un incentivo inmediato para informar de ellas al empleador con prontitud y exactitud. La resolución del problema de agencia requiere el establecimiento de un sistema de compensación con incentivos que sirva para identificar de una forma más estrecha los intereses de los empleadores con los de los empleados.

Para desarrollar una teoría aceptable de la empresa es fundamental comprender los incentivos internos, puesto que ellos determinan en gran medida el comportamiento de los individuos dentro de 
las organizaciones (Baker, Jensen y Murphy, 1988). Aun manteniendo constante la remuneración total, la forma en que la retribución es recibida puede afectar la medida en que los diferentes objetivos sean logrados. En el centro de todo sistema de incentivos hay un método de evaluación del desempeño, con lo que se interrelacionan los dos problemas. Sería conveniente introducir ex - ante un sistema de incentivos y tener efectos redistributivos ex - post (Watts y Zimmerman, 1990).

A la hora de diseñar los sistemas de incentivos debe tenerse en cuenta que normalmente sólo se podrá conocer el resultado de la acción, y no la acción llevada a cabo por el agente, resultado que también estará condicionado por la incertidumbre que rodea a la actividad económica, además de por las asimetrías en la distribución de información entre el principal y el agente. La información imperfecta tanto sobre la acción del agente, como sobre la conveniencia de dicha acción, conducen al llamado problema principal - agente, que surge precisamente porque las acciones de un individuo, el agente, afectan a otro individuo, el principal (Stiglitz, 1989).

En el problema de los incentivos se busca la elección del sistema de información apropiado y el diseño de un mecanismo de reparto de recompensas basado en el sistema de información (Gjesdal, 1982). Podríamos decir, que uno de los aspectos fundamentales es el valor de la información.

La teoría de la agencia busca los contratos eficientes que armonicen el problema de incentivos (Holmstrom, 1979; Ricart i Costa, 1987). Se intentará diseñar el contrato que consigna una asignación eficiente de riesgos y en el que el principal y el agente coincidan en la decisión que deba tomarse (Wilson, 1968). La estructura de incentivos a considerar será un sistema de retribución que permitirá, por una parte, compensar los costes privados que les supone la transmisión de 
información en el sentido de un mayor nivel de exigencias sobre el cumplimiento de los objetivos y, por otra, incentivar al empleado a cumplir las normas de comportamiento establecidas por el empleador. En el caso de que el empleador disponga de la información relevante respecto a cada uno de los empleados, el sistema de incentivos sólo perseguirá que el empleado atienda las normas de comportamiento dictadas por el empleador. Entonces cualquier estructura retributiva del empleado que se establezca en función de la diferencia entre el nivel real de consecución del objetivo fijado y el nivel previsto del mismo nos permitirá alcanzar el propósito. El problema se complica cuando el empleador no conoce la verdadera información con un coste mínimo. El mecanismo, que permite dar forma a este entramado de contratos que constituye la empresa, no es otro que el sistema de información contable. A través de él, se puede llegar a incrementar el valor de la empresa en la medida que puede reducir la asimetría de información y la incertidumbre y, por lo tanto, los costes contractuales derivados de decisiones disfuncionales, de vigilancia y de garantía (Prieto Moreno, 1997).

Cuando se diseñan contratos de incentivos para los empleados de una empresa existen problemas de riesgo moral. Hay un balance a mantener entre la provisión de incentivos y la total supresión del riesgo. Proveer incentivos es deseable para que los empleados sean responsables de sus acciones; esto implica que la compensación de los empleados o las futuras renegociaciones deben depender de su desempeño en los puestos asignados. Los contratos eficientes equilibran los costes de soportar el riesgo con las ganancias de los incentivos que resultan de ello (Milgrom y Roberts). En la mayoría de las situaciones, los intentos de imponer a los empleados responsabilidades sobre sus acciones, les expone a riesgos porque raramente habrá medidas perfectas del comportamiento. En este tipo de situaciones, aunque la calidad del esfuerzo o la exactitud de la información no pueden ser observadas en sí mismas, con frecuencia puede inferirse algo sobre ellas 
a partir de los resultados observados y la compensación basada en los resultados puede ser una forma eficaz de proveer incentivos. El problema general de motivar a una persona para actuar en nombre de otra es conocido entre los economistas como el problema interesado - agente.

En este caso, los incentivos retributivos se recogen en los contratos denominados planes de compensación. Los planes de compensación se componen generalmente de una remuneración fija, que suele revisarse todos los años en función de la inflación, y de una remuneración variable que está conectada con distintas medidas del funcionamiento de la empresa. Generalmente la retribución depende no sólo de los resultados obtenidos por el agente sino de la comparación con los resultados obtenidos por otros agentes. Los planes de compensación más usuales (Smith y Watts, 1982) son los siguientes: planes en función del resultado contable, planes en función de la actuación, planes en función del precio de las acciones. El diseño de estos contratos de incentivos óptimos está gobernado por varios principios: principio de información, principio de intensidad de los incentivos, principio de intensidad de la vigilancia, principio de igualdad de las compensaciones, (Milgrom y Roberts).

En consecuencia, el empleador posee dos grandes vías para inducir al empleado a tener un comportamiento más acorde con sus objetivos. La primera consiste en incorporar en el contrato laboral un sistema de remuneración que haga recaer sobre el empleado una parte de la consecuencia de sus actos. La segunda consiste en supervisar la actividad del empleado, directamente, a través de terceros, o por la información contable.

Los dos problemas planteados: evaluación del rendimiento y sistemas de recompensa, han sido examinados por la teoría de la agencia. Así, los modelos de agencia se han dividido tradicionalmente en dos enfoques diferenciados. Por un lado, los modelos de acción no 
observable recogen situaciones en las que la asimetría de información viene generada por la no observación de la acción o decisión del agente; en nuestro caso la imposibilidad manifestada por parte del empleador de medir el esfuerzo de los empleados con un coste mínimo. Y por otro, los modelos de información no observable contienen los problemas de incentivos asociados con la no observación de alguna información relevante que posee el agente, los sistemas de remuneración de los empleados.

Jensen y Meckling también se ocupan de resolver estos problemas bajo lo que ellos denominan conocimiento, control y estructura organizativa. Estos autores siguen la línea de lo establecido por Hayek, quien subrayó la importancia del conocimiento para el buen funcionamiento de una economía. Sin embargo, éstos a diferencia de Hayek tienen en cuenta que existen una serie de costes en la transmisión y generación del conocimiento. Los componentes de una organización, al tratar de maximizar sus propias funciones objetivo buscan deliberadamente el conocimiento. La cuestión no es la de si puede transmitirse el conocimiento, sino a qué coste puede realizarse y si merece la pena hacerlo. El control y el conocimiento son complementarios en el análisis de las organizaciones.

Según Jensen y Meckling, si los empleados tuvieran el derecho de la enajenabilidad quedaría resuelto el problema del control, entendiendo por control tanto la medición del rendimiento para evaluar las acciones como las recompensas y castigos impuestas en consecuencia. Sin embargo, mientras que las empresas pueden vender activos, sus trabajadores no reciben el derecho a enajenar sus puestos o cualquier otro activo o poder de decisión bajo su control, ni pueden embolsarse los beneficios. Esto significa que no hay un proceso descentralizado automático que tienda a garantizar que los poderes de decisión en la empresa se dirigirán a los agentes que poseen los conocimientos 
específicos pertinentes para su ejercicio. Significa también que no hay un sistema automático de medida y recompensa del rendimiento que incentive a los agentes para utilizar sus derechos de decisión de un modo que contribuya a los intereses de la organización. Se requiere una indicación explícita por parte de la dirección y la creación de mecanismos para sustituir a la enajenabilidad.

El caso más común es el de los contratos de trabajo: estos contratos tienden a ser de naturaleza general y son rara vez enajenables. Los costes de transacción son una de las razones para la prevalencia de este tipo de contratos. El valor de los conocimientos del propietario para los competidores actuales o potenciales es otra razón a favor del mantenimiento de relaciones laborales a largo plazo, porque reduce el coste de impedir el flujo de conocimientos valiosos hacia los otros agentes. Aún en estos contratos de trabajo es imposible estructurar un sistema de incentivos y control que conduzca a los empleados a comportarse exactamente como desearía el empleador. Además, estos sistemas son costosos de diseñar y poner en práctica. Los costes de agencia son, la suma de los costes de diseño, puesta en práctica y mantenimiento de sistemas adecuados de incentivos y control, unidos a las pérdidas resultantes de la dificultad de resolver completamente estos problemas.

La determinación del nivel óptimo de descentralización exige compensar los costes de malas decisiones debidas a información deficiente y los costes debidos a objetivos contradictorios. La clave de la eficiencia es asignar los poderes de decisión a cada agente en cada nivel de un modo que se minimice la suma de costes debidos a información deficiente y a objetivos contradictorios. En consecuencia, los problemas organizativos de la empresa deberían resolverse desarrollando un conjunto de reglas del juego: distribuir los poderes de decisión entre los agentes de la empresa; crear un sistema de control que proporcione 
instrumentos para la medición del rendimiento y que especifique la correspondencia entre las recompensas y castigos y las mediciones del rendimiento. En realidad, la especificación del sistema de medida y evaluación del rendimiento, junto al mecanismo para regular incentivos, es la especificación de la función objetivo.

Estamos apoyando al funcionamiento de la organización. Las relaciones laborales se parecen a la coalición, donde cada miembro decide su participación en la tarea colectiva maximizando su propia utilidad individual, sin que exista un objetivo que represente explícitamente los objetivos del grupo. Se trata, por tanto, de la situación opuesta a la del modelo de equipo. Para superar el conflicto manteniendo los rasgos básicos del modelo de coalición, existen dos caminos principales, establecer un sistema de negociación que permita llegar a un compromiso entre lo que aporta y recibe cada uno, o diseñar un sistema de incentivos que permitiendo a los miembros de la coalición maximizar su utilidad individual, asegure de la mejor manera posible la viabilidad del grupo. La negociación exige que los acuerdos surgidos de ella sean vinculantes, al igual que la negociación laboral. Pero la coalición no asegura una eficiente asignación de los recursos, por esta razón se plantea un modelo laboral (teoría de la agencia) donde sí existen relaciones jerárquicas que permiten internalizar las externalidades, bien a través de sistemas de supervisión o bien a través de introducir sistemas de incentivos. Así, por ejemplo, Holmstrom (1982) desarrolla los premios y castigos y Alchiam y Demsetz (1972) la supervisión.

En ausencia de disciplina de mercados, las partes de la firma deben idear estrategias administrativas, para controlar el comportamiento y establecer un reparto en la capacidad de tomar decisiones. Estas dos actividades (llamadas el problema organizativo), son llevadas a cabo automáticamente por los mercados, pero deben de desarrollarse, dentro de las compañías, a través de costosas estrategias administrativas. El 
controlar el comportamiento supone medir la actuación y recompensar y castigar dicho comportamiento. Además de la medida de la actuación, todas las organizaciones deben recompensar las actuaciones favorables $y$, en algunos casos, castigar los comportamientos no deseados. Por lo tanto, todas las organizaciones deben construir tres sistemas: Sistemas que midan la actuación, sistemas que recompensen y castiguen la actuación, y sistemas que asignen capacidades de decisión.

En definitiva, la contabilidad y los sistemas de información juegan un papel fundamental en el funcionamiento de la organización (Hopwood, 1978).

\section{5.- CONCLUSIONES}

"Lo que hace un problema de un problema es que contiene una contradicción", José Ortega y Gasset.

La falta de información por parte del empleador de la actuación de los empleados conlleva el principal problema con el cual debemos enfrentarnos.

La empresa no es sino un conjunto de contratos en el cual la información va fluyendo de una manera interesada entre los partícipes en la misma.

Queremos estudiar concretamente las singularidades del contrato de empleo, cuyas características más relevantes nos permiten situarlo dentro de la teoría de la agencia. 
El marco teórico propuesto gira en torno a la Teoría de la Agencia, ya que otras alternativas como la teoría de los costes de transacción, la teoría del alisamiento de beneficios, la teoría de juegos de Nash y diferentes teorías sociológicas, quedan más alejadas de la relación contractual empleador - empleado, como ha quedado justificado. La Teoría de la Agencia, es el marco conceptual, específico para la relación empleador - empleado. Nos encontramos con individuos diferenciados, con objetivos diferentes, con información asimétrica, con racionalidad limitada, con contratos incompletos, con costes de agencia, etc. Por esta razón, la información contable podría servir para alinear los intereses contrapuestos, evitar el comportamiento oportunista, renegociar los contratos, disminuir los costes de agencia...

La información contable, debe servir también para resolver los problemas que se plantean dentro de la organización de la empresa. Debe ayudar a asignar los derechos de decisión y sobre todo a proporcionar una medida del rendimiento y una medida de compensación, por medio de castigos o recompensas, de ese rendimiento. En nuestro estudio planteamos la utilidad de la información contable para regular incentivos.

En definitiva, enmarcamos el tema dentro de la Teoría Positiva de la Contabilidad, donde ante la existencia de información asimétrica y racionalidad limitada, nos planteamos la necesidad de renegociaciones posteriores (convenios colectivos), que unido a la existencia de costes contractuales para esas renegociaciones (que se verían muy incrementados si no fuera por la existencia del sistema de información contable), nos lleva a la necesidad de la información contable para la renegociación. El sistema de información contable puede servir como mecanismo de información y control reduciendo la asimetría de la información (costes precontractuales) y los comportamientos oportunistas 
que se producen con posterioridad a la realización de los contratos (costes postcontractuales). Trataremos de demostrar la utilidad del sistema de información contable como instrumento para la reducción de los costes contractuales derivados de la renegociación de los contratos, particularizando en el posible uso de la información contable como mecanismo para regular incentivos (Hipótesis general postulada por la Teoría Positiva de la Contabilidad). 
CAPÍTULO 2: EL CONTRATO DE EMPLEO Y SUS GARANTÍAS

EN EL DERECHO POSITIVO 


\section{0.- INTRODUCCIÓN}

"El secreto de mi éxito está en pagar como si fuera pródigo y vender como si estuviera en quiebra", Henry Ford.

Dentro del nexo de contratos que constituyen la empresa, nos centraremos en el contrato de empleo, como aquel que se desarrolla entre los empleados y los empleadores. Aprovecharemos este capítulo para analizar el contrato de trabajo y las garantías que por parte del derecho positivo se recogen para el perfeccionamiento y la salvaguarda de este contrato a largo plazo; analizando el Estatuto de los Trabajadores como marco legal de referencia pero con el hecho reseñable de que la reforma laboral consecuencia de la Ley 3/2012, de 6 de julio, de medidas urgentes para la reforma del mercado laboral, modifica aspectos claves del Estatuto de los Trabajadores, que sin duda tienen su repercusión en la negociación colectiva llevada a cabo por parte de las empresas.

El espíritu del presente capítulo guarda una estrecha relación con el capítulo anterior. Se trata de un intento de llegar al contrato de empleo desde la relación contractual de agencia, en un intento de la resolución de los posibles problemas, a través de la negociación colectiva.

Así, dividimos este capítulo en tres secciones. En la primera sección, realizamos unas precisiones terminológicas del contrato de empleo, necesarias para entender los aspectos jurídicos, sociales y organizativos de este contrato en la negociación colectiva. En la segunda sección, tratamos de analizar la creciente utilidad de la información contable a través del análisis de diferentes textos legales y jurisprudencia aplicada, todo ello dentro de las garantías que debe proporcionar el derecho positivo al contrato de trabajo. Por último en la tercera sección, 
realizamos unas breves reflexiones y comentarios sobre el conjunto del capítulo.

\section{1.- EL CONTRATO DE EMPLEO}

"Debe reconocerse que el ideal de los empleadores es obtener producción sin empleados y el de los empleados obtener ingresos sin trabajar", E. F. Schumacher.

Como ya hemos analizado, el marco conceptual que nos ofrece la teoría de la agencia podemos aplicarlo a un sinnúmero de relaciones entre agentes económicos individuales; trasladando esa relación, fruto de los contratos incompletos, a un tipo concreto de relación contractual que se produce en el seno de la empresa: la relación de empleo.

Definimos el contrato de empleo como un acuerdo bilateral entre empleador y empleado que implica expectativas y comportamientos recíprocos. En el intento de satisfacer sus propias necesidades, los firmantes en el contrato intercambian algo de valor, de manera que el empleador proporciona una compensación al esfuerzo realizado por parte del empleado. En el acuerdo contractual que soporta dicho intercambio se efectúa una descripción de la relación de empleo, incluyendo cómo se organiza, gobierna, evalúa y recompensa.

Siguiendo las diferencias clasificaciones, expuestas en la sección de la teoría de los contratos del capítulo anterior, se puede considerar que nos encontramos ante un acuerdo esencialmente explícito, pese a que ciertas condiciones o ciertos acuerdos puedan ser implícitos; establecido 
tanto para el largo como para el corto plazo, según las necesidades de personal concretas de cada empresa, e incompleto, ya que no están detallados todos los compromisos a priori y acuerdos de carácter bilateral, porque la relación se establece entre empleador y cada uno de los empleados por separado. Es preciso, no obstante, reconocer la intervención en la práctica en esa relación de un tercer protagonista encargado de velar por el cumplimiento de las obligaciones contractuales, sobretodo, de aquellas que conciernen al empleador: los sindicatos. Por otra parte, también se puede considerar que el estado juega un cuarto papel en esta relación contractual, al aparecer la mayoría de las veces como garante del cumplimiento de este contrato.

Además, la posibilidad de observar el comportamiento del trabajador, con mayor o menor grado de exactitud, incentivará a retribuir en función de los comportamientos realizados o de los resultados obtenidos. En resumen, el contrato de empleo es bilateral, incompleto (explícito, aunque con partes implícitas), de duración variable (generalmente de largo plazo) y basado en comportamientos o en resultados del trabajador.

Evidenciadas las características de esa relación contractual laboral, parece claro que tanto empleador como empleado deben asumir un papel activo en la dinámica continua que supone la existencia de unos contratos incompletos y al menos en parte implícitos. Es decir, ambos deben estar abiertos a posibles renegociaciones de las condiciones de trabajo iniciales y a solucionar los posibles conflictos que puedan presentarse durante su desarrollo.

Sin embargo, hay que destacar que esta relación de empleo es peculiar frente a otras relaciones contractuales. Ésta se presenta cuando el principal, normalmente el empleador, contrata a un agente (empleado), para que realice un determinado trabajo a cambio de una compensación 
económica. No obstante, se hace preciso señalar que la relación de empleo constituye un típico ejemplo de ambigüedad cuando se trata de identificar quién asume realmente el papel de principal y quién el de agente. El empleado deja de actuar como agente cuando es el que toma la iniciativa de iniciar la tarea y de desarrollarla con gran autonomía y el empleador adopta una postura pasiva percibiendo los frutos finales de su trabajo y pagándole por ello. Se podría definir la relación de empleo como una relación de agencia mutua (Pérez Santana, 1999).

En realidad, la esencia del contrato de empleo está en el intercambio transaccional de derechos que se genera en un determinado periodo de tiempo, partiendo de la idea de que los individuos cooperan con otros para satisfacer sus expectativas particulares. En esta línea, Jensen y Meckling señalan que los intercambios voluntarios entre individuos buscan alinear sus respectivos derechos de propiedad, es decir, la posibilidad de recibir ciertos recursos que no poseen a cambio de ofrecer otros. El intercambio laboral se basa en que el trabajador ofrece esfuerzo, productividad, rendimiento, disponibilidad a cambio de que el empleador le conceda una retribución y unas determinadas condiciones de trabajo.

Sin embargo, no siempre es posible que ese intercambio de derechos se produzca con eficiencia, sino que en el marco de la agencia cabe destacar dos causas de los problemas de agencia. Así, si partimos de que los individuos son utilitaristas esto implica que tratarán de satisfacer sus intereses particulares de forma prioritaria y podrán, en consecuencia, entrar en conflicto los objetivos de empleado y empleador. Esta conflictividad se agrava cuando dichas relaciones se encuentran inmersas en contextos de incertidumbre, provocados por el desigual reparto de la información entre las partes acerca de aspectos relevantes para el acuerdo, es decir, por la existencia de asimetrías informativas. 
De este modo, cuanto mayor sea el conflicto de intereses y la brecha informativa entre ellos, mayor es la probabilidad de que el individuo que posee información privada realice conductas oportunistas que perjudiquen el buen término del acuerdo. En concreto, Arruñada (1990) señala algunos de los conflictos más comunes en la contratación laboral: 1) incumplimientos de las obligaciones contractuales, el empleado escamotea esfuerzo y el empleador el pago de la retribución o las condiciones pactadas; 2) manipulación de las mediciones del rendimiento del empleado, por parte del trabajador si persigue mayores compensaciones salariales, o por parte del empleador, cuando persigue pagar lo menos posible; 3) comportamiento aprovechado sobre el capital humano específico del empleado, si el trabajador presiona al empleador por tenerlo (huelgas) o el empleador no garantiza su continuidad en la empresa. Estos y otros problemas exigen a las partes establecer algún mecanismo de salvaguarda contractual como los desarrollados por el derecho positivo, en la siguiente sección.

El contrato de trabajo, definido en el Estatuto de los Trabajadores, será de aplicación a los trabajadores que voluntariamente presten sus servicios por cuenta ajena y dentro del ámbito de organización y dirección de otra persona, física o jurídica, denominada empleador o empresario, artículo 1 del ET.

El trabajo asalariado de cuya regulación se ocupa el Derecho del Trabajo constituye el factor primordial de la producción de bienes y servicios; de aquí que la disciplina económica y la disciplina jurídica de las relaciones laborales sean, en buena parte, coextensas: el contenido de muchas normas de Derecho del Trabajo es, evidentemente, económico.

Además en el artículo 5 del ET, se establece como deber del trabajador el cumplimiento de las órdenes e instrucciones del empresario (principal) en el ejercicio regular de sus facultades directivas. De la misma 
manera, en el artículo 20 del ET, se establece que el trabajador (agente) estará obligado a realizar el trabajo convenido bajo la dirección del empresario (principal) o persona en quien éste delegue. En definitiva, que el contrato de trabajo se presumirá existente entre todo el que presta un servicio por cuenta y dentro del ámbito de organización y dirección de otro y el lo que recibe a cambio de una retribución a aquél, artículo 8 del ET. Es decir, del análisis de estos artículos del ET podemos ver la similitud con una relación contractual de agencia entre el trabajador por cuenta ajena o agente y el empleador, empresario o principal de la relación.

Se excluye de manera clara, la actividad de las personas que intervengan en operaciones mercantiles por cuenta de uno o más empresarios, siempre que queden personalmente obligados a responder del buen fin de la operación, asumiendo el riesgo y ventura de la misma, artículo 1 del ET; considerándose una relación laboral de carácter especial, artículo 2 del ET. Lo que quiere decir que cuando se responde de la operación es porque los intereses de empleador y empleado son los mismos, es decir, no hay divergencia de intereses, que es una de las características fundamentales del contrato de trabajo o contrato de agencia, aún cuando dentro de los deberes laborales figura contribuir a la mejora de la productividad, artículo 5 del ET.

El contrato de trabajo no tiene nada que ver con el contrato societario. Mientras que en el acuerdo societario se armonizan intereses coincidentes, en el contrato entre empresario y trabajador se enfrentan intereses contradictorios; mientras que las partes que intervienen en el pacto social son jurídicamente iguales, trabajador y empresario se sitúan en posición desigual; el elemento esencial del acuerdo societario, la puesta en común de un bien con el ánimo de obtener y repartir ganancias, falta por completo en la relación trabajador - empresario. 
Dentro de las fuentes de la relación laboral, el artículo 3 del ET menciona las disposiciones legales y reglamentarias del estado; los convenios colectivos; la voluntad de las partes manifestada en el contrato de trabajo; y los usos y costumbres locales y profesionales. Con este artículo podemos apreciar que no sólo el contrato de trabajo es fuente de la relación laboral, sino que más bien ante la imposibilidad de recoger todas las posibles contingencias de la relación laboral en este contrato; se ajustarán estos contratos incompletos con otras fuentes, entre las cuales se encuentran los convenios colectivos.

En el cumplimiento de la obligación de trabajar asumida en el contrato, el trabajador (agente) debe al empresario (principal) la diligencia y la colaboración en el trabajo que marquen las disposiciones legales, los convenios colectivos y las órdenes o instrucciones adoptadas por aquél en el ejercicio regular de sus facultades de dirección y, en su defecto, por los usos y costumbres. En cualquier caso, el trabajador y el empresario se someterán en sus prestaciones recíprocas a las exigencias de la buena fe, artículo 20 del ET. La buena fe viene como consecuencia de la información incompleta de la relación contractual, en palabras de la relación de agencia, de la información asimétrica.

Las relaciones colectivas de trabajo y en particular el convenio colectivo, surge como medio de equilibrar las posiciones entre empresarios y trabajadores, cuya desigualdad había confirmado el contrato singular de trabajo. La negociación colectiva, surge pues con una significación jurídica concreta: lograr el remedio a la ineficacia de los contratos individuales, tradicionalmente colocados bajo el dominio patronal en cuanto que la relación entre un empresario y un trabajador es una típica relación entre un detentador de poder y quien no detenta el poder (relación de agencia). El convenio colectivo sirve para completar el contrato de trabajo, es decir, puede ser entendido como una norma de origen contractual. 
En la sección siguiente vamos a examinar a los integrantes de este contrato de trabajo y por consiguiente de los convenios colectivos: el trabajador y el empresario. El trabajador dependiente es titular de una serie de derechos que se mantienen en el contrato de trabajo. El trabajador también se constituye en deudor; el trabajador se compromete a trabajar, se obliga a prestar un servicio por cuenta y bajo la dependencia organizativa de un empresario. El empresario ostenta, en cuanto sujeto o parte de una relación jurídica, una posición doble, de crédito y de débito, que se corresponden respectivamente con las posiciones de deuda y de crédito del trabajador. La negociación colectiva juega un papel fundamental en armonizar las relaciones entre empleador y empleados.

\section{2.- MARCO REGULADOR}

"La ley es la conciencia de la humanidad", Concepción Arenal.

Con esta sección, pretendemos argumentar la utilidad creciente de la información contable en las relaciones laborales, entre empleador y empleados o sus representantes, mediante el análisis de diferentes textos legales y jurisprudencia. Utilizaremos citas literales de los diferentes textos, con el fin de que éstos mismos sirvan para su justificación, y así huir de argumentaciones teóricas, que quedaron expuestas en el capítulo anterior.

Con tal fin dividimos la sección en siete apartados. Así, en el primer apartado, dentro del marco de los deberes laborales, propone a la 
contabilidad como mecanismo de información y control para evaluar la labor desempeñada por los trabajadores. El segundo apartado, se dedica a la participación de los trabajadores en la empresa y cómo la información contable puede instrumentalizar esa participación. El tercer apartado, se ocupa de la modificación, suspensión y extinción del contrato de trabajo basado en causas económicas, donde la contabilidad sirve como elemento probatorio. El cuarto apartado, abarca el derecho de información de los representantes de los trabajadores, particularizado en el derecho a conocer la evolución y perspectivas económico - financieras de la empresa. El quinto apartado, trata de la cláusula de descuelgue salarial. En el sexto apartado, analizamos el marco de negociación colectiva de nuestro país: los acuerdos para el empleo y la negociación colectiva. Por último, en el séptimo apartado, se realiza un pequeño análisis de la regulación legal en otros países de nuestro entorno.

\subsection{1.- DEBERES LABORALES: LA DIRECCIÓN DE LA EMPRESA. LA INFORMACIÓN CONTABLE PARA LOS EMPLEADORES}

"Se ha permitido a la dirección que actúe como si fuera la propietaria; pero son los accionistas, no los directivos, quienes poseen las empresas, y ya están empezando a darse cuenta", Thomas Boone Pickens, JR.

Los empleados o trabajadores de la empresa no sólo poseen derechos, también tienen que cumplir una serie de deberes marcados por la dirección de la empresa. En este marco, debemos tener en cuenta que la empresa se enfrenta con tres problemas fundamentalmente: cómo medir el rendimiento de los trabajadores; como controlar el rendimiento de esos trabajadores y cómo recompensar ese rendimiento. 
Si utilizáramos el término "arquitectura organizativa" de Brickley, Smith y Zimmerman (1995) ó Jensen y Meckling (1995), dentro de los tres problemas planteados: asignación de los derechos de decisión, sistemas de control y regulación de incentivos; tratamos de resolver el tercer problema. En el momento que se asignan los derechos de decisión, la gerencia debe asegurarse que los sistemas de evaluación y recompensa de la empresa, proporcionan a los tomadores de decisiones, los incentivos apropiados para llevar a cabo decisiones que incrementen el valor. Puede que los tomadores de decisión (empleados), incluso teniendo la información relevante que necesitan, no tengan los incentivos necesarios para tomar decisiones que converjan a maximizar la utilidad de la empresa. El principal reto es maximizar la probabilidad de que los tomen las decisiones tengan: la información relevante para tomar decisiones y que tengan los incentivos para usar la información de forma productiva. El mercado proporciona una arquitectura que promueve el uso eficiente de los recursos: a través de las transacciones del mercado, los derechos de decisión sobre los recursos acaban siendo poseídos por los individuos que tienen un conocimiento específico relevante; también el mercado proporciona un mecanismo para evaluar y recompensar el rendimiento de los poseedores de recursos. Sin embargo, en la empresa, a los empleados se les dota de autoridad para usar los recursos de la empresa, pero ellos no son los dueños, por ello parece que tienen menos incentivos para preocuparse por el uso eficiente de los recursos. Para controlar este problema de agencia, es necesario desarrollar un sistema de control que sea consistente con la asignación de los derechos de decisión. Además de este sistema de control o sistema de evaluación del rendimiento, creemos de vital importancia, el sistema de recompensas que alinee los intereses de los empleados con los empleadores.

El problema organizativo planteado de esta manera se centra, por tanto, en el diseño de mecanismos que asignen los derechos de decisión, midan el rendimiento y lo premien y/o castiguen. Es en la resolución de 
este entramado, donde pensamos que los sistemas de información contable, incluidos los de carácter interno, pueden jugar un importante papel, ya que cuentan con instrumentos diseñados, entre otros fines, tanto para lograr la concurrencia de los derechos de decisión y del conocimiento, como para controlar el comportamiento de los individuos en el seno de la organización.

El artículo 20.3 del Estatuto de los Trabajadores establece que El empresario podrá adoptar las medidas que estime más oportunas de vigilancia y control para verificar el cumplimiento por el trabajador de sus obligaciones y deberes laborales... Pues bien el empresario puede utilizar la supervisión directa para asegurarse que el trabajador actúa con la máxima diligencia; pero también puede utilizar otros métodos indirectos como la medida del rendimiento del trabajador, que puede ser proporcionada por el sistema de información contable.

La cuestión que nos planteamos en este punto sería la siguiente: ¿Qué tipo de información requieren las organizaciones para evaluar y hacer un seguimiento de las actuaciones emprendidas por los trabajadores y con ello el rendimiento alcanzado? Creemos que con el fin de cubrir esta necesidad se hace imprescindible dedicar un importante esfuerzo a la implantación dentro de la organización de un sistema de información contable que actúe como mecanismo que influya, y a la vez controle el comportamiento de los individuos, y cuya información sea la base que con posterioridad justifique un sistema de recompensas.

Cuando desde estas líneas nos referimos al rendimiento desarrollado por un trabajador, no lo hacemos en los términos estrictos de la definición de este concepto, cuál sería la cantidad de salidas (outputs) que el proceso económico obtiene en un determinado tiempo de transformación, sino que lo consideramos desde una óptica más amplia. 
Para operar y sobrevivir en el entorno actual no basta con ser capaces de producir una mayor cantidad de bienes que las empresas competidoras, sino que se hace necesario desarrollar los procesos productivos siguiendo una importante pauta, cual es: producir al mínimo coste, productos o servicios que satisfagan las necesidades de los clientes y que, además, consigan satisfacer a los empleados. El cumplimiento de esta máxima es indisociable con la búsqueda y el mantenimiento de una ventaja competitiva por parte de las organizaciones y es el fundamento de lo que se ha dado en llamar programas de calidad total.

Por tanto, si pretendemos crear un sistema de medida del rendimiento donde estén recogidos todos aquellos indicadores que tienen potencial para informar sobre la forma en que se están llevando a cabo las actuaciones de los distintos miembros de la organización, hemos de incorporar, entre otras, aquellas variables que transmitan información sobre los siguientes parámetros: calidad, tiempo invertido, capacidad, etc.

Dicho de otro modo, el sistema de información contable afronta el reto de proporcionar información que va más allá de la simple recolección de datos financieros, información que se ha revelado como insuficiente, entre otras razones, porque debido al retraso en su obtención se hace imposible el acometer acciones correctoras que modifiquen la situación actual, para incorporar indicadores de carácter no financiero que van a definir, en último término, el rendimiento global de la empresa.

Consecuencia de esta capacidad, es el hecho de que la información contable posibilita el funcionamiento de un conjunto de indicadores que se articulan haciendo que la estrategia previamente concebida y diseñada por la organización, se haga más comprensible y cercana, mostrando de forma clara, la manera de contribuir a la misma, desde todos los niveles de la empresa. 
Una vez medido el rendimiento procede la compensación. El artículo 26.3 del Estatuto de los Trabajadores establece que Mediante la negociación colectiva, o en su defecto, el contrato individual, se determinará la estructura del salario, que deberá comprender el salario base, como retribución fijada por unidad de tiempo o de obra y, en su caso, complementos salariales fijados en función de circunstancias relativas a las condiciones personales del trabajador, al trabajo realizado o a la situación y resultados de la empresa... Esta situación de la empresa, es decir, la imagen fiel de la situación patrimonial, financiera y económica de la empresa viene proporcionada por la llevanza de la contabilidad siguiendo unos principios contables generalmente aceptados. Por otra parte, consideramos que dicho salario no puede ser consolidado, ya que la situación y resultados de la empresa no son fijos en el tiempo, más bien están sujetos a grandes oscilaciones por el entorno y el mercado.

\subsection{2.- DERECHOS LABORALES: PARTICIPACIÓN DE LOS EMPLEADOS EN LA EMPRESA}

"Cualquier cosa a la que denominemos realidad se nos revela solamente a través de una construcción activa en la que participamos", Ilya Prigogine.

Según las diferentes teorías del "management", se debe fomentar la participación de los trabajadores en la empresa, para de esa manera conseguir optimizar los beneficios y el valor de la empresa. Esa misma idea podemos analizarla a lo largo de los diferentes textos legales como se expone a continuación. 
El artículo 37.1 de la Constitución Española establece que la ley garantizará el derecho a la negociación colectiva laboral entre los representantes de los trabajadores y empresarios, así como la fuerza vinculante de los convenios.

El artículo 7 de la Constitución Española establece que Los sindicatos de trabajadores y las asociaciones empresariales contribuyen a la defensa y promoción de los intereses económicos y sociales que les son propios... Esa promoción se consigue con la participación de los trabajadores en la empresa como se menciona en el artículo 129 de la CE. Este artículo 129 de la CE establece que Los poderes públicos promoverán eficazmente las diversas formas de participación en la empresa...

¿Qué entendemos por participación en la empresa? Consideramos que la participación en la empresa deber ser entendida en un sentido amplio:

- Participación política, es decir participación en el gobierno y en las decisiones.

- Participación económica, es decir en los resultados.

Para participar en las decisiones de la empresa, debe existir un sistema de información, que mediante su análisis trate de optimizar los objetivos de la empresa. Una parte de ese posible sistema de información puede venir proporcionado por el sistema de información contable.

Dejando al margen la participación política, vamos a centrarnos en la participación económica. ¿Cómo hacemos esa participación efectiva? ¿Cómo se miden los resultados de la empresa? Pues bien para hacer esa participación efectiva, los trabajadores deben confiar en los resultados de la empresa, es decir, deben ser calculados de manera que representen la imagen fiel de la situación de la empresa. Así, para proporcionar una cifra 
de resultados de la empresa necesitamos utilizar la contabilidad de la empresa. La contabilidad financiera, más concretamente nos debe proporcionar el resultado de la empresa.

El artículo 4.1.g del Estatuto de los Trabajadores establece que LoS trabajadores tienen como derechos básicos, con el contenido y alcance que para cada uno de los mismos disponga su específica normativa, los de: .... participación en la empresa... El artículo 26.3 del Estatuto de los Trabajadores recoge el carácter salarial de la participación en beneficios, ya que incluye entre otros complementos salariales los fijados en función de los resultados de la empresa.

En el Estatuto de la Sociedad Europea relativo a la posición de los trabajadores establece que El órgano de dirección o de administración y los representantes de los trabajadores tendrán derecho a negociar y pactar convenios colectivos sobre aspectos que sean de interés para los trabajadores de la Sociedad Europea, incluidas las condiciones de participación en el capital o en los beneficios de la Sociedad Europea.

La Ley 10/1997, de 24 de Abril, sobre derechos de información y consulta de los trabajadores de las empresas y grupos de trabajadores de dimensión comunitaria, surge para La mejora de los instrumentos de participación de los trabajadores en la empresa..., según aparece recogido en la Exposición de Motivos.

2.2.3.- DERECHOS LABORALES: LA JUSTIFICACIÓN DE LA MODIFICACIÓN, SUSPENSIÓN Y EXTINCIÓN DEL CONTRATO DE TRABAJO 
"En este mundo, la mitad de las teorías no tienen otra razón que justificar nuestros actos", Pavel Vejinov.

Uno de los puntos dónde la información contable es más necesaria, es el recogido en el Capítulo III del Título I del Estatuto de los Trabajadores referente a la modificación, suspensión y extinción del contrato de trabajo. La contabilidad proporciona la información necesaria y suficiente para poder llevar a cabo algún tipo de modificación, suspensión y extinción del contrato de trabajo.

El artículo 40.1 del Estatuto de los Trabajadores establece que El traslado de trabajadores que no hayan sido contratados específicamente para prestar sus servicios en empresas con centros de trabajo móviles o itinerantes a un centro de trabajo distinto de la misma empresa que exija cambios de residencia requerirá la existencia de razones económicas, técnicas, organizativas o de producción que lo justifiquen, o bien contrataciones referidas a la actividad empresarial. ¿Quién pone de manifiesto la existencia de razones económicas?

El artículo 40.2 del Estatuto de los Trabajadores establece que El traslado a que se refiere el número anterior deberá ir precedido de un periodo de consultas con los representantes de los trabajadores... Dicho periodo de consultas deberá versar sobre las causas motivadoras de la decisión empresarial y la posibilidad de evitar o reducir sus efectos, así como las medidas necesarias para atenuar sus consecuencias para los trabajadores afectados. El análisis de la información contable nos puede proporcionar las causas económicas. La cuantificación de la aplicación de las medidas necesarias para solucionar esa situación puede venir definida por la contabilidad previsional.

El artículo 40.4 del Estatuto de los Trabajadores reitera este aspecto, Por razones económicas, técnicas, organizativas o de 
producción..., la empresa podrá efectuar desplazamientos temporales de sus trabajadores...

El artículo 41.1 del Estatuto de los Trabajadores establece que La dirección de la empresa, cuando existan probadas razones económicas, técnicas, organizativas o de producción podrá acordar modificaciones sustanciales de las condiciones de trabajo... "Se entenderá que concurren las causas a las que se refiere este artículo cuando la adopción de las medidas propuestas contribuya a mejorar la situación de la empresa a través de una más adecuada organización de sus recursos, que favorezca su posición competitiva en el mercado o una mejor respuesta a las exigencias de la demanda" (versión no vigente del ET) "Se considerarán tales las que estén relacionadas con la competitividad, productividad u organización técnica o del trabajo en la empresa" (Versión vigente desde Julio 2012).

También podemos utilizar la información contable no sólo para la modificación sino para la suspensión del contrato. El artículo 45.1.j del Estatuto de los Trabajadores establece que El contrato de trabajo podrá suspenderse por las siguientes causas... causas económicas, técnicas, organizativas o de producción.

El artículo 47.1 del Estatuto de los Trabajadores establece que El contrato de trabajo podrá ser suspendido, a iniciativa del empresario, por causas económicas, técnicas, organizativas o de producción... "La autorización de esta medida procederá cuando de la documentación obrante en el expediente se desprenda razonablemente que tal medida temporal es necesaria para la superación de una situación de carácter coyuntural de la actividad de la empresa" (Versión no vigente del ET). "Se entiende que concurren causas económicas cuando de los resultados de la empresa se desprenda una situación económica negativa, en casos tales como la existencia de pérdidas actuales o previstas, o la disminución 
persistente de su nivel de ingresos ordinarios o ventas. En todo caso, se entenderá que la disminución es persistente si durante dos trimestres consecutivos el nivel de ingresos ordinarios o ventas de cada trimestre es inferior al registrado en el mismo trimestre del año anterior (Versión vigente).

Abundando en la misma línea, el artículo 47.2 del Estatuto de los Trabajadores (versión vigente) estable que La jornada de trabajo podrá reducirse por causas económicas, técnicas, organizativas o de producción...

El artículo 48.1 del Estatuto de los Trabajadores establece que $A$ I cesar las causas legales de suspensión, el trabajador tendrá derecho a la reincorporación al puesto de trabajo reservado... Los representantes sindicales deberían evaluar la información contable para comprobar cuando cesan esas causas económicas.

Además de la modificación y suspensión, El contrato de trabajo se extinguirá por despido colectivo fundado en causas económicas, técnicas, organizativas o de producción... y por causas objetivas legalmente procedentes según establece el artículo 49.1.i y 49.1.I del Estatuto de los Trabajadores.

Según el artículo 51.1 del Estatuto de los Trabajadores ... se entenderá por despido colectivo la extinción de contratos de trabajo fundada en causas económicas, técnicas, organizativas o de producción, cuando, en un periodo de noventa días, la extinción afecte al menos a ... "Se entenderá que concurren las causas a las que se refiere el presente artículo, cuando la adopción de las medidas propuestas contribuya, si las aludidas son económicas, a superar una situación económica negativa de la empresa o, si son técnicas, organizativas o de producción, a garantizar la viabilidad futura de la empresa y del empleo a través de una adecuada 
organización de los recursos" (Versión no vigente del ET). "Se entiende que concurren causas económicas cuando de los resultados de la empresa se desprenda una situación económica negativa, en casos tales como la existencia de pérdidas actuales o previstas, o la disminución persistente de su nivel de ingresos ordinarios o ventas. En todo caso, se entenderá que la disminución es persistente si durante dos trimestres consecutivos el nivel de ingresos ordinarios o ventas de cada trimestre es inferior al registrado en el mismo trimestre del año anterior. (Versión vigente del ET). Esta extinción requiere autorización de la autoridad laboral que la prestará en función del respaldo documental de dichas circunstancias y de las medidas propuestas (Antes de la reforma).

El artículo 51.2 del Estatuto de los Trabajadores establece que La comunicación a la autoridad laboral y a los representantes legales de los trabajadores deberá ir acompañada de toda la documentación necesaria para acreditar las causas motivadoras del expediente y la justificación de las medidas a adoptar, en los términos que reglamentariamente se determinen (Antes de la reforma). Después de la reforma, la comunicación a los representantes legales de los trabajadores y a la autoridad laboral deberá ir acompañada de una memoria explicativa de las causas del despido colectivo y de los restantes aspectos..., así como de la documentación contable y fiscal y los informes técnicos...

El artículo 52.c del Estatuto de los Trabajadores referente a la extinción del contrato por causas objetivas establece que El contrato podrá extinguirse cuando exista la necesidad objetivamente acreditada de amortizar puestos de trabajo por alguna de las causas previstas en el artículo 51.1 de esta ley y en número inferior al establecido en el mismo.

La concurrencia de razones objetivas, económicas o de los otros tipos no ha sido suficiente como causa que justifique la decisión de despedir, se exige la documentación que lo acredite. Así en la Sentencia 
del Tribunal Superior de Justicia de Cataluña de 17/6/96 se dijo que el legislador no ha aunado a una situación económica negativa o a disfunciones técnicas la medida extintiva ... será además preciso que se acredite que tal medida contribuye a superar dicha situación negativa o a garantizar la viabilidad futura de la empresa y el empleo.

En el despido objetivo es necesario ver hasta qué punto la situación económica va por delante de las normas jurídicas, y va a ser la situación económica la que va a condicionar la aplicación de estas normas. Los conceptos jurídicos de causas económicas, técnicas, organizativas o de producción se determinan no por la norma jurídica sino que son influidos por la economía. En el despido objetivo hay un hecho actual y una finalidad de futuro; el hecho actual hay que probarlo $y$ acreditarlo.

Según Sentencia del Tribunal Superior de Justicia de Castilla y León de 14 de Abril de 1997, el despido objetivo requiere el concurso de tres elementos. El primero es la concurrencia de una causa o factor desencadenante de los problemas de rentabilidad o eficacia, según cuatro esferas de posible afectación; la de los medios o instrumentos de producción (causas técnicas); la de los sistemas y métodos del trabajo personal (causas organizativas); la de los productos o servicios que la empresa pretende colocar en el mercado (causas productivas); y la de los resultados de explotación (causas económicas, en sentido restringido). El segundo elemento sería la amortización de uno o varios puestos de trabajo, de tal modo que la medida ha de formar parte de un plan o proyecto de recuperación del equilibrio de la empresa. Y, por último, la conexión de funcionalidad o instrumentalidad entre la extinción o extinciones de los contratos de trabajo y la superación de la situación desfavorable. 
Como hemos comentado, según el artículo 51.1 y 52.c del Estatuto de los Trabajadores, la causa económica equivale a situación económica negativa de la empresa. ¿Qué se entiende por situación económica negativa? Vamos a examinar los diferentes supuestos que pueden producirse. Beneficios decrecientes, la sentencia del TSJ de Castilla y León (Valladolid) de 29 de Noviembre de 1994 afirma que ya no se precisa una situación prácticamente crítica sino que basta una mala evolución de los beneficios; sin embargo, otras muchas sentencias y opiniones doctrinales discrepan de estos criterios y mantienen que no puede ser considerado como constitutivo de causa económica el simple hecho de que los beneficios empresariales se hayan ido reduciendo año a año. Pérdidas, no toda clase de pérdidas puede ser tenida en cuenta a este objeto, pues no puede concederse relevancia a este fin a pérdidas de escasa entidad, en proporción al volumen de la empresa; para que puedan ser tomadas en consideración las pérdidas han de ser importantes, en relación con las coordenadas económicas y envergadura de la compañía. La situación económica negativa ha de estar vigente y ha de ser real y efectiva en el mismo momento en que se lleva a cabo el despido; si las pérdidas se produjeron en el ejercicio inmediato anterior, pero ya se han superado en el momento en que la empresa despidió al trabajador, no puede de ningún modo, considerarse procedente el despido. La situación de pérdidas no tiene por qué ser irreversible al no requerirse la situación de crisis definitiva. La situación negativa ha de referirse a la empresa en su totalidad, no sólo a una sucursal, delegación, departamento, división, etc. Ahora bien, el hecho de que las pérdidas de ciertas porciones o elementos parciales de la empresa no den lugar a la aplicación de causas económicas, no significa que no puedan adoptarse, por razón de tales pérdidas, medidas organizativas o de producción; por el contrario es totalmente posible, en principio que se lleven a cabo tal clase de medidas con el objeto de eliminar esas pérdidas parciales. Pérdidas endémicas, sufridas desde mucho atrás, en estos casos estimamos que no puede ser de aplicación el despido por causas 
económicas. Pérdidas debidas a la gestión del empresario quedan muy definidas en la Sentencia del Juzgado de lo Social no 31 de Madrid de 28 de Septiembre de 1994 la deficiente gestión empresarial no impedirá la prosperabilidad de la medida, salvo en los supuestos de despidos dolosos $y$ fraudulentos.

Situación económica negativa que la jurisprudencia tendía a asimilar las que hoy están vigentes en la nueva versión del Estatuto de los Trabajadores). "Se entiende que concurren causas económicas cuando de los resultados de la empresa se desprenda una situación económica negativa, en casos tales como la existencia de pérdidas actuales o previstas, o la disminución persistente de su nivel de ingresos ordinarios o ventas. En todo caso, se entenderá que la disminución es persistente si durante dos trimestres consecutivos el nivel de ingresos ordinarios o ventas de cada trimestre es inferior al registrado en el mismo trimestre del año anterior.

Para probar la existencia de causas económicas se utilizarán por el empresario los documentos propios de las cuentas anuales de los empresarios que se regulan en los artículos 34 y siguientes del Código de Comercio; así como los que determinaba el artículo 171 del Real Decreto Legislativo 1564/1989, de 22 de Diciembre, en cuanto a las sociedades anónimas, y el artículo 84 de la Ley 2/1995, de 23 de Marzo, en cuanto a las compañías de responsabilidad limitada (Hoy Título VII de Ley de Sociedades de Capital) Pero como la situación de crisis ha de estar vigente en el momento del despido, momento que no es fácil que coincida con el cierre del ejercicio precedente, además se ha de acreditar, mediante los documentos contables, informes y auditorías pertinentes que en dicho momento sigue existiendo en la empresa la situación de pérdidas. 
En el Real Decreto 1483/2012, de 29 de octubre, por el que se aprueba el Reglamento de los procedimientos de despido colectivo y de suspensión de contratos y reducción de jornada, en su artículo 4, se concreta la documentación necesaria en los despidos colectivos por causas económicas.

1. En los despidos colectivos por causas económicas, la documentación presentada por el empresario incluirá una memoria explicativa que acredite, en la forma señalada en los siguientes apartados, los resultados de la empresa de los que se desprenda una situación económica negativa.

2. Para la acreditación de los resultados alegados por la empresa, el empresario podrá acompañar toda la documentación que a su derecho convenga y, en particular, deberá aportar las cuentas anuales de los dos últimos ejercicios económicos completos, integradas por balance de situación, cuentas de pérdidas y ganancias, estado de cambios en el patrimonio neto, estado de flujos de efectivos, memoria del ejercicio e informe de gestión o, en su caso, cuenta de pérdidas y ganancias abreviada y balance y estado de cambios en el patrimonio neto abreviados, debidamente auditadas en el caso de empresas obligadas a realizar auditorías, así como las cuentas provisionales al inicio del procedimiento, firmadas por los administradores o representantes de la empresa que inicia el procedimiento. En el caso de tratarse de una empresa no sujeta a la obligación de auditoría de las cuentas, se deberá aportar declaración de la representación de la empresa sobre la exención de la auditoría.

3. Cuando la situación económica negativa alegada consista en una previsión de pérdidas, el empresario, además de aportar la documentación a que se refiere el apartado anterior, deberá informar de los criterios utilizados para su estimación. Asimismo, deberá presentar un informe técnico sobre el volumen y el carácter permanente o transitorio de esa previsión de pérdidas basado en datos obtenidos a través de las cuentas anuales, de los datos del sector al que pertenece la empresa, de 
la evolución del mercado y de la posición de la empresa en el mismo o de cualesquiera otros que puedan acreditar esta previsión.

4. Cuando la situación económica negativa alegada consista en la disminución persistente del nivel de ingresos o ventas, el empresario deberá aportar, además de la documentación prevista en el apartado 2, la documentación fiscal o contable acreditativa de la disminución persistente del nivel de ingresos ordinarios o ventas durante, al menos, los tres trimestres consecutivos inmediatamente anteriores a la fecha de la comunicación de inicio del procedimiento de despido colectivo, así como la documentación fiscal o contable acreditativa de los ingresos ordinarios o ventas registrados en los mismos trimestres del año inmediatamente anterior.

No obstante, a pesar de la literalidad de la norma en cuanto a la extinción del contrato por causas económicas; dentro de la propia jurisdicción de Burgos, podemos encontrarnos con tratamientos muy distintos, como podemos destacar en las siguientes sentencias.

Sentencia TSJ de Castilla y León (sede Burgos) de fecha 1/10/2014 en la cual se desestima pretensión de la Delegación de Trabajo de la Junta de Castilla y León sobre nulidad de acuerdo de regulación de empleo por causas económicas, con las siguientes fundamentos de derecho entre otros... Se entiende que concurren causas económicas cuando de los resultados de la empresa se desprenda una situación económica negativa, en casos tales como existencia de pérdidas actuales o previstas, o disminución persistente del nivel de ingresos ordinarios o ventas. Indicándose en la STS de 25 de junio de 2014, señala que la decisión judicial deberá valorar no solo la situación actual negativa, sino si concurre un nexo de razonabilidad entre lo pretendido y la causa desencadenante invocada. La situación económica negativa, o los cambios en la demanda de productos o servicios, que la empresa pretenda colocar en el mercado, deben relacionarse razonablemente con 
los contratos de trabajo que se pretenden extinguir, puesto que dicha relación es el presupuesto constitutivo para la extinción contractual. Ahora bien, para la justificación del despido económico o productivo, es preciso que concurran los siguientes requisitos:

a). Acreditar la situación económica negativa o, en su caso, cambios en la demanda de los productos y servicios que la empresa quiera colocar en el mercado.

b). Determinar de qué modo las situaciones descritas inciden en los contratos de trabajo que se pretenden extinguir.

c). Probar la adecuación de las medidas adoptadas para hacer frente a dicha necesidad.

De tal manera que no se ha liquidado, en el marco legal actual, la funcionalidad entre la causa económica y productiva y las extinciones contractuales, sino que ha modificado su formulación, que ya no exigiría a la consecución de objetivos futuros, como preservar o favorecer la posición competitiva de la empresa, o prevenir una evolución negativa de la misma o mejorar la situación de la misma, bastando con que el empresario acredite la concurrencia de causas económicas y productivas, y la proporcionalidad de la medida, ...

Sentencia TSJ de Castilla y León (sede Burgos) de fecha 10/07/2014 en la cual se desestima recurso de suplicación frente a sentencia que declaraba la improcedencia del despido por causas económicas, con las siguientes fundamentos de derecho entre otros... Producida la reforma, concretada en el RDL 10/2010 de 16 de junio EDL 2010/91481 y la Ley 35/2010 de 17 de septiembre EDL 2010/177120, es tesis común que la misma viene a facilitar el despido objetivo: suprimiendo la declaración del mismo como nulo en los supuestos de defectos formales que dan lugar a partir de ahora a la declaración de improcedencia, ampliando el supuesto de extinción por causas económicas, al incluir, junto a las pérdidas actuales, las previstas y la disminución persistente de ingresos al suprimir en las causas técnicas, organizativas o productivas la exigencia de que la medida sirva para 
superar las dificultades que impidan el buen funcionamiento de la empresa, al suprimir la exigencia en los despidos objetivos de que exista "la necesidad objetivamente acreditada de amortizar puestos de trabajo" que exigía el Art. 52 ET EDL 1995/13475 y que ahora ha desaparecido. Ahora bien, siendo esto así hay que tener en cuenta que en la propia exposición de motivos de la ley 35/2010 se establece como objetivo fundamental "reforzar los instrumentos de flexibilidad interna en el desarrollo de las relaciones laborales $y$, en particular, las medidas de reducción temporal de jornada, como mecanismo que permita el mantenimiento del empleo durante las situaciones de crisis económica, reduciendo el recurso a las extinciones de contratos y ofreciendo mecanismos alternativos más sanos que la contratación temporal para favorecer la adaptabilidad de las empresas". Que el Art 51, tanto para las causas económicas, como para las restantes, sigue exigiendo el requisito de la razonabilidad de la decisión extintiva, que ha de adoptarse con una finalidad cuya acreditación incumbe a la empresa, a saber que en las causas económicas la medida extintiva ha de servir para preservar o favorecer la posición competitiva de la empresa en el mercado, que en las restantes ha de servir para favorecer la posición competitiva igualmente o dar una mejor respuesta a las exigencias de la demanda. Mantiene, pues, el legislador el juicio de razonabilidad lo que obliga al órgano judicial en cada caso a examinar si las causas existen, y si la medida es razonable para conseguir los fines que justifican la extinción acordada...

\subsection{4.- DERECHOS LABORALES: DERECHO DE INFORMACIÓN A LOS REPRESENTANTES DE LOS TRABAJADORES}

"Ser libre, hoy, es estar informado", George Menager.

Los trabajadores o sus representantes deben estar informados como ya quedó mencionado en los apartados anteriores. Esto es debido a 
su implicación en la participación de la empresa y para conocer, cuantificar y tratar de evitar las situaciones negativas como consecuencia de la existencia de causas económicas que motiven la modificación, suspensión y extinción del contrato de trabajo. Además el derecho a la negociación colectiva del artículo 4 del Estatuto de los Trabajadores también implica derecho a estar informado.

Así el artículo 64.1 del Estatuto de los Trabajadores establece que El comité de empresa tendrá derecho a ser informado y consultado por el empresario sobre aquellas cuestiones que puedan afectar a los trabajadores, así como sobre la situación de la empresa... (incorporado en la nueva redacción del ET).

El artículo 64.2 del Estatuto de los Trabajadores especifica el derecho de información: El comité de empresa tendrá las siguientes competencias: a) recibir información que le será facilitada trimestralmente, al menos, sobre la evolución general del sector económico al que pertenece la empresa; b) sobre la situación económica de la empresa y la evolución reciente y probable de sus actividades, incluidas las medioambientales que tengan repercusión directa en el empleo, así como la producción y ventas, incluido el programa de producción...

El artículo 64.4 del Estatuto de los Trabajadores (en su nueva versión) recoge expresamente que el comité de empresa, con la periodicidad que proceda en cada caso, tendrá derecho a conocer el balance, la cuenta de resultados, la memoria y, en el caso de que la empresa revista la forma de sociedad por acciones o participaciones, de los demás documentos que se den a conocer a los socios, y en las mismas condiciones que a éstos. ¿Por qué no se recoge expresamente que tendrá derecho a conocer las cuentas anuales, ya que de manera expresa se está dejando fuera el estado de cambios en el patrimonio neto y el estado de flujos de efectivo? 
Según el artículo 1 de la Ley 10/1997, de 24 de Abril, sobre derechos de información y consulta de los trabajadores de las empresas y grupos de trabajadores de dimensión comunitaria, La presente ley tiene por objeto regular los derechos de información y consulta de los trabajadores en las empresas y grupos de empresas de dimensión comunitaria. Entendido ese derecho de información, en su más amplio sentido, también tienen derecho al conocimiento proporcionado por el sistema de información contable. El artículo 12.1 establece que Sin perjuicio de la autonomía de las partes, el acuerdo entre la dirección central y la comisión negociadora deberá contener... d) las atribuciones del comité de empresa europeo y el procedimiento de información y consulta del mismo. El artículo 18.1 establece que El comité de empresa europeo tendrá derecho a ser informado y consultado sobre aquellas cuestiones que afecten al conjunto de la empresa o grupo de empresas de dimensión comunitaria $o$, al menos, a dos centros de trabajo o empresas del grupo situados en Estados miembros diferentes. El artículo 18.2 establece que Sin perjuicio de otras cuestiones que puedan plantearse, en la reunión anual se analizarán aquellas relacionadas con la estructura de la empresa, su situación económica y financiera, la evolución probable de las actividades, la producción y las ventas, la situación y evolución probable del empleo, las inversiones, los cambios sustanciales que afecten a la organización, la introducción de nuevos métodos de trabajo o de producción, los traslados de producción, las fusiones, la reducción del tamaño o el cierre de empresas, centros de trabajo o partes importantes de éstos, y los despidos colectivos.

En la Carta Comunitaria de los Derechos Sociales Fundamentales de los Trabajadores, en su artículo 17 se establece que La información, la consulta y la participación de los trabajadores debe desarrollarse según mecanismos adecuados y teniendo en cuenta las practicas vigentes en los diferentes Estados miembros. El artículo 18 lo matiza: Esa 
información, esa consulta y esa participación deben llevarse a cabo en el momento oportuno, y en particular en los casos siguientes: ... cambios tecnológicos,... reestructuraciones..., con motivo de procedimientos de despido colectivo, ... con trabajadores transfronterizos...

En la Directiva 94/45/CE del Consejo, de 22 de Septiembre de 1994, sobre la constitución de un comité de empresa europeo o de un procedimiento de información y consulta a los trabajadores en las empresas y grupos de empresas de dimensión comunitaria también se recogen estos aspectos en el artículo 7.

En el Estatuto de la Sociedad Europea, relativo a la posición de los trabajadores, se establece: Artículo 5 Los trabajadores de la Sociedad Europea estarán representados por un órgano denominado órgano propio. El órgano de dirección o de administración de la Sociedad Europea informará al órgano propio, como mínimo cada tres meses, de la marcha de los asuntos de la Sociedad Europea y de su evolución previsible, teniendo en cuenta, en su caso, las informaciones relativas a las empresas controladas por la Sociedad Europea que puedan tener una incidencia significativa en la marcha de los asuntos de dicha Sociedad Europea. El órgano de dirección o el órgano de administración comunicará sin demora al órgano propio cualquier información que pueda tener repercusiones importantes en la situación de la Sociedad Europea. El artículo 6 establece que Podrán establecerse otros modelos distintos de los indicados en los artículos 4 y 5, mediante convenio... El convenio celebrado deberá, como mínimo, garantizar a los representantes de los trabajadores de la Sociedad Europea a) la información trimestral...

Una vez apuntado el esquema legal de reconocimiento de potestades de información a unos concretos sujetos colectivos con funciones de representación del personal, resta ahora concretar ese 
derecho de información. En primer lugar habría que diferenciar entre potestades expresas y potestades implícitas de información.

Las potestades expresas de información serían aquellas que están enunciadas positivamente en la norma y cuya cobertura material ha sido señalada por el legislador mediante la utilización bien de mecanismos de atribución genérica, bien de mecanismos de atribución específica o taxativa. Como potestades informativas que quedan identificadas por la mera indicación expresa de la materia general sobre la que recaen podemos encontrar la referente a la información económica empresarial, como quedó mencionado anteriormente. El mecanismo de atribución específico o taxativo implicaría, desde la norma, señalar el contenido exacto de la información a suministrar.

Junto al anterior mecanismo de otorgamiento positivo expreso, ya genérico, ya taxativo, de potestades de información, y como excepción, es posible aludir a otros poderes de información cuya atribución normativa tan sólo puede deducirse de otros poderes o facultades reconocidos expresamente por la ley y de la posición jurídica singular que ésta construye. Entrarían, pues, conceptualmente dentro de los denominados poderes inherentes o implícitos que pueden inferirse por interpretación de las normas más que por su texto directo. Se trata así de determinadas potestades de información implícitas, no previstas expresamente en la norma pero que resultan necesarias para el cumplimiento de otras funciones o poderes de los representantes de los trabajadores. Nos referimos especialmente a la información suministrada en el transcurso de la negociación colectiva, cuya inicial cobertura por el principio de buena fe para negociar, obliga la referencia al estándar de la buena fe, aplicable al ámbito colectivo.

La función genérica de defensa y promoción de los intereses de los trabajadores exige de sus representantes actuaciones o intervenciones de 
carácter puntual, estén o no previstas expresamente en las normas, y en consecuencia requieren la plena disponibilidad de todos aquellos medios instrumentales que las pueden hacer efectivas, entre ellas, y de un modo esencial, la posesión de una adecuada información de tipo económico. Hay que resaltar que estamos hablando de plena disponibilidad, así que el contenido del Estatuto de los Trabajadores tiene una naturaleza de disposición mínima, susceptible no sólo de mejora desde la negociación colectiva sino también desde posiciones interpretativas. También de un modo implícito el Estatuto de los Trabajadores cubre y reconoce la facultad de los representantes de los trabajadores de solicitar y exigir una información, esté o no nominada expresamente en la norma, cuando aquella encuentre su base justificativa en el ejercicio de esa función representativa.

Así, del contenido del artículo 64 del Estatuto de los Trabajadores, podemos deducir que la pretensión normativa no ha sido la de destacar exhaustivamente la materia precisa sobre la que debe recaer la obligada información, sino tan sólo la de dar una mera indicación, de carácter mínimo, de lo que el empresario ha de informar a los representantes de los trabajadores, dejando en última instancia que sean la particular complejidad empresarial y la función representativa que en ella se desarrolla, las que precisen los documentos o informaciones que en su caso y en su momento deben ser puestos en conocimiento de los representantes de los trabajadores.

Además, el último inciso del artículo 61.4.,a) del Estatuto de los Trabajadores exige para los representantes de los trabajadores el mismo tratamiento que se dispense a los socios a la hora de acceder a la información societaria, tanto en el examen de determinados documentos como en la facultad de exigir información adicional sobre la base de intereses individuales de los socios y específicos de los representantes que han sido originados por el ejercicio de sus funciones representativas. 
En definitiva, que los representantes son también titulares de la misma relación jurídica de contenido informativo que une a socios y administradores.

Esa interpretación finalista del reconocimiento de las potestades informativas en general, y de la referente a aspectos económicos en especial, encuentra por lo demás su articulación práctica en facilitar una labor informativa por parte de los mismos representantes, que no puede quedar obstaculizada o impedida por criterios excesivamente formales y restrictivos originados por un simple ajuste a una norma expresa y detallada. Por el contrario, ha de reconocerse en principio, y sobre una base justificativa clara en el ejercicio de actividades representativas, cualesquiera demandas informativas de los representantes que directa o indirectamente tuvieran afectación con aspectos económicos generales de la empresa.

La negociación colectiva puede constituir asimismo ámbito de cobertura de aplicación de la teoría de los poderes implícitos de información. El suministro de una determinada información por quien la detente a la otra parte que carece de ella, puede verse sin duda como instrumento de ayuda, de cooperación, de respeto hacia la posición negociadora de la contraparte, en suma, expresión de una real intencionalidad de conseguir un acuerdo final, es decir, el convenio colectivo. El suministro de oportuna información a la otra parte podría justificar las propias posturas y pretensiones en la negociación.

En atención a este criterio de la relevancia de una información por la necesidad de justificar o acreditar las posiciones negociadoras, la exigencia de un suministro vendría a cumplir así con dos tipos de objetivos. Por un lado, salvaguardar la capacidad negociadora de la contraparte, en tanto que ésta se vería claramente mermada e incluso negada si no cuenta con los necesarios elementos de juicio con los cuales 
proseguir la negociación. Y por otro lado, impedir que la mera alegación de determinadas razones justificativas de una propuesta, y la negativa a proporcionar los medios necesarios para su acreditación pueda provocar un impasse negocial que culminase con la ruptura de la negociación misma, defraudando así el deseo de la otra parte de buena fe de llegar a un acuerdo.

\subsection{5.- DERECHOS LABORALES: OTROS DERECHOS EN LA NEGOCIACIÓN}

"El genio convierte la excepción en regla", Eugenio Trias.

Cuando se dan una serie de circunstancias económicas puede dirigirse la negociación colectiva, dejando de aplicar normas aún vigentes. Siendo muy importante resaltar la evolución surgida con la modificación del Estatuto de los Trabajadores, fruto de la reforma laboral. Con la redacción actual se puede dejar de aplicar tanto el convenio colectivo del sector como el de empresa, mientras que en la anterior redacción sólo era referido al convenio sectorial o de ámbito superior.

En la redacción anterior, el artículo 82.3 del Estatuto de los Trabajadores establece que... Sin perjuicio de lo anterior, los Convenios Colectivos de ámbito superior a la empresa establecerán las condiciones y procedimientos por los que podría no aplicarse el régimen salarial del mismo, a las empresas cuya estabilidad económica pudiera verse dañada como consecuencia de tal aplicación. Si dichos Convenios Colectivos no contienen la citada cláusula de inaplicación, esta última sólo podrá producirse por acuerdo entre el empresario y los representantes de los trabajadores cuando así lo requiera la situación económica de la empresa. 
En la redacción vigente, artículo 82.3 del Estatuto de los Trabajadores... sin perjuicio de lo anterior, cuando concurran causas económicas, técnicas, organizativas o de producción, por acuerdo entre la empresa y los representantes de los trabajadores legitimados para negociar un convenio colectivo... se podrá proceder ... a inaplicar en la empresa las condiciones de trabajo previstas en el convenio colectivo aplicable, sea este de sector o de empresa ...

Hasta tal punto se pretende particularizar y flexibilizar la relación laboral, acorde con las condiciones económicas de cada empresa, que el propio artículo 84 del Estatuto de los Trabajadores recoge que la regulación de las condiciones establecidas en un convenio de empresa, que podrá negociarse en cualquier momento de la vigencia de los convenios colectivos de ámbito superior, tendrá prioridad aplicativa respecto del convenio sectorial....

El artículo 85.3 del Estatuto de los Trabajadores establece que Sin perjuicio de la libertad de contratación a que se refiere el párrafo anterior, los Convenios Colectivos habrán de expresar como contenido mínimo lo siguiente... c) procedimientos para solventar de manera efectiva las discrepancias que puedan surgir para la no aplicación de las condiciones de trabajo a que se refiere el artículo 82.3. En la redacción anterior, al ser sólo previsto la inaplicación del convenio sectorial se recogía que... para la no aplicación... en el ámbito del convenio cuando éste sea superior al de empresa, de conformidad con lo establecido en el artículo 82.3.

\subsection{6.- LA EVOLUCIÓN DE LA NEGOCIACIÓN COLECTIVA:}


"Soy realista. Ser realista es preferir una reforma modesta, que permita otra, a un milagro imposible", Alí Bourguiba.

Los convenios colectivos son una parte muy importante para establecer las condiciones laborales de los trabajadores, siendo mayor su referencia en los últimos años del estudio.

El primer acuerdo para la Negociación Colectiva data de 1997, siendo el siguiente en el año 2002 (fecha de inicio del trabajo de análisis de los convenios colectivos de empresa de Burgos); pero es a partir de este año 2002, cuando se publican nuevos acuerdos-compromisos para la Negociación Colectiva.

En el Acuerdo para la Negociación Colectiva 2002 se recoge que ...la moderación de costes salariales y la flexibilidad interna de las empresas resultan de efectiva aplicación, en especial ante situaciones de dificultades de las empresas que pudieran dañar el empleo...La negociación colectiva no es ajena a la situación económica. ..CCOO, UGT, CEOE y CEPYME consideramos que la negociación salarial debe tomar como primera referencia la inflación prevista, fijada por el Gobierno para el año 2002. En segundo lugar, puede haber incrementos superiores a la inflación prevista dentro de los límites derivados del incremento de la productividad.

Queremos destacar: el Acuerdo para el Empleo y la Negociación Colectiva 2010,2011 y 2012; y II Acuerdo para el Empleo y la Negociación Colectiva 2012,2013 y 2014; como referencias actuales para el proceso de negociación abierto entre patronal y sindicatos para renovar a partir de 2015 el II Acuerdo, que estableció una senda de moderación salarial y de beneficios empresariales (junio 2015). 
En el acuerdo para la Negociación Colectiva 2010, 2011, 2012 se recoge que los criterios para determinar los incrementos salariales deberán ser objetivos y tener en consideración las realidades específicas de cada sector o empresa. ...Cláusula de inaplicación: La llamada cláusula de inaplicación del régimen salarial o de descuelgue salarial forma parte del contenido mínimo de los convenios colectivos de ámbito superior al de empresa.

En el II Acuerdo para la Negociación Colectiva 2012, 2013, 2014 (todavía antes de la reforma laboral) se recoge que Los convenios sectoriales deberán propiciar la negociación en la empresa, a iniciativa de las partes afectadas, de jornada, funciones y salarios por ser el ámbito más adecuado para configurar estas materias. $Y$ ello sin perjuicio de otras alternativas complementarias a los convenios de empresa, como son los acuerdos o pactos de empresa suscritos por sujetos legitimados en el artículo 87.1 del ET. ..El ámbito superior de negociación debe respetar el equilibrio contractual de las partes a nivel de empresa hasta el término de la vigencia de este convenio colectivo...Es necesario preservar el ámbito provincial de negociación y favorecer que tales convenios, por su proximidad a la empresa, potencien la flexibilidad que la misma necesita para adaptarse a un mercado cambiante y competitivo, además de no olvidar que es el ámbito de negociación que más cobertura facilita a empresas y trabajadores.

Flexibilidad en materia salarial: Los firmantes consideran conveniente que las estructuras salariales tengan complementos variables, de forma que un porcentaje determinado de la cuantía salarial se haga depender de la situación y resultados de la empresa. ..A efectos de posibilitar esta implantación, se ha de tener en cuenta que mediante acuerdo entre la empresa y la representación legal de los trabajadores se podría modificar la estructura y cuantías salariales vigentes a través del artículo 41 del ET...Los convenios colectivos debieran promover la 
racionalización de las estructuras salariales, para sustituir conceptos retributivos obsoletos e improductivos por otros vinculados a la productividad y retribuciones en la empresa...En tal sentido, la negociación colectiva constituye un instrumento adecuado para establecer la definición y criterios de una estructura salarial (conceptos fijos y variables, salarios mínimos, complementos $u$ otros) adecuada a la realidad sectorial y de empresa, teniendo en cuenta su directa relación con los nuevos sistemas de organización del trabajo y los incentivos a la producción, la calidad o los resultados, entre otros...A tal fin, en la definición de los conceptos variables deberían tomarse en consideración criterios de objetividad y claridad en su implantación; la delimitación de porcentajes de retribución variable sobre la retribución total; los derechos de información y participación en la empresa de los representantes de los trabajadores y la consideración de realidades específicas de cada sector o empresa...Por otro lado, los convenios colectivos deberán incluir componentes adicionales de actualización de salarios basadas en la evolución de indicadores económicos (salario variable) asociados a la marcha de la empresa (beneficios, ventas, productividad, etc.). De forma preferente, los incrementos derivados de estos componentes adicionales de actualización se integrarán en la parte variable del salario, que debe adecuarse a la realidad sectorial y empresarial.

Inaplicación: Las causas que justifican la inaplicación temporal en la empresa de alguna de las condiciones laborales pactadas en el convenio sectorial -incluido régimen salarial o cualquiera de las condiciones laborales enumeradas en el párrafo anterior- debe ser determinada por el mismo, que podrá contemplar, entre otras, la disminución persistente del nivel de ingresos; o cuando la situación y perspectivas económicas de la empresa pudieran verse afectadas negativamente por la aplicación de aquellas condiciones, siempre y cuando se justifique la inaplicación por su afectación al mantenimiento del empleo. Para la concreción de tales causas, los negociadores podrán 
tomar como referencia parámetros que permitan objetivar la justificación, como son, entre otros, la disminución de resultados, de ventas o de productividad en el último ejercicio o en los doce últimos meses. Siendo recomendable que se defina asimismo, con carácter previo, por las partes no sólo el concepto sino también el referente cuantitativo -porcentual o el que se estime oportuno-que determina que se active la inaplicación.

Cada vez se particulariza más las relaciones laborales, habiendo una corriente muy importante partidaria de ligar los salarios a elementos como la productividad o los beneficios de las empresas. En el proceso de negociación seguido para firmar la renovación del II Acuerdo para el Empleo y la Negociación Colectiva, firmado el 8 de junio de 2015, ha habido múltiples desencuentros, apuntando como puntos más destacables los siguientes:

El principio de acuerdo (Febrero 2015) entre la patronal CEOE, CEPYME y los sindicatos mayoritarios, CCOO y UGT, incluía una subida salarial de entre el $0,6 \%$ y que podría llegar al $1 \%$ en determinadas empresas que se encuentren en situación especialmente favorable. No obstante las posturas sindicales empezaron con diferentes pretensiones: así para un escenario de crecimiento se exigía que la subida salarial tenga en cuenta el IPC y la productividad; mientras que la CEOE proponía la subida salarial ligada al crecimiento de la economía española (PIB). Los sindicatos, no obstante, llegaron incluso a aceptar la subida salarial vinculada al PIB, pero incluyendo a la inflación como referencia para su revisión.

El Banco de España, en su informe "Negociación Colectiva, rigideces salariales y empleo" publicado en Abril 2015, se llegó a alinear con la CEOE al reclamar mayor flexibilidad salarial en la negociación colectiva. Desde la Secretaría de Estado de Empleo, se muestra el interés 
del ligar salarios a elementos como la productividad o los beneficios de las empresas.

Finalmente en el acuerdo firmado en junio de 2015 para la negociación colectiva 2015,2016 y 2017, los salarios podrían subir hasta un $1 \%$ en 2015 y hasta un 1,5\% en 2016. El pacto incorpora también una cláusula de revisión salarial frente a la inflación que, en su caso, operará de la siguiente forma: los convenios negociados deberán tener en cuenta que el sumatorio de los salarios de 2015 y 2016 será mayor a la suma de las inflaciones de ambos años, en función proporcional de los salarios inicialmente pactados, es decir, las empresas y los sectores podrán actualizar los salarios a partir de que los precios suban más allá del 2,5\%, entre la suma de 2015 y 2016. De esta forma, ambas partes, se han encontrado en la mitad del camino, entre las propuestas de unos y de otros. La subida salarial para 2015, situada en un techo del $1 \%$, era la propuesta máxima de CEOE y CEPYME. Los empresarios empezaron la negociación ofreciendo un incremento para 2015 del 0,6\%.Para 2016, su propuesta estaba entre el 1,3\% y el 1,5\%, que al final es el techo salarial propuesta para 2016. Los sindicatos empezaron la discusión pidiendo una subida de las retribuciones para este año del 1,5\%. Sin embargo, a medida que ha transcurrido la negociación han admitido el techo del 1\%. Los empresarios han hecho una concesión en la redacción del acuerdo, con una cláusula de revisión respecto a la inflación que, en principio, se negaban rotundamente a aceptar, porque no querían que los salarios recuperaran la referencia de la inflación.

En este III acuerdo para el empleo y la negociación colectiva 2015, 2016 y 2017, se recogen numerosas ideas que hemos ido plasmando a lo largo de todo el trabajo, que nos gustaría traer a colación. Así se recoge que la negociación colectiva es el espacio natural... para facilitar la capacidad de adaptación de las empresas, fijar las condiciones de trabajo y modelos que permitan mejorar la productividad... Se fija, dentro de los 
derechos de información y consulta, que dentro de la empresa se facilite información sobre la situación económica de la empresa... Dentro de los criterios en materia salarial, los convenios colectivos han de promover la racionalización de las estructuras salariales, con el fin de renovar los conceptos retributivos con criterios objetivos y de equidad, dando entrada a aquéllos que se encuentran vinculados a la productividad y resultados en la empresa ... Aún habiendo fijado un incremento salarial máximo para cada uno de los años, los negociadores deberán tener en cuenta las circunstancias específicas... de tal manera que los porcentajes de incremento salarial podrán modularse en cada sector o empresa dentro de los límites derivados del incremento de productividad ...

La reforma laboral vigente ha pretendido consagrar la descentralización de la negociación colectiva y el descuelgue de los convenios. En tal sentido, la sentencia del Tribunal Constitucional de 22 de enero de 2015, explica que la norma impugnada "parte de la consideración de la empresa como un espacio especialmente propicio para la negociación colectiva de cara a la fijación de las condiciones de trabajo que resulten ajustadas a las concretas características y necesidades de la empresa y sus trabajadores", razón por la que "ha optado por dar preferencia al resultado de una negociación descentralizada" (convenio de empresa) cuando se trata de regular condiciones de trabajo que afectan a determinadas materias. Por tanto, "ni imposibilita la negociación colectiva de ámbito superior sobre las materias respecto de las cuales se prevé tal prioridad ni resta eficacia normativa a la regulación sectorial ya existente, que seguirá siendo de aplicación en todas las empresas de su ámbito que no aprueben su propio convenio colectivo".

Una vez firmado este acuerdo, la Comisión Europea en las recomendaciones en materias de política económica y reformas que el ejecutivo comunitario ha dirigido a España, reclama que los salarios se 
vinculen a la productividad, teniendo en cuenta las diferencias entre regiones, sectores y empresas. Así el ejecutivo comunitario apuesta por "promover el alineamiento de los salarios y la productividad, en consulta con los interlocutores sociales y de acuerdo con las prácticas nacionales, teniendo en cuenta las diferencias locales y las condiciones del mercado laboral, así como las divergencias en resultados económicos entre regiones, sectores y empresas".

\subsection{7.- LA REGULACIÓN EN OTROS PAÍSES DE NUESTRO ENTORNO}

"Inteligencia es la capacidad de aceptar el entorno", William Faulkner.

Como ya hemos comentado, el marco legal de la regulación de la negociación colectiva en España la constituye fundamentalmente el Estatuto de los Trabajadores.

Se puede observar que la información, que debe ser suministrada a los representantes de los trabajadores por la dirección de la empresa puede clasificarse en tres categorías: información económica de carácter general; información contable de carácter externo; e información contable de carácter interno.

En Alemania, el suministro de información contable a los trabajadores por parte de las empresas está regulado por la "Betriebsverfassungsgertz" y la "Mitbestimmengsgesetz". El suministro de información con fines sociales es en Alemania una parte más de las cuentas anuales y la participación de los trabajadores y sus representantes en el proceso de toma de decisiones es un fenómeno 
aceptado, y, además, los sindicatos juegan un importante papel en este proceso.

En Francia, existe el informe Sugreau, en el cual se regula la información financiera que tienen que suministrar las empresas a los trabajadores en el proceso de negociación colectiva.

En Bélgica, existe un Real Decreto, dedicado específicamente a regular qué información financiera y económica tienen que suministrar las empresas a los sindicatos y como debe hacerse tal suministro. Se dice que los trabajadores tienen el mismo derecho a la información financiera y económica que la propia empresa y que esta información deberá estar auditada e, incluso, que el Comité de Empresa podrá solicitar comentarios a los auditores. Se recoge la siguiente información: información básica, información de carácter anual e información de carácter periódico.

En el Reino Unido, es en la Employment Protection Act de 1975 donde se obliga a las empresas a suministrar información a los sindicatos para la negociación colectiva.

La legislación norteamericana recoge que cualquier empresa se encuentra bajo la obligación de ofrecer información necesaria y relevante al sindicato para la elaboración del convenio colectivo. Aún así, no especifica qué tipo de información debe ser proporcionada por la empresa.

Según Laffarga (1993), las prácticas sobre el suministro de información financiera son más avanzadas en materia de regulación en los países de la Europa Continental, aunque no igual en todos, que en los del área de influencia anglosajona, el Reino Unido y Estados Unidos, aunque éstos últimos se preocupen más por la calidad de la información que de la cantidad de la misma. 
A pesar de la diferencia existente entre la legislación laboral de diferentes países europeos, desde la década de los años sesenta se produjeron variados intentos comunitarios de introducción de fórmulas de información y consulta a los representantes de los trabajadores. Se intentaron dos canales de homogeneización. El primero de ellos, intentaría establecer un canal de representación general de los intereses de los trabajadores en la empresa, de fuerte inspiración germánica. El segundo de ellos, a través de Directivas cuyo objetivo inmediato era la introducción de garantías de protección de los trabajadores en determinadas situaciones, que a tal efecto, como uno de los instrumentos de tutela, pretendían introducir derechos de información y consulta.

Los proyectos canalizados a través de la primera de las vías, que pretendían la formulación de un diseño global de la representación de los trabajadores, fracasaron por la fuerte impronta germanista de los proyectos, que como tales no eran bien aceptados por aquellos estados miembros con modelos normativos y sindicales diversos a los de Alemania. Así ocurrió con la denominada propuesta de $5^{a}$ Directiva referente a la estructura de las sociedades anónimas y a los poderes y obligaciones de sus órganos, así como a la propuesta de Directiva Vredeling, sobre derechos de información y consulta de los trabajadores en las empresas multinacionales.

Por el contrario, sí que tuvieron resultados positivos aquellas otras propuestas de Directivas que en modo alguno pretendían introducir una filosofía general de convergencia institucional, sino tan sólo de introducción indirecta de derechos de información y consulta como objetivos meramente instrumentales de tutela de las condiciones de trabajo de los trabajadores. 
Bruselas ha propuesto un marco general para desarrollar la negociación sobre sus estrategias, que llevará a una armonización de las legislaciones nacionales en este campo. La Comisión considera que mantener bien informados a los trabajadores, no sólo en lo que atañe a las puras relaciones laborales sino también en torno a la vida de la compañía, irá en beneficio de la fortaleza del mundo empresarial.

El enfoque de la Comisión trata de canalizar la regulación comunitaria de los derechos de información y consulta de los trabajadores mediante su inclusión en la Carta Comunitaria de los Derechos Sociales fundamentales. Los artículos 17 y 18 de la Carta Comunitaria de Derechos Sociales Fundamentales se refieren al reconocimiento a nivel comunitario de un derecho de información, consulta y participación de los trabajadores.

También las Resoluciones del Parlamento Europeo sobre los problemas sociales y de empleo insistían en la necesidad de que los trabajadores participen, mediante representantes elegidos por sufragio directo y voto secreto, en las decisiones de su empresa y disfruten de derechos de información y consulta, especialmente en las empresas multinacionales (Resolución de 16 de Abril de 1985).

La Directiva 2002/14/CE del Parlamento Europeo y del Consejo, de 11 de marzo de 2002, por la que se establece un marco general relativo a la información y a la consulta de los trabajadores en la Comunidad Europea - Declaración conjunta del Parlamento Europeo, el Consejo y la Comisión relativa a la representación de los trabajadores establece... la información y la consulta de los trabajadores, que abarca tres ámbitos relativos a la empresa: las evoluciones de carácter económico, financiero y estratégico; la estructura y la evolución previsible del empleo y las medidas derivadas ;y las decisiones que puedan provocar cambios 
sustanciales en la organización del trabajo y en las relaciones contractuales.

La medida, que afectará a todas las empresas con al menos cincuenta empleados, obliga a los empresarios a facilitar información sobre los contratos, la actividad de la empresa y su gestión. La Comisión considera que el nuevo mecanismo de consultas a los trabajadores reforzará la dimensión social de la UE y tendrá efectos positivos para la economía europea, ya que la iniciativa servirá para incrementar la motivación de los trabajadores y aumentará la productividad laboral. La directiva establece un marco concreto sobre la información y consulta a los trabajadores. Se obliga al empresario a informar a los trabajadores sobre la evolución, tanto reciente como previsible, de las actividades de la empresa, así como de la situación económica y financiera. También se deberá informar a los representantes de los trabajadores sobre la situación laboral, su estructura y la evolución previsible del empleo en el seno de la empresa, así como la evaluación hecha por el empresario sobre el empleo que puede estar amenazado. Además se tendrá que informar a los trabajadores sobre los cambios sustanciales en lo que se refiere a la organización del trabajo y de las relaciones contractuales.

La directiva prevé que en este último aspecto el empresario trate de lograr un acuerdo con los trabajadores antes de adoptar esa decisión. En caso de que se adopte una decisión relativa a este último punto violando gravemente la obligación de información y consulta a los trabajadores, la medida no tendrá valor jurídico en las relaciones contractuales, hasta que se haya rectificado la violación o se haya hecho una reparación adecuada. La consulta a los trabajadores deberá efectuarse con base en un diálogo o intercambio de puntos de vista. La propuesta específica lo que se entiende por consulta: el derecho de los representantes de los trabajadores a reunirse con el empresario para obtener una respuesta motivada sobre algún punto concreto. La 
propuesta deja en manos de los Estados miembros cómo los interlocutores sociales deben establecer para cada empresa los dispositivos propios de información y consulta de los trabajadores. Algunas de estas informaciones que se dan a conocer a los representantes de los trabajadores pueden caer dentro del epígrafe de informaciones confidenciales, que éstos no pueden revelar incluso cuando haya expirado su mandato. Por otro lado, el empresario puede no tener la obligación de comunicar ciertas informaciones cuando la violación de su confidencialidad pudiera afectar de manera grave a la empresa.

\section{3.- CONCLUSIONES}

"El sentido común llevado a un grado nada común es lo que el mundo llama sabiduría", Samuel Coleridge.

El término poder es un término de extendida utilización en muy diferentes contextos y con sentidos muy distintos. Para los economistas de empresa es habitual decir que alguien perteneciente a una organización tiene un mayor poder de negociación si está en condiciones de obtener una fracción mayor del excedente producido por la organización. La fuente principal del poder surge del valor de los recursos que cada participante en la organización haya aportado al proceso de producción. Así concebido, el poder dentro de la organización hace referencia al control que los individuos ejercen sobre los recursos susceptibles de crear valor, pero a un control de naturaleza diferente al que vendría determinado a través de un contrato explícito en un mercado competitivo. 
Históricamente una de las principales fuentes de poder ha sido la conferida por los mecanismos legales previstos en la ley: las fuentes del iure de poder. Desde esta perspectiva, la concepción anterior del poder en las organizaciones pudiera parecer poco consistente pues, en ella, se hacía referencia a los derechos de control sobre los recursos no especificados en los contratos voluntarios. Pero esta inconsistencia es sólo aparente pues, en un mundo de contratación incompleta, los contratos no pueden contemplar los derechos y obligaciones de las partes en todas las contingencias. Precisamente a través de determinados mecanismos legales, la ley ofrece a las partes derechos de control con eventualidades no previstas en los contratos, los derechos conocidos como derechos residuales de control.

Probablemente, el mecanismo de iure más poderoso ofrecido por la ley es la propiedad. La ley permite a los individuos ser los propietarios tanto de activos físicos como de activos intangibles, y los propietarios pueden no sólo contratar sus activos con la organización en los términos que consideren oportunos, sino que la propiedad les confiere también el derecho a especificar cómo deben utilizarse sus activos en aquellas situaciones no contempladas en los contratos de empleo. Es este derecho de control el que proporciona poder al propietario en cualesquiera negociaciones sobre el uso del activo. Naturalmente, el poder del propietario depende del mayor o menor grado de importancia del derecho residual de control y del mayor o menor grado de unicidad del activo, es decir, del coste de reemplazar este último.

El control del capital humano debiera ser en la empresa moderna una fuerte de poder más importante que el control sobre los activos físicos, pues casi todos los derechos de control sobre aquel son de carácter residual, es decir, no son derechos que puedan asignarse a través de un contrato. Ello es debido a que la ley no permite que una 
persona pueda transferir a otra los derechos residuales de control sobre su capital humano durante un periodo ilimitado de tiempo.

En el mundo real, los contratos no son completamente contingentes y la ley no puede garantizar con su perfección el cumplimiento de los mismos. Por ello, las organizaciones tienen que negociar continuadamente en el tiempo los derechos y las obligaciones de las partes sin poder limitarse a adherirse a un contrato.

Los sistemas de relaciones laborales vienen caracterizándose, desde hace algún tiempo, por ser cada vez más cooperativos y menos conflictivos, a pesar de la divergencia de intereses entre las dos partes de la relación de empleo. Esto es, la cooperación, la colaboración ha ganado terreno a costa del conflicto, del antagonismo, de la confrontación. Estamos ante unas relaciones laborales más cooperativas, con una buena dosificación del papel que juegan en las mismas el conflicto y la colaboración. Nueva dosificación que, por una parte ha venido impuesta por la evolución de las circunstancias económicas, tecnológicas y productivas, y por otra ha sido favorecida por la propia dinámica sindical.

Por otra parte, quizás motivado por la coyuntura económica negativa global, estamos asistiendo a una importante reordenación de las organizaciones sindicales, que exige revisar, y reducir, el papel jugado por el conflicto en el desarrollo de la acción sindical, aumentando los márgenes de la negociación y de la corresponsabilidad frente a la de actitud de pura denuncia u oposición. En estos momentos, la tutela de los intereses de los trabajadores puede llevarse a cabo mejor desde planteamientos de cooperación, de transmisión de información que desde planteamientos de conflicto $u$ oscurantistas. Antes que oponerse sistemáticamente a las decisiones empresariales de carácter económico, resulta más fructífero conocer la causa de esa decisión y colaborar en su 
aplicación; aunque a veces esa participación pueda modificar, considera en muchos casos casi de carácter inamovible.

Cada uno de los grupos que se relacionan con la empresa, incurren en un proceso de intercambio con la empresa, proporcionando algún tipo de activo o aportación a la empresa a cambio de una contraprestación, siendo de aplicación los principios vistos en el análisis del enfoque de agencia. En este sentido, la denominada teoría stakeholder, construida como una generalización del modelo de agencia, se caracteriza con incluir las relaciones contractuales en las que todos los partícipes de la empresa se ven envueltos.

Por último, destacamos que las nuevas condiciones económicas, tanto globales, como las relacionadas con la situación económicofinanciera particular de cada empresa, favorecen la participación descrita. La participación en el nuevo entorno económico, mejora la eficiencia industrial, permite usar de manera más eficiente las capacidades de los trabajadores, reduce la oposición de éstos a los cambios tecnológicos u organizativos, y debe conseguir, en general, una mayor satisfacción de los trabajadores, en sintonía con los objetivos perseguidos por el conjunto de la empresa.

Es esa búsqueda de la consecución de los objetivos comunes, los que favorecen la negociación colectiva y evidencia las novedades legislativas en materia de suspensión, modificación y extinción de contratos por un lado; y la inaplicación de parte de los convenios colectivos de empresa por otra parte; aspectos que bajo nuestro punto de vista deben servirse de la información económica facilitada por los sistemas de información contable de las empresas.

No sólo juega la empresa juega un papel cada vez más importante sino que incluso el propio centro de trabajo es un elemento clave a 
considerar. El Tribunal de Justicia de la UE en sentencia de 13 de mayo de 2015 que la definición de despido colectivo empleada en la ley española es contraria al derecho de la Unión. La sentencia ve ilegal que la normativa española utilice la empresa como única unidad de referencia, y no el lugar del centro de trabajo, a la hora de determinar si los despidos deben calificarse como colectivos. No parece por tanto razonable en estos momentos la referencia única a los convenios colectivos sino que debe hacerse a los convenios colectivos de empresa y si fuera posible a los convenios colectivos de centros de trabajo.

Incluso ahondando en la negociación, parece cada vez más claro que se debe particularizar lo más posible para flexibilizar las condiciones no sólo al centro de trabajo sino incluso a los propios trabajadores. En sentencia de la Audiencia Nacional de fecha 18 de marzo de 2015, se desestima la demanda formulada por sindicato que sostenía que la implantación unilateral por parte de la empresa de un programa, en el que se establece un mecanismo de evaluación de los empleados compensando su esfuerzo y dedicación mediante una recompensa económica variable, vulnera su derecho a la negociación colectiva. Se desestima porque ni la voluntad empresarial al establecer este programa, ni la voluntad individual de los trabajadores manifestada por la aceptación de la oferta voluntaria formulada por la empresa, puede entenderse modificación, alteración o desconocimiento de lo pactado con carácter general por el convenio colectivo de empresa. 
CAPÍTULO 3: REVISIÓN DE LA LITERATURA TEÓRICA Y EMPÍRICA: ESTADO ACTUAL DE LA CUESTIÓN 


\section{0.- INTRODUCCIÓN}

"Si no somos corresponsales del pasado, tampoco tendremos derecho a reclamarnos legítimos propietarios del futuro", Fernando Savater.

El tema de la información contable y las relaciones laborales, y como particularidad la información contable en la negociación colectiva de las empresas, ha sido tratado por diferentes autores y bajo diferentes puntos de vista. Sin embargo, a pesar de su importancia se han obtenido pocas conclusiones evidentes (Lau y Nelson, 1981). En este capítulo, pretendemos realizar una revisión bibliográfica de los diferentes aspectos que tienen relación con el tema; para posteriormente y con base en la opinión racionalmente fundamentada por los diferentes autores, decantarnos por el análisis de un aspecto en particular: la utilización de la información contable en la renegociación de los contratos, es decir, su uso en la negociación colectiva y específicamente, la utilidad de la información para regular los incentivos, es decir, su posible utilidad para determinar las variaciones salariales incluidas dentro de los convenios colectivos de empresa.

Con tal motivo, dividimos este capítulo en nueve secciones. En primer lugar, encuadramos el tema dentro del marco teórico, desarrollado minuciosamente en los capítulos anteriores. En segundo lugar, trataremos de justificar porqué los empleados son usuarios de la información contable. En la tercera sección, planteamos la información contable que se suministra a los empleados, una vez quedó analizado que éstos son usuarios de la información. En cuarto lugar, examinamos cuándo se suministra esta información contable a los empleados. En la quinta sección, evaluamos la reacción de los empleados ante ese suministro de la información contable y a la oportunidad de su transmisión en diferentes 
momentos. En sexto lugar y como punto central, contrastamos la utilidad de la información contable en la negociación colectiva para ambas partes, empleadores y empleados. En la séptima sección, desarrollamos las ideas de otros autores, de disciplinas distintas a la contabilidad, y que también se preocupan por este tema. En la sección octava, como paso previo a las conclusiones, describimos la relevancia de este tema por su relación con los aspectos sociales de la contabilidad. Por último, realizamos unos comentarios y breves conclusiones sobre la revisión bibliográfica.

El origen del estudio de este tema podemos citarlo en un trabajo de Pillsbury "Organized labor's view of corporate financial information" publicado en 1958. Su desarrollo posterior tuvo su momento culminante entre los años 1980-1990, y sobre todo en Alemania, Estados Unidos, Gran Bretaña y los países escandinavos. En España, apenas hay estudios sobre el tema, si exceptuamos los trabajos de Pons (1996) y Laffarga (1993). Al inicio de los 90, el tema queda estancado; recuperando nuevamente su oportunidad y relevancia a finales de los años 90, como queda patente en el congreso de la Asociación Europea de Contabilidad (E.A.A.) celebrado en Antwerp (Bélgica) en Abril de 1998, donde se vuelve a plantear la necesidad de retomar el tema, en palabras del profesor Hassink. A partir del año 2000, no ha habido nuevas aportaciones relevantes, a pesar de que las circunstancias económicas desfavorables parece que sugieren una mayor relación con los planteamientos necesarios en las revisiones salariales de los convenios colectivos de las empresas. Además, gran parte de esta concepción de la información contable para los empleados, está subyacente en las diferentes posturas de las empresas hacia la responsabilidad social, donde los empleados son un grupo de interés interno a considerar en igual medida que lo son los socios y accionistas. 


\section{1.- LA INFORMACIÓN CONTABLE COMO POSIBLE SOLUCIÓN EN LA RENEGOCIACIÓN DE LOS CONTRATOS: EVALUACIÓN DEL RENDIMIENTO Y MÉTODOS DE RECOMPENSA}

"El espacio intersubjetivo es esencialmente asimétrico", Emmanuel Lévinas.

La información contable, planteada en términos de las relaciones laborales, nos puede servir para evaluar el rendimiento y como mecanismo de control (Baiman y Demski, 1980). Esto significa que puede ayudar a resolver uno de los problemas organizativos planteados por Jensen y Meckling (1995): sistema de control (Prince, 1963; Golembiewski, 1964; Caplan, 1966; Hofstede, 1968; Hopwood, 1973). Esto implica una doble vertiente: un problema de evaluación del rendimiento y un problema de fijación de métodos de recompensa. Nos encontramos ya en el marco de referencia central, cual es la resolución de los problemas básicos de la teoría de la agencia: si la toma de decisiones se delega al agente, entonces la información debe usarse como elemento que motive y para reducir los costes de agencia (Demski y Feltham, 1976).

En este sentido, se contrasta cómo el método de pago y la información asimétrica son variables que afectan al cumplimiento (Chow, Cooper y Waller, 1988). Surge la utilización, no sólo de los datos proporcionados por la contabilidad financiera, sino la contabilidad analítica, planteando los presupuestos y los costes estándares. El uso de los presupuestos puede hacer, que cuando el principal no tenga mucho control sobre el agente, estos presupuestos motiven el esfuerzo. Si hemos decidido asignar los derechos de decisión al agente y para evitar el comportamiento oportunista de éste, la utilización de los presupuestos 
puede además de motivar la actuación del agente, redundar en un aumento del rendimiento y servir como método para la evaluación de este rendimiento, para luego poder fijar el método de recompensa. Incluso el efecto de la información asimétrica queda disminuido según constata Chow (1988). Este autor analiza el hecho de que la disposición de más información por parte de los subordinados no hace que aumenten las expectativas, sino todo lo contrario, es decir, si los trabajadores dispusieran de información, incluida la contable, podría disminuirse los costes de la renegociación de los contratos.

La desviación entre el comportamiento del agente respecto a lo deseado por el principal queda recogido a lo largo de diferente bibliografía. Las empresas sometidas a un fuerte control obtienen más rentabilidad real (McEachern, 1975); mientras que las que están controladas en su mayoría por la dirección y poco por los accionistas o con débil sistema de control tienden a sobrevalorar los beneficios a pesar de que la rentabilidad real o eficacia no es mayor que en el caso anterior (Saloman y Smith, 1979). Así pues, la resolución del problema del sistema de control llega a ser fundamental para el cumplimiento de los objetivos de la empresa.

El problema de control, de la actuación del agente por parte del principal, se puede minimizar si se mide el esfuerzo y se recompensa o castiga en función de ese esfuerzo; pero esa evaluación tiene un coste (Demski y Feltham, 1978). Si intentáramos medir el esfuerzo, el coste sería enorme, además de la dificultad innata (Basu, Lal, Srinivasan y Staelin, 1985), al ser el esfuerzo algo intangible; entonces, podríamos intentar evaluar en función de las tareas realizadas, por ejemplo el número de piezas fabricadas por cierto operario en la cadena de producción, pero cuando sobre la misma pieza trabajan varios operarios, la medición se hace dificultosa y el coste se multiplica. Trataremos de encontrar aquel sistema de evaluación que minimice ese coste. ¿Puede el 
sistema de información contable hacer mínimo ese coste? Dejando el método de evaluación, y centrándonos en el problema de la remuneración, se intenta encontrar aquel método que aumente el rendimiento incluso a pesar del aumento del coste, limitado con el análisis coste - beneficio.

El tema tan tratado de la remuneración o los incentivos de los directivos y su relación con el rendimiento es una parte del problema planteado, cual es la renegociación de los contratos, y las remuneraciones a percibir por el conjunto de los empleados de la empresa y no sólo por los directivos. Si el primer asunto es perfectamente consistente con la teoría de la agencia (Jensen y Murphy, 1990), de la misma manera se planteará el segundo problema: la renegociación salarial de los empleados frente a los empleadores, agentes frente a principales; si bien en este caso los empleadores pueden no ser quienes tienen la propiedad de la empresa sino más bien quienes llevan la dirección y gestión de la misma, por lo que el término principal no lo es en sentido estricto (Baker, Jensen y Murphy, 1988). De la misma manera que no hay completa información por parte del accionista sobre la actuación del agente, tampoco el empleador tiene esa información detallada sobre la actuación, el esfuerzo, de los empleados. Estamos ante la presencia de racionalidad limitada. Del mismo modo, Berné, Pedraja y Rivera (1997) plantean la posibilidad de estudiar el problema de los sistemas de retribución bajo tres líneas de investigación: teoría del control organizacional, teoría del análisis de los costes de transacción y teoría de la agencia.

La existencia del problema de agencia, sobretodo visto en términos de la divergencia de intereses entre el principal y el agente, es punto de unión de diferentes trabajos. Incluso el uso de la remuneración variable o paga ligada a productividad incide en este planteamiento. Se pretende eliminar distinciones entre trabajadores de cuello azul y de cuello blanco; 
cuando muchas veces los de cuello blanco podrían representar el nexo más inmediato con el principal (Hulme y Bevan, 1975). Si a los de cuello azul se les paga en función del tiempo de presencia, estamos dentro del posible comportamiento oportunista de los mismos. Además, si los trabajadores de cuello blanco tienen una paga de participación en beneficios, se crea una posición más divergente.

Según Jiambalvo (1979) el proceso que deberemos seguir tiene como punto de partida un esfuerzo que se materializa en un resultado, en ese momento procede la evaluación de ese rendimiento o resultado, para finalmente fijar la remuneración. Así, Chow (1983) trata de contrastar, mediante un experimento de laboratorio, aquel método de compensación que aumente el esfuerzo de los trabajadores y el grado de cumplimiento, es decir, que minimice los costes de agencia, que surgen como consecuencia de la dificultad en la observación del esfuerzo del agente por parte del principal. Los agentes, pudiendo elegir, seleccionarán el tipo de compensación que estimen más conveniente en función de su habilidad y su aversión al riesgo: desviación en el comportamiento del agente respecto de los intereses del principal. Para alinear los intereses del agente con los del principal, se plantean diferentes modelos que no sólo recogen cifras de beneficios sino que incluyen crecimiento (Meeks y Whittington, 1975).

Según Baiman y Demski (1980) cuando hay una relación de agencia, la información se puede usar en dos vías: antes o después de que el agente actúe, "decision influencing" o "decision facilitating", respectivamente. Si planteamos el uso de la información contable después de la actuación del agente y como medio para recompensar el rendimiento, se abarca el uso del sistema de información contable como elemento motivador. Así, se plantea la remuneración variable y, fundamentalmente la participación en beneficios (Blanchflower y Oswald, 1987). No interesa tanto cuánto se gana sino cómo se gana (Jensen y 
Murphy, 1990). El método de recompensa es visto como un problema crucial ya que por ejemplo dentro de los métodos de regulación de incentivos, se citan las recompensas y pocas veces los castigos. Hay una aparente asimetría entre castigos y recompensas (Baker, Jensen y Murphy, 1988). Incluso el gobierno británico publicó en 1986 un documento "Green Paper" proponiendo cambios importantes en el modo de pagar los salarios a los empleados: Uno de estos cambios era ligar salarios a beneficios, mientras que la otra propuesta, iba más allá, proponiendo el pago en acciones de las propias empresas. El planteamiento de esta remuneración variable nos puede llevar a evitar el comportamiento oportunista del agente con respecto al principal, ayudando a crear una mejor atmósfera, un mayor interés, más lealtad, más efectividad y facilitando las negociaciones, (Wallace y Hanson, 1984). Así vemos entrelazarse el uso de la información contable antes y después de la actuación del agente. La utilización de la información contable para recompensar el rendimiento puede hacer aumentar el rendimiento de los trabajadores.

En la línea de evitar ese comportamiento oportunista por parte del agente, también se plantea el uso de la remuneración diferida y el pago por la antigüedad. De este modo, si el empleado o agente no quiere perder ese beneficio diferido deberá evitar, aunque sea mínimamente, ese comportamiento divergente que le podría llevar a la extinción del contrato por parte de la empresa. De igual manera, la circunstancia de tener derecho a un pago diferido por su permanencia en la empresa, haría disminuir la probabilidad de dimisión, y de esta manera el coste producido por este cese o dimisión (Hutchens, 1989). Se tiende a hacer contratos con beneficios a largo plazo, para evitar incumplimientos de obligaciones, connaturales a la separación entre la propiedad y la dirección de la empresa, en línea con la explicación dada desde la economía laboral en aplicación de la teoría de Lazear (Hutchens, 1987). Según, Lazear (1981) el salario debe aumentar con la antigüedad para estimular la 
productividad de los jóvenes, ya que este salario diferido puede disminuir los problemas de agencia: los agentes tratan de minimizar el esfuerzo mientras que los principales desean un aumento de la productividad.

La incidencia del método de remuneración en el rendimiento es un problema muy trabajado por diferentes autores: Blanchflower (1986), Richardson y Nejad (1986), Wright (1986)... Así, por ejemplo Dewe, Dunnt y Richardson (1988), mediante el uso de cuestionarios y análisis de regresión, examinan el efecto que produce la remuneración vía opciones de compra de acciones en el rendimiento. Todos estos trabajos lo que permiten concluir es que hay diferentes actitudes respecto al ejercer o no la opción de compra; y todos, en definitiva, evidencian que hay una aversión al riesgo por parte de los trabajadores o agentes de la empresa. La aversión al riesgo de los empleados combinada con una neutralidad frente al riesgo por parte de los empleadores implica que debamos buscar un sistema de incentivos para alinear estos intereses (Seiler, 1984).

De hecho se está pasando de una retribución fija a una variable, retribuyendo al trabajador según su categoría/puesto, sus competencias, su desempeño, etc. Se trata de utilizar técnicas adecuadas para objetivar lo más posible las contribuciones de un empleado. Su evaluación suministra información sobre el potencial y el rendimiento actual del empleado. Así, proponemos que la medición de la actividad de los empleados es mucho más precisa sobre los resultados que por las conductas y actitudes; es decir, aquellos factores cuantificables y medibles que conducen a una apreciación objetiva de la actividad de los empleados. Además, en línea con la idea de participación del factor humano en el proyecto de empresa, centraremos el estudio en la retribución basada en la participación de los resultados de la empresa, fundamentalmente en la participación en los beneficios. Esta idea se centra fundamentalmente en la participación colectiva de los empleados en los beneficios de la compañía para hacer coincidir los intereses de los 
empleados con los de los empleadores cuyos beneficios quedarán determinados proporcionalmente al resultado anual de la organización al objeto de incitar al incremento de la productividad, reduciendo los salarios en función de los variables y contribuyendo a la creación del espíritu de equipo, aumentando así el compromiso y la identificación con la empresa. Por último, comentar el papel de los incentivos como método de intentar una mayor motivación, fidelización y productividad, entre la empresa y los empleados (Porret, 1999).

Por todo esto, un gran número de autores centran sus estudios en diseñar aquellos contratos que minimicen los costes de agencia (Ronen y Livingstone, 1975). Estos contratos se pueden ver para tres grupos de personas: los cargos directivos, las divisiones o secciones dentro de la empresa, y los empleados o trabajadores de la empresa (Jennergren, 1980). La compensación óptima es una función convexa, incrementándose la misma cuando aumenta la tolerancia al riesgo por parte del agente (Basu, Lal, Srinivasan y Staelin, 1985). Nos encontramos como punto de partida con la separación entre la propiedad y la dirección. Estamos dentro de las premisas de la teoría de la agencia: ausencia de información o información asimétrica y aversión al riesgo por parte del agente. Así, es más fácil observar el resultado que el medio, es decir, el esfuerzo. Con lo cual se intenta buscar aquel contrato de trabajo que maximiza la utilidad de ambos, con la utilización del concepto de óptimo de Pareto. Se crea un contrato de incentivos entre empleador y empleado que aumente la utilidad del agente sin disminuir la del principal (Harris y Raviv, 1979). Este contrato de compensación se puede basar en la cifra de beneficios o en el valor o cotización de las acciones o participaciones (Bushman y Indjejekian, 1992). Dejamos a un lado la teoría neoclásica de la empresa, en la cual se ignoran los costes de información y que, implícitamente asume que todas las partes pueden observar el comportamiento de la contraparte. 
El estudio teórico del tema puede ser también asimilado con la teoría de los sindicatos propuesta por Wilson (1968). Un sindicato es un grupo de individuos que toma una decisión común sobre asuntos salariales, entre otros, en una situación de incertidumbre. Bajo esta teoría se intenta encontrar el óptimo en el sentido de Pareto cuando los miembros sindicales o los trabajadores son adversos al riesgo y hay diferentes probabilidades de conseguir la propuesta de acuerdo salarial.

Desde la teoría de la agencia, para medir el rendimiento se plantean dos posibilidades o utilizar alguna medida del desempeño o utilizar los sistemas de información (Eisenhardt, 1988). Se intenta determinar el contrato óptimo entre el principal y el agente, es decir, el contrato más eficiente entre el basado en el comportamiento y el realizado en base a los resultados. Según Eisenhardt, la opción entre uno y otro dependerá del coste de la información. Además la dificultad de medir el esfuerzo, hace que se opte generalmente por la medición de los resultados, lo que requiere la utilización de un correcto sistema de información.

Además, la mayor parte de la literatura analizada, no tiene en cuenta los aspectos normativos, el aspecto fundamental es interpretar qué está ocurriendo y no cual debería ser el papel de la información contable en la negociación colectiva (Amernic y Craig, 1992), lo cual nos estrecha el marco teórico dentro de la teoría positiva de la contabilidad.

El papel de la información contable en la negociación colectiva puede quedar enmarcado en el paradigma de utilidad y en la teoría de la agencia (Hassink, 1995). Según este autor, la información contable es útil para tomar decisiones por diferentes usuarios, entre los que se encuentran los trabajadores, como parte del contrato establecido por la empresa con éstos. El utilitarismo implica que la información contable que se suministra por parte de las empresas tiene que ser útil para la toma de 
decisiones; esta función utilitarista que sitúa el requisito de relevancia por encima de cualquier otro, implica como figura central al usuario de la información contable (American Accounting Asociation, 1966).

El planteamiento a seguir, va inmerso dentro de la relación de la contabilidad con las relaciones industriales y podría concretizarse en la relación que pudiera existir entre la información contable y los salarios de las empresas. Incluso se crean experimentos de laboratorio y se aplica la teoría de juegos de Nash para buscar esa posible relación (Chalos, Cherian y Harris, 1991). La teoría de juegos se usa fundamentalmente para analizar el comportamiento racional en situaciones de conflicto. Además en la mayoría de las pruebas que utilizan la teoría de juegos se supone la posesión de información completa (Roth y Murnighan, 1982), mientras que en nuestro caso estamos en presencia de información incompleta, mejor dicho información asimétrica. Por otra parte, la utilización de la teoría de juegos aplicada por estos autores, se centra fundamentalmente en la suma cero, es decir, que las ganancias de una parte, empleador o empleado, son coincidentes y de signo opuesto con las pérdidas de la otra parte. Contrariamente, el tema, bajo otro punto de vista, puede ser expuesto como que la utilización de la información contable en la determinación de los salarios nos lleve a mejorar el objetivo de las dos partes: principal y agente. 


\section{2.- LOS EMPLEADOS: USUARIOS DE LA INFORMACIÓN CONTABLE}

"Sólo los científicos pueden establecer los objetivos de su búsqueda, pero la sociedad, como soporte de la ciencia, debe tener en cuenta sus propias necesidades", John F. Kennedy.

Según the Financial Accounting Standards Board, de Estados Unidos y the Canadian Institute of Chartered Accountants, la información contable debe ir orientada a diferentes usuarios, entre los cuales incluyen a los empleados y a los sindicatos.

El "Corporate Report" identifica a los trabajadores como usuarios de la información contable (Institute of Chartered Accountants in England and Wales, 1975), indicando que esta información interesa a los mismos y a sus representantes, ya que como estamento base de la producción estarán interesados en los resultados obtenidos por las organizaciones para la revisión de los convenios, la negociación de las condiciones de trabajo, la propia continuidad del empleo, etc...

Sin embargo, la información que utilizan los sindicatos y los representantes de los trabajadores no tiene porqué coincidir con la utilizada por los diferentes tipos de usuarios; así Craft (1981) destaca que hay diferentes factores dentro de cada empresa y cada organización sindical, que pueden alterar el contenido de la información contable útil para cada sindicato. Para Amernic y Craig, (1992) hay dos factores que inciden fundamentalmente en el uso que se hace de la información contable: la ambigüedad de la parte empresarial "employer equivocality" $y$ la heterogeneidad sindical "union heterogeneity". Para estos autores, cuando la ambigüedad empresarial es baja y la heterogeneidad sindical alta, la contabilidad puede servir como un primer punto para la discusión. 
Existen diferentes maneras de usar esa información contable dependiendo de varios factores (Rahman y McCosh, 1976). Los usuarios más importantes "high-use style" centran su importancia en la toma de decisiones y en la evaluación del comportamiento. Los usuarios menos importantes "low-use style" consideran la información contable relativamente insignificante, prestando más atención a las relaciones interpersonales. Los usuarios medios "medium-use style" consideran tanto a la información contable como a las relaciones interpersonales. Podríamos considerar a los trabajadores dentro de este último tipo de usuarios; ya que utilizan tanto la información contable como cualquier otra que puedan conseguir por otros medios.

Durante los últimos años han existido presiones para la transmisión, a todos los grupos que constituyen la empresa, de más información contable. La presión ha venido por parte de los empleados y sus representantes sindicales. El hecho es que los diferentes gobiernos han aceptado esa necesidad. Además, la dirección de la empresa también se plantea esa circunstancia como necesidad, ya que se cree que puede traer efectos positivos: implicación, motivación, cooperación, etc. Sólo para corroborar esta situación, de que los empleados también son usuarios de la información contable, podemos citar el proyecto de $\mathrm{V}$ Directiva de la Unión Europea.

Existe un crecimiento de la demanda de información contable ya que se entiende la información como una posesión de poder. En el entorno de conflictividad laboral la posesión de más y mejor información por una de las partes permite enfrentarse a la negociación con terceros desde una situación de poder (Del Brío González, 1995). La asimetría informativa es fuente de situaciones de desequilibrio y se hace necesario asumir el coste de la información si el beneficio esperado con la negociación supera ese coste. Los empleados quieren tener acceso a la 
información contable para mejorar su posición negociadora y los empleadores deben suministrar esa información porque el beneficio que pueden obtener con una negociación ágil y racional (menor conflictividad social y mayor productividad de los trabajadores), superará los costes de transmitir esa información.

La información contable puede ser aceptada por los trabajadores si facilita que los empleados tomen decisiones, y siempre que se constate que mediante su utilización se mejora el bienestar o la situación de los trabajadores de cada empresa (Cooper y Essex, 1977). En la legislación de Bélgica, Holanda, Dinamarca, Noruega y Suecia encontramos situaciones donde se exige la transmisión de información a los empleados para que éstos participen en la toma de decisiones. La Organización Internacional del Trabajo (O.I.T.), en su recomendación 129, ya sugiere la transmisión de esa información. Si los diferentes grupos de personas relacionados con la empresa son usuarios de la información contable, no se puede entender por qué casi nunca se considera a los trabajadores en el momento de confeccionar esta información (Cooper y Sherer, 1984), si después de todo los intereses de los trabajadores no van a ser independientes de los de otros grupos.

Si la empresa debe suministrar información contable a los representantes de los trabajadores nos faltaría determinar el nivel de agregación de esa información: nacional, sectorial, o de empresa. Así, limitaremos el tema centrándonos en la información a nivel de empresa y la posible utilidad de esa información para esa toma de decisiones, como por ejemplo las decisiones relacionadas con el incremento salarial y todas aquellas otras que constituyen el contenido de los convenios colectivos de empresa.

Sin embargo, incluso a nivel de empresa existen opiniones discordantes. Moore, Gold y Levie (1979) y Moore y Levie (1981) plantean 
reservas al uso de la información contable por parte de los sindicatos y los trabajadores. Jackson-Cox, Mcqueeny y Thirkell (1984) diferencian entre trabajadores de cuello azul y de cuello blanco, entre miembros del comité de empresa o miembros sindicales, y entre representantes a tiempo parcial o de tiempo completo. Para Reeves y Mcgvern (1981), por parte de la empresa se incrementa la predisposición a dar información a los diferentes usuarios, entre los que incluyen a los trabajadores, sindicatos y representantes de los trabajadores. Owen y Lloyd (1985) distinguen el uso de la información contable dependiendo de la naturaleza de la organización, es decir, de la empresa. Así, para estos autores la importancia de la información depende de los objetivos y de la cultura de la empresa y de los sindicatos.

Si optáramos por llevar el contrato de agencia hasta límites insospechados, podríamos decir que los usuarios de la información contable no son realmente los empleados sino sus representantes o los sindicatos. De esta manera, nos encontramos ante un nuevo contrato de agencia, de una parte como principales los empleados, y por otra parte los agentes (Maunders, 1984), es decir, los representantes de los trabajadores o los sindicatos. No llegaremos hasta tanta abstracción sino que entenderemos a los empleados junto a los representantes de los trabajadores como agentes, de los principales o empleadores. 


\section{3.- QUÉ INFORMACIÓN CONTABLE SE SUMINISTRA A LOS EMPLEADOS}

"Un artista es el que produce cosas que los demás no necesitan, pero que él, por alguna razón, piensa que sería una buena idea proporcionárselas", Andy Warhol.

Intentaremos responder a dos preguntas fundamentalmente: Qué información económica suministra la empresa a los trabajadores o sus representantes, y a quién dentro de los empleados se suministra esta información. Podríamos decir que se examina la importancia de la información en la estrategia negociadora.

En cuanto a la primera pregunta, no todas las empresas suministran el mismo tipo de información; según Jackson-Cox, Thirkell y McQueeney (1984) podemos encontrar dos tipos de empresas: Aquellas que suministran la información como una rutina "the integrated approach" y aquellas otras que sólo dejan acceso a la información específica en determinadas situaciones "ad-hoc approach". Por esta razón, para tratar de unificar el carácter de esa información, el gobierno inglés trató de regular el derecho a obtener información, al menos de contenido mínimo "shopping list".

La información que generalmente se transmite a los empleados es la referente a salario base, productividad, condiciones de trabajo, despidos, condiciones de empleo, seguridad en el trabajo y condiciones a largo plazo (Sherer, Soutworth y Turley, 1981). Según estos autores, toda esta información es considerada insuficiente por parte de los empleados. Además, se nota un diferente grado de información por parte de las empresas dependiendo del tamaño; así las pequeñas empresas son las que menos informan. Todo esto puede ser debido a que en las pequeñas 
empresas no existe una separación rígida entre la propiedad y la dirección, mientras que la separación es radical en las grandes empresas y se requiere más información por parte de los diferentes usuarios.

En cuanto a la segunda pregunta, el uso e incluso la petición de esta información es distinto por parte de los trabajadores de cuello blanco y de cuello azul; el uso de la información depende de la naturaleza de la representación sindical (Jackson-Cox, Thirkell y McQueeney, 1984. Según Pacitti (1990), la información que tiene por objetivo implicar a los individuos en particular, debería ser distinta de la información que se transmite a los representantes de los trabajadores y que utilizarán en la negociación colectiva. . Sin embargo, el derecho a recibir la información es igual para todos los empleados (Pacitti, 1990). Nos encontramos, otra vez, con la información asimétrica de la situación económica de la empresa y el poco interés en cuanto a la transmisión de esa información por parte del principal o parte empleadora en la empresa. Los empleados no pueden obtener toda la información deseada y tampoco pueden controlar el proceso de su elaboración.

El carácter asimétrico de la información queda recogido en el siguiente hecho, estudiado por Roth, Murnighan y Schoumaker (1988): Ios acuerdos se toman en los últimos segundos de la negociación. Esto puede ser debido a que no se dispone de la información necesaria para tomar decisiones y es sólo tras su suministro cuando se toman decisiones. Según estos autores, el $41 \%$ de los acuerdos se alcanzaron en los últimos treinta segundos, y el 53\% de éstos en los últimos cinco segundos.

Para Gospel (1978) podemos encontrar tres posturas en lo referente a la transmisión de la información contable a los empleados. La postura del avestruz "the ostrich approach", para la cual hay una falta de interés por los datos de la empresa; postura claramente rechazable. La 
postura de información mínima o "shopping list", antes comentada. La postura de información de interés razonable para los empleados "the decision orientated approach", antes analizada. El segundo planteamiento podría ser un punto de partida hasta llegar a la última posición.

Para Ogden y Bougen (1985), el deseo de recibir información por parte de los empleados es una postura que se remonta hacia el concepto marxista de lucha de clases entre trabajo y capital; y cómo debido al conflicto de intereses se valora el mayor contenido y calidad de la información contable. Los empleadores quieren ser capaces de usar a los trabajadores de la manera más flexible posible, tratando de minimizar su coste; mientras que los empleados quieren ejercer algún control sobre la labor de los empleadores, para de alguna manera minimizar su inseguridad y explotación. Así, según la opinión de estos autores, los trabajadores van a demandar diferentes informaciones, que gradualmente pueden resumirse de la siguiente manera: toda la información o sólo información en determinadas situaciones. Desde las empresas, se revelará información siempre y cuando el beneficio esperado supere al coste de preparar y proporcionar esa información.

La transmisión de información a los empleados puede llevarse a cabo bajo dos modalidades no excluyentes. Información particularizada en cada empleado "role related information" e información generalizada al conjunto de los empleados "employee reporting" (Maunders, 1981). Dejando al margen la información del primer tipo y centrándonos en la segunda modalidad podemos conseguir los siguientes objetivos: informar a los empleados, influir directamente a los empleados; e influir a los empleados a través de otras personas (sus representantes). La información puede ser decisiva, en el campo motivacional en el siguiente aspecto; cuanto más control se ejerce sobre los empleados, menos confianza se tiene sobre la labor de los directivos (Fox, 1974), por tal razón, la información trata de devolver esa confianza a pesar del control. 
La influencia ejercida por la información no es uniforme ya que la negociación presenta diferentes actividades (Walton y Mckersie, 1965). "Distributive bargaining", su función es resolver puros conflictos de intereses, representa juegos de suma fija. "Integrative bargaining", trata de encontrar intereses complementarios y solucionar los problemas con un beneficio compartido, según la teoría de juegos de suma variable. "Attitudinal structuring", cuyo misión es influir la actitud de la contraparte. "Intraorganisational bargaining", tratando de encontrar el consenso entre los diferentes grupos que participan directamente o indirectamente en la negociación, es decir, alinear expectativas del agente con las del principal (Tracy y Peterson, 1986). Pues bien, dependiendo en qué grado de la negociación estemos en cada situación, el contenido de la información contable se verá modificado.

Nos centraremos, en lo que algunos autores denominan "social reporting", es decir la comunicación de los efectos económico - sociales de la actuación de una organización económica, más concretamente dentro del "employee reporting". La primera justificación de estos informes sociales referidos a los empleados está en el concepto de empresa como nexo de contratos, diferentes stakeholders, incluyendo empleados, accionistas, deudores, proveedores, gobierno... (Lefebvre, Vandemaele y Delbeke, 1988). Otra justificación, mucho más filosófica, indica que los empleados tienen los mismos derechos de información que los accionistas y la dirección tiene el deber de transmitir esta información a todas las partes interesadas (Cooper, 1977).

Los problemas, que se deben solucionar en lo referente a la información contable que se debe revelar para la negociación colectiva, surgen como consecuencia de la contraposición de intereses entre empleadores y empleados (Barbash, 1979). Esta naturaleza adversa de estos grupos que componen la empresa nos puede llevar, mediante el 
análisis de los diferentes objetivos de cada parte, a plantear los diferentes factores que inciden en la transmisión de la información contable (Craft, 1981). Según este autor, el primer factor sería el poder de negociación que a medida que es mayor para la dirección disminuye la necesidad de suministrar esa información contable. En segundo lugar, la independencia de la empresa; si la empresa aplica el convenio del sector, no tiene demasiados incentivos para aumentar la transmisión de la información. En tercer lugar, la conflictividad; si existe una buena sintonía con la organización sindical se suele tender a dar más información que la mínima legal, porque incluso este hecho hace mejorar la cooperación entre las dos partes. En cuarto lugar, la estabilidad del sindicato; si dentro de los representantes de los trabajadores hay un liderazgo y no hay facciones discordantes se evita la conflictividad y estaríamos en la situación planteada por el tercer factor. En quinto y último lugar, Craft cita la formación sindical que puede facilitar la comprensión y la discusión de todo tipo de información, incluso, la contable.

Pero, esa información que se puede o debe transmitir a los empleados, ¿debe ser exclusivamente preparada para ellos o es la generalmente utilizada por el resto de los usuarios? La transmisión de la misma información puede llevar a su incomprensión y quizás a querer participar en la cifra de beneficios, que en algunas ocasiones pudiera parecer excesivamente elevada; para Pacitti (1990), se deberían elaborar unos estados más simplificados y especialmente destinados a la comprensión por parte de los empleados de la empresa.

En Gran Bretaña, se plantearon las dos opciones. Para "the Green Paper" se prima la exclusividad: estados del valor añadido, informes de empleados, etc. Mientras que para "the White Paper" la información debe generalizarse, teniendo acceso a las cuentas anuales, de la misma manera que los accionistas de las empresas (Gospel, 1978). Según "the accounting standards commitee", los empleados tienen otras necesidades 
como por ejemplo, conocer la seguridad del empleo... En un estudio, realizado por Purdy (1981), sobre la información transmitida a los empleados en el Reino Unido se comprueba cómo se ha aumentado la información presentada a los sindicatos. Principalmente basado en las siguientes razones: presión hacia las grandes empresas, estrategia en las relaciones industriales, emergencia de la democracia industrial, etc. Según este autor, esta información se utiliza por parte sindical para valorar, criticar y mejorar la situación del conjunto de los trabajadores. Además, es un dato destacable el hecho de que las empresas que tienen una larga tradición en informar a los empleados son aquellas que hace tiempo que han contado con una fuerte presencia sindical; lo que parece indicar que la información suministrada por parte de la empresa depende directamente de la presencia o el poder sindical existente en cada empresa y surge para disminuir la presión sindical y quizás la conflictividad laboral.

En Estados Unidos, la ley más importante en materia de negociación colectiva "the National Labor Relations Act" (NLRA), dispone que los empleados necesitan información para afrontar la negociación colectiva, como por ejemplo datos sobre salarios, productividad y en general información del balance de la empresa.

Se vislumbra que ha aumentado el interés por la transmisión de la información a los empleados, a lo largo de diferentes países. En Canadá, se obliga a transmitir una información de contenido mínimo a los representantes de los trabajadores (Jain, 1981). En Australia, la información se centra fundamentalmente en la justificación documental de la incapacidad de pago (Clarke y Craig, 1991). En Alemania, la transmisión de información de la empresa a los empleados aparece regulada en las "Betriebsverfassungsgesetz"y "Mitbestimmungsgesetz", las cuales estipulan la participación de los trabajadores en las decisiones empresariales y desarrollan el derecho a la información, respectivamente. 
En Francia, el Informe Sudreau (1975). En Bélgica se dictó un Real Decreto sobre la información económico - financiera a suministrar a los comités de trabajadores (1973). Los comités de los trabajadores tienen derecho a recibir información y a revisarla. La información se divide en cuatro niveles: información económica, legal, técnica y directiva. Dejando el contenido y centrándonos en la frecuencia, se establecen cuatro tipos de informes: información básica, antes de las reuniones del comité; información anual, las cuentas anuales; información periódica, trimestralmente; e información ocasional, debido a circunstancias particulares (Lefebvre, Lin y Nuffel, 1995).

No debemos olvidar que el problema de la revelación de información también va inmerso dentro del tamaño y del grado de dispersión de la información proporcionada. Así, para Cuthbert y Whitaker (1977) a nivel de empresa o de planta industrial se puede producir más transmisión de información. El único problema que podríamos discutir sería si esta información a nivel de planta es para todos los empleados o únicamente para los representantes de estos trabajadores. 


\section{4.- CUÁNDO SE SUMINISTRA LA INFORMACIÓN CONTABLE A LOS EMPLEADOS}

"Los patrones no quieren dar nada y los obreros quieren tomarlo todo", René Barjavel.

El hecho que la información contenida en las cuentas anuales sea comprensible, relevante, comparable, oportuna y sobretodo fiable, facilita el uso de la misma en la renegociación de los contratos. La fiabilidad u objetividad como punto central de discusión queda demostrada en la literatura cuando se plantea, incluso ante los tribunales, la capacidad para pagar de las empresas "Ability To Pay". De nuevo, estamos ante información asimétrica, en este caso completo conocimiento por parte de la dirección o principal en términos relación empleador - empleado y casi total desconocimiento, o por lo menos dudas sobre su exactitud, por parte de los trabajadores o agentes de la relación. En palabras de Clarke y Craig (1991): Ios beneficios son privados y las pérdidas son públicas.

La capacidad de pago de las empresas "ATP" es un asunto muy tratado en las negociaciones colectivas, es algo que admite diferentes criterios. Los sindicatos temen la manipulación y dudan de que las valoraciones realizadas por las empresas sean las más reales, más bien creen que son la medición que más beneficia a la empresa y más perjudica a los trabajadores (Briloff, 1972,1981). Si la información contable se manipula puede ser debido a que realmente sí tiene impacto en las subidas salariales, y es por esta razón por la cual se dedica tanto esfuerzo en esconder la realidad económica de las empresas (Yamaji, 1986). Incluso la teoría del alisamiento del beneficio podría explicar esta postura de manipulación (Gordon, 1964). 
Sin embargo, puede que no sólo sea manipulación sino que la información contable, no es el único dato que se debe tener en cuenta para fijar la incapacidad o capacidad de pago (Clarke, Craig y Amernic, 1990). Según estos autores, los representantes de los trabajadores encuentran unas limitaciones al uso de la información contable: falta de información futura, demora en su transmisión, énfasis en la información dirigida a los accionistas, irrelevancia.

El momento en el que se transmite más información contable y más frecuentemente es durante e inmediatamente antes de las huelgas (Waterhouse, Gibbins y Richardson, 1990,1993). Debido a que las huelgas tienen un coste elevado, tanto a corto como a largo plazo, planteamos que la huelga podría ser evitada si se transmitiera información periódicamente y no sólo debido a la conflictividad laboral. Si se informa durante las huelgas es para resolver la conflictividad laboral y favorecer un acuerdo; así, si se informara periódicamente trataríamos de prevenir la conflictividad y evitar llegar a la huelga, disminuyendo ese coste de la renegociación bajo presión sindical. Por otra parte, si se informa durante las negociaciones es debido a que esta información es relevante, lo que puede indicar que existe alguna relación entre la información contable y la negociación colectiva.

Bajo la perspectiva de Ogden (1992) la transmisión de información contable a los trabajadores implicaría que éstos quisieran incluso participar en la gestión y organización de la empresa, ante lo cual se plantea un fuerte rechazo por parte de las organizaciones empresariales. Además, los empresarios se reafirman en la necesidad de no suministrar información contable a los empleados, ya que de lo contrario, si dispusieran de información de la empresa, podrían efectuar alguna medida de presión, como por ejemplo paradas de producción o huelgas, en el momento más inoportuno para la empresa. En definitiva, según este autor, el beneficio potencial procedente de la transmisión y cooperación 
de los trabajadores, se podría volver en un coste de mucha mayor magnitud para la empresa.

La transmisión de la información contable es diferente según cuatro factores socioeconómicos (Lewis, Parker y Sutcliffe, 1984). Estos factores son: las nuevas tecnologías, el sector industrial, la presión sindical y la recesión económica. Según estos autores, siempre que hay un periodo de gran interés por la información, posteriormente va seguido de un plazo de estancamiento o escaso interés por la misma.

Generalmente la información contable se revela a los empleados, sindicatos y representantes de los trabajadores como consecuencia de la política de dirección de la empresa y casi nunca como respuesta a peticiones sindicales (Mitchell, Sams, Tweedie y White, 1980). Según este autor, la información se utiliza, por parte de los trabajadores, para evaluar la seguridad en el empleo, hacer peticiones de incrementos salariales y examinar las posibilidades de promoción. Estos trabajadores no creen que pueda hacer mejorar la productividad ni la eficiencia, a pesar de que ese es su primer objetivo cuando se plantea dentro de la estrategia de la dirección de la empresa.

Para el empleador, existen diferentes costes como consecuencia de preparar esa información y transmitirla a los empleados. Así, que en principio sólo suministran la información contable cuando el coste de la obtención y preparación de esa información es superado por los beneficios con posibilidades de consecución durante la negociación colectiva (Kleiner, 1984); lo que generalmente sucede cuando tratan de evidenciar la incapacidad de pago. Por parte del empleado, sólo se utilizará la información contable cuando los beneficios que obtengan superen los costes de su utilización (Sherer, Southworth y Turley, 1981). 


\section{5.- REACCIÓN DE LOS EMPLEADOS ANTE LA INFORMACIÓN CONTABLE}

"No puedes hablar a los trabajadores de la necesidad de beneficios si no les das participación en ellos. Rinden lo mismo, pero a final de año, si hay beneficios gritan ¡Hurra!, en lugar de ¡Ladrón!”, Philip Basendale.

No todas las empresas tienen el mismo carácter y tipo de actividad, con lo que la diferencia de utilización de la información contable queda más palpable todavía. Así por ejemplo, Amernic (1985) plantea, mediante el método del caso, la utilización de la contabilidad para la negociación en una gran universidad canadiense. La diferente disponibilidad de los datos financiero - contables se puede apreciar a lo largo de toda la literatura revisada. Por un lado, la parte sindical expone la falta de información que queda en sus manos; mientras que la empresa razona esa escasez de información, escudándose en la protección integral de los datos de la empresa. Así pues, nos encontramos dentro del marco conceptual de partida, cual era la existencia de información asimétrica.

La forma de utilizar esa información asimétrica por parte de la dirección y los sindicatos se analiza por la teoría de la agencia (Salamon y Smith, 1979). Unimos dos ideas: información asimétrica y maximización de los propios beneficios. En base a esas dos ideas trataremos de analizar la reacción de empleados y empleadores. Los empleados tienden a disminuir sus pretensiones a medida que transcurre el conflicto salarial. Los empleadores tienden a aumentar las concesiones a medida que se desarrolla el conflicto. Así pues, el salario de equilibrio será aquel que concilie las dos posturas (Hicks, 1964). No obstante, las posturas de ambas partes, se pueden desplazar según sea el grado de información disponible para cada parte, como por ejemplo la duración de la huelga prevista o la incapacidad de pago por parte empresarial. Así, por ejemplo 
el empleador es indiferente entre el incremento salarial y una cierta duración de la huelga, si el valor de los costes de la huelga es coincidente con la nueva petición salarial (Yamaji, 1986).

La receptividad de la información contable por parte de los empleados no siempre es total, sino todo lo contrario. Los empleados presumen la posible manipulación de los datos para afrontar la negociación. Además los empleados encuentran demasiado agregada la información que se les suministra. Existen multitud de estudios sobre la diferente elección del método contable en fechas anteriores, próximas o durante la negociación (Tomczyk, 1975; Oakes, 1988; Richardson, 1992) etc.

Liberty y Zimmerman, (1986) examinan la hipótesis de que los empleadores reducen (manipulan) las ganancias durante las negociaciones; hipótesis rechazada, ya que se puede deshacer la manipulación por parte sindical. En el otro sentido, Cullinan y Knoblett (1994) analizan las elecciones contables referentes a la amortización y la valoración de las existencias según el grado de sindicación existente en la empresa. Así, mediante el uso de variables dummy contrastan la hipótesis siguiente: la existencia de mayor sindicación lleva aparejada un mayor maquillaje de los estados contables, con el objetivo de tener argumentos en contra de las subidas salariales, propuestas por los representantes de los trabajadores. Hipótesis que queda contrastada y que sobretodo es más evidente en empresas de algún sector específico. Al fin y al cabo, lo que tratan de demostrar las empresas es su incapacidad o limitación para hacer frente a nuevas subidas salariales.

En la misma línea, Yamaji (1986) contrastó cómo las empresas que cierran sus cuentas en Noviembre y Diciembre son más "pesimistas" que aquellas que lo hacen en Marzo por una razón fundamentalmente: las que 
cierran en Diciembre están próximas al proceso negociador, mientras que las que lo hacen en Marzo, tiene lugar después del proceso.

Los diferentes factores y características de la relación empleador empleado junto al grado de utilidad de la información para el sindicato nos llevan a delimitar las diferentes posturas de la relación empleador empleado: desde conflicto permanente con poca información y poca utilización por parte sindical; hasta cooperación con mucha información y utilización por parte de los representantes de los trabajadores.

La reacción de los empleados es de aceptación o de rechazo. Así, quienes aceptan la información contable es porque la toman como información veraz y objetiva. Knights y Collinson (1987) concluyen que los trabajadores ven la información contable como objetiva, incluso cuando demuestra situaciones de insolvencia o de grandes pérdidas; los que más aceptan esta información son los hombres, trabajadores de cuello azul, según estos autores. Sin embargo, a medida que los trabajadores se van formando se tiende a rechazar esta información, al entenderla como información de carácter subjetivo (Bougen, 1989).

Así por ejemplo, dentro de la negociación típica "distributive bargaining" (Walton y Mckersie, 1965), la reacción de los empleados frente a la información contable es variada. Para Craft (1981) el hecho de transmitir información da poder a la otra parte (los empleados) y aumentan las peticiones, con lo que recomienda no revelar información. Por otra parte, Peel y Pope (1981) consideran que es mejor transmitir esa información ya que disminuyen las expectativas de los trabajadores; si después de todo, los empleados desarrollan expectativas racionales.

De la misma manera, Oakes y Covaleski (1994) examinan la reacción de los empleados ante las medidas de control por parte de los empleadores. Así, concluyen que los empleados tienden a rechazar las 
medidas técnicas como análisis de métodos y tiempos, mientras que se muestran a favor de los resultados contables como mecanismo para evaluar su actuación. Una vez analizado el rendimiento según hemos señalado, plantean dos mecanismos para fijar las recompensas: Repartir el ahorro del coste o repartir los beneficios.

Como dato significativo, que puede en algunas ocasiones, demostrar que la reacción de los empleados ante el suministro de la información contable es positiva; podríamos destacar el hecho de que el número de días perdidos como consecuencia de huelgas es mucho menor en Alemania y Japón que en Estados Unidos. Es en Alemania y en Japón, donde se transmite más información contable a los empleados, sindicatos y representantes de los trabajadores (Kleiner, 1984).

\section{6.- LA UTILIDAD DE LA INFORMACIÓN CONTABLE EN LAS RELACIONES LABORALES}

"La experiencia no es interesante hasta que empieza a repetirse... de hecho, hasta que no lo hace, difícilmente es experiencia", Elizabeth Bowen.

La información contable deja de ser una simple técnica e incluso amplía su ámbito de actuación, desarrollando cifras y datos de interés no sólo en el aspecto económico sino también desde el punto de vista social. Además la contabilidad, a través de sus estados financieros, facilita información tanto de carácter cuantitativo como cualitativo. 
La información contable puede ser vista con diferentes usos estratégicos: puede ser una herramienta que dé consenso o bien como una relación adversa (Mcbarnet, Weston y Whelan, 1993). La relación adversa o contraria la podemos observar cuando los sindicatos realizan las siguientes afirmaciones: la información no es adecuada, la información es útil para la dirección, la información es preparada por los directivos... El uso consensuado queda recogido en diferentes momentos e incluso en documentos legales. Así por ejemplo, la Comisión Europea propone instrumentos apropiados para promover la participación, consulta e información de trabajadores...

La información contable es generalmente más accesible para los directivos o empleadores que para los sindicatos o empleados. Sin embargo, el hecho de no trasmitir información económico - financiera a los empleados puede tener un efecto perjudicial en la negociación colectiva, entendido en términos de mayores expectativas y mayores peticiones de incrementos salariales (Nabil Elias, 1990). Este autor, mediante el uso de un experimento de laboratorio, comprueba como cuando los sindicatos no tienen esa información, las expectativas son más altas y se hace más difícil llegar a un acuerdo. Por otra parte, y como era de suponer, cuando los sindicatos poseen esa información y la utilizan racionalmente; así, con cifras positivas aumentan las peticiones y disminuyen con pérdidas. Sólo la diferencia entre la posesión o no de la información anteriormente a la negociación es significativa en el caso de que existan pérdidas, ya que cuando hay beneficios, según este autor, las diferencias no son representativas. Hay que tener en cuenta, que no llegar a un acuerdo rápido tiene un coste, afecta a la competitividad. Así pues, según las conclusiones de este trabajo, se puede mantener la hipótesis inicial: la información contable puede reducir el coste de la renegociación de los contratos. Más estudios sobre el uso de la información contable en las negociaciones empleador - empleado podemos encontrar bajo diferentes puntos de vista. Desde una posición 
normativa, Granof (1973), Lau y Nelson (1981) y Cascio (1982). Desde una perspectiva macroeconómica Foley y Maunders (1979). Nuestro planteamiento se basa en una posición positivista: qué efecto produce la información contable en la negociación colectiva, y no la posición normativa.

La relación entre información y formulación de expectativas también es analizada por Pope y Peel (1981). Sus hipótesis suponen que los agentes económicos cuando forman sus expectativas sobre una determinada variable pueden producir predicciones. En muchos aspectos las hipótesis de expectativas racionales son análogas con las hipótesis de eficiencia de mercado. Los sindicatos o cualquier otro agente, cuando predicen variables utilizan más información que la que está directamente implicada en la predicción efectuada, tomando como base de una forma mecánica el comportamiento pasado de una determinada variable. Al igual que Elias, estos autores concluyen que el suministro por parte de las empresas de información demandada por los sindicatos para la negociación colectiva, no va a debilitar la posición de la empresa en la negociación. El problema de valorar cuál deberá ser el nivel óptimo de suministro de información se reduce a una simple transacción costebeneficio. Si el suministrar una parcela más de información fuese tan importante que la misma ocasionase un incremento salarial, los sindicatos obtendrían esa información fuera de la empresa, y por lo tanto, no sería necesario suministrársela. El suministro de información no ocasiona coste neto a las empresas, lo que sirve es para reducir los conflictos presentes y futuros entre empresas y sindicato; en definitiva, mejorar las relaciones laborales.

Toda esta información tiene diversa y variada utilidad; así, por ejemplo, para Bougen, Ogden y Outram (1990), la información contable sirve para determinar el salario en las industrias del sector de la minería del carbón. En esta misma línea, podemos citar los trabajos de Palmer 
(1977), Foley y Maunders (1977), Pope y Peel (1981), quienes tratan de modelizar la utilidad de la contabilidad en la negociación salarial. Se trata, en definitiva, de encontrar algún método que resuelva los conflictos de intereses entre las dos partes del contrato de trabajo: de una parte el principal o empleador y, por el otro lado el agente o parte trabajadora de la empresa (Ogden y Bougen, 1985). Estos conflictos de intereses se atenúan o se agravan dependiendo de la situación por la que atraviesa la empresa o la sociedad en la que ésta se encuentra inmersa. Por ejemplo, según Bougen, Ogden y Outram (1990) y referido al caso británico de la minería del carbón; la contabilidad fue aceptada por los trabajadores desde 1870 hasta 1914, mientras que tras el desarrollo de la Primera Guerra Mundial se rechazó su utilización en la determinación de las condiciones salariales.

Un caso, que ha sido objeto de estudio, en tantas ocasiones como el de la minería del carbón, es el de las industrias del sector metalúrgico. Parece vislumbrarse que, aquellas empresas o sectores con más presencia sindical y con más conflictividad laboral, tratan de encontrar algún método que disminuya esa falta de entendimiento, que lógicamente queda manifestado en un mayor coste para las empresas. Se trataba de utilizar algún sistema que permitiera a las empresas modernizar la producción, aumentar la productividad como respuesta al aumento de la competitividad y a la disminución de la demanda (DeAngelo, Harry y DeAngelo, Linda, 1991). Pretendían que ante circunstancias de crisis o de menores beneficios, se hicieran sacrificios por todos los stakeholders de la empresa: menores dividendos para los accionistas, menores salarios para los trabajadores de cuello azul, menores compensaciones para los empleados de cuello blanco, etc. Para facilitar estos sacrificios en las empresas metalúrgicas se tendía a aumentar la visión de las pérdidas de la empresa durante la etapa de negociaciones. Contrariamente, según Liberty y Zimmerman (1986), no hay evidencia de que se modifiquen las 
prácticas contables por parte de la dirección para conseguir ese efecto "catastrófico".

La utilidad y relevancia de la información contable en las relaciones industriales no puede quedar limitada al uso que se hace de la misma en diferentes sectores industriales. Esa representatividad de la información contable queda más implícita en su utilización dispar por las empresas de diferentes países. Si hasta ahora hemos comentado el caso de Gran Bretaña, no debemos dejar de citar el caso australiano como caso también significativo. Surge la cuestión tan tratada de si la información contable convencional no sirve para los trabajadores (Clarke y Craig, 1992) y debe elaborarse diferente información dependiendo del usuario al que va dirigida. Sin embargo para otros autores debido a la dificultad de elaborar diferentes informaciones o estados financieros, el hecho de proporcionar información contable a los empleados, incluso siendo la estándar, implica una mayor participación de los trabajadores y según un caso estudiado por Geoffrey George (1994) puede hacer que la empresa pase de pérdidas a beneficios. En otro caso estudiado por el mismo autor, se comprueba como la empresa que no proporciona información contable a los empleados o a sus representantes, tarda mucho más en encontrar un acuerdo que en el caso de que los empleados sí dispongan de esa información.

En la misma línea, pero centrado en el caso norteamericano, Jain (1981) se plantea el porqué de la importancia de la información contable para la negociación colectiva. Intenta justificar que se debe avanzar en la transmisión de la información económico - financiera, hasta ahora prácticamente encaminada hacia los accionistas. Para los empleadores, el hecho de que los sindicatos conozcan estos datos de las empresas en las que desempeñan su actividad, puede dar racionalidad a las peticiones de los trabajadores. Mientras que para los sindicatos el conocimiento de esa información tiende a eliminar la desigualdad entre las partes. Para 
este autor, habría que resolver una serie de problemas relacionados con la confidencialidad de la información, su frecuencia, su contenido, etc. Así propone que se deberían entremezclar tres posturas: información mínima exigida por ley, información voluntaria por parte de la empresa e información a petición de los trabajadores para su uso inmediato.

Si los lugares tradicionales de investigación de este tema han sido Gran Bretaña, Estados Unidos y Australia, a partir de finales de los años 80, Japón se contagia del interés por este tema. Para Yamaji (1986) hay una correlación entre el incremento salarial y el beneficio por empleado, sin embargo esta correlación es desigual a lo largo del tiempo; es más importante hasta la crisis del petróleo en 1974, y es más atenuada a partir de esta fecha, en parte porque esta crisis incidió gravemente en la capacidad para afrontar nuevas subidas salariales por parte de las empresas. Morishima (1991) trata de buscar la relación o dependencia entre la duración y la subida de la negociación colectiva con el grado de información contable que se transmite a los empleados o sus representantes sindicales. Según este autor la negociación cambia claramente cuando se dispone de información por ambas partes, a pesar de la divergencia de intereses (Cousineau y Lacroix, 1986) y de tratarse de información asimétrica (Abowd y Tracy, 1989). Así, presenta un modelo en el cual la negociación es función de la información, entendiendo a esta información como variable independiente. Este planteamiento contrasta con el modelo norteamericano, en el cual, cuanto menos información disponen los sindicatos hay menos peticiones, con lo que se hace más fácil la discusión (Kleiner y Bouillon, 1988). Avanzando un poco más en los objetivos planteados en este trabajo, en un documento posterior Morishima (1991) estudia el efecto de la información no sólo en la negociación colectiva sino incluso en la rentabilidad y en la productividad de las empresas. Como conclusión última de los trabajos de este autor podríamos establecer la siguiente: la transmisión de la información contable facilita la negociación, lo que redunda en que 
disminuyen los costes de renegociación, y que en último lugar queda visible en un aumento de las rentabilidades de la empresa.

Pretendemos examinar la posible existencia de relación o dependencia entre la modificación salarial negociada en convenio colectivo y la información contable extraída de las cuentas anuales de cada empresa. Si utilizáramos técnicas estadísticas, una vez descritos y analizados los datos referentes a las cuentas anuales y a los salarios de los convenios colectivos de empresa, ¿podríamos establecer una ley que fijara el comportamiento futuro de cada empresa? ¿Podríamos predecir, inducir o inferir la posible subida salarial (variable dependiente) en función de algunos 0 ratios relevantes de las empresas (variables independientes)?

En teoría económica, los salarios se fijan según la oferta y la demanda de trabajo por parte de los mercados. Sin embargo, algunos de los factores más importantes son la situación económica de la empresa y su capacidad para pagar salarios más altos "ability to pay" (Zulauf, 1965).

El trabajo importante más antiguo fue realizado por Pillsbury (1958), entrevistando a 55 jefes sindicales sobre la actitud de los sindicatos y los trabajadores hacia los informes financiero - contables de las empresas. En este estudio, se establece que los sindicatos usan los estados financieros en la misma medida que lo hacen los inversores y el resto de usuarios, es decir para evaluar la actuación pasada y para tomar decisiones sobre el comportamiento futuro.

Horwitz y Shabahang (1971) trataron de determinar qué información financiera es más utilizada por los sindicatos para negociar la subida salarial. Al fin y al cabo, esta pregunta no hace sino incidir en el impacto de la contabilidad en el comportamiento de los individuos. Estos autores consideran dos tipos de variables que tienen impacto en la 
modificación salarial: variables relacionadas con la productividad y por otro lado, variables relacionadas con la capacidad de pago. Dentro de las variables relacionadas con la productividad utilizan las siguientes: beneficio neto de explotación sobre las ventas, ventas sobre valor neto y tasa de inversión en equipos. Dentro del otro grupo relacionado con la capacidad de pago usan variables que tratan de medir la liquidez: activo circulante sobre pasivo circulante, dividendos por acción, beneficio neto sobre activos y beneficios por acción. Según un análisis estadístico utilizando técnicas de regresión concluyen que dos variables son significativas: el margen y los dividendos por acción. Es decir, una variable que mide la rentabilidad de la empresa con base en el entorno, y otra variable que nos indica que los empleados quieren participar en esa rentabilidad, de igual forma que lo hacen los accionistas, vía dividendos.

Sparks y Wilton (1971), en la misma línea investigaron esa dependencia o correlación en empresas canadienses planteando factores económicos y otros factores institucionales. Encontraron evidencia mínima únicamente con respecto a las cifras de beneficios.

Tomczyk (1975), estudió los factores que tienen mayor influencia en la fijación de los salarios en empresas papeleras, por un lado, y en empresas químicas, por otro. Lo significativo de este estudio es que no son las mismas variables económicas las que intervienen en la fijación de los salarios, esto a pesar de la similitud entre las empresas papeleras y las químicas. Además para este autor, son los últimos datos los más influyentes.

Cooper y Essex (1977) señalan la necesidad de analizar si la contabilidad suministra información relevante para investigar modelos de racionalidad limitada en un entorno complejo y cambiante que tenga como objetivo mejorar el bienestar de los trabajadores. Así, mediante el análisis de diferentes cuestionarios obtienen las siguientes conclusiones. Hay una 
poca utilización de los datos contables por parte de los representantes sindicales. Los factores más utilizados para justificar las demandas salariales fueron el coste de la vida, la comparación con otros trabajadores que ocupan los mismos puestos, seguido de las ganancias de la empresa.

El proceso de negociación es un conjunto de toma de decisiones entre los empleadores y los empleados y sindicatos; y la decisión óptima será aquella que se tome con los mejores datos disponibles, Palmer (1977). Se plantea como objetivo: determinar en qué medida están influidos los resultados de la negociación colectiva por los datos contables, y qué mejoras pueden ser incluidas con estos datos en el proceso de negociación colectiva. Mediante el análisis de una batería de preguntas, se pueden destacar las siguientes observaciones: la figura del experto en contabilidad aparece en el proceso de negociación como un técnico o un informador, pero nunca implicado en el proceso de negociación. Los representantes de los trabajadores prefieren que la información que se les suministra se encuentre auditada. En definitiva, que las relaciones industriales en las empresas mejorarían, y lo harían con una relación directamente proporcional a la cantidad y calidad que tengan los datos contables que se vayan a suministrar.

Foley y Maunders (1977) avanzan un escalón e intentan construir un modelo completo y multivariable para tomar decisiones en el proceso de negociación colectiva, el cual podría, lógicamente, ser necesario para predecir la relación entre la información y los resultados del convenio colectivo en circunstancias particulares. Empleando un modelo similar al de Horwitz y Shabahang (1971) encuentran tres variables estadísticamente significativas: la cifra de negocios y el beneficio por acción como coeficientes positivos; y el ratio de solvencia como coeficiente negativo. Aún así dicen que es muy dudoso que los datos de las cuentas anuales puedan afectar a los incrementos salariales. 
Encuentran una alta colinealidad y un bajo coeficiente de regresión. Un aspecto fundamental y novedoso, aportado por estos autores, es que la información contable se necesita tanto antes de la negociación como durante el proceso de la negociación e incluso después de concluida la negociación. Después de concluida la negociación es importante la información por al menos dos razones: para interpretar el convenio, y para vender el convenio a los empleados, justificando las ventajas obtenidas a través del resultado alcanzado en el convenio.

Peel y Pope (1981) estudian si hay factores económicos que pueden influir en la negociación colectiva a nivel de empresa. Además, se muestran claramente partidarios a la transmisión de información contable, ya que es mayor el coste de la negociación, que en este caso queda atenuado, que el coste de revelar la información. Quieren ir más allá y buscan un modelo capaz de predecir el futuro. Teniendo en cuenta la escasa evidencia de los modelos de Horwitz y Shabahang (1971) y Foley y Maunders (1977), introducen otras variables independientes además de las ya utilizadas. Así, plantean el poder predictivo de la rentabilidad anormal con respecto a los cambios salariales. Asumiendo la hipótesis de mercados semieficientes, los precios de las acciones deberían recoger toda la información pública disponible. En definitiva, lo que plantea es que los sindicatos forman las expectativas racionalmente, aunque con una racionalidad limitada debido a la información asimétrica; sólo a medida que esta información disminuya su carácter asimétrico disminuirá la limitación de las decisiones de los empleados, quedándonos con un modelo de expectativas totalmente racionales.

En un trabajo posterior, Peel y Pope (1984) presentan dos posibilidades para el estudio del salario como variable dependiente. En un modelo plantean que los salarios sólo se determinan dentro de un proceso político (Wiles, 1973) y por lo tanto es sólo ese proceso político el que sirve para determinar el valor de la variable dependiente. Mientras 
que en otro modelo, los salarios están en función de ese proceso político y de variables económicas. El hecho de que los salarios dependan de la información presentada, es decir, que dependa de variables económicas: productividad, liquidez y beneficios ya había sido planteado por otros autores (Horwitz y Shabahang, 1971) y (Foley y Maunders, 1977). Para Peel y Pope, no existe una evidencia empírica de correlación entre los salarios y las variables contables. Por esta razón, plantea otro tipo de información, como las expectativas del mercado de valores, que realmente está recogiendo información más bien interna. En definitiva, las expectativas del mercado pueden no ser más que la manera de particularizar la capacidad para afrontar una subida salarial por parte de la empresa, ante el hecho de que la información con base en el coste histórico no refleja realmente las posibilidades futuras de la empresa.

Podríamos analizar, desde otra perspectiva, cual es la variación de los salarios en función de la cotización de las acciones. Sin embargo, los empleados suelen preferir fijar los salarios en función de cifras contables y no sólo de cotizaciones, que van a recoger las fluctuaciones del mercado y que la mayoría de las veces están fuera de su control. Aunque de esta manera podríamos ver como se puede tender a alisar el beneficio para evitar la excesiva fluctuación del mismo en previsión de situaciones indeseadas de caídas bruscas de beneficios (Sloan, 1993). Se pretende buscar un método de remuneración que alinee los intereses del principal con los de los agentes (Holmström, 1979).

Los determinantes fundamentales de las demandas salariales son: la comparación con otras empresas, la capacidad de pago de las empresas, y el coste de la vida (Chamberlain y Khun, 1986). Mientras que la comparación y el coste de la vida se obtienen de fuentes no contables, la capacidad de pago debe obtenerse de los estados contables. Según, las pruebas realizadas por este autor, la capacidad de pago realmente se 
convierte en incapacidad de pago para contrarrestar las peticiones salariales de los sindicatos.

La influencia de la información contable en la negociación colectiva varía según diferentes factores (Hassink, 1995). Este autor, señala tres factores diferenciadores: empresas lucrativas o sin ánimo de lucro; tamaño de las compañías; y sector industrial. Después de un análisis de 765 convenios colectivos y los informes anuales de estas empresas, Hassink examina cómo sólo las empresas lucrativas utilizan esa información contable y que son las empresas de mayor tamaño las que utilizan la información contable en mayor medida. Concluye demostrando la máxima utilización de la información contable en los convenios colectivos que incluyen algún punto sobre la participación en los beneficios por parte de los empleados.

En el congreso de la Asociación Europea de Contabilidad (E.A.A.), celebrado en Antwerp (Bélgica) en Abril de 1998, Hassink presenta el siguiente trabajo: Examina la utilidad de los diferentes estados contables e incluso de las diferentes partes de cada estado contable; también plantea a los sindicatos si éstos necesitan más información; y por último busca evidencia sobre la utilidad de los estados contables en la negociación colectiva, dependiendo de las diferentes características de los distintos usuarios de la información contable. Para este estudio realiza una batería de encuestas o cuestionarios a diferentes sindicatos holandeses, obteniendo las siguientes conclusiones. Respecto a la primera cuestión, Hassink constata: Más de la mitad de los sindicatos encuestados utilizan la información contable contenida en las cuentas anuales. Dentro de las diferentes fuentes de información utilizadas, éstos sitúan en los primeros lugares las fuentes orales y los indicadores macroeconómicos, aunque la información contable interna y externa sigue ocupando un lugar relevante. Dentro de la información contable externa, consideran a las notas a los estados financieros como de crucial 
importancia junto al beneficio de explotación y los costes laborales. De la segunda cuestión, destaca que los representantes de los trabajadores, a pesar de utilizar la información contable, la consideran insuficiente. Desearían más información sobre cifras de productividad y posibilidades de empleo futuro o seguridad en el empleo. Respecto a la tercera cuestión, los sindicatos consideran que sin la utilización de la información contable, la negociación sería más difícil, costosa y duradera. Así mismo, se constata como a mayor formación en temas económicos, se considera más importante el papel de la información contable en la negociación colectiva.

Dentro de la revisión de la literatura hasta ahora hemos apuntado trabajos de autores y/o referencias en países de Europa, América, Asia y Oceanía. Como último botón de muestra, nos gustaría señalar el trabajo de Ebimobowei y Yadirichukwu, publicado en Abril de 2012 en una revista árabe, en la cual se analizan los informes que se presentan a los empleados dentro del contexto de negociación colectiva aplicado a empresas de Nigeria.

Dentro de los trabajos realizados en España podríamos destacar el estudio empírico de Laffarga (1993), quien mediante una serie de cuestionarios realizados por entrevistas, planteaba los siguientes objetivos: Analizar el impacto que tiene el mayor o menor suministro de información contable por parte de las empresas en el proceso de negociación colectiva; analizar el posible potencial que pudiera tener la información contable al ser utilizada de una forma efectiva en el proceso de negociación colectiva; y analizar el convencimiento de que la utilización de la información contable de una manera efectiva puede ayudar a los negociadores a conseguir los intereses de sus representados. 
En la misma línea y dentro del ámbito español está el trabajo realizado por Angela Pons (1996) sobre la información contable y las relaciones laborales. Mediante una serie de entrevistas personales trata de encontrar evidencia sobre el tipo de información contable que reciben los órganos de representación de los trabajadores y de cómo afecta esa información a las negociaciones laborales. Respecto a la información que reciben los representantes de los trabajadores, se constata que reciben más información de lo reglamentado, considerando fiable y necesaria la información recibida. En lo referente al segundo objetivo de la investigación, de las respuestas recibidas se puede concluir que la información más influyente en las relaciones laborales es la de la coyuntura económica, los datos del sector y los de otras filiales. La información contable se releva a un segundo lugar. Sin embargo, la información contable sí ocupa un lugar preferente en dos casos: la discusión de regulaciones de empleo y en el descuelgue del convenio colectivo de ámbito superior. En la misma línea Sherer, Southworth y Turley (1981) constatan que la información contable apenas se utiliza para determinar el salario, pero sí se utiliza en lo referente a los despidos y en la exposición de las condiciones a largo plazo, es decir aquellos aspectos relacionados con el mantenimiento del empleo.

Aunque las empresas no divulguen información específica para ser utilizada en las relaciones laborales, una prueba de la importancia que para la información contable tiene las mismas se encuentra en que en todos los documentos en los que se hace referencia a los usuarios de la información contable aparecen los trabajadores y sus representantes Laffarga (2003).

Beatriz García Osma, Araceli Mora y Ana M. Sabater (2010) en un trabajo publicado por el Ivie estudian la posible relación entre la elección contable que contribuye a manipular los resultados y la negociación colectiva de la empresa. Utilizando una muestra de empresas 
norteamericanas no encuentran evidencia de tal manipulación. Sí que es importante destacar la elección estratégica de cuándo negociar e incluso el uso temporal de la disposición de la información para los representantes de los trabajadores. Todo parece indicar que la propia obtención de información es poder para la negociación.

Ana María Sabater en diferentes trabajos de investigación publicados a partir de 2005, analiza los efectos de la firma de los convenios colectivos de empresa sobre el movimiento en precio, volumen de negociación y volatilidad. Además analiza si la divulgación voluntaria de información en prensa escrita afecta al resultado de la negociación así como al comportamiento de los precios de las acciones afectadas por la firma del convenio. Plantea un elemento más de información asimétrica: la firma de un convenio propio para la empresa plantea un conflicto entre el deseo de influenciar al mercado con una política agresiva de divulgación de buenas noticias, paliando el efecto negativo que la firma del convenio tiene sobre el mercado.

El último de estos trabajos publicado data de 2011. Ana María Sabater y Joaquina Laffarga realizan un análisis empírico de la reacción del mercado bursátil español ante la firma de los convenios colectivos de empresa.

\section{7.- LA INFORMACIÓN CONTABLE EN LAS RELACIONES INDUSTRIALES: CONOCIMIENTO MULTIDISCIPLINAR}

"Cada teoría científica es una teoría general, sin lo cual no sería científica", Khaled Bakdâch. 
Pretendemos utilizar el sistema de información contable para facilitar la toma de decisiones y más concretamente, interrelacionando la contabilidad y las relaciones industriales. La información contable puede evitar la conflictividad laboral ya que facilita la justificación de ciertas decisiones difíciles para la dirección (Bougen, 1989). Puede disminuir los costes contractuales derivados de la renegociación de los contratos. La interrelación y la posible disminución de los costes de agencia se puede observar en la participación en beneficios o en el sistema de remuneración variable.

Existe una interrelación entre la contabilidad y las relaciones industriales, pero incluso el desarrollo abarca un conocimiento multidisciplinar, como demuestra el planteamiento que se hace desde la economía laboral. Así, para evitar el conflicto de intereses y el comportamiento oportunista del agente, incluso se plantea el pago de salarios altos "efficiency wages" (Campbell III, 1993), que producen un aumento de la productividad, un incremento de la cifra de negocios, una disminución de los costes por dimisión y despidos, y, en definitiva, una menor desviación entre lo deseado por el agente y la optimización de beneficios buscada por el principal. Dentro de la economía laboral y en relación con este tema, podemos encontrar dos corrientes: por una parte quienes ligan el rendimiento al sistema de compensación (Leonard, Murphy, Gibbons, Abowd...); y, por otra parte quienes fijan la compensación en función del rendimiento (Ehrenberg, 1990). Para los primeros, la variable dependiente es el rendimiento, mientras que para los segundos es la compensación.

No sólo la economía laboral forma parte de las disciplinas que se ocupan de la resolución del problema organizativo planteado por Jensen y Meckling, también la psicología industrial trata de buscar soluciones. Los sistema de compensación afectan al rendimiento (Bognano y Ehrenberg, 
1990) de tal manera que según un estudio empírico realizado por los autores anteriormente citados sobre el circuito de golf europeo (PGA Tour); cuanto mayores son los premios, mejores metas se consiguen, a pesar de la mayor presión psicológica que pudiera existir por la categoría de ciertas competiciones. Además los sistemas de evaluación y los métodos de recompensa, como elementos que disminuyen el comportamiento oportunista del agente, varían dependiendo de la relación empleador - empleado, incluso dependiendo del ciclo de la empresa, dentro de las cuatro etapas del clásico ciclo de mercado: nacimiento, desarrollo, madurez y declive. Pueden ser utilizados para atraer, motivar o retener (Ellig, 1984).

Se exige un conocimiento interdisciplinar ya que incluso hay una interrelación entre las diferentes disciplinas. Así, por ejemplo, se examina el uso de la información contable en la evaluación del rendimiento, en los presupuestos participativos, y en los efectos organizativos (Brownell, 1982). De nuevo, según palabras de este autor, planteamos la utilidad de la información contable para resolver los problemas organizativos.

\section{8.- LA INFORMACIÓN CONTABLE Y SU PAPEL EN LA SOCIEDAD}

"En nuestros días, la marea histórica ha inundado las torres de marfil. Si el hombre deja de ser social, acaba automáticamente no siendo hombre del todo", Ramón de Garciasol. 
Debemos olvidarnos de la contabilidad como una mera técnica; la contabilidad da significado (Burchell, 1980), legitimidad (Richardson, 1987), estimula la participación (Swieringa y Weick, 1987) y actúa como un instrumento social (Ogden y Bougen, 1985). Pero la información contable debe cumplir una serie de requisitos para que sea convincente en la relación empleador - empleado. Su lenguaje debe ser aceptado por los diferentes usuarios; evitando, en la medida de lo posible, el uso particular de esta información en interés propio; debe garantizarse su objetividad (Amernic y Craig, 1992).

Además desde finales de la década de los sesenta empieza a surgir en Europa una preocupación por el carácter social de la contabilidad (informe Sudreau en Francia), lo que incluye el considerar como usuarios a los trabajadores, siendo únicamente discutible si usuarios externos o usuarios internos. Esos usuarios exigen mayor provisión de información en al menos los siguientes puntos: seguridad del trabajador en su puesto de trabajo; posibilidades de promoción e incremento salarial; y poder adquisitivo del empleado (Del Brío González, 1995). Existen dos enfoques para la elaboración de esa información (Cooper, 1984): modelo de la soberanía del consumidor y modelo orientado a la decisión.

La notoriedad social que adquiere la información contable en nuestros días queda incluso reflejada en la utilización que se viene haciendo por parte de las empresas del Valor Añadido, los informes sociales, la auditoría social, la contabilidad de recursos humanos... El Valor Añadido es un indicador de la riqueza creada por la actividad de la empresa en diferentes ámbitos: sistema financiero, el estado, los trabajadores, etc. El Estado del Valor Añadido "E.V.A." tiene múltiples posibilidades, se puede utilizar para alinear los intereses contrapuestos entre los diferentes elementos que componen el contrato de empresa (Dierks y Patel, 1997). El Valor Añadido tiene pues múltiples utilidades: 
fijación de formas de remuneración, información de la empresa, análisis por parte sindical... (Burchell, Clubb y Hopwood, 1985), es decir, sirve para determinar y para representar la situación de la empresa a diferentes usuarios.

Los informes sociales "employee reports" buscan más datos que los incluidos en las cuentas anuales y tienen como usuarios destacados a los trabajadores y a los representantes sindicales (Firth, 1990). El informe social o sobre los empleados refleja la contribución de la empresa a la mejora del mercado de trabajo mientras que el informe sobre el valor añadido recoge la contribución de la empresa a la riqueza nacional en conjunto, conteniendo información sobre la participación de cada uno de los agentes empresariales en la creación de dicha riqueza. Se intenta que esa información sirva para mejorar las relaciones, disminuir la hostilidad y aumentar la cooperación (Craig y Hussey, 1982). Otra vez, observamos cómo los trabajadores son parte importante de esta relación de empresa. Debemos entender la empresa como un nexo contractual de múltiples participantes, que en nuestro caso particular, referiremos al contrato empleador - empleado. Donde antes sólo existía el accionista, ahora existen un buen número de stakeholders, entre los cuales se incluyen a los trabajadores de las empresas (Sharp, 1971). Hasta tal punto se tiene en cuenta la importancia de los trabajadores como parte integrante de la empresa que, incluso en 1977, el gobierno británico obligaba a presentar cierta información a la parte representante de los trabajadores (ACAS). Cuestiones como eficiencia, productividad, participación empiezan a ser comunes en el entorno de la empresa.

Se pretende convertir lo social en económico y lo económico en social (Hopwood, 1985). De ahí, que queramos entremezclar la negociación colectiva (lo social) y el sistema de información contable (lo económico) El comité y los representantes de los trabajadores se plantean dos prioridades relacionando lo social con lo económico: la 
comprensión de la contabilidad por la sociedad; y el uso de la contabilidad para la sociedad (Tricker, 1975). Se examina el papel socioeconómico de la contabilidad (Burchell, 1980; Cooper y Sherer, 1984; Tinker, 1980).

La información contable debe estar involucrada no sólo en la práctica social sino con el comportamiento organizacional de cada empresa (Becker y Neuheuser, 1975). Así por ejemplo se citan diferentes casos donde la información contable puede ser utilizada: para fijar políticas de estabilidad económica, control de precios y salarios, planificación, etc. (Hopwood, 1979). La contabilidad no sólo proporciona cifras sino que puede servir como mecanismo de influencia social y económica (Burchell, Clubb, Hopwood, Hughes y Nahapiet, 1980). Según estos autores, cuando hay un desacuerdo sobre los objetivos y poca incertidumbre causa - efecto, la contabilidad sirve para promover o discutir los intereses particulares "ammunition machines". En el caso de que haya desacuerdo en lo referente a los objetivos acompañado de incertidumbre causa - efecto la contabilidad puede servir para legitimar y justificar las acciones "rationalization machines".

Así, para Miller (1971) los contables deberían estar más implicados en el proceso de negociación. Lau y Nelson (1981) exponen que los contables deberían conocer más datos de la negociación colectiva. Para Tang (1985) los contables tendrían que jugar un papel más activo en la negociación.

Esta importancia de la contabilidad desde el punto de vista social queda concretada en los aspectos asociados con las relaciones humanas. En pleno siglo XXI, se habla de calidad total, y esas ideas de calidad, de mejora continua, de liderazgo, deben incluir no sólo datos económicos sino datos sociales y datos relacionados con el personal de la empresa. La información contable puede servir como sistema de información del comportamiento humano (Driver y Mock, 1975). Ese sistema de 
información del comportamiento humano, nos puede servir para medir el rendimiento y fijar las recompensas o los castigos (Mock, 1971). Además el sistema de dirección de cada empresa nos marca las necesidades de ese sistema de información, no siendo necesaria la misma información para una organización altamente jerarquizada que para la repartida en áreas de responsabilidad o la empresa claramente descentralizada.

La información contable, incluso, se plantea, usada en ciertos términos, como posible solución a dos de los problemas de la sociedad industrial de nuestros días: la rigidez de los salarios y el desempleo (Lorne Carmichael, 1990) Si conseguimos que el esfuerzo de los trabajadores sea medido, al menos indirectamente, por el sistema de información contable y además se remunera en función de ese rendimiento; se mejora la actitud por parte de los trabajadores, implicando un aumento de productividad y consecuentemente se pueden producir menos despidos e incluso más contrataciones. Ante la eventual circunstancia de que una disminución de la demanda, hiciera desaparecer parte de los beneficios empresariales; las empresas podrían cambiar la actitud preponderante de despido de los trabajadores por una disminución de sus salarios, en consonancia con la situación real de la empresa. Para llegar a esta situación, habría que convencer a los sindicatos, de la relevancia y objetividad de la información contable; y cómo se puede utilizar la información contable para negociar las condiciones de los contratos, incluyendo las condiciones de empleo (Duncan, 1988). Tanta importancia se le da al uso de la información contable para la renegociación de los contratos que incluso en Gran Bretaña se propusieron rebajas impositivas si los trabajadores aceptaban su utilización en detrimento del índice de los precios al consumo.

También desde la economía laboral se plantea la participación en beneficios como medio de negociación salarial para evitar el desempleo. Todas las empresas deberían abonar una paga de reparto de beneficios, 
por convenio o por ley; de esta manera se evitaría la discusión anual de la subida salarial (Holmlund, 1990). En todo caso, se podría discutir el porcentaje de participación en esos beneficios. De esta manera reduciríamos los costes motivados por la renegociación de los contratos. El problema podría surgir por la posible no aceptación de este sistema de remuneración por parte de los trabajadores, al ser éstos, los agentes, adversos al riesgo. Este hecho explicaría la no implantación masiva de este sistema por parte de las empresas.

La importancia del estudio de los factores que inciden en la variación de los salarios, podría ser vista para determinar anticipadamente las consecuencias en el desempleo y en la inflación, para poder adelantar medidas correctoras de estos posibles desequilibrios (Peel y Pope, 1984).

La información contable en la negociación colectiva puede servir para reivindicar el papel que la contabilidad social puede jugar interrelacionando las organizaciones con la sociedad, en nuestro caso con los empleados y/o sus representantes en las relaciones laborales. Williams y Adams (2013) resaltan que las empresas tienen una responsabilidad social con los empleados en términos de contabilidad, entre otros aspectos.

Actualmente existe un nexo de unión cada vez más importante entre la información suministrada a los empleados (incluida la contable) y la responsabilidad social de las empresas. El propio término "responsabilidad" implica responder, defender o justificar, lo que se dice, hace $u$ omite; por lo cual una buena manera de que las empresas sean responsables hacia uno de sus grupos de interés (los empleados) es hacerles partícipes de la información contable de la misma. De hecho, uno de los aspectos claves en la responsabilidad social corporativa tiene que ver con los aspectos sociales, entre los cuales los empleados son quizás el sujeto más tratado. 
La guía para la elaboración de memorias de sostenibilidad propuesta por GRI incluye dentro de sus contenidos básicos indicadores del desempeño de prácticas laborales. El cuadro integrado de indicadores de RSC propuestos por AECA en su documento número 7 sobre RSC incluye indicadores relacionados con las relaciones laborales tanto en sus indicadores financieros como en los indicadores sociales.

La Directiva 2014/95/UE establece para grandes empresas la obligatoriedad de incluir en el informe de gestión, una estado no financiero que contenga información, en la medida de lo posible que resulte necesaria para comprender la evolución, los resultados y la situación de la empresa, y el impacto de su actividad relativa como mínimo a cuestiones medioambientales y sociales, así como relativas al personal...

En definitiva el informe integrado que se propone dentro del ámbito de las memorias de sostenibilidad y la responsabilidad social trata de responder a las necesidades de información de todos los grupos de interés, avanzando desde un enfoque básicamente financiero a uno global que incluya toda la información relevante para evaluar el desempeño e impacto de la organización.

\section{9.- CONCLUSIONES}

"Para hacer investigación científica con éxito no tienes que saberlo todo. Basta con saber de una cosa no conocida", Arthur Leonard Schawlow. 
La contabilidad afecta al comportamiento humano (Amernic, 1983), facilita la toma de decisiones, y como tal debería jugar un mayor papel en la negociación colectiva. La información contable ha sido introducida por diferentes autores como elemento que facilita la resolución del problema de incentivos, debido a la información asimétrica, la existencia de contratos incompletos, racionalidad limitada y el comportamiento oportunista como consecuencia de la divergencia de intereses entre la actuación del agente y el objetivo del principal.

Se preparan informes destinados a los accionistas, a la dirección, a los acreedores y por qué no, para la negociación empleador - empleado. Hasta ahora, parece que se ha primado el uso de la información contable por parte de los accionistas y de los acreedores; sin embargo, los trabajadores pueden ser el motor de la empresa, dentro de la idea de empresa entendida como un nexo de contratos. De hecho, éstos demandan cada vez más información, incluida la contable. El único punto de discusión podría ser determinar si los trabajadores son usuarios internos o externos de esa información contable.

Otro punto común de la revisión bibliográfica, es el que trata de determinar qué información contable se suministra (teoría positiva) y se debería suministrar (teoría normativa) a los empleados. Encontramos posiciones claramente divergentes; desde los que indican que debe ser una ley la que marque la información mínima a transmitir, hasta los que plantean que debe tratarse de una emisión de información voluntaria. También se discute, si la información contable que deben poseer los empleados o sus representantes debe ser exclusivamente preparada para ellos, como usuarios específicos, o si por el contrario todos los usuarios deberían disponer de una información estandarizada.

Además, el tipo de información contable transmitida a los empleados, sindicatos o representantes de los trabajadores depende de 
la situación por la que atraviesa la empresa. Por esta razón, se debe plantear la siguiente cuestión: ¿Cuándo se informa a los empleados? Las opiniones mayoritarias indican que la empresa tiende a informar para dejar entrever o demostrar su incapacidad de pago, es decir, evidenciar su incapacidad para afrontar una subida salarial.

Si como hemos visto no siempre los empleados disponen ni del mismo contenido de información contable ni tienen acceso a ésta en el mismo horizonte temporal. Nos debemos plantear cómo reaccionan los empleados ante esta información. Problemas como la falta de fiabilidad e información oportunista constituyen el elemento común en este punto. Por el contrario, si el contable fuera visto como objetivo e independiente, podría ser el intermediario entre las dos partes contrapuestas: empleador y empleado (Goggans, 1964).

Una vez analizados estos aspectos, más bien formales, intentaremos determinar el problema de fondo: la utilidad de la información contable en la negociación colectiva. Abarcaremos diferentes aspectos: las expectativas con y sin información contable, la conflictividad, la cooperación, la productividad... En definitiva, recogeremos diferentes opiniones sobre el tema central: ¿Puede la información contable reducir el coste de la renegociación de los contratos? ¿Es útil la información contable como mecanismo regulador de incentivos? Después de todo, los contables son especialistas de los datos de las empresas y deberían ayudar a plantear los términos para la discusión de los convenios colectivos de cada empresa. Además, la negociación colectiva, según algunos juzgados, es cada vez más pública que privada y en esta línea se puede introducir el mayor uso que debe tener la información pública, tal como por ejemplo el contenido de las cuentas anuales de las empresas. Incluso se podría discutir quién afecta a quién: si la información contable afecta a la negociación colectiva o si, por el contrario, la negociación colectiva afecta a la información contable. 
Los diferentes planteamientos exigirán un conocimiento multidisciplinar. Por esta razón intercalamos opiniones procedentes de autores de diferentes disciplinas: contabilidad, economía laboral, derecho, organización, psicología, etc.

Todo ello, en la línea desarrollada por Hopwood (1985), de la importancia de la información contable en su relación con la sociedad y los aspectos sociales. Se pretende convertir lo social en económico y lo económico en social. 
CAPÍTULO 4: ANÁLISIS EXPLORATORIO 


\title{
4.0.- INTRODUCCIÓN
}

\author{
"Señales son del juicio \\ ver que todos le perdemos, \\ unos por carta de más, \\ y otros por carta de menos"; Lope de Vega.
}

Una vez analizado el marco legal de la información contable en las relaciones laborales, la negociación colectiva como parte de las relaciones de agencia empleador - empleados, y el marco conceptual, vamos a proceder al análisis empírico del punto fundamental de la tesis: La posible importancia de la información contable para la variación salarial dentro de la negociación colectiva a nivel de empresa; su probable utilidad al reducir los costes de la renegociación; y su utilidad para regular incentivos dentro de la empresa.

Con tal motivo, dividimos el capítulo en ocho secciones. En la primera sección, iniciamos el trabajo exploratorio apuntando alguno de los trabajos revisados con la literatura disponible expuesta en el capítulo tercero, fruto del cual podemos contextualizar nuestro trabajo. En la segunda sección, planteamos el modelo para abordar el objetivo previsto y así poder enlazar el cuerpo de conocimientos que desde la teoría nos permitan explicar, en su caso, las observaciones extraídas de la realidad. En la tercera sección, exponemos las fuentes de información seleccionadas para el análisis empírico. En la cuarta sección, se describe la muestra de empresas elegida para llevar a cabo la contrastación empírica. En la quinta sección, se explican brevemente las técnicas estadísticas necesarias para desarrollar el trabajo empírico. En la sexta sección, realizamos una primera aproximación a los resultados descriptivos/exploratorios a partir de los convenios y las encuestas del año 2000. En la séptima sección, realizamos otro intento de aproximación 
a resultados descriptivos/exploratorios a partir de los convenios y las cuentas anuales de los periodos 2002/2003 al periodo 2013/2014. Con estos resultados podemos vislumbrar unas primeras conclusiones sobre aspectos tales como: qué información contable se suministra a los empleados o sus representantes; a quién se informa dentro del grupo de los empleados; cuándo se suministra esa información contable; cómo reaccionan los empleados ante esa información suministrada por la dirección de la empresa; para qué utilizan esa información los empleados y para qué utilizan esa información los empleadores o la dirección durante la negociación colectiva, etc. Por último, en la octava sección, realizamos unas breves conclusiones del conjunto del capítulo, que nos dará pie al intento de fase explicativa del siguiente capítulo.

\title{
4.1.- BREVE REVISIÓN EMPÍRICA
}

\author{
“¿lgnoras \\ que es menester un gran fondo \\ de doctrina y de talento \\ para ejercerla, y que es tonto \\ el que no pesa la carga \\ antes de echársela al hombro"; Bretón de los Herreros.
}

Sentadas las bases teóricas de la investigación en los capítulos precedentes y la revisión completa de la literatura, pasamos ahora a centrarnos en las aportaciones empíricas que han permitido aproximar la teoría a la realidad de las empresas y, en particular, al estudio de la información contable y su utilización en los convenios colectivos de las empresas. 
Es preciso, no obstante, decir que a pesar de la extensa evidencia empírica acerca de la utilidad de la información contable en las diferentes facetas de las relaciones laborales, no ocurre lo mismo con el tema que nos ocupa en particular: la utilidad de la información contable en la negociación de los convenios colectivos de empresa.

No pretendemos ser demasiado exhaustivos en nuestro recorrido por la evidencia empírica existente, nos interesa, sin embargo, utilizarla como soporte en la creación de un marco empírico con el que llevar a buen término nuestra investigación. Así, proponemos una breve agrupación de estudios que se relacionan con nuestro objeto de investigación (Anexo 2).

Dentro de un primer grupo de trabajos, referidos a la relación entre el suministro de la información contable y los resultados de la empresa, destacamos el trabajo de Morishima (1991). En este trabajo, se trata de determinar la posible incidencia en los resultados de la empresa, de la transmisión de información contable a los empleados. Así, mediante una serie de encuestas se concluye que la mayor difusión de la información contable a los diferentes empleados de la empresa nos lleva a una disminución de los costes de personal (gastos de personal dividido por valor añadido), un aumento de la productividad (valor añadido dividido por el número de empleados) y un aumento de la rentabilidad (ROA o margen). Incluso, bajo otro punto de vista, podríamos decir que la mayor transmisión de información contable, no hace que aumenten las peticiones salariales por parte de los sindicatos en la negociación del convenio colectivo de empresa y que además facilita el desarrollo de la negociación y la consiguiente firma del convenio. Destacamos este trabajo, ya que como comentamos en el capítulo anterior, trataremos de determinar tanto si la información contable influye en los resultados como 
si los resultados sirven para determinar la información contable que se transmite a los empleados.

Un importante número de trabajos, tanto por su número como por sus aportaciones, se dedican mediante una serie de encuestas a investigar la importancia que tiene la información contable para los convenios colectivos, es decir, en qué aspectos es la información contable más utilizada en el contenido de los convenios colectivos. Hassink (1995) indica que en los convenios colectivos, sobre todo se hace referencia a la información contable para los planes de participación en beneficios por parte de los empleados o para argumentar la posible incapacidad, por parte de la empresa, de hacer frente a esta participación de beneficios. Por otra parte, concluye que las empresas que más importancia dan a la información contable en los diferentes puntos de los convenios colectivos son las empresas de gran tamaño, las que negocian convenios de empresa y las empresas lucrativas.

Por otra parte, en la revisión empírica, hemos encontrado sobretodo experimentos de laboratorio para examinar el comportamiento de los trabajadores, sindicatos o representantes de los trabajadores ante el suministro, por parte de la dirección de la empresa, de información financiera o contable referente a la misma. Dentro de este tipo de trabajos, sólo queremos destacar el realizado por Elias (1990), el cual mediante un experimento de laboratorio realizado entre ochenta alumnos de postgrado, divididos en cuarenta parejas de discusión, concluye que los alumnos que hacían el papel de trabajadores, es decir, los empleados disminuyen las expectativas ante el aumento del suministro de información contable, por lo tanto se hace más fácil llegar a concluir el acuerdo y consecuentemente a reducir el conflicto. $Y$ este hecho se hace aún más apreciable cuando la empresa presenta pérdidas. 
En la línea del trabajo anterior, pero por medio de encuestas realizadas a los sindicatos negociadores, otro grupo de trabajos se ha dedicado al estudio del uso que se puede hacer de la información contable por los agentes sociales en la negociación colectiva de empresa. Hassink (1998) concluye indicando que la información contable se utiliza por los sindicatos, de la misma manera que se utilizan los indicadores macroeconómicos, ya que los estados financieros son un buen indicador de la salud de la empresa. Por esta razón, si la información contable se utiliza por parte de los representantes de los trabajadores, este hecho podría indicar que sin el suministro de los estados financieros a los sindicatos o representantes de los trabajadores, la negociación se haría más difícil, larga y costosa.

Avanzado un peldaño más, otros trabajos intentan aplicando el método del caso, determinar qué datos contables tienen mayor incidencia en la negociación colectiva empleador - empleado, a nivel de empresa. Así Zulauf (1965), en su tesis doctoral, y mediante el análisis de una serie de casos, comprueba como el punto central de discusión es la posible incapacidad de pago por parte de las empresas "Ability to Pay"; así, las variables contables que más incidencia tienen en esa magnitud son: el beneficio, la rentabilidad de la inversión y la liquidez de la empresa.

Dentro de un objetivo similar al trabajo anterior, queremos destacar el trabajo de Horwitz y Shabahang (1972), quienes tratan de encontrar las variables contables que son más significativas para las peticiones y las variaciones salariales. Así, mediante el estudio para un 95\% de significación, de datos referentes a 15 empresas durante los años 1945 1965, examinan los coeficientes de correlación de variables relacionadas con productividad, liquidez y rentabilidad; concluyen que únicamente el beneficio neto y el dividendo por acción son variables significativas y en sentido contrario. Por un lado el beneficio neto incide en sentido directo 
en la variación salarial, mientras que el dividendo por acción lo hace en sentido inverso.

Del mismo estilo que el trabajo anterior, debemos destacar el estudio realizado por Peel y Pope (1984). Estos autores tratan de determinar las variables económicas que influyen en la variación salarial pactada en convenio de empresa. Con este motivo obtienen como variable dependiente las cifras de incremento salarial de 95 empresas del Reino Unido y por otra parte, como variables independientes, dos tipos de factores: variables contables y variables de modelos financieros. Las variables contables son similares a las del estudio anterior, que al fin y al cabo son las mismas utilizadas en los modelos de predicción de quiebras y que realmente sintetizan la capacidad de pago "ATP" de las empresas. Mientras que la novedad del modelo viene al introducir una variable típica de modelos de la economía financiera: la rentabilidad anormal, medida como la diferencia entre la rentabilidad real y la teórica para la empresa. Mediante unas regresiones estudia la influencia de estas variables en la variación salarial. Los resultados obtenidos nos muestran que no existe asociación significativa con relación a las variables contables; pero que sí existe correlación con respecto a las respuestas del mercado de capitales. Esto puede indicar que la variación salarial no sólo tiene en cuenta información contable externa sino que también está influenciada por información interna que puede ser conocida por los inversores y tomada en cuenta para fijar la rentabilidad anormal; o lo que es lo mismo que el precio de los títulos puede ser un buen indicador de la situación económico - financiera de la empresa.

Un trabajo referido al entorno japonés destacable es el de Yamaji (1986). En este estudio se trata de examinar la incidencia de la contabilidad en las variaciones salariales mediante un análisis de correlación. Dentro de las conclusiones de este trabajo queremos sobresaltar las siguientes: en el periodo 1966 a 1973 existe una alta 
correlación entre la cifra de ingresos prevista por empleado y la variación salarial; mientras que en el periodo de 1974 a 1983 apenas existe correlación. La explicación dada a esta circunstancia es que a partir de 1974 tuvo una enorme incidencia en las empresas japonesas la crisis del petróleo y por esta razón, podríamos decir que los datos macroeconómicos relegan a los microeconómicos, como por ejemplo la información contable, a un segundo lugar en la fijación de los salarios de las empresas. Además también se afirma que la información contable es utilizada en la negociación colectiva, ya que si no fuera así, no se maquillarían las cifras contables para contrarrestar las peticiones salariales sindicales. El hecho más novedoso de este trabajo creemos que es la utilización como variable independiente de una cifra contable previsional y no las cifras del ejercicio anterior, como ocurría en los trabajos anteriormente citados.

En España, podemos destacar el trabajo realizado por Laffarga (1993), que estudia el impacto de la información contable en la negociación colectiva, al considerar a la información no como un fin sino como un medio para la negociación. Así, se realiza un análisis descriptivo de la situación de la negociación en la provincia de Cádiz, entrevistando a 30 negociadores, tanto representantes de la empresa como de los trabajadores, que abarcan el $78 \%$ de los convenios firmados en la provincia de Cádiz. Como datos más importantes del estudio, podemos destacar que en la negociación, los factores más importantes para influir en el resultado de la misma son el IPC y los beneficios de la empresa. También, debemos destacar el siguiente hecho: la incapacidad de la empresa para pagar sirve para mitigar las peticiones sindicales, pero sin embargo cuando existe una capacidad manifiesta, difícilmente sirve para aumentar la petición salarial.

También en España, tenemos un trabajo posterior al de Laffarga (1993), realizado por Pons (1996). Por medio de una serie de encuestas, 
intenta determinar la información contable que es suministrada a los trabajadores y la información que se utiliza en la negociación. Como aspecto más significativo del estudio, queremos destacar el hecho de que los negociadores por parte de los trabajadores, consideran que la información más influyente en las relaciones laborales es la coyuntura económica, los datos del sector y los datos de otras filiales; relegando a un segundo lugar la información contable.

Mientras que en los trabajos anteriores, se planteaba la información que se utilizaba en la negociación colectiva, Ana María Sabater (2005), por el contrario estudia los cambios que se producen en la información y la repercusión financiera de la firma de los convenios colectivos. Así mediante el estudio de eventos, analiza los 96 convenios colectivos de empresa aprobados por 45 empresas entre los años 1995 y 2001, para entre otras cosas mostrar los cambios que la negociación colectiva produce en el precio, volumen y volatilidad en la cotización en el mercado continuo español de las empresas seleccionadas.

\title{
4.2.- MODELO PROPUESTO
}

\author{
"Cosas veredes, el Cid, \\ que farán fablar las piedras"; Romancero del Cid \\ (Romance72).
}

Los capítulos anteriores nos han permitido proponer este modelo bajo un enfoque contractual, a través del cual se pretende profundizar en los factores determinantes de la negociación colectiva a nivel de empresa y en los efectos y el papel que la información contable provoca sobre la 
misma, y más concretamente sobre la retribución pactada en los convenios colectivos de empresa. El estudio de la información contable como mecanismo que puede favorecer la negociación colectiva, reduciendo los costes de agencia y facilitando la regulación de incentivos, va a quedar enmarcado en el esquema conceptual que propone la teoría de la agencia, dentro de los mecanismos que reducen la asimetría informativa entre empleador y empleados.

El estudio de la negociación colectiva de las empresas es muy complejo debido, en parte, a la diversidad de variables que es necesario considerar de forma interrelacionada. Con este fin, proponemos un modelo de negociación - información en un contexto de agencia, por tratarse de situaciones en las que existen conflictos de intereses, asimetrías informativas e incertidumbre.

Las dos partes, fundamento de este modelo, son el empleador o principal y los empleados o agentes. Entre estos, se establecen una serie de contratos bilaterales, incompletos y con relación vertical de autoridad que constituyen el contrato de empleo. En este contrato de empleo podemos destacar las siguientes características relevantes: asimetría informativa, incertidumbre, racionalidad limitada y oportunismo. Todas estas características nos conducen a un problema de información cuya resolución implica unos costes de agencia. Dentro de estos costes de agencia podemos diferenciar unos costes ex-ante, costes de formalización contractual y costes de garantía; y costes ex-post, costes de control y costes de oportunismo que derivan en la pérdida residual. Todos estos problemas, derivados de la asimetría de la información y la incertidumbre, pueden verse reducidos mediante un adecuado uso de la contabilidad como sistema de información, control y regulación de incentivos (Anexo 1). 
Así la información contable va a ser utilizada para la negociación colectiva, para reducir los costes de agencia y para la regulación de incentivos. El uso de la información contable va a ser planteado bajo dos situaciones: antes de y después de la formalización del contrato o de la renegociación. La información contable va a ser examinada a través de los convenios colectivos de empresa, para facilitar la participación de los trabajadores o para mejorar la comunicación entre empleador-empleados. La encuesta servirá para comprobar si realmente la información contable sirve o no, si sería deseable o no; para reducir la asimetría de la información en el proceso negociador ex-ante. Por último, la información procedente de las cuentas anuales, nos debería servir para verificar si existe algún reflejo económico-financiero ex - post, según el mecanismo seguido en el proceso negociador y el reconocimiento en el convenio colectivo de empresa aprobado.

\section{3.- FUENTES DE INFORMACIÓN}

"Ella gastó todo el charco

en escarpín de un tobillo,

$y$, por subir más arriba, la corriente daba brincos.

Bailar el agua delante

solo con ella lo he visto."; Quevedo.

Los datos para llevar a cabo el estudio provienen de las tres siguientes fuentes: 
- Los 303 convenios colectivos de empresa depositados en la oficina territorial de trabajo de Burgos (Boletín Oficial de la provincia de Burgos) entre el 1 de enero de 2002 y el 31 de diciembre de 2014, que corresponden a 69 empresas (Anexo 5). Previamente para una primera aproximación explicativa, se utilizaron los convenios de empresa vigentes en el año 2000 (Anexo 3).

- Las cuentas anuales de las empresas que depositan su correspondiente convenio de empresa, obtenidas a través de la base de datos SABI.

- Encuestas - entrevistas realizadas a los responsables de recursos humanos de las empresas seleccionadas. Los cuestionarios se llevaron a cabo a finales del año 2000.

Con carácter previo al envío de las encuestas, concertamos entrevistas con negociadores de convenios colectivos tanto desde el punto de vista patronal como sindical, que permitieron cribar el cuestionario inicialmente previsto así como enriquecer nuestros conocimientos sobre el estado de la cuestión.

Con el objetivo propuesto en el modelo, dividimos el cuestionario en las siguientes cuatro partes: una primera parte identificativa, una segunda tratando de posicionar la negociación colectiva de la empresa, una tercera parte para obtener datos sobre la información contable que suministra la empresa a los trabajadores, y por último, en la cuarta parte interrelacionamos la información contable con la negociación colectiva.

En la primera parte, parte identificativa, pretendemos obtener información sobre aspectos generales de la empresa: el tamaño, la actividad principal de la empresa, su estructura de propiedad, etc. 
En la segunda parte, negociación colectiva, intentamos profundizar en el conocimiento de la negociación del convenio colectivo en el seno de la empresa.

En la tercera parte, información contable, nos centramos en el posicionamiento de la contabilidad para la empresa: contabilidad interna o contabilidad externa, cifras más utilizadas, etc.

Por último en la cuarta parte, pretendemos obtener evidencias que corroboran la opinión manifestada en la segunda y tercera partes, dejando para el final la pregunta objetivo de la encuesta: “¿Estarían dispuestos a negociar prescindiendo del IPC y sólo con base en datos contables?".

\section{4.- LA MUESTRA}

"Nunca llegamos a hacernos a la idea de que contamos menos para los demás de lo que ellos cuentan para nosotros", Graham Greene.

Seleccionamos como año de referencia el 2002, ya que una de las partes del trabajo es el estudio de la utilidad de la información contable para la regulación de incentivos (particularizado al impacto de la información contable en la variación salarial), considerando que a partir de la puesta en circulación del euro como moneda única se produciría una situación coyuntural estable, al margen de circunstancias macroeconómicas de años precedentes como una alta tasa de inflación o el esfuerzo económico general para cumplir con las condiciones de convergencia de la Unión Europea. 
Sin embargo, hay que considerar que la situación económica negativa en la que estamos embarcados desde finales de 2007 puede lastrar las pretendidas conclusiones generales sobre parámetros de comportamiento ante la diferente situación económica, ya que no disponemos de periodos en los que podamos concluir con una situación económica favorable.

Por otra parte nos hemos decantado por seleccionar a todas las empresas de la provincia de Burgos que poseen convenio colectivo de empresa. En un primer momento, nos planteamos la posibilidad de seleccionar a todas las empresas que cotizan en el mercado continuo o que presentan las cuentas anuales auditadas en la CNMV con el fin de eliminar la reducción geográfica a la provincia de Burgos, pero lo descartamos, ya que estaríamos perdiendo referencias de empresas de diferentes tamaños, ya que las empresas que cotizan en el mercado continuo son por lo general de un tamaño grande.

De esta manera al seleccionar todas las empresas de la provincia de Burgos que negocian convenio de empresa podemos examinar empresas de diferentes tamaños, de diferentes sectores de actividad y con diferentes características y abarcamos toda la población.

\section{5.- METODOLOGÍA}

"La dialéctica es el método erróneo de reflexión. El que reflexiona no se equivoca, por eso piensa dialécticamente", Derjavyn. 
Para el desarrollo del trabajo empírico, necesitamos acudir a diversas herramientas estadísticas que permitan transformar la base de datos de los convenios colectivos de empresa, los datos de las cuentas anuales y los datos obtenidos a partir de los cuestionarios, en unos resultados más o menos relevantes para nuestra investigación. Dentro de estos paquetes estadísticos, hemos utilizado SPAD.

Para la utilización de estas técnicas estadísticas; en primer lugar, se recopiló la información de las empresas, previamente obtenida de las tres fuentes de datos.

Posteriormente se codifican los datos para tratarlos estadísticamente. Una vez codificados los datos se pasa a su tabulación. Para ello, hemos formado una base de datos que servirá como punto de partida para el estudio empírico.

La mayor parte de las variables definidas en el modelo tiene un carácter no paramétrico (cualitativo) cuyo tratamiento no puede ser tan intensivo como si fueran cuantitativas.

En función de los objetivos concretos de cada fase del trabajo: descriptiva, exploratoria y explicativa, utilizamos las técnicas estadísticas adecuadas. 


\section{6.- RESULTADOS ANALISIS CONVENIOS Y ENCUESTAS (AÑO 2000)}

"No es tan malo

no ser bueno y parecerlo

como serlo y no mostrarlo"; Calderón de la Barca.

\section{A) ANALISIS DESCRIPTIVO: CONVENIOS COLECTIVOS DE EMPRESA}

Del análisis de los convenios colectivos de empresa de las 46 empresas vigentes a finales del año 2000 podemos extraer los siguientes resultados (Anexo 4 y 12):

- 26 empresas de las 46 , es decir un $56,5 \%$, revisan la subida salarial firmada en convenio cuando el IPC real es distinto al IPC previsto, el cual es tenido en cuenta para el planteamiento de la variación salarial. Esta revisión del IPC no siempre está prevista en igual sentido; así algunas empresas sólo revisan el salario al alza, otras al alza y a la baja, otras sólo revisan cuando la diferencia entre el IPC real y el previsto es mayor que una cierta diferencia, otras sin embargo revisan siempre que haya diferencia y para cualquier valor que pueda tomar...En definitiva, la mayoría de las empresas garantizan el mantenimiento del poder adquisitivo al mantener como valor de referencia el IPC real.

- 13 empresas de las 46 de la muestra, un $28,3 \%$ mencionan el suministro de la información contable como un punto más dentro del contenido del convenio colectivo. Aún cuando por el Estatuto de los Trabajadores las empresas tienen obligación de suministrar información mínima a los representantes de los trabajadores; 13 empresas lo recogen 
explícitamente entre su clausulado. Dentro de este grupo de empresas la información contable prefijada es la misma, información trimestral sobre evolución del sector, situación de la producción y ventas de la empresa e información anual con las cuentas anuales de la empresa, excepto para tres empresas que transforman la obligación trimestral legal en bimensual.

- 7 empresas de las 46, un 15,2\% plantean la participación en beneficios de los empleados en la empresa. Esta participación toma las siguientes referencias: facturación (2 casos), resultado del ejercicio antes de impuestos (1 caso), resultado de explotación (2 casos), beneficios auditados (1 caso), rentabilidad (1 caso).

\section{B) ANALISIS DESCRIPTIVO: ENCUESTAS}

Como segunda fuente de datos, seleccionamos las encuestas entrevistas realizadas, teniendo en cuenta que la primera encuesta se hizo a finales de 2000 (Anexo 8, 9 y 14).

De las encuestas realizadas en el año 2000, destacamos los siguientes valores descriptivos:

- Sólo 1 empresa, de las 45 encuestadas, sitúa como más importante la jornada laboral que el salario, dentro de los diferentes puntos de la negociación colectiva, lo cual implica la importancia que tiene la fijación de la variación salarial para un $98 \%$ de las empresas de la muestra.

- Dentro de los sistemas de remuneración: 42 empresas, es decir un 93\% utilizan más habitualmente los sistemas de remuneración basados exclusivamente en una remuneración fija, frente a 2 empresas que emplean un 
sistema mixto de remuneración y tan sólo 1 empresa que utiliza un sistema de remuneración exclusivamente variable. Esto quiere decir que si 7 empresas utilizan la participación de los trabajadores en beneficios y sólo 3 empresas dicen utilizar, aun que sea parcialmente, un sistema de remuneración variable; no todas las empresas que utilizan participación en beneficios, lo consideran un sistema de remuneración sino quizás una mera gratificación con poco poder específico en la regulación de incentivos.

- Para 43 empresas, la transmisión de información económica puede ayudar a mejorar la participación de los trabajadores. Sin embargo, si vemos que sólo 7 empresas utilizan la participación de los trabajadores en beneficios, podemos cuestionarnos qué participación de los trabajadores se favorece con la transmisión de información contable. Todo parece indicar que se trata de una participación política, es decir, en la asignación de derechos de decisión pero en absoluto vinculada a la percepción salarial vía negociación, lo que no impide que quede reservada para la fijación del salario base de cada trabajador.

- En línea con la pregunta anterior, también 43 empresas creen que la transmisión de información contable favorece la negociación colectiva, lo cual puede ser una consecuencia de la participación conseguida por los trabajadores en las diferentes decisiones de la empresa y no sólo en las decisiones referentes a la firma del convenio colectivo.

- Un $80 \%$ de las empresas, es decir 36 empresas, no considera a los trabajadores como usuarios de la información contable, a pesar de que la mayoría de las 
mismas consideraba que la transmisión de información contable mejora la participación de los trabajadores y favorece la negociación colectiva. Esto puede ser debido a qué las empresas cuando se habla de usuarios se refieren en su mayoría a usuarios externos y además obligatorios.

- Este carácter de usuarios obligatorios se corresponde con el siguiente dato; 43 empresas suministran sólo información mínima legal.

- La información contable más empleada en la negociación colectiva es la proporcionada por la contabilidad interna, para 40 empresas. Esta circunstancia unida a las dos anteriores, nos parece indicar que los datos de la información contable interna (productividad, costes, eficiencia, etc.), en la mayor parte de los casos, no se considera taxativamente información contable sino información relacionada con el entorno de la producción.

- Por otra parte, tanto la información contable interna como externa, manifiestan ponerla en disposición en la mayoría de los casos, 95\%, en manos de los representantes de los trabajadores, es decir, que no todos los empleados disponen de la misma, dato consecuente con la no consideración de usuarios de la misma a los trabajadores de las empresas.

- La divulgación de la información contable es independiente de los resultados de la empresa, es decir, no depende de que la empresa obtenga beneficios o pérdidas, 44-45 empresas lo corroboran.

- Por otra parte, parece que el momento en el que más se intensifica la transmisión de la información contable es durante la negociación, lo cual va en línea con la idea de 
que la transmisión de información contable favorece la negociación colectiva.

- Sin embargo, a pesar de la importancia de la información contable para la negociación colectiva, la mayoría de las empresas tienen más en cuenta el IPC que los datos contables para fijar el incremento salarial. No obstante si sólo 1 empresa considera más importante para fijar la variación salarial en las remuneraciones fijas los datos contables, son 20 empresas las que lo consideran más importante que el IPC para el incremento en las remuneraciones variables.

- Dentro de los datos contables, el más relevante para las empresas es la cifra de beneficios, 36 empresas frente a otros datos como la cifra de ventas o la solvencia.

- Por último, 25 empresas creen que las exigencias salariales de los trabajadores se moderarían si ante situaciones de pérdidas o menores beneficios, los trabajadores dispusieran de información contable. Aún cuando todas las empresas consideran que con la misma información contable y ante situaciones de incrementos de beneficios las exigencias salariales de los trabajadores se incrementarían. Esto implica que ante aumento de beneficios todos los trabajadores quieren beneficiarse salarialmente de esta circunstancia pero ante un aumento de las pérdidas un $44 \%$ de los trabajadores no quieren ser partícipes de esta situación.

- A pesar, de toda esta implicación de la información contable en la negociación de los convenios colectivos de empresa, sólo 11 empresas estarían dispuestas a negociar prescindiendo del IPC y sólo con base en datos contables. 
En resumen, la mayor parte de las empresas entrevistadas consideran de vital importancia la fijación del salario en los convenios colectivos de empresa.

Dentro de esta fijación salarial habitualmente es más utilizado el sistema de remuneración fijo. Aún cuando sí consideran la remuneración variable y sobretodo la relacionada con datos económicos - internos. Esos datos económicos son considerados como útiles para potenciar la participación de los trabajadores y favorecer la negociación colectiva, a pesar de que como información típicamente contable sólo se transmite la información mínima legal a los representantes de los trabajadores. Esto es debido a que consideran de mucha más relevancia en el ámbito de la negociación colectiva a la otra información contable distinta de la depositada en el registro mercantil.

Y así, la transmisión de esta información contable al ser, en la mayoría de los casos, ajena a circunstancias del entorno y el quedar circunscrita al área de producción sí se considera importante para la fijación de las remuneraciones variables e incluso los trabajadores aceptarían aumentar o disminuir sus incrementos salariales en función de estas cifras. Sin embargo, al recoger el convenio colectivo, incrementos salariales tanto fijos como variables, no parece que los sindicatos estén dispuestos a prescindir del IPC para la negociación colectiva ya que con el IPC al menos en teoría se mantiene el poder adquisitivo de los trabajadores, ya que como observamos del análisis de los convenios colectivos, en los convenios se muestra una enorme preocupación por el mantenimiento del salario en términos reales al revisar el IPC previsto en función del IPC real.

C) INTENTO DE ANALISIS EXPLORATORIO CON AMBAS FUENTES DE DATOS 
Con el paquete estadístico SPAD, intentamos buscar agrupaciones entre las empresas según sus convenios colectivos de empresa y la respuesta dada en las encuestas circularizadas en el año 2000.

No podemos establecer ninguna agrupación clara y razonable entre las dos fuentes de datos.

Consideramos que la razón más importante para no encontrar ningún tipo de relación y/o agrupación es que las encuestas realizadas iban encaminadas a tener una primera aproximación sobre la intención por parte de las empresas del papel de la información contable en la negociación y los convenios colectivos reflejan la realidad que parece obviamente que es muy distinta a la intención deseada por los representantes de las empresas.

\title{
4.7.- RESULTADOS ANALISIS CONVENIOS $Y$ CUENTAS ANUALES (AÑOS 2002/2003-2013/2014)
}

\author{
"Nadie diga en este mundo \\ de esta agua no beberé \\ por muy turbia que la vea \\ le puede apretar la sed,"; refranero popular.
}

\section{A) ANALISIS DESCRIPTIVO: CONVENIOS COLECTIVOS DE EMPRESA}

Hemos analizado los Convenios Colectivos de empresa, suscritos de una parte por los representantes de la empresa y de otra, por la representación legal de los trabajadores y presentados en la Oficina 
Territorial de Trabajo de Burgos, de conformidad con lo dispuesto en el artículo 90.2 y 3 del Real Decreto Legislativo 1/1995, de 24 de marzo, que aprueba el texto refundido de la Ley del Estatuto de los Trabajadores, en redacción dada por la Ley 3/2012 de 6 de junio, de medidas urgentes para la reforma del mercado laboral, R.D. 713/2010, de 28 de mayo, sobre Registro y Depósito de Convenios y Acuerdos Colectivos de Trabajo (BOE 12/06/2010), R.D. 831/95 de 30 de mayo, sobre traspaso de funciones y servicios de la Administración del Estado a la Comunidad de Castilla y León en materia de Trabajo y Orden de 21 de noviembre de 1996 (BO CyL 22/11/1996) de las Consejerías de Presidencia y Administración Territorial y de Industria, Comercio y Turismo, por la que se definen las funciones de las Oficinas Territoriales de Trabajo.

El conjunto de población supone 69 empresas, que abarcando desde el año 2002 hasta el fin de 2014, alcanzan 303 convenios colectivos de empresa (Anexo 6 y 13).

Entre todas estas empresas están incluidos diferentes áreas de actividad.

Alguna de éstas ha dejado de estar presentes en Burgos, otras se han liquidado y otras han sufrido alguna operación de restructuración empresarial o cambio de nombre, entre otras circunstancias.

El análisis descriptivo ha consistido en analizar básicamente los siguientes aspectos:

- Jornada laboral anual.

- Compromiso de contratos, si lo hubiera en algún caso.

- Forma de determinar la revisión salarial.

- Forma de determinar la participación en beneficios, si lo hubiera. 
- Relación de pagas extras llamadas de "beneficios" añadidas a las dos legalmente reguladas, en el caso de que las hubiera.

- Análisis de otros sistemas de retribución variable recogidos en alguno de los convenios.

- Referencias contables en los convenios colectivos, si las hubiera.

\section{Análisis descriptivo de la jornada anual:}

Para el conjunto de empresas analizado en todo el periodo: la jornada mínima anual ha sido de 1.598 horas (Montefibre Hispania 20112014) y la jornada máxima anual asciende a 1.826 horas (Hostal Tres Condes 2002-2009 y Planificación-Control Logístico 2008-2010).

La diferencia entre valores máximos y mínimos depende más de la empresa que del momento temporal, ya que existen empresas que en el año 2002 establecieron menores horas de jornada anual que otras empresas en el año 2014.

La tendencia fundamental es la reducción de la jornada laboral anual en la revisión de los convenios colectivos.

Sólo 6 empresas amplían la jornada anual.

Destacable el convenio colectivo de Grupo Antolín Dapsa para los años 2013 al 2017, en el cual se amplían el número de horas en 16 horas anuales para ese periodo.

\section{Análisis descriptivo del compromiso de contratos:}

Sólo en 3 casos de los 303 analizados se hace referencia: 
- Ardasa 2002-2003: 20 contratos indefinidos condicionados a la facturación de un determinado pedido.

- Cerámicas Gala 2012-2014: compromiso al mantenimiento del empleo indefinido sin aplicar procedimientos de extinción objetiva.

- Grupo Antolín Dapsa 2013-2017: compromiso al mantenimiento del empleo, en caso contrario se alza la revisión-bajada salarial propuesta.

En los dos últimos casos, este compromiso va acompañado de congelación y/o reducción salarial

Ninguna referencia a más facturación, más beneficios, menor jornada laboral y nuevas contrataciones.

\section{Análisis descriptivo de la revisión salarial:}

Previamente conviene destacar que para todo el periodo analizado el PC real nunca ha sido inferior al previsto, excepto en el año 2014 que incluso ha sido negativo.

La mayor parte de las empresas aumentan los salarios basándose en el IPC previsto (en algún caso más un diferencial) y ajustándose al alza en el momento que es conocido el IPC real, siempre que éste sea superior al IPC previsto. (Excepto en el 2014, esta clausula de revisión a la baja con el IPC real no sería necesaria al no haber sido nunca éste inferior al previsto).

Alguna empresa limita la revisión al IPC real, cuando entre éste y el IPC previsto haya una diferencia superior a un porcentaje. 
En los convenios de los últimos años, a raíz de la crisis económica de finales de 2007, no es generalizado el mantenimiento del poder adquisitivo basado en el IPC.

Algunas empresas optan por disminución salarial (en primeros años de la crisis):

- Cerámicas Gala 2010-2012.

- Grupo Antolín Dapsa 2013-2017 (en años impares).

- Heimbach Ibérica 2012.

Otras empresas optan por la congelación salarial (Después de la disminución salarial previa, en algunos casos):

- Cerámicas Gala 2012-2014 (año previo disminución salarial).

- Duo Fast 2012-2013 (siguiente año +1\%).

- Edscha 2012-2013 (siguiente año +IPC real si es positivo).

- Gonvarri 2012-2014 (siguientes años hasta +1\%).

- Grupo Antolín Ara 2013 (siguientes años hasta +0,5\%).

- Grupo Antolín Ardasa 2013-2015 (siguiente año +IPC real si es positivo).

- Grupo Antolín Dapsa 2013-2017 (en años impares disminución salarial).

- Grupo Antolín Eurotrim 2014 (siguientes años hasta $+0,75 \%)$.

- Heimbach Ibérica 2013 (siguientes años hasta +4\%).

- Kronospan 2014.

- Moncor 2000 (siguientes año 50\% de IPC real).

- Nicolás Correa 2012-2014.

- Pepsico Manufacturing 2012-2013 (siguientes años +0,5\%).

- Pierre Guerin Ibérica 2012 (siguiente año +0,5\%).

- $\quad$ Stork Interibérica 2012-2013. 
Sólo una empresa opta por vincular a ciertas referencias empresariales:

- Montefibre Hispania 2011-2014. Revisión salarial lineal de hasta 1.000 euros anuales, vinculada a beneficios antes de impuestos auditados, con una subida mínima lineal (hasta este convenio la referencia era el IPC).

Todas las empresas toman como referencia el IPC del conjunto de España, excepto:

- Centro Gerontológico Burgos 2012-2013, las referencias son al IPC Castilla y León.

- Saint Gobain Vicasa 2013, revisión positiva sobre el porcentaje aplicado vinculada a la diferencia entre IPC España e IPC Unión Europea (armonizando IPC excluyendo carburantes).

\section{Análisis descriptivo de la participación en beneficios:}

- AMVISA 2003-2004, participación variable en resultados siempre que superen $0,3 \mathrm{M} €$, desde el $4 \%$ al $6 \%$ de los resultados antes de impuestos.

- EDB 2002-2003, incremento salarial de hasta el 1,5\% vinculada a facturación - compras + variación de existencias.

- EXPLOSIVOS COMPAÑíA INDUSTRIAL ALAVESA 20052006, incremento salarial de hasta el $2 \%$ vinculado a la facturación.

- FABISA 2004-2007, reparto lineal del 7\% de beneficios auditados (en el convenio del año siguiente es sustituido por una gratificación vinculada a los quinquenios). 
- GRUPO ANTOLIN ARA 2004-2006, paga adicional del 3,5\% de los beneficios (en los años siguientes es sustituido por una cantidad fija anual).

- HIPERBARIC 2014-2016, retribución por beneficios cuando el BAI sea positivo, pero no cuantificado con datos contables sino con el $1,1 \%$ de la base de la empresa por contingencias comunes.

- LENNOX REFAC 2003-2005, bonus de hasta el 2\% vinculado a EBIT.

- SAINT GOBAIN, VICASA 2003-2005, hasta el 4,5\% en función del cumplimiento de objetivo de CFBE.

- THYSSEN 2005-2016, gratificación por beneficios según una fórmula que tiene en cuenta los beneficios netos auditados y el número de personas en plantilla.

- TRW 2004, paga de resultados en función del beneficio de gestión, rentabilidad de los activos y rentabilidad de las ventas.

\section{Análisis descriptivo de la paga extra de "beneficios":}

23 empresas de las 69 recogen en su convenio colectivo una paga por beneficios. Paga por beneficios que en ningún momento va vinculada a la consecución de beneficios ya que no es sino una cantidad fija, en el mayor número de los casos, aún cuando la empresa obtuviera pérdidas.

Esa paga de beneficios puede ser desde media paga extra, una paga extra, un porcentaje del sueldo mensual (desde el $6 \%$ al $15 \%$ ) o una cantidad fija determinada.

No hay ninguna relación entre la existencia o no de esta paga extra de beneficios con la participación variable efectiva en los beneficios de las empresas. 
Destacable el convenio colectivo de Grupo Antolín Ara 2007-2009, en el cual se sustituye la participación variable en los beneficios de la empresa del 3,5\% por una paga extra final a realizar en el mes de septiembre de cada año, que en 2017 equivaldría a 450 euros adicionales de salario anual.

\section{Análisis descriptivo de otras remuneraciones variables:}

La mayor parte de las empresas industriales tienen alguna retribución variable vinculada con el rendimiento, consumo, cantidad, calidad del trabajo, etc.; es decir de alguna manera relacionada con indicadores de productividad:

- Adisseo 2003 contempla una paga variable lineal si las horas de parada son menores a unos valores objetivo, que posteriormente se modifica con respecto una tasa de rendimiento, a partir de 2007.

- Alphacan 2005-2007, Amvisa 2003-2004 contemplan paga de productividad.

- Cerámicas Gala 2004-2006, complemento por cantidad y calidad del trabajo.

- Edscha a partir de 2012 primas de productividad.

- Fabisa 2004-2007, primas por rendimiento y tiempos.

- Gonvarri, primas de producción.

- Grupo Antolín Ara, Ardasa, Dapsa, primas de producción.

- Manufacturas Orive, prima de producción.

- Montefibre Hispania, prima de producción.

- Rottneros Miranda, prima de producción.

- Saint Gobain, prima de productividad.

- Siro Briviesca, prima vinculada a consumo de MOD y materiales.

- VB Autobaterías, primas de productividad. 
- Helados Miko, sector comercial, registra un remuneración variable o comisión sobre ventas netas cobradas.

\section{Análisis descriptivo de las referencias contables:}

15 empresas de las 69 hacen alguna referencia contable.

Principalmente en la obligatoriedad de suministrar a los representantes de los trabajadores, el seguimiento de los resultados económicos. En algunos casos con carácter mensual, bimensual o trimestral.

Entre otras empresas, Artepref en 2002 ya recogía la necesidad de suministrar información contable junto a un plan de viabilidad cuando la empresa plantea la no aplicación total del convenio (incrementos salariales) por pérdidas de explotación durante 2 ejercicios consecutivos que afecten a la estabilidad.

No obstante existe la obligatoriedad recogida en el Estatuto de los Trabajadores, de facilitar esta información contable a los representantes de los trabajadores.

Destacable el convenio de Heimbach Ibérica 2012-2016, en el cual existe un compromiso de capitalización por parte de la matriz (coincide con reducción y congelación salarial).

B) ANALISIS DESCRIPTIVO: CUENTAS ANUALES

Hemos seleccionado una batería de ratios para posicionar la situación económica financiera de las 69 empresas que negocian convenio colectivo de empresa en la provincia de Burgos, además de 
otros indicadores de actividad y generación de valor, relativizados con el número de empleados de cada empresa.

Así, los ratios e indicadores de SABI utilizados han sido (Anexo 17):

- Current Ratio.

- Liquidity Ratio.

- Solvency Ratio.

- Return on shareholder funds.

- Return on total assets.

- Profit margin.

- Net assets turnover.

- Cifra de negocio por empleado.

- Gasto de personal por empleado.

- Resultado de explotación por empleado.

- Resultado del ejercicio por empleado.

- Cash flow del ejercicio por empleado.

- Valor Agregado por empleado.

\section{C) INTENTO DE ANALISIS EXPLORATORIO CON AMBAS FUENTES DE DATOS}

Tal y como dijimos en el apartado anterior, la inexistente posibilidad de encontrar agrupaciones entre el comportamiento de las empresas en cuanto a los convenios colectivos de empresa y la respuesta dada en las encuestas sobre negociación, nos obliga al intento de búsqueda de otra posible fuente de relación. 
En este sentido, utilizamos la totalidad de los convenios colectivos de empresa y la totalidad de las cuentas anuales de las empresas. En este caso, hemos dejado la intencionalidad de la respuesta de las encuestas para fijarnos en la realidad tanto de los convenios aprobados como de los indicadores procedentes de las cuentas anuales.

En primer lugar, puesto que casi todas las empresas utilizan la referencia al IPC, hemos seleccionado la variable información contable externa (para los convenios que vinculan al menos parcialmente una paga a referencias contables externas como facturación, resultado, etc.) y la variable información contable interna (para las empresas que aplican además remuneraciones basadas en datos de productividad, tiempos, rendimientos, etc.).

Posteriormente, hemos realizado 4 agrupaciones de empresas:

- Empresas que utilizan sólo variable información contable externa. Grupo 1.

- Empresas que utilizan sólo variable información contable interna. Grupo 2.

- Empresas que utilizan ambas variables: información contable externa e interna. Grupo 3.

- Empresas que no utilizan ninguna de las dos variables. Grupo 4.

Con los siguientes resultados: $10 \%$ de las empresas pertenecen al grupo 1 , casi $20 \%$ pertenecen al grupo 2, sólo 1 empresa pertenece al grupo 3 y el $70 \%$ de las empresas pertenecen al grupo 4. 
En segundo lugar, hemos agrupado las empresas en estos 4 grupos, para calcular los promedios de los ratios SABI en cada uno de estos grupos.

Tampoco hemos conseguido encontrar ninguna relación lógica entre las agrupaciones. No hay ninguna conclusión relevante entre la mejor situación económico-financiera o la mayor generación de valor entre las empresas, según que utilicen o no en sus convenios colectivos la información contable interna y/o externa.

\title{
4.8.- CONCLUSIONES
}

\author{
"Que el no llegar da dolor \\ pues indica que mal tasas \\ $y$ eres del otro deudor; \\ mas iay de ti si te pasasi, \\ si te pasas es peor"; Muñoz Seca en La Venganza de Don \\ Mendo.
}

Con las encuestas enviadas a los responsables de recursos humanos de todas las empresas que negociaban convenios colectivos de empresa en el año 2000, hemos tomado una primera aproximación de diferentes aspectos de la negociación colectiva; y en concreto nos gustaría destacar las siguientes respuestas, que ya fueron planteadas en el estado de la cuestión previamente analizado: 
- ¿Qué información contable se suministra a los empleados o sus representantes? En principio, sólo suministran la información contable externa (mínima legal) pero en diferentes momentos de la negociación sobre todo se utiliza la información contable interna.

- ¿A quién se suministra esta información contable? Casi unánimemente a los representantes de los trabajadores.

- ¿Cuándo se suministra esta información contable? Se intensifica su transmisión durante la negociación.

- ¿Cuál es la magnitud contable que más condiciona la negociación colectiva? La cifra de resultados para la gran mayoría; sólo unos pocos consideran la cifra de negocio.

- ¿Qué percepción tienen los empresarios sobre las pretensiones de los trabajadores ante mínimos resultados (incluso pérdidas) 0 mayores beneficios? Se percibe la utilidad de la información contable ya que se considera que las pretensiones se reducirían ante situaciones desfavorables y aumentarían ante situaciones favorables.

- Sin embargo, el referente común a todos los convenios es el IPC, que se aplica en la casi totalidad de los convenios casi con carácter automático.

Con el resultado de estas encuestas, que recoge en su mayor parte opiniones sobre pretensiones en la negociación, y la realidad de los convenios colectivos de empresa del año 2000, intentamos realizar agrupaciones de empresas, para encontrar algún tipo de relación entre las respuestas dadas por los responsables de recursos humanos y los convenios colectivos firmados; sin poder destacar ninguna relación razonable.

Ante esta falta de evidencia empírica, retomamos el trabajo utilizando la información económica financiera de cada empresa y los convenios colectivos firmados en el periodo 2002-2014. En una primera 
aproximación, agrupamos las empresas según utilizan la información contable externa o interna para establecer alguna remuneración adicional, ya que al igual que en el trabajo del año 2000, es indudable que la mayor parte de las remuneraciones toma la referencia del IPC. Para posteriormente, apoyándonos en diferentes ratios financieros e indicadores de creación valor, tratar de establecer alguna relación entre la mayor o menor cifra de estos ratios y el uso o no de información contable externa e interna para establecer otras remuneraciones complementarias.

Nuevamente no hemos conseguido ninguna evidencia empírica razonable. Una de las razones podría ser el periodo convulso que hemos vivido desde finales del año 2007 y cómo el éxito de las negociaciones puede haber sido conseguir la supervivencia de la empresa, en lugar de un aumento superior de las remuneraciones salariales. Idéntica situación a la descrita en el trabajo de Yamaji (1986) en el cual las empresas japonesas en plena crisis del petróleo utilizan los datos macroeconómicos en lugar de los microeconómicos.

Por esta falta de evidencia y la importancia que consideramos tiene la información contable de cada empresa en las relaciones laborales, acrecentado incluso desde el nuevo marco legal vigente desde la reforma laboral, intentaremos en un próximo capítulo descifrar las claves de la negociación, el interés o no de la información contable, la credibilidad de la misma, su relación con la mejora de la eficiencia, etc.

Consideramos que este trabajo de investigación puede facilitar el conocimiento del modelo deseable en la negociación colectiva, más teniendo en cuenta que en el transcurso de las negociaciones para la firma del acuerdo interconfederal para la negociación colectiva en 2015, se hacía referencia, entre otras magnitudes, al IPC, PIB, productividad, etc.; y para tal fin, en el siguiente capítulo, realizaremos una encuesta a los directores de personal presentes en la red de directores de recursos 
humanos de Castilla y León, entrevistándonos posteriormente con los responsables sindicales de las organización más representativas en Burgos para tomar de primera mano su reacción ante la respuesta dada por los directores de recursos humanos. Por último, apuntaremos los datos más relevantes, dentro de nuestros objetivos del trabajo de investigación, de todos los convenios colectivos firmados durante el año 2015, manteniendo el ámbito provincial empresarial, pero teniendo en cuenta todos los firmados en las nueve provincias de Castilla y León. 
CAPÍTULO 5: LA TEORÍA POSITIVA EN LAS RELACIONES LABORALES:

ANÁLISIS EXPLICATIVO 


\section{0.- INTRODUCCIÓN}

"Hay que tener razón, pero no a destiempo", Buero Vallejo.

Los capítulos precedentes han servido para crear el marco conceptual de la tesis y proponer un modelo bajo un enfoque contractual. Este modelo nos indica la necesidad de profundizar en los factores determinantes de la negociación colectiva a nivel de empresa y en los efectos que la información contable provoca sobre la misma y más concretamente sobre la retribución pactada en los convenios colectivos de empresa.

Para ello, en el capítulo anterior iniciamos el camino empírico para describir y explorar los fenómenos observados, y que nos han servido para desembocar en este capítulo, fruto de una reflexión pausada y que nos permitirá alimentar las hipótesis subyacentes de la teoría positiva de la contabilidad en su aplicación a las relaciones laborales, apoyándonos en el análisis empírico previamente comentado.

Con tal motivo, dividimos el capítulo en cinco secciones. En la primera sección, sintetizamos la teoría positiva de la contabilidad aplicada a las relaciones laborales como armazón fundamental de este análisis explicativo. En la segunda sección, como consecuencia de los resultados obtenidos en el análisis exploratorio del capítulo anterior y la teoría subyacente en este trabajo de investigación, formulamos los postulados susceptibles de explicación. En la tercera sección, exponemos la metodología utilizada. En la cuarta sección, mostramos los resultados de la investigación. Por último, la quinta sección, se dedica a hacer unos breves comentarios sobre el conjunto del capítulo. 


\section{1.- TEORÍA SUBYACENTE}

"La disciplina es la parte más importante del éxito", Truman Capote

De entre las relaciones que se pueden producir entre agentes económicos, nos hemos detenido en el análisis de las que se desarrollan en el seno de las organizaciones de carácter cooperativo; asumiendo las siguientes consideraciones:

El empleado sigue un modelo utilitarista de comportamiento, es decir, es autointeresado, con racionalidad limitada, adverso al riesgo y capaz de buscar las mejores alternativas para satisfacer sus expectativas particulares. Por otra parte, el empleador o la empresa también tiene su propia función de utilidad, lo que puede provocar una situación de conflicto de intereses, el cual se agrava por el desigual reparto de información entre los individuos, es decir, por la existencia de asimetrías informativas.

En estas relaciones de empleo, la existencia de intereses divergentes y de asimetrías informativas, puede hacer naufragar la relación de agencia, ya que el individuo que posee información privilegiada puede utilizarla para satisfacer sus propios intereses perjudicando a los de la otra parte.

El problema de selección adversa puede producirse cuando los empleadores no hacen una selección acertada del empleado, por no conocer, en el momento de la contratación, sus verdaderas cualidades como profesional. Por esta razón, en la mayor parte de los contratos se fija un salario inicial según convenio, que podrá ser revisado en la medida en que se disponga de la suficiente información para evaluar la actuación del empleado. 
El problema del riesgo moral se produce cuando el empleado, aprovechando su discrecionalidad para gestionar ciertos recursos del trabajo diario, persigue fines particulares, que se desvían de lo pretendido por la empresa. Así, con la revisión del salario pactado en los convenios colectivos de empresa, tomando como referencia indicadores económicos de la empresa que vinculen el salario de cada empleado, se trata de intensificar el esfuerzo del empleado, es decir, reducir el problema de riesgo moral.

\section{2.- POSTULADOS GENERALES}

"Los postulados son definiciones disfrazadas", H. Poincaré

En el capítulo cuarto, hemos descrito y analizado las observaciones fruto de los convenios colectivos de empresa, de las encuestas realizadas y de las cuentas anuales de las empresas de la provincia de Burgos, que negocian convenio colectivo de empresa.

Este análisis descriptivo, nos ha permitido explorar la realidad de la negociación colectiva a nivel de empresa en la provincia de Burgos, que unido al marco teórico propuesto en el capítulo primero; nos permite formular los siguientes postulados generales:

1. La información contable reduce los costes de agencia.

2. La información contable sirve como sistema regulador de incentivos. 
En el primer postulado, podemos observar de manera implícita el marco teórico propuesto, y más concretamente la información asimétrica, que nos permite proponer a la información contable como primer elemento común, ya que lo que se discute no es la oportunidad y fiabilidad de la información contable. Esto nos permite suponer que al menos existe un punto de acuerdo: la información contable, disponible para ambas partes, se convierte en el único tipo de información simétrica y en muchos casos referente para inaplicar los convenios colectivos.

En el segundo postulado, podemos entrever la racionalidad limitada del marco teórico propuesto. La información contable, que como supusimos en el primer postulado es un elemento, que al menos no se discute, se presenta como fiel reflejo de la situación económico-financiera de la empresa; que puede ser utilizada como sistema regulador de incentivos y de alguna manera puede conciliar intereses de las dos partes, empleador y empleados.

Ante la existencia de información asimétrica, al menos con la información contable, el empleado sabe datos sobre la empresa en la cual presta sus servicios y el empleador conoce indirectamente el esfuerzo de sus empleados con las cifras contables resultantes. La existencia de la información contable como dato reconocido y contrastado, evita la búsqueda y elaboración de otra información, que sin duda incrementaría los costes de su obtención.

De esta manera, la información contable sirve para poner de acuerdo a las partes sobre los datos económicos de la empresa, reduciendo la asimetría de la información; ya que nunca se discute sobre la fiabilidad de la información económica, que se presupone, sino sobre los términos del convenio. 
Queda patente, que la información contable juega un papel importante en la regulación de incentivos, aún cuando por la divergencia de intereses los objetivos pretendidos por cada una de las partes integrantes de este contrato de empleo es totalmente distinto. Para los empleadores, la información contable será útil en la medida que justifique una subida salarial inferior a la garantizada con la aplicación de la revisión con el IPC; mientras que para los empleados su validez, viene después de haber garantizado el IPC, y siempre como un suplemento a este salario inicial.

\section{3.- METODOLOGÍA}

"Los hombres más capaces de pensar sobre el amor son los que menos lo han vivido; y los que lo han vivido suelen ser incapaces de meditar sobre él.", José Ortega y Gasset.

El capítulo anterior nos ha permitido obtener información general respecto a la negociación colectiva a nivel empresa y la utilización que se hace de la información contable en aras de facilitar la firma de éstos. El análisis descriptivo de los convenios también nos ha permitido disponer de información detallada de las diferentes variables que confluyen en la firma de los convenios colectivos de empresa. Un primer estudio correlacional, intentó determinar la relación entre la información contable y la variación salarial planteada en los convenios colectivos de empresa por un lado; y por otro la relación entre los diferentes convenios colectivos y su reflejo en la mejora de los datos económicos de las empresas. 
En este capítulo intentaremos explicar las causas de la poca utilización de la información contable en la firma de los convenios colectivos de empresa; tratando de generar un modelo que facilite la utilización de la información contable en estos convenios colectivos, lo que sin duda redundará en una reducción de los costes ex - ante en la negociación y ex - post en la relación de empleo.

Hasta ahora hemos analizado y tratado convenios colectivos de empresas de la provincia de Burgos, mientras que en este punto ampliaremos el tamaño del estudio a empresas de la comunidad de Castilla y León, intentando poder generalizar comportamientos que nos sirven en la búsqueda del modelo de negociación. Para ello, en un primer lugar hemos enviado encuestas a los responsables de recursos humanos incluidos en la "Red de Directores de Personal de Castilla y León", que nos deben permitir ampliar nuestro conocimiento, entre otras cosas, sobre los aspectos más determinantes en la firma de los convenios colectivos bajo el punto de vista del empleador en la relación de empleo.

En segundo lugar, hemos fijado entrevistas con los responsables provinciales de los tres sindicatos más representativos, tratando de ampliar nuestro conocimiento bajo el punto de vista de los empleados de esta relación de empleo.

Por último, hemos vuelto a testar la realidad de los convenios colectivos de empresa, pero en este caso ampliando a todas las empresas de Castilla y León que han firmado convenio colectivo de empresa entre el 1 de enero y el 31 de mayo de 2015, y registrados a través de la oficina territorial de trabajo de su provincia. 


\section{4.- RESULTADOS}

"Mi alma es un solo un cuerpo que fallece por fundirse y rozarse con los objetivos vivos y difuntos", Rafael Alberti.

\section{A) ENCUESTAS A LA RED DE DIRECTORES DE RECURSOS} HUMANOS DE CASTILLA Y LEÓN

La encuesta se dirigió a los responsables de recursos humanos de las empresas de Castilla y León integradas dentro de la red de directores de recursos humanos de Castilla y León CEDERED. A través de CEDERED se envió vía correo electrónico 65 encuestas en el mes de mayo de 2015, habiendo cerrado la recepción de respuestas a finales del mes de junio de 2015 (Anexo 10, 11, 15 y 16).

De las 65 encuestas enviadas, hemos recibido respuesta de 40 encuestas, $62 \%$ sobre el total enviadas.

Los resultados más representativos fueron los siguientes:

Los factores que consideran más importantes a la hora de la firma del convenio colectivo de empresa son los económicos; bien los de la situación económica de la empresa o bien la situación económica sectorial, relegando al último lugar la situación económica general. Jugando un papel también muy importante las relaciones empresa/sindicatos; lo que quizás quiere demostrar que son los comportamientos receptivos de los sindicatos los que optan por considerar más importantes las situaciones económicas particulares que las generales, con lo que puede que vayan tendiendo a alinear intereses y posiblemente, el uso de la información contable sea una de los catalizadores de ese cambio, facilitando la distribución salarial. 
Las materias más determinantes en la negociación y en la discusión para la firma de los convenios colectivos de empresa son sin ninguna duda las que se refieren a la retribución fija y a los incrementos salariales. En segundo lugar también parece muy importante la negociación en lo referente a la jornada laboral, mientras que lo que se refiere a la retribución variable o productividad queda relegado a un segundo plano. Nuevamente la distribución salarial, bien en términos monetarios o en términos de distribución del tiempo de trabajo, juega un papel determinante.

Dentro del proceso de discusión del III Acuerdo para la Negociación Colectiva, hubo bastante debate para determinar la referencia utilizable en la revisión salarial. En la tercera pregunta de la encuesta, se pregunta a los directores de recursos humanos, por la referencia que considerarían más aceptable para establecer la revisión salarial. La respuesta más valorada es la información económica de la propia empresa. Sigue siendo importante la referencia al IPC pero no al PIB, factor que apenas es considerado. La información económica de la empresa y concretamente la contable siempre la hemos considerado como referencia válida en las relaciones laborales y evidentemente confirma los postulados básicos fijados en la sección segunda de este capítulo.

La información económica de la empresa más relevante para fijar tanto el incremento salarial como los complementos variables es la información del momento de la negociación, aunque también es considerada la proyección de la información económica prevista para futuros ejercicios. No es tomada apenas como referencia la información económica de años anteriores. La propia negociación que en muchos de los casos finaliza en un convenio de empresa con una vigencia superior al año natural puede favorecer el uso de esta información previsional. 
Tampoco existen demasiadas diferencias entre la referencia económica más valorada para referenciar tanto el incremento salarial como los complementos variables. Los resultados son la referencia más valorada. En segundo lugar aparece la productividad. Parece que reconocerían la participación en el "excedente" lo que de alguna manera vincularía el salario con el resultado y no siempre con el esfuerzo. A más facturación o más calidad, en principio habría mayor esfuerzo por parte de los empleados, pero estas referencias no son las establecidas en las primeras posiciones.

Para los directores de recursos humanos, la información contable es considerada poco por los representantes sindicales para modular las posiciones en la negociación. Un $60 \%$ de los encuestados manifiesta esa opinión, siendo una cifra ligeramente similar los que consideran que lo utilizan nada o mucho. Más tarde lo comentaremos al entrevistar a los representantes sindicales, pero se muestra una clara asimetría informativa o desconfianza entre las partes.

A pesar de la respuesta anterior, consideran que la situación y los resultados de la empresa serían aceptados por un 77,50\% para establecer las subidas salariales y las remuneraciones variables, lo que evidencia el carácter preferente de la información contable dando conformidad a los postulados señalados anteriormente.

En la legislación laboral podemos encontrar como la situación económica negativa puede llevar a la inaplicación del convenio colectivo de empresa, y preguntamos a los responsables de recursos humanos si verían positivo que la legislación laboral incluyera que en el caso de situación económica positiva se incluyera a los trabajadores como partícipes de esta participación; siendo prácticamente la mitad los que se decantan por la inclusión y los que no lo hacen. No parece muy consecuente esta interpretación desde el punto de vista empresarial; si se 
tienden a remuneración variable, parece que lo recomendable fuera en todos los sentidos. Lo difícil pudiera venir por el tipo de participación, en qué porcentaje, hasta que límites, etc. Es francamente difícil poder defender una posición simétrica cuando la parte empresarial no acepta esta consideración.

Y por último, en aras de tener una primera aproximación a las posibilidades vistas por ambas partes para rebajar la alta cifra de desempleo en España, preguntamos a los directores de recursos humanos sobre la posibilidad de sustituir incremento salarial por reducción de jornada, un 70\% de las respuestas entendieron que no sería aceptado por los sindicatos. Quisimos formular esta pregunta en términos de percepción para las partes porque en última instancia el gobierno (de ver que esta medida sería aceptada por ambas partes), podría establecer mecanismos fiscales, entre otras medidas, para dirigir a las empresas hacia esta recomendación. Sería de alguna manera una situación anticipatoria de los expedientes de regulación de empleo, que sí han funcionado en el largo periplo de crisis en España y temporalmente podría servir para hacer partícipes a los trabajadores de la mejora económica de cada empresa, lo que ocurre es que en lugar de vía salario sería vía reducción del tiempo de trabajo. De ser así, también la información contable habría servido como sistema regulador de incentivos en términos de jornada laboral.

B) ENTREVISTA A LOS SINDICATOS MÁS REPRESENTATIVOS SOBRE LA OPINIÓN MANIFESTADA POR LOS DIRECTORES DE RECURSOS HUMANOS EN LAS ENCUESTAS ENVIADAS A TRAVÉS DE CEDERED

Con un primer análisis de los resultados de las encuestas de los directivos, establecimos reuniones con los responsables y expertos en 
negociación colectiva de los tres sindicatos más representativos en la provincia de Burgos: UGT, CCOO y USO.

Esta entrevista nos permitirá contrastar las opiniones empresariales con la percepción de los representantes de los trabajadores sobre aspectos clave de la negociación colectiva, referencias para la revisión salarial y predisposición o no a aceptar las opiniones manifestadas por los directivos de recursos humanos.

En cuanto a los factores que consideran más importantes a la hora de la firma del convenio colectivo de empresa coinciden totalmente con la opinión de la parte empresarial: son los económicos; bien los de la situación económica de la empresa o bien la situación económica sectorial, relegando al último lugar la situación económica general. No obstante destaca el valor que para los sindicatos tiene el convenio sectorial, sobre todo según nos han manifestado en las entrevistas, porque juega como una especie de paraguas, en el sentido de que no siempre la situación económica de la empresa refleja la realidad de la explotación de la empresa, y en especial manifiestan los sindicatos que en el caso de empresas que forman parte de un grupo, puede ocurrir que las empresas intenten demostrar una posición económica negativa de la empresa pero que en muchos casos viene motivada por la redirección de la facturación de la empresa hacia otras compañías que componen el grupo de empresas. Consideramos que en este caso se tendrían que incorporar en la negociación colectiva referencias al grupo empresarial para así hacer partícipes también a los empleados, en ciertos casos, de la rentabilidad global del conglomerado. También destacamos la percepción por parte de los representantes de los trabajadores que las empresas muestran peores cifras en momentos previos a la negociación, cifras que mejoran en cuanto se produce la firma de los convenios colectivos de la empresa. 
Las materias más determinantes en la negociación y en la discusión para la firma de los convenios colectivos de empresa son también las que se refieren a la retribución fija y a los incrementos salariales. Por el contrario consideran aún más determinante la productividad y la retribución variable que lo referente a la jornada laboral y la flexibilidad. El motivo no es otro que los representantes de los trabajadores ya consideran su implicación con la empresa para establecer la flexibilidad necesaria de la jornada laboral, que facilite la productividad para la empresa y en consecuencia su mejora salarial. La mayor queja sindical por la flexibilidad de la jornada laboral no viene tanto por su fijación sino por la poca premura en el anticipo por parte de la empresa de las nuevas necesidades horarias que le pueda permitir la conciliación del trabajo con su tiempo de descanso y ocio.

La referencia que considerarían más aceptable para establecer la revisión salarial es el IPC. A pesar de que admiten la información económica de la empresa, no genera demasiada confianza ni credibilidad por lo que buscan una referencia externa planteando también como alternativa la situación económica media del sector en el que se mueve la empresa. Para no consideran el PIB aunque fue planteado como alternativa válida dentro del proceso de discusión del ANC.

Para los representantes sindicales la información económica de la empresa más relevante para fijar tanto el incremento salarial como los complementos variables es toda la información disponible tanto anterior, del momento de la negociación, como futura. No quieren en absoluto prescindir de la información económica anterior y el argumento es claro, si en base con información económica anterior los trabajadores han sido consecuentes y han sufrido la crudeza de la crisis, entre otras cosas, con congelación o reducción salarial, se quiere establecer esta premisa inicial para otra vez intentarse hacer partícipes de la mejora económica pretendida. 
Es importante la diferencia entre la referencia económica más valorada para referenciar tanto el incremento salarial como los complementos variables, ya que mientras los directivos consideran a los resultados son la referencia más valorada; los representantes de los trabajadores consideran a la productividad. Los sindicatos nos transmiten en la entrevista que los resultados, como ya comentamos en los comentarios a la primera pregunta de la encuesta, no siempre reflejan la verdadera realidad económica, en gran parte por temas fiscales, y que la productividad sí que refleja el verdadero esfuerzo de un factor productivo importante como es la mano de obra directa.

Para los representantes sindicales, la información contable es considerada poco o nada para modular las posiciones en la negociación. Es síntoma de la desconfianza hacia la misma ya que sí que consideran que es un factor determinante en la negociación.

A pesar de la respuesta anterior, consideran que la situación y los resultados de la empresa sí serían aceptados para establecer las subidas salariales y las remuneraciones variables. Existe un problema de asimetría y desconfianza, no se discute para nada el papel informativo de la contabilidad y su utilidad para el establecimiento de incentivos, según los postulados propuestos anteriormente.

Los representantes sindicales abogan, sin ninguna duda, porque en la legislación laboral se incorporara que en el caso de situación económica positiva se incluyera a los trabajadores como partícipes de esta participación. Parece totalmente consecuente esta interpretación con su posición anterior de reconocimiento de la situación económica de la empresa como aspecto fundamental en la firma del convenio colectivo de empresa; no así la posición empresarial, ya que no todos lo verían aceptable pese a que propugnan la retribución variable como uno de los 
métodos más viables para favorecer la productividad, entre otras medidas.

En último lugar, solicitamos la opinión a los representantes sindicales acerca de las medidas que consideran que pueden favorecer la reducción de la alta tasa de desempleo, para en la medida de lo posible, incorporarlas dentro de los puntos clave de la negociación colectiva. En primer lugar les preguntamos si consideran la posibilidad de sustituir incremento salarial por disminución del tiempo de trabajo, ante la posibilidad, postulada por algunos estudiosos, de que no habrá trabajo para toda la población activa. Taxativamente, los tres responsables entrevistados niegan esta posibilidad, por las siguientes razones:

- Aunque el sindicato como interlocutor en la negociación pudiera no estar en contra de esta medida, la alta insolidaridad de los trabajadores (incluso los afiliados) les impediría defender con el consentimiento de sus afiliados esta posibilidad.

- La reducción o congelación salarial llevada a cabo durante el largo periodo de crisis y las nuevas contrataciones con salarios muy bajos, supondría un esfuerzo en mucho casos inasumible por los trabajadores, y la revisión salarial, aunque mínima, puede paliar la brecha salarial.

- Consideran que la mejor manera de repartir el tiempo de trabajo es eliminar completamente las horas extras, a pesar de que muchos trabajadores y también afiliados se benefician de las mismas.

- Por último consideran que una de las soluciones para reducir la tasa de desempleo no pasa por la reducción salarial sino por el aumento real de los salarios, para generar mayor consumo. Esta última idea, unida a la solidaridad demostrada por los representantes sindicales entrevistados con la situación económica de cada empresa, nos deja entrever que una alternativa es la generación de mayor capacidad adquisitiva, la cual se puede dar, 
por ejemplo con la reducción impositiva hacia las rentas del trabajo o los impuestos indirectos sobre el consumo.

C) CONVENIOS COLECTIVOS DE EMPRESA: EMPRESAS CASTILLA Y LEÓN (01-01-2015 AL 31-05-2015)

Después de haber analizado los convenios colectivos de empresa de la provincia de Burgos, en primer lugar en los periodos 1998-2000 y posteriormente 2002-2014, pasamos a verificar la realidad de los últimos convenios publicados entre enero y mayo de 2015, y referidos a los convenios de ámbito provincial de las nueve provincias de Castilla y León.

En concreto, se trata de 30 convenios de empresa: Ávila (3), Burgos (3), León (5), Palencia (6), Salamanca (1), Segovia (2), Soria (1), Valladolid (7) y Zamora (2) (Anexo 7).

Nos vamos a referir concretamente a dos aspectos recogidos en los convenios: la cláusula de revisión salarial y el establecimiento de otras remuneraciones ligadas al rendimiento, en su mayor parte.

En cuanto a la cláusula de revisión salarial, queremos destacar la inclusión de mayores referencias a la situación económica de la empresa, en concreto la que tiene que ver con la información contable externa, sufriendo un punto de inflexión con los anteriores convenios revisados, en los cuales la referencia casi unánime era el IPC.

Por otra parte, también queremos destacar el aumento de las referencias a la productividad, como elemento fundamental para establecer las remuneraciones variables basadas en el rendimiento. Al igual que los otros convenios anteriores analizados, lo que no podemos establecer es ninguna relación entre el uso de la información contable 
externa con la inclusión o no de la referencia a información contable interna.

Concretamente en 10 empresas de las 30 analizadas, es decir, en una tercera parte se hace referencia a la información contable externa:

- ADISSEO: EBITDA grupo.

- PIERRE GUERIN: Resultado neto.

- STORK INTERIBERICA: No pérdidas.

- HEDISA: Beneficios.

- REAl fundación hospital REINA CATÓlicA: Beneficio explotación.

- SEVERIANO SERVICIO MOVIL: Resultado neto/Facturación.

- ENUSA: Resultados.

- INDUSTRIAS DEL CUARZO: Resultado de explotación.

- ONTEX: Resultado explotación / Facturación.

- TECOPY: Resultados.

Este resultado y la referencia a la información contable externa duplican a la utilización en los convenios analizados 2002-2014. Concretamente ninguna de las tres empresas de Burgos, tenía antes referencias a la información contable externa como forma de hacer partícipes a los trabajadores, aunque mínimamente en los resultados. También queremos señalar como esta participación, con especial referencia a los resultados, refrenda la opinión manifestada por los directores de recursos humanos encuestados y los representes sindicales entrevistados.

La referencia a la información contable interna, mayoritariamente a la productividad, se produce también en 10 de los 30 casos analizados. No siempre son los mismos casos de los que utilizan la referencia contable interna, al igual que sucedía en el análisis de los convenios de los periodos anteriores. Sin embargo, sí aumenta el uso aunque al ser 
también un número importante de empresas las que lo recogían previamente, no llega a duplicar la utilización como reconocíamos en el caso anterior.

\section{5.- CONCLUSIONES}

"El arte no es un arte para las masas desde su nacimiento; se vuelve arte para las masas como resultado de una suma de esfuerzos", Maiakovski.

Una vez analizadas las respuestas dadas a las encuestas y tras el debate con los representantes sindicales, centrado fundamentalmente sobre la mejor referencia para vincular las revisiones salariales, concluimos que se debería hacer el esfuerzo para establecer una formulación que, mediante coeficientes de ponderación, tuviera en cuenta: la situación económica del sector, la información económica de cada empresa y el IPC. Indirectamente es lo que hacen las diferentes partes para fijar sus posiciones negociadores, pero genera tensiones en la negociación, amplia la divergencia de intereses y distrae la realidad empresarial hacia aspectos sólo cuantitativos.

En esta crisis hemos aprendido entre todos que la supervivencia de la empresa es el último objetivo común y que la negociación no tiene por qué suponer una posición ganadora. Se trata de fijar unas reglas básicas asumidas por todos que sirvan para cuantificar la situación económica de la empresa (generando credibilidad), y en base a esa cuantificación fijar la mejor manera para regular los incentivos que retroalimente la mejora de la situación económica de la empresa. 
Situación que de alguna manera se ha visto implementada en los nuevos convenios colectivos aprobados en 2015, donde parece que la contabilidad juega un mayor papel como sistema para la regulación de incentivos. 
CONCLUSIONES 
En estas páginas finales pretendemos ofrecer una breve panorámica de los distintos capítulos desarrollados, así como destacar las principales implicaciones y reflexiones emanadas de la tesis doctoral.

Al inicio de esta investigación nos planteábamos un interrogante: ¿es la información contable un factor clave para la negociación colectiva? La reflexión sobre esta cuestión nos llevó a delimitar el contenido del estudio: La utilidad de la información contable en la negociación de los convenios colectivos de empresa.

Los fundamentos teóricos de la tesis, desarrollados en el capítulo primero, se desarrollan dentro de un marco conceptual que permite profundizar en el entendimiento del contrato de empleo que se establece en el seno de la empresa y la renegociación de esos contratos vía negociación colectiva de empresa. A pesar de la diversidad de enfoques teóricos que han tratado este tema, seleccionamos la teoría de la agencia, en su vertiente positiva, como la perspectiva teórica más adecuada para nuestro objeto de tesis.

La empresa, base de nuestro estudio, es aquella organización compleja que opera en situación de incertidumbre e información limitada, de donde surgen los problemas derivados de la ausencia de información perfecta. Así, como primera referencia al marco teórico, lo hacemos a partir de la nueva economía institucional.

La economía de la información se desarrolla en la teoría de los contratos ya que es la empresa es una ficción legal, un nexo de contratos, entre los cuales vamos a plantear específicamente el contrato de empleo, que se establece entre el empleador y el empleado. Todos los intercambios requieren procesos contractuales para que puedan hacerse realidad. 
En estos contratos, cabe distinguir dos tipos esenciales de problemas, relacionados con el perfeccionamiento y la salvaguardia del intercambio (Arruñada, 1999). Los problemas relacionados con el perfeccionamiento vienen como consecuencia de la renegociación, al no ser los contratos perfectamente cerrados o explícitos. Los problemas del segundo tipo, vienen definidos por la proclividad de los individuos a anteponer el logro de sus propios intereses al cumplimiento de sus obligaciones.

Al formar parte los trabajadores de la empresa, se puede extender la contratación relacional a la relación de empleo, es decir, al contrato entre propietarios de los activos no humanos y propietarios del capital humano. La idea básica es mantener los activos en manos de diversas entidades, pero al mismo tiempo ahorrar en costes de transacción debido a las negociaciones y renegociaciones de los contratos, aprovechando las relaciones a largo plazo.

La Teoría de la Agencia proporciona un marco teórico útil para analizar el proceso contractual en la empresa. Define una relación de agencia todo contrato en el que al menos una parte, el agente, se compromete a realizar algo para otra parte, el principal. La relación laboral es aquella en la cual el trabajador se compromete a cambio de un salario, que puede o no ser función de diversos indicadores de productividad, a proporcionar un esfuerzo, productividad o rendimiento al empleador.

Las empresas incurren en costes a fin de coordinar tareas altamente interdependientes, para las cuales se requiere reunir, procesar y transmitir una gran cantidad de información, desde la alta dirección hasta los destinatarios de la misma. Los costes de negociación son los costes de transacción asociados a las negociaciones entre las partes; incluyen el tiempo empleado y los recursos gastados tanto en negociar como en mejorar la posición negociadora, así como las pérdidas 
soportadas por el fracaso o el retardo en conseguir un acuerdo eficiente. Además, también se incurren en costes de supervisión y costes para motivar a los trabajadores en quienes se ha delegado capacidad de decisión, costes de agencia. Entre ellos podemos citar los costes de formalización contractual, los de garantía, los de control y la pérdida residual. En general, son costes de las relaciones contractuales dirigidos a eliminar el conflicto entre las partes y reducir las posibilidades de incumplimiento. En definitiva, son costes de negociar y sacar adelante el contrato, en un primer momento, y posteriormente el convenio laboral; incluyendo los costes de coordinación y los costes de motivación, como los de medir la actuación, crear incentivos y exigir el cumplimiento de los acuerdos para asegurar que los empleados siguen las instrucciones, cumplen los compromisos y mantienen los acuerdos.

La información contable puede ayudar a resolver uno de los problemas organizativos planteados por Jensen y Meckling (1995): el sistema de control en su doble vertiente, evaluación del rendimiento y métodos de recompensa. Es necesario desarrollar un sistema de control que sea consistente con la asignación de los derechos de decisión. Este sistema de control estará formado por el sistema de evaluación del rendimiento y el sistema de recompensa que alinee los intereses de los empleados con los empleadores. El problema organizativo planteado de esta manera se centra, por tanto, en el diseño de mecanismos que asignen los derechos de decisión, midan el rendimiento y lo premien y/o castiguen. Es en la resolución de este entramado, donde pueden jugar un papel determinante los sistemas de información contable.

La contabilidad, incluida la contabilidad de gestión, puede desempeñar un papel importante para influir en el comportamiento e incrementar el conocimiento y la innovación. Los sistemas de información contable, como instrumentos para la evaluación y el control del rendimiento global e individual, juegan un papel de fundamental 
importancia en la motivación de los integrantes de la empresa, induciendo determinadas conductas y penalizando otras.

En definitiva, nuestro planteamiento va inmerso dentro de la teoría de la agencia y más concretamente dentro de la Teoría Positiva de la Contabilidad, donde nos encontramos ante la presencia de: contratos incompletos, racionalidad limitada, información asimétrica y, divergencia de intereses. Esto implica la necesidad de renegociaciones posteriores (convenios colectivos), que unido a la existencia de costes contractuales para esas renegociaciones (que se verían muy incrementados si no fuera por la existencia del sistema de información contable), nos lleva a la necesidad de la información contable para la renegociación. El sistema de información contable puede servir como mecanismo de información y control reduciendo la asimetría de la información (costes precontractuales) y los comportamientos oportunistas que se producen con posterioridad a la realización de los contratos (costes postcontractuales).

El marco legal, desarrollado en el capítulo segundo, nos va a permitir ahondar en la relación de empleo sugerida en el capítulo anterior y particularizar las circunstancias que configuran el modelo de negociación colectiva en España, desde la posición inicial del Estatuto de los Trabajadores, modificada tras la consiguiente reforma laboral, hasta la última realidad puesta de manifiesto en el Acuerdo para la Negociación Colectiva de Junio de 2015.

La referencia a la utilización de la información contable de las empresas viene expresamente recogida en el Estatuto de los trabajadores. Así, nos gustaría mencionar sucintamente las siguientes referencias: 
- Artículo 26 que fija que para establecer el salario se tendrá en cuenta, entre otros factores, la situación y resultados de la empresa.

- Artículo 47 que establece que para la suspensión del contrato o reducción de jornada por causas económicas, se entiende que concurren estas causas económicas cuando de los resultados de la empresa se desprenda una situación económica negativa, en casos tales como la existencia de pérdidas actuales o previstas, o la disminución persistente de su nivel de ingresos ordinarios o ventas. En todo caso, se entenderá que la disminución es persistente si durante dos trimestres consecutivos el nivel de ingresos ordinarios o ventas de cada trimestre es inferior al registrado en el mismo trimestre del año anterior.

- Artículo 51, despido colectivo con una redacción similar al artículo 47 en lo que se refiere a la concurrencia de las causas económicas.

- Artículo 64, el comité de empresa, tendrá derecho a conocer el balance, la cuenta de resultados, la memoria y, en el caso de que la empresa, revista la forma de sociedad por acciones o participaciones, los demás documentos que se den a conocer a los socios, y en las mismas condiciones que a éstos.

Destacar que en el III acuerdo para el empleo y la negociación colectiva 2015, 2016 y 2017 se recoge que la negociación colectiva es el espacio natural... para facilitar la capacidad de adaptación de las empresas, fijar las condiciones de trabajo y modelos que permitan mejorar la productividad... Se fija, dentro de los derechos de información y consulta, que dentro de la empresa se facilite información sobre la situación económica de la empresa... Dentro de los criterios en materia salarial, los convenios colectivos han de promover la racionalización de las estructuras salariales, con el fin de renovar los conceptos retributivos 
con criterios objetivos y de equidad, dando entrada a aquéllos que se encuentran vinculados a la productividad y resultados en la empresa...

El marco teórico y legal, debe ser completado con las aportaciones de carácter empírico que, sobre el tema, se han realizado en la comunidad científica, según el desarrollo del capítulo tercero. El resumen de este conjunto de trabajos nos ha permitido acotar el tema, ya contextualizado en el contrato de agencia. Para este fin, se ha realizado un recorrido por la literatura empírica sobre la relación empleador empleados, partiendo de finales de los años cincuenta y llegando a las fechas más recientes.

El origen del estudio de este tema podemos citarlo en un trabajo de Pillsbury "Organized labor`s view of corporate financial information" publicado en 1958. Su desarrollo posterior tuvo su momento culminante entre los años 1980-1990, y sobre todo en Alemania, Estados Unidos, Gran Bretaña y los países escandinavos. En España, apenas hay estudios sobre el tema, si exceptuamos los trabajos de Pons (1996) y Laffarga (1993). A partir del año 2000, no hemos podido constatar más aportaciones relevantes a pesar del mayor uso de la información contable por parte de las empresas, motivado en gran parte por las circunstancias económicas negativas coyunturales y empresariales. El último trabajo que hemos podido examinar en España es de Sabater y Laffarga (2011) quienes analizan la relación entre cotización bursátil y la firma de los convenios colectivos de empresa.

Cubiertos estos capítulos, se propone un modelo basado en el planteamiento teórico adoptado - teoría de la agencia - y en el estado de la cuestión, previamente presentado. A ello se ha dedicado el capítulo cuarto y quinto. Para cumplir con el objetivo de la tesis, se seleccionan unas fuentes de información y la metodología necesaria para el tratamiento de dichos datos. Se plantean dos fases de trabajo que 
servirán para dar por cumplido el estudio empírico: una primera fase exploratoria y un intento explicativo.

Las fuentes de información se han captado en dos momentos distintos: en primer lugar hacia el año 2000 y en segundo lugar con continuidad desde el año 2002 hasta mayo de 2015. Habiendo utilizado información proveniente de: convenios colectivos de empresa, cuentas anuales, encuestas a las empresas y entrevistas a los representantes sindicales.

Así, en primer lugar hemos realizado un análisis de los convenios colectivos de empresa de la provincia de Burgos en el año 2000 que junto al análisis de sus cuentas anuales, nos permitió lanzar una primera encuesta a las empresas para testar la utilidad de la información contable en la negociación colectiva.

Posteriormente volvemos a analizar los convenios colectivos de todas las empresas que lo negocian en la provincia de Burgos hasta diciembre de 2014, junto a sus cuentas anuales. Ante la imposibilidad de encontrar relaciones que generalicen el comportamiento de las empresas según los elementos más importantes de sus convenios colectivos y la información económica de las mismas, pasamos a una tercera etapa.

En esta tercera etapa, realizamos encuesta a los directores de recursos humanos de empresas de Castilla y León; con los resultados de esta encuesta nos entrevistamos con los sindicatos más representativos en la provincia de Burgos para tener de primera mano el sentimiento o reacción ante las opiniones empresariales. Y por último, en cuarto lugar, verificamos con los convenios colectivos de empresa de las nueve provincias de Castilla y León, publicados entre enero y mayo de 2015, la realidad de la negociación colectiva, pudiendo así vislumbrar las 
diferencias acaecidas desde los primeros convenios firmados en el año 2000 con estos últimos, 15 años después.

Del análisis minucioso realizado sobre las diferentes fuentes de datos, podemos destacar los siguientes resultados:

- En los convenios colectivos del año 2000 , sólo 7 de las 46 empresas planteaban la participación real de los empleados en los beneficios, a través de la referencia a magnitudes contables: facturación y resultados en casi todos los casos.

- En los convenios colectivos del periodo 2002-2014, 10 de las 69 empresas establecen la participación variable en beneficios con referencias también en resultados en la mayor parte de los casos.

- En los convenios 2002-2014, 17 de las 69 empresas utilizan algún tipo de remuneración variable que considera datos básicos de la contabilidad interna. Cifra muy superior a la referencia a datos de contabilidad externa, pero que aún así no hemos podido encontrar ninguna relación o tipología entre este tipo de empresas.

- En la encuesta enviada en el año 2000 a los responsables de recursos humanos de las empresas con convenio colectivo de empresa en la provincia de Burgos, casi la totalidad consideraban que la transmisión de información contable ayuda a mejorar la participación de los trabajadores y favorece la negociación colectiva.

- Destacamos que en el año 2000, sólo 11 de las 46 empresas estaban dispuestas a negociar prescindiendo del IPC y basándose únicamente en datos contables. Esto parece indicar que ante la coyuntura económica positiva no se considera tan importante hacer partícipes a los trabajadores, considerando que la referencia al IPC y su 
diferencial ya recoge las pretensiones sindicales en la negociación colectiva.

- Sin embargo, en la encuesta realizada en 2015, los responsables de recursos humanos de las empresas de Castilla y León, consideran los factores económicos empresariales o sectoriales y no los generales los más importantes, quizás por el efecto superlativo de la crisis dentro de las empresas.

- Así la referencia más valorada por parte de la empresa para establecer la revisión salarial es la información económica de la propia empresa y no el IPC según manifestaban en el año 2000.

- Aún así no hay un consenso absoluto entre los directores de recursos humanos de hacer partícipes a los trabajadores de la situación económica positiva vía referencia datos económicos de la empresa.

- Esta opinión coincide con la respuesta dada por los sindicatos en las entrevistas, en el sentido que la referencia que consideran más aceptable es el IPC. No consideran que la situación contable refleja la verdadera situación de cada empresa, sobre todo teniendo en cuenta que los grupos de empresas pueden derivar resultados de una a otra empresa. Así el diferencial que se aplicara sobre el IPC serviría para modular las peticiones cuando la situación económica positiva de la empresa lo permita.

- Por último, es importante la concienciación que muestran los sindicatos hacia la productividad, sin duda porque estos años han podido sentir como esa productividad puede hacer mantener el empleo, y así ver recompensado su esfuerzo dentro de los mejores resultados "internos" de las empresas.

- En los últimos convenios publicados desde enero hasta mayo de 2015 referido a empresas de Castilla y León, 10 de 
las 30 empresas analizadas hacen referencia a la información contable externa para fijar algún tipo de participación económica a los trabajadores; cifra muy superior a la preexistente en los años 2000 al 2014 para establecer revisiones salariales.

- También en una tercera parte de estas empresas se hace referencia a la información contable interna y a la productividad, en la mayor parte de los casos.

La información contable sí se utiliza como regulador de incentivos, ya que la variación salarial según el IPC se considera como precio del factor trabajo y sólo los datos contables pueden informar sobre esas recompensas o castigos que percibirán los trabajadores como incentivo añadido a su salario pactado.

Incidir en el uso oportunista de la información contable, fiel reflejo del marco teórico propuesto por la teoría de la agencia; para las empresas el deseo de utilizar la información contable lo es para reducir los salarios, mientras que para los trabajadores siempre lo sería para aumentar el salario básico más el IPC real ya garantizado en el convenio colectivo de empresa.

Constatamos la potencialidad de la información contable para la regulación de incentivos, ya que aún cuando la mayoría de las empresas de la muestra consideran que la transmisión de información contable favorece la negociación colectiva, sólo unas pocas, en el momento actual, utilizan la información contable además del IPC. Al ser la evaluación del rendimiento costosa y difícil, surge un problema de incentivos y nos creemos en la obligación de encontrar un sistema de compensación. En resumen, pretendemos reivindicar el papel de la información contable como apoyo a los sistemas de compensación, para la solución de los problemas relacionados con la regulación de incentivos. 
El último avance deseable sería el establecimiento de un modelo que sirviera para vincular los salarios a la situación económica de la empresa. En el III Acuerdo para la Negociación Colectiva 2015-2017 se han establecido unos máximos de subida salarial para continuar con un escenario de no confrontación sindical y favorecer la competitividad de las empresas. En nuestro caso, creemos que se podría avanzar en los siguientes términos:

- Si la empresa mantiene cifras de facturación y los resultados netos son positivos y la rentabilidad financiera (ROE) no es inferior a un tanto por ciento (que podría fijarse por sectores y tamaño de la empresa, según la información disponible por la Central de Balances del Banco de España) ni superior al doble de ese tipo de interés, garantizar a todos los trabajadores el IPC en la siguiente revisión salarial.

- Si la empresa reduce cifras de facturación y/o los resultados son negativos se dejaría de aplicar la subida salarial referenciada al IPC. (Esta situación ya se produce además acompañada de otras medidas como expedientes de regulación de empleo, inaplicación de convenio, etc.)

- Pero si la empresa aumenta la facturación, los resultados netos son positivos y la rentabilidad financiera (ROE) es superior al doble de ese tipo de interés fijado anteriormente (coste de oportunidad), los trabajadores también tendrían derecho a una prima variable de participación en resultados.

- Simultáneamente todas las empresas debían avanzar en el establecimiento de medidas de productividad; sería deseable que se estandarizan por sectores de actividad y se graduaran con el peso específico de cada empresa. De esta manera los agentes sociales perderían esa desconfianza actual hacia los datos contables y se harían copartícipes en la consecución de los objetivos comunes. 
En definitiva, del conjunto de los resultados alcanzados en nuestro trabajo podemos sentirnos, al menos en parte, satisfechos porque creemos que se ha avanzado un poco más en el objetivo propuesto. En el devenir de la tesis nos ha ayudado la constatación de la utilidad de este estudio en los años embarcados en este trabajo y la confluencia de mi formación jurídico - económica y las sinergias entre mi docencia en la Facultad de Ciencias Económicas y la Escuela Universitaria de Relaciones Laborales de Burgos.

Creemos que se ha ampliado el estudio en el campo de las retribuciones, ya que en la mayoría de los casos hasta la fecha, se ha estudiado la retribución de los directivos; mientras que en nuestro trabajo, nos referimos a los trabajadores de convenio, es decir, todos los empleados de las empresas excepto el personal de alta dirección, que en muchos casos no forma parte del convenio. Además, las circunstancias en las que se desarrolla el trabajo, especialmente la baja, controlada e incluso negativa tasa de inflación, hace que las condiciones de crecimiento macroeconómico no desvirtúe el sentido de la tesis.

No obstante, a pesar de los avances en la senda investigadora, debemos reconocer en este punto las carencias y limitaciones de este trabajo, de tal forma que nos sirva de incentivo para continuar el camino iniciado.

El hecho de haber seleccionado a las empresas de la provincia de Burgos, como comentábamos en el capítulo 4, supone disponer de una muestra con empresas de diferentes sectores y tamaños. Sin embargo, ésta es una de las principales limitaciones: la muestra se compone únicamente de 69 empresas. Por otra parte, los convenios colectivos de empresa no se publican anualmente, sino que la mayoría tiene una vigencia superior al año; este hecho impide asociar variaciones salariales 
firmadas antes de saber cuáles serán las circunstancias económico financieras sobrevenidas.

Todas las limitaciones anteriores creemos que pueden justificar las posibilidades de ampliación de este trabajo, que lo consideramos como un estímulo para seguir cubriendo etapas en el estudio de la información contable en las relaciones laborales.

Dentro de las líneas futuras de investigación, apuntamos las siguientes:

- Comparar las opiniones de las empresas de la provincia de Burgos con la de empresas de otras provincias; para tratar de extrapolarlo al conjunto de empresas españolas.

- En empresas cotizadas, tratar de analizar el comportamiento de la cotización con la diferente manera de establecer la variación salarial y la aplicación de referencias contables que vinculen salario con datos económicos contables de las empresas.

- Analizar la posible relación entre mejora de productividad y participación variable en resultados para todos los trabajadores.

- Intensificar el análisis causa - efecto con el estudio del caso, de alguna empresa que ha pasado de no utilizar información contable en la negociación colectiva a sí utilizarla.

Como punto final en las posibilidades de esta tesis y los futuros trabajos de investigación que de éste pudieran surgir, nos plantearíamos el efecto de una retribución según cifras económico - financieras en el cambio estratégico de las empresas y en la productividad, competitividad y rentabilidad de las mismas. ¿Qué influencia tendría este sistema de 
regulación de incentivos en el rendimiento de los trabajadores y en las cifras económicas de las empresas?

Llegados a este punto, sólo nos queda desear que este trabajo y los apuntes sobre líneas futuras de investigación, no se queden en deseos sino que el interés y la necesidad de seguir profundizando sobre el tema, suponga un inicio y un camino a continuar. 
ANEXO 1

MODELO TEÓRICO 
PÁGINA 270 


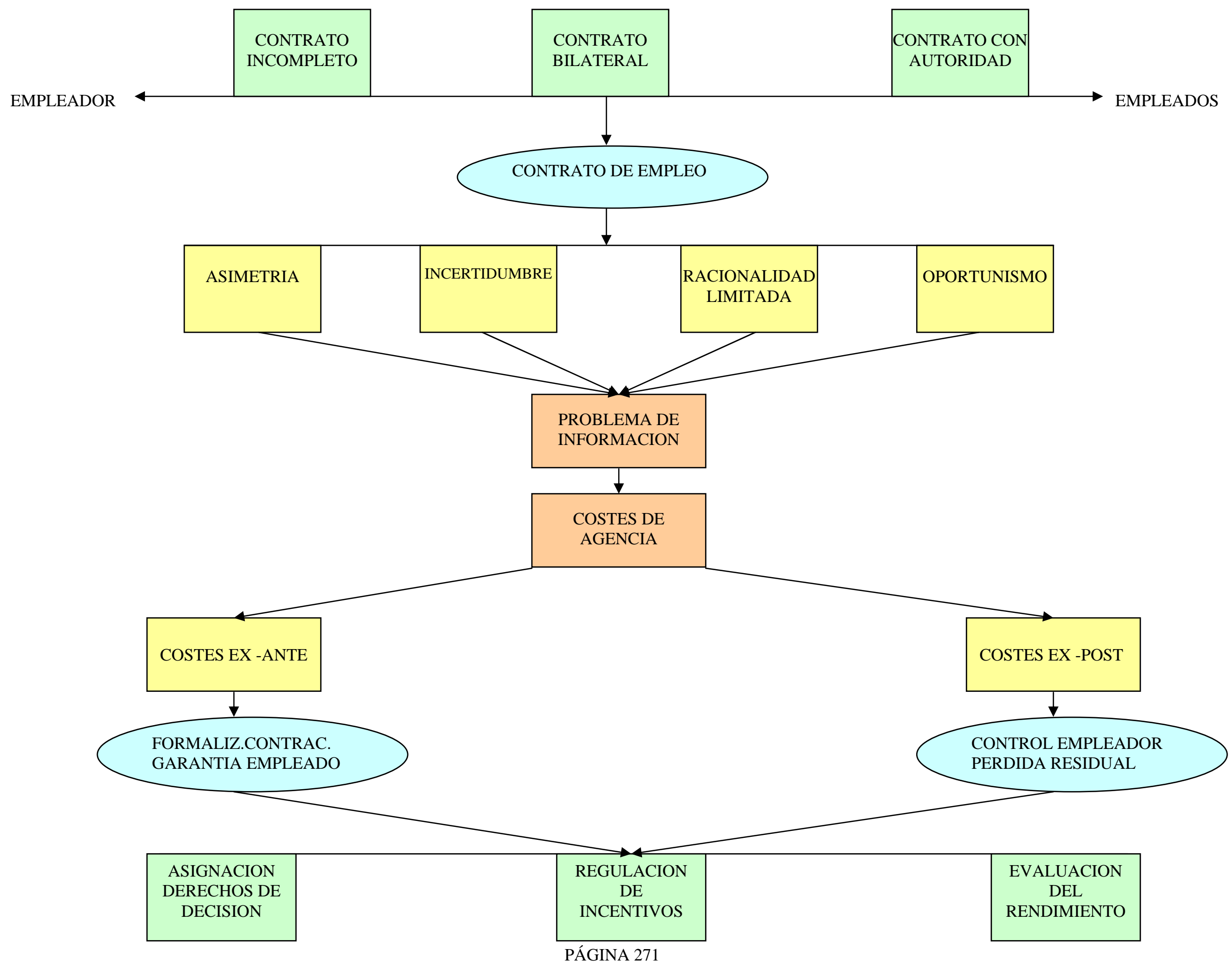


PÁGINA 272 


\section{ANEXO 2}

CUADRO RESUMEN TRABAJOS EMPÍRICOS MÁS REPRESENTATIVOS 
PÁGINA 274 


\section{CUADRO RESUMEN DE TRABAJOS EMPÍRICOS MÁS REPRESENTATIVOS}

\begin{tabular}{|c|c|c|c|c|}
\hline AUTOR & OBJETIVOS & MUESTRA & $\begin{array}{l}\text { TRATAMIENTO } \\
\text { ESTADIST. }\end{array}$ & CONCLUSIONES \\
\hline $\begin{array}{ll}\text { Horwitz } & \text { y } \\
\text { Shabahang } & \\
\text { (1971) } & \end{array}$ & 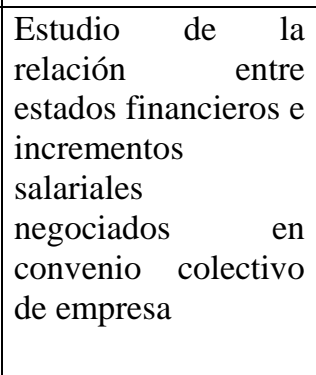 & $\begin{array}{lrr}15 & \text { empresas } & \text { con } \\
\text { convenio colectivo } \\
\text { de empresa } & \text { entre } \\
1945 \text { y } 1967 & \end{array}$ & \begin{tabular}{|lr} 
Estudio & de \\
correlaciones & entre \\
el & incremento \\
salarial & como \\
variable & dependiente \\
y & diferentes \\
variables & contables \\
como & \\
independientes &
\end{tabular} & 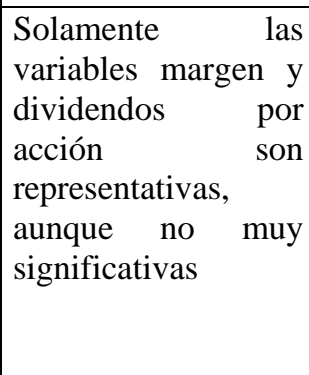 \\
\hline $\begin{array}{l}\text { Foley y Maunders } \\
\text { (1971) }\end{array}$ & $\begin{array}{|lr|}\text { El mismo que } \\
\text { Hortwitz } & \text { y } \\
\text { Shabahang (1971) }\end{array}$ & $\begin{array}{l}117 \text { empresas con } \\
\text { convenio colectivo } \\
\text { de empresa durante } \\
1971-1972\end{array}$ & \begin{tabular}{|lr|}
\multicolumn{2}{|l}{ Regresión } \\
multivariante & entre \\
el & incremento \\
salarial & como \\
variable & dependiente \\
y & diferentes \\
variables & contables \\
como & \\
independientes
\end{tabular} & $\begin{array}{l}\text { Las tres variables } \\
\text { que son algo } \\
\text { significativas son la } \\
\text { cifra de negocios, el } \\
\text { beneficio por acción } \\
\text { y la solvencia. Sin } \\
\text { embargo, hay poca } \\
\text { significación y una } \\
\text { alta colinealidad. }\end{array}$ \\
\hline $\begin{array}{l}\text { Peel y Pope } \\
\text { (1984) }\end{array}$ & 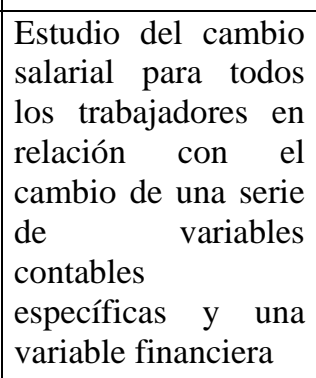 & $\begin{array}{l}95 \text { empresas durante } \\
1977-1980\end{array}$ & \begin{tabular}{|l|} 
Regresión \\
multivariante similar \\
a los dos casos \\
anteriores
\end{tabular} & $\begin{array}{l}\text { Ninguna variable } \\
\text { contable era } \\
\text { significativa } \\
\text { Solo la rentabilidad } \\
\text { anormal (rent. Real } \\
\text { - rent. Teórica) era } \\
\text { representativa }\end{array}$ \\
\hline $\begin{array}{l}\text { Nay } \\
(1991)\end{array}$ & $\begin{array}{l}\text { Relación cifras de } \\
\text { estados financieros } \\
\text { y cifras salariales }\end{array}$ & $\begin{array}{ll}49 \text { unidades de } \\
\text { negociación de } 20 \\
\text { compañías aéreas } \\
\text { entre } 1981-1985\end{array}$ & Análisis PROBIT & $\begin{array}{l}\text { La variable: coste } \\
\text { salarial/total costes } \\
\text { es significativa. No } \\
\text { lo son el margen ni } \\
\text { la solvencia. }\end{array}$ \\
\hline
\end{tabular}




\begin{tabular}{|c|c|c|c|c|}
\hline AUTOR & OBJETIVOS & MUESTRA & $\begin{array}{l}\text { TRATAMIENTO } \\
\text { ESTADIST. }\end{array}$ & CONCLUSIONES \\
\hline $\begin{array}{|ll|}\text { Liberty } & y \\
\text { Zimmerman } & \\
(1986) & \\
\end{array}$ & $\begin{array}{l}\text { Estudio del posible } \\
\text { incremento de los } \\
\text { gastos contables en } \\
\text { la fase previa a la } \\
\text { negociación } \\
\text { colectiva }\end{array}$ & \begin{tabular}{|l} 
Estados financieros \\
de 85 empresas
\end{tabular} & \begin{tabular}{|l|} 
Estimaciones con un \\
modelo \\
autoregresivo
\end{tabular} & $\begin{array}{l}\text { No se puede apoyar } \\
\text { la hipótesis de la } \\
\text { manipulación } \\
\text { contable }\end{array}$ \\
\hline $\begin{array}{l}\text { Yamaji } \\
\text { (1986) }\end{array}$ & \begin{tabular}{|l|} 
Estudio de las \\
políticas contables \\
en las fases cercanas \\
a la negociación \\
colectiva
\end{tabular} & \begin{tabular}{|l}
38 empresas con sus \\
estados financieros
\end{tabular} & Análisis de datos & $\begin{array}{l}\text { Las previsiones } \\
\text { económico- } \\
\text { financieras vienen a } \\
\text { ser mucho más } \\
\text { negativas en las } \\
\text { empresas que las } \\
\text { hacen públicas en } \\
\text { fechas anteriores a } \\
\text { la negociación } \\
\text { colectiva }\end{array}$ \\
\hline \begin{tabular}{|l|} 
Elias \\
$(1990)$
\end{tabular} & $\begin{array}{|lr|}\text { Esudio } & \text { del } \\
\text { comportamiento de } & \text { los trabajadores ante } \\
\text { el suministro de } \\
\text { información } \\
\text { contable }\end{array}$ & 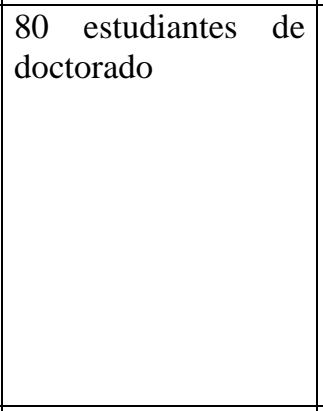 & 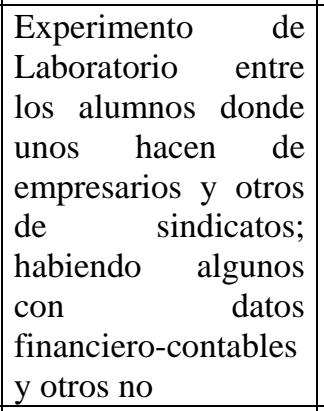 & $\begin{array}{l}\text { Los empleados con } \\
\text { más información } \\
\text { contable disminuyen } \\
\text { las expectativas ante } \\
\text { un aumento salarial } \\
\text { cuando las cifras } \\
\text { contables muestran } \\
\text { pérdidas }\end{array}$ \\
\hline $\begin{array}{l}\text { Morishima } \\
(1991)\end{array}$ & $\begin{array}{|lr|}\text { Estudio del impacto } \\
\text { de la transmisión de } \\
\text { información } \\
\text { contable a r los } \\
\text { trabajadores, en } \\
\text { datos económico- } \\
\text { financieros } \\
\end{array}$ & \begin{tabular}{|lr|}
$127 \quad$ negociadores, \\
empresarios r y \\
sindicatos, en el año \\
\multicolumn{2}{|c}{}
\end{tabular} & $\begin{array}{|ll|}\begin{array}{l}\text { Encuestas } \\
\text { entrevistas }\end{array} & \mathrm{y} \\
\end{array}$ & $\begin{array}{|lr|}\text { Asociación } & \text { positiva } \\
\text { con una mayor } \\
\text { productividad r y } \\
\text { remtabilidad. }\end{array}$ \\
\hline $\begin{array}{l}\text { Hassink } \\
\text { (1995) }\end{array}$ & 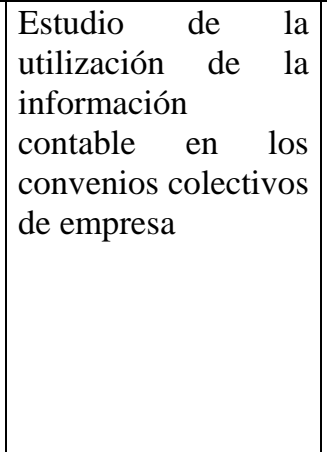 & \begin{tabular}{|lr}
765 & convenios \\
colectivos & de \\
empresas & en \\
Holanda & \\
\end{tabular} & $\begin{array}{|lll|}\begin{array}{l}\text { Análisis } \\
\text { muestra }\end{array} & \text { de } & \text { la } \\
\end{array}$ & \begin{tabular}{|lr} 
La información \\
contable se utiliza \\
en dos sentidos: para \\
fijar los planes de \\
participación \\
beneficios y para \\
argumentar \\
posible incapacidad \\
de pago para hacer \\
frente al aumento \\
salarial
\end{tabular} \\
\hline
\end{tabular}




\section{ANEXO 3}

\section{RELACIÓN DE EMPRESAS EN BURGOS CON CONVENIO COLECTIVO EN \\ DICIEMBRE 2000}


PÁGINA 278 
EMPRESAS QUE NEGOCIAN CONVENIO COLECTIVO DE EMPRESA EN LA PROVINCIA DE BURGOS (DICIEMBRE 2000)

ANSA LEMFORDER S.A.(97/2) (00/3)

APLICACIONES MECÁNICAS VÁLVULAS INDUSTRIALES S.A. AMVISA (99/1)

ARTEPREF GERARDO DE LA CALLE, S.A. (99/3)

CERÁMICAS GALA S.A.(97/1) (98/3) (99/1)

COMPAÑÍA CONCESION. DE SERVICIOS DE SERVICIOS, S.L. CISER (99/2)

COMPAÑÍA DEL FRÍO ALIMENTARIO COFRALIM (97/1)

CONFECCIONES ORY S.A. (97/2) (98/3) (00/3)

CRIADEROS MINERALES Y DERIVADOS S.A. CRIMIDESA (98/3)

DIARIO DE BURGOS, TALLER DE IMPRESIÓN S.L. (98/3) (00/1)

DISPOSITIVOS DE ACCESORIOS DE PUERTAS S.A. DAPSA (98/3)

DORLYL IBERICA S.L. (98/2)

DUO FAST DE ESPAÑA S.A. (98/3) (00/3)

EDB S.A. (97/1) (98/2) (00/2)

ELF ATOCHEM ESPAÑA S.A. (97/1) (98/3) (99/4) (00/1)

FABRICACIÓN DE BISAGRAS S.A. FABISA (98/2)

FÁBRICAS LUCÍA DEL NORTE S.A. FALUNORSA (97/2)

GALLETAS CORAL S.A. (97/1) (98/3)

GONVARRI INDUSTRIAL S.A. (99/3)

HELADOS MIKO S.A. (99/2)

HORMIGONES Y EXCAVACIONES GERARDO DE LA CALLE S.L. (99/3)

HOSTAL TRES CONDES (99/1)

J.J. BIS 95 S.L. (97/2)

KIMBERLY CLARK MIRANDA S.A. (97/2) (98/3)

LA CELLOPHANE ESPAÑOLA, S.A. (98/3) (00/3)

LENNOX REFAC S.A. (97/1) (00/3)

MANUFACTURAS ORIVE S.A. (97/2) (98/3) (00/3)

MONTEFIBRE HISPANIA S.A. (97/1) (98/3)

NICOLÁS CORREA S.A. (97/1) (98/2) (99/2) (00/1)

ONNYX RSU (98/2) (99/1)

PIERRE GUERIN IBÉRICA S.A. (99/4)

PROSIDER IBÉRICA S.A. (97/1) (99/2)

REPOSTERÍA MARTÍNEZ S.A. (97/2) (98/3) (00/3)

RHONE POULENC NUTRICIÓN ANIMAL S.A RPNA (98/4) (99/3)

ROTTNEROS MIRANDA S.A. (99/4)

SAN MIGUEL FÁBRICAS DE CERVEZA Y MALTA S.A. (98/3)

SCHINDLER S.A. (97/1) (97/2) (99/2)

SNACK VENTURES S.A. (97/2)

SOMA S.L. (98/3) (00/3)

STORK INTER IBÉRICA S.A. (97/1) (98/2) (99/3) (00/2)

STORK SISTEMAS ALIMENTARIOS S.A. (97/2)

TALLERES ARA S.L. (98/3)

TRANS UNION GAS ASOCIACION S.A. TUGASA (98/2) (99/4)

TRW OCCUPANT RESTRAINT SYSTEMS S.A. (98/3)

UNIÓN ESPAÑOLA DE EXPLOSIVOS S.A. (97/2)

VB AUTOBATERÍAS S.A. (99/4)

VICASA S.A. (97/1) (99/3) (00/2) 
PÁGINA 280 
ANEXO 4

\section{RELACIÓN DE EMPRESAS EN BURGOS CON CONVENIO COLECTIVO EN \\ DICIEMBRE 2014}


PÁGINA 282 


\section{LISTADO DE TODAS LAS EMPRESAS QUE HAN PUBLICADO \\ CONVENIO COLECTIVO DE EMPRESA \\ PRESENTADO EN LA OFICINA TERRITORIAL DE TRABAJO \\ (DELEGACIÓN TERRITORIAL DE BURGOS, JUNTA DE CYL) \\ Y PUBLICADO EN EL B.O. PROVINCIA DE BURGOS \\ ENTRE LOS PERIODOS 01-01-2002 Y 31-12-2014}

ADISSEO

ALPHACAN

AMVISA

AQUAGEST

ARDASA

ARTEPREF

ATE SISTEMAS Y PROYECTOS SINGULARES

AVENTIS

CALFERMAN

CENTRO GERONTOLOGICO BURGOS

CERAMICAS GALA

CESPA

CLAU 2000

COMPAÑÍA MINERA RIO TIRON

CONFECCIONES ORY

DEXMUSA

DIARIO DE BURGOS

DUO FAST

EDB

EDSCHA

ESTACIONAMIENTOS Y SERVICIOS 
EXPAL

EXPLOSIVOS COMPAÑÍA INDUSTRIA ALAVESA ECIA

FABISA

GALLETAS CORAL

GALLETAS JESUS ANGULO ORTEGA

GONVARRI INDUSTRIAL

GRUPO ANTOLIN ARA

GRUPO ANTOLIN ARDASA

GRUPO ANTOLIN DAPSA

GRUPO ANTOLIN EUROTRIM

GRUPO GARCIA CAMARERO

GRUPO GERARDO DE LA CALLE

GRUPO ITEVELESA

HEIMBACH IBERICA

HELADOS MIIKO

HIPERBARIC

HORMIGONES Y EXCAVACIONES GERARDO DE LA CALLE

HOSTAL TRES CONDES

JOHNSON CONTROL AUTOBATERIAS

KRONOSPAN

LA FLOR BURGALESA

LENNOX REFAC

MANUFACTURAS ORIVE

MINAS DE RIO TIRON CRIMIDESA

MONCOR 2000

MONTEFIBRE HISPANIA

MUEBLES MARIA LUISA 
NICOLAS CORREA

PASCUAL HERMANOS

PEPSICO MANUFACTURING

PIERRE GUERIN IBERICA

PLANIFICACION Y CONTROL LOGISTICO

PROSIDER IBERICA

ROTTNEROS MIRANDA

SAINT GOBAIN VICASA

SCHINDLER

SERVICIOS SEMAT

SIRO BRIVIESCA

SNACK VENTURES MANUFACTURING

STORK INTERIBERICA

TECNICAS MEDIOAMBIENTALES TECMED

THYSSSEN KRUPP ELEVADORES

TRANS UNION GAS TUGASA

TRW AUTOMOTIVE

URBASER

VB AUTOBATERIAS

ZAMORANO LIMPIEZAS MIRANDA

ZF ANSA LEMFORDER 
PÁGINA 286 


\section{ANEXO 5}

\section{CUADRO RESUMEN CONVENIOS COLECTIVOS DICIEMBRE 2000}


PÁGINA 288 


\begin{tabular}{|c|c|c|c|c|c|c|c|c|c|c|}
\hline EMPRESA & CENTRO & FUENTE & VIGENCIA & $\begin{array}{l}\text { JORNADA } \\
\text { LABORAL }\end{array}$ & $\begin{array}{c}\text { COMPROMISO } \\
\text { CONTRATOS }\end{array}$ & $\begin{array}{l}\text { REVISIÓN } \\
\text { SALARIAL }\end{array}$ & $\begin{array}{c}\text { PARTICIP. } \\
\text { BENEFICIOS }\end{array}$ & \begin{tabular}{|c|} 
PAGAS \\
EXTRAS
\end{tabular} & $\begin{array}{l}\text { OTRAS } \\
\text { PAGAS }\end{array}$ & $\begin{array}{l}\text { INFORMAC. } \\
\text { CONTABLE }\end{array}$ \\
\hline $\begin{array}{c}\text { ANSA } \\
\text { LEMFORDER } \\
\text { S.A. }\end{array}$ & BURGOS & $\begin{array}{c}\text { B.O. } \\
\text { BURGOS } \\
7-8-97\end{array}$ & $\begin{array}{c}1-1-97 \\
\text { HASTA } \\
31-12-99\end{array}$ & 1764 horas & & $\begin{array}{c}\text { 1997: +2,20\% } \\
\text { REVISION + } \\
\text { si IPC > 3\% } \\
\text { 1998: +2\% } \\
\text { REVISION + } \\
\text { si IPC > } \\
2,12 \% \\
\text { 1999: +2\% } \\
\text { REVISION + } \\
\text { si IPC > } \\
2,11 \% \\
\end{array}$ & & \begin{tabular}{|c|}
3 \\
Julio \\
Navidad \\
Primavera
\end{tabular} & $\begin{array}{l}\text { Primas a la } \\
\text { producción }\end{array}$ & \\
\hline$\frac{\underline{\text { ZF ANSA }}}{\underline{\text { LEMFORDER }}} \frac{\underline{\text { S.L. }}}{}$ & BURGOS & $\begin{array}{c}\text { B.O. } \\
\text { BURGOS } \\
30-8-2000\end{array}$ & $\begin{array}{c}1-1-00 \\
\text { HASTA } \\
31-12-00\end{array}$ & 1755 horas & & $\begin{array}{lr}2000:+2,10 \% \\
\text { REVISION + } \\
\text { si } & \text { IPC > } \\
& 2,10 \%\end{array}$ & $\begin{array}{l}\text { Si FACTURAC. } \\
\text { mayor o igual a } \\
7200 \text { millones } \\
\text { Revisión si } \\
\text { IPC > 2\% }\end{array}$ & $\begin{array}{c}3 \\
\text { Julio } \\
\text { Navidad } \\
\text { Primavera }\end{array}$ & $\begin{array}{l}\text { Primas a la } \\
\text { producción }\end{array}$ & \\
\hline $\begin{array}{c}\frac{\text { APLICACION. }}{\text { METÁLICAS }} \\
\frac{\frac{\text { VÁLVULAS }}{\text { INDUSTRIA. }}}{\underline{\text { S.A. }}} \\
\underline{\text { AMVISA }}\end{array}$ & BURGOS & $\begin{array}{c}\text { B.O. } \\
\text { BURGOS } \\
22-1-99\end{array}$ & $\begin{array}{c}1-1-99 \\
\text { HASTA } \\
31-12-00\end{array}$ & 1736 horas & $\begin{array}{c}3 \text { nuevos contratos } \\
\text { fijos }\end{array}$ & $\begin{array}{c}\text { 1999: IPC } \\
\text { previsto + 1\% } \\
\text { REVISION + } \\
\text { IPC real si } \\
\text { diferencia > } \\
0,2 \\
\text { 2000: IPC } \\
\text { previsto + } \\
0,5 \% \\
\text { REVISION } \\
\text { igual que } \\
1999\end{array}$ & \begin{tabular}{|c} 
Función de \\
RESULTADOS \\
EJERCICIO \\
ANTES \\
IMPUESTOS \\
Result menores a \\
50 millones \\
$4 \%$ s/ rtdos \\
Rtdos entre 50 Y \\
80 millones \\
$5 \%$ s/ rtdos \\
Rtdos entre 80 y \\
110 millones \\
$5,5 \%$ s/ rtdos \\
Rtdos mayores a \\
110 millones \\
$6 \%$ s/ rtdos.
\end{tabular} & $\begin{array}{c}3 \\
\text { Abril } \\
\text { Julio } \\
\text { Diciembre }\end{array}$ & $\begin{array}{c}\text { Prima de } \\
\text { productividad }\end{array}$ & \\
\hline
\end{tabular}




\begin{tabular}{|c|c|c|c|c|c|c|c|c|c|c|}
\hline EMPRESA & CENTRO & FUENTE & VIGENCIA & $\begin{array}{l}\text { JORNADA } \\
\text { LABORAL }\end{array}$ & $\begin{array}{c}\text { COMPROMISO } \\
\text { CONTRATOS }\end{array}$ & $\begin{array}{l}\text { REVISIÓN } \\
\text { SALARIAL }\end{array}$ & $\begin{array}{c}\text { PARTICIP. } \\
\text { BENEFICIOS }\end{array}$ & $\begin{array}{c}\text { PAGAS } \\
\text { EXTRAS }\end{array}$ & $\begin{array}{l}\text { OTRAS } \\
\text { PAGAS }\end{array}$ & $\begin{array}{l}\text { INFORMAC. } \\
\text { CONTABLE }\end{array}$ \\
\hline $\begin{array}{c}\text { ARTEPREF } \\
\text { GERARDO } \\
\text { DE LA } \\
\text { CALLE } \\
\text { S.A. }\end{array}$ & TODOS & $\begin{array}{c}\text { B.O. } \\
\text { BURGOS } \\
24-8-99\end{array}$ & $\begin{array}{c}1-7-99 \\
\text { HASTA } \\
31-12-00\end{array}$ & 1760 horas & & IPC real & & $\begin{array}{c}2 \\
\text { Verano } \\
\text { Navidad }\end{array}$ & & \\
\hline $\begin{array}{c}\text { CERAMICAS } \\
\text { GALA } \\
\text { S.A. }\end{array}$ & BURGOS & $\begin{array}{c}\text { B.O. } \\
\text { BURGOS } \\
7-4-97\end{array}$ & 1997 & & & $\begin{array}{c}\text { Tablas } \\
+ \text { IPC } \\
\text { previsto }= \\
2,6 \%\end{array}$ & & $\begin{array}{c}3 \\
\text { San Pedro } \\
\text { Navidad } \\
\text { Benef. }\end{array}$ & & \\
\hline $\begin{array}{c}\text { CERÁMICAS } \\
\text { GALA } \\
\text { S.A. }\end{array}$ & BURGOS & $\begin{array}{c}\text { B.O. } \\
\text { BURGOS } \\
31-7-98\end{array}$ & $\begin{array}{c}1-1-98 \\
\text { HASTA } \\
31-12-99\end{array}$ & $\begin{array}{c}\text { 1759,25 } \\
\text { horas }\end{array}$ & $\begin{array}{c}\text { Pasar a fijos } 6 \\
\text { contratos } \\
\text { eventuales }\end{array}$ & $\begin{array}{c}\text { IPC previsto } \\
\text { con garantía } \\
\text { de IPC real }\end{array}$ & & $\begin{array}{c}3 \\
\text { San Pedro } \\
\text { Navidad } \\
\text { Benef. }\end{array}$ & & \\
\hline $\begin{array}{c}\text { CERÁMICAS } \\
\text { GALA } \\
\text { S.A. }\end{array}$ & BURGOS & $\begin{array}{c}\text { B.O. } \\
\text { BURGOS } \\
\text { 30-3-99 }\end{array}$ & 1999 & & & Tablas & & $\begin{array}{c}3 \\
\text { San Pedro } \\
\text { Navidad } \\
\text { Benef. }\end{array}$ & & \\
\hline $\begin{array}{c}\text { COMPAÑÍA } \\
\text { CONCES. DE } \\
\text { SERVICIOS } \\
\text { S.L. } \\
\text { CISER }\end{array}$ & BURGOS & $\begin{array}{c}\text { B.O. } \\
\text { BURGOS } \\
\text { 24-6-99 }\end{array}$ & $\begin{array}{c}11-5-99 \\
\text { HASTA } \\
31-12-00\end{array}$ & $\begin{array}{l}40 \text { horas } \\
\text { semanales }\end{array}$ & & $\begin{array}{c}\text { 1999: IPC } \\
\text { previsto } \\
2000:+2 \%\end{array}$ & & $\begin{array}{c}3 \\
\text { Benef. } \\
\text { Julio } \\
\text { Navidad }\end{array}$ & & $\begin{array}{c}\text { El } \\
\text { representante } \\
\text { legal de los } \\
\text { trabajadores } \\
\text { recibirá } \\
\text { información } \\
\text { sobre la } \\
\text { evolución } \\
\text { general del } \\
\text { sector y la } \\
\text { situación de la } \\
\text { empresa }\end{array}$ \\
\hline $\begin{array}{l}\text { COMP.FRIO } \\
\text { ALIMEN S.A. } \\
\text { COFRALIM }\end{array}$ & BURGOS & $\begin{array}{c}\text { B.O. } \\
\text { BURGOS } \\
28-4-97\end{array}$ & $\begin{array}{c}1-1-97 \\
\text { HASTA } \\
31-12-98\end{array}$ & 1797 horas & & Tablas & & 2 & & \\
\hline
\end{tabular}




\begin{tabular}{|c|c|c|c|c|c|c|c|c|c|c|}
\hline EMPRESA & CENTRO & FUENTE & VIGENCIA & $\begin{array}{l}\text { JORNADA } \\
\text { LABORAL }\end{array}$ & $\begin{array}{c}\text { COMPROMISO } \\
\text { CONTRATOS }\end{array}$ & $\begin{array}{l}\text { REVISIÓN } \\
\text { SALARIAL }\end{array}$ & $\begin{array}{c}\text { PARTICIP. } \\
\text { BENEFICIOS }\end{array}$ & \begin{tabular}{|c|} 
PAGAS \\
EXTRAS
\end{tabular} & $\begin{array}{l}\text { OTRAS } \\
\text { PAGAS }\end{array}$ & $\begin{array}{l}\text { INFORMAC. } \\
\text { CONTABLE }\end{array}$ \\
\hline $\begin{array}{c}\text { CONFECC. } \\
\text { ORY } \\
\text { S.A. }\end{array}$ & BURGOS & $\begin{array}{c}\text { B.O. } \\
\text { BURGOS } \\
27-8-97\end{array}$ & $\begin{array}{c}1-1-97 \\
\text { HASTA } \\
31-12-97\end{array}$ & 1758 horas & & $\begin{array}{c}\text { Tablas } \\
\text { REVISION + } \\
\text { si IPC > 2,6\% }\end{array}$ & & \begin{tabular}{|c|}
3 \\
Julio,Nav \\
Benef.
\end{tabular} & $\begin{array}{c}\text { Plus de } \\
\text { productividad }\end{array}$ & \\
\hline $\begin{array}{c}\text { CONFECC. } \\
\text { ORY } \\
\text { S.A. }\end{array}$ & BURGOS & $\begin{array}{c}\text { B.O. } \\
\text { BURGOS } \\
7-7-98\end{array}$ & $\begin{array}{c}1-1-98 \\
\text { HASTA } \\
31-12-98\end{array}$ & 1754 horas & & $\begin{array}{c}+2,1 \% \\
\text { REVISION + } \\
\text { si IPC > 2,1\% } \\
\text { 1999: IPC }\end{array}$ & & $\begin{array}{c}3 \\
\text { Julio,Nav } \\
\text { Benef. }\end{array}$ & $\begin{array}{c}\text { Plus de } \\
\text { productividad }\end{array}$ & \\
\hline $\begin{array}{c}\text { CONFECC. } \\
\text { ORY } \\
\text { S.A. }\end{array}$ & BURGOS & $\begin{array}{c}\text { B.O. } \\
\text { BURGOS } \\
22-8-2000\end{array}$ & $\begin{array}{c}1-1-00 \\
\text { HASTA } \\
31-12-02\end{array}$ & 1742 horas & & $\begin{array}{c}\text { 2000:+ 3\% } \\
\text { REVISION + } \\
\text { IPC real } \\
\text { 2001: IPC } \\
\text { previsto + 0,5 } \\
\text { REVISION + } \\
\text { IPC real } \\
\text { 2002: IPC } \\
\text { previsto + 0,5 } \\
\text { REVISION + } \\
\text { IPC real }\end{array}$ & & \begin{tabular}{|c}
3 \\
Julio,Nav \\
Benef.
\end{tabular} & $\begin{array}{c}\text { Plus de } \\
\text { productividad }\end{array}$ & \\
\hline $\begin{array}{c}\text { CRIADEROS } \\
\text { MINERALES } \\
\text { Y } \\
\text { DERIVADOS } \\
\text { S.A. } \\
\text { CRIMIDESA }\end{array}$ & $\begin{array}{c}\text { CEREZO DE } \\
\text { RIO TIRÓN } \\
\text { (BURGOS) }\end{array}$ & $\begin{array}{c}\text { B.O. } \\
\text { BURGOS } \\
1-9-98\end{array}$ & $\begin{array}{c}1-1-98 \\
\text { HASTA } \\
31-12-00\end{array}$ & 1752 horas & $\begin{array}{c}\text { Contrato } \\
\text { indefinido con } 8 \\
\text { trabajadores }\end{array}$ & $\begin{array}{c}\text { 1998: IPC } \\
\text { real +1,5 } \\
\text { 1999: IPC } \\
\text { real + 1,25 } \\
\text { 2000: IPC } \\
\text { real + 1,25 }\end{array}$ & & \begin{tabular}{|c}
3 \\
Junio \\
Diciembre \\
Septiemb.
\end{tabular} & $\begin{array}{c}\text { Prima de } \\
\text { producción } \\
\text { según toneladas } \\
\text { producidas en } \\
\text { el conjunto de } \\
\text { la empresa }\end{array}$ & \\
\hline
\end{tabular}




\begin{tabular}{|c|c|c|c|c|c|c|c|c|c|c|}
\hline EMPRESA & CENTRO & FUENTE & VIGENCIA & $\begin{array}{l}\text { JORNADA } \\
\text { LABORAL }\end{array}$ & $\begin{array}{l}\text { COMPROMISO } \\
\text { CONTRATOS }\end{array}$ & $\begin{array}{l}\text { REVISIÓN } \\
\text { SALARIAL }\end{array}$ & $\begin{array}{c}\text { PARTICIP. } \\
\text { BENEFICIOS }\end{array}$ & $\begin{array}{l}\text { PAGAS } \\
\text { EXTRAS }\end{array}$ & $\begin{array}{l}\text { OTRAS } \\
\text { PAGAS }\end{array}$ & $\begin{array}{l}\text { INFORMAC. } \\
\text { CONTABLE }\end{array}$ \\
\hline $\begin{array}{l}\text { DIARIO DE } \\
\text { BURGOS } \\
\text { TALLER DE } \\
\text { IMPRESIÓN } \\
\text { S.L. }\end{array}$ & BURGOS & $\begin{array}{c}\text { B.O. } \\
\text { BURGOS } \\
\text { 21-8-98 }\end{array}$ & $\begin{array}{c}1-1-98 \\
\text { HASTA } \\
31-12-00\end{array}$ & $\begin{array}{c}36 \text { horas } \\
\text { semanales }\end{array}$ & & $\begin{array}{c}\text { 1998: +2,6\% } \\
\text { REVISION + } \\
\text { con IPC real } \\
\text { 1999: IPC } \\
\text { previsto + 0,5 } \\
\text { REVISION } \\
\text { igual } \\
\text { 2000: IPC } \\
\text { previsto + 0,5 } \\
\text { REVISION } \\
\text { igual }\end{array}$ & & $\begin{array}{c}4 \\
\text { Verano } \\
\text { Octubre } \\
\text { Navidad } \\
\text { Benef. }\end{array}$ & & \\
\hline $\begin{array}{l}\text { DIARIO DE } \\
\text { BURGOS } \\
\text { TALLER DE } \\
\text { IMPRESIÓN } \\
\text { S.L. } \\
\end{array}$ & BURGOS & $\begin{array}{c}\text { B.O. } \\
\text { BURGOS } \\
7-2-2000\end{array}$ & $\begin{array}{c}1-1-99 \\
\text { HASTA } \\
31-12-00\end{array}$ & $\begin{array}{c}36 \text { horas } \\
\text { semanales }\end{array}$ & & $\begin{array}{c}\text { IPC previsto } \\
+0,5 \% \\
\text { REVISION } \\
+ \text { igual a IPC } \\
\text { real }\end{array}$ & & $\begin{array}{c}4 \\
\text { Verano } \\
\text { Octubre } \\
\text { Navidad } \\
\text { Benef. }\end{array}$ & & \\
\hline $\begin{array}{c}\text { DISPOSITIV. } \\
\text { DE } \\
\text { ACCESORIOS } \\
\text { DE PUERTAS } \\
\text { S.A. } \\
\text { DAPSA } \\
\end{array}$ & BURGOS & $\begin{array}{c}\text { B.O. } \\
\text { BURGOS } \\
4-9-98\end{array}$ & $\begin{array}{c}1-1-98 \\
\text { HASTA } \\
31-12-00\end{array}$ & $\begin{array}{l}\text { 1998: } 1776 \\
\text { 1999: } 1772 \\
\text { 2000: } 1764\end{array}$ & & $\begin{array}{c}\text { 1998: +3\% } \\
\text { 1999: IPC } \\
\text { real +0,7 } \\
\text { 2000: IPC } \\
\text { real +0,8 }\end{array}$ & & $\begin{array}{c}3 \\
\text { Julio } \\
\text { Navidad } \\
\text { Primavera }\end{array}$ & $\begin{array}{l}\text { Primas de } \\
\text { producción }\end{array}$ & \\
\hline $\begin{array}{c}\text { DORLYL } \\
\text { IBERICA S.L. }\end{array}$ & $\begin{array}{c}\text { MIRANDA DE } \\
\text { EBRO } \\
\text { (BURGOS) }\end{array}$ & $\begin{array}{c}\text { B.O. } \\
\text { BURGOS } \\
12-1-98\end{array}$ & $\begin{array}{c}1-1-97 \\
\text { HASTA } \\
31-12-97\end{array}$ & 1744 horas & & Tablas & & $\begin{array}{c}3 \\
\text { Primavera } \\
\text { Verano } \\
\text { Navidad }\end{array}$ & & \\
\hline
\end{tabular}




\begin{tabular}{|c|c|c|c|c|c|c|c|c|c|c|}
\hline EMPRESA & CENTRO & FUENTE & VIGENCIA & $\begin{array}{l}\text { JORNADA } \\
\text { LABORAL }\end{array}$ & $\begin{array}{c}\text { COMPROMISO } \\
\text { CONTRATOS }\end{array}$ & $\begin{array}{l}\text { REVISIÓN } \\
\text { SALARIAL }\end{array}$ & $\begin{array}{c}\text { PARTICIP. } \\
\text { BENEFICIOS }\end{array}$ & $\begin{array}{l}\text { PAGAS } \\
\text { EXTRAS }\end{array}$ & $\begin{array}{l}\text { OTRAS } \\
\text { PAGAS }\end{array}$ & $\begin{array}{l}\text { INFORMAC. } \\
\text { CONTABLE }\end{array}$ \\
\hline $\begin{array}{c}\text { DUO FAST } \\
\text { DE ESPAÑA } \\
\text { S.A. }\end{array}$ & BURGOS & $\begin{array}{c}\text { B.O. } \\
\text { BURGOS } \\
12-8-98\end{array}$ & $\begin{array}{c}1-1-98 \\
\text { HASTA } \\
31-12-99\end{array}$ & 1752 horas & & $\begin{array}{l}\text { 1999: IPC } \\
\text { previsto + 0,9 } \\
\text { REVISION + } \\
\text { respecto a } \\
\text { IPC real }\end{array}$ & & $\begin{array}{c}2 \\
\text { Verano } \\
\text { Navidad }\end{array}$ & & $\begin{array}{c}\text { Trimestral al } \\
\text { comité de } \\
\text { empresa sobre } \\
\text { evolución del } \\
\text { sector, } \\
\text { situación de la } \\
\text { producción y } \\
\text { ventas de la } \\
\text { empresa }\end{array}$ \\
\hline $\begin{array}{c}\text { DUO FAST } \\
\text { DE ESPAÑA } \\
\text { S.A. }\end{array}$ & BURGOS & $\begin{array}{c}\text { B.O. } \\
\text { BURGOS } \\
7-7-2000\end{array}$ & $\begin{array}{c}1-1-00 \\
\text { HASTA } \\
31-12-01\end{array}$ & 1752 horas & & $\begin{array}{l}\text { 2000: Tablas } \\
\text { REVISION + } \\
\text { IPC real >3\% } \\
\text { 2001: IPC } \\
\text { previsto + } 1 \\
\text { REVISION + } \\
\text { IPC real }\end{array}$ & & $\begin{array}{c}2 \\
\text { Verano } \\
\text { Navidad }\end{array}$ & & $\begin{array}{l}\text { Trimestral al } \\
\text { comité de } \\
\text { empresa sobre } \\
\text { evolución del } \\
\text { sector, } \\
\text { situación de la } \\
\text { producción y } \\
\text { ventas de la } \\
\text { empresa }\end{array}$ \\
\hline EDB S.A. & $\begin{array}{c}\text { QUINTANIL. } \\
\text { SOBRESIER. } \\
\text { (BURGOS) }\end{array}$ & $\begin{array}{c}\text { B.O. } \\
\text { BURGOS } \\
\text { 5-2-97 }\end{array}$ & $\begin{array}{c}1-1-96 \\
\text { HASTA } \\
31-12-96\end{array}$ & 1736 horas & & Tablas & & $\begin{array}{c}2 \\
\text { Junio } \\
\text { Diciembre }\end{array}$ & & $\begin{array}{l}\text { Trimestral al } \\
\text { comité de } \\
\text { empresa sobre } \\
\text { evolución del } \\
\text { sector, } \\
\text { situación de la } \\
\text { producción y } \\
\text { ventas de la } \\
\text { empresa }\end{array}$ \\
\hline
\end{tabular}




\begin{tabular}{|c|c|c|c|c|c|c|c|c|c|c|}
\hline EMPRESA & CENTRO & FUENTE & VIGENCIA & $\begin{array}{l}\text { JORNADA } \\
\text { LABORAL }\end{array}$ & $\begin{array}{c}\text { COMPROMISO } \\
\text { CONTRATOS }\end{array}$ & \begin{tabular}{|l|} 
REVISIÓN \\
SALARIAL \\
\end{tabular} & $\begin{array}{c}\text { PARTICIP. } \\
\text { BENEFICIOS }\end{array}$ & $\begin{array}{l}\text { PAGAS } \\
\text { EXTRAS }\end{array}$ & $\begin{array}{l}\text { OTRAS } \\
\text { PAGAS } \\
\end{array}$ & $\begin{array}{l}\text { INFORMAC. } \\
\text { CONTABLE }\end{array}$ \\
\hline EDB S.A. & $\begin{array}{c}\text { QUINTANIL. } \\
\text { SOBRESIER. } \\
\text { (BURGOS) }\end{array}$ & $\begin{array}{c}\text { B.O. } \\
\text { BURGOS } \\
16-3-98\end{array}$ & $\begin{array}{c}1-1-97 \\
\text { HASTA } \\
31-12-98\end{array}$ & 1736 horas & & 1998: +1,65\% & $\begin{array}{c}\text { Posible } \\
\text { incremento } \\
+0,45 \% \\
\text { controlando } \\
\text { absentismo y si } \\
\text { la FACTURAC. } \\
\text { alcanza } 1500 \\
\text { millones }\end{array}$ & 2 & $\begin{array}{l}\text { Primas de } \\
\text { producción }\end{array}$ & $\begin{array}{l}\text { Trimestral al } \\
\text { comité de } \\
\text { empresa sobre } \\
\text { evolución del } \\
\text { sector, } \\
\text { situación de la } \\
\text { producción y } \\
\text { ventas de la } \\
\text { empresa }\end{array}$ \\
\hline EDB S.A. & $\begin{array}{c}\text { QUINTANIL. } \\
\text { SOBRESIER. } \\
\text { (BURGOS) }\end{array}$ & $\begin{array}{c}\text { B.O. } \\
\text { BURGOS } \\
26-4-2000\end{array}$ & $\begin{array}{c}1-1-99 \\
\text { HASTA } \\
31-12-01\end{array}$ & 1736 horas & & IPC real & $\begin{array}{c}\text { Posible } \\
\text { incremento hasta } \\
1,5 \% \\
\text { Si } \\
\text { FACTURAC. } \\
\text { + COMPRAS } \\
\text { - VAR. } \\
\text { EXISTENCIAS } \\
\text { alcanza 1000, } \\
1100 \text { y } 1200 \\
\text { millones para } \\
\text { 1999,2000,2001 } \\
\text { respectivamente }\end{array}$ & 2 & $\begin{array}{l}\text { Primas de } \\
\text { producción }\end{array}$ & $\begin{array}{c}\text { Trimestral al } \\
\text { comité de } \\
\text { empresa sobre } \\
\text { evolución del } \\
\text { sector, } \\
\text { situación de la } \\
\text { producción y } \\
\text { ventas de la } \\
\text { empresa }\end{array}$ \\
\hline
\end{tabular}




\begin{tabular}{|c|c|c|c|c|c|c|c|c|c|c|}
\hline EMPRESA & CENTRO & FUENTE & VIGENCIA & $\begin{array}{l}\text { JORNADA } \\
\text { LABORAL }\end{array}$ & $\begin{array}{c}\text { COMPROMISO } \\
\text { CONTRATOS }\end{array}$ & $\begin{array}{l}\text { REVISIÓN } \\
\text { SALARIAL }\end{array}$ & $\begin{array}{l}\text { PARTICIP. } \\
\text { BENEFICIOS }\end{array}$ & $\begin{array}{l}\text { PAGAS } \\
\text { EXTRAS }\end{array}$ & $\begin{array}{l}\text { OTRAS } \\
\text { PAGAS }\end{array}$ & $\begin{array}{l}\text { INFORMAC. } \\
\text { CONTABLE }\end{array}$ \\
\hline $\begin{array}{c}\text { ELF } \\
\text { ATOCHEM } \\
\text { ESPAÑA S.A. }\end{array}$ & $\begin{array}{c}\text { MIRANDA DE } \\
\text { EBRO } \\
\text { (BURGOS) }\end{array}$ & $\begin{array}{c}\text { B.O. } \\
\text { BURGOS } \\
11-2-97\end{array}$ & $\begin{array}{c}1-1-96 \\
\text { HASTA } \\
31-12-97\end{array}$ & 1744 horas & & $\begin{array}{c}\text { 1996: +2,95\% } \\
+1 \% \text { en } \\
\text { función de } \\
\text { accidentes y } \\
\text { absentismo }\end{array}$ & & $\begin{array}{c}3 \\
\text { Primavera } \\
\text { Verano } \\
\text { Navidad }\end{array}$ & & $\begin{array}{c}\text { Trimestral al } \\
\text { comité de } \\
\text { empresa sobre } \\
\text { evolución del } \\
\text { sector, } \\
\text { situación de la } \\
\text { producción y } \\
\text { ventas de la } \\
\text { empresa } \\
\text { Anual cuentas } \\
\text { anuales }\end{array}$ \\
\hline $\begin{array}{c}\text { ELF } \\
\text { ATOCHEM } \\
\text { ESPAÑA S.A. }\end{array}$ & $\begin{array}{c}\text { MIRANDA DE } \\
\text { EBRO } \\
\text { (BURGOS) }\end{array}$ & $\begin{array}{c}\text { B.O. } \\
\text { BURGOS } \\
18-8-98\end{array}$ & $\begin{array}{c}1-1-98 \\
\text { HASTA } \\
31-12-98\end{array}$ & 1744 horas & & $\begin{array}{c}+3 \% \\
+1 \% \text { en } \\
\text { función de } \\
\text { accidentes y } \\
\text { absentismo }\end{array}$ & & $\begin{array}{c}3 \\
\text { Primavera } \\
\text { Verano } \\
\text { Navidad }\end{array}$ & & $\begin{array}{c}\text { Trimestral al } \\
\text { comité de } \\
\text { empresa sobre } \\
\text { evolución del } \\
\text { sector, } \\
\text { situación de la } \\
\text { producción y } \\
\text { ventas de la } \\
\text { empresa } \\
\text { Anual cuentas } \\
\text { anuales }\end{array}$ \\
\hline
\end{tabular}




\begin{tabular}{|c|c|c|c|c|c|c|c|c|c|c|}
\hline EMPRESA & CENTRO & FUENTE & VIGENCIA & $\begin{array}{l}\text { JORNADA } \\
\text { LABORAL }\end{array}$ & $\begin{array}{c}\text { COMPROMISO } \\
\text { CONTRATOS }\end{array}$ & $\begin{array}{l}\text { REVISIÓN } \\
\text { SALARIAL }\end{array}$ & $\begin{array}{c}\text { PARTICIP. } \\
\text { BENEFICIOS }\end{array}$ & $\begin{array}{c}\text { PAGAS } \\
\text { EXTRAS }\end{array}$ & $\begin{array}{l}\text { OTRAS } \\
\text { PAGAS }\end{array}$ & $\begin{array}{l}\text { INFORMAC. } \\
\text { CONTABLE }\end{array}$ \\
\hline $\begin{array}{c}\text { ELF } \\
\text { ATOCHEM } \\
\text { ESPAÑA S.A. }\end{array}$ & $\begin{array}{c}\text { MIRANDA DE } \\
\text { EBRO } \\
\text { (BURGOS) }\end{array}$ & $\begin{array}{c}\text { B.O. } \\
\text { BURGOS } \\
20-12-99\end{array}$ & $\begin{array}{c}1-1-99 \\
\text { HASTA } \\
31-12-01\end{array}$ & 1736 horas & & Tablas & & $\begin{array}{c}3 \\
\text { Primavera } \\
\text { Verano } \\
\text { Navidad }\end{array}$ & & $\begin{array}{c}\text { Trimestral al } \\
\text { comité de } \\
\text { empresa sobre } \\
\text { evolución del } \\
\text { sector, } \\
\text { situación de la } \\
\text { producción y } \\
\text { ventas de la } \\
\text { empresa } \\
\text { Anual cuentas } \\
\text { anuales }\end{array}$ \\
\hline $\begin{array}{l}\frac{\text { FABRICAC. }}{\underline{\text { DE }}} \\
\frac{\text { BISAGRAS }}{\underline{\text { S.A. }}} \\
\underline{\text { FABISA }}\end{array}$ & BURGOS & $\begin{array}{c}\text { B.O. } \\
\text { BURGOS } \\
\text { 3-4-98 }\end{array}$ & $\begin{array}{c}1-1-98 \\
\text { HASTA } \\
31-12-00\end{array}$ & $\begin{array}{l}\text { 1998: } 1776 \\
\text { 1999: } 1776 \\
\text { 2000: } 1768\end{array}$ & & \begin{tabular}{|c} 
1998: $4 \%$ \\
1999:4\% \\
2000:3,5\% \\
REVISION + \\
si el IPC real \\
supera el 2\%
\end{tabular} & $\begin{array}{c}\text { Participación en } \\
\text { BENEFICIOS } \\
\text { AUDITADOS } \\
\text { del 20\%(98),15\% } \\
\text { (99),10\%(2000) }\end{array}$ & $\begin{array}{c}2 \\
\text { Verano } \\
\text { Navidad }\end{array}$ & & \\
\hline $\begin{array}{l}\text { FABRICAS } \\
\text { LUCIA DEL } \\
\text { NORTE S.A. }\end{array}$ & BURGOS & $\begin{array}{c}\text { B.O. } \\
\text { BURGOS } \\
\text { 30-7-97 }\end{array}$ & $\begin{array}{c}1-1-97 \\
\text { HASTA } \\
31-12-98\end{array}$ & $\begin{array}{l}\text { 1997: } 1756 \\
\text { 1998: } 1752\end{array}$ & & $\begin{array}{c}+3 \% \\
\text { REVISION } \\
\text { con IPC real }\end{array}$ & & $\begin{array}{c}4 \\
\text { julio, dic } \\
\text { marzo,sep }\end{array}$ & $\begin{array}{l}\text { Primas a la } \\
\text { producción }\end{array}$ & \\
\hline $\begin{array}{l}\text { GALLETAS } \\
\text { CORAL S.A. }\end{array}$ & $\begin{array}{c}\text { MIRANDA DE } \\
\text { EBRO } \\
\text { (BURGOS) }\end{array}$ & $\begin{array}{c}\text { B.O. } \\
\text { BURGOS } \\
5-6-97\end{array}$ & $\begin{array}{c}1-1-97 \\
\text { HASTA } \\
31-12-97\end{array}$ & & & $\begin{array}{c}+2 \% \\
\text { REVISION + } \\
\text { IPC real }\end{array}$ & & $\begin{array}{c}3 \\
\text { julio,dic } \\
\text { benef. }\end{array}$ & & \\
\hline $\begin{array}{l}\text { GALLETAS } \\
\text { CORAL S.A. }\end{array}$ & $\begin{array}{c}\text { MIRANDA DE } \\
\text { EBRO } \\
\text { (BURGOS) }\end{array}$ & $\begin{array}{c}\text { B.O. } \\
\text { BURGOS } \\
\text { 3-9-98 }\end{array}$ & $\begin{array}{c}1-1-98 \\
\text { HASTA } \\
31-12-00\end{array}$ & & & $\begin{array}{l}+3 \% \text { sin } \\
\text { revisión }\end{array}$ & & $\begin{array}{c}3 \\
\text { julio,dic } \\
\text { bnenef. }\end{array}$ & & \\
\hline
\end{tabular}




\begin{tabular}{|c|c|c|c|c|c|c|c|c|c|c|}
\hline EMPRESA & CENTRO & FUENTE & VIGENCIA & $\begin{array}{l}\text { JORNADA } \\
\text { LABORAL }\end{array}$ & $\begin{array}{c}\text { COMPROMISO } \\
\text { CONTRATOS }\end{array}$ & $\begin{array}{l}\text { REVISIÓN } \\
\text { SALARIAL }\end{array}$ & $\begin{array}{c}\text { PARTICIP. } \\
\text { BENEFICIOS }\end{array}$ & $\begin{array}{c}\text { PAGAS } \\
\text { EXTRAS }\end{array}$ & $\begin{array}{l}\text { OTRAS } \\
\text { PAGAS }\end{array}$ & $\begin{array}{l}\text { INFORMAC. } \\
\text { CONTABLE }\end{array}$ \\
\hline $\begin{array}{l}\text { GONVARRI } \\
\text { INDUSTRIAL } \\
\text { S.A. }\end{array}$ & BURGOS & $\begin{array}{c}\text { B.O. } \\
\text { BURGOS } \\
\text { 3-8-99 }\end{array}$ & $\begin{array}{c}1-1-99 \\
\text { HASTA } \\
31-12-01\end{array}$ & 1760 horas & & $\begin{array}{c}\text { 1999: +2\% } \\
\text { REVISION + } \\
\text { IPC real } \\
\text { 2000: IPC } \\
\text { previsto } \\
\text { REVISION + } \\
\text { IPC real } \\
\text { 2001: IPC } \\
\text { previsto } \\
\text { REVISION + } \\
\text { IPC real }\end{array}$ & & $\begin{array}{c}2 \\
\text { Junio } \\
\text { Diciembre }\end{array}$ & $\begin{array}{c}\text { Prima } \\
\text { producción }\end{array}$ & \\
\hline $\begin{array}{l}\text { HELADOS } \\
\text { MIKO S.A }\end{array}$ & BURGOS & $\begin{array}{c}\text { B.O. } \\
\text { BURGOS } \\
\text { 3-5-99 }\end{array}$ & $\begin{array}{c}1-1-99 \\
\text { HASTA } \\
31-12-00\end{array}$ & 1797 horas & & Tablas & & $\begin{array}{c}2 \\
\text { Julio } \\
\text { Diciembre }\end{array}$ & & \\
\hline $\begin{array}{c}\text { HORMIGON. } \\
\text { Y EXCAVAC. } \\
\text { GERARDO } \\
\text { DE LA } \\
\text { CALLE S.L. }\end{array}$ & TODOS & $\begin{array}{c}\text { B.O. } \\
\text { BURGOS } \\
24-8-99\end{array}$ & $\begin{array}{c}1-7-99 \\
\text { HASTA } \\
31-12-00\end{array}$ & 1760 horas & & $\begin{array}{c}\text { Tablas } \\
\text { REVISION + } \\
\text { IPC real }\end{array}$ & & $\begin{array}{c}2 \\
\text { Verano } \\
\text { Navidad }\end{array}$ & & \\
\hline $\begin{array}{c}\text { HOSTAL } \\
\text { TRES } \\
\text { CONDES } \\
\text { S.A. }\end{array}$ & $\begin{array}{c}\text { ARANDA DE } \\
\text { DUERO } \\
\text { (BURGOS) }\end{array}$ & $\begin{array}{c}\text { B.O. } \\
\text { BURGOS } \\
\text { 24-3-99 }\end{array}$ & $\begin{array}{c}1-1-99 \\
\text { HASTA } \\
31-12-01\end{array}$ & 1826 horas & & $\begin{array}{c}\text { 1999: sin } \\
\text { incremento } \\
\text { 2000: }+0,5 \% \\
\text { 2001: IPC } \\
\text { real }\end{array}$ & & $\begin{array}{c}2 \\
\text { Junio } \\
\text { Navidad }\end{array}$ & & \\
\hline J.J.BIS 95 S.L. & BURGOS & $\begin{array}{c}\text { B.O. } \\
\text { BURGOS } \\
14-8-97\end{array}$ & $\begin{array}{c}1-5-97 \\
\text { HASTA } \\
30-4-98\end{array}$ & 1820 horas & & Tablas & & $\begin{array}{c}2 \\
\text { Junio } \\
\text { Navidad }\end{array}$ & & \\
\hline $\begin{array}{c}\text { KIMBERLY- } \\
\text { CLARK } \\
\text { MIRANDA }\end{array}$ & $\begin{array}{c}\text { MIRANDA DE } \\
\text { EBRO } \\
\text { (BURGOS) }\end{array}$ & $\begin{array}{c}\text { B.O. } \\
\text { BURGOS } \\
22-9-97\end{array}$ & $\begin{array}{c}1-1-97 \\
\text { HASTA } \\
31-12-97\end{array}$ & 1770 horas & & $\begin{array}{c}+2,8 \% \\
\text { REVISION + } \\
\text { IPC real }\end{array}$ & & $\begin{array}{c}2 \\
\text { Verano } \\
\text { Navidad }\end{array}$ & $\begin{array}{l}\text { Prima de } \\
\text { producción }\end{array}$ & $\begin{array}{c}\text { Trimestral } \\
\text { evolución ... }\end{array}$ \\
\hline
\end{tabular}




\begin{tabular}{|c|c|c|c|c|c|c|c|c|c|c|}
\hline EMPRESA & CENTRO & FUENTE & VIGENCIA & $\begin{array}{l}\text { JORNADA } \\
\text { LABORAL }\end{array}$ & $\begin{array}{c}\text { COMPROMISO } \\
\text { CONTRATOS }\end{array}$ & $\begin{array}{l}\text { REVISIÓN } \\
\text { SALARIAL }\end{array}$ & $\begin{array}{c}\text { PARTICIP. } \\
\text { BENEFICIOS }\end{array}$ & $\begin{array}{c}\text { PAGAS } \\
\text { EXTRAS }\end{array}$ & $\begin{array}{l}\text { OTRAS } \\
\text { PAGAS }\end{array}$ & $\begin{array}{l}\text { INFORMAC. } \\
\text { CONTABLE }\end{array}$ \\
\hline $\begin{array}{c}\text { KIMBERLY } \\
\text { CLARK } \\
\text { MIRANDA } \\
\text { S.A. }\end{array}$ & $\begin{array}{c}\text { MIRANDA DE } \\
\text { EBRO } \\
\text { (BURGOS) }\end{array}$ & $\begin{array}{c}\text { B.O. } \\
\text { BURGOS } \\
22-7-98\end{array}$ & $\begin{array}{c}1-1-98 \\
\text { HASTA } \\
31-12-98\end{array}$ & 1764 horas & & $\begin{array}{c}+2,7 \% \\
\text { REVISION + } \\
\text { IPC real }\end{array}$ & & $\begin{array}{c}2 \\
\text { Verano } \\
\text { Navidad }\end{array}$ & $\begin{array}{c}\text { Prima de } \\
\text { producción }\end{array}$ & $\begin{array}{c}\text { Trimestral al } \\
\text { comité de } \\
\text { empresa sobre } \\
\text { evolución del } \\
\text { sector, } \\
\text { situación de la } \\
\text { producción y } \\
\text { ventas de la } \\
\text { empresa } \\
\text { Anual cuentas } \\
\text { anuales }\end{array}$ \\
\hline $\begin{array}{c}\text { LA } \\
\text { CELLOPHAN } \\
\text { ESPAÑOLA } \\
\text { S.A. }\end{array}$ & TODOS & $\begin{array}{c}\text { B.O. } \\
\text { BURGOS } \\
27-8-98\end{array}$ & $\begin{array}{c}1-1-98 \\
\text { HASTA } \\
31-12-99\end{array}$ & 1768 horas & & $\begin{array}{c}\text { 1998: +2,7\% } \\
\text { 1999: +2,5\% } \\
\text { REVISION si } \\
\text { IPC real de } \\
\text { dos años } \\
\text { supera el } \\
\text { 4,3\% }\end{array}$ & & $\begin{array}{c}4 \\
\text { Julio } \\
\text { Navidad } \\
\text { Octubre } \\
\text { Primavera }\end{array}$ & $\begin{array}{c}\text { Participación } \\
\text { en la } \\
\text { producción }\end{array}$ & $\begin{array}{c}\text { Trimestral al } \\
\text { comité de } \\
\text { empresa sobre } \\
\text { evolución del } \\
\text { sector, } \\
\text { situación de la } \\
\text { producción y } \\
\text { ventas de la } \\
\text { empresa } \\
\text { Anual cuentas } \\
\text { anuales } \\
\text { Igual para los } \\
\text { delegados } \\
\text { sindicales }\end{array}$ \\
\hline
\end{tabular}




\begin{tabular}{|c|c|c|c|c|c|c|c|c|c|c|}
\hline EMPRESA & CENTRO & FUENTE & VIGENCIA & $\begin{array}{l}\text { JORNADA } \\
\text { LABORAL }\end{array}$ & $\begin{array}{c}\text { COMPROMISO } \\
\text { CONTRATOS }\end{array}$ & $\begin{array}{l}\text { REVISIÓN } \\
\text { SALARIAL }\end{array}$ & $\begin{array}{c}\text { PARTICIP. } \\
\text { BENEFICIOS }\end{array}$ & $\begin{array}{c}\text { PAGAS } \\
\text { EXTRAS }\end{array}$ & $\begin{array}{l}\text { OTRAS } \\
\text { PAGAS }\end{array}$ & $\begin{array}{l}\text { INFORMAC. } \\
\text { CONTABLE }\end{array}$ \\
\hline $\begin{array}{c}\text { UCB FILMS } \\
\text { LA } \\
\text { CELLOPHAN } \\
\text { ESPAÑOLA } \\
\text { S.A. }\end{array}$ & TODOS & $\begin{array}{c}\text { B.O. } \\
\text { BURGOS } \\
31-8-2000\end{array}$ & $\begin{array}{c}1-1-00 \\
\text { HASTA } \\
31-12-01\end{array}$ & $\begin{array}{l}\text { 2000: } 1752 \\
\text { 2001: } 1744\end{array}$ & & $\begin{array}{c}\text { 2000: +2,5\% } \\
\text { REVISION + } \\
\text { IPC real } \\
\text { 2001: IPC } \\
\text { previsto } \\
\text { REVISION } \\
\text { IPC real de } \\
\text { dos años + } 1\end{array}$ & & $\begin{array}{c}4 \\
\text { Julio } \\
\text { Navidad } \\
\text { Octubre } \\
\text { Primavera }\end{array}$ & $\begin{array}{c}\text { Participación } \\
\text { en la } \\
\text { producción }\end{array}$ & $\begin{array}{c}\text { Trimestral al } \\
\text { comité de } \\
\text { empresa sobre } \\
\text { evolución del } \\
\text { sector, } \\
\text { situación de la } \\
\text { producción y } \\
\text { ventas de la } \\
\text { empresa } \\
\text { Anual cuentas } \\
\text { anuales } \\
\text { Igual para los } \\
\text { delegados } \\
\text { sindicales }\end{array}$ \\
\hline $\begin{array}{c}\text { LENNOX } \\
\text { REFAC S.A. }\end{array}$ & BURGOS & $\begin{array}{c}\text { B.O. } \\
\text { BURGOS } \\
1-7-97\end{array}$ & $\begin{array}{c}1-1-97 \\
\text { HASTA } \\
31-12-97\end{array}$ & 1752 horas & & $\begin{array}{c}+3 \% \\
\text { REVISION + } \\
\text { IPC real }\end{array}$ & & $\begin{array}{c}2 \\
\text { Verano } \\
\text { Navidad }\end{array}$ & & $\begin{array}{c}\text { Bimestral } \\
\text { cuenta de } \\
\text { producción. } \\
\text { Anual cuentas } \\
\text { anuales. }\end{array}$ \\
\hline $\begin{array}{c}\text { LENNOX } \\
\text { REFAC S.A. }\end{array}$ & BURGOS & $\begin{array}{c}\text { B.O. } \\
\text { BURGOS } \\
27-7-2000\end{array}$ & $\begin{array}{c}1-1-00 \\
\text { HASTA } \\
31-12-02\end{array}$ & $\begin{array}{l}\text { 2000: } 1748 \\
\text { 2001: } 1744 \\
\text { 2002: } 1740\end{array}$ & & \begin{tabular}{|c} 
2000: + 3\% \\
REVISION+ \\
IPC real > \\
$2 \%$ \\
2001: IPC \\
previsto + 1 \\
2002: IPC \\
previsto + 1 \\
REVISION + \\
IPC real \\
\end{tabular} & & $\begin{array}{c}2 \\
\text { Verano } \\
\text { Navidad }\end{array}$ & & $\begin{array}{c}\text { Bimestral } \\
\text { cuenta de } \\
\text { producción. } \\
\text { Anual cuentas } \\
\text { anuales. }\end{array}$ \\
\hline $\begin{array}{l}\text { MANUFACT. } \\
\text { ORIVE S.A. }\end{array}$ & $\begin{array}{c}\text { MIRANDA DE } \\
\text { EBRO } \\
\text { (BURGOS) } \\
\end{array}$ & $\begin{array}{c}\text { B.O. } \\
\text { BURGOS } \\
22-7-97\end{array}$ & $\begin{array}{c}1-1-97 \\
\text { HASTA } \\
31-12-97 \\
\end{array}$ & 1755 horas & & $\begin{array}{c}+2 \% \\
\text { REVISION + } \\
\text { IPC real }\end{array}$ & & $\begin{array}{c}3 \\
\text { Juli,dic. } \\
\text { Benef. }\end{array}$ & $\begin{array}{l}\text { Prima de } \\
\text { producción }\end{array}$ & \\
\hline
\end{tabular}




\begin{tabular}{|c|c|c|c|c|c|c|c|c|c|c|}
\hline EMPRESA & CENTRO & FUENTE & VIGENCIA & $\begin{array}{l}\text { JORNADA } \\
\text { LABORAL }\end{array}$ & $\begin{array}{c}\text { COMPROMISO } \\
\text { CONTRATOS }\end{array}$ & $\begin{array}{l}\text { REVISIÓN } \\
\text { SALARIAL }\end{array}$ & $\begin{array}{l}\text { PARTICIP. } \\
\text { BENEFICIOS }\end{array}$ & $\begin{array}{c}\text { PAGAS } \\
\text { EXTRAS }\end{array}$ & $\begin{array}{l}\text { OTRAS } \\
\text { PAGAS }\end{array}$ & $\begin{array}{l}\text { INFORMAC. } \\
\text { CONTABLE }\end{array}$ \\
\hline $\begin{array}{l}\text { MANUFACT. } \\
\text { ORIVE S.A. }\end{array}$ & $\begin{array}{c}\text { MIRANDA DE } \\
\text { EBRO } \\
\text { (BURGOS) }\end{array}$ & $\begin{array}{c}\text { B.O. } \\
\text { BURGOS } \\
14-8-98\end{array}$ & $\begin{array}{c}1-1-98 \\
\text { HASTA } \\
31-12-98\end{array}$ & 1755 horas & & $\begin{array}{c}+2,6 \% \\
\text { REVISION + } \\
\text { IPC real }\end{array}$ & & $\begin{array}{c}3 \\
\text { Juli,dic. } \\
\text { Benef. }\end{array}$ & $\begin{array}{l}\text { Prima de } \\
\text { producción }\end{array}$ & \\
\hline $\begin{array}{l}\text { MANUFACT. } \\
\text { ORVIE S.A. }\end{array}$ & $\begin{array}{c}\text { MIRANDA DE } \\
\text { EBRO } \\
\text { (BURGOS) }\end{array}$ & $\begin{array}{c}\text { B.O. } \\
\text { BURGOS } \\
14-7-2000\end{array}$ & $\begin{array}{c}1-1-00 \\
\text { HASTA } \\
31-12-00\end{array}$ & 1755 horas & & $\begin{array}{c}+2,5 \% \\
\text { REVISION + } \\
\text { IPC real }\end{array}$ & & $\begin{array}{c}3 \\
\text { Juli,dic. } \\
\text { Benef. }\end{array}$ & $\begin{array}{l}\text { Prima de } \\
\text { producción }\end{array}$ & \\
\hline $\begin{array}{c}\text { MONTEFIBR } \\
\text { HISPANIA } \\
\text { S.A. }\end{array}$ & $\begin{array}{c}\text { MIRANDA DE } \\
\text { EBRO } \\
\text { (BURGOS) }\end{array}$ & $\begin{array}{c}\text { B.O. } \\
\text { BURGOS } \\
12-3-97\end{array}$ & 1997 & 1751 horas & & Tablas & & & $\begin{array}{c}\text { Prima } \\
\text { producción } \\
\text { Gratificación } \\
\text { Productividad }\end{array}$ & \\
\hline $\begin{array}{c}\text { MONTEFIBR } \\
\text { HISPANIA } \\
\text { S.A. }\end{array}$ & $\begin{array}{c}\text { MIRANDA DE } \\
\text { EBRO } \\
\text { (BURGOS) }\end{array}$ & $\begin{array}{c}\text { B.O. } \\
\text { BURGOS } \\
22-7-98\end{array}$ & 1998 & 1751 horas & & Tablas & & & $\begin{array}{c}\text { Prima } \\
\text { producción } \\
\text { Gratificación } \\
\text { Productividad }\end{array}$ & \\
\hline$\frac{\frac{\text { NICOLAS }}{\text { CORREA }}}{\underline{\text { S.A. }}}$ & BURGOS & $\begin{array}{c}\text { B.O. } \\
\text { BURGOS } \\
\text { 15-6-97 }\end{array}$ & $\begin{array}{c}1-1-97 \\
\text { HASTA } \\
31-12-97\end{array}$ & 1790 horas & & $\begin{array}{c}\text { IPC real + } \\
1,25 \% \\
\text { REVISION + } \\
\text { si IPC real } \\
\text { supera el } \\
2,6 \%\end{array}$ & $\begin{array}{c}\text { Si RTDO NETO } \\
\text { DE } \\
\text { EXPLOTACION } \\
\text { fuera } 300 \\
\text { millones o mas + } \\
0,5 \% \text {. } \\
\text { Si el RNE fuera } \\
\text { superior a } 600 \\
\text { millones paga de } \\
50.000 \text { pts }\end{array}$ & $\begin{array}{c}2 \\
\text { Julio } \\
\text { Navidad }\end{array}$ & $\begin{array}{c}\text { Prima de } \\
\text { producción }\end{array}$ & \\
\hline $\begin{array}{c}\text { NICOLAS } \\
\text { CORREA } \\
\text { S.A. }\end{array}$ & BURGOS & $\begin{array}{c}\text { B.O. } \\
\text { BURGOS } \\
6-3-98\end{array}$ & $\begin{array}{c}1-1-98 \\
\text { HASTA } \\
31-12-98\end{array}$ & 1790 horas & & $\begin{array}{c}+4,25 \% \\
\text { REVISION + } \\
\text { si IPC real } \\
\text { supera al } \\
2,25 \%\end{array}$ & & $\begin{array}{c}2 \\
\text { Julio } \\
\text { Navidad }\end{array}$ & $\begin{array}{l}\text { Prima de } \\
\text { producción }\end{array}$ & \\
\hline
\end{tabular}




\begin{tabular}{|c|c|c|c|c|c|c|c|c|c|c|}
\hline EMPRESA & CENTRO & FUENTE & VIGENCIA & $\begin{array}{l}\text { JORNADA } \\
\text { LABORAL }\end{array}$ & $\begin{array}{c}\text { COMPROMISO } \\
\text { CONTRATOS }\end{array}$ & $\begin{array}{l}\text { REVISIÓN } \\
\text { SALARIAL }\end{array}$ & $\begin{array}{l}\text { PARTICIP. } \\
\text { BENEFICIOS }\end{array}$ & $\begin{array}{c}\text { PAGAS } \\
\text { EXTRAS }\end{array}$ & $\begin{array}{l}\text { OTRAS } \\
\text { PAGAS }\end{array}$ & $\begin{array}{l}\text { INFORMAC. } \\
\text { CONTABLE }\end{array}$ \\
\hline$\frac{\frac{\text { NICOLAS }}{\text { CORREA }}}{\underline{\text { S.A. }}}$ & BURGOS & $\begin{array}{c}\text { B.O. } \\
\text { BURGOS } \\
22-6-99\end{array}$ & $\begin{array}{c}1-1-99 \\
\text { HASTA } \\
31-12-99\end{array}$ & 1781 horas & & $\begin{array}{c}+3,3 \% \\
\text { REVISION } \\
\text { IPC real + } \\
1,80 \%\end{array}$ & $\begin{array}{c}\text { Retribución } \\
\text { variable en } \\
\text { función de } \\
\text { objetivos del } 4 \% \\
\text { FACTURAC. } \\
\text { BºNTIMP }\end{array}$ & $\begin{array}{c}2 \\
\text { Julio } \\
\text { Navidad }\end{array}$ & $\begin{array}{c}\text { Prima de } \\
\text { producción }\end{array}$ & \\
\hline $\begin{array}{c}\text { NICOLAS } \\
\text { CORREA } \\
\text { S.A. }\end{array}$ & BURGOS & $\begin{array}{c}\text { B.O. } \\
\text { BURGOS } \\
21-3-2000\end{array}$ & $\begin{array}{c}1-1-00 \\
\text { HASTA } \\
31-12-02\end{array}$ & $\begin{array}{l}\text { 2000:1775 } \\
\text { 2001: } 1769 \\
\text { 2002: } 1763\end{array}$ & & $\begin{array}{c}\text { 2000:+3,3\% } \\
(50 \% \\
\text { porcentual y } \\
50 \% \text { lineal) } \\
\text { 2001: IPC } \\
\text { previsto + } \\
\text { 1,75\% } \\
\text { REVISION + } \\
\text { IPC real } \\
\text { 2002: IPC } \\
\text { previsto } \\
\text { +1,75\% } \\
\text { REVISION + } \\
\text { IPC real }\end{array}$ & & $\begin{array}{c}2 \\
\text { Julio } \\
\text { Navidad }\end{array}$ & & \\
\hline $\begin{array}{c}\text { ONIX R S.U. } \\
\text { S.A. }\end{array}$ & $\begin{array}{c}\text { ARANDA DE } \\
\text { DUERO } \\
\text { (BURGOS) }\end{array}$ & $\begin{array}{c}\text { B.O. } \\
\text { BURGOS } \\
27-1-98\end{array}$ & $\begin{array}{c}1-1-97 \\
\text { HASTA } \\
31-12-99\end{array}$ & $\begin{array}{c}37 \text { horas } \\
\text { semanales }\end{array}$ & & $\begin{array}{c}\text { IPC previsto } \\
\text { x } 90 \%\end{array}$ & & $\begin{array}{c}3 \\
\text { marzo } \\
\text { julio,dic. }\end{array}$ & & \\
\hline $\begin{array}{l}\text { ONIX R S.U. } \\
\text { S.A. }\end{array}$ & $\begin{array}{c}\text { ARANDA DE } \\
\text { DUERO } \\
\text { (BURGOS) }\end{array}$ & $\begin{array}{c}\text { B.O. } \\
\text { BURGOS } \\
9-3-99\end{array}$ & & & & Tablas & & & & \\
\hline
\end{tabular}




\begin{tabular}{|c|c|c|c|c|c|c|c|c|c|c|}
\hline EMPRESA & CENTRO & FUENTE & VIGENCIA & $\begin{array}{l}\text { JORNADA } \\
\text { LABORAL }\end{array}$ & $\begin{array}{l}\text { COMPROMISO } \\
\text { CONTRATOS }\end{array}$ & $\begin{array}{l}\text { REVISIÓN } \\
\text { SALARIAL }\end{array}$ & $\begin{array}{c}\text { PARTICIP. } \\
\text { BENEFICIOS }\end{array}$ & $\begin{array}{l}\text { PAGAS } \\
\text { EXTRAS }\end{array}$ & $\begin{array}{l}\text { OTRAS } \\
\text { PAGAS }\end{array}$ & $\begin{array}{l}\text { INFORMAC. } \\
\text { CONTABLE }\end{array}$ \\
\hline $\begin{array}{c}\text { PIERRE } \\
\text { GUERIN } \\
\text { IBERICA S.A. }\end{array}$ & BURGOS & $\begin{array}{c}\text { B.O. } \\
\text { BURGOS } \\
\text { 23-11-99 }\end{array}$ & $\begin{array}{c}1-1-99 \\
\text { HASTA } \\
31-12-00\end{array}$ & $\begin{array}{l}\text { 1999: } 1748 \\
\text { 2000: } 1740\end{array}$ & & IPC real & & $\begin{array}{c}2 \\
\text { Verano } \\
\text { Navidad }\end{array}$ & & $\begin{array}{c}\text { Bimensual al } \\
\text { comité de } \\
\text { empresa } \\
\text { resultado de la } \\
\text { cuenta de } \\
\text { producción, } \\
\text { ventas y } \\
\text { evolución } \\
\end{array}$ \\
\hline $\begin{array}{c}\text { PROSIDER } \\
\text { IBERICA } \\
\text { S.A. }\end{array}$ & TODOS & $\begin{array}{c}\text { B.O. } \\
\text { BURGOS } \\
25-3-97\end{array}$ & $\begin{array}{c}1-1-97 \\
\text { HASTA } \\
31-12-98\end{array}$ & $\begin{array}{l}\text { 1997: } 1756 \\
\text { 1998: } 1752\end{array}$ & & $\begin{array}{c}\text { 1997: +3,1\% } \\
\text { 1998: IPC } \\
\text { previsto + } \\
0,5 \%\end{array}$ & & $\begin{array}{c}3 \\
\text { Verano } \\
\text { Navidad } \\
\text { Benefic }\end{array}$ & & \\
\hline $\begin{array}{c}\text { PROSIDER } \\
\text { IBERICA } \\
\text { S.A. }\end{array}$ & TODOS & $\begin{array}{c}\text { B.O. } \\
\text { BURGOS } \\
25-3-97\end{array}$ & $\begin{array}{c}1-1-99 \\
\text { HASTA } \\
31-12-00\end{array}$ & 1752 horas & & $+2 \%$ & & $\begin{array}{c}3 \\
\text { Verano } \\
\text { Navidad } \\
\text { Benefic }\end{array}$ & & \\
\hline $\begin{array}{c}\text { REPOSTERIA } \\
\text { MARTINEZ } \\
\text { S.A. }\end{array}$ & $\begin{array}{c}\text { BRIVIESCA } \\
\text { (BURGOS) }\end{array}$ & $\begin{array}{c}\text { B.O. } \\
\text { BURGOS } \\
2-9-97\end{array}$ & $\begin{array}{c}1-1-97 \\
\text { HASTA } \\
31-12-97\end{array}$ & 1781 horas & & Tablas & & $\begin{array}{c}3 \\
\text { Verano } \\
\text { Navidad } \\
\text { B }^{\circ}\end{array}$ & & \\
\hline $\begin{array}{c}\text { REPOSTERIA } \\
\text { MARTINEZ } \\
\text { S.A. }\end{array}$ & $\begin{array}{c}\text { BRIVIESCA } \\
\text { (BURGOS) }\end{array}$ & $\begin{array}{c}\text { B.O. } \\
\text { BURGOS } \\
\text { 31-8-98 }\end{array}$ & $\begin{array}{c}1-1-98 \\
\text { HASTA } \\
31-12-99\end{array}$ & 1776 horas & & $\begin{array}{c}\text { IPC previsto } \\
+0,5 \\
\text { REVISION + } \\
\text { IPC real }\end{array}$ & & $\begin{array}{c}3 \\
\text { Verano } \\
\text { Navidad } \\
\mathrm{B}^{\mathbf{0}}\end{array}$ & & \\
\hline
\end{tabular}




\begin{tabular}{|c|c|c|c|c|c|c|c|c|c|c|}
\hline EMPRESA & CENTRO & FUENTE & VIGENCIA & $\begin{array}{l}\text { JORNADA } \\
\text { LABORAL }\end{array}$ & $\begin{array}{c}\text { COMPROMISO } \\
\text { CONTRATOS }\end{array}$ & $\begin{array}{l}\text { REVISIÓN } \\
\text { SALARIAL }\end{array}$ & $\begin{array}{c}\text { PARTICIP. } \\
\text { BENEFICIOS }\end{array}$ & $\begin{array}{c}\text { PAGAS } \\
\text { EXTRAS }\end{array}$ & $\begin{array}{l}\text { OTRAS } \\
\text { PAGAS }\end{array}$ & $\begin{array}{l}\text { INFORMAC. } \\
\text { CONTABLE }\end{array}$ \\
\hline $\begin{array}{c}\text { REPOSTERIA } \\
\text { MARTINEZ } \\
\text { S.A. }\end{array}$ & $\begin{array}{c}\text { BRIVIESCA } \\
\text { (BURGOS) }\end{array}$ & $\begin{array}{c}\text { B.O. } \\
\text { BURGOS } \\
19-9-2000\end{array}$ & $\begin{array}{c}1-1-00 \\
\text { HASTA } \\
31-12-00\end{array}$ & 1776 horas & & $\begin{array}{c}+3,75 \% \\
\text { REVISION + } \\
\text { IPC real > } \\
3,75 \%\end{array}$ & & $\begin{array}{c}3 \\
\text { Verano } \\
\text { Navidad } \\
\text { B }^{\circ}\end{array}$ & & \\
\hline $\begin{array}{c}\text { RHONE } \\
\text { POULENC } \\
\text { NUTRICION } \\
\text { ANIMAL } \\
\text { S.A. }\end{array}$ & TODOS & $\begin{array}{c}\text { B.O. } \\
\text { BURGOS } \\
\text { 23-10-98 }\end{array}$ & $\begin{array}{c}1-1-98 \\
\text { HASTA } \\
31-12-98\end{array}$ & 1714 horas & & $\begin{array}{c}+2,1 \% \\
\text { REVISION + } \\
\text { si IPC real es } \\
\text { superior a } \\
2,1 \%\end{array}$ & & $\begin{array}{c}2 \\
\text { Verano } \\
\text { Diciembre }\end{array}$ & & \\
\hline $\begin{array}{c}\text { RHONE } \\
\text { POULENC } \\
\text { NUTRICION } \\
\text { ANIMAL } \\
\text { S.A. }\end{array}$ & TODOS & $\begin{array}{c}\text { B.O. } \\
\text { BURGOS } \\
8-7-99\end{array}$ & $\begin{array}{c}1-1-99 \\
\text { HASTA } \\
31-12-00\end{array}$ & $\begin{array}{l}\text { 1999: } 1672 \\
\text { 2000: } 1664\end{array}$ & & $\begin{array}{c}+3 \% \\
\text { REVISION + } \\
\text { si IPC real es } \\
\text { superior al } \\
2 \% \\
\end{array}$ & & $\begin{array}{c}2 \\
\text { Verano } \\
\text { Diciembre }\end{array}$ & & \\
\hline $\begin{array}{c}\text { ROTTNEROS } \\
\text { MIRANDA } \\
\text { S.A. }\end{array}$ & TODOS & $\begin{array}{c}\text { B.O. } \\
\text { BURGOS } \\
\text { 24-11-99 }\end{array}$ & $\begin{array}{c}1-1-99 \\
\text { HASTA } \\
31-12-00\end{array}$ & $\begin{array}{l}\text { 1999:1760 } \\
\text { 2000: } 1752\end{array}$ & & $\begin{array}{c}\text { IPC previsto } \\
\quad+0,5 \\
\text { IPC previsto } \\
\text { REVISION } \\
\text { con IPC real }\end{array}$ & & $\begin{array}{c}4 \\
\text { Verano } \\
\text { Navidad } \\
\text { Paga de } \\
\text { convenio } \\
\text { Paga de } \\
\text { beneficios }\end{array}$ & $\begin{array}{l}\text { Primas de } \\
\text { producción }\end{array}$ & $\begin{array}{c}\text { Trimestral al } \\
\text { comité de } \\
\text { empresa sobre } \\
\text { evolución del } \\
\text { sector, } \\
\text { situación de la } \\
\text { producción y } \\
\text { ventas de la } \\
\text { empresa } \\
\text { Anual cuentas } \\
\text { anuales }\end{array}$ \\
\hline
\end{tabular}




\begin{tabular}{|c|c|c|c|c|c|c|c|c|c|c|}
\hline EMPRESA & CENTRO & FUENTE & VIGENCIA & $\begin{array}{l}\text { JORNADA } \\
\text { LABORAL }\end{array}$ & $\begin{array}{l}\text { COMPROMISO } \\
\text { CONTRATOS }\end{array}$ & $\begin{array}{l}\text { REVISIÓN } \\
\text { SALARIAL }\end{array}$ & $\begin{array}{l}\text { PARTICIP. } \\
\text { BENEFICIOS }\end{array}$ & $\begin{array}{l}\text { PAGAS } \\
\text { EXTRAS }\end{array}$ & $\begin{array}{l}\text { OTRAS } \\
\text { PAGAS }\end{array}$ & $\begin{array}{l}\text { INFORMAC. } \\
\text { CONTABLE }\end{array}$ \\
\hline $\begin{array}{l}\text { SAN MIGUEL } \\
\text { FABRICAS } \\
\text { DE CERVEZA } \\
\text { Y MALTA } \\
\text { S.A. }\end{array}$ & BURGOS & $\begin{array}{c}\text { B.O. } \\
\text { BURGOS } \\
6-8-98\end{array}$ & $\begin{array}{c}1-1-98 \\
\text { HASTA } \\
31-3-01\end{array}$ & $\begin{array}{l}40 \text { horas } \\
\text { semanales }\end{array}$ & & $\begin{array}{c}\text { IPC previsto } \\
\text { REVISION+ } \\
\text { - si diferencia } \\
\text { de IPC real } \\
\text { supera el } \\
0,3 \%\end{array}$ & & $\begin{array}{c}4 \\
\text { Navidad } \\
\text { Verano } \\
\text { San Pedro } \\
\text { S. Miguel }\end{array}$ & & $\begin{array}{l}\text { Trimestral al } \\
\text { comité de } \\
\text { empresa sobre } \\
\text { evolución del } \\
\text { sector, } \\
\text { situación de la } \\
\text { producción y } \\
\text { ventas de la } \\
\text { empresa } \\
\text { Anual cuentas } \\
\text { anuales }\end{array}$ \\
\hline $\begin{array}{l}\text { SCHINDLER } \\
\text { S.A. }\end{array}$ & BURGOS & $\begin{array}{c}\text { B.O. } \\
\text { BURGOS } \\
20-1-97\end{array}$ & $\begin{array}{c}1-1-96 \\
\text { HASTA } \\
31-12-96\end{array}$ & 1784 & & $\begin{array}{l}\text { Tablas } \\
\text { IPC real }\end{array}$ & & $\begin{array}{c}2 \\
\text { Verano } \\
\text { Navidad }\end{array}$ & & \\
\hline $\begin{array}{l}\text { SCHINDLER } \\
\text { S.A. }\end{array}$ & BURGOS & $\begin{array}{c}\text { B.O. } \\
\text { BURGOS } \\
\text { 3-12-97 }\end{array}$ & $\begin{array}{c}1-1-97 \\
\text { HASTA } \\
31-12-97\end{array}$ & 1784 & & $\begin{array}{l}\text { Tablas } \\
\text { IPC real }\end{array}$ & & $\begin{array}{c}2 \\
\text { Verano } \\
\text { Navidad }\end{array}$ & & \\
\hline$\frac{\text { SCHINDLER }}{\underline{\text { S.A. }}}$ & BURGOS & $\begin{array}{c}\text { B.O. } \\
\text { BURGOS } \\
21-6-99\end{array}$ & $\begin{array}{c}1-1-98 \\
\text { HASTA } \\
31-12-00\end{array}$ & 1780 & & $\begin{array}{c}\text { Tablas } \\
\text { IPC real }\end{array}$ & $\begin{array}{c}\text { 1999: si se } \\
\text { cumple objetivo } \\
\text { de FACTURAC. } \\
+0,5 \% \\
2000:+0,25 \%\end{array}$ & $\begin{array}{c}2 \\
\text { Verano } \\
\text { Navidad }\end{array}$ & & \\
\hline
\end{tabular}




\begin{tabular}{|c|c|c|c|c|c|c|c|c|c|c|}
\hline EMPRESA & CENTRO & FUENTE & VIGENCIA & $\begin{array}{l}\text { JORNADA } \\
\text { LABORAL }\end{array}$ & $\begin{array}{c}\text { COMPROMISO } \\
\text { CONTRATOS }\end{array}$ & $\begin{array}{l}\text { REVISIÓN } \\
\text { SALARIAL }\end{array}$ & $\begin{array}{c}\text { PARTICIP. } \\
\text { BENEFICIOS }\end{array}$ & $\begin{array}{l}\text { PAGAS } \\
\text { EXTRAS }\end{array}$ & $\begin{array}{l}\text { OTRAS } \\
\text { PAGAS }\end{array}$ & $\begin{array}{l}\text { INFORMAC. } \\
\text { CONTABLE }\end{array}$ \\
\hline $\begin{array}{c}\text { SNACK } \\
\text { VENTURES } \\
\text { S.A. }\end{array}$ & BURGOS & $\begin{array}{c}\text { B.O. } \\
\text { BURGOS } \\
19-11-97\end{array}$ & $\begin{array}{c}1-1-96 \\
\text { HASTA } \\
31-12-00\end{array}$ & 1792 horas & & $\begin{array}{c}\text { 1996: } 4 \% \\
\text { REVISION + } \\
\text { IPC real } \\
\text { 1997: IPC } \\
\text { real +0,3\% } \\
\text { 1998: IPC } \\
\text { real + 0,5\% } \\
\text { 1999: IPC } \\
\text { real + 0,6\% } \\
2000: \text { IPC } \\
\text { real + 0,7\% } \\
\end{array}$ & & $\begin{array}{c}3 \\
\text { Marzo } \\
\text { Julio } \\
\text { Diciembre }\end{array}$ & & \\
\hline $\begin{array}{c}\text { SOMA } \\
\text { S.L. }\end{array}$ & BURGOS & $\begin{array}{c}\text { B.O. } \\
\text { BURGOS } \\
\text { 31-7-98 }\end{array}$ & $\begin{array}{c}1-1-98 \\
\text { HASTA } \\
31-12-98\end{array}$ & 1780 horas & & Tablas & & $\begin{array}{c}2 \\
\text { Verano } \\
\text { Navidad }\end{array}$ & & \\
\hline SOMA S.L. & BURGOS & $\begin{array}{c}\text { B.O. } \\
\text { BURGOS } \\
17-7-2000\end{array}$ & $\begin{array}{c}1-6-00 \\
\text { HASTA } \\
1-6-02\end{array}$ & 1780 horas & & $\begin{array}{c}2000: \text { tablas } \\
2001:+1,8 \% \\
2002:+1,8 \%\end{array}$ & & $\begin{array}{c}2 \\
\text { Verano } \\
\text { Navidad }\end{array}$ & & \\
\hline $\begin{array}{c}\text { STORK } \\
\text { INTER } \\
\text { IBERICA } \\
\text { S.A. }\end{array}$ & BURGOS & $\begin{array}{c}\text { B.O. } \\
\text { BURGOS } \\
17-6-97\end{array}$ & $\begin{array}{c}1-1-97 \\
\text { HASTA } \\
31-12-97\end{array}$ & 1752 horas & & $\begin{array}{c}+3,2 \% \\
\text { REVISION + } \\
\text { IPC real }\end{array}$ & & $\begin{array}{c}2 \\
\text { Verano } \\
\text { Navidad }\end{array}$ & & $\begin{array}{l}\text { Bimensual al } \\
\text { comité de } \\
\text { empresa de la } \\
\text { cuenta de } \\
\text { producción, } \\
\text { ventas y } \\
\text { perspectivas de } \\
\text { futuro }\end{array}$ \\
\hline $\begin{array}{l}\text { STORK } \\
\text { INTER } \\
\text { IBERICA } \\
\text { S.A. }\end{array}$ & BURGOS & $\begin{array}{c}\text { B.O. } \\
\text { BURGOS } \\
\text { 14-5-98 }\end{array}$ & $\begin{array}{c}1-1-98 \\
\text { HASTA } \\
31-12-98\end{array}$ & 1752 horas & & $\begin{array}{c}+2 \% \\
\text { REVISION + } \\
\text { IPC real }\end{array}$ & & $\begin{array}{c}2 \\
\text { Verano } \\
\text { Navidad }\end{array}$ & & $\begin{array}{l}\text { Bimensual al } \\
\text { comité de } \\
\text { empresa de la } \\
\text { cuenta de } \\
\text { producción, } \\
\text { ventas y } \\
\text { perspectivas de } \\
\text { futuro } \\
\end{array}$ \\
\hline
\end{tabular}




\begin{tabular}{|c|c|c|c|c|c|c|c|c|c|c|}
\hline EMPRESA & CENTRO & FUENTE & VIGENCIA & $\begin{array}{l}\text { JORNADA } \\
\text { LABORAL }\end{array}$ & $\begin{array}{l}\text { COMPROMISO } \\
\text { CONTRATOS }\end{array}$ & $\begin{array}{l}\text { REVISIÓN } \\
\text { SALARIAL }\end{array}$ & $\begin{array}{c}\text { PARTICIP. } \\
\text { BENEFICIOS }\end{array}$ & $\begin{array}{l}\text { PAGAS } \\
\text { EXTRAS }\end{array}$ & $\begin{array}{l}\text { OTRAS } \\
\text { PAGAS }\end{array}$ & $\begin{array}{l}\text { INFORMAC. } \\
\text { CONTABLE }\end{array}$ \\
\hline $\begin{array}{c}\text { STORK } \\
\text { INTER } \\
\text { IBERICA } \\
\text { S.A. }\end{array}$ & BURGOS & $\begin{array}{c}\text { B.O. } \\
\text { BURGOS } \\
13-7-99\end{array}$ & $\begin{array}{c}1-1-99 \\
\text { HASTA } \\
31-12-00\end{array}$ & $\begin{array}{l}\text { 1999: } 1744 \\
\text { 2000: } 1736\end{array}$ & & IPC + 1\% & & $\begin{array}{c}2 \\
\text { Verano } \\
\text { Navidad }\end{array}$ & & $\begin{array}{l}\text { Bimensual al } \\
\text { comité de } \\
\text { empresa ... }\end{array}$ \\
\hline $\begin{array}{l}\text { STORK } \\
\text { INTER } \\
\text { IBERICA } \\
\text { S.A. }\end{array}$ & BURGOS & $\begin{array}{c}\text { B.O. } \\
\text { BURGOS } \\
7-4-2000\end{array}$ & $\begin{array}{c}1-1-00 \\
\text { HASTA } \\
31-12-00\end{array}$ & & & Tablas & & $\begin{array}{c}2 \\
\text { Verano } \\
\text { Navidad }\end{array}$ & & \\
\hline $\begin{array}{c}\text { STORK } \\
\text { SISTEMAS } \\
\text { ALIMENTAR } \\
\text { S.A. }\end{array}$ & BURGOS & $\begin{array}{c}\text { B.O. } \\
\text { BURGOS } \\
6-8-97\end{array}$ & $\begin{array}{c}1-1-97 \\
\text { HASTA } \\
31-12-97\end{array}$ & 1752 horas & & $\begin{array}{c}+3,2 \% \\
\text { REVISION + } \\
\text { IPC real }\end{array}$ & & $\begin{array}{c}2 \\
\text { Verano } \\
\text { Navidad }\end{array}$ & & $\begin{array}{l}\text { Bimensual al } \\
\text { comité de } \\
\text { empresa de la } \\
\text { cuenta de } \\
\text { producción, } \\
\text { ventas y } \\
\text { perspectivas de } \\
\text { futuro }\end{array}$ \\
\hline $\begin{array}{l}\text { TALLERES } \\
\text { ARA S.L. }\end{array}$ & BURGOS & $\begin{array}{c}\text { B.O. } \\
\text { BURGOS } \\
17-9-98\end{array}$ & $\begin{array}{c}1-1-98 \\
\text { HASTA } \\
31-12-00\end{array}$ & $\begin{array}{l}\text { 1998: } 1782 \\
\text { 1999: } 1774 \\
\text { 2000: } 1770\end{array}$ & & $\begin{array}{c}\text { 1998: +1,75\% } \\
\text { + lineal } \\
\text { REVISION + } \\
\text { si IPC real es } \\
\text { mayor al } \\
2,1 \% \\
\text { 1999: IPC } \\
\text { previsto + 0,7 } \\
\text { REVISION + } \\
\text { IPC real } \\
\text { 2000: IPC } \\
\text { previsto + 0,6 } \\
\text { REVISION + } \\
\text { IPC real }\end{array}$ & & $\begin{array}{c}3 \\
\text { Navidad } \\
\text { Primavera } \\
\text { Verano }\end{array}$ & $\begin{array}{l}\text { Incentivos a la } \\
\text { producción }\end{array}$ & \\
\hline
\end{tabular}




\begin{tabular}{|c|c|c|c|c|c|c|c|c|c|c|}
\hline EMPRESA & CENTRO & FUENTE & VIGENCIA & $\begin{array}{l}\text { JORNADA } \\
\text { LABORAL }\end{array}$ & $\begin{array}{c}\text { COMPROMISO } \\
\text { CONTRATOS }\end{array}$ & $\begin{array}{l}\text { REVISIÓN } \\
\text { SALARIAL }\end{array}$ & $\begin{array}{c}\text { PARTICIP. } \\
\text { BENEFICIOS }\end{array}$ & $\begin{array}{c}\text { PAGAS } \\
\text { EXTRAS }\end{array}$ & $\begin{array}{l}\text { OTRAS } \\
\text { PAGAS }\end{array}$ & $\begin{array}{l}\text { INFORMAC. } \\
\text { CONTABLE }\end{array}$ \\
\hline $\begin{array}{c}\text { TUGA S.A. } \\
\text { EMPRESA } \\
\text { DISTRIBUID } \\
\text { DE GASES } \\
\text { LICUADOS } \\
\text { DEL } \\
\text { PETROLEO }\end{array}$ & TODOS & $\begin{array}{c}\text { B.O. } \\
\text { BURGOS } \\
27-2-98\end{array}$ & $\begin{array}{c}1-1-97 \\
\text { HASTA } \\
31-12-98\end{array}$ & 1760 horas & & $\begin{array}{c}\text { 1997: } \\
\text { congelación } \\
\text { 1998: }+3,1 \%\end{array}$ & & $\begin{array}{c}3 \\
\text { Julio } \\
\text { Navidad } \\
\mathrm{B}^{\circ}\end{array}$ & & \\
\hline $\begin{array}{c}\text { TRANS } \\
\text { UNION GAS } \\
\text { ASOCIACIÓN } \\
\text { S.A. } \\
\text { TUGA S.A. }\end{array}$ & TODOS & $\begin{array}{c}\text { B.O. } \\
\text { BURGOS } \\
27-10-99\end{array}$ & $\begin{array}{c}1-1-99 \\
\text { HASTA } \\
31-12-00\end{array}$ & 1760 horas & & $+2,25 \%$ & & $\begin{array}{c}3 \\
\text { Julio } \\
\text { Navidad } \\
\mathrm{B}^{\circ}\end{array}$ & & \\
\hline$\frac{\underline{\text { TRW }}}{\frac{\text { OCCUPANT }}{\text { RESTRAINT }}} \frac{\text { SYSTEMS }}{\underline{\text { S.A. }}}$ & TODOS & $\begin{array}{c}\text { B.O. } \\
\text { BURGOS } \\
\text { 20-7-98 }\end{array}$ & $\begin{array}{c}1-1-98 \\
\text { HASTA } \\
31-12-00\end{array}$ & $\begin{array}{l}\text { 1998: } 1744 \\
\text { 1999: } 1740 \\
\text { 2000: } 1736\end{array}$ & & $\begin{array}{c}+2,9 \% \\
\text { REVISION + } \\
\text { si IPC real } \\
\text { supera al } \\
2,3 \%\end{array}$ & $\begin{array}{c}\text { Paga de } \\
\text { resultados = f ( } \\
50 \% \mathrm{~B}^{\mathrm{o}} \\
\text { GESTION + } \\
30 \% \text { ROAE + } \\
20 \% \text { RENT } \\
\text { VENTAS ) }\end{array}$ & $\begin{array}{c}2 \\
\text { Verano } \\
\text { Navidad }\end{array}$ & $\begin{array}{c}\text { Prima de } \\
\text { producción }\end{array}$ & \\
\hline $\begin{array}{c}\text { UNION } \\
\text { ESPAÑOLA } \\
\text { DE } \\
\text { EXPLOSIVOS } \\
\text { S.A. }\end{array}$ & $\begin{array}{c}\text { PARAMO DE } \\
\text { MASA } \\
\text { (BURGOS) }\end{array}$ & $\begin{array}{c}\text { B.O. } \\
\text { BURGOS } \\
28-11-97\end{array}$ & $\begin{array}{c}1-1-97 \\
\text { HASTA } \\
31-12-98\end{array}$ & 1752 horas & & $\begin{array}{l}\text { 1997: } 2,6 \% \\
\text { 1998: } 2,3 \%\end{array}$ & & 2 & & \\
\hline $\begin{array}{c}\text { VB } \\
\text { AUTOBAT. } \\
\text { S.A. }\end{array}$ & BURGOS & $\begin{array}{c}\text { B.O. } \\
\text { BURGOS } \\
\text { 26-11-99 }\end{array}$ & $\begin{array}{c}1-1-99 \\
\text { HASTA } \\
31-12-01\end{array}$ & $\begin{array}{l}\text { 1999: } 1736 \\
\text { 2000: } 1720 \\
\text { 2001: } 1712\end{array}$ & $\begin{array}{c}\text { Se harán fijos a } 6 \\
\text { trabajadores }\end{array}$ & $\begin{array}{l}\text { 1999: IPC } \\
\text { real +0,5 } \\
\text { 2000: IPC } \\
\text { real +0,75 } \\
\text { 2001: IPC } \\
\text { real + 0,75 } \\
\end{array}$ & & $\begin{array}{c}3 \\
\text { Abril } \\
\text { Julio } \\
\text { Diciembre }\end{array}$ & & $\begin{array}{l}\text { Información } \\
\text { periódica de } \\
\text { producción }\end{array}$ \\
\hline VICASA & BURGOS & $\begin{array}{c}\text { B.O. } \\
\text { BURGOS } \\
12-5-97\end{array}$ & 1997 & & & Tablas & & & & \\
\hline
\end{tabular}




\begin{tabular}{|c|c|c|c|c|c|c|c|c|c|c|}
\hline EMPRESA & CENTRO & FUENTE & VIGENCIA & \begin{tabular}{|l} 
JORNADA \\
LABORAL
\end{tabular} & $\begin{array}{c}\text { COMPROMISO } \\
\text { CONTRATOS }\end{array}$ & $\begin{array}{l}\text { REVISIÓN } \\
\text { SALARIAL }\end{array}$ & $\begin{array}{l}\text { PARTICIP. } \\
\text { BENEFICIOS }\end{array}$ & $\begin{array}{c}\text { PAGAS } \\
\text { EXTRAS }\end{array}$ & $\begin{array}{l}\text { OTRAS } \\
\text { PAGAS }\end{array}$ & $\begin{array}{l}\text { INFORMAC. } \\
\text { CONTABLE }\end{array}$ \\
\hline VICASA & BURGOS & $\begin{array}{c}\text { B.O. } \\
\text { BURGOS } \\
26-8-99\end{array}$ & $\begin{array}{c}1-1-99 \\
\text { HASTA } \\
31-12-01\end{array}$ & $\begin{array}{l}\text { 1999: } 1760 \\
\text { 2000: } 1752 \\
\text { 2001: } 1744\end{array}$ & & $\begin{array}{c}\text { IPC previsto } \\
\text { REVISION + } \\
\text { IPC real si se } \\
\text { llega a un } \\
\text { deteminado } \\
\text { CASH } \\
\text { FLOW } \\
\text { BRUTO DE } \\
\text { EXPLOTAC. }\end{array}$ & $\begin{array}{c}\text { Referencia } \\
\text { CASH FLOW } \\
\text { BRUTO DE } \\
\text { EXPLOTACION }\end{array}$ & $\begin{array}{c}2 \\
\text { Julio } \\
\text { Navidad }\end{array}$ & $\begin{array}{c}\text { Prima por } \\
\text { objetivos y } \\
\text { productividad }\end{array}$ & \\
\hline VICASA & BURGOS & $\begin{array}{c}\text { B.O. } \\
\text { BURGOS } \\
12-4-2000\end{array}$ & $\begin{array}{c}1-1-00 \\
\text { HASTA } \\
31-12-00\end{array}$ & & & Tablas & & & & \\
\hline
\end{tabular}




\section{ANEXO 6}

\section{CUADRO RESUMEN CONVENIOS COLECTIVOS DICIEMBRE 2014}


PÁGINA 310 


\begin{tabular}{|c|c|c|c|c|c|c|c|c|c|}
\hline EMPRESA & FUENTE & $\begin{array}{l}\text { VIGENCIA } \\
\text { INICIAL }\end{array}$ & $\begin{array}{l}\text { JORNADA } \\
\text { LABORAL }\end{array}$ & $\begin{array}{c}\text { COMPROMISO } \\
\text { CONTRATOS }\end{array}$ & $\begin{array}{l}\text { REVISIÓN } \\
\text { SALARIAL }\end{array}$ & $\begin{array}{l}\text { PARTICIP. } \\
\text { BENEFICIOS }\end{array}$ & $\begin{array}{c}\text { PAGAS } \\
\text { EXTRAS }\end{array}$ & $\begin{array}{c}\text { OTRAS } \\
\text { REMUNERAC. }\end{array}$ & $\begin{array}{c}\text { REFER. } \\
\text { CONTABLE }\end{array}$ \\
\hline $\begin{array}{c}\text { ADISSEO } \\
\text { Burgos }\end{array}$ & $\begin{array}{c}\text { B.O. } \\
\text { BURGOS } \\
22-04-03\end{array}$ & $\begin{array}{c}\text { 01-01-2002 } \\
\text { HASTA } \\
31-12-2002\end{array}$ & & & Tablas 2002 & & & & \\
\hline $\begin{array}{c}\text { ADISSEO } \\
\text { Burgos }\end{array}$ & $\begin{array}{c}\text { B.O. } \\
\text { BURGOS } \\
16-02-04\end{array}$ & $\begin{array}{c}\text { 01-01-2003 } \\
\text { HASTA } \\
31-12-2005\end{array}$ & $\begin{array}{l}\text { 2003: } 1.640 \\
\text { 2004: } 1.636 \\
\text { 2005: } 1.636\end{array}$ & & $\begin{array}{l}\text { +IPC previsto } \\
+1 \% \\
\text { Revisión + si } \\
\text { IPCr mayor } \\
\text { que IPCp }\end{array}$ & & $\begin{array}{l}\text { Media } \\
\text { paga extra } \\
\text { como } \\
\text { particip. } \\
\text { en } \\
\text { beneficios }\end{array}$ & $\begin{array}{l}\text { Paga variable } \\
\text { lineal si no hay } \\
\text { accidentes con } \\
\text { baja médica } \\
\text { Paga variable } \\
\text { lineal si las } \\
\text { horas de parada } \\
\text { son menores a } \\
\text { unos valores }\end{array}$ & \\
\hline $\begin{array}{c}\text { ADISSEO } \\
\text { Burgos }\end{array}$ & $\begin{array}{c}\text { B.O. } \\
\text { BURGOS } \\
14-04-04\end{array}$ & $\begin{array}{c}\text { 01-01-2004 } \\
\text { HASTA } \\
31-12-2004\end{array}$ & & & Tablas 2004 & & & & \\
\hline $\begin{array}{c}\text { ADISSEO } \\
\text { Burgos }\end{array}$ & $\begin{array}{c}\text { B.O. } \\
\text { BURGOS } \\
15-03-06\end{array}$ & $\begin{array}{c}\text { 01-01-2005 } \\
\text { HASTA } \\
31-12-2005\end{array}$ & & & Tablas 2005 & & & & \\
\hline $\begin{array}{c}\text { ADISSEO } \\
\text { Burgos }\end{array}$ & $\begin{array}{c}\text { B.O. } \\
\text { BURGOS } \\
\text { 30-07-07 }\end{array}$ & $\begin{array}{c}\text { 01-01-2007 } \\
\text { HASTA } \\
31-12-2008\end{array}$ & 1.634 & & $\begin{array}{l}\text { +IPC previsto } \\
+0,6 \% \\
\text { Revisión + si } \\
\text { IPCr mayor } \\
\text { que IPCp }\end{array}$ & & $\begin{array}{l}\text { Media } \\
\text { paga extra } \\
\text { como } \\
\text { particip. } \\
\text { en } \\
\text { beneficios }\end{array}$ & $\begin{array}{c}\text { Paga variable } \\
\text { lineal si no hay } \\
\text { accidentes con } \\
\text { baja médica } \\
\\
\text { Paga variable } \\
\text { lineal si la tasa } \\
\text { de rendimiento } \\
\text { sintético es } \\
\text { superior a unos } \\
\text { objetivos } \\
\text { escalonados }\end{array}$ & $\begin{array}{l}\text { Seguimiento de } \\
\text { rtdos } \\
\text { económicos } \\
\text { con carácter } \\
\text { trimestral }\end{array}$ \\
\hline
\end{tabular}




\begin{tabular}{|c|c|c|c|c|c|c|c|}
\hline $\begin{array}{c}\text { ADISSEO } \\
\text { Burgos }\end{array}$ & $\begin{array}{c}\text { B.O. } \\
\text { BURGOS } \\
27-02-08\end{array}$ & $\begin{array}{c}\text { 01-01-2008 } \\
\text { HASTA } \\
31-12-2008\end{array}$ & & Tablas 2008 & & & \\
\hline $\begin{array}{c}\text { ADISSEO } \\
\text { Burgos }\end{array}$ & $\begin{array}{c}\text { B.O. } \\
\text { BURGOS } \\
\text { 01-07-09 }\end{array}$ & $\begin{array}{c}\text { 01-01-2009 } \\
\text { HASTA } \\
31-12-2010\end{array}$ & 1.634 & $\begin{array}{c}\text { + IPC real + } \\
\text { 0,65\% } \\
\\
\text { Garantía } \\
\text { +0,65\% }\end{array}$ & $\begin{array}{l}\text { Media } \\
\text { paga extra } \\
\text { como } \\
\text { particip. } \\
\text { en } \\
\text { beneficios }\end{array}$ & $\begin{array}{l}\text { Paga variable } \\
\text { lineal si no hay } \\
\text { accidentes con } \\
\text { baja médica } \\
\text { Paga variable } \\
\text { lineal si la tasa } \\
\text { de rendimiento } \\
\text { sintético es } \\
\text { superior a unos } \\
\text { objetivos } \\
\text { escalonados }\end{array}$ & $\begin{array}{l}\text { Seguimiento de } \\
\text { rtdos } \\
\text { económicos } \\
\text { con carácter } \\
\text { trimestral }\end{array}$ \\
\hline $\begin{array}{c}\text { ADISSEO } \\
\text { Burgos }\end{array}$ & $\begin{array}{c}\text { B.O. } \\
\text { BURGOS } \\
24-05-10\end{array}$ & $\begin{array}{c}\text { 01-01-2010 } \\
\text { HASTA } \\
31-12-2010\end{array}$ & & Tablas 2010 & & & \\
\hline $\begin{array}{c}\text { ADISSEO } \\
\text { Burgos }\end{array}$ & $\begin{array}{c}\text { B.O. } \\
\text { BURGOS } \\
05-04-11\end{array}$ & $\begin{array}{c}\text { 01-01-2011 } \\
\text { HASTA } \\
31-12-2011\end{array}$ & & Tablas 2010 & & & \\
\hline $\begin{array}{c}\text { ADISSEO } \\
\text { Burgos }\end{array}$ & $\begin{array}{c}\text { B.O. } \\
\text { BURGOS } \\
14-07-11\end{array}$ & $\begin{array}{c}\text { 1-01-2011 } \\
\text { HASTA } \\
31-12-2012\end{array}$ & 1.634 & $\begin{array}{c}\text { +IPC real + } \\
0,60 \% \\
\\
\text { Garantía } \\
+0,60 \%\end{array}$ & $\begin{array}{l}\text { Media } \\
\text { paga extra } \\
\text { como } \\
\text { particip. } \\
\text { en } \\
\text { beneficios }\end{array}$ & $\begin{array}{l}\text { Paga variable } \\
\text { lineal si no hay } \\
\text { accidentes con } \\
\text { baja médica } \\
\\
\text { Paga variable } \\
\text { lineal si la tasa } \\
\text { de rendimiento } \\
\text { sintético es } \\
\text { superior a unos } \\
\text { objetivos } \\
\text { escalonados }\end{array}$ & $\begin{array}{l}\text { Seguimiento de } \\
\text { rtdos } \\
\text { económicos } \\
\text { con carácter } \\
\text { trimestral }\end{array}$ \\
\hline
\end{tabular}




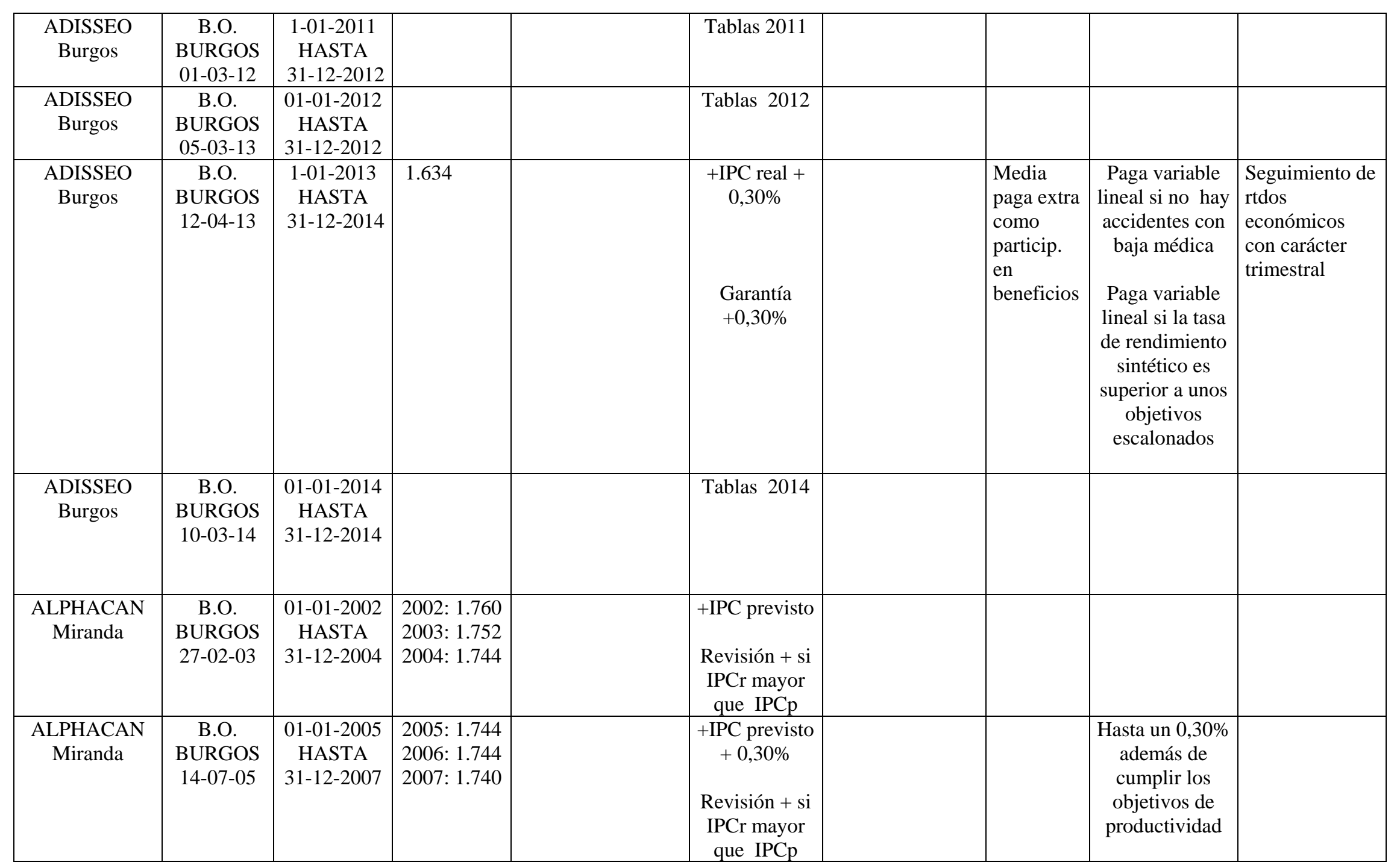




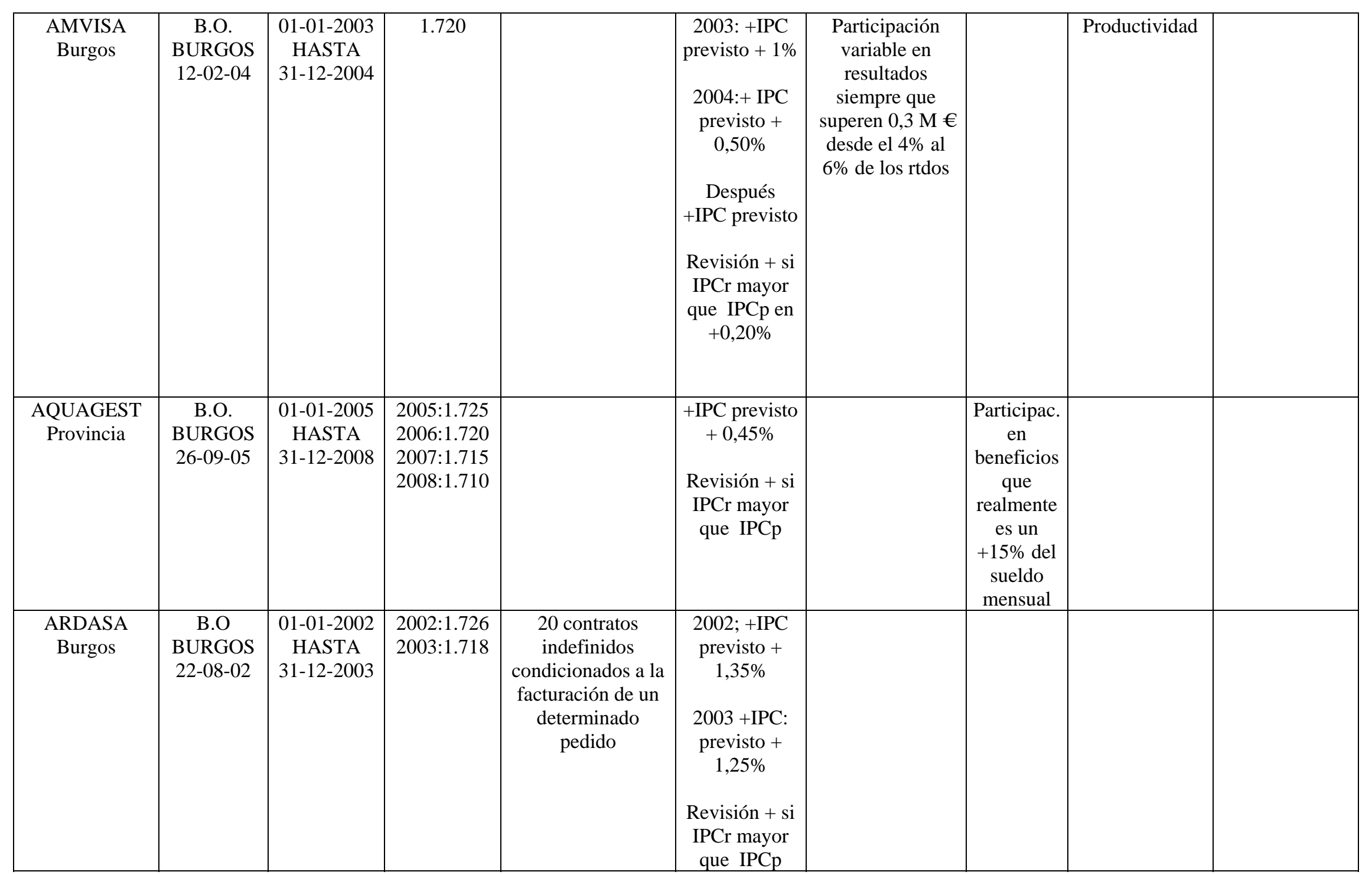




\begin{tabular}{|c|c|c|c|c|c|}
\hline $\begin{array}{c}\text { ARDASA } \\
\text { Burgos }\end{array}$ & $\begin{array}{c}\text { B.O } \\
\text { BURGOS } \\
\text { 15-06-05 }\end{array}$ & $\begin{array}{c}01-01-2004 \\
\text { HASTA } \\
31-12-2007\end{array}$ & 1.718 & $\begin{array}{c}\text { 2004: +IPC } \\
\text { real } \\
\text { 2005: +IPC } \\
\text { previsto } \\
\text { 2006:+ IPC } \\
\text { previsto + } \\
\text { 0,50\% } \\
\text { 2007: +IPC } \\
\text { previsto + } \\
\text { 0,75\% } \\
\text { Revisión + si } \\
\text { IPCr mayor } \\
\text { que IPCp }\end{array}$ & \\
\hline ARTEPREF & $\begin{array}{c}\text { B.O } \\
\text { BURGOS } \\
16-04-02\end{array}$ & $\begin{array}{c}\text { 01-01-2002 } \\
\text { HASTA } \\
31-12-2002\end{array}$ & 1.744 & & $\begin{array}{l}\text { No aplicación } \\
\text { por pérdidas de } \\
\text { explotación } 2 \\
\text { ejercicios que } \\
\text { afecten a la } \\
\text { estabilidad } \\
\text { En ese caso } \\
\text { información } \\
\text { económica y } \\
\text { plan de } \\
\text { viabilidad }\end{array}$ \\
\hline
\end{tabular}




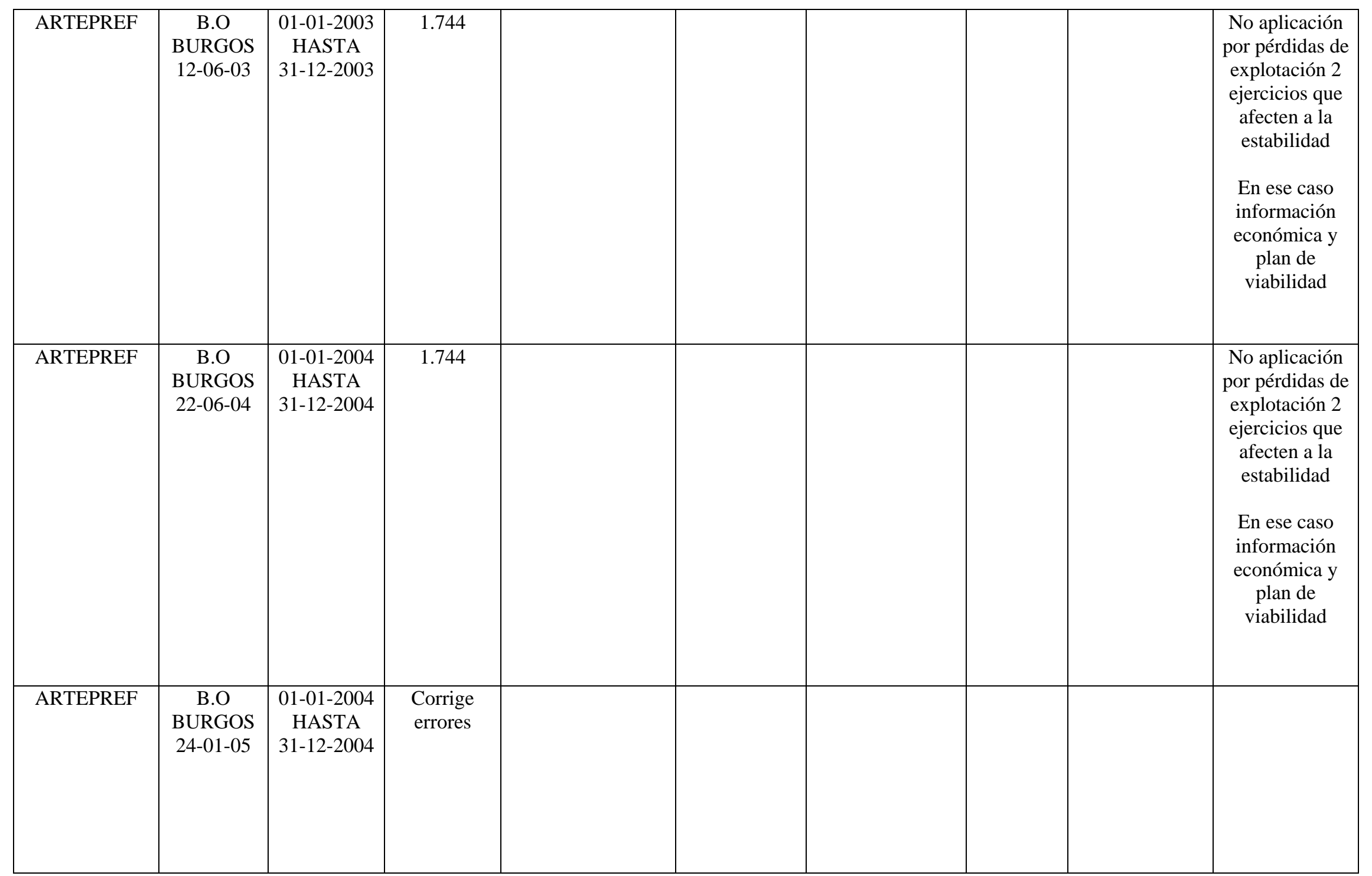




\begin{tabular}{|c|c|c|c|c|c|}
\hline ARTEPREF & $\begin{array}{c}\text { B.O } \\
\text { BURGOS } \\
11-05-05\end{array}$ & $\begin{array}{c}\text { 01-01-2005 } \\
\text { HASTA } \\
31-12-2005\end{array}$ & 1.744 & & $\begin{array}{l}\text { No aplicación } \\
\text { por pérdidas de } \\
\text { explotación } 2 \\
\text { ejercicios que } \\
\text { afecten a la } \\
\text { estabilidad } \\
\text { En ese caso } \\
\text { información } \\
\text { económica y } \\
\text { plan de } \\
\text { viabilidad }\end{array}$ \\
\hline ARTEPREF & $\begin{array}{c}\text { B.O } \\
\text { BURGOS } \\
27-07-05\end{array}$ & $\begin{array}{c}\text { 01-01-2005 } \\
\text { HASTA } \\
31-12-2005\end{array}$ & & Tablas 2005 & \\
\hline ARTEPREF & $\begin{array}{c}\text { B.O } \\
\text { BURGOS } \\
\text { 30-08-06 }\end{array}$ & $\begin{array}{c}\text { 01-01-2006 } \\
\text { HASTA } \\
31-12-2006\end{array}$ & 1.740 & & $\begin{array}{l}\text { No aplicación } \\
\text { por pérdidas de } \\
\text { explotación } 2 \\
\text { ejercicios que } \\
\text { afecten a la } \\
\text { estabilidad } \\
\text { En ese caso } \\
\text { información } \\
\text { económica y } \\
\text { plan de } \\
\text { viabilidad }\end{array}$ \\
\hline
\end{tabular}




\begin{tabular}{|c|c|c|c|c|c|}
\hline ARTEPREF & $\begin{array}{c}\text { B.O } \\
\text { BURGOS } \\
09-08-07\end{array}$ & $\begin{array}{c}\text { 01-01-2007 } \\
\text { HASTA } \\
31-12-2007\end{array}$ & 1.740 & & $\begin{array}{c}\text { No aplicación } \\
\text { por pérdidas de } \\
\text { explotación } 2 \\
\text { ejercicios que } \\
\text { afecten a la } \\
\text { estabilidad } \\
\text { En ese caso } \\
\text { información } \\
\text { económica y } \\
\text { plan de } \\
\text { viabilidad }\end{array}$ \\
\hline ARTEPREF & $\begin{array}{c}\text { B.O } \\
\text { BURGOS } \\
\text { 13-04-09 }\end{array}$ & $\begin{array}{c}\text { 01-01-2008 } \\
\text { HASTA } \\
31-12-2008\end{array}$ & 1.736 & $\begin{array}{c}+ \text { IPC } \\
\text { previsto+ 1\% } \\
\text { Revisión + si } \\
\text { IPCr mayor } \\
\text { que IPCp }\end{array}$ & $\begin{array}{c}\text { No aplicación } \\
\text { por pérdidas de } \\
\text { explotación } 2 \\
\text { ejercicios que } \\
\text { afecten a la } \\
\text { estabilidad } \\
\text { En ese caso } \\
\text { información } \\
\text { económica y } \\
\text { plan de } \\
\text { viabilidad }\end{array}$ \\
\hline ARTEPREF & $\begin{array}{c}\text { B.O } \\
\text { BURGOS } \\
09-03-10\end{array}$ & $\begin{array}{c}\text { 01-01-2009 } \\
\text { HASTA } \\
31-12-2009\end{array}$ & 1.736 & & $\begin{array}{c}\text { No aplicación } \\
\text { por pérdidas de } \\
\text { explotación } 2 \\
\text { ejercicios que } \\
\text { afecten a la } \\
\text { estabilidad } \\
\text { En ese caso } \\
\text { información } \\
\text { económica y } \\
\text { plan de } \\
\text { viabilidad }\end{array}$ \\
\hline
\end{tabular}




\begin{tabular}{|c|c|c|c|c|c|}
\hline ARTEPREF & $\begin{array}{c}\text { B.O } \\
\text { BURGOS } \\
25-08-11\end{array}$ & $\begin{array}{c}01-01-2010 \\
\text { HASTA } \\
31-12-2011\end{array}$ & 1.736 & & \begin{tabular}{|c} 
No aplicación \\
por pérdidas de \\
explotación 2 \\
ejercicios que \\
afecten a la \\
estabilidad \\
\\
En ese caso \\
información \\
económica y \\
plan de \\
viabilidad
\end{tabular} \\
\hline $\begin{array}{c}\text { ATE } \\
\text { SISTEMAS Y } \\
\text { PROYECTOS } \\
\text { SINGULARES } \\
\text { Provincia }\end{array}$ & $\begin{array}{c}\text { B.O. } \\
\text { BURGOS } \\
\text { 13-01-15 }\end{array}$ & $\begin{array}{l}\text { Adhesión al } \\
\text { convenio }\end{array}$ & & & \\
\hline $\begin{array}{c}\text { AVENTIS } \\
\text { Burgos }\end{array}$ & $\begin{array}{c}\text { B.O. } \\
\text { BURGOS } \\
\text { 05-03-02 }\end{array}$ & $\begin{array}{c}01-01-2002 \\
\text { HASTA } \\
31-12-2002\end{array}$ & & Tablas 2002 & \\
\hline CALFERMAN & $\begin{array}{c}\text { B.O. } \\
\text { BURGOS } \\
\text { 12-05-05 }\end{array}$ & $\begin{array}{c}01-01-2005 \\
\text { HASTA } \\
31-12-2005\end{array}$ & 1.744 & & \begin{tabular}{|c} 
No aplicación \\
por pérdidas de \\
explotación 2 \\
ejercicios que \\
afecten a la \\
estabilidad \\
\\
En ese caso \\
información \\
económica y \\
plan de \\
viabilidad
\end{tabular} \\
\hline
\end{tabular}




\begin{tabular}{|c|c|c|c|c|c|}
\hline CALFERMAN & $\begin{array}{c}\text { B.O. } \\
\text { BURGOS } \\
27-07-05\end{array}$ & $\begin{array}{c}\text { 01-01-2005 } \\
\text { HASTA } \\
31-12-2005\end{array}$ & & Tablas 2005 & \\
\hline CALFERMAN & $\begin{array}{c}\text { B.O. } \\
\text { BURGOS } \\
\text { 14-09-06 }\end{array}$ & $\begin{array}{c}\text { 01-01-2006 } \\
\text { HASTA } \\
31-12-2006\end{array}$ & 1.740 & & $\begin{array}{l}\text { No aplicación } \\
\text { por pérdidas de } \\
\text { explotación } 2 \\
\text { ejercicios que } \\
\text { afecten a la } \\
\text { estabilidad } \\
\text { En ese caso } \\
\text { información } \\
\text { económica y } \\
\text { plan de } \\
\text { viabilidad }\end{array}$ \\
\hline CALFERMAN & $\begin{array}{c}\text { B.O. } \\
\text { BURGOS } \\
02-08-07\end{array}$ & $\begin{array}{c}\text { 01-01-2007 } \\
\text { HASTA } \\
31-12-2007\end{array}$ & 1.740 & & $\begin{array}{l}\text { No aplicación } \\
\text { por pérdidas de } \\
\text { explotación } 2 \\
\text { ejercicios que } \\
\text { afecten a la } \\
\text { estabilidad } \\
\text { En ese caso } \\
\text { información } \\
\text { económica y } \\
\text { plan de } \\
\text { viabilidad }\end{array}$ \\
\hline CALFERMAN & $\begin{array}{c}\text { B..O. } \\
\text { BURGOS } \\
\text { 16-04-09 }\end{array}$ & $\begin{array}{c}01-01-2008 \\
\text { HASTA } \\
31-12-2008\end{array}$ & 1.736 & $\begin{array}{c}+ \text { IPC } \\
\text { previsto+ } 1 \% \\
\text { Revisión + si } \\
\text { IPCr mayor } \\
\text { que IPCp }\end{array}$ & \\
\hline
\end{tabular}




\begin{tabular}{|c|c|c|c|c|c|}
\hline CALFERMAN & $\begin{array}{c}\text { B.O. } \\
\text { BURGOS } \\
09-07-10\end{array}$ & $\begin{array}{c}\text { 01-01-2009 } \\
\text { HASTA } \\
31-12-2009\end{array}$ & 1.736 & $+2,3 \%$ & \\
\hline $\begin{array}{c}\text { CENTRO } \\
\text { GERONTOLOGICO } \\
\text { Burgos }\end{array}$ & $\begin{array}{c}\text { B.O. } \\
\text { BURGOS } \\
22-07-14\end{array}$ & $\begin{array}{c}\text { 01-01-2014 } \\
\text { HASTA } \\
31-12-2015\end{array}$ & 1.792 & $\begin{array}{l}\text { Tablas } 2014 \\
\text { Tablas } 2015\end{array}$ & \\
\hline $\begin{array}{c}\text { CERAMICAS } \\
\text { GALA } \\
\text { Burgos }\end{array}$ & $\begin{array}{c}\text { B.O. } \\
\text { BURGOS } \\
08-07-04\end{array}$ & $\begin{array}{c}\text { 01-01-2004 } \\
\text { HASTA } \\
31-12-2006\end{array}$ & 1.759 & $\begin{array}{c}\text { 2004: +2,60\% } \\
\text { 2005:+ IPC } \\
\text { previsto + } \\
0,70 \% \\
\text { 2006:+IPC } \\
\text { previsto + } \\
\text { 0,80\% } \\
\text { Revisión + si } \\
\text { IPCr mayor } \\
\text { que IPCp }\end{array}$ & $\begin{array}{c}\text { Complemento } \\
\text { por calidad y } \\
\text { cantidad de } \\
\text { trabajo } \\
\text { Sistema de } \\
\text { puntos }\end{array}$ \\
\hline $\begin{array}{c}\text { CERAMICAS } \\
\text { GALA } \\
\text { Burgos }\end{array}$ & $\begin{array}{c}\text { B.O. } \\
\text { BURGOS } \\
22-01-08\end{array}$ & $\begin{array}{c}01-01-2007 \\
\text { HASTA } \\
31-12-2009\end{array}$ & & $\begin{array}{l}\text { +IPC previsto } \\
+0,75 \% \\
\text { Revisión + si } \\
\text { IPCr mayor } \\
\text { que IPCp }\end{array}$ & \\
\hline
\end{tabular}




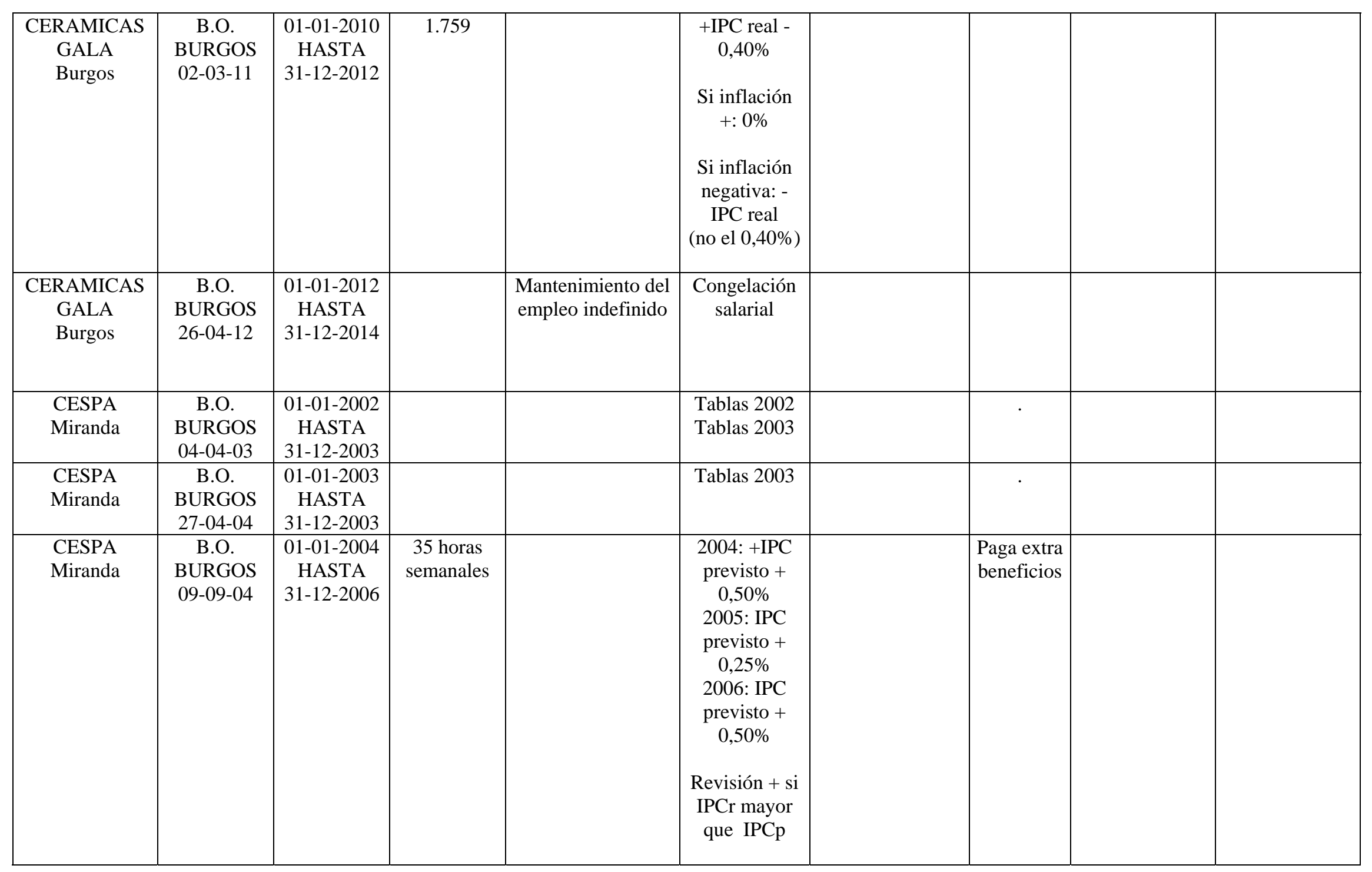




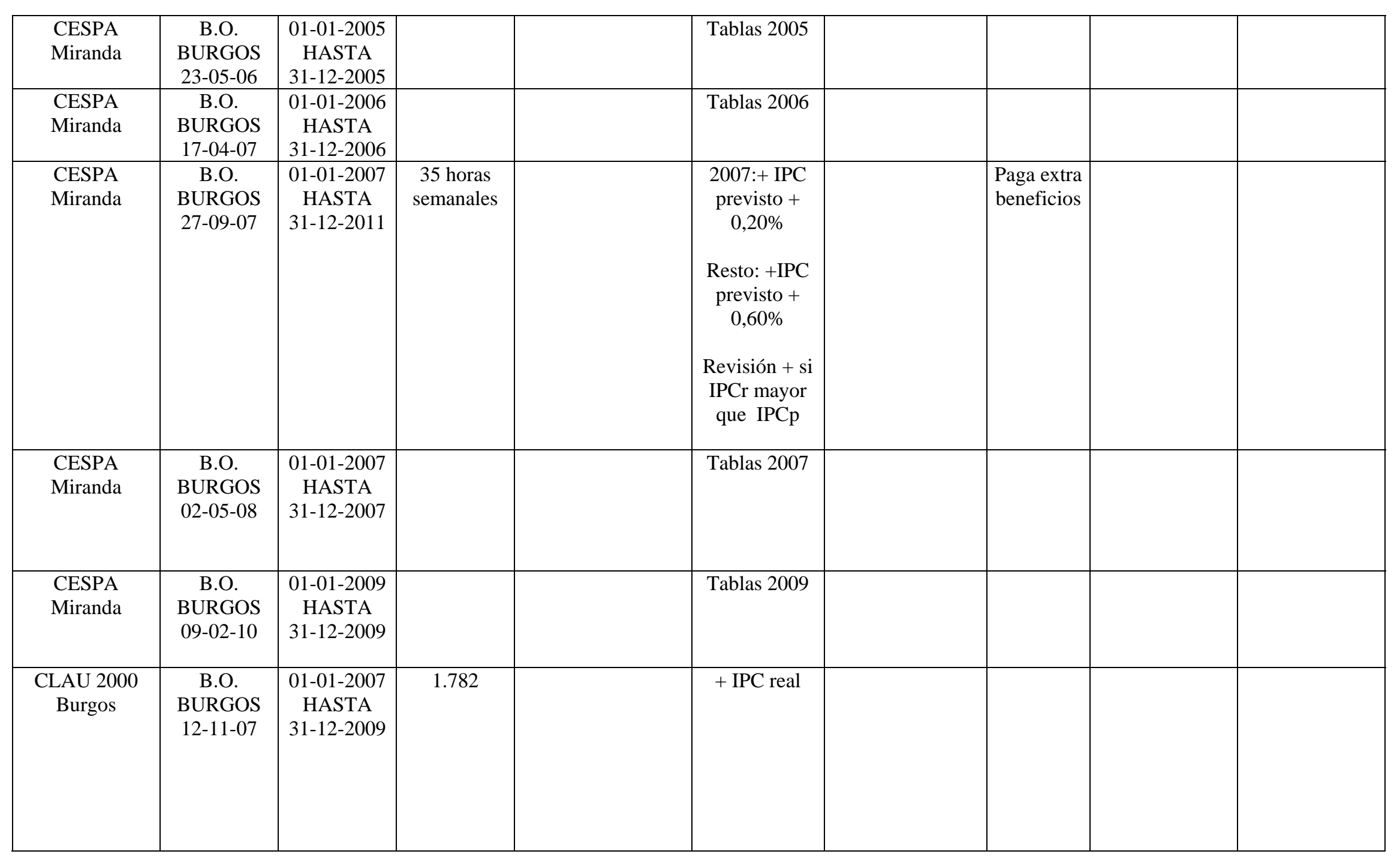




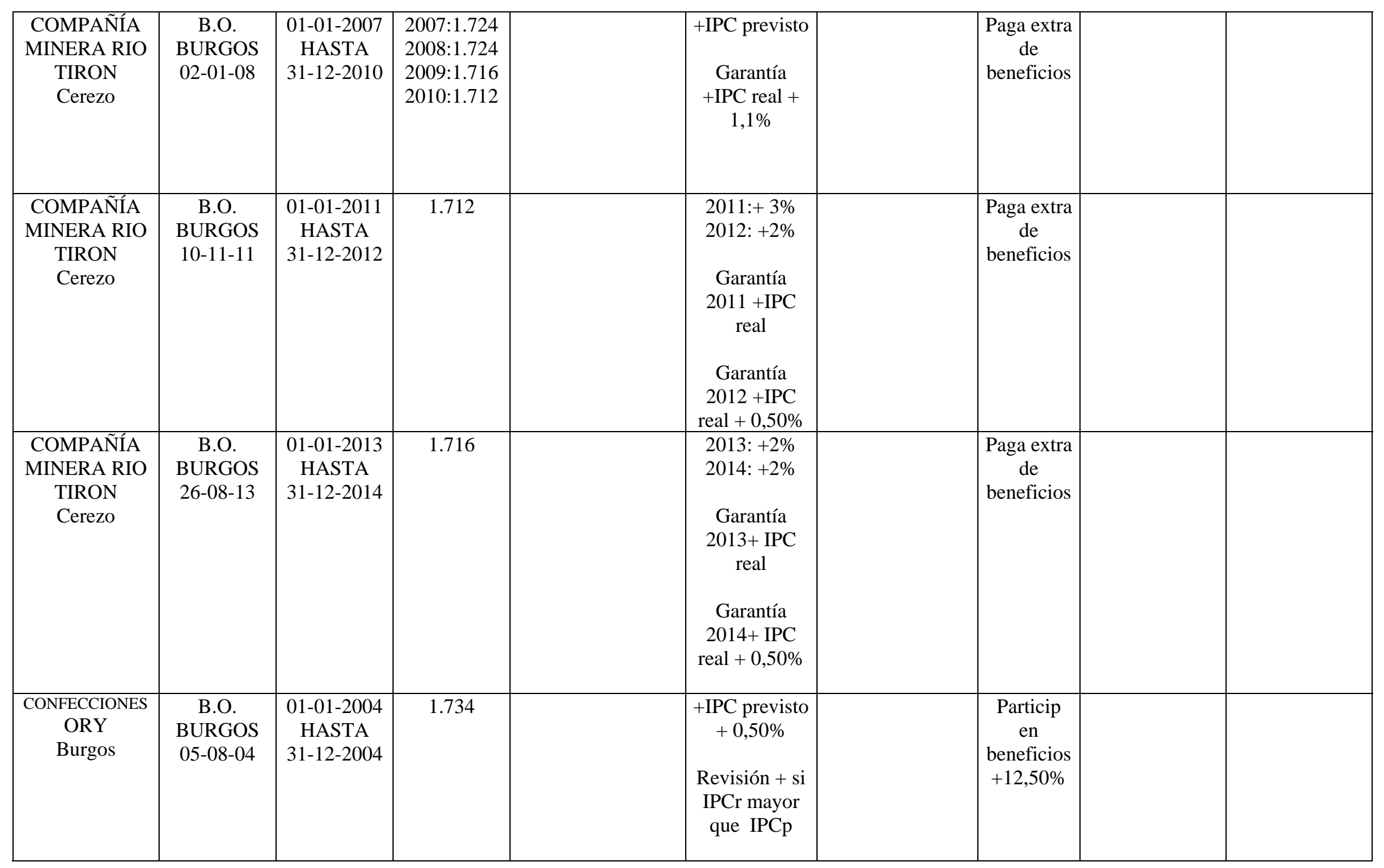




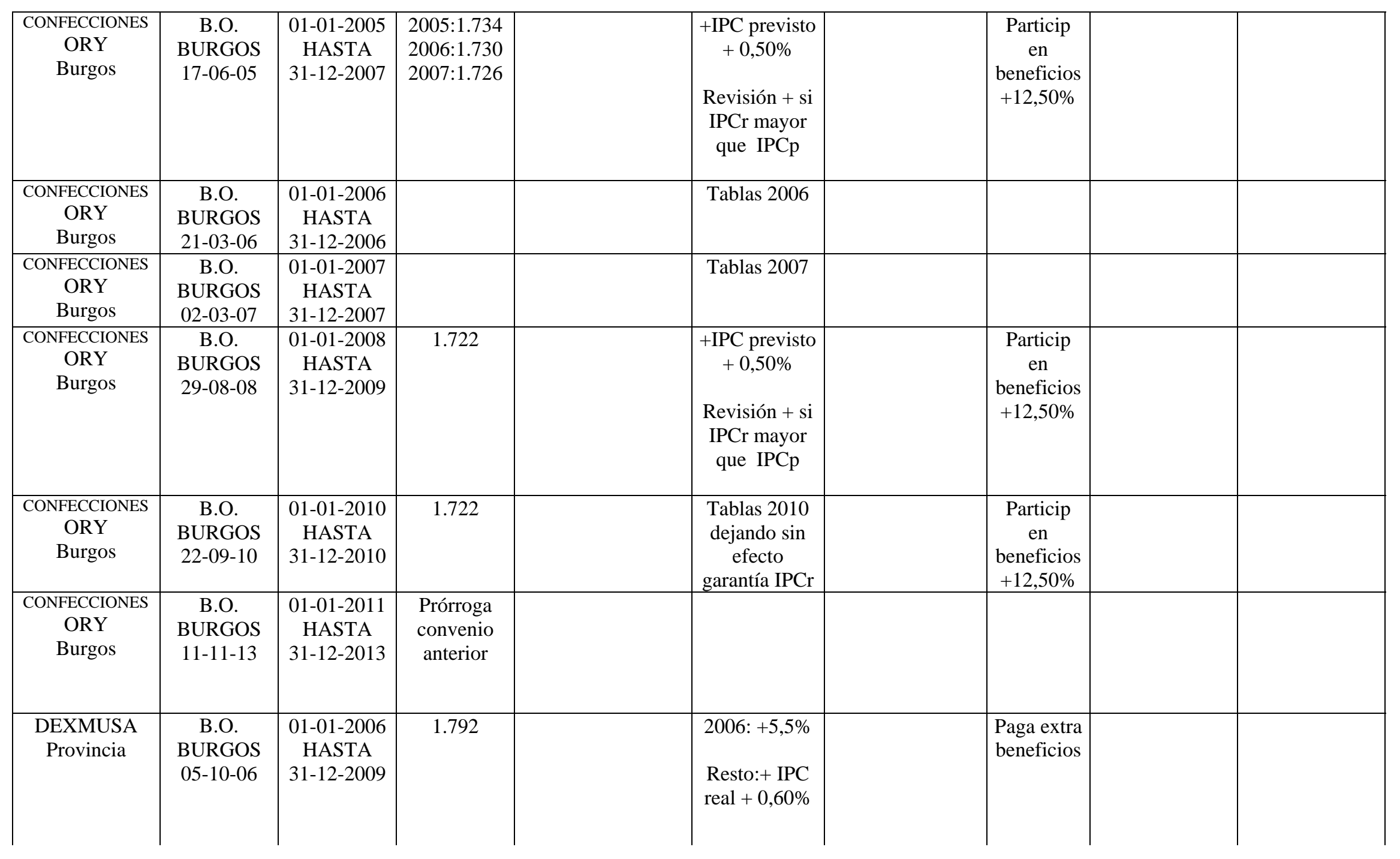




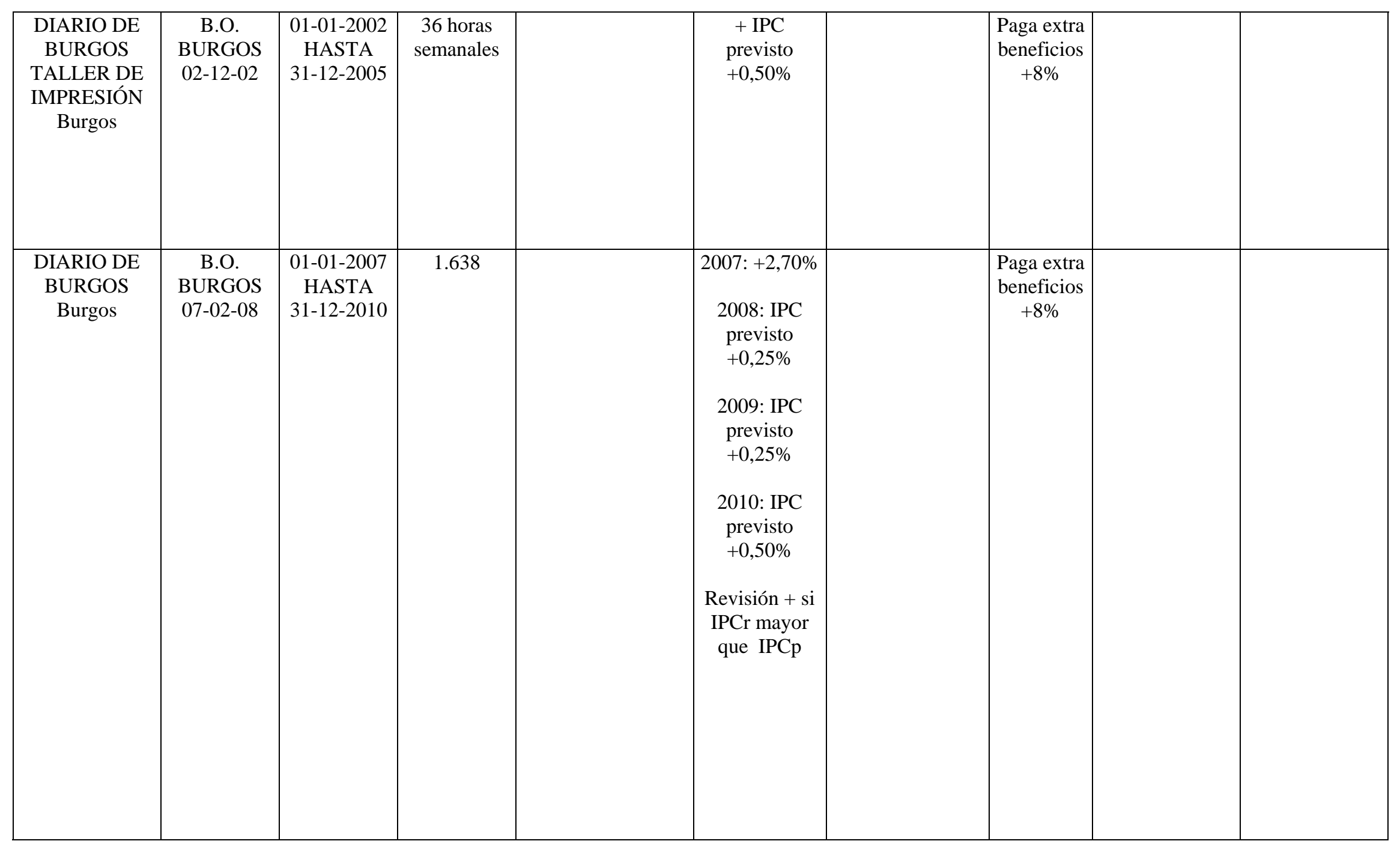




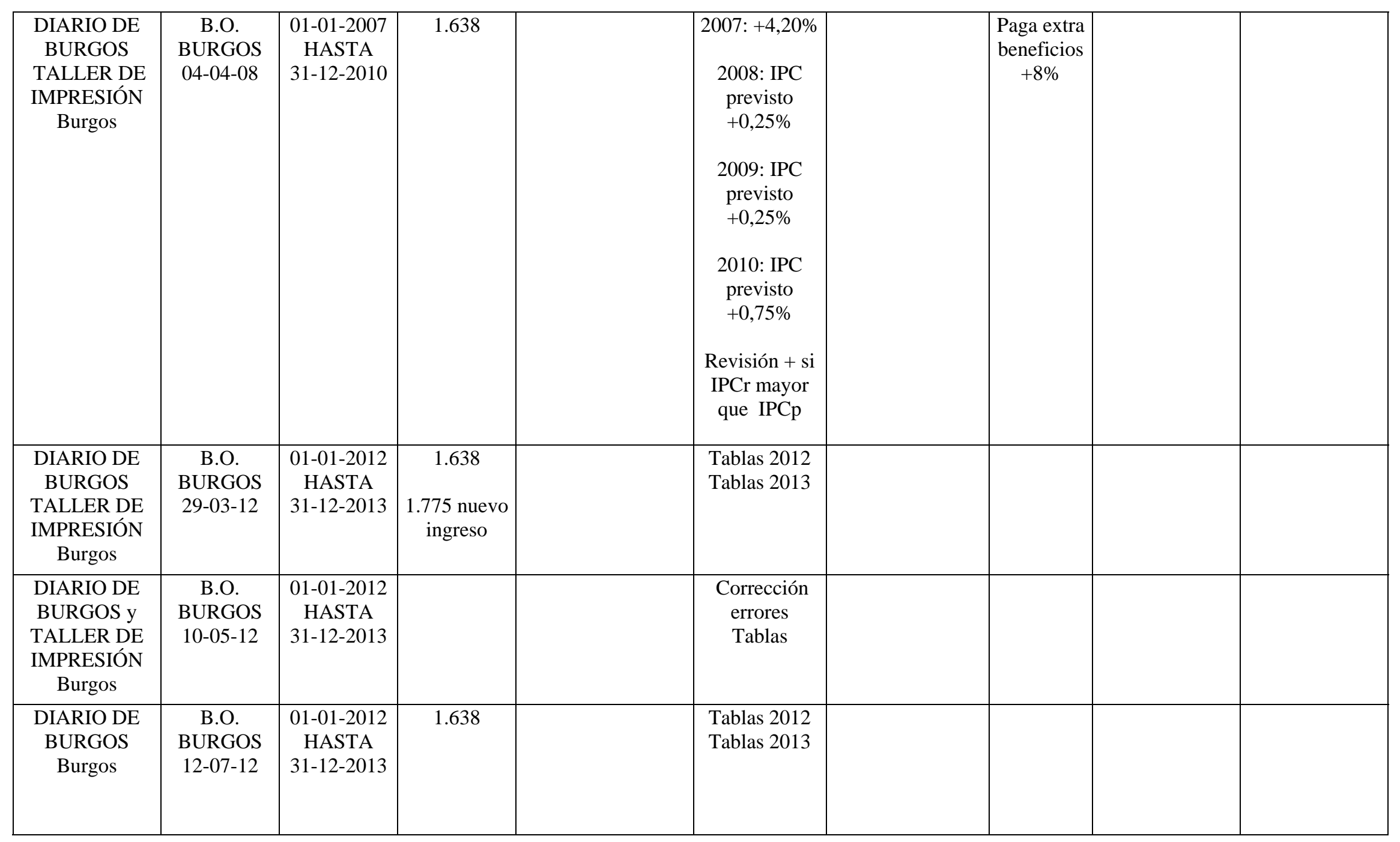




\begin{tabular}{|c|c|c|c|c|c|}
\hline $\begin{array}{c}\text { DUO FAST } \\
\text { Burgos }\end{array}$ & $\begin{array}{c}\text { B.O. } \\
\text { BURGOS } \\
29-08-02\end{array}$ & $\begin{array}{c}\text { 01-01-2002 } \\
\text { HASTA } \\
31-12-2003\end{array}$ & 1.744 & $\begin{array}{c}\text { 2002: +3\% } \\
\text { 2003:+ IPC } \\
\text { previsto + 1\% } \\
\text { 2002: } \\
\text { revisión + si } \\
\text { IPC real } \\
\text { mayor al 3\% } \\
\text { 2003: } \\
\text { revisión + si } \\
\text { IPC previsto } \\
\text { e IPC real } \\
\text { difiere más de } \\
+0,5 \%\end{array}$ & $\begin{array}{c}\text { Con carácter } \\
\text { trimestral }\end{array}$ \\
\hline $\begin{array}{c}\text { DUO FAST } \\
\text { Burgos }\end{array}$ & $\begin{array}{c}\text { B.O. } \\
\text { BURGOS } \\
27-08-04\end{array}$ & $\begin{array}{c}\text { 01-01-2004 } \\
\text { HASTA } \\
31-12-2004\end{array}$ & 1.736 & $\begin{array}{c}+2 \% \\
\text { Revisión }+ \text { si } \\
\text { IPC real } \\
\text { mayor al 2\% }\end{array}$ & $\begin{array}{c}\text { Con carácter } \\
\text { trimestral }\end{array}$ \\
\hline $\begin{array}{c}\text { DUO FAST } \\
\text { Burgos }\end{array}$ & $\begin{array}{c}\text { B.O. } \\
\text { BURGOS } \\
02-06-05\end{array}$ & $\begin{array}{c}\text { 01-01-2005 } \\
\text { HASTA } \\
31-12-2005\end{array}$ & $\begin{array}{l}1.728 \\
\end{array}$ & $\begin{array}{c}+2 \% \\
\text { Revisión }+ \text { si } \\
\text { IPC real } \\
\text { mayor al 2\% }\end{array}$ & $\begin{array}{c}\text { Con carácter } \\
\text { trimestral }\end{array}$ \\
\hline $\begin{array}{c}\text { DUO FAST } \\
\text { Burgos }\end{array}$ & $\begin{array}{c}\text { B.O. } \\
\text { BURGOS } \\
01-08-06\end{array}$ & $\begin{array}{c}01-01-2006 \\
\text { HASTA } \\
31-12-2006\end{array}$ & 1.728 & $\begin{array}{c}+2 \% \\
\text { Revisión + si } \\
\text { IPC real es } \\
\text { mayor al } \\
1,5 \%\end{array}$ & $\begin{array}{c}\text { Con carácter } \\
\text { trimestral }\end{array}$ \\
\hline
\end{tabular}




\begin{tabular}{|c|c|c|c|c|c|}
\hline $\begin{array}{c}\text { DUO FAST } \\
\text { Burgos }\end{array}$ & $\begin{array}{c}\text { B.O. } \\
\text { BURGOS } \\
\text { 11-05-07 }\end{array}$ & $\begin{array}{c}01-01-2007 \\
\text { HASTA } \\
31-12-2009\end{array}$ & $\begin{array}{l}2007: 1.720 \\
2008: 1.720 \\
2009: 1.712\end{array}$ & \begin{tabular}{|c|} 
2007:+IPC \\
previsto + 1\% \\
o+1,90\% \\
(para salarios \\
más bajos) \\
\\
2008:+ IPC \\
previsto + 1\% \\
\\
2009:+IPC \\
previsto + \\
$0,75 \%$ o \\
$1,65 \%$ \\
\\
$2007:$ Revisa \\
+ si IPC real \\
es mayor al \\
$2 \%$ \\
\\
2008 y 2009: \\
garantía IPC \\
real + \\
diferencial \\
\end{tabular} & $\begin{array}{c}\text { Con carácter } \\
\text { trimestral }\end{array}$ \\
\hline $\begin{array}{c}\text { DUO FAST } \\
\text { Burgos }\end{array}$ & $\begin{array}{c}\text { B.O. } \\
\text { BURGOS } \\
\text { 12-02-08 }\end{array}$ & $\begin{array}{c}01-01-2008 \\
\text { HASTA } \\
31-12-2008\end{array}$ & $\begin{array}{l}\text { Solución } \\
\text { conflicto } \\
\text { por } \\
\text { despidos } \\
\end{array}$ & & \\
\hline $\begin{array}{l}\text { DUO FAST } \\
\text { Burgos }\end{array}$ & $\begin{array}{c}\text { B.O. } \\
\text { BURGOS } \\
24-07-12\end{array}$ & $\begin{array}{c}01-01-2012 \\
\text { HASTA } \\
31-12-2012\end{array}$ & 1.712 & $\begin{array}{l}\text { Congelación } \\
2012\end{array}$ & $\begin{array}{c}\text { Con carácter } \\
\text { trimestral }\end{array}$ \\
\hline
\end{tabular}




\begin{tabular}{|c|c|c|c|c|c|c|c|}
\hline $\begin{array}{c}\text { DUO FAST } \\
\text { Burgos }\end{array}$ & $\begin{array}{c}\text { B.O. } \\
\text { BURGOS } \\
24-06-13\end{array}$ & $\begin{array}{c}\text { 01-01-2013 } \\
\text { HASTA } \\
31-12-2014\end{array}$ & 1.712 & $\begin{array}{c}\text { 2013: } \\
\text { congelación } \\
2014:+1 \%\end{array}$ & & & $\begin{array}{c}\text { Con carácter } \\
\text { trimestral }\end{array}$ \\
\hline $\begin{array}{c}\text { EDB } \\
\text { Quintanilla }\end{array}$ & $\begin{array}{c}\text { B.O. } \\
\text { BURGOS } \\
\text { 13-12-02 }\end{array}$ & $\begin{array}{c}01-01-2002 \\
\text { HASTA } \\
31-12-2003\end{array}$ & 1.736 & +IPC real & $\begin{array}{l}\text { Hasta el 1,5\% } \\
\text { adicional } \\
\text { vinculado a } \\
\text { facturación, } \\
\text { compras y var. } \\
\text { existencias }\end{array}$ & & $\begin{array}{c}\text { Con carácter } \\
\text { trimestral }\end{array}$ \\
\hline $\begin{array}{c}\text { EDB } \\
\text { Quintanilla }\end{array}$ & $\begin{array}{c}\text { B.O. } \\
\text { BURGOS } \\
\text { 28-03-08 }\end{array}$ & $\begin{array}{c}\text { 01-01-2007 } \\
\text { HASTA } \\
31-12-2009\end{array}$ & 1.712 & $\begin{array}{c}\text { +IPC real + } \\
0,50 \%\end{array}$ & & & $\begin{array}{c}\text { Con carácter } \\
\text { trimestral }\end{array}$ \\
\hline $\begin{array}{c}\text { EDB } \\
\mathrm{y} \\
\text { EXPAL } \\
\text { Quintanilla }\end{array}$ & $\begin{array}{c}\text { B.O. } \\
\text { BURGOS } \\
\text { 01-06-11 }\end{array}$ & $\begin{array}{c}\text { 01-01-2010 } \\
\text { HASTA } \\
31-12-2012\end{array}$ & 1.704 & +IPC real & & & $\begin{array}{c}\text { Con carácter } \\
\text { trimestral }\end{array}$ \\
\hline $\begin{array}{c}\text { EDSCHA } \\
\text { Burgos }\end{array}$ & $\begin{array}{c}\text { B.O. } \\
\text { BURGOS } \\
22-02-13\end{array}$ & $\begin{array}{c}01-01-2012 \\
\text { HASTA } \\
31-12-2013\end{array}$ & 1.748 & $\begin{array}{c}0 \% \\
\text { Asumiendo } \\
\text { tablas del } \\
\text { sector y } \\
\text { absorción }\end{array}$ & & $\begin{array}{l}\text { Primas de } \\
\text { producción }\end{array}$ & \\
\hline $\begin{array}{c}\text { EDSCHA } \\
\text { Burgos }\end{array}$ & $\begin{array}{c}\text { B.O. } \\
\text { BURGOS } \\
17-06-13\end{array}$ & $\begin{array}{c}01-01-2012 \\
\text { HASTA } \\
31-12-2013\end{array}$ & & $\begin{array}{l}\text { Tablas } 2012 \\
\text { Tablas } 2013\end{array}$ & & & \\
\hline
\end{tabular}




\begin{tabular}{|c|c|c|c|c|c|c|c|}
\hline $\begin{array}{c}\text { EDSCHA } \\
\text { Burgos }\end{array}$ & $\begin{array}{c}\text { B.O. } \\
\text { BURGOS } \\
\text { 21-10-14 }\end{array}$ & $\begin{array}{c}\text { 01-01-2014 } \\
\text { HASTA } \\
31-12-2016\end{array}$ & $\begin{array}{l}2014: 1.748 \\
2015: 1.752 \\
2016: 1.752\end{array}$ & $\begin{array}{c}\text { +IPC real o } \\
0 \% \\
\text { nunca } \\
\text { negativo }\end{array}$ & & \begin{tabular}{|c|}
$120 €$ lineales \\
vinculados a \\
objetivos de \\
accidentalidad \\
y productividad
\end{tabular} & \\
\hline $\begin{array}{l}\text { ESTACION. } \\
\text { Y } \\
\text { SERVICIOS } \\
\text { Burgos }\end{array}$ & $\begin{array}{c}\text { B.O. } \\
\text { BURGOS } \\
\text { 30-07-04 }\end{array}$ & $\begin{array}{c}01-01-2004 \\
\text { HASTA } \\
31-12-2006\end{array}$ & 1.737 & $\begin{array}{c}\text { +IPC real } \\
+1 \%\end{array}$ & $\begin{array}{l}\text { Paga extra } \\
\text { de benef. }\end{array}$ & & Trimestral \\
\hline $\begin{array}{c}\text { ESTACION. } \\
\text { Y } \\
\text { SERVICIOS } \\
\text { Burgos }\end{array}$ & $\begin{array}{c}\text { B.O. } \\
\text { BURGOS } \\
\text { 15-03-06 }\end{array}$ & $\begin{array}{c}\text { 01-01-2006 } \\
\text { HASTA } \\
31-12-2006\end{array}$ & & Tablas 2006 & & & \\
\hline $\begin{array}{c}\text { ESTACION. } \\
\text { Y } \\
\text { SERVICIOS } \\
\text { Burgos }\end{array}$ & $\begin{array}{c}\text { B.O. } \\
\text { BURGOS } \\
29-10-07\end{array}$ & $\begin{array}{c}01-01-2007 \\
\text { HASTA } \\
31-12-2009\end{array}$ & 1.731 & $\begin{array}{c}+ \text { +IPC real } \\
+1 \%\end{array}$ & $\begin{array}{l}\text { Paga extra } \\
\text { de benef. }\end{array}$ & & Trimestral \\
\hline $\begin{array}{c}\text { ESTACION. } \\
\text { Y } \\
\text { SERVICIOS } \\
\text { Burgos }\end{array}$ & $\begin{array}{c}\text { B.O. } \\
\text { BURGOS } \\
\text { 12-02-08 }\end{array}$ & $\begin{array}{c}01-01-2008 \\
\text { HASTA } \\
31-12-2008\end{array}$ & & Tablas 2008 & & & \\
\hline $\begin{array}{c}\text { ESTACION. } \\
\text { Y } \\
\text { SERVICIOS } \\
\text { Burgos }\end{array}$ & $\begin{array}{c}\text { B.O. } \\
\text { BURGOS } \\
\text { 26-02-09 }\end{array}$ & $\begin{array}{c}\text { 01-01-2009 } \\
\text { HASTA } \\
31-12-2009\end{array}$ & & Tablas 2009 & & & \\
\hline
\end{tabular}




\begin{tabular}{|c|c|c|c|c|c|c|}
\hline $\begin{array}{c}\text { ESTACION. } \\
\text { Y } \\
\text { SERVICIOS } \\
\text { Burgos }\end{array}$ & $\begin{array}{c}\text { B.O. } \\
\text { BURGOS } \\
25-10-10\end{array}$ & $\begin{array}{c}01-01-2010 \\
\text { HASTA } \\
31-12-2011\end{array}$ & 1.731 & $\begin{array}{c}\text { +IPC real } \\
+0,25 \%\end{array}$ & $\begin{array}{l}\text { Paga extra } \\
\text { de benef. }\end{array}$ & Trimestral \\
\hline $\begin{array}{l}\text { ESTACION. } \\
\text { Y } \\
\text { SERVICIOS } \\
\text { Miranda }\end{array}$ & $\begin{array}{c}\text { B.O. } \\
\text { BURGOS } \\
01-02-11\end{array}$ & $\begin{array}{c}01-01-2010 \\
\text { HASTA } \\
31-12-2011\end{array}$ & 1.731 & +IPC real & $\begin{array}{l}\text { Paga extra } \\
\text { de benef. }\end{array}$ & Trimestral \\
\hline $\begin{array}{l}\text { ESTACION. } \\
\text { Y } \\
\text { SERVICIOS } \\
\text { Burgos }\end{array}$ & $\begin{array}{c}\text { B.O. } \\
\text { BURGOS } \\
07-03-11\end{array}$ & $\begin{array}{c}01-01-2011 \\
\text { HASTA } \\
31-12-2011\end{array}$ & & Tablas 2010 & . & \\
\hline $\begin{array}{l}\text { ESTACION. } \\
\text { Y } \\
\text { SERVICIOS } \\
\text { Miranda }\end{array}$ & $\begin{array}{c}\text { B.O. } \\
\text { BURGOS } \\
14-03-11\end{array}$ & $\begin{array}{c}01-01-2011 \\
\text { HASTA } \\
31-12-2011\end{array}$ & & Tablas 2010 & . & \\
\hline $\begin{array}{c}\text { ESTACION. } \\
\text { Y } \\
\text { SERVICIOS } \\
\text { Aranda }\end{array}$ & $\begin{array}{c}\text { B.O. } \\
\text { BURGOS } \\
06-05-11\end{array}$ & $\begin{array}{c}01-01-2011 \\
\text { HASTA } \\
31-12-2011\end{array}$ & 1.731 & +IPC real & . & Trimestral \\
\hline $\begin{array}{c}\text { ESTACION. } \\
\text { Y } \\
\text { SERVICIOS } \\
\text { Burgos }\end{array}$ & $\begin{array}{c}\text { B.O. } \\
\text { BURGOS } \\
16-02-12\end{array}$ & $\begin{array}{c}01-01-2011 \\
\text { HASTA } \\
31-12-2011\end{array}$ & & Tablas 2011 & . & \\
\hline
\end{tabular}




\begin{tabular}{|c|c|c|c|c|c|c|c|}
\hline $\begin{array}{l}\text { ESTACION. } \\
\text { Y } \\
\text { SERVICIOS } \\
\text { Aranda }\end{array}$ & $\begin{array}{c}\text { B.O. } \\
\text { BURGOS } \\
\text { 16-02-12 }\end{array}$ & $\begin{array}{c}01-01-2011 \\
\text { HASTA } \\
31-12-2011\end{array}$ & & Tablas 2011 & & & \\
\hline $\begin{array}{c}\text { ESTACION. } \\
\text { Y } \\
\text { SERVICIOS } \\
\text { Burgos }\end{array}$ & $\begin{array}{c}\text { B.O. } \\
\text { BURGOS } \\
\text { 05-09-12 }\end{array}$ & $\begin{array}{c}01-01-2012 \\
\text { HASTA } \\
31-12-2013\end{array}$ & 1.731 & $\begin{array}{l}2012:+0,50 \% \\
2013:+0,60 \%\end{array}$ & & $\begin{array}{l}\text { Paga extra } \\
\text { de benef. }\end{array}$ & Trimestral \\
\hline $\begin{array}{l}\text { ESTACION. } \\
\text { Y } \\
\text { SERVICIOS } \\
\text { Aranda }\end{array}$ & $\begin{array}{c}\text { B.O. } \\
\text { BURGOS } \\
26-12-12\end{array}$ & $\begin{array}{c}\text { 01-01-2012 } \\
\text { HASTA } \\
31-12-2013\end{array}$ & 1.731 & $\begin{array}{l}2012:+0,50 \% \\
2013:+0,60 \%\end{array}$ & & & Trimestral \\
\hline $\begin{array}{c}\text { ESTACION. } \\
\text { Y } \\
\text { SERVICIOS } \\
\text { Miranda }\end{array}$ & $\begin{array}{c}\text { B.O. } \\
\text { BURGOS } \\
26-12-12\end{array}$ & $\begin{array}{c}01-01-2012 \\
\text { HASTA } \\
31-12-2013\end{array}$ & 1.731 & $\begin{array}{l}\text { 2012: }+0,50 \% \\
\text { 2013: }+0,60 \%\end{array}$ & & $\begin{array}{c}\text { Paga extra } \\
\text { de benef. }\end{array}$ & Trimestral \\
\hline $\begin{array}{c}\text { EXPAL } \\
\text { Quintanilla }\end{array}$ & $\begin{array}{c}\text { B.O. } \\
\text { BURGOS } \\
\text { 09-06-14 }\end{array}$ & $\begin{array}{c}\text { 01-01-2013 } \\
\text { HASTA } \\
31-12-2015\end{array}$ & 1.696 & $\begin{array}{l}\text { 2013: }+120 € \\
2014:+0,5 \% \\
2014:+0,5 \%\end{array}$ & & & $\begin{array}{c}\text { Con carácter } \\
\text { trimestral }\end{array}$ \\
\hline $\begin{array}{c}\text { EXPLOSIVOS } \\
\text { COMPAÑÍA } \\
\text { INDUSTRIA } \\
\text { ALAVESA } \\
\text { ECIA } \\
\text { Quintanilla }\end{array}$ & $\begin{array}{c}\text { B.O. } \\
\text { BURGOS } \\
22-11-05\end{array}$ & $\begin{array}{c}\text { 01-01-2005 } \\
\text { HASTA } \\
31-12-2006\end{array}$ & 1.720 & +IPC real & $\begin{array}{l}\text { Hasta el 2\% } \\
\text { adicional } \\
\text { vinculado a } \\
\text { facturación }\end{array}$ & & $\begin{array}{l}\text { Con carácter } \\
\text { trimestral }\end{array}$ \\
\hline
\end{tabular}




\begin{tabular}{|c|c|c|c|c|c|c|c|}
\hline $\begin{array}{l}\text { FABISA } \\
\text { Burgos }\end{array}$ & $\begin{array}{c}\text { B.O. } \\
\text { BURGOS } \\
\text { 13-01-05 }\end{array}$ & $\begin{array}{c}\text { 01-01-2004 } \\
\text { HASTA } \\
31-12-2007\end{array}$ & $\begin{array}{l}2004: 1.756 \\
2005: 1.756 \\
2006: 1.756 \\
2007: 1.748\end{array}$ & + IPC real & $\begin{array}{c}\text { Reparto lineal } \\
\text { del } 7 \% \text { de } \\
\text { beneficios } \\
\text { auditados }\end{array}$ & & $\begin{array}{c}\text { Prima por rdtos } \\
\text { tiempos }\end{array}$ \\
\hline $\begin{array}{l}\text { FABISA } \\
\text { Burgos }\end{array}$ & $\begin{array}{c}\text { B.O. } \\
\text { BURGOS } \\
\text { 21-11-08 }\end{array}$ & $\begin{array}{c}\text { 01-01-2008 } \\
\text { HASTA } \\
31-12-2011\end{array}$ & 1.748 & 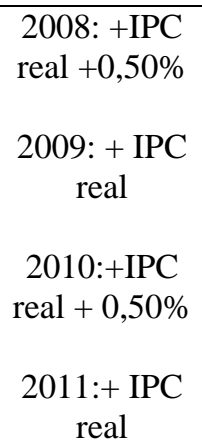 & $\begin{array}{c}\text { Sustituida por } \\
100 € \text { por } \\
\text { quinquenio }\end{array}$ & & \\
\hline $\begin{array}{c}\text { GALLETAS } \\
\text { CORAL } \\
\text { Miranda }\end{array}$ & $\begin{array}{c}\text { B.O. } \\
\text { BURGOS } \\
\text { 12-06-07 }\end{array}$ & $\begin{array}{c}\text { 01-01-2007 } \\
\text { HASTA } \\
31-12-2009\end{array}$ & 1.784 & $\begin{array}{c}+3 \% \\
\text { Revisión + si } \\
\text { IPC real } \\
\text { mayor al 3\% }\end{array}$ & & $\begin{array}{c}\text { Paga extra } \\
\text { de } \\
\text { beneficios }\end{array}$ & \\
\hline $\begin{array}{l}\text { GALLETAS } \\
\text { CORAL } \\
\text { Miranda }\end{array}$ & $\begin{array}{c}\text { B.O. } \\
\text { BURGOS } \\
10-08-10\end{array}$ & $\begin{array}{c}\text { 01-01-2010 } \\
\text { HASTA } \\
31-12-2010\end{array}$ & 1.784 & $+1 \%$ & & $\begin{array}{c}\text { Paga extra } \\
\text { de } \\
\text { beneficios }\end{array}$ & \\
\hline $\begin{array}{c}\text { GALLETAS } \\
\text { CORAL } \\
\text { Miranda }\end{array}$ & $\begin{array}{c}\text { B.O. } \\
\text { BURGOS } \\
11-01-12\end{array}$ & $\begin{array}{c}01-01-2011 \\
\text { HASTA } \\
31-12-2013\end{array}$ & 1.784 & $+1,50 \%$ & & $\begin{array}{c}\text { Paga extra } \\
\text { de } \\
\text { beneficios }\end{array}$ & \\
\hline
\end{tabular}




\begin{tabular}{|c|c|c|c|c|c|c|}
\hline $\begin{array}{l}\text { GALLETAS } \\
\text { CORAL } \\
\text { Miranda }\end{array}$ & $\begin{array}{c}\text { B.O. } \\
\text { BURGOS } \\
06-11-14\end{array}$ & $\begin{array}{c}\text { 01-01-2014 } \\
\text { HASTA } \\
31-12-2016\end{array}$ & 1.788 & $\begin{array}{c}+1,50 \% \\
\text { Revisión + si } \\
\text { IPC real } \\
\text { mayor a } \\
1,50 \%\end{array}$ & $\begin{array}{c}\text { Paga extra } \\
\text { de } \\
\text { beneficios }\end{array}$ & \\
\hline $\begin{array}{l}\text { GALLETAS } \\
\text { JESUS } \\
\text { ANGULO } \\
\text { ORTEGA } \\
\text { Lerma }\end{array}$ & $\begin{array}{c}\text { B.O. } \\
\text { BURGOS } \\
\text { 27-05-11 }\end{array}$ & $\begin{array}{c}01-01-2011 \\
\text { HASTA } \\
31-12-2014\end{array}$ & $\begin{array}{c}40 \text { horas } \\
\text { semanales }\end{array}$ & $\begin{array}{l}\text { 2011: tablas } \\
\text { Resto: +IPC } \\
\text { real }+0,20 \%\end{array}$ & $\begin{array}{c}\text { Paga extra } \\
\text { de } \\
\text { beneficios }\end{array}$ & \\
\hline $\begin{array}{c}\text { GALLETAS } \\
\text { JESUS } \\
\text { ANGULO } \\
\text { ORTEGA } \\
\text { Lerma }\end{array}$ & $\begin{array}{c}\text { B.O. } \\
\text { BURGOS } \\
\text { 23-02-12 }\end{array}$ & $\begin{array}{c}01-01-2012 \\
\text { HASTA } \\
31-12-2012\end{array}$ & & Tablas 2012 & & \\
\hline $\begin{array}{c}\text { GALLETAS } \\
\text { JESUS } \\
\text { ANGULO } \\
\text { ORTEGA } \\
\text { Lerma }\end{array}$ & $\begin{array}{c}\text { B.O. } \\
\text { BURGOS } \\
21-02-13\end{array}$ & $\begin{array}{c}\text { 01-01-2013 } \\
\text { HASTA } \\
31-12-2013\end{array}$ & & Tablas 2013 & & \\
\hline $\begin{array}{c}\text { GALLETAS } \\
\text { JESUS } \\
\text { ANGULO } \\
\text { ORTEGA } \\
\text { Lerma }\end{array}$ & $\begin{array}{c}\text { B.O. } \\
\text { BURGOS } \\
28-02-14\end{array}$ & $\begin{array}{c}\text { 01-01-2014 } \\
\text { HASTA } \\
31-12-2014\end{array}$ & & Tablas 2014 & & \\
\hline $\begin{array}{l}\text { GONVARRI } \\
\text { INDUSTRIAL } \\
\text { Burgos }\end{array}$ & $\begin{array}{c}\text { B.O. } \\
\text { BURGOS } \\
\text { 26-08-02 }\end{array}$ & $\begin{array}{c}\text { 01-01-2002 } \\
\text { HASTA } \\
31-12-2004\end{array}$ & $\begin{array}{l}2002: 1.744 \\
2003: 1.736 \\
2004: 1.728\end{array}$ & $\begin{array}{c}+3 \% \\
\text { Revisión + si } \\
\text { IPC real } \\
\text { mayor al 3\% }\end{array}$ & $\begin{array}{l}2 \text { Pagas } \\
\text { extras por } \\
\text { rdto }\end{array}$ & $\begin{array}{c}\text { Prima de } \\
\text { producción }\end{array}$ \\
\hline
\end{tabular}




\begin{tabular}{|c|c|c|c|c|c|c|}
\hline $\begin{array}{l}\text { GONVARRI } \\
\text { INDUSTRIAL } \\
\text { Burgos }\end{array}$ & $\begin{array}{c}\text { B.O. } \\
\text { BURGOS } \\
10-08-05\end{array}$ & $\begin{array}{c}01-01-2005 \\
\text { HASTA } \\
31-12-2007\end{array}$ & $\begin{array}{l}2002: 1.720 \\
2003: 1.712 \\
2004: 1.704\end{array}$ & $\begin{array}{c}\text { 2005:+ IPC } \\
\text { previsto } \\
\text { 2006:+IPC } \\
\text { previsto } \\
\text { 2007: +IPC } \\
\text { previsto } \\
\text { +0,75\% } \\
\text { Revisión + si } \\
\text { IPCr mayor } \\
\text { que IPCp }\end{array}$ & $\begin{array}{l}2 \text { Pagas } \\
\text { extras por } \\
\text { rdto }\end{array}$ & $\begin{array}{c}\text { Prima de } \\
\text { producción }\end{array}$ \\
\hline $\begin{array}{l}\text { GONVARRI } \\
\text { INDUSTRIAL } \\
\text { Burgos }\end{array}$ & $\begin{array}{c}\text { B.O. } \\
\text { BURGOS } \\
10-09-08\end{array}$ & $\begin{array}{c}01-01-2008 \\
\text { HASTA } \\
31-12-2010\end{array}$ & $\begin{array}{l}2008: 1.704 \\
2009: 1.696 \\
2010: 1.696\end{array}$ & $\begin{array}{l}\text { +IPCprevisto } \\
\quad+1,15 \% \\
\text { Revisión + si } \\
\text { IPCr mayor } \\
\text { que IPCp }\end{array}$ & $\begin{array}{l}2 \text { Pagas } \\
\text { extras por } \\
\text { rdto }\end{array}$ & $\begin{array}{c}\text { Prima de } \\
\text { producción }\end{array}$ \\
\hline $\begin{array}{c}\text { GONVARRI } \\
\text { INDUSTRIAL } \\
\text { Burgos }\end{array}$ & $\begin{array}{c}\text { B.O. } \\
\text { BURGOS } \\
13-08-10\end{array}$ & $\begin{array}{c}01-01-2011 \\
\text { HASTA } \\
31-12-2011\end{array}$ & $\begin{array}{l}\text { Prórroga } \\
2011\end{array}$ & & & \\
\hline $\begin{array}{l}\text { GONVARRI } \\
\text { INDUSTRIAL } \\
\text { Burgos }\end{array}$ & $\begin{array}{c}\text { B.O. } \\
\text { BURGOS } \\
18-02-13\end{array}$ & $\begin{array}{c}01-01-2012 \\
\text { HASTA } \\
31-12-2013\end{array}$ & $\begin{array}{l}\text { 2012:1.704 } \\
\text { 2013:1.712 }\end{array}$ & $0 \%$ & $\begin{array}{l}2 \text { Pagas } \\
\text { extras por } \\
\text { rdto }\end{array}$ & $\begin{array}{c}\text { Prima de } \\
\text { producción }\end{array}$ \\
\hline
\end{tabular}




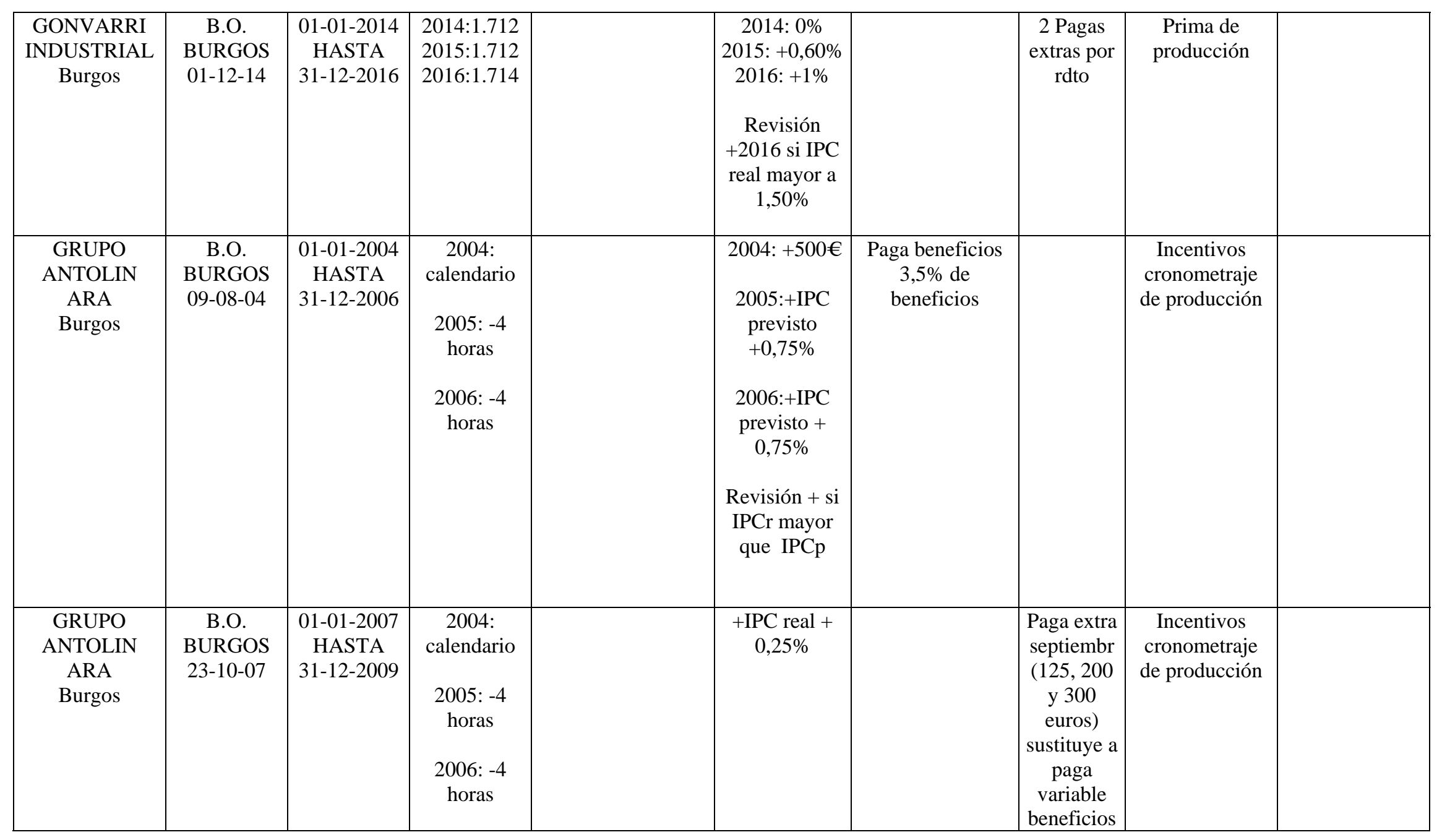




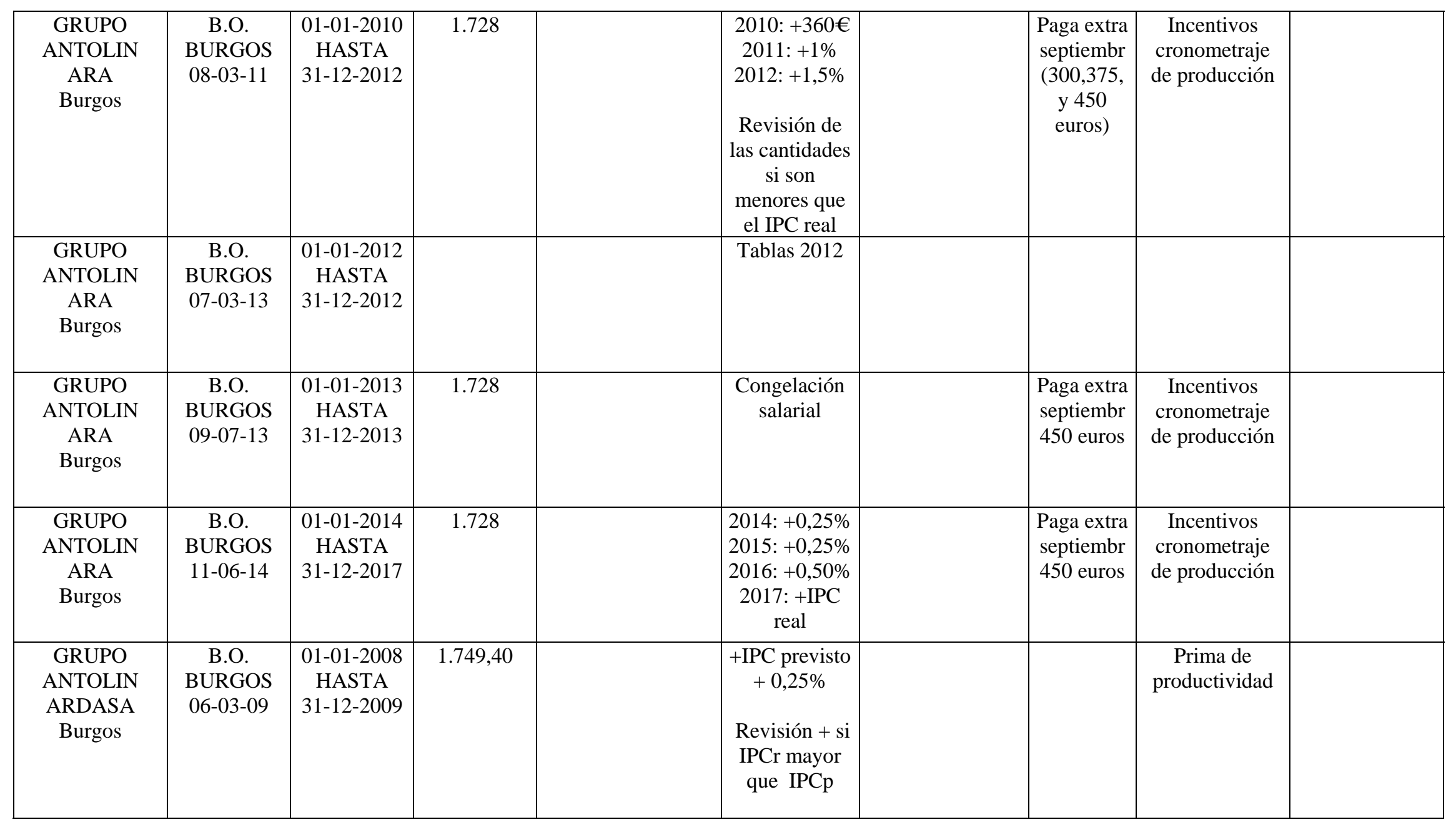




\begin{tabular}{|c|c|c|c|c|c|}
\hline $\begin{array}{c}\text { GRUPO } \\
\text { ANTOLIN } \\
\text { ARDASA } \\
\text { Burgos }\end{array}$ & $\begin{array}{c}\text { B.O. } \\
\text { BURGOS } \\
11-03-11\end{array}$ & $\begin{array}{c}\text { 01-01-2010 } \\
\text { HASTA } \\
31-12-2012\end{array}$ & $1.749,40$ & $\begin{array}{c}\text { 2010:+0,50\% } \\
\text { 2011: }+1 \% \\
\text { 2012: }+1,5 \% \\
\\
\text { Revisión + de } \\
\text { las cantidades } \\
\text { si son } \\
\text { menores que } \\
\text { el IPC real } \\
\end{array}$ & $\begin{array}{c}\text { Prima de } \\
\text { productividad }\end{array}$ \\
\hline $\begin{array}{l}\text { GRUPO } \\
\text { ANTOLIN } \\
\text { DAPSA } \\
\text { Burgos }\end{array}$ & $\begin{array}{c}\text { B.O. } \\
\text { BURGOS } \\
\text { 14-09-04 }\end{array}$ & $\begin{array}{c}\text { 01-01-2004 } \\
\text { HASTA } \\
31-12-2006\end{array}$ & $\begin{array}{l}\text { 2004: } 1.736 \\
\text { 2005: } 1.728 \\
\text { 2006: } 1.728\end{array}$ & $\begin{array}{c}\text { 2004: +IPC } \\
\text { real } \\
\text { 2005:+IPC } \\
\text { real +050\% } \\
\text { 2006:+IPC } \\
\text { real + 0,50\% }\end{array}$ & $\begin{array}{l}\text { Primas a la } \\
\text { producción }\end{array}$ \\
\hline $\begin{array}{l}\text { GRUPO } \\
\text { ANTOLIN } \\
\text { DAPSA } \\
\text { Burgos }\end{array}$ & $\begin{array}{c}\text { B.O. } \\
\text { BURGOS } \\
04-01-08\end{array}$ & $\begin{array}{c}\text { 01-01-2007 } \\
\text { HASTA } \\
31-12-2009\end{array}$ & 1.728 & +IPC real & $\begin{array}{l}\text { Primas a la } \\
\text { producción }\end{array}$ \\
\hline $\begin{array}{c}\text { GRUPO } \\
\text { ANTOLIN } \\
\text { DAPSA } \\
\text { Burgos }\end{array}$ & $\begin{array}{c}\text { B.O. } \\
\text { BURGOS } \\
09-05-11\end{array}$ & $\begin{array}{c}01-01-2010 \\
\text { HASTA } \\
31-12-2012\end{array}$ & 1.728 & $\begin{array}{c}\text { 2010: +1,5\% } \\
\text { 2011:+ 1\% } \\
\text { 2012: +1,5\% } \\
\text { Revisión + en } \\
\text { lo que el IPCr } \\
\text { exceda \% } \\
\end{array}$ & $\begin{array}{l}\text { Primas a la } \\
\text { producción }\end{array}$ \\
\hline
\end{tabular}




\begin{tabular}{|c|c|c|c|c|c|c|}
\hline $\begin{array}{l}\text { GRUPO } \\
\text { ANTOLIN } \\
\text { DAPSA } \\
\text { Burgos }\end{array}$ & $\begin{array}{c}\text { B.O. } \\
\text { BURGOS } \\
08-04-14\end{array}$ & $\begin{array}{c}01-01-2013 \\
\text { HASTA } \\
31-12-2017\end{array}$ & $\begin{array}{l}2013: 1.728 \\
2014: 1.736 \\
2015: 1.744 \\
2016: 1.744 \\
2017: 1.744\end{array}$ & $\begin{array}{l}\text { Mantenimiento } \\
\text { empleo sino en } \\
\text { 2017: } 0 \% \text { en vez } \\
\text { de }-1 \%\end{array}$ & $\begin{array}{c}\text { 2013:-1,4\% } \\
\text { 2014: } 0 \% \\
\text { 2015: }-1 \% \\
\text { 2016: } 0 \% \\
\text { 2017: }-1 \%\end{array}$ & $\begin{array}{l}\text { Primas a la } \\
\text { producción }\end{array}$ \\
\hline $\begin{array}{c}\text { GRUPO } \\
\text { ANTOLIN } \\
\text { EUROTRIM } \\
\text { Burgos }\end{array}$ & $\begin{array}{c}\text { B.O. } \\
\text { BURGOS } \\
24-09-03\end{array}$ & $\begin{array}{c}01-01-2003 \\
\text { HASTA } \\
31-12-2003\end{array}$ & 1.744 & & $\begin{array}{c}+ \text { IPC } \\
\text { previsto + } \\
0,5 \% \\
\\
\text { Revisión + si } \\
\text { IPC mayor a } \\
2 \%\end{array}$ & \\
\hline $\begin{array}{c}\text { GRUPO } \\
\text { ANTOLIN } \\
\text { EUROTRIM } \\
\text { Burgos }\end{array}$ & $\begin{array}{c}\text { B.O. } \\
\text { BURGOS } \\
08-06-04\end{array}$ & $\begin{array}{c}\text { 01-01-2004 } \\
\text { HASTA } \\
31-12-2005\end{array}$ & Calendario & & $\begin{array}{c}+ \text { IPC } \\
\text { previsto }+ \\
0,25 \% \\
\text { Revisión si } \\
\text { IPC mayor a } \\
\text { 2\% para } \\
\text { garantizar } 2 \%\end{array}$ & \\
\hline $\begin{array}{c}\text { GRUPO } \\
\text { ANTOLIN } \\
\text { EUROTRIM } \\
\text { Burgos }\end{array}$ & $\begin{array}{c}\text { B.O. } \\
\text { BURGOS } \\
\text { 23-08-06 }\end{array}$ & $\begin{array}{c}\text { 01-01-2006 } \\
\text { HASTA } \\
31-12-2008\end{array}$ & 1.736 & & $\begin{array}{l}\text { +IPCprevisto } \\
\text { Revisión + si } \\
\text { IPCr mayor } \\
\text { que IPCp }\end{array}$ & \\
\hline $\begin{array}{c}\text { GRUPO } \\
\text { ANTOLIN } \\
\text { EUROTRIM } \\
\text { Burgos }\end{array}$ & $\begin{array}{c}\text { B.O. } \\
\text { BURGOS } \\
\text { 13-11-09 }\end{array}$ & $\begin{array}{c}01-01-2009 \\
\text { HASTA } \\
31-12-2010\end{array}$ & 1.736 & & $\begin{array}{c}+1,5 \% \\
\text { Revisión + si } \\
\text { IPC real } \\
\text { supera el } \\
1,5 \%\end{array}$ & \\
\hline
\end{tabular}




\begin{tabular}{|c|c|c|c|c|c|c|}
\hline $\begin{array}{c}\text { GRUPO } \\
\text { ANTOLIN } \\
\text { EUROTRIM } \\
\text { Burgos }\end{array}$ & $\begin{array}{c}\text { B.O. } \\
\text { BURGOS } \\
\text { 16-05-11 }\end{array}$ & $\begin{array}{c}\text { 01-01-2011 } \\
\text { HASTA } \\
31-12-2013\end{array}$ & $\begin{array}{l}2011: 1.752 \\
2012: 1.752 \\
2013: 1.744\end{array}$ & +IPC real & & \\
\hline $\begin{array}{c}\text { GRUPO } \\
\text { ANTOLIN } \\
\text { EUROTRIM } \\
\text { Burgos }\end{array}$ & $\begin{array}{c}\text { B.O. } \\
\text { BURGOS } \\
\text { 15-03-13 }\end{array}$ & $\begin{array}{c}\text { 01-01-2013 } \\
\text { HASTA } \\
31-12-2013\end{array}$ & & $\begin{array}{c}\text { 2013: } 6 \text { días } \\
\text { vacaciones } \\
\text { por no } \\
\text { consolidar } \\
\text { IPC } 2012\end{array}$ & & \\
\hline $\begin{array}{c}\text { GRUPO } \\
\text { ANTOLIN } \\
\text { EUROTRIM } \\
\text { Burgos }\end{array}$ & $\begin{array}{c}\text { B.O. } \\
\text { BURGOS } \\
26-12-14\end{array}$ & $\begin{array}{c}\text { 01-01-2014 } \\
\text { HASTA } \\
31-12-2017\end{array}$ & $\begin{array}{l}2014: 1,752 \\
2015: 1.752 \\
2016: 1.752 \\
2017: 1.736\end{array}$ & $\begin{array}{c}2014: 0 \% \\
2015:+0,25 \% \\
2016:+0,50 \% \\
2017+0,75 \% \\
\\
\text { Revisión + en } \\
\text { lo que el IPCr } \\
\text { exceda del } \\
1 \% 2016 \text { y } \\
1,5 \% 2017 \\
\end{array}$ & & \\
\hline $\begin{array}{c}\text { GRUPO } \\
\text { GARCIA } \\
\text { CAMARERO }\end{array}$ & $\begin{array}{c}\text { B.O. } \\
\text { BURGOS } \\
\text { 15-04-03 }\end{array}$ & $\begin{array}{c}\text { 01-01-2003 } \\
\text { HASTA } \\
31-12-2003\end{array}$ & 1.775 & $\begin{array}{c}+3 \% \\
\text { Revisión + si } \\
\text { IPCr superior } \\
\text { a 3\% }\end{array}$ & $\begin{array}{c}\text { Paga extra } \\
\text { de benef }\end{array}$ & Trimestral \\
\hline $\begin{array}{c}\text { GRUPO } \\
\text { GARCIA } \\
\text { CAMARERO }\end{array}$ & $\begin{array}{c}\text { B.O. } \\
\text { BURGOS } \\
01-04-04\end{array}$ & $\begin{array}{c}\text { 01-01-2004 } \\
\text { HASTA } \\
31-12-2004\end{array}$ & 1.775 & $\begin{array}{c}+3,5 \% \\
\text { Revisión + si } \\
\text { IPCr superior } \\
\text { a 3,5\% }\end{array}$ & $\begin{array}{c}\text { Paga extra } \\
\text { de benef }\end{array}$ & Trimestral \\
\hline
\end{tabular}




\begin{tabular}{|c|c|c|c|c|c|c|}
\hline $\begin{array}{c}\text { GRUPO } \\
\text { GARCIA } \\
\text { CAMARERO }\end{array}$ & $\begin{array}{c}\text { B.O. } \\
\text { BURGOS } \\
\text { 19-07-06 }\end{array}$ & $\begin{array}{c}\text { 01-01-2006 } \\
\text { HASTA } \\
31-12-2006\end{array}$ & 1.762 & $\begin{array}{c}+ \text { +IPC real } \\
+0,50 \%\end{array}$ & $\begin{array}{c}\text { Paga extra } \\
\text { de benef }\end{array}$ & Trimestral \\
\hline $\begin{array}{c}\text { GRUPO } \\
\text { GARCIA } \\
\text { CAMARERO }\end{array}$ & $\begin{array}{c}\text { B.O. } \\
\text { BURGOS } \\
31-07-07\end{array}$ & $\begin{array}{c}01-01-2007 \\
\text { HASTA } \\
31-12-2007\end{array}$ & 1.762 & $\begin{array}{c}+3 \% \\
\text { Revisión + si } \\
\text { IPCr superior } \\
\text { a 3\% }\end{array}$ & $\begin{array}{c}\text { Paga extra } \\
\text { de benef }\end{array}$ & Trimestral \\
\hline $\begin{array}{c}\text { GRUPO } \\
\text { GARCIA } \\
\text { CAMARERO }\end{array}$ & $\begin{array}{c}\text { B.O. } \\
\text { BURGOS } \\
14-08-08\end{array}$ & $\begin{array}{c}\text { 01-01-2008 } \\
\text { HASTA } \\
31-12-2008\end{array}$ & 1.761 & $\begin{array}{c}\text { +IPC real } \\
+0,80 \%\end{array}$ & $\begin{array}{c}\text { Paga extra } \\
\text { de benef }\end{array}$ & Trimestral \\
\hline $\begin{array}{c}\text { GRUPO } \\
\text { GARCIA } \\
\text { CAMARERO }\end{array}$ & $\begin{array}{c}\text { B.O. } \\
\text { BURGOS } \\
08-02-10\end{array}$ & $\begin{array}{c}\text { 01-01-2009 } \\
\text { HASTA } \\
31-12-2010\end{array}$ & $\begin{array}{l}\text { 2009:1.760 } \\
\text { 2010: } 1758\end{array}$ & $\begin{array}{l}\text { 2009:+IPC } \\
\quad \text { real } \\
\text { 2010: +IPC } \\
\text { real }+0,70 \%\end{array}$ & $\begin{array}{c}\text { Paga extra } \\
\text { de benef }\end{array}$ & Trimestral \\
\hline $\begin{array}{c}\text { GRUPO } \\
\text { GARCIA } \\
\text { CAMARERO }\end{array}$ & $\begin{array}{c}\text { B.O. } \\
\text { BURGOS } \\
13-11-12\end{array}$ & $\begin{array}{c}\text { 01-01-2011 } \\
\text { HASTA } \\
31-12-2012\end{array}$ & 1.758 & $\begin{array}{c}2011: 0 \% \\
\text { 2012: }-5 \%\end{array}$ & $\begin{array}{c}\text { Paga extra } \\
\text { de benef }\end{array}$ & Trimestral \\
\hline
\end{tabular}




\begin{tabular}{|c|c|c|c|c|c|}
\hline $\begin{array}{c}\text { GRUPO } \\
\text { GERARDO } \\
\text { DE LA CALLE }\end{array}$ & $\begin{array}{c}\text { B.O. } \\
\text { BURGOS } \\
\text { 23-06-04 }\end{array}$ & $\begin{array}{c}01-01-2004 \\
\text { HASTA } \\
31-12-2004\end{array}$ & 1.744 & $\begin{array}{c}\text { +IPC real + } \\
0,50 \%\end{array}$ & $\begin{array}{l}\text { No aplicación } \\
\text { por pérdidas de } \\
\text { explotación } 2 \\
\text { ejercicios que } \\
\text { afecten a la } \\
\text { estabilidad } \\
\text { En ese caso } \\
\text { información } \\
\text { económica y } \\
\text { plan de } \\
\text { viabilidad }\end{array}$ \\
\hline $\begin{array}{c}\text { GRUPO } \\
\text { GERARDO } \\
\text { DE LA CALLE }\end{array}$ & $\begin{array}{c}\text { B.O. } \\
\text { BURGOS } \\
\text { 24-01-05 }\end{array}$ & $\begin{array}{c}01-01-2004 \\
\text { HASTA } \\
31-12-2004\end{array}$ & & Error 2004 & \\
\hline $\begin{array}{c}\text { GRUPO } \\
\text { GERARDO } \\
\text { DE LA CALLE }\end{array}$ & $\begin{array}{c}\text { B.O. } \\
\text { BURGOS } \\
\text { 10-05-05 }\end{array}$ & $\begin{array}{c}\text { 01-01-2005 } \\
\text { HASTA } \\
31-12-2005\end{array}$ & 1.744 & $\begin{array}{c}+ \text { IPC real + } \\
0,50 \%\end{array}$ & $\begin{array}{l}\text { No aplicación } \\
\text { por pérdidas de } \\
\text { explotación } 2 \\
\text { ejercicios que } \\
\text { afecten a la } \\
\text { estabilidad } \\
\text { En ese caso } \\
\text { información } \\
\text { económica y } \\
\text { plan de } \\
\text { viabilidad }\end{array}$ \\
\hline $\begin{array}{c}\text { GRUPO } \\
\text { GERARDO } \\
\text { DE LA CALLE }\end{array}$ & $\begin{array}{c}\text { B.O. } \\
\text { BURGOS } \\
\text { 27-07-05 }\end{array}$ & $\begin{array}{c}\text { 01-01-2005 } \\
\text { HASTA } \\
31-12-2005\end{array}$ & & Tablas 2005 & \\
\hline
\end{tabular}




\begin{tabular}{|c|c|c|c|c|c|}
\hline $\begin{array}{c}\text { GRUPO } \\
\text { GERARDO } \\
\text { DE LA CALLE }\end{array}$ & $\begin{array}{c}\text { B.O. } \\
\text { BURGOS } \\
\text { 13-09-06 }\end{array}$ & $\begin{array}{c}01-01-2006 \\
\text { HASTA } \\
31-12-2006\end{array}$ & 1.740 & $\begin{array}{c}\text { +IPC real + } \\
0,50 \%\end{array}$ & $\begin{array}{c}\text { No aplicación } \\
\text { por pérdidas de } \\
\text { explotación } 2 \\
\text { ejercicios que } \\
\text { afecten a la } \\
\text { estabilidad } \\
\text { En ese caso } \\
\text { información } \\
\text { económica y } \\
\text { plan de } \\
\text { viabilidad }\end{array}$ \\
\hline $\begin{array}{c}\text { GRUPO } \\
\text { GERARDO } \\
\text { DE LA CALLE }\end{array}$ & $\begin{array}{c}\text { B.O. } \\
\text { BURGOS } \\
08-08-07\end{array}$ & $\begin{array}{c}01-01-2007 \\
\text { HASTA } \\
31-12-2007\end{array}$ & 1.740 & $\begin{array}{c}\text { 2007:+IPC } \\
\text { real + 0,50\% } \\
\text { 2008: +IPC } \\
\text { real +1\% }\end{array}$ & $\begin{array}{c}\text { No aplicación } \\
\text { por pérdidas de } \\
\text { explotación } 2 \\
\text { ejercicios que } \\
\text { afecten a la } \\
\text { estabilidad } \\
\text { En ese caso } \\
\text { información } \\
\text { económica y } \\
\text { plan de } \\
\text { viabilidad }\end{array}$ \\
\hline $\begin{array}{c}\text { GRUPO } \\
\text { GERARDO } \\
\text { DE LA CALLE }\end{array}$ & $\begin{array}{c}\text { B.O. } \\
\text { BURGOS } \\
01-10-08\end{array}$ & $\begin{array}{c}01-01-2008 \\
\text { HASTA } \\
31-12-2008\end{array}$ & 1.736 & $\begin{array}{c}+ \text { +IPC real } \\
+1 \%\end{array}$ & $\begin{array}{l}\text { No aplicación } \\
\text { por pérdidas de } \\
\text { explotación } 2 \\
\text { ejercicios que } \\
\text { afecten a la } \\
\text { estabilidad } \\
\text { En ese caso } \\
\text { información } \\
\text { económica y } \\
\text { plan de } \\
\text { viabilidad }\end{array}$ \\
\hline
\end{tabular}




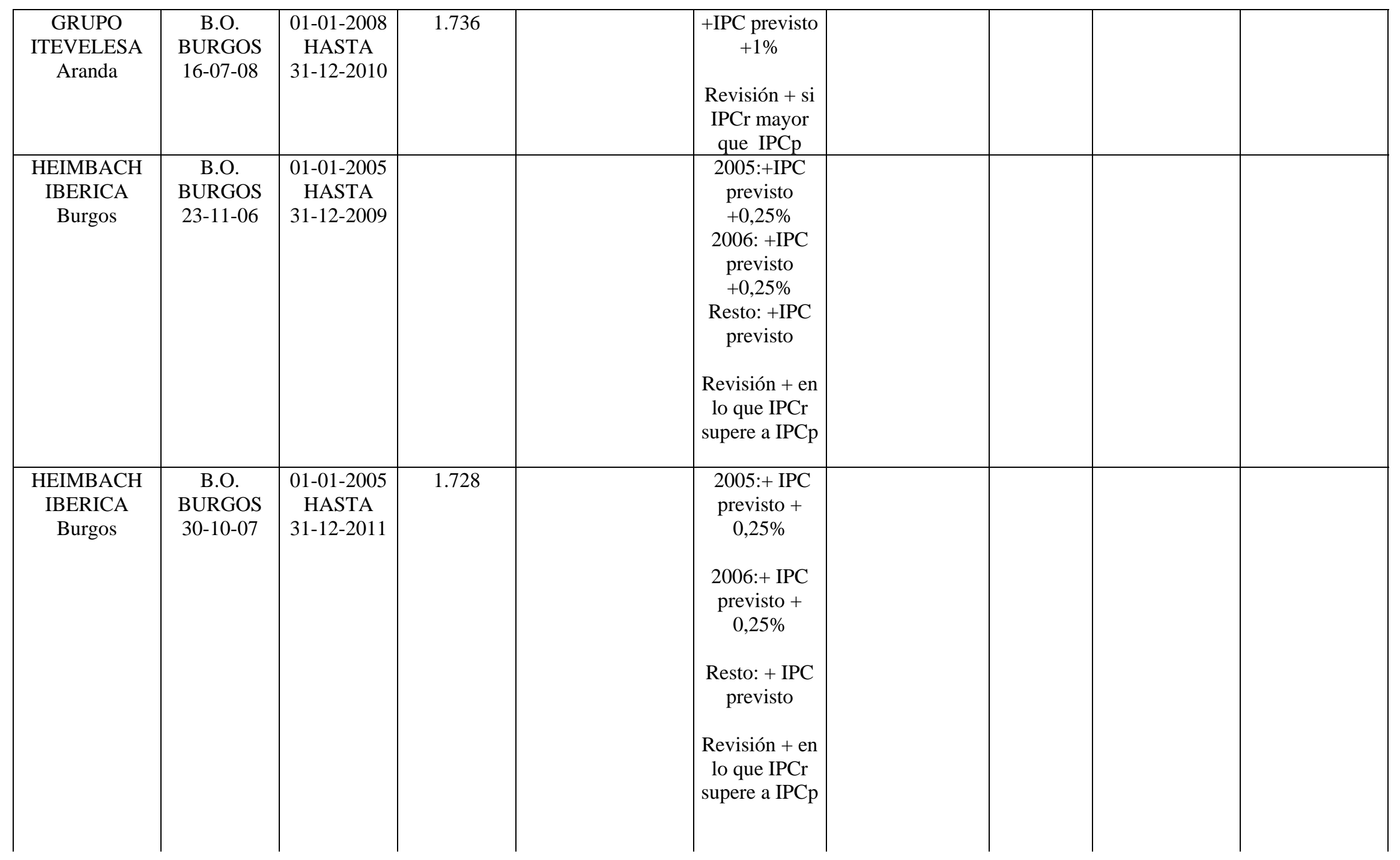




\begin{tabular}{|c|c|c|c|c|c|c|}
\hline $\begin{array}{c}\text { HEIMBACH } \\
\text { IBERICA } \\
\text { Burgos }\end{array}$ & $\begin{array}{c}\text { B.O. } \\
\text { BURGOS } \\
\text { 24-12-09 }\end{array}$ & $\begin{array}{c}\text { 01-01-2005 } \\
\text { HASTA } \\
31-12-2011\end{array}$ & & $\begin{array}{l}\text { 2011: sólo } \\
\text { subida si } \\
\text { hubiera } \\
\text { pérdidas de } \\
\text { poder } \\
\text { adquisitivo } \\
\text { acumulado } \\
\text { 2007-2011 }\end{array}$ & & \\
\hline $\begin{array}{c}\text { HEIMBACH } \\
\text { IBERICA } \\
\text { Burgos }\end{array}$ & $\begin{array}{c}\text { B.O. } \\
\text { BURGOS } \\
02-03-11\end{array}$ & $\begin{array}{c}\text { 01-01-2011 } \\
\text { HASTA } \\
31-12-2011\end{array}$ & Calendario & & & \\
\hline $\begin{array}{c}\text { HEIMBACH } \\
\text { IBERICA } \\
\text { Burgos }\end{array}$ & $\begin{array}{c}\text { B.O. } \\
\text { BURGOS } \\
01-12-11\end{array}$ & $\begin{array}{c}\text { 01-01-2012 } \\
\text { HASTA } \\
31-12-2012\end{array}$ & Calendario & & & \\
\hline $\begin{array}{c}\text { HEIMBACH } \\
\text { IBERICA } \\
\text { Burgos }\end{array}$ & $\begin{array}{c}\text { B.O. } \\
\text { BURGOS } \\
\text { 15-02-12 }\end{array}$ & $\begin{array}{c}\text { 01-01-2012 } \\
\text { HASTA } \\
31-12-2016\end{array}$ & 1.728 & $\begin{array}{c}2012:-7 \% \\
\text { 2013: } 0 \% \\
\text { 2014: }+2 \% \\
\text { 2015: }+4 \% \\
2016:+4 \%\end{array}$ & & $\begin{array}{c}\text { Compromiso } \\
\text { de } \\
\text { capitalización } \\
\text { 2012-2016 }\end{array}$ \\
\hline $\begin{array}{c}\text { HEIMBACH } \\
\text { IBERICA } \\
\text { Burgos }\end{array}$ & $\begin{array}{c}\text { B.O. } \\
\text { BURGOS } \\
28-11-12\end{array}$ & $\begin{array}{c}\text { 01-01-2013 } \\
\text { HASTA } \\
31-12-2013\end{array}$ & Calendario & & & \\
\hline $\begin{array}{c}\text { HEIMBACH } \\
\text { IBERICA } \\
\text { Burgos }\end{array}$ & $\begin{array}{c}\text { B.O. } \\
\text { BURGOS } \\
02-01-14\end{array}$ & $\begin{array}{c}\text { 01-01-2014 } \\
\text { HASTA } \\
31-12-2014\end{array}$ & Calendario & & & \\
\hline $\begin{array}{c}\text { HELADOS } \\
\text { MIKO } \\
\text { Burgos }\end{array}$ & $\begin{array}{c}\text { B.O. } \\
\text { BURGOS } \\
01-04-03\end{array}$ & $\begin{array}{c}\text { 01-01-2003 } \\
\text { HASTA } \\
31-12-2004\end{array}$ & 1.797 & $\begin{array}{l}\text { 2003: Tablas } \\
\text { 2004: +IPC } \\
\text { real + 0,4\% }\end{array}$ & $\begin{array}{c}\text { Comisiones } \\
\text { sobre ventas } \\
\text { netas cobradas }\end{array}$ & \\
\hline
\end{tabular}




\begin{tabular}{|c|c|c|c|c|c|c|}
\hline $\begin{array}{c}\text { HIPERBARIC } \\
\text { Burgos }\end{array}$ & $\begin{array}{c}\text { B.O. } \\
\text { BURGOS } \\
\text { 30-01-14 }\end{array}$ & $\begin{array}{c}01-01-2014 \\
\text { HASTA } \\
31-12-2016\end{array}$ & 1.736 & $\begin{array}{l}\text { 2014: }+3,4 \% \\
\text { Resto: }+0,5 \%\end{array}$ & $\begin{array}{c}\text { Retribución por } \\
\text { beneficios del } \\
1,1 \% \text { de la base } \\
\text { empresa por } \\
\text { contingencias } \\
\text { comunes si el } \\
\text { BAI es positivo }\end{array}$ & \\
\hline $\begin{array}{c}\text { HORMIGON. } \\
\text { Y } \\
\text { EXCAVAC.. } \\
\text { GERARDO } \\
\text { DE LA CALLE }\end{array}$ & $\begin{array}{c}\text { B.O. } \\
\text { BURGOS } \\
\text { 16-06-03 }\end{array}$ & $\begin{array}{c}01-01-2003 \\
\text { HASTA } \\
31-12-2003\end{array}$ & 1.744 & $\begin{array}{c}\text { +IPC real } \\
+0,5 \%\end{array}$ & & $\begin{array}{l}\text { No aplicación } \\
\text { por pérdidas de } \\
\text { explotación } 2 \\
\text { ejercicios que } \\
\text { afecten a la } \\
\text { estabilidad } \\
\text { En ese caso } \\
\text { información } \\
\text { económica y } \\
\text { plan de } \\
\text { viabilidad }\end{array}$ \\
\hline
\end{tabular}




\begin{tabular}{|c|c|c|c|c|c|}
\hline $\begin{array}{c}\text { HORMIGON. } \\
\text { Y } \\
\text { EXCAVAC.. } \\
\text { GERARDO } \\
\text { DE LA CALLE }\end{array}$ & $\begin{array}{c}\text { B.O. } \\
\text { BURGOS } \\
24-06-04\end{array}$ & $\begin{array}{c}\text { 01-01-2004 } \\
\text { HASTA } \\
31-12-2004\end{array}$ & 1.744 & $\begin{array}{c}+ \text { IPC real } \\
+0,5 \%\end{array}$ & $\begin{array}{c}\text { No aplicación } \\
\text { por pérdidas de } \\
\text { explotación } 2 \\
\text { ejercicios que } \\
\text { afecten a la } \\
\text { estabilidad } \\
\text { En ese caso } \\
\text { información } \\
\text { económica y } \\
\text { plan de } \\
\text { viabilidad } \\
\end{array}$ \\
\hline $\begin{array}{c}\text { HORMIGON. } \\
\text { Y } \\
\text { EXCAVAC.. } \\
\text { GERARDO } \\
\text { DE LA CALLE }\end{array}$ & $\begin{array}{c}\text { B.O. } \\
\text { BURGOS } \\
\text { 24-01-05 }\end{array}$ & $\begin{array}{c}\text { 01-01-2004 } \\
\text { HASTA } \\
31-12-2004\end{array}$ & Error 2004 & & \\
\hline $\begin{array}{c}\text { HORMIGON. } \\
\text { Y } \\
\text { EXCAVAC.. } \\
\text { GERARDO } \\
\text { DE LA CALLE }\end{array}$ & $\begin{array}{c}\text { B.O. } \\
\text { BURGOS } \\
09-05-05\end{array}$ & $\begin{array}{c}\text { 01-01-2005 } \\
\text { HASTA } \\
31-12-2005\end{array}$ & 1.744 & $\begin{array}{l}+ \text { +IPC real } \\
+0,5 \%\end{array}$ & $\begin{array}{l}\text { No aplicación } \\
\text { por pérdidas de } \\
\text { explotación } 2 \\
\text { ejercicios que } \\
\text { afecten a la } \\
\text { estabilidad } \\
\text { En ese caso } \\
\text { información } \\
\text { económica y } \\
\text { plan de } \\
\text { viabilidad } \\
\end{array}$ \\
\hline $\begin{array}{c}\text { HORMIGON. } \\
\text { Y } \\
\text { EXCAVAC.. } \\
\text { GERARDO } \\
\text { DE LA CALLE }\end{array}$ & $\begin{array}{c}\text { B.O. } \\
\text { BURGOS } \\
27-07-05\end{array}$ & $\begin{array}{c}\text { 01-01-2005 } \\
\text { HASTA } \\
31-12-2005\end{array}$ & & Tablas 2005 & \\
\hline
\end{tabular}




\begin{tabular}{|c|c|c|c|c|c|}
\hline $\begin{array}{c}\text { HORMIGON. } \\
\text { Y } \\
\text { EXCAVAC.. } \\
\text { GERARDO } \\
\text { DE LA CALLE }\end{array}$ & $\begin{array}{c}\text { B.O. } \\
\text { BURGOS } \\
04-09-06\end{array}$ & $\begin{array}{c}\text { 01-01-2006 } \\
\text { HASTA } \\
31-12-2006\end{array}$ & 1.740 & $\begin{array}{c}\text { +IPC real } \\
+0,5 \%\end{array}$ & $\begin{array}{l}\text { No aplicación } \\
\text { por pérdidas de } \\
\text { explotación } 2 \\
\text { ejercicios que } \\
\text { afecten a la } \\
\text { estabilidad } \\
\text { En ese caso } \\
\text { información } \\
\text { económica y } \\
\text { plan de } \\
\text { viabilidad }\end{array}$ \\
\hline $\begin{array}{c}\text { HORMIGON. } \\
\text { Y } \\
\text { EXCAVAC.. } \\
\text { GERARDO } \\
\text { DE LA CALLE }\end{array}$ & $\begin{array}{c}\text { B.O. } \\
\text { BURGOS } \\
\text { 16-08-07 }\end{array}$ & $\begin{array}{c}01-01-2007 \\
\text { HASTA } \\
31-12-2007\end{array}$ & 1.740 & $\begin{array}{l}\text { 2007: +IPC } \\
\text { real +0,5\% } \\
\text { 2008: +IPC } \\
\text { real +1\% }\end{array}$ & $\begin{array}{l}\text { No aplicación } \\
\text { por pérdidas de } \\
\text { explotación } 2 \\
\text { ejercicios que } \\
\text { afecten a la } \\
\text { estabilidad } \\
\text { En ese caso } \\
\text { información } \\
\text { económica y } \\
\text { plan de } \\
\text { viabilidad } \\
\end{array}$ \\
\hline $\begin{array}{c}\text { HORMIGON. } \\
\text { Y } \\
\text { EXCAVAC.. } \\
\text { GERARDO } \\
\text { DE LA CALLE }\end{array}$ & $\begin{array}{c}\text { B.O. } \\
\text { BURGOS } \\
\text { 13-01-09 }\end{array}$ & $\begin{array}{c}\text { 01-01-2008 } \\
\text { HASTA } \\
31-12-2008\end{array}$ & 1.736 & $\begin{array}{c}\text { 2008: +IPC } \\
\text { real }+1 \%\end{array}$ & $\begin{array}{l}\text { No aplicación } \\
\text { por pérdidas de } \\
\text { explotación } 2 \\
\text { ejercicios que } \\
\text { afecten a la } \\
\text { estabilidad } \\
\text { En ese caso } \\
\text { información } \\
\text { económica y } \\
\text { plan de } \\
\text { viabilidad }\end{array}$ \\
\hline
\end{tabular}




\begin{tabular}{|c|c|c|c|c|c|c|c|}
\hline $\begin{array}{c}\text { HORMIGON. } \\
\text { Y } \\
\text { EXCAVAC.. } \\
\text { GERARDO } \\
\text { DE LA CALLE }\end{array}$ & $\begin{array}{c}\text { B.O. } \\
\text { BURGOS } \\
08-03-10\end{array}$ & $\begin{array}{c}01-01-2009 \\
\text { HASTA } \\
31-12-2009\end{array}$ & 1.736 & $2008:+0,9 \%$ & & & $\begin{array}{l}\text { No aplicación } \\
\text { por pérdidas de } \\
\text { explotación } 2 \\
\text { ejercicios que } \\
\text { afecten a la } \\
\text { estabilidad } \\
\text { En ese caso } \\
\text { información } \\
\text { económica y } \\
\text { plan de } \\
\text { viabilidad }\end{array}$ \\
\hline $\begin{array}{l}\text { HOSTAL } \\
\text { TRES } \\
\text { CONDES } \\
\text { Aranda }\end{array}$ & $\begin{array}{c}\text { B.O. } \\
\text { BURGOS } \\
\text { 17-06-02 }\end{array}$ & $\begin{array}{c}01-01-2002 \\
\text { HASTA } \\
31-12-2004\end{array}$ & 1.826 & $\begin{array}{c}2002:+3,5 \% \\
2003:+2 \% \\
2004:+2 \%\end{array}$ & & & \\
\hline $\begin{array}{l}\text { HOSTAL } \\
\text { TRES } \\
\text { CONDES } \\
\text { Aranda }\end{array}$ & $\begin{array}{c}\text { B.O. } \\
\text { BURGOS } \\
\text { 08-09-05 }\end{array}$ & $\begin{array}{c}01-01-2005 \\
\text { HASTA } \\
31-12-2009\end{array}$ & 1.826 & $\begin{array}{c}2005:+2,5 \% \\
2006:+3 \% \\
2007:+3,5 \% \\
2008:+4 \% \\
2009:+5 \%\end{array}$ & $\begin{array}{c}\text { Media } \\
\text { paga } \\
\text { como de } \\
\text { beneficios }\end{array}$ & & \\
\hline $\begin{array}{c}\text { JOHSON } \\
\text { CONTROL } \\
\text { AUTOBAT. } \\
\text { Burgos }\end{array}$ & $\begin{array}{c}\text { B.O. } \\
\text { BURGOS } \\
27-01-12\end{array}$ & $\begin{array}{c}01-01-2011 \\
\text { HASTA } \\
31-12-2013\end{array}$ & 1.696 & $\begin{array}{l}\text { +IPCprevisto } \\
\text { Revisión + en } \\
\text { lo que IPCr } \\
\text { supere a IPCp }\end{array}$ & & $\begin{array}{c}\text { Hasta }+0,50 \% \\
\text { vinculado a } \\
\text { productividad, } \\
\text { seguridad y } \\
\text { calidad }\end{array}$ & \\
\hline $\begin{array}{c}\text { JOHSON } \\
\text { CONTROL } \\
\text { AUTOBAT. } \\
\text { Burgos }\end{array}$ & $\begin{array}{c}\text { B.O. } \\
\text { BURGOS } \\
\text { 03-07-12 }\end{array}$ & $\begin{array}{c}\text { 01-01-2012 } \\
\text { HASTA } \\
31-12-2012\end{array}$ & & Tablas 2012 & & & \\
\hline
\end{tabular}




\begin{tabular}{|c|c|c|c|c|c|c|}
\hline $\begin{array}{c}\text { JOHSON } \\
\text { CONTROL } \\
\text { AUTOBAT. } \\
\text { Burgos }\end{array}$ & $\begin{array}{c}\text { B.O. } \\
\text { BURGOS } \\
24-05-13\end{array}$ & $\begin{array}{c}01-01-2012 \\
\text { HASTA } \\
31-12-2012\end{array}$ & & $\begin{array}{c}\text { Tablas } \\
\text { revisadas } \\
2012 \text { y } 2013\end{array}$ & & \\
\hline $\begin{array}{c}\text { JOHSON } \\
\text { CONTROL } \\
\text { AUTOBAT } \\
\text { Burgos } \\
.\end{array}$ & $\begin{array}{c}\text { B.O. } \\
\text { BURGOS } \\
28-07-14\end{array}$ & $\begin{array}{c}\text { 01-01-2014 } \\
\text { HASTA } \\
31-12-2017\end{array}$ & 1.696 & $\begin{array}{l}\text { 2014:0\% } \\
\text { 2015: +0,\% } \\
\text { 2016:+0,50\% } \\
\text { 2017: +1\% } \\
\text { Revisión } \\
\text { 2015 2016: } \\
\text { +IPC real /2 } \\
\text { Revisión } \\
\text { 2017: + IPC } \\
\text { real }\end{array}$ & & $\begin{array}{l}\text { Hasta }+0,50 \% \\
\text { vinculado a } \\
\text { productividad, } \\
\text { seguridad y } \\
\text { calidad }\end{array}$ \\
\hline $\begin{array}{l}\text { KRONOSPAN } \\
\text { Salas }\end{array}$ & $\begin{array}{c}\text { B.O. } \\
\text { BURGOS } \\
21-10-14\end{array}$ & $\begin{array}{l}01-01-2014 \\
\text { HASTA } \\
31-12-2014\end{array}$ & 1.752 & $0 \%$ & & \\
\hline $\begin{array}{c}\text { LA FLOR } \\
\text { BURGALESA } \\
\text { Burgos }\end{array}$ & $\begin{array}{c}\text { B.O. } \\
\text { BURGOS } \\
25-01-11\end{array}$ & $\begin{array}{l}01-11-2010 \\
\text { HASTA } \\
31-12-2014\end{array}$ & $\begin{array}{l}2010: 1.792 \\
2011: 1.792 \\
2012: 1.792 \\
2013: 1.784 \\
2014: 1.784\end{array}$ & $\begin{array}{c}\text { 2011: }+1 \% \\
\text { 2012: +1\% } \\
\text { 2013: }+2 \% \\
\text { 2014: }+2 \% \\
\\
\text { Ajuste + para } \\
\text { llegar al IPC } \\
\text { real + 10\% } \\
\text { s/IPC real }\end{array}$ & $\begin{array}{c}\text { Paga extra } \\
\text { de } \\
\text { beneficios }\end{array}$ & \\
\hline
\end{tabular}




\begin{tabular}{|c|c|c|c|c|c|c|}
\hline $\begin{array}{c}\text { LA FLOR } \\
\text { BURGALESA } \\
\text { Burgos }\end{array}$ & $\begin{array}{c}\text { B.O. } \\
\text { BURGOS } \\
04-04-11\end{array}$ & $\begin{array}{l}01-11-2011 \\
\text { HASTA } \\
31-12-2011\end{array}$ & & Tablas 2011 & & \\
\hline $\begin{array}{c}\text { LA FLOR } \\
\text { BURGALESA } \\
\text { Burgos }\end{array}$ & $\begin{array}{c}\text { B.O. } \\
\text { BURGOS } \\
22-02-12\end{array}$ & $\begin{array}{l}\text { 01-01-2011 } \\
\text { HASTA } \\
31-12-2012\end{array}$ & & $\begin{array}{c}\text { Tablas } 2011 \text { y } \\
2012\end{array}$ & & \\
\hline $\begin{array}{c}\text { LA FLOR } \\
\text { BURGALESA } \\
\text { Burgos }\end{array}$ & $\begin{array}{c}\text { B.O. } \\
\text { BURGOS } \\
21-02-13\end{array}$ & $\begin{array}{c}01-11-2012 \\
\text { HASTA } \\
31-12-2013\end{array}$ & & $\begin{array}{c}\text { Tablas } 2012 \\
\text { y } 2013\end{array}$ & & \\
\hline $\begin{array}{c}\text { LA FLOR } \\
\text { BURGALESA } \\
\text { Burgos }\end{array}$ & $\begin{array}{c}\text { B.O. } \\
\text { BURGOS } \\
06-02-14\end{array}$ & $\begin{array}{l}01-11-2013 \\
\text { HASTA } \\
31-12-2014\end{array}$ & & $\begin{array}{c}\text { Tablas } 2013 \mathrm{y} \\
2014\end{array}$ & & \\
\hline $\begin{array}{c}\text { LENNOX } \\
\text { REFAC } \\
\text { Burgos }\end{array}$ & $\begin{array}{c}\text { B.O. } \\
\text { BURGOS } \\
\text { 23-01-04 }\end{array}$ & $\begin{array}{l}01-01-2003 \\
\text { HASTA } \\
31-12-2005\end{array}$ & $\begin{array}{l}2003: 1.736 \\
2004: 1.732 \\
2005: 1.728\end{array}$ & $\begin{array}{c}\text { 2002: +IPC } \\
\text { real } \\
\text { Resto: +IPC } \\
\text { real + 20€ } \\
\text { mes }\end{array}$ & $\begin{array}{c}\text { Bonus vinculado } \\
\text { a EBIT hasta } \\
+2 \%\end{array}$ & $\begin{array}{c}\text { Bimestral } \\
\text { cuenta de } \\
\text { producción. } \\
\text { Anual cuentas } \\
\text { anuales. }\end{array}$ \\
\hline $\begin{array}{c}\text { LENNOX } \\
\text { REFAC } \\
\text { Burgos }\end{array}$ & $\begin{array}{c}\text { B.O. } \\
\text { BURGOS } \\
\text { 23-08-06 }\end{array}$ & $\begin{array}{c}01-01-2006 \\
\text { HASTA } \\
31-12-2008\end{array}$ & $\begin{array}{l}2006: 1.724 \\
2007: 1.720 \\
2008: 1.716\end{array}$ & $\begin{array}{c}\text { 2006: +IPC } \\
\text { real+ 30€mes } \\
\text { 2007: +IPC } \\
\text { real + 32€ } \\
\text { mes } \\
\text { 2008: +IPC } \\
\text { real + 35€ } \\
\text { mes }\end{array}$ & & $\begin{array}{c}\text { Bimestral } \\
\text { cuenta de } \\
\text { producción. } \\
\text { Anual cuentas } \\
\text { anuales. }\end{array}$ \\
\hline
\end{tabular}




\begin{tabular}{|c|c|c|c|c|c|}
\hline $\begin{array}{c}\text { LENNOX } \\
\text { REFAC } \\
\text { Burgos }\end{array}$ & $\begin{array}{c}\text { B.O. } \\
\text { BURGOS } \\
17-06-10\end{array}$ & $\begin{array}{c}\text { 01-01-2009 } \\
\text { HASTA } \\
31-12-2010\end{array}$ & $\begin{array}{l}2009: 1.716 \\
2010: 1.716 \\
2011: 1.712\end{array}$ & $\begin{array}{c}2009:+0,20 \% \\
2010:+25 € \\
\text { mes } \\
2011:+1,14 \% \\
\\
\text { Revisión } \\
+2010 \text { y } 2011 \\
\text { si IPC real } \\
\text { mayor a } 1 \%\end{array}$ & $\begin{array}{c}\text { Bimestral } \\
\text { cuenta de } \\
\text { producción. } \\
\text { Anual cuentas } \\
\text { anuales. }\end{array}$ \\
\hline $\begin{array}{c}\text { LENNOX } \\
\text { REFAC } \\
\text { Burgos }\end{array}$ & $\begin{array}{c}\text { B.O. } \\
\text { BURGOS } \\
\text { 13-07-12 }\end{array}$ & $\begin{array}{c}01-01-2011 \\
\text { HASTA } \\
31-12-2012\end{array}$ & 1.712 & $\begin{array}{c}\text { 2011: }+2 \% \\
\text { 2012: }+1 \% \\
\text { (para 2012 } \\
\text { siempre } \\
\text { mínimo 22€ } \\
\text { mes) }\end{array}$ & $\begin{array}{c}\text { Bimestral } \\
\text { cuenta de } \\
\text { producción. } \\
\text { Anual cuentas } \\
\text { anuales. }\end{array}$ \\
\hline $\begin{array}{c}\text { LENNOX } \\
\text { REFAC } \\
\text { Burgos }\end{array}$ & $\begin{array}{c}\text { B.O. } \\
\text { BURGOS } \\
04-07-13\end{array}$ & $\begin{array}{c}\text { 01-01-2013 } \\
\text { HASTA } \\
31-12-2013\end{array}$ & 1.712 & $+25 €$ mes & $\begin{array}{c}\text { Bimestral } \\
\text { cuenta de } \\
\text { producción. } \\
\text { Anual cuentas } \\
\text { anuales. }\end{array}$ \\
\hline $\begin{array}{c}\text { LENNOX } \\
\text { REFAC } \\
\text { Burgos }\end{array}$ & $\begin{array}{c}\text { B.O. } \\
\text { BURGOS } \\
\text { 12-09-14 }\end{array}$ & $\begin{array}{c}\text { 01-01-2014 } \\
\text { HASTA } \\
31-12-2015\end{array}$ & $\begin{array}{l}2014: 1.720 \\
2015: 1.728\end{array}$ & $+15 €$ mes & $\begin{array}{c}\text { Bimestral } \\
\text { cuenta de } \\
\text { producción. } \\
\text { Anual cuentas } \\
\text { anuales. }\end{array}$ \\
\hline $\begin{array}{c}\text { MANUFACT. } \\
\text { ORIVE } \\
\text { Miranda }\end{array}$ & $\begin{array}{c}\text { B.O. } \\
\text { BURGOS } \\
\text { 06-06-02 }\end{array}$ & $\begin{array}{c}01-01-2002 \\
\text { HASTA } \\
31-12-2002\end{array}$ & Calendario & Tablas 2002 & \\
\hline
\end{tabular}




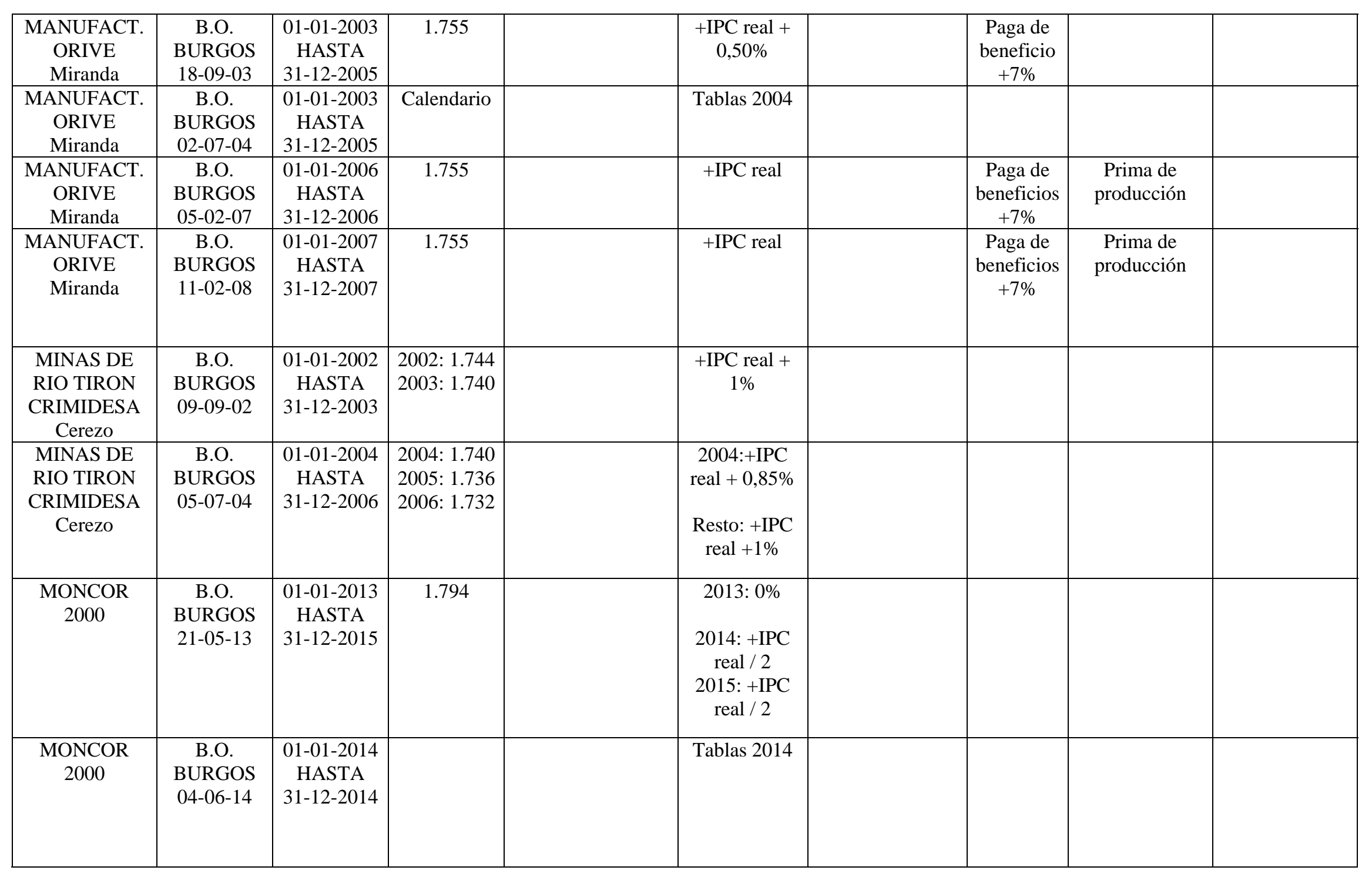




\begin{tabular}{|c|c|c|c|c|c|c|}
\hline $\begin{array}{c}\text { MONCOR } \\
2000\end{array}$ & $\begin{array}{c}\text { B.O. } \\
\text { BURGOS } \\
11-08-14\end{array}$ & $\begin{array}{c}01-01-2014 \\
\text { HASTA } \\
31-12-2014\end{array}$ & & $\begin{array}{l}\text { Ampliación } \\
\text { tablas } 2014\end{array}$ & & \\
\hline $\begin{array}{c}\text { MONTEFIBR } \\
\text { HISPANIA } \\
\text { Miranda }\end{array}$ & $\begin{array}{c}\text { B.O. } \\
\text { BURGOS } \\
\text { 14-08-03 }\end{array}$ & $\begin{array}{c}\text { 13-06-2003 } \\
\text { HASTA } \\
31-12-2006\end{array}$ & 1.598 & $\begin{array}{c}\text { 2004: + IPC } \\
\text { previsto + } \\
0,20 \% \\
\\
\text { 2005: + IPC } \\
\text { previsto + } \\
0,40 \% \\
\\
2006:+ \text { IPC } \\
\text { previsto + } \\
0,60 \% \\
\text { Revisión + en } \\
\text { lo que IPCr } \\
\text { supere a IPCp }\end{array}$ & $\begin{array}{l}\text { Paga extra } \\
\text { beneficios }\end{array}$ & $\begin{array}{c}\text { Prima de } \\
\text { producción } \\
\text { Gratificación } \\
\text { productividad }\end{array}$ \\
\hline $\begin{array}{c}\text { MONTEFIBR } \\
\text { HISPANIA } \\
\text { Miranda }\end{array}$ & $\begin{array}{c}\text { B.O. } \\
\text { BURGOS } \\
\text { 02-02-06 }\end{array}$ & $\begin{array}{c}01-01-2003 \\
\text { HASTA } \\
31-12-2006\end{array}$ & $\begin{array}{l}\text { Modificac. } \\
\text { Grupos } \\
\text { Profesión }\end{array}$ & & & \\
\hline
\end{tabular}




\begin{tabular}{|c|c|c|c|c|c|c|c|}
\hline $\begin{array}{c}\text { MONTEFIBR } \\
\text { HISPANIA } \\
\text { Miranda }\end{array}$ & $\begin{array}{c}\text { B.O. } \\
\text { BURGOS } \\
\text { 25-09-07 }\end{array}$ & $\begin{array}{c}24-05-2007 \\
\text { HASTA } \\
31-12-2010\end{array}$ & 1.598 & $\begin{array}{c}\text { 2007: + IPC } \\
\text { previsto } \\
\text { 2008: +IPC } \\
\text { previsto } \\
\text { 2009: +IPC } \\
\text { previsto } \\
\text { +0,50\% } \\
\text { 2010:+ IPC } \\
\text { previsto + } \\
\text { 0,50\% } \\
\text { Revisión + en } \\
\text { lo que IPCr } \\
\text { supere a IPCp }\end{array}$ & $\begin{array}{l}\text { Paga extra } \\
\text { beneficios }\end{array}$ & $\begin{array}{c}\text { Prima de } \\
\text { producción } \\
\text { Gratificación } \\
\text { productividad }\end{array}$ & \\
\hline $\begin{array}{c}\text { MONTEFIBR } \\
\text { HISPANIA } \\
\text { Miranda }\end{array}$ & $\begin{array}{c}\text { B.O. } \\
\text { BURGOS } \\
27-02-12\end{array}$ & $\begin{array}{c}\text { 01-01-2011 } \\
\text { HASTA } \\
31-12-2014\end{array}$ & 1.598 & $\begin{array}{l}\text { Vinculado a } \\
\text { beneficios } \\
\text { antes de } \\
\text { impuestos } \\
\text { auditados } \\
\text { con una } \\
\text { subida } \\
\text { mínima lineal }\end{array}$ & $\begin{array}{l}\text { Paga extra } \\
\text { beneficios }\end{array}$ & $\begin{array}{c}\text { Prima de } \\
\text { producción } \\
\text { Gratificación } \\
\text { productividad }\end{array}$ & Mensual \\
\hline $\begin{array}{l}\text { MUEBLES } \\
\text { MARIA } \\
\text { LUISA } \\
\text { Villanueva } \\
\end{array}$ & $\begin{array}{c}\text { B.O. } \\
\text { BURGOS } \\
24-11-04\end{array}$ & $\begin{array}{c}\text { 01-01-2004 } \\
\text { HASTA } \\
31-12-2006\end{array}$ & $\begin{array}{l}2004: 1.803 \\
\text { Resto:1.794 }\end{array}$ & + IPC real + 1 & & & \\
\hline $\begin{array}{l}\text { MUEBLES } \\
\text { MARIA } \\
\text { LUISA } \\
\text { Villanueva }\end{array}$ & $\begin{array}{c}\text { B.O. } \\
\text { BURGOS } \\
29-01-07\end{array}$ & $\begin{array}{c}01-01-2007 \\
\text { HASTA } \\
31-12-2009\end{array}$ & $\begin{array}{l}\text { 2007:1.790 } \\
\text { Resto:1.786 }\end{array}$ & +IPC real + 1 & & & \\
\hline $\begin{array}{c}\text { MUEBLES } \\
\text { MARIA } \\
\text { LUISA } \\
\text { Villanueva }\end{array}$ & $\begin{array}{c}\text { B.O. } \\
\text { BURGOS } \\
25-10-10\end{array}$ & $\begin{array}{c}\text { 01-01-2010 } \\
\text { HASTA } \\
31-12-2012\end{array}$ & 1.786 & +IPC real + 1 & & & \\
\hline
\end{tabular}




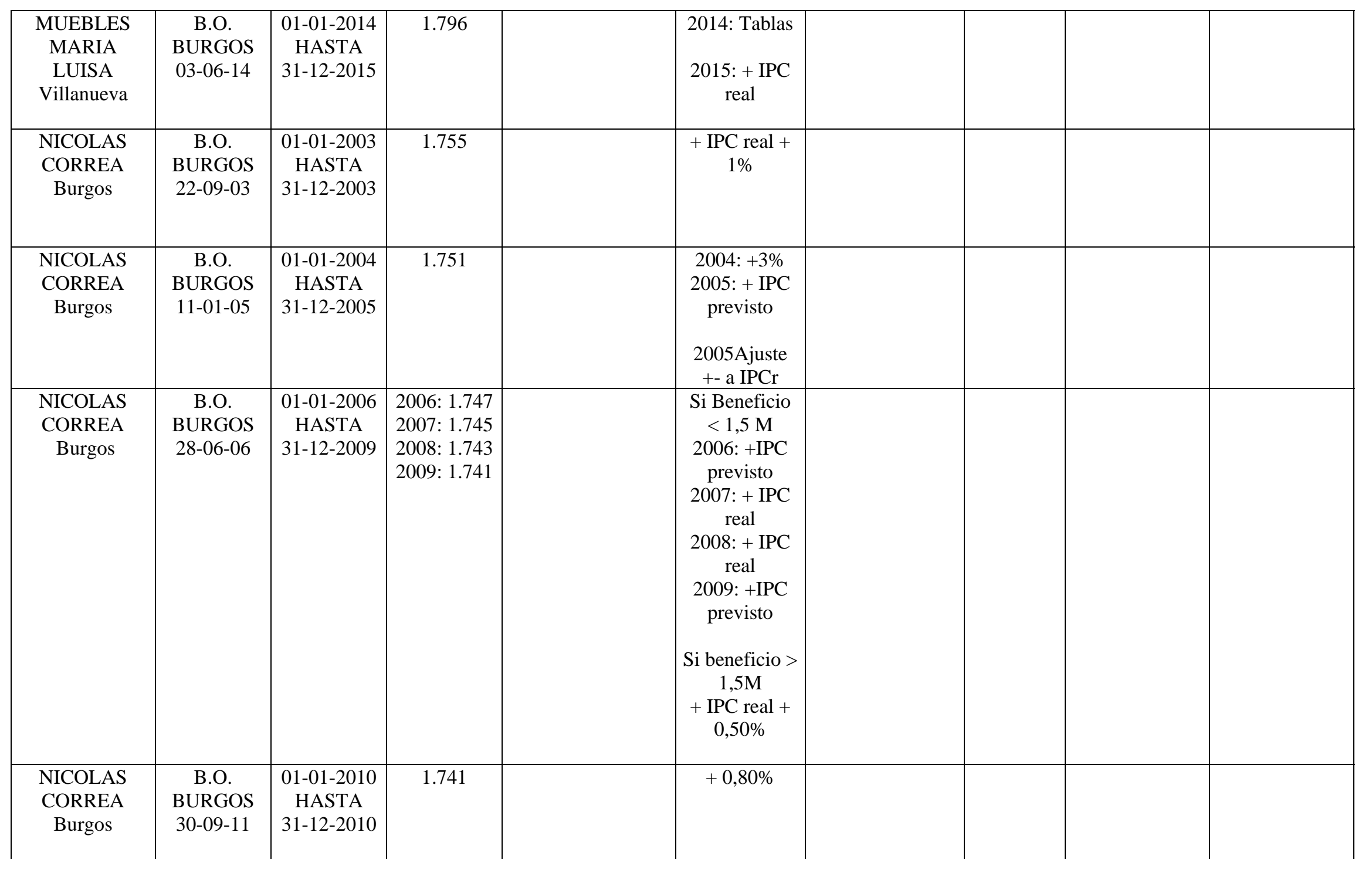




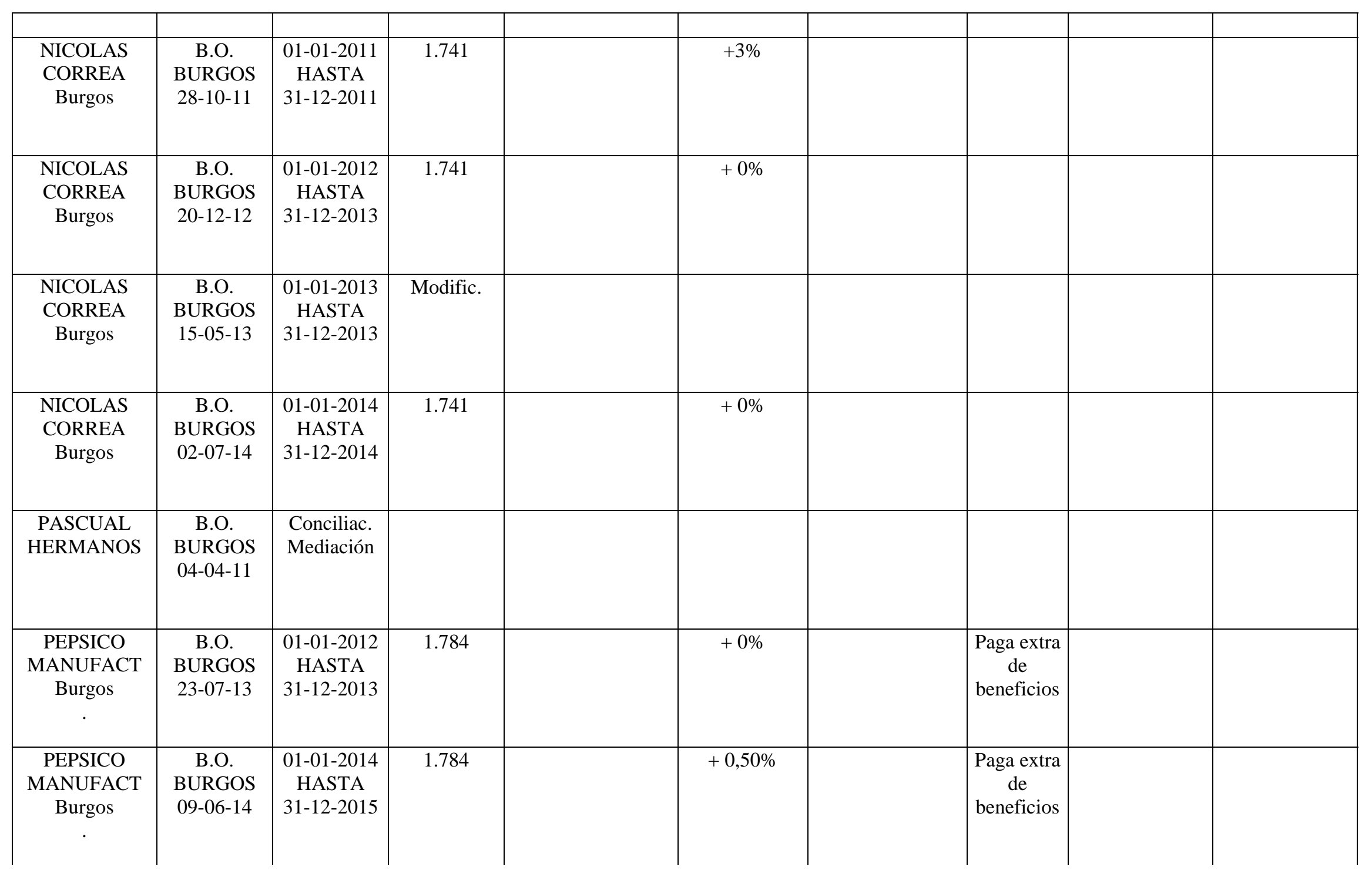




\begin{tabular}{|c|c|c|c|c|c|c|}
\hline $\begin{array}{l}\text { PIERRE } \\
\text { GUERIN } \\
\text { IBERICA } \\
\text { Burgos }\end{array}$ & $\begin{array}{c}\text { B.O. } \\
\text { BURGOS } \\
18-12-03\end{array}$ & $\begin{array}{c}\text { 01-01-2003 } \\
\text { HASTA } \\
31-12-2003\end{array}$ & 1.740 & + IPC real & & $\begin{array}{c}\text { Información } \\
\text { bimensual }\end{array}$ \\
\hline $\begin{array}{l}\text { PIERRE } \\
\text { GUERIN } \\
\text { IBERICA } \\
\text { Burgos }\end{array}$ & $\begin{array}{c}\text { B.O. } \\
\text { BURGOS } \\
23-08-04\end{array}$ & $\begin{array}{c}\text { 01-01-2004 } \\
\text { HASTA } \\
31-12-2006\end{array}$ & $\begin{array}{l}2004: 1.740 \\
2005: 1.736 \\
2006: 1.728\end{array}$ & + IPC real & & $\begin{array}{c}\text { Información } \\
\text { bimensual }\end{array}$ \\
\hline $\begin{array}{c}\text { PIERRE } \\
\text { GUERIN } \\
\text { IBERICA } \\
\text { Burgos }\end{array}$ & $\begin{array}{c}\text { B.O. } \\
\text { BURGOS } \\
28-10-13\end{array}$ & $\begin{array}{c}\text { 01-01-2012 } \\
\text { HASTA } \\
31-12-2014\end{array}$ & 1.728 & $\begin{array}{c}\text { 2012: 0\% } \\
\text { Resto: }+0,5 \%\end{array}$ & & $\begin{array}{c}\text { Información } \\
\text { bimensual }\end{array}$ \\
\hline $\begin{array}{c}\text { PLANIFIC. } \\
\text { Y } \\
\text { CONTROL } \\
\text { LOGISTICO }\end{array}$ & $\begin{array}{c}\text { B.O. } \\
\text { BURGOS } \\
10-08-07\end{array}$ & $\begin{array}{c}\text { 01-01-2007 } \\
\text { HASTA } \\
31-12-2010\end{array}$ & & $\begin{array}{c}\text { IPC } \\
\text { previsto }+1 \%\end{array}$ & & \\
\hline $\begin{array}{c}\text { PLANIFIC. } \\
\text { Y } \\
\text { CONTROL } \\
\text { LOGISTICO }\end{array}$ & $\begin{array}{c}\text { B.O. } \\
\text { BURGOS } \\
08-07-08\end{array}$ & $\begin{array}{c}\text { 01-01-2008 } \\
\text { HASTA } \\
31-12-2010\end{array}$ & 1.826 & Tablas 2008 & & \\
\hline $\begin{array}{l}\text { PROSIDER } \\
\text { IBERICA }\end{array}$ & $\begin{array}{c}\text { B.O. } \\
\text { BURGOS } \\
29-10-03\end{array}$ & $\begin{array}{c}\text { 01-01-2003 } \\
\text { HASTA } \\
31-12-2004\end{array}$ & Calendario & $\begin{array}{c}\text { + IPC } \\
\text { previsto } \\
+0,50 \% \\
\\
\text { Revisión + en } \\
\text { lo que IPCr } \\
\text { supere a IPCp }\end{array}$ & $\begin{array}{l}\text { Paga extra } \\
\text { de } \\
\text { beneficios }\end{array}$ & \\
\hline
\end{tabular}




\begin{tabular}{|c|c|c|c|c|c|c|c|c|}
\hline $\begin{array}{c}\text { PROSIDER } \\
\text { IBERICA }\end{array}$ & $\begin{array}{c}\text { B.O. } \\
\text { BURGOS } \\
12-01-06\end{array}$ & $\begin{array}{c}\text { 01-01-2005 } \\
\text { HASTA } \\
31-12-2007\end{array}$ & Calendario & $\begin{array}{c}\text { + IPC } \\
\text { previsto } \\
+0,50 \% \\
\text { Revisión + en } \\
\text { lo que IPCr } \\
\text { supere a IPCp }\end{array}$ & & $\begin{array}{c}\text { Paga extra } \\
\text { de } \\
\text { beneficios }\end{array}$ & & \\
\hline $\begin{array}{c}\text { ROTTNEROS } \\
\text { MIRANDA } \\
\text { Miranda }\end{array}$ & $\begin{array}{c}\text { B.O. } \\
\text { BURGOS } \\
\text { 15-05-06 }\end{array}$ & $\begin{array}{c}\text { 01-01-2005 } \\
\text { HASTA } \\
31-12-2008\end{array}$ & & $\begin{array}{c}\text { 2005: +IPCr } \\
+0,30 \% \\
\text { 2006: }+ \text { IPCr } \\
\quad+0,40 \% \\
\text { 2007: + IPCr } \\
\quad+0,40 \% \\
\text { 2008: }+ \text { IPCr } \\
+0,50 \%\end{array}$ & & & $\begin{array}{c}\text { Prima de } \\
\text { producción }\end{array}$ & Trimestral \\
\hline $\begin{array}{c}\text { SAINT } \\
\text { GOBAIN } \\
\text { VICASA } \\
\text { Burgos }\end{array}$ & $\begin{array}{c}\text { B.O. } \\
\text { BURGOS } \\
08-08-03\end{array}$ & $\begin{array}{c}\text { 01-01-2003 } \\
\text { HASTA } \\
31-12-2005\end{array}$ & $\begin{array}{l}2003: 1.744 \\
2004: 1.728 \\
2005: 1.728\end{array}$ & +IPC real & $\begin{array}{l}\text { En función del } \\
\text { cumplimiento del } \\
\text { CFBE previsto, } \\
\text { variable desde el } \\
1 \% \text { de la masa } \\
\text { salarial al 4,5\%. } \\
\text { (reparto } 40 \% \\
\text { lineal resto según } \\
\text { resto de aumento } \\
\text { de incentivos) }\end{array}$ & & $\begin{array}{c}\text { Prima global de } \\
\text { productividad }\end{array}$ & \\
\hline $\begin{array}{c}\text { SAINT } \\
\text { GOBAIN } \\
\text { VICASA } \\
\text { Burgos }\end{array}$ & $\begin{array}{c}\text { B.O. } \\
\text { BURGOS } \\
\text { 21-04-04 }\end{array}$ & $\begin{array}{c}01-01-2004 \\
\text { HASTA } \\
31-12-2004\end{array}$ & & Tablas 2004 & & & & \\
\hline
\end{tabular}




\begin{tabular}{|c|c|c|c|c|c|}
\hline $\begin{array}{l}\text { SAINT } \\
\text { GOBAIN } \\
\text { VICASA } \\
\text { Burgos }\end{array}$ & $\begin{array}{c}\text { B.O. } \\
\text { BURGOS } \\
18-07-05\end{array}$ & $\begin{array}{c}\text { 01-01-2005 } \\
\text { HASTA } \\
31-12-2005\end{array}$ & & Tablas 2005 & \\
\hline $\begin{array}{c}\text { SAINT } \\
\text { GOBAIN } \\
\text { VICASA } \\
\text { Burgos }\end{array}$ & $\begin{array}{c}\text { B.O. } \\
\text { BURGOS } \\
\text { 16-08-06 }\end{array}$ & $\begin{array}{c}\text { 01-01-2006 } \\
\text { HASTA } \\
31-12-2007\end{array}$ & 1.728 & +IPC real & $\begin{array}{l}\text { Prima global de } \\
\text { productividad } \\
\text { Prima anual en } \\
\text { función de } \\
\text { rendimiento y } \\
\text { calidad }\end{array}$ \\
\hline $\begin{array}{c}\text { SAINT } \\
\text { GOBAIN } \\
\text { VICASA } \\
\text { Burgos }\end{array}$ & $\begin{array}{c}\text { B.O. } \\
\text { BURGOS } \\
28-01-08\end{array}$ & $\begin{array}{c}\text { 01-01-2008 } \\
\text { HASTA } \\
31-12-2010\end{array}$ & 1.720 & +IPC real & $\begin{array}{l}\text { Prima global de } \\
\text { productividad } \\
\text { Prima anual en } \\
\text { función de } \\
\text { rendimiento y } \\
\text { calidad } \\
\end{array}$ \\
\hline $\begin{array}{c}\text { SAINT } \\
\text { GOBAIN } \\
\text { VICASA } \\
\text { Burgos }\end{array}$ & $\begin{array}{c}\text { B.O. } \\
\text { BURGOS } \\
\text { 23-12-11 }\end{array}$ & $\begin{array}{c}\text { 01-01-2011 } \\
\text { HASTA } \\
31-12-2012\end{array}$ & 1.720 & $\begin{array}{l}2011:+1,40 \% \\
2012:+1,30 \%\end{array}$ & $\begin{array}{l}\text { Prima anual en } \\
\text { función de } \\
\text { rendimiento y } \\
\text { calidad }\end{array}$ \\
\hline $\begin{array}{l}\text { SAINT } \\
\text { GOBAIN } \\
\text { VICASA } \\
\text { Burgos }\end{array}$ & $\begin{array}{c}\text { B.O. } \\
\text { BURGOS } \\
10-05-13\end{array}$ & $\begin{array}{c}01-01-2013 \\
\text { HASTA } \\
31-12-2013\end{array}$ & 1.720 & $\begin{array}{c}\text { 2011: +0,55\% } \\
\text { Revisión + } \\
\text { vinculada a } \\
\text { diferencia } \\
\text { IPC España } \\
\text { con IPC EU } \\
\text { (considerando } \\
\text { petróleo para } \\
\text { armonizar) }\end{array}$ & $\begin{array}{l}\text { Prima anual en } \\
\text { función de } \\
\text { coste técnico y } \\
\text { seguridad }\end{array}$ \\
\hline
\end{tabular}




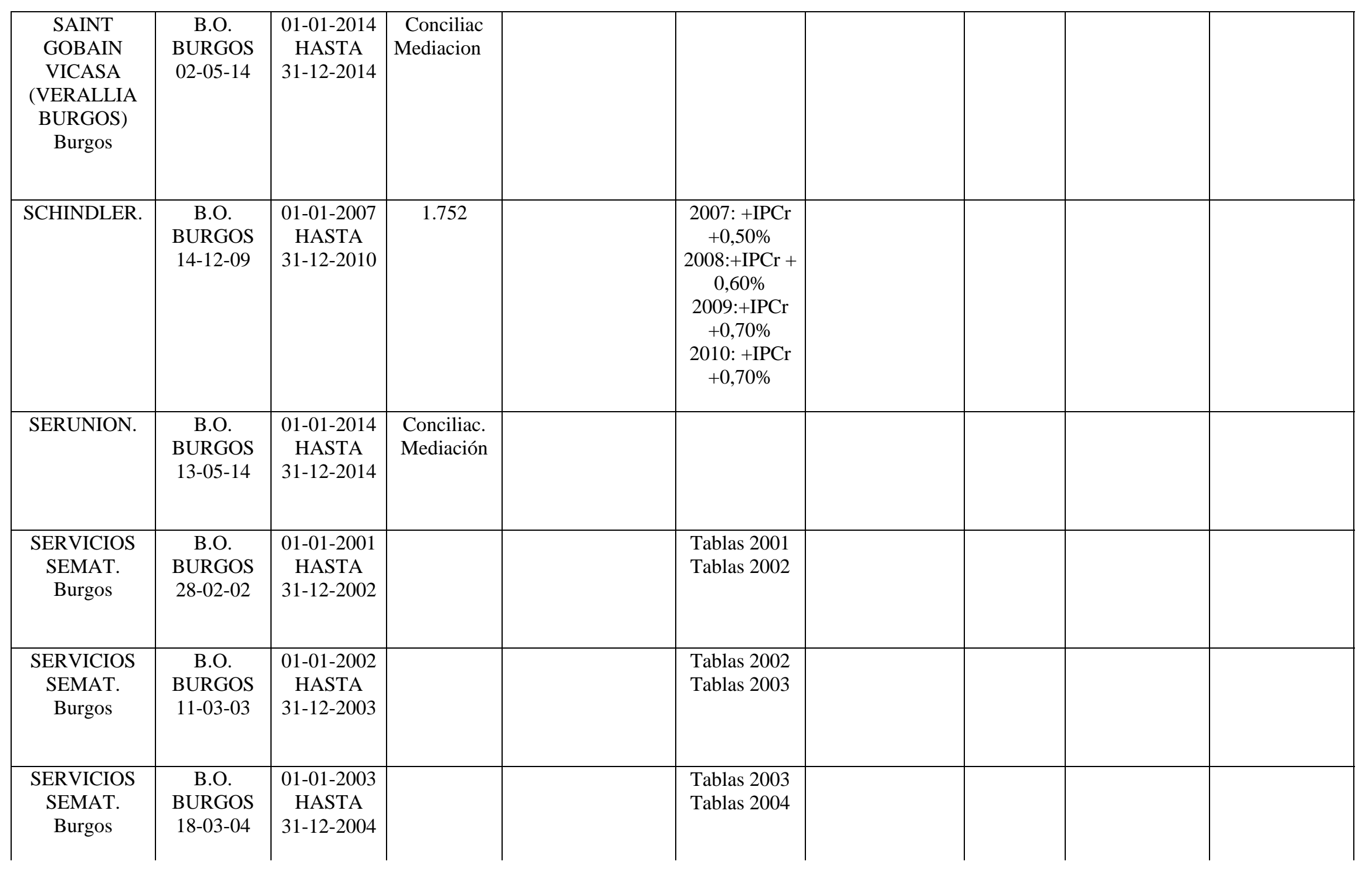




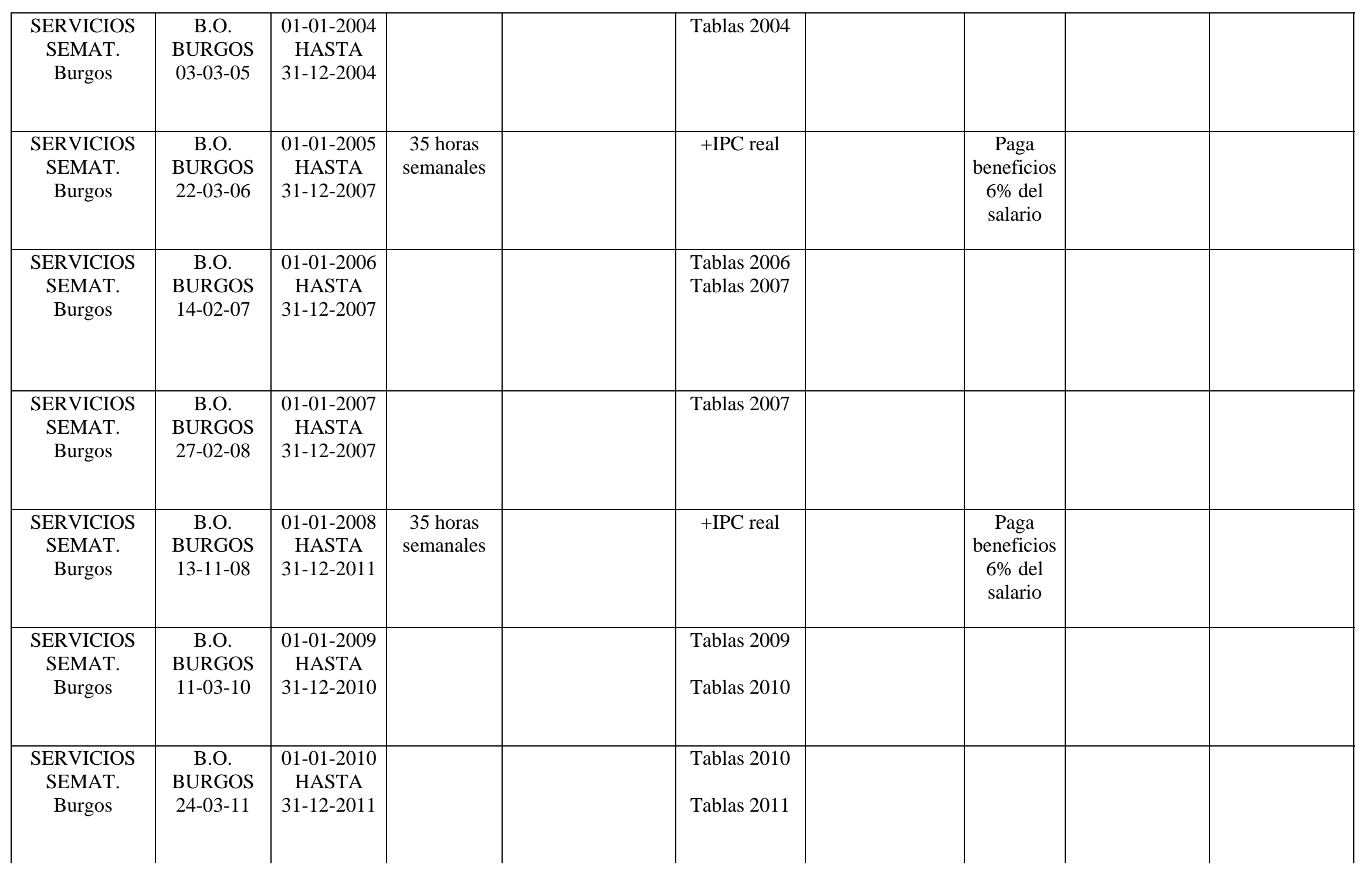




\begin{tabular}{|c|c|c|c|c|c|c|}
\hline $\begin{array}{c}\text { SERVICIOS } \\
\text { SEMAT. } \\
\text { Burgos }\end{array}$ & $\begin{array}{c}\text { B.O. } \\
\text { BURGOS } \\
08-02-12\end{array}$ & $\begin{array}{c}01-01-2011 \\
\text { HASTA } \\
31-12-2011\end{array}$ & & Tablas 2011 & & \\
\hline $\begin{array}{l}\text { SERVICIOS } \\
\text { SEMAT. } \\
\text { Burgos }\end{array}$ & $\begin{array}{c}\text { B.O. } \\
\text { BURGOS } \\
18-02-13\end{array}$ & $\begin{array}{c}\text { 01-01-2012 } \\
\text { HASTA } \\
31-12-2012\end{array}$ & $\begin{array}{c}35 \text { horas } \\
\text { semanales }\end{array}$ & Tablas 2012 & $\begin{array}{c}\text { Paga } \\
\text { beneficios } \\
6 \% \text { del } \\
\text { salario }\end{array}$ & \\
\hline $\begin{array}{c}\text { SERVICIOS } \\
\text { SEMAT. } \\
\text { Burgos }\end{array}$ & $\begin{array}{c}\text { B.O. } \\
\text { BURGOS } \\
22-07-14\end{array}$ & $\begin{array}{c}\text { 01-01-2014 } \\
\text { HASTA } \\
31-12-2014\end{array}$ & $\begin{array}{c}35 \text { horas } \\
\text { semanales }\end{array}$ & Tablas 2014 & $\begin{array}{c}\text { Paga } \\
\text { beneficios } \\
6 \% \text { del } \\
\text { salario }\end{array}$ & \\
\hline $\begin{array}{c}\text { SIRO } \\
\text { BRIVIESCA. } \\
\text { Briviesca }\end{array}$ & $\begin{array}{c}\text { B.O. } \\
\text { BURGOS } \\
14-09-10\end{array}$ & $\begin{array}{c}\text { 01-01-2009 } \\
\text { HASTA } \\
31-12-2009\end{array}$ & $\begin{array}{c}\text { Turnos de } \\
\text { trabajo }\end{array}$ & & & \\
\hline $\begin{array}{c}\text { SIRO } \\
\text { BRIVIESCA. } \\
\text { Briviesca }\end{array}$ & $\begin{array}{c}\text { B.O. } \\
\text { BURGOS } \\
01-03-13\end{array}$ & $\begin{array}{c}\text { 01-01-2011 } \\
\text { HASTA } \\
31-12-2015\end{array}$ & $\begin{array}{c}\text { 2011-13: } \\
1.768 \\
2014-15: \\
1.760\end{array}$ & $\begin{array}{c}2011:+2 \% \\
2012:+2 \% \\
2013:+2 \% \\
2014:+1,5 \% \\
2015:+1,5 \%\end{array}$ & & $\begin{array}{c}\text { Mejora } \\
\text { product. } \\
\text { Vinculada a } \\
\text { consumo MOD } \\
\text { y materiales }\end{array}$ \\
\hline $\begin{array}{c}\text { SIRO } \\
\text { BRIVIESCA. } \\
\text { Briviesca }\end{array}$ & $\begin{array}{c}\text { B.O. } \\
\text { BURGOS } \\
01-09-14\end{array}$ & $\begin{array}{c}\text { 01-01-2011 } \\
\text { HASTA } \\
31-12-2019\end{array}$ & & Tablas & & $\begin{array}{c}\text { Mejora } \\
\text { product. } \\
\text { Vinculada a } \\
\text { consumo MOD } \\
\text { y materiales }\end{array}$ \\
\hline
\end{tabular}




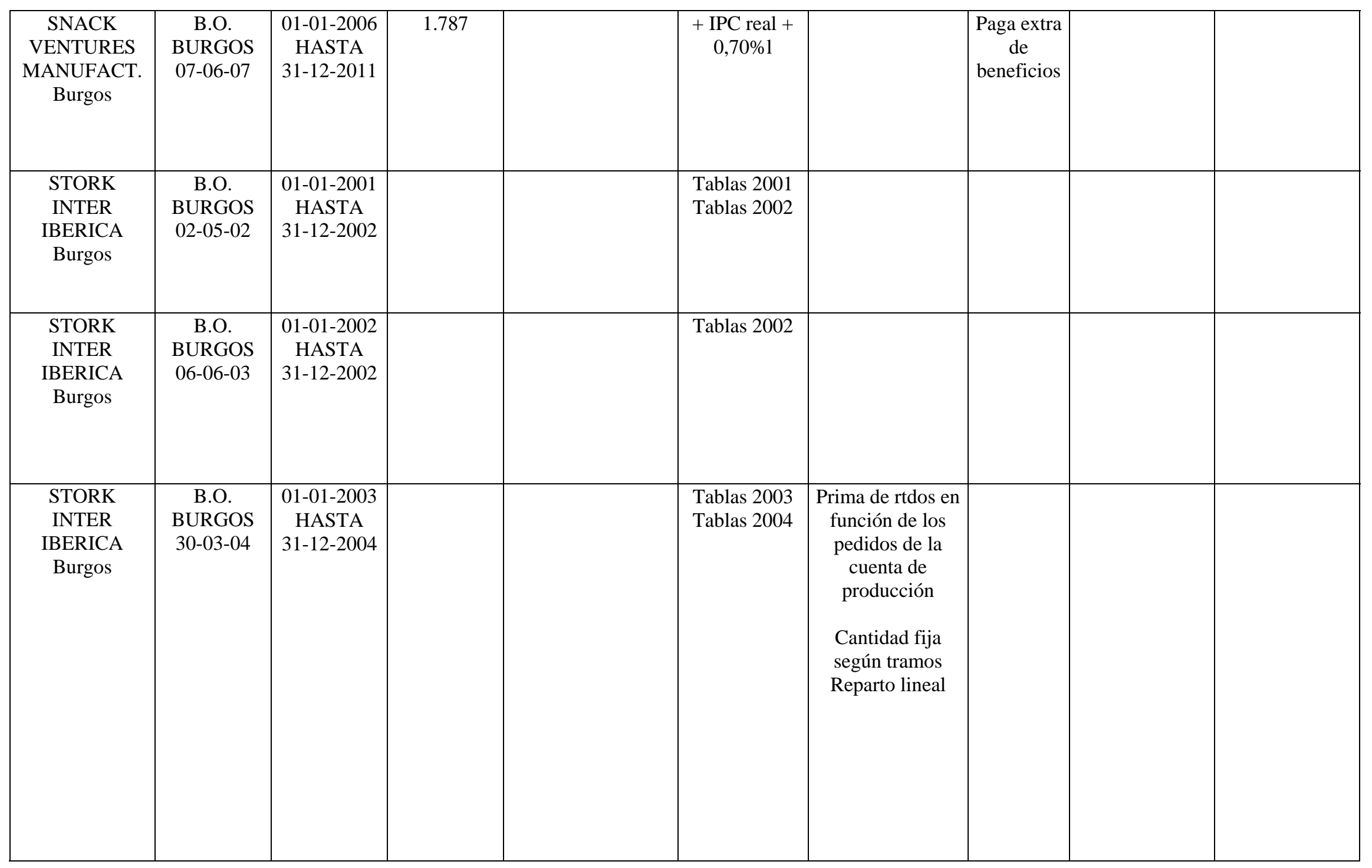




\begin{tabular}{|c|c|c|c|c|c|}
\hline $\begin{array}{c}\text { STORK } \\
\text { INTER } \\
\text { IBERICA } \\
\text { Burgos }\end{array}$ & $\begin{array}{c}\text { B.O. } \\
\text { BURGOS } \\
\text { 22-06-05 }\end{array}$ & $\begin{array}{c}\text { 01-01-2005 } \\
\text { HASTA } \\
31-12-2007\end{array}$ & $\begin{array}{l}2005: 1.704 \\
2006: 1.696 \\
2007: 1.688\end{array}$ & $\begin{array}{c}\text { 2005: +IPC } \\
\text { prevsto + 1\% } \\
\text { 2006: +IPC } \\
\text { previsto + } \\
\text { 1,25\% } \\
\text { 2007: +IPC } \\
\text { previsto } \\
+1,50 \% \\
\text { Revisión + en } \\
\text { lo que IPCr } \\
\text { supere a IPCp }\end{array}$ & Bimensual \\
\hline $\begin{array}{c}\text { STORK } \\
\text { INTER } \\
\text { IBERICA } \\
\text { Burgos }\end{array}$ & $\begin{array}{c}\text { B.O. } \\
\text { BURGOS } \\
\text { 26-07-05 }\end{array}$ & $\begin{array}{c}01-01-2005 \\
\text { HASTA } \\
31-12-2005\end{array}$ & $\begin{array}{l}\text { Corrección } \\
\text { de errores }\end{array}$ & & \\
\hline $\begin{array}{c}\text { STORK } \\
\text { INTER } \\
\text { IBERICA } \\
\text { Burgos }\end{array}$ & $\begin{array}{c}\text { B.O. } \\
\text { BURGOS } \\
\text { 24-05-06 }\end{array}$ & $\begin{array}{c}\text { 01-01-2005 } \\
\text { HASTA } \\
31-12-2006\end{array}$ & & $\begin{array}{l}\text { Tablas } 2005 \\
\text { Tablas } 2006\end{array}$ & \\
\hline $\begin{array}{c}\text { STORK } \\
\text { INTER } \\
\text { IBERICA } \\
\text { Burgos }\end{array}$ & $\begin{array}{c}\text { B.O. } \\
\text { BURGOS } \\
\text { 21-07-06 }\end{array}$ & $\begin{array}{c}\text { 01-01-2006 } \\
\text { HASTA } \\
31-12-2006\end{array}$ & $\begin{array}{l}\text { Corrección } \\
\text { de errores }\end{array}$ & & \\
\hline $\begin{array}{c}\text { STORK } \\
\text { INTER } \\
\text { IBERICA } \\
\text { Burgos }\end{array}$ & $\begin{array}{c}\text { B.O. } \\
\text { BURGOS } \\
28-02-07\end{array}$ & $\begin{array}{c}01-01-2006 \\
\text { HASTA } \\
31-12-2007\end{array}$ & & $\begin{array}{l}\text { Tablas } 2006 \\
\text { Tablas } 2007\end{array}$ & \\
\hline
\end{tabular}




\begin{tabular}{|c|c|c|c|c|c|c|}
\hline $\begin{array}{l}\text { STORK } \\
\text { INTER } \\
\text { IBERICA } \\
\text { Burgos }\end{array}$ & $\begin{array}{c}\text { B.O. } \\
\text { BURGOS } \\
\text { 25-02-08 }\end{array}$ & $\begin{array}{c}01-01-2007 \\
\text { HASTA } \\
31-12-2007\end{array}$ & & Tablas 2007 & & \\
\hline $\begin{array}{l}\text { STORK } \\
\text { INTER } \\
\text { IBERICA } \\
\text { Burgos }\end{array}$ & $\begin{array}{c}\text { B.O. } \\
\text { BURGOS } \\
\text { 02-09-08 }\end{array}$ & $\begin{array}{c}\text { 01-01-2008 } \\
\text { HASTA } \\
31-12-2010\end{array}$ & 1.688 & $\begin{array}{c}\text { 2008: +IPC } \\
\text { previsto + } \\
0,50 \% \\
\text { 2009: +IPC } \\
\text { previstol + } \\
1 \% \\
\text { 2010: +IPC } \\
\text { previsto } \\
\text { +1,50\% } \\
\text { Revisión + en } \\
\text { lo que IPCr } \\
\text { supere a IPCp }\end{array}$ & $\begin{array}{l}\text { Prima de rtdos en } \\
\text { función de los } \\
\text { pedidos de la } \\
\text { cuenta de } \\
\text { producción } \\
\\
\text { Cantidad fija } \\
\text { según tramos } \\
\text { Reparto lineal }\end{array}$ & Bimensual \\
\hline $\begin{array}{l}\text { STORK } \\
\text { INTER } \\
\text { IBERICA } \\
\text { Burgos }\end{array}$ & $\begin{array}{c}\text { B.O. } \\
\text { BURGOS } \\
\text { 30-05-11 }\end{array}$ & $\begin{array}{c}01-01-2011 \\
\text { HASTA } \\
31-12-2011\end{array}$ & Calendario & & & \\
\hline $\begin{array}{c}\text { STORK } \\
\text { INTER } \\
\text { IBERICA } \\
\text { Burgos } \\
\end{array}$ & $\begin{array}{c}\text { B.O. } \\
\text { BURGOS } \\
\text { 25-08-11 }\end{array}$ & $\begin{array}{c}\text { 01-01-2009 } \\
\text { HASTA } \\
31-12-2011\end{array}$ & & $\begin{array}{l}\text { Tablas } 2009 \\
\text { Tablas } 2010 \\
\text { Tablas } 2011\end{array}$ & & \\
\hline $\begin{array}{l}\text { STORK } \\
\text { INTER } \\
\text { IBERICA } \\
\text { Burgos }\end{array}$ & $\begin{array}{c}\text { B.O. } \\
\text { BURGOS } \\
02-01-13\end{array}$ & $\begin{array}{c}\text { 01-01-2012 } \\
\text { HASTA } \\
31-12-2012\end{array}$ & 1.688 & $0 \%$ & $\begin{array}{l}\text { Prima de rtdos en } \\
\text { función de los } \\
\text { pedidos de la } \\
\text { cuenta de } \\
\text { producción... }\end{array}$ & Bimensual \\
\hline
\end{tabular}




\begin{tabular}{|c|c|c|c|c|c|c|c|}
\hline $\begin{array}{c}\text { STORK } \\
\text { INTER } \\
\text { IBERICA } \\
\text { Burgos }\end{array}$ & $\begin{array}{c}\text { B.O. } \\
\text { BURGOS } \\
17-01-14\end{array}$ & $\begin{array}{c}\text { 01-01-2013 } \\
\text { HASTA } \\
31-12-2013\end{array}$ & 1.688 & $0 \%$ & \begin{tabular}{|c|} 
Prima de rtdos en \\
función de los \\
pedidos de \\
producción \\
Cantidad fija \\
según tramos \\
Reparto linea \\
\end{tabular} & l & Bimensual \\
\hline $\begin{array}{l}\text { TECNICAS } \\
\text { MEDIOAMB. } \\
\text { TECMED }\end{array}$ & $\begin{array}{c}\text { B.O. } \\
\text { BURGOS } \\
07-05-02\end{array}$ & $\begin{array}{c}\text { 01-01-2003 } \\
\text { HASTA } \\
31-12-2003\end{array}$ & & Tablas 2002 & & & \\
\hline $\begin{array}{c}\text { TECNICAS } \\
\text { MEDIOAMB. } \\
\text { TECMED }\end{array}$ & $\begin{array}{c}\text { B.O. } \\
\text { BURGOS } \\
\text { 28-03-03 }\end{array}$ & $\begin{array}{c}\text { 01-01-2003 } \\
\text { HASTA } \\
31-12-2003\end{array}$ & & $\begin{array}{c}\text { +IPC real + } \\
2 \%\end{array}$ & & & \\
\hline $\begin{array}{l}\text { TECNICAS } \\
\text { MEDIOAMB. } \\
\text { TECMED }\end{array}$ & $\begin{array}{c}\text { B.O. } \\
\text { BURGOS } \\
\text { 31-03-04 }\end{array}$ & $\begin{array}{c}\text { 01-01-2003 } \\
\text { HASTA } \\
31-12-2003\end{array}$ & & $\begin{array}{c}+ \text { +IPC real + } \\
2 \%\end{array}$ & & & \\
\hline $\begin{array}{c}\text { THYSSEN } \\
\text { KRUPP } \\
\text { ELEVADOR } \\
\text { Provincia }\end{array}$ & $\begin{array}{c}\text { B.O. } \\
\text { BURGOS } \\
\text { 08-11-05 }\end{array}$ & $\begin{array}{c}\text { 01-01-2005 } \\
\text { HASTA } \\
31-12-2006\end{array}$ & $\begin{array}{l}\text { 2005:1.772 } \\
\text { 2006: } 1.764\end{array}$ & $\begin{array}{l}\text { +IPC real } \\
+1 \%\end{array}$ & \begin{tabular}{|} 
Gratificación de \\
beneficios en \\
función de \\
beneficios netos \\
auditados y el \\
número de \\
personas en \\
plantilla
\end{tabular} & & \\
\hline $\begin{array}{c}\text { THYSSEN } \\
\text { KRUPP } \\
\text { ELEVADOR. } \\
\text { Provincia }\end{array}$ & $\begin{array}{c}\text { B.O. } \\
\text { BURGOS } \\
\text { 13-11-07 }\end{array}$ & $\begin{array}{c}\text { 01-01-2007 } \\
\text { HASTA } \\
31-12-2009\end{array}$ & $\begin{array}{l}\text { 2007:1.754 } \\
\text { 2008: } 1.744 \\
\text { 2009:1.736 }\end{array}$ & $\begin{array}{l}+ \text { +IPC real } \\
+0,80 \%\end{array}$ & \begin{tabular}{|c|} 
Gratificación de \\
beneficios en \\
función de \\
beneficios netos \\
auditados y el \\
número de \\
personas en \\
plantilla \\
\end{tabular} & & \\
\hline
\end{tabular}




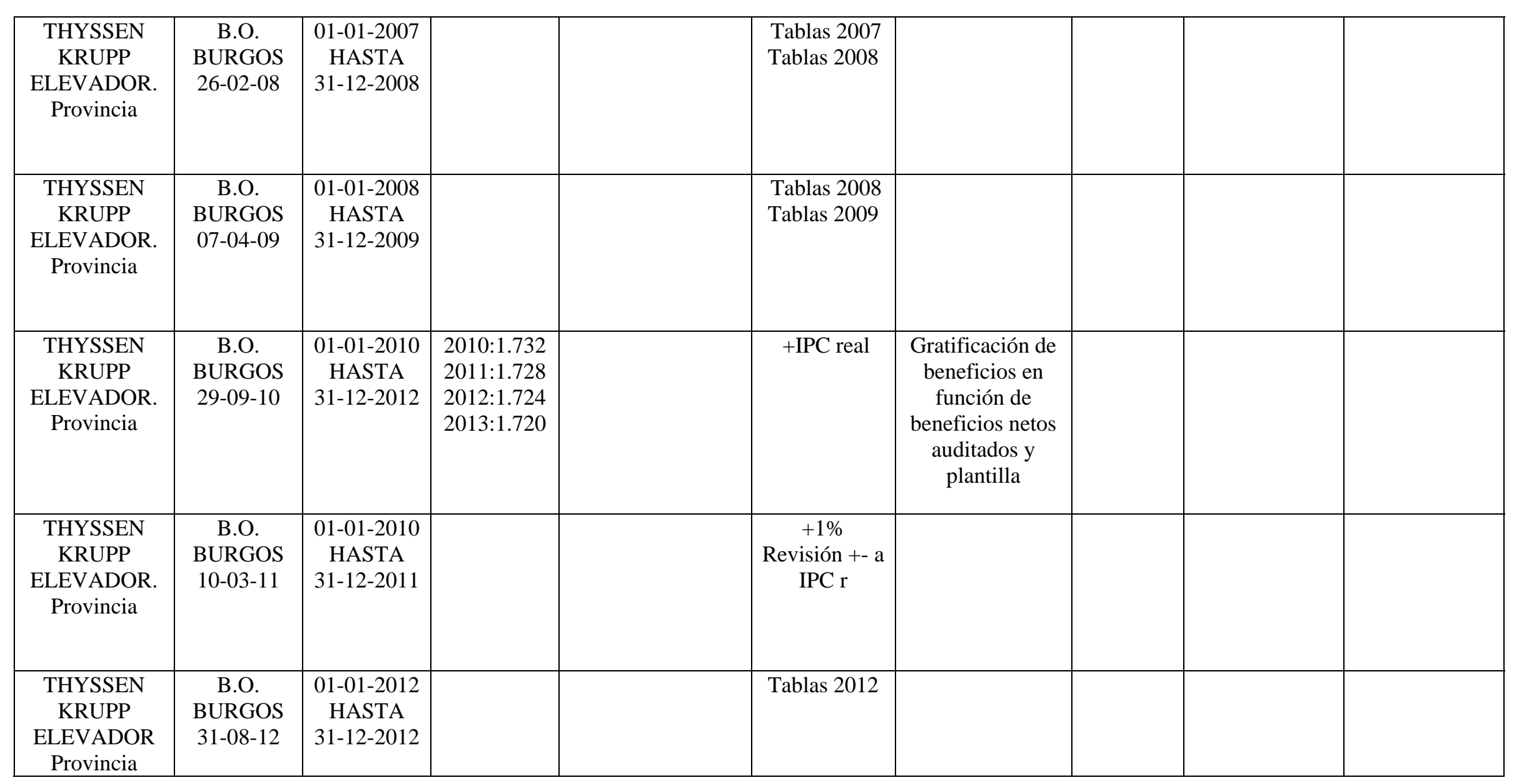




\begin{tabular}{|c|c|c|c|c|c|c|c|}
\hline $\begin{array}{c}\text { THYSSEN } \\
\text { KRUPP } \\
\text { ELEVADOR. } \\
\text { Provincia }\end{array}$ & $\begin{array}{c}\text { B.O. } \\
\text { BURGOS } \\
01-09-14\end{array}$ & \begin{tabular}{|c|}
$01-01-2013$ \\
HASTA \\
$31-12-2016$
\end{tabular} & 1.720 & $\begin{array}{c}\text { 2013: Tablas } \\
\text { 2014: +1,50\% } \\
\text { 2015: +IPC } \\
\text { real } \\
\text { 2016: + IPC } \\
\text { real }\end{array}$ & $\begin{array}{l}\text { Gratificación de } \\
\text { beneficios en } \\
\text { función de } \\
\text { beneficios netos } \\
\text { auditados y } \\
\text { plantilla }\end{array}$ & & \\
\hline $\begin{array}{c}\text { TRANS } \\
\text { UNION } \\
\text { GAS } \\
\text { TUGASA } \\
\text { Provincia }\end{array}$ & $\begin{array}{c}\text { B.O. } \\
\text { BURGOS } \\
\text { 26-09-03 }\end{array}$ & $\begin{array}{c}01-01-2003 \\
\text { HASTA } \\
31-12-2004\end{array}$ & 1.760 & $+4 \%$ & & \begin{tabular}{|l} 
Paga extra \\
de \\
beneficios
\end{tabular} & \\
\hline $\begin{array}{c}\text { TRANS } \\
\text { UNION } \\
\text { GAS } \\
\text { TUGASA } \\
\text { Provincia }\end{array}$ & $\begin{array}{c}\text { B.O. } \\
\text { BURGOS } \\
\text { 12-05-09 }\end{array}$ & $\begin{array}{c}\text { 01-01-2009 } \\
\text { HASTA } \\
31-12-2009\end{array}$ & 1.760 & $+2 \%$ & & $\begin{array}{l}\text { Paga extra } \\
\text { de } \\
\text { beneficios }\end{array}$ & \\
\hline $\begin{array}{c}\text { TRW } \\
\text { AUTOMOTIV } \\
\text { Quintanaortuño }\end{array}$ & $\begin{array}{c}\text { B.O. } \\
\text { BURGOS } \\
\text { 19-04-02 }\end{array}$ & \begin{tabular}{|c|}
$01-01-2002$ \\
HASTA \\
$31-12-2002$
\end{tabular} & Calendario & $\begin{array}{l}\text { Tablas } 2001 \\
\text { Tablas } 2002\end{array}$ & & & \\
\hline $\begin{array}{c}\text { TRW } \\
\text { AUTOMOTIV } \\
\text { Quintanaortuño }\end{array}$ & $\begin{array}{c}\text { B.O. } \\
\text { BURGOS } \\
07-05-02\end{array}$ & \begin{tabular}{|c|}
$01-01-2002$ \\
HASTA \\
$31-12-2002$
\end{tabular} & & Tablas 2002 & & & \\
\hline $\begin{array}{c}\text { TRW } \\
\text { AUTOMOTIV } \\
\text { Quintanaortuño }\end{array}$ & $\begin{array}{c}\text { B.O. } \\
\text { BURGOS } \\
07-04-03\end{array}$ & \begin{tabular}{|c|}
$01-01-2003$ \\
HASTA \\
$31-12-2003$
\end{tabular} & & Tablas 2003 & & & \\
\hline
\end{tabular}




\begin{tabular}{|c|c|c|c|c|c|c|c|c|}
\hline \begin{tabular}{|c|} 
TRW \\
AUTOMOTIV \\
Quintanaortuño
\end{tabular} & $\begin{array}{c}\text { B.O. } \\
\text { BURGOS } \\
17-05-04\end{array}$ & $\begin{array}{c}\text { 01-01-2004 } \\
\text { HASTA } \\
31-12-2004\end{array}$ & 1.720 & $\begin{array}{c}\text { +IPC } \\
\text { previsto } \\
+1,50 \% \\
\text { Revisión sólo } \\
+ \text { si IPCr }> \\
\text { IPCp }\end{array}$ & $\begin{array}{l}\text { Paga de rtdos en } \\
\text { función de } \\
\text { beneficio de } \\
\text { gestión, } \\
\text { rentabilidad de } \\
\text { activos } \\
\text { empleados y } \\
\text { rentabilidad de } \\
\text { las ventas } \\
\\
\text { Además paga de } \\
\text { beneficios del } \\
1,50 \% \text { de } \\
\text { beneficio de } \\
\text { gestión }\end{array}$ & & & \\
\hline $\begin{array}{l}\text { URBASER } \\
\text { Aranda }\end{array}$ & $\begin{array}{c}\text { B.O. } \\
\text { BURGOS } \\
06-07-05\end{array}$ & $\begin{array}{c}01-01-2005 \\
\text { HASTA } \\
31-12-2008 \\
\end{array}$ & $\begin{array}{c}35 \text { horas } \\
\text { semanales }\end{array}$ & + IPC real & & & & \\
\hline $\begin{array}{l}\text { URBASER } \\
\text { Aranda }\end{array}$ & $\begin{array}{c}\text { B.O. } \\
\text { BURGOS } \\
\text { 15-03-06 }\end{array}$ & $\begin{array}{c}01-01-2006 \\
\text { HASTA } \\
31-12-2006\end{array}$ & & Tablas 2006 & & & & \\
\hline $\begin{array}{c}\text { URBASER } \\
\text { Aranda }\end{array}$ & $\begin{array}{c}\text { B.O. } \\
\text { BURGOS } \\
28-02-07\end{array}$ & $\begin{array}{c}01-01-2007 \\
\text { HASTA } \\
31-12-2007\end{array}$ & & Tablas 2007 & & & & \\
\hline $\begin{array}{c}\text { URBASER } \\
\text { Aranda }\end{array}$ & $\begin{array}{c}\text { B.O. } \\
\text { BURGOS } \\
\text { 05-03-08 }\end{array}$ & $\begin{array}{c}01-01-2008 \\
\text { HASTA } \\
31-12-2008\end{array}$ & & Tablas 2008 & & & & \\
\hline $\begin{array}{l}\text { URBASER } \\
\text { Aranda }\end{array}$ & $\begin{array}{c}\text { B.O. } \\
\text { BURGOS } \\
08-07-11\end{array}$ & $\begin{array}{c}01-01-2009 \\
\text { HASTA } \\
31-12-2012\end{array}$ & $\begin{array}{c}35 \text { horas } \\
\text { semanales }\end{array}$ & + IPC real & & $\begin{array}{c}\text { Paga extra } \\
\text { de } \\
\text { beneficios }\end{array}$ & & \\
\hline $\begin{array}{c}\text { URBASER } \\
\text { Aranda }\end{array}$ & $\begin{array}{c}\text { B.O. } \\
\text { BURGOS } \\
25-04-12\end{array}$ & $\begin{array}{c}\text { 01-01-2001 } \\
\text { HASTA } \\
31-12-2011\end{array}$ & & Tablas 2011 & & & & \\
\hline
\end{tabular}




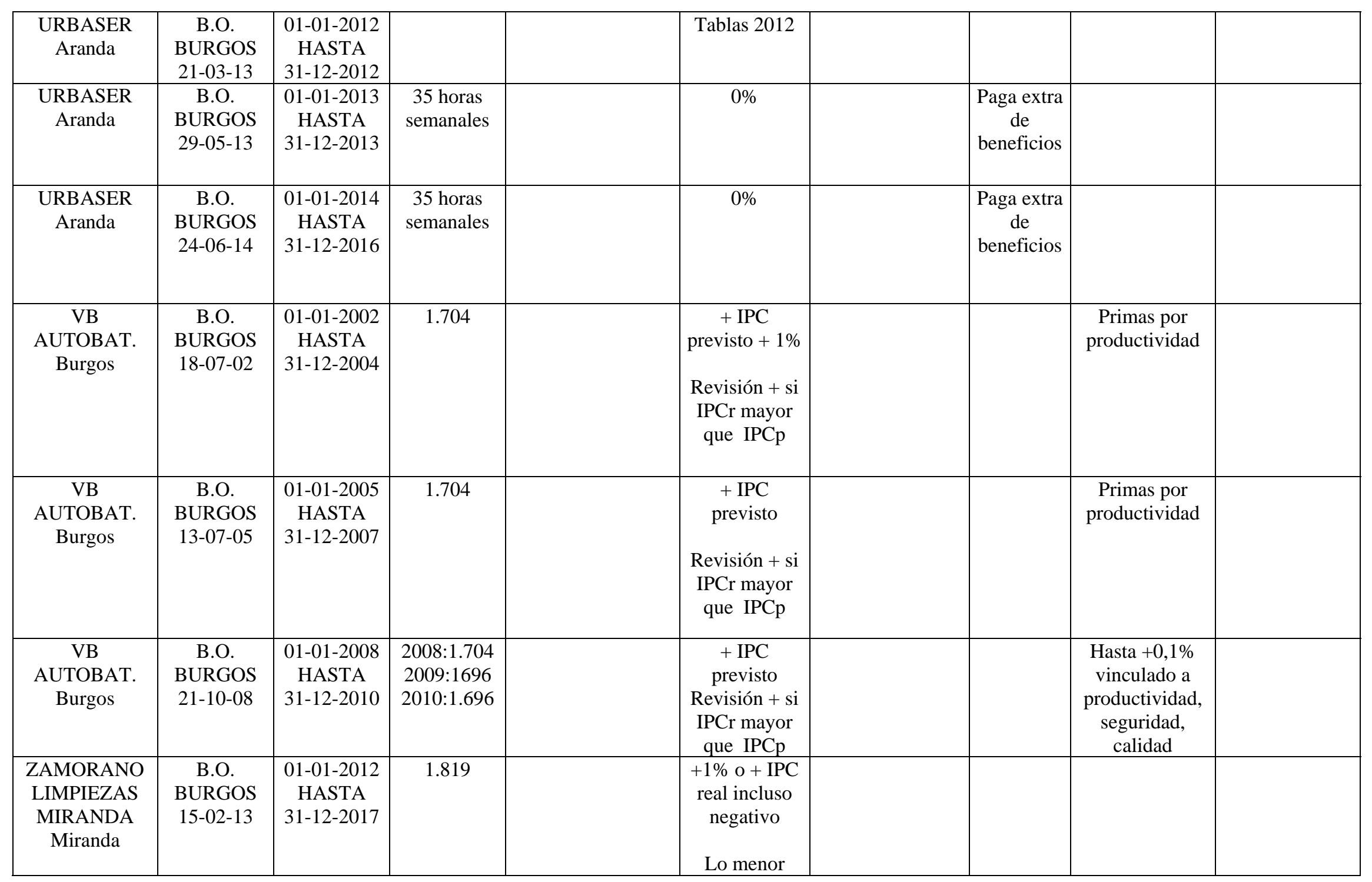




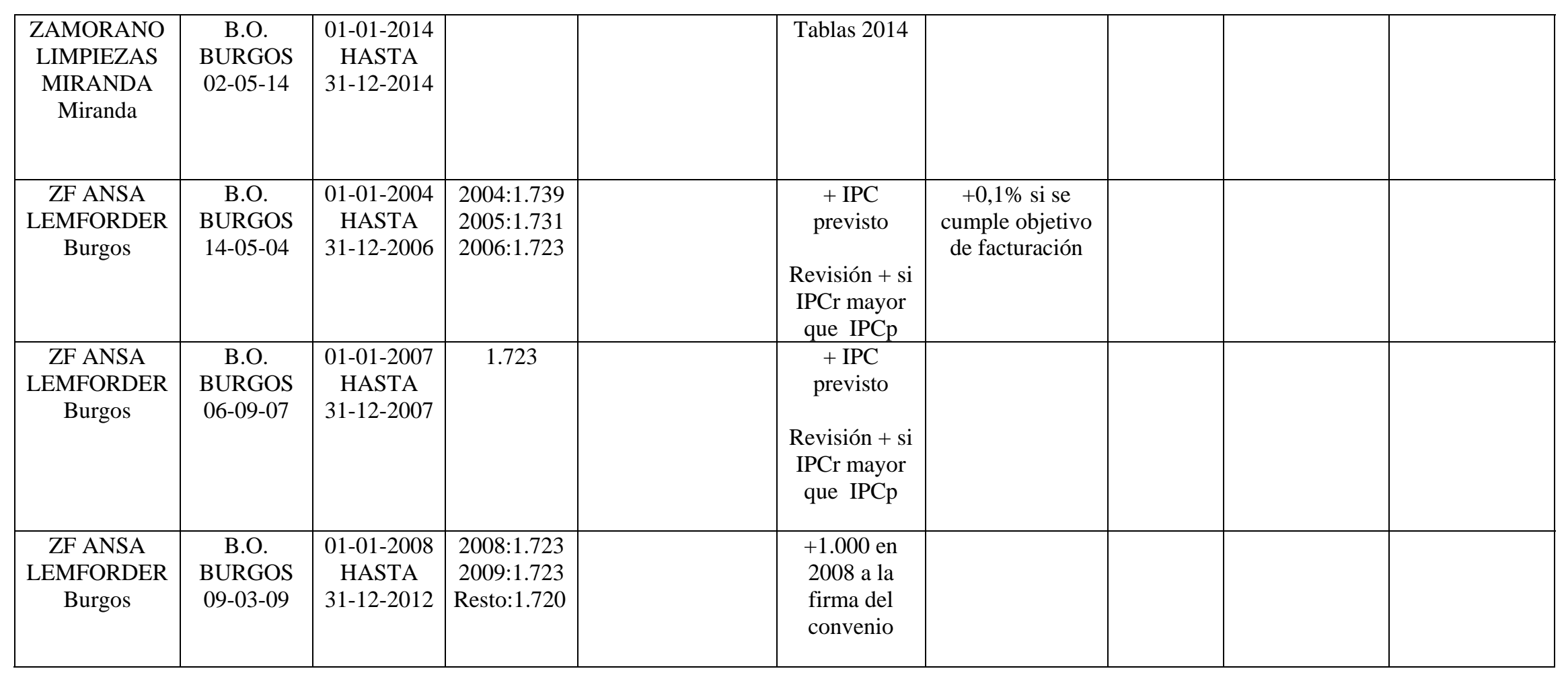


PÁGINA 374 


\section{ANEXO 7}

\section{CUADRO RESUMEN CONVENIOS COLECTIVOS MAYO 2015}


PÁGINA 376 


\begin{tabular}{|c|c|c|c|c|c|c|c|c|c|}
\hline EMPRESA & FUENTE & $\begin{array}{l}\text { VIGENCIA } \\
\text { INICIAL }\end{array}$ & $\begin{array}{l}\text { JORNADA } \\
\text { LABORAL }\end{array}$ & $\begin{array}{c}\text { COMPROMISO } \\
\text { CONTRATOS }\end{array}$ & $\begin{array}{l}\text { REVISIÓN } \\
\text { SALARIAL }\end{array}$ & $\begin{array}{l}\text { PARTICIP. } \\
\text { BENEFICIOS }\end{array}$ & $\begin{array}{l}\text { PAGAS } \\
\text { EXTRAS }\end{array}$ & $\begin{array}{c}\text { OTRAS } \\
\text { REMUNERAC. }\end{array}$ & $\begin{array}{c}\text { REFER. } \\
\text { CONTABLE }\end{array}$ \\
\hline $\begin{array}{c}\text { CASTA } \\
\text { AREVALO } \\
\text { Ávila } \\
\end{array}$ & $\begin{array}{c}\text { B.O.P. } \\
\text { 19/03/2015 }\end{array}$ & $2015-2018$ & $\begin{array}{l}\text { 2015: } 1.625 \\
\text { Resto: } 1650\end{array}$ & & $\begin{array}{l}+\operatorname{IPCr}(\mathrm{si} \\
\text { positivo) }\end{array}$ & & & & \\
\hline $\begin{array}{c}\text { CLINICA } \\
\text { SANTA } \\
\text { TERESA } \\
\text { Ávila }\end{array}$ & \begin{tabular}{|c|} 
B.O.P. \\
19/02/2015
\end{tabular} & 2015 & 1.784 horas & & \begin{tabular}{|c} 
No revisión \\
Se desvincula \\
expresamente \\
del IPC
\end{tabular} & & & & \\
\hline $\begin{array}{c}\text { MULTILOGIC } \\
\text { Ávila }\end{array}$ & $\begin{array}{c}\text { B.O.P. } \\
\text { 06/05/2015 }\end{array}$ & 2015-2019 & \begin{tabular}{|l|}
1.780 horas \\
\end{tabular} & & $\begin{array}{l}\text { 2016: }+0,5 \% \\
\text { 2017: }+0,6 \% \\
2018:+0,7 \% \\
2019:+0,8 \%\end{array}$ & & & $\begin{array}{c}\text { Sistema de } \\
\text { rendimiento y } \\
\text { productividad } \\
\text { Primas a la } \\
\text { producción }\end{array}$ & \\
\hline $\begin{array}{c}\text { ADISSEO } \\
\text { Burgos }\end{array}$ & $\begin{array}{c}\text { B.O.P. } \\
04 / 05 / 2015\end{array}$ & 2015-2016 & 1.634 horas & & $\begin{array}{l}\text { +IPC r con } \\
\text { mínimo 1,5\% } \\
\text { y máximo 3\% }\end{array}$ & & $\begin{array}{c}\text { Media } \\
\text { paga extra } \\
\text { de } \\
\text { beneficios }\end{array}$ & $\begin{array}{l}\text { En función de: } \\
\text { Accidentalidad } \\
\text { Tasa de rdto } \\
\text { Tonel. prod. } \\
\text { EBITDA grupo } \\
\text { Tiempos trabaj }\end{array}$ & \\
\hline $\begin{array}{c}\text { PIERRE } \\
\text { GUERIN } \\
\text { Burgos }\end{array}$ & $\begin{array}{c}\text { B.O.P. } \\
\text { 18/03/2015 }\end{array}$ & 2015-2017 & 1.728 horas & & $+0,75 \%$ & $\begin{array}{l}1 \text { por mil del } \\
\text { beneficio neto } \\
+50 \text { euros } \\
\text { trimestrales si } \\
\text { resultado neto } \\
\text { anual es positivo }\end{array}$ & & & $\begin{array}{l}\text { Información } \\
\text { trimestral }\end{array}$ \\
\hline
\end{tabular}




\begin{tabular}{|c|c|c|c|c|c|c|c|c|}
\hline $\begin{array}{c}\text { STORK } \\
\text { INTERIB. } \\
\text { Burgos }\end{array}$ & \begin{tabular}{|c|} 
B.O.P. \\
29/01/2015
\end{tabular} & 2015 & 1.688 horas & Congelación & $\begin{array}{l}+250 \text { euros si } \\
\text { finaliza } 2015 \text { sin } \\
\text { pérdidas }\end{array}$ & & $\begin{array}{c}\text { Prima de rtdos } \\
\text { de pedidos }\end{array}$ & $\begin{array}{l}\text { Información } \\
\text { bimensual }\end{array}$ \\
\hline $\begin{array}{c}\text { CC \& CC } \\
\text { BEMBIBRE } \\
\text { León }\end{array}$ & \begin{tabular}{|c|} 
B.O.P. \\
10/03/2015
\end{tabular} & 2015-2017 & 1.764 horas & $\begin{array}{l}\text { + IPC r con } \\
\text { máximo } 2 \%\end{array}$ & & & & \\
\hline $\begin{array}{c}\text { CEMENTOS } \\
\text { TUDELA } \\
\text { VEGUIN } \\
\text { León }\end{array}$ & $\begin{array}{c}\text { B.O.P. } \\
\text { 13/04/2015 }\end{array}$ & $2015-2016$ & 1.752 horas & $\begin{array}{c}\text { +IPC r } \\
\text { condicionado } \\
\text { a un mínimo } \\
\text { de } \\
\text { producción }\end{array}$ & & \begin{tabular}{|c} 
Paga extra \\
de \\
beneficios
\end{tabular} & & \\
\hline $\begin{array}{c}\text { EMBUTIDOS } \\
\text { Y JAMONES } \\
\text { EZEQUIEL } \\
\text { León } \\
\end{array}$ & \begin{tabular}{|c|} 
B.O.P. \\
08/05/2015
\end{tabular} & $2015-2019$ & $\begin{array}{l}40 \text { horas } \\
\text { semanales }\end{array}$ & $+0,5 \%$ & & & & \\
\hline $\begin{array}{l}\text { HEDISA } \\
\text { León }\end{array}$ & $\begin{array}{c}\text { B.O.P. } \\
\text { 06/05/2015 }\end{array}$ & $2015-2020$ & 1.760 horas & $\begin{array}{c}+0,5 \% \text { si } \\
\text { beneficios } \\
\text { anuales son } \\
\text { superior en } \\
\text { un } 25 \% \text { al } \\
\text { año anterior }\end{array}$ & & & & \\
\hline $\begin{array}{c}\text { REAL } \\
\text { FUNCACION } \\
\text { HOSPITAL } \\
\text { REINA } \\
\text { CATOLICA } \\
\text { León }\end{array}$ & $\begin{array}{c}\text { B.O.P. } \\
\text { 10/03/2015 }\end{array}$ & $2015-2018$ & & & \begin{tabular}{|l} 
Paga de \\
productividad \\
trimestral \\
mínima del 3\% \\
siempre que la \\
empresa obtenga \\
un mínimo \\
beneficio \\
explotación \\
trimestral
\end{tabular} & & & \\
\hline
\end{tabular}




\begin{tabular}{|c|c|c|c|c|c|c|c|}
\hline $\begin{array}{c}\text { EUROPRALINE } \\
\text { Palencia }\end{array}$ & \begin{tabular}{|c|} 
B.O.P. \\
26/01/2015
\end{tabular} & $2015-2016$ & 1.784 horas & $\begin{array}{c}\text { A negociar en } \\
\text { diciembre }\end{array}$ & & $\begin{array}{l}\text { El importe } \\
\text { se reparte } \\
\text { entre las } \\
12 \text { pagas }\end{array}$ & \\
\hline $\begin{array}{c}\text { PRODUCTOS } \\
\text { SOLUBLES } \\
\text { Palencia }\end{array}$ & $\begin{array}{c}\text { B.O.P. } \\
07 / 01 / 2015\end{array}$ & $2015-2016$ & 1.784 horas & & & & $\begin{array}{c}\text { Objetivo } \\
\text { general de } \\
\text { empresa }\end{array}$ \\
\hline $\begin{array}{c}\text { SEVERIANO } \\
\text { SERVICIO } \\
\text { MOVIL } \\
\text { Palencia }\end{array}$ & $\begin{array}{c}\text { B.O.P. } \\
\text { 15/04/2015 }\end{array}$ & 2015 & 1.826 horas & $+0,2 \%$ & $\begin{array}{l}\text { Cantidad lineal } \\
\text { según tabla en } \\
\text { función de } \\
\text { resultado neto / } \\
\text { facturación }\end{array}$ & & \\
\hline $\begin{array}{c}\text { SIRO VENTA } \\
\text { DE BAÑOS } \\
\text { Palencia }\end{array}$ & $\begin{array}{c}\text { B.O.P. } \\
\text { 30/04/2015 }\end{array}$ & $2015-2017$ & \begin{tabular}{|l|}
1.760 horas \\
\end{tabular} & $\begin{array}{c}\text { 2015: +1,5\% } \\
\text { 2016: +1\% } \\
\text { 2017: +1\% } \\
\text { Además un } \\
\text { variable en } \\
\text { función de } \\
\text { productividad }\end{array}$ & & $\begin{array}{l}\text { Paga extra } \\
\text { de } \\
\text { beneficios }\end{array}$ & $\begin{array}{l}\text { Variable en } \\
\text { función de } \\
\text { absentismo } \\
\text { Calidad } \\
\text { siniestralidad }\end{array}$ \\
\hline $\begin{array}{c}\text { TAPAPAMA } \\
\text { RESTAUR. } \\
\text { Palencia }\end{array}$ & $\begin{array}{c}\text { B.O.P. } \\
\text { 16/03/2015 }\end{array}$ & $2015-2018$ & 1.796 horas & $\begin{array}{c}2015:+1 \% \\
2016:+1,3 \%\end{array}$ & & & \\
\hline
\end{tabular}




\begin{tabular}{|c|c|c|c|c|c|c|c|c|}
\hline $\begin{array}{c}\text { VERTICE DE } \\
\text { INNOVAC Y } \\
\text { DESARROL } \\
\text { ALIMENTOS } \\
\text { Palencia }\end{array}$ & \begin{tabular}{|c|} 
B.O.P. \\
01/04/2015
\end{tabular} & 2015-2018 & 1.792 horas & $\begin{array}{c}\text { 2015: una } \\
\text { mensualidad } \\
\text { bruta anual } \\
\text { 2016: } 40 \% \text { de } \\
\text { mensualidad } \\
\text { bruta anual } \\
\text { Resto: +2,5\% } \\
\text { o +IPC r + } \\
\text { 0,25\% }\end{array}$ & & $\begin{array}{l}\text { Paga extra } \\
\text { de } \\
\text { beneficios }\end{array}$ & & \\
\hline $\begin{array}{c}\text { ENUSA } \\
\text { Salamanca }\end{array}$ & $\begin{array}{c}\text { B.O.P. } \\
\text { 06/02/2015 }\end{array}$ & 2014 & 1.720 horas & & $\begin{array}{l}\text { Participación en } \\
\text { resultados según } \\
\text { resultados del } \\
\text { centro }\end{array}$ & & $\begin{array}{c}\text { Prima de } \\
\text { productividad }\end{array}$ & \\
\hline $\begin{array}{l}\text { INDUSTRIAS } \\
\text { DEL CUARZO } \\
\text { Segovia }\end{array}$ & $\begin{array}{c}\text { B.O.P. } \\
\text { 23/03/2015 }\end{array}$ & 2015-2016 & & $\begin{array}{c}\text { 2015: IPC r } \\
\text { mínimo } \\
+1,5 \% \\
\text { 2016: }+0,5 \% \\
\text { y revisión a } \\
\text { IPC r } \\
\text { condicionado } \\
\text { a la mejora de } \\
\text { rtdo } \\
\text { explotación } \\
\text { respecto al } \\
2015\end{array}$ & $\begin{array}{l}\text { Hasta un 2,5\% } \\
\text { según formula } \\
\text { que incluye entre } \\
\text { otros al rtdo } \\
\text { explotación y la } \\
\text { comparación } \\
\text { entre rtdo } \\
\text { previsto y real }\end{array}$ & & $\begin{array}{l}\text { Prima global de } \\
\text { productividad }\end{array}$ & $\begin{array}{c}\text { Información } \\
\text { mensual }\end{array}$ \\
\hline $\begin{array}{l}\text { ONTEX } \\
\text { Segovia }\end{array}$ & $\begin{array}{c}\text { B.O.P. } \\
\text { 27/04/2015 }\end{array}$ & 2015-2019 & $\begin{array}{l}\text { 2015: } 1792 \\
\text { 2016: } 1792 \\
\text { 2017: } 1792 \\
\text { 2018: } 1784 \\
\text { 2019: } 1784\end{array}$ & $\begin{array}{c}2015:+1 \% \\
2016:+0,9 \% \\
2017:+0,9 \% \\
2018:+0,9 \% \\
2019:+1 \%\end{array}$ & $\begin{array}{l}\text { Incremento de } \\
\text { revaloración con } \\
\text { referencia rtdo } \\
\text { explotación / } \\
\text { facturación si es } \\
\text { al menos el 3\% }\end{array}$ & & & \\
\hline
\end{tabular}




\begin{tabular}{|c|c|c|c|c|c|c|c|}
\hline $\begin{array}{c}\text { TRASTIERNES } \\
\text { Soria }\end{array}$ & $\begin{array}{c}\text { B.O.P. } \\
\text { 27/04/2015 }\end{array}$ & $2015-2019$ & 1.800 horas & & & & \\
\hline $\begin{array}{c}\text { CEVA } \\
\text { Valladolid }\end{array}$ & $\begin{array}{c}\text { B.O.P. } \\
\text { 27/02/2015 }\end{array}$ & 2015 & & $+1,5 \%$ & & $\begin{array}{c}\text { Plus } \\
\text { productividad }\end{array}$ & \\
\hline $\begin{array}{c}\text { CORTES } \\
\text { BARTOLOME } \\
\text { Valladolid }\end{array}$ & $\begin{array}{c}\text { B.O.P. } \\
\text { 04/02/2015 }\end{array}$ & $2015-2017$ & $\begin{array}{c}40 \text { horas } \\
\text { semanales }\end{array}$ & $\begin{array}{c}\text { El mayor } \\
\text { entre IPC r y } \\
\text { el } 0,80 \%\end{array}$ & & & \\
\hline $\begin{array}{c}\text { DHL } \\
\text { EXPRESS } \\
\text { Valladolid }\end{array}$ & $\begin{array}{c}\text { B.O.P. } \\
\text { 13/04/2015 }\end{array}$ & 2015-2017 & & $\begin{array}{c}\text { 2015: +2\% } \\
\text { Resto: }+1,5 \% \\
\text { Revisable + si } \\
\text { el IPC r } \\
\text { acumulado } \\
\text { fuera superior }\end{array}$ & & & \\
\hline $\begin{array}{c}\text { HIJOS DE } \\
\text { CIRIACO } \\
\text { SANCHEZ } \\
\text { Valladolid }\end{array}$ & $\begin{array}{c}\text { B.O.P. } \\
14 / 02 / 2015\end{array}$ & 2015 & $\begin{array}{l}8 \text { horas } \\
\text { diarias }\end{array}$ & Congelación & & & \\
\hline $\begin{array}{l}\text { INDUSTRIAS } \\
\text { LACTEAS } \\
\text { VALLISOLET } \\
\text { Valladolid }\end{array}$ & $\begin{array}{c}\text { B.O.P. } \\
02 / 03 / 2015\end{array}$ & $2015-2016$ & 1.760 horas & Congelación & $\begin{array}{c}\text { Paga extra } \\
\text { de } \\
\text { beneficios }\end{array}$ & $\begin{array}{c}\text { Plus de } \\
\text { rendimiento }\end{array}$ & \\
\hline $\begin{array}{c}\text { GRUPO } \\
\text { MONDELEZ } \\
\text { ESPAÑA } \\
\text { Valladolid }\end{array}$ & $\begin{array}{c}\text { B.O.P. } \\
\text { 16/03/2015 }\end{array}$ & 2015-2016 & 1.776 horas & $+0,6 \%$ & & & \\
\hline $\begin{array}{c}\text { RUSTICAS } \\
\text { PIEDRAS } \\
\text { NEGRAS } \\
\text { Valladolid }\end{array}$ & $\begin{array}{c}\text { B.O.P. } \\
\text { 18/04/2015 }\end{array}$ & 2015 & 1.795 horas & & & & \\
\hline
\end{tabular}




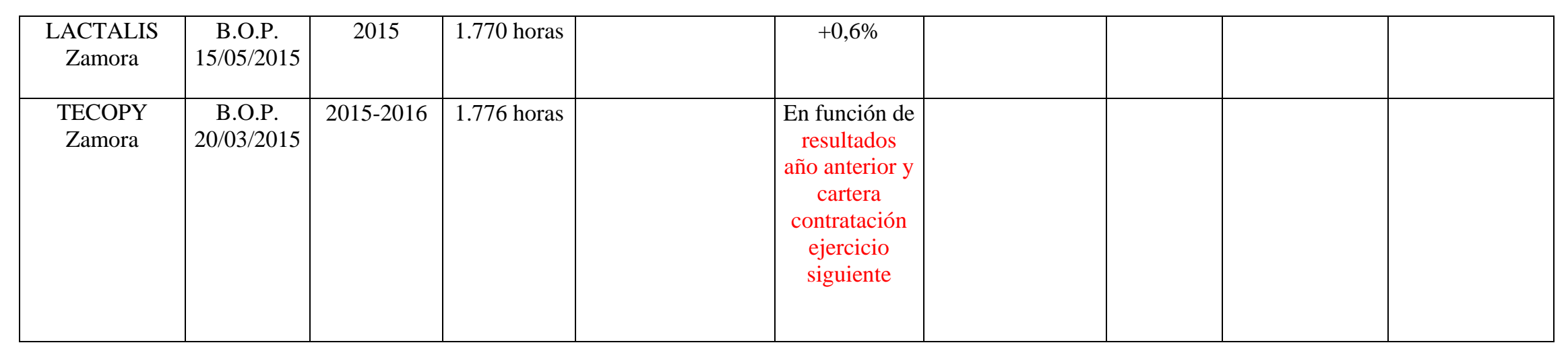




\section{ANEXO 8}

CARTA ENCUESTA NOVIEMBRE 2000 
PÁGINA 384 


\section{UNIVERSIDAD DE BURGOS DEPARTAMENTO DE ECONOMÍA Y ADMINISTRACION DE EMPRESAS}

Burgos, 13 de Noviembre de 2000

Estimado Señor:

$\mathrm{D}^{\mathrm{a}}$. Begoña Prieto Moreno, Directora del Departamento de Economía y Administración de Empresas de la Universidad de Burgos, en su propio nombre y en el del autor: D. Pablo Aguilar Conde, SOLICITA su colaboración para la recopilación de datos para la realización de la tesis doctoral "LA UTILIDAD DE LA INFORMACIÓN CONTABLE PARA LA NEGOCIACIÓN DE CONVENIOS COLECTIVOS DE EMPRESA EN LA PROVINCIA DE BURGOS”, y así mismo MANIFIESTA su compromiso y el del mencionado autor de garantizar la confidencialidad de la información recibida.

Por supuesto, dado que el objeto del trabajo es puramente académico, los datos recibidos sólo podrán ser presentados de manera agregada con el objeto de que no pueda ser identificada ninguna de las empresas que hayan facilitado información. Además le garantizamos que una vez elaborado el mencionado trabajo de investigación los datos serán destruidos.

Agradeciéndole por anticipado su colaboración, y rogándole nos respondan la encuesta adjunta en el tiempo más breve que les sea posible, quedamos a su disposición para cuantas dudas puedan tener sobre la misma y sobre el objeto de la investigación en el teléfono 947-276958 y 947-259038 (Preguntar por Pablo Aguilar). Aprovechamos la ocasión para saludarles atentamente.

Fdo. Da . Begoña Prieto Moreno

Directora del Departamento de Economía y Administración de Empresas 
PÁGINA 386 
ANEXO 9

ENCUESTA NOVIEMBRE 2000 
PÁGINA 388 


\section{I) DATOS IDENTIFICATIVOS}

1) Denominación social de la empresa a la que pertenece:

2) Domicilio social:

3) Actividad de la empresa: (CNAE)

4) Tipo de empresa (geográficamente):
a) Local
b) Regional
c) Nacional

5) Tipo de empresa (capital)
a) Perteneciente a grupo multinacional
b) Pertenenciente a grupo nacional
c) Familiar

6) Tamaño (datos referidos a 1999)
a) Cifra de activo total:
b) Cifra de negocio:
c) Número medio de trabajadores

7) En su empresa, ¿se negocia convenio de empresa?
a) Sí
b) No

8) En caso de que negocien convenio de empresa, ¿cuanto tiempo llevan haciéndolo?
a) Este es el primer año
b) Dos años
c) Tres años
d) Más de tres años

9) Cargo en la empresa de la persona que responde la encuesta 


\section{II) NEGOCIACIÓN COLECTIVA}

10) En su opinión, cual de las siguientes áreas es la más importante en la negociación colectiva
a) Salario
b) Jornada Laboral

11) ¿Qué sistemas de remuneración son más habituales en su empresa?
a) Los basados exclusivamente en una remuneración fija
b) Los basados exclusivamente en una remuneración variable
c) Los basados en un sistema mixto de remuneración

12) Considera que las condiciones económicas deben fijarse con base en:
a) La información contable
b) Las recomendaciones económicas gubernamentales

13) Considera que la fijación de las condiciones económicas del convenio colectivo, apoyándose en la información económica proporcionada por la contabilidad, puede ayudar a mejorar la participación de los trabajadores en la empresa:
a) Sí
b) No

14) En su opinión, la disponibilidad de información contable, favorece la negociación colectiva:
a) Sí
b) No 
15) Considera a los trabajadores, como usuarios de la información contable.
a) Sí
b) No

16) ¿Qué tipo de información contable se suministra a los empleados?
a) Mínima/Legal
b) Información "ad-hoc"
c) Ninguna

17) ¿Cuál de la siguiente información contable es más empleada en la negociación colectiva?
a) La suministrada por la contabilidad financiera (cuentas anuales)
b) La proporcionada por la contabilidad interna (productividad, costes, eficiencia ...)
c) Ambas por igual

18) ¿A quién se suministra la información contable externa?
a) A todos los empleados
b) A los representantes de los trabajadores
c) Sólo a los empleados que lo solicitan
d) A mandos intermedios y personal directivo
e) A todos los grupos interesados
f) A nadie

19) ¿A quién se suministra la información contable interna?
a) A todos los empleados
b) A los representantes de los trabajadores
c) Sólo a los empleados que lo solicitan
d) A mandos intermedios y personal directivo
e) A todos los grupos interesados
f) A nadie

20) ¿En qué situación se proporciona más información contable externa?
a) Situación de beneficios
b) Situación de pérdidas
c) La divulgación de información es independiente de las situaciones anteriores

21) ¿En qué situación se proporciona más información contable interna?
a) Situación de beneficios
b) Situación de pérdidas
c) La divulgación de información es independiente de las situaciones anteriores

22) En qué momento se suministra más información contable
a) Antes de la negociación
b) Durante la negociación
c) Después de la negociación 
23) En los convenios colectivos de empresa, para qué se utiliza más la información contable
a) Para fijar planes de remuneración
b) Para dejar de aplicar convenios de ámbito superior
c) Otros: Cítelos

24) Para establecer los incrementos en remuneraciones fijas, se tiene más en cuenta
a) El IPC
b) Datos contables
c) Otros. Cítelos:

25) Para establecer los incrementos en remuneraciones variables, se tiene más en cuenta
a) El IPC
b) Datos contables
c) Otros. Cítelos:

26) Cual de los siguientes datos contables es el más importante en la fijación de la retribución fija en su empresa
a) Cifra de beneficios
b) Dividendos repartidos
c) Cifra de ventas
d) Solvencia y liquidez
e) Ninguno de los anteriores

27) Cual de los siguientes datos contables es el más importante en la fijación de la retribución variable en su empresa
a) Cifra de beneficios
b) Dividendos repartidos
c) Cifra de ventas
d) Solvencia y liquidez
e) Ninguno de los anteriores

28) Las remuneraciones complementarias anuales (paga de productividad, objetivos, etc.), se suelen materializar en
a) Retribución monetaria
b) Retribución en acciones
c) Remuneración diferida (fondos de pensiones)
d) Remuneración en especie
e) Otros. Cítelos: 
29) Ante una situación de pérdidas o de menores beneficios, puesta de manifiesto a través de la información contable, ¿cree que las exigencias salariales de los trabajadores se moderarían si dispusieran de esa información contable?
a) Sí
b) No

30) Ante una situación de incremento de beneficios, puesta de manifiesto a través de la información contable, ¿cree que las exigencias salariales de los trabajadores se incrementarían si dispusieran de esa información contable?
a) Sí
b) No

31) Estaría dispuesto a negociar prescindiendo de datos del IPC y sólo con base en datos contables
a) Sí
b) No 
PÁGINA 394 
ANEXO 10

\section{CARTA ENCUESTA MAYO 2015}


PÁGINA 396 


\section{UNIVERSIDAD DE BURGOS \\ DEPARTAMENTO DE ECONOMÍA Y ADMINISTRACION DE EMPRESAS}

Burgos, 8 de Mayo de 2015

Estimado Señor:

$D^{a}$. Begoña Prieto Moreno y D. Pablo Aguilar Conde, profesores de Economía Financiera y Contabilidad del Departamento de Economía y Administración de Empresas de la Universidad de Burgos, SOLICITAN su colaboración para la recopilación de datos relacionados con el trabajo de investigación "LA UTILIDAD DE LA INFORMACIÓN CONTABLE PARA LA NEGOCIACIÓN DE CONVENIOS COLECTIVOS DE EMPRESA EN LA PROVINCIA DE BURGOS", y así mismo MANIFIESTAN su compromiso de garantizar la confidencialidad de la información recibida.

Por supuesto, dado que el objeto del trabajo es puramente académico, los datos recibidos sólo podrán ser presentados de manera agregada con el objeto de que no pueda ser identificada ninguna de las empresas que hayan facilitado información. Además, le garantizamos que una vez elaborado el mencionado trabajo de investigación los datos serán destruidos.

Agradeciéndole por anticipado su colaboración, y rogándole nos respondan la encuesta adjunta en el tiempo más breve que les sea posible, quedamos a su disposición para cuantas dudas puedan tener sobre la misma y sobre el objeto de la investigación en el teléfono 947-276958 y 947-259038 (Preguntar por Pablo Aguilar). Aprovechamos la ocasión para saludarles atentamente.

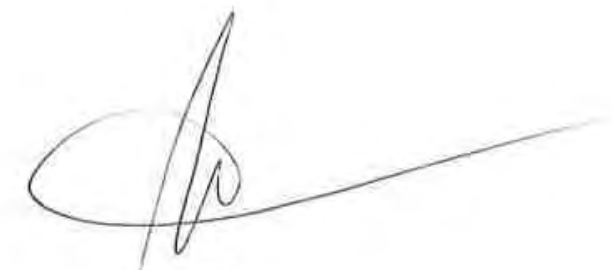

Fdo. Da. Begoña Prieto Moreno

Departamento de Economía y Administración de Empresas

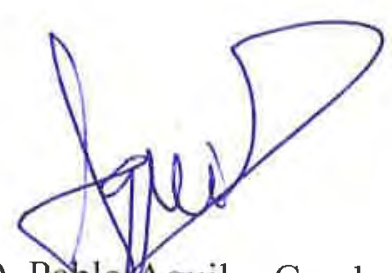

Universidad de Burgos

$$
\begin{aligned}
& \text { FACULTAD DE CIENCAS } \\
& \text { ECONOUICAS Y EMPRESARIALES } \\
& \text { Plaza Intanta Elena, s/n" } \\
& \text { co001 B URGOS }
\end{aligned}
$$

\section{FACULTAD DE CIENCIAS ECONOMICAS Y EMPRESARIALES \\ C/Los Parralillos, s/n $\quad 09001$ BURGOS Tel.: (947) $259038 \quad$ Fax: (947) 276958}


PÁGINA 398 
ANEXO 11

ENCUESTA MAYO 2015 
PÁGINA 400 


\section{I) NEGOCIACIÓN COLECTIVA}

1) De la siguiente relación, valore de 1 a 6 (siendo 1 menos importante y 6 más importante), los factores que considere más determinantes en la negociación del convenio colectivo de empresa:
a) Convenio sectorial
b) Poder de los sindicatos y calidad de las relaciones representantes sindicales / empresa
c) Coyuntura económica general
d) Coyuntura y situación económica del sector al que pertenece la empresa
e) Situación económica de la empresa

2) De la siguiente relación, valore de 1 a 6 (siendo 1 menos importante y 6 más importante), las materias que considere más determinantes para la firma del convenio colectivo de empresa:
a) Condiciones económicas: retribución fija
b) Jornada laboral
c) Flexibilidad tanto de jornada como funcional
d) Derechos sindicales
e) Derechos sociales, permisos, etc.
f) Condiciones de trabajo y productividad: retribución variable
g) Incrementos salariales
h) Mantenimiento-creación de empleo

3) De la siguiente relación, valore de 1 a 6 (siendo 1 menos importante y 6 más importante), las referencias que considere mejor aceptadas por ambas partes en la firma del convenio colectivo de empresa, en lo que se refiere a la revisión salarial:
a) PIB
b) IPC
c) Información económica propia de la empresa (tanto estrictamente financiera como de productividad/calidad)




\section{II) INFORMACIÓN ECONÓMICA}

4) De la información económica de la empresa, valore de 1 a 6 (siendo 1 menos importante y 6 más importante), la que podría aceptarse por ambas partes para referenciar el incremento salarial
a) Información económica de años anteriores
b) Información económica del momento de la negociación
c) Información económica prevista para futuros ejercicios

5) De la información económica de la empresa, valore de 1 a 6 (siendo 1 menos importante y 6 más importante), la que podría aceptarse por ambas partes para referenciar el incremento salarial
a) Facturación
b) Resultados
c) Cash flow
d) Productividad
e) Inversión

6) De la información económica de la empresa, valore de 1 a 6 (siendo 1 menos importante y 6 más importante), la que podría aceptarse por ambas partes para establecer complementos variables
a) Información económica de años anteriores
b) Información económica del momento de la negociación
c) Información económica prevista para futuros ejercicios

7) De la información económica de la empresa, valore de 1 a 6 (siendo 1 menos importante y 6 más importante), la que podría aceptarse por ambas partes para establecer complementos variables
a) Facturación
b) Resultados
c) Cash flow
d) Productividad
e) Calidad 
8) Indique si en su opinión, los representantes de los trabajadores consideran la información económica que se les suministra, como factor determinante a la hora de negociar y modular sus posiciones en la negociación:
a) Mucho
b) Poco
c) Nada

9) Indique si en su opinión si la situación y resultados de la empresa, sería aceptado por los representantes de los trabajadores para establecer:
a) La subida salarial
b) Las remuneraciones variables
c) La subida salarial y las remuneraciones variables
d) Ninguna de las anteriores

10) En la legislación laboral podemos encontrar como la situación económica negativa puede llevar, entre otros casos, a la inaplicación del convenio colectivo. Considera que sería positivo que la legislación laboral incluyera que en el caso de situación económica positiva, los trabajadores también tienen que ser partícipes (económicamente) de esa situación
a) Sí
b) No

11) Con la actual situación de desempleo y con inflación en datos negativos, considere que los sindicatos aceptarían sustituir subida salarial por reducción de jornada que diera lugar a nuevas contrataciones, para compensar esa reducción, sin que supusiera un coste añadido para la empresa
a) Sí
b) No 
PÁGINA 404 
ANEXO 12

\section{RESULTADOS CONVENIOS DICIEMBRE 2000}


PÁGINA 406 


\begin{tabular}{|c|c|c|c|}
\hline EMPRESA & REVISION & PART. B ${ }^{\circ}$ & INF. CONT. \\
\hline ANSA LEMFORDER S.A. & 1 & 1 & 0 \\
\hline AMVISA & 1 & 0 & 0 \\
\hline ARTEPREF GERARDO DE LA CALLE S.A. & 0 & 0 & 0 \\
\hline CERAMICAS GALA S.A. & 1 & 0 & 0 \\
\hline CISER S.L. & 0 & 0 & 1 \\
\hline COFRALIM & 0 & 0 & 0 \\
\hline CONFECCIONES ORY S.A. & 1 & 0 & 0 \\
\hline CRIMIDESA & 0 & 0 & 0 \\
\hline DIARIO DE BURGOS S.L. & 1 & 0 & 0 \\
\hline DAPSA & 0 & 0 & 0 \\
\hline DORLYL IBERICA S.L. & 0 & 0 & 0 \\
\hline DUOFAST DE ESPAÑA S.A. & 1 & 0 & 1 \\
\hline EDB S.A. & 0 & 1 & 1 \\
\hline ELF ATOCHEM ESPAÑA S.A. & 0 & 0 & 1 \\
\hline FABISA & 1 & 1 & 0 \\
\hline FALUNORSA & 1 & 0 & $\overline{0}$ \\
\hline GALLETAS CORAL S.A. & 1 & 0 & 0 \\
\hline GONVARRI INDUSTRIAL S.A. & 1 & 0 & 0 \\
\hline HELADOS MIKO S.A. & 0 & 0 & 0 \\
\hline HORMIGONES Y EXCAVACIONES G.C. & 1 & 0 & 0 \\
\hline HOSTAL TRES CONDES & 0 & 0 & 0 \\
\hline JJ BIS 95 S.L. & 0 & 0 & 0 \\
\hline KIMBERLY CLARK MIRANDA S.A. & 1 & 0 & 1 \\
\hline LA CELLOPHANE ESPAÑOLA S.A. & 1 & 0 & 1 \\
\hline LENNOX REFAC S.A. & 1 & 0 & 1 \\
\hline MANUFACTURAS ORIVE S.A. & 1 & 0 & 0 \\
\hline MONTEFIBRE HISPANIA S.A. & 0 & 0 & 0 \\
\hline NICOLAS CORREA S.A. & 1 & 1 & 0 \\
\hline ONNYX RSU & 0 & 0 & 0 \\
\hline PIERRE GUERIN IBERICA S.A. & 0 & 0 & 1 \\
\hline PROSIDER IBERICA S.A. & 0 & 0 & 0 \\
\hline REPOSTERIA MARTINEZ S.A. & 1 & 0 & 0 \\
\hline RHONE POULENC S.A. & 1 & 0 & 0 \\
\hline ROTTNEROS MIRANDA S.A. & 1 & 0 & 1 \\
\hline SAN MIGUEL S.A. & 1 & 0 & 1 \\
\hline SCHINDLER S.A. & 0 & 1 & 0 \\
\hline SNACK VENTURES S.A. & 1 & 0 & $\overline{0}$ \\
\hline SOMA S.L. & 0 & 0 & 0 \\
\hline STORK INTERIBERICA S.A. & 1 & 0 & 1 \\
\hline STORK SISTEMAS ALIMENTARIOS S.A. & 1 & 0 & 1 \\
\hline TALLERES ARA S.L. & 1 & 0 & 0 \\
\hline TUGASA & 0 & 0 & 0 \\
\hline TRW S.A. & 1 & 1 & 0 \\
\hline UNION ESPAÑOLA DE EXPLOSIVOS S.A. & 0 & 0 & 0 \\
\hline VB AUTOBATERIAS S.A. & 0 & 0 & 1 \\
\hline VICASA S.A. & 1 & 1 & 0 \\
\hline
\end{tabular}


PÁGINA 408 
ANEXO 13

\section{RESULTADOS CONVENIOS DICIEMBRE 2014}


PÁGINA 410 


\begin{tabular}{|c|c|c|c|c|c|c|c|c|}
\hline EMPRESAS AÑO 2002 & \begin{tabular}{|l|} 
REVISION \\
IPC
\end{tabular} & \begin{tabular}{|l|} 
REVISION \\
FIJA
\end{tabular} & \begin{tabular}{|l|} 
REVISION \\
VARIABLE
\end{tabular} & \begin{tabular}{|l|} 
NO \\
REVISION
\end{tabular} & PART. B ${ }^{\circ}$ & \begin{tabular}{|c|} 
PAGA \\
EXTRA
\end{tabular} & \begin{tabular}{c|} 
OTRAS \\
REM.
\end{tabular} & INF. CONT. \\
\hline ADISSEO & 1 & & & & & & & \\
\hline ALPHACAN & 1 & & & & & & & \\
\hline \multicolumn{9}{|l|}{ AMVISA } \\
\hline \multicolumn{9}{|l|}{ AQUAGEST } \\
\hline \multicolumn{9}{|l|}{ ARDASA } \\
\hline \multicolumn{9}{|l|}{ ARTEPREF } \\
\hline \multicolumn{9}{|l|}{ AVENTIS } \\
\hline \multirow{2}{*}{\multicolumn{9}{|c|}{ CALFERMAN }} \\
\hline & & & & & & & & \\
\hline \multicolumn{9}{|l|}{ CERAMICAS GALA } \\
\hline \multicolumn{9}{|l|}{ CESPA } \\
\hline \multirow{2}{*}{\multicolumn{9}{|c|}{ CLAU 2000}} \\
\hline COMPAÑÍA MINERA RIO TIROI & & & & & & & & \\
\hline CONFECCIONES ORY & & & & & & & & \\
\hline DEXMUSA & & & & & & & & \\
\hline DIARIO DE BURGOS & 1 & & & & & 1 & & \\
\hline DUO FAST & 1 & & & & & & & 1 \\
\hline EDB & 1 & & & & 1 & & & 1 \\
\hline EDSCHA & & & & & & & & \\
\hline ESTACIONAMIENTOS Y SERVICIOS & & & & & & & & \\
\hline EXPAL & & & & & & & & \\
\hline EXPLOSIVOS COMPAÑÍA INDUSTRIA ALAVES/ & & & & & & & & \\
\hline FABISA & & & & & & & & \\
\hline GALLETAS CORAL & & & & & & & & \\
\hline GALLETAS JESUS ANGULO & & & & & & & & \\
\hline GONVARRI INDUSTRIAL & 1 & & & & & 1 & 1 & \\
\hline GRUPO ANTOLIN ARA & & & & & & & & \\
\hline GRUPO ANTOLIN ARDASF & & & & & & & & \\
\hline GRUPO ANTOLIN DAPSA & & & & & & & & \\
\hline GRUPO ANTOLIN EUROTRIN & & & & & & & & \\
\hline GRUPO GARCIA CAMARERC & & & & & & & & \\
\hline GRUPO GERARDO DE LA CALLE & & & & & & & & \\
\hline GRUPO ITEVELESA & & & & & & & & \\
\hline HEIMBACH IBERIC $f$ & & & & & & & & \\
\hline HELADOS MIKO & & & & & & & & \\
\hline HIPERBARIC & & & & & & & & \\
\hline HORMIGONES Y EXC GERARDO DE LA CALLE & 1 & & & & & & & 1 \\
\hline HOSTAL TRES CONDES & 1 & & & & & & & \\
\hline JOHNSON CONTROL AUTOBATERIAS & & & & & & & & \\
\hline KRONOSPAN & & & & & & & & \\
\hline LA FLOR BURGALESA & & & & & & & & \\
\hline LENNOX REFAC & 1 & & & & 1 & & & 1 \\
\hline MANUFACTURAS ORIVE & 1 & & & & & 1 & & \\
\hline MINAS DE RIO TIRON CRIMIDES $f$ & 1 & & & & & & & \\
\hline MONCOR 2000 & & & & & & & & \\
\hline MONTEFIBRE HISPANIA & & & & & & & & \\
\hline MUEBLES MARIA LUIS $A$ & & & & & & & & \\
\hline NICOLAS CORREA & & & & & & & & \\
\hline PASCUAL HERMANOS & & & & & & & & \\
\hline PEPSICO MANUFACTURING & & & & & & & & \\
\hline PIERRE GUERIN IBERICA & & & & & & & & \\
\hline PLANIFICACION Y CONTROL LOGISTICC & & & & & & & & \\
\hline PROSIDER IBERICA & & & & & & & & \\
\hline ROTTNEROS MIRANDA & & & & & & & & \\
\hline SAINT GOBAIN VICAS $A$ & & & & & & & & \\
\hline SCHINDLER & & & & & & & & \\
\hline SERUNION & & & & & & & & \\
\hline SERVICIOS SEMAT & 1 & & & & & & & \\
\hline SIRO BRIVIESCA & & & & & & & & \\
\hline SNACK VENTURES MANUFACTURING & & & & & & & & \\
\hline STORK INTERIBERICA & 1 & & & & 1 & & & 1 \\
\hline TECNICAS MEDIOAMBIENTALES TECMED & & & & & & & & \\
\hline THYSSEN KRUPP ELEVADORES & & & & & & & & \\
\hline TRANS UNION GAS TUGASA & & & & & & & & \\
\hline TRW AUTOMOTIVE & 1 & & & & & & & \\
\hline URBASER & & & & & & & & \\
\hline VB AUTOBATERIAS & 1 & & & & & & 1 & \\
\hline ZAMORANO LIMPIEZAS MIRAND/ & & & & & & & & \\
\hline ZF ANSA LEMFORDER & & & & & & & & \\
\hline
\end{tabular}




\begin{tabular}{|c|c|c|c|c|c|c|c|c|}
\hline EMPRESAS AÑO 2003 & \begin{tabular}{|l|} 
REVISION \\
IPC
\end{tabular} & \begin{tabular}{|l|} 
REVISION \\
FIJA \\
\end{tabular} & \begin{tabular}{|l|} 
REVISION \\
VARIABLE \\
\end{tabular} & \begin{tabular}{|l|} 
NO \\
REVISION \\
\end{tabular} & PART. B ${ }^{\circ}$ & \begin{tabular}{|c|} 
PAGA \\
EXTRA \\
\end{tabular} & \begin{tabular}{|c|} 
OTRAS \\
REM. \\
\end{tabular} & INF. CONT. \\
\hline ADISSEO & 1 & & & & & 1 & 1 & \\
\hline ALPHACAN & 1 & & & & & & & \\
\hline AMVISA & 1 & & & & 1 & & 1 & \\
\hline \multicolumn{9}{|l|}{ AQUAGEST } \\
\hline ARDASA & 1 & & & & & & & \\
\hline ARTEPREF & & & & & & & & 1 \\
\hline AVENTIS & 1 & & & & & & & \\
\hline \multicolumn{9}{|l|}{ CALFERMAN } \\
\hline \multicolumn{9}{|l|}{ CENTRO GERONTOLOGICO } \\
\hline \multicolumn{9}{|l|}{ CERAMICAS GALA } \\
\hline CESPA & 1 & & & & & & & \\
\hline \multicolumn{9}{|l|}{ CLAU 2000} \\
\hline \multicolumn{9}{|l|}{ COMPAÑÍA MINERA RIO TIROI } \\
\hline \multicolumn{9}{|l|}{ CONFECCIONES ORY } \\
\hline \multicolumn{9}{|l|}{ DEXMUSA } \\
\hline DIARIO DE BURGOS & 1 & & & & & 1 & & \\
\hline DUO FAST & 1 & & & & & & & 1 \\
\hline EDB & 1 & & & & 1 & & & 1 \\
\hline \multicolumn{9}{|l|}{ EDSCHA } \\
\hline \multicolumn{9}{|l|}{ ESTACIONAMIENTOS Y SERVICIOS } \\
\hline EXPAL & & & & & & & & \\
\hline EXPLOSIVOS COMPAÑÍA INDUSTRIA ALAVES/ & & & & & & & & \\
\hline FABISA & & & & & & & & \\
\hline GALLETAS CORAL & & & & & & & & \\
\hline GALLETAS JESUS ANGULO & & & & & & & & \\
\hline GONVARRI INDUSTRIAL & 1 & & & & & 1 & 1 & \\
\hline GRUPO ANTOLIN ARA & & & & & & & & \\
\hline GRUPO ANTOLIN ARDASF & & & & & & & & \\
\hline GRUPO ANTOLIN DAPSA & & & & & & & & \\
\hline GRUPO ANTOLIN EUROTRIN & 1 & & & & & & & \\
\hline GRUPO GARCIA CAMARERC & 1 & & & & & 1 & & 1 \\
\hline GRUPO GERARDO DE LA CALLE & & & & & & & & \\
\hline GRUPO ITEVELESA & & & & & & & & \\
\hline HEIMBACH IBERICA & & & & & & & & \\
\hline HELADOS MIKO & 1 & & & & & & 1 & \\
\hline HIPERBARIC & & & & & & & & \\
\hline HORMIGONES Y EXC GERARDO DE LA CALLE & 1 & & & & & & & 1 \\
\hline HOSTAL TRES CONDES & 1 & & & & & & & \\
\hline JOHNSON CONTROL AUTOBATERIAS & & & & & & & & \\
\hline KRONOSPAN & & & & & & & & \\
\hline LA FLOR BURGALESA & & & & & & & & \\
\hline LENNOX REFAC & 1 & & & & 1 & & & 1 \\
\hline MANUFACTURAS ORIVE & 1 & & & & & 1 & & \\
\hline MINAS DE RIO TIRON CRIMIDES $A$ & 1 & & & & & & & \\
\hline MONCOR 2000 & & & & & & & & \\
\hline MONTEFIBRE HISPANIA & & & & & & & & \\
\hline MUEBLES MARIA LUISA & & & & & & & & \\
\hline NICOLAS CORREA & 1 & & & & & & & \\
\hline PASCUAL HERMANOS & & & & & & & & \\
\hline PEPSICO MANUFACTURING & & & & & & & & \\
\hline PIERRE GUERIN IBERICA & 1 & & & & & & & 1 \\
\hline PLANIFICACION Y CONTROL LOGISTICC & & & & & & & & \\
\hline PROSIDER IBERICA & 1 & & & & & 1 & & \\
\hline ROTTNEROS MIRANDA & & & & & & & & \\
\hline SAINT GOBAIN VICASA & 1 & & & & 1 & & 1 & \\
\hline SCHINDLER & & & & & & & & \\
\hline SERUNION & & & & & & & & \\
\hline SERVICIOS SEMAT & 1 & & & & & & & \\
\hline SIRO BRIVIESCA & & & & & & & & \\
\hline SNACK VENTURES MANUFACTURING & & & & & & & & \\
\hline STORK INTERIBERICA & 1 & & & & 1 & & & 1 \\
\hline TECNICAS MEDIOAMBIENTALES TECMED & 1 & & & & & & & \\
\hline THYSSEN KRUPP ELEVADORES & & & & & & & & \\
\hline TRANS UNION GAS TUGASA & & 1 & & & & 1 & & \\
\hline TRW AUTOMOTIVE & 1 & & & & & & & \\
\hline URBASER & & & & & & & & \\
\hline VB AUTOBATERIAS & 1 & & & & & & 1 & \\
\hline ZAMORANO LIMPIEZAS MIRANDI & & & & & & & & \\
\hline ZF ANSA LEMFORDER & & & & & & & & \\
\hline
\end{tabular}




\begin{tabular}{|c|c|c|c|c|c|c|c|c|}
\hline EMPRESAS AÑO 2004 & \begin{tabular}{|l|} 
REVISION \\
IPC
\end{tabular} & \begin{tabular}{|l|} 
REVISION \\
FIJA
\end{tabular} & \begin{tabular}{|l} 
REVISION \\
VARIABLE
\end{tabular} & \begin{tabular}{|l|} 
NO \\
REVISION
\end{tabular} & PART. B ${ }^{\circ}$ & \begin{tabular}{|c|} 
PAGA \\
EXTRA
\end{tabular} & \begin{tabular}{|c|} 
OTRAS \\
REM.
\end{tabular} & INF. CONT. \\
\hline ADISSEO & 1 & & & & & 1 & 1 & \\
\hline ALPHACAN & 1 & & & & & & & \\
\hline AMVISA & 1 & & & & 1 & & 1 & \\
\hline \multicolumn{9}{|l|}{ AQUAGEST } \\
\hline ARDASA & 1 & & & & & & & \\
\hline ARTEPREF & & & & & & & & 1 \\
\hline AVENTIS & 1 & & & & & & & \\
\hline \multicolumn{9}{|l|}{ CALFERMAN } \\
\hline \multicolumn{9}{|l|}{ CENTRO GERONTOLOGICO } \\
\hline CERAMICAS GALA & 1 & & & & & & 1 & \\
\hline CESPA & 1 & & & & & 1 & & \\
\hline \multicolumn{9}{|l|}{ CLAU 2000} \\
\hline \multicolumn{9}{|l|}{ COMPAÑÍA MINERA RIO TIRON } \\
\hline CONFECCIONES ORY & 1 & & & & & 1 & & \\
\hline \multicolumn{9}{|l|}{ DEXMUSA } \\
\hline DIARIO DE BURGOS & 1 & & & & & 1 & & \\
\hline DUO FAST & 1 & & & & & & & 1 \\
\hline EDB & 1 & & & & 1 & & & 1 \\
\hline \multicolumn{9}{|l|}{ EDSCHA } \\
\hline ESTACIONAMIENTOS Y SERVICIOS & 1 & & & & & 1 & & 1 \\
\hline \multicolumn{9}{|l|}{ EXPAL } \\
\hline \multicolumn{9}{|l|}{ EXPLOSIVOS COMPAÑÍA INDUSTRIA ALAVES/ } \\
\hline FABISA & 1 & & & & 1 & & 1 & \\
\hline \multicolumn{9}{|l|}{ GALLETAS CORAL } \\
\hline GALLETAS JESUS ANGULO & & & & & & & & \\
\hline GONVARRI INDUSTRIAL & 1 & & & & & 1 & 1 & \\
\hline GRUPO ANTOLIN ARA & 1 & & & & 1 & & 1 & \\
\hline GRUPO ANTOLIN ARDASF & & & & & & & & \\
\hline GRUPO ANTOLIN DAPSA & & & & & & & & \\
\hline GRUPO ANTOLIN EUROTRIN & 1 & & & & & & & \\
\hline GRUPO GARCIA CAMARERC & 1 & & & & & 1 & & 1 \\
\hline GRUPO GERARDO DE LA CALLE & 1 & & & & & & & 1 \\
\hline GRUPO ITEVELESA & & & & & & & & \\
\hline HEIMBACH IBERICA & & & & & & & & \\
\hline HELADOS MIKO & 1 & & & & & & 1 & \\
\hline HIPERBARIC & & & & & & & & \\
\hline HORMIGONES Y EXC GERARDO DE LA CALLE & 1 & & & & & & & 1 \\
\hline HOSTAL TRES CONDES & 1 & & & & & & & \\
\hline JOHNSON CONTROL AUTOBATERIAS & & & & & & & & \\
\hline KRONOSPAN & & & & & & & & \\
\hline LA FLOR BURGALESA & & & & & & & & \\
\hline LENNOX REFAC & 1 & & & & 1 & & & 1 \\
\hline MANUFACTURAS ORIVE & 1 & & & & & 1 & & \\
\hline MINAS DE RIO TIRON CRIMIDESA & 1 & & & & & & & \\
\hline MONCOR 2000 & & & & & & & & \\
\hline MONTEFIBRE HISPANIA & 1 & & & & & 1 & 1 & \\
\hline MUEBLES MARIA LUISA & 1 & & & & & & & \\
\hline NICOLAS CORREA & 1 & & & & & & & \\
\hline PASCUAL HERMANOS & & & & & & & & \\
\hline PEPSICO MANUFACTURING & & & & & & & & \\
\hline PIERRE GUERIN IBERICA & 1 & & & & & & & 1 \\
\hline PLANIFICACION Y CONTROL LOGISTICC & & & & & & & & \\
\hline PROSIDER IBERICA & 1 & & & & & 1 & & \\
\hline ROTTNEROS MIRANDA & & & & & & & & \\
\hline SAINT GOBAIN VICASA & 1 & & & & 1 & & 1 & \\
\hline SCHINDLER & & & & & & & & \\
\hline SERUNION & & & & & & & & \\
\hline SERVICIOS SEMAT & 1 & & & & & & & \\
\hline SIRO BRIVIESCA & & & & & & & & \\
\hline SNACK VENTURES MANUFACTURING & & & & & & & & \\
\hline STORK INTERIBERICA & 1 & & & & 1 & & & 1 \\
\hline TECNICAS MEDIOAMBIENTALES TECMED & 1 & & & & & & & \\
\hline THYSSEN KRUPP ELEVADORES & & & & & & & & \\
\hline TRANS UNION GAS TUGASA & & 1 & & & & 1 & & \\
\hline TRW AUTOMOTIVE & 1 & & & & 1 & & & \\
\hline URBASER & & & & & & & & \\
\hline VB AUTOBATERIAS & 1 & & & & & & 1 & \\
\hline ZAMORANO LIMPIEZAS MIRAND/ & & & & & & & & \\
\hline ZF ANSA LEMFORDER & 1 & & & & 1 & & & \\
\hline
\end{tabular}




\begin{tabular}{|c|c|c|c|c|c|c|c|c|}
\hline EMPRESAS AÑO 2005 & \begin{tabular}{|l|} 
REVISION \\
IPC \\
\end{tabular} & \begin{tabular}{|l|} 
REVISION \\
FIJA
\end{tabular} & \begin{tabular}{|l} 
REVISION \\
VARIABLE \\
\end{tabular} & \begin{tabular}{|l|} 
NO \\
REVISION \\
\end{tabular} & PART. B ${ }^{\circ}$ & \begin{tabular}{|c|} 
PAGA \\
EXTRA \\
\end{tabular} & \begin{tabular}{|c|} 
OTRAS \\
REM. \\
\end{tabular} & INF. CONT. \\
\hline ADISSEO & 1 & & & & & 1 & 1 & \\
\hline ALPHACAN & 1 & & & & & & 1 & \\
\hline AMVISA & 1 & & & & 1 & & 1 & \\
\hline AQUAGEST & 1 & & & & & 1 & & \\
\hline ARDASA & 1 & & & & & & & \\
\hline ARTEPREF & 1 & & & & & & & 1 \\
\hline AVENTIS & 1 & & & & & & & \\
\hline CALFERMAN & 1 & & & & & & & 1 \\
\hline \multicolumn{9}{|l|}{ CENTRO GERONTOLOGICO } \\
\hline CERAMICAS GALA & 1 & & & & & & 1 & \\
\hline CESPA & 1 & & & & & 1 & & \\
\hline \multicolumn{9}{|l|}{ CLAU 2000} \\
\hline \multicolumn{9}{|l|}{ COMPAÑÍA MINERA RIO TIRON } \\
\hline CONFECCIONES ORY & 1 & & & & & 1 & & \\
\hline \multicolumn{9}{|l|}{ DEXMUSA } \\
\hline DIARIO DE BURGOS & 1 & & & & & 1 & & \\
\hline DUO FAST & 1 & & & & & & & 1 \\
\hline EDB & 1 & & & & 1 & & & 1 \\
\hline \multicolumn{9}{|l|}{ EDSCHA } \\
\hline ESTACIONAMIENTOS Y SERVICIOS & 1 & & & & & 1 & & 1 \\
\hline \multicolumn{9}{|l|}{ EXPAL } \\
\hline EXPLOSIVOS COMPAÑÍA INDUSTRIA ALAVES & 1 & & & & 1 & & & 1 \\
\hline FABISA & 1 & & & & 1 & & 1 & \\
\hline \multicolumn{9}{|l|}{ GALLETAS CORAL } \\
\hline \multicolumn{9}{|l|}{ GALLETAS JESUS ANGULO } \\
\hline GONVARRI INDUSTRIAL & 1 & & & & & 1 & 1 & \\
\hline GRUPO ANTOLIN ARA & 1 & & & & 1 & & 1 & \\
\hline \multicolumn{9}{|l|}{ GRUPO ANTOLIN ARDASF } \\
\hline \multicolumn{9}{|l|}{ GRUPO ANTOLIN DAPSA } \\
\hline GRUPO ANTOLIN EUROTRIN & 1 & & & & & & & \\
\hline GRUPO GARCIA CAMARERC & 1 & & & & & 1 & & 1 \\
\hline GRUPO GERARDO DE LA CALLE & 1 & & & & & & & 1 \\
\hline GRUPO ITEVELESA & & & & & & & & \\
\hline HEIMBACH IBERICA & 1 & & & & & & & \\
\hline HELADOS MIKO & 1 & & & & & & 1 & \\
\hline HIPERBARIC & & & & & & & & \\
\hline HORMIGONES Y EXC GERARDO DE LA CALLE & 1 & & & & & & & 1 \\
\hline HOSTAL TRES CONDES & 1 & & & & & 1 & & \\
\hline JOHNSON CONTROL AUTOBATERIAS & & & & & & & & \\
\hline KRONOSPAN & & & & & & & & \\
\hline LA FLOR BURGALESA & & & & & & & & \\
\hline LENNOX REFAC & 1 & & & & 1 & & & 1 \\
\hline MANUFACTURAS ORIVE & 1 & & & & & 1 & & \\
\hline MINAS DE RIO TIRON CRIMIDES & 1 & & & & & & & \\
\hline MONCOR 2000 & & & & & & & & \\
\hline MONTEFIBRE HISPANIA & 1 & & & & & 1 & 1 & \\
\hline MUEBLES MARIA LUISA & 1 & & & & & & & \\
\hline NICOLAS CORREA & 1 & & & & & & & \\
\hline PASCUAL HERMANOS & & & & & & & & \\
\hline PEPSICO MANUFACTURING & & & & & & & & \\
\hline PIERRE GUERIN IBERICA & 1 & & & & & & & 1 \\
\hline PLANIFICACION Y CONTROL LOGISTICC & & & & & & & & \\
\hline PROSIDER IBERICA & 1 & & & & & 1 & & \\
\hline ROTTNEROS MIRANDA & 1 & & & & & & 1 & 1 \\
\hline SAINT GOBAIN VICASA & 1 & & & & 1 & & 1 & \\
\hline SCHINDLER & & & & & & & & \\
\hline SERUNION & & & & & & & & \\
\hline SERVICIOS SEMAT & 1 & & & & & 1 & & \\
\hline SIRO BRIVIESCA & & & & & & & & \\
\hline SNACK VENTURES MANUFACTURING & & & & & & & & \\
\hline STORK INTERIBERICA & 1 & & & & 1 & & & 1 \\
\hline TECNICAS MEDIOAMBIENTALES TECMED & 1 & & & & & & & \\
\hline THYSSEN KRUPP ELEVADORES & 1 & & & & 1 & & & \\
\hline TRANS UNION GAS TUGASA & & 1 & & & & 1 & & \\
\hline TRW AUTOMOTIVE & & & & & & & & \\
\hline URBASER & 1 & & & & & & & \\
\hline VB AUTOBATERIAS & 1 & & & & & & 1 & \\
\hline ZAMORANO LIMPIEZAS MIRANDI & & & & & & & & \\
\hline ZF ANSA LEMFORDER & 1 & & & & 1 & & & \\
\hline
\end{tabular}




\begin{tabular}{|c|c|c|c|c|c|c|c|c|}
\hline EMPRESAS AÑO 2006 & \begin{tabular}{|l|} 
REVISION \\
IPC
\end{tabular} & \begin{tabular}{|l|} 
REVISION \\
FIJA
\end{tabular} & \begin{tabular}{|l|} 
REVISION \\
VARIABLE \\
\end{tabular} & \begin{tabular}{|l|} 
NO \\
REVISION \\
\end{tabular} & PART. B ${ }^{\circ}$ & \begin{tabular}{|c|} 
PAGA \\
EXTRA \\
\end{tabular} & \begin{tabular}{|c|} 
OTRAS \\
REM. \\
\end{tabular} & INF. CONT. \\
\hline ADISSEO & 1 & & & & & 1 & 1 & \\
\hline ALPHACAN & 1 & & & & & & 1 & \\
\hline AMVISA & 1 & & & & 1 & & 1 & \\
\hline AQUAGEST & 1 & & & & & 1 & & \\
\hline ARDASA & 1 & & & & & & & \\
\hline ARTEPREF & 1 & & & & & & & 1 \\
\hline AVENTIS & 1 & & & & & & & \\
\hline CALFERMAN & 1 & & & & & & & 1 \\
\hline \multicolumn{9}{|l|}{ CENTRO GERONTOLOGICO } \\
\hline CERAMICAS GALA & 1 & & & & & & 1 & \\
\hline CESPA & 1 & & & & & 1 & & \\
\hline \multicolumn{9}{|l|}{ CLAU 2000} \\
\hline \multicolumn{9}{|l|}{ COMPAÑÍA MINERA RIO TIRON } \\
\hline CONFECCIONES ORY & 1 & & & & & 1 & & \\
\hline DEXMUSA & 1 & & & & & 1 & & \\
\hline DIARIO DE BURGOS & 1 & & & & & & & 1 \\
\hline DUO FAST & 1 & & & & & & & 1 \\
\hline EDB & 1 & & & & 1 & & & 1 \\
\hline \multicolumn{9}{|l|}{ EDSCHA } \\
\hline ESTACIONAMIENTOS Y SERVICIOS & 1 & & & & & 1 & & 1 \\
\hline \multicolumn{9}{|l|}{ EXPAL } \\
\hline EXPLOSIVOS COMPAÑÍA INDUSTRIA ALAVES/ & 1 & & & & 1 & & & 1 \\
\hline FABISA & 1 & & & & 1 & & 1 & \\
\hline \multicolumn{9}{|l|}{ GALLETAS CORAL } \\
\hline \multicolumn{9}{|l|}{ GALLETAS JESUS ANGULO } \\
\hline GONVARRI INDUSTRIAL & 1 & & & & & 1 & 1 & \\
\hline GRUPO ANTOLIN ARA & 1 & & & & 1 & & 1 & \\
\hline \multicolumn{9}{|l|}{ GRUPO ANTOLIN ARDASF } \\
\hline \multicolumn{9}{|l|}{ GRUPO ANTOLIN DAPSA } \\
\hline GRUPO ANTOLIN EUROTRIN & 1 & & & & & & & \\
\hline GRUPO GARCIA CAMARERC & 1 & & & & & 1 & & 1 \\
\hline GRUPO GERARDO DE LA CALLE & 1 & & & & & & & 1 \\
\hline \multicolumn{9}{|l|}{ GRUPO ITEVELESA } \\
\hline HEIMBACH IBERICA & 1 & & & & & & & \\
\hline HELADOS MIKO & 1 & & & & & & 1 & \\
\hline HIPERBARIC & & & & & & & & \\
\hline HORMIGONES Y EXC GERARDO DE LA CALLE & 1 & & & & & & & 1 \\
\hline HOSTAL TRES CONDES & 1 & & & & & 1 & & \\
\hline JOHNSON CONTROL AUTOBATERIAS & & & & & & & & \\
\hline KRONOSPAN & & & & & & & & \\
\hline LA FLOR BURGALESA & & & & & & & & \\
\hline LENNOX REFAC & 1 & & & & & & & 1 \\
\hline MANUFACTURAS ORIVE & 1 & & & & & 1 & 1 & \\
\hline MINAS DE RIO TIRON CRIMIDES & 1 & & & & & & & \\
\hline MONCOR 2000 & & & & & & & & \\
\hline MONTEFIBRE HISPANIA & 1 & & & & & 1 & 1 & \\
\hline MUEBLES MARIA LUISA & 1 & & & & & & & \\
\hline NICOLAS CORREA & & & 1 & & & & & \\
\hline PASCUAL HERMANOS & & & & & & & & \\
\hline PEPSICO MANUFACTURING & & & & & & & & \\
\hline PIERRE GUERIN IBERICA & 1 & & & & & & & 1 \\
\hline PLANIFICACION Y CONTROL LOGISTICC & & & & & & & & \\
\hline PROSIDER IBERICA & 1 & & & & & 1 & & \\
\hline ROTTNEROS MIRANDA & 1 & & & & & & 1 & 1 \\
\hline SAINT GOBAIN VICASA & 1 & & & & & & 1 & \\
\hline SCHINDLER & & & & & & & & \\
\hline SERUNION & & & & & & & & \\
\hline SERVICIOS SEMAT & 1 & & & & & 1 & & \\
\hline SIRO BRIVIESCA & & & & & & & & \\
\hline SNACK VENTURES MANUFACTURING & 1 & & & & & 1 & & \\
\hline STORK INTERIBERICA & 1 & & & & 1 & & & 1 \\
\hline TECNICAS MEDIOAMBIENTALES TECMED & 1 & & & & & & & \\
\hline THYSSEN KRUPP ELEVADORES & 1 & & & & 1 & & & \\
\hline TRANS UNION GAS TUGASA & & 1 & & & & 1 & & \\
\hline TRW AUTOMOTIVE & & & & & & & & \\
\hline URBASER & 1 & & & & & & & \\
\hline VB AUTOBATERIAS & 1 & & & & & & 1 & \\
\hline ZAMORANO LIMPIEZAS MIRANDI & & & & & & & & \\
\hline ZF ANSA LEMFORDER & 1 & & & & 1 & & & \\
\hline
\end{tabular}




\begin{tabular}{|c|c|c|c|c|c|c|c|c|}
\hline EMPRESAS AÑO 2007 & \begin{tabular}{|l|} 
REVISION \\
IPC
\end{tabular} & \begin{tabular}{|l|} 
REVISION \\
FIJA
\end{tabular} & \begin{tabular}{|l|} 
REVISION \\
VARIABLE \\
\end{tabular} & \begin{tabular}{|l|} 
NO \\
REVISION \\
\end{tabular} & PART. B ${ }^{\circ}$ & \begin{tabular}{|c|} 
PAGA \\
EXTRA \\
\end{tabular} & \begin{tabular}{|c|} 
OTRAS \\
REM. \\
\end{tabular} & INF. CONT. \\
\hline ADISSEO & 1 & & & & & 1 & 1 & 1 \\
\hline ALPHACAN & 1 & & & & & & 1 & \\
\hline AMVISA & 1 & & & & 1 & & 1 & \\
\hline AQUAGEST & 1 & & & & & 1 & & \\
\hline ARDASA & 1 & & & & & & & \\
\hline ARTEPREF & 1 & & & & & & & 1 \\
\hline AVENTIS & 1 & & & & & & & \\
\hline CALFERMAN & 1 & & & & & & & 1 \\
\hline \multicolumn{9}{|l|}{ CENTRO GERONTOLOGICO } \\
\hline CERAMICAS GALA & 1 & & & & & & & \\
\hline CESPA & 1 & & & & & 1 & & \\
\hline CLAU 2000 & 1 & & & & & & & \\
\hline COMPAN̂IIA MINERA RIO TIRON & 1 & & & & & 1 & & \\
\hline CONFECCIONES ORY & 1 & & & & & 1 & & \\
\hline DEXMUSA & 1 & & & & & 1 & & \\
\hline DIARIO DE BURGOS & 1 & & & & & 1 & & \\
\hline DUO FAST & 1 & & & & & & & 1 \\
\hline EDB & 1 & & & & & & & 1 \\
\hline \multicolumn{9}{|l|}{ EDSCHA } \\
\hline ESTACIONAMIENTOS Y SERVICIOS & 1 & & & & & 1 & & 1 \\
\hline \multicolumn{9}{|l|}{ EXPAL } \\
\hline EXPLOSIVOS COMPAÑÍA INDUSTRIA ALAVES। & 1 & & & & 1 & & & 1 \\
\hline FABISA & 1 & & & & 1 & & 1 & \\
\hline GALLETAS CORAL & 1 & & & & & 1 & & \\
\hline \multicolumn{9}{|l|}{ GALLETAS JESUS ANGULO } \\
\hline GONVARRI INDUSTRIAL & 1 & & & & & 1 & 1 & \\
\hline GRUPO ANTOLIN ARA & 1 & & & & & 1 & 1 & \\
\hline \multicolumn{9}{|l|}{ GRUPO ANTOLIN ARDASF } \\
\hline GRUPO ANTOLIN DAPSA & 1 & & & & & & 1 & \\
\hline GRUPO ANTOLIN EUROTRIN & 1 & & & & & & & \\
\hline GRUPO GARCIA CAMARERC & 1 & & & & & 1 & & 1 \\
\hline GRUPO GERARDO DE LA CALLE & 1 & & & & & & & 1 \\
\hline \multicolumn{9}{|l|}{ GRUPO ITEVELESA } \\
\hline HEIMBACH IBERICA & 1 & & & & & & & \\
\hline HELADOS MIKO & 1 & & & & & & 1 & \\
\hline \multicolumn{9}{|l|}{ HIPERBARIC } \\
\hline HORMIGONES Y EXC GERARDO DE LA CALLE & 1 & & & & & & & 1 \\
\hline HOSTAL TRES CONDES & 1 & & & & & 1 & & \\
\hline \multicolumn{9}{|l|}{ JOHNSON CONTROL AUTOBATERIAS } \\
\hline \multicolumn{9}{|l|}{ KRONOSPAN } \\
\hline \multicolumn{9}{|l|}{ LA FLOR BURGALESA } \\
\hline LENNOX REFAC & 1 & & & & & & & 1 \\
\hline MANUFACTURAS ORIVE & 1 & & & & & 1 & 1 & \\
\hline MINAS DE RIO TIRON CRIMIDESA & 1 & & & & & & & \\
\hline MONCOR 2000 & & & & & & & & \\
\hline MONTEFIBRE HISPANIA & 1 & & & & & 1 & 1 & \\
\hline MUEBLES MARIA LUISA & 1 & & & & & & & \\
\hline NICOLAS CORREA & & & 1 & & & & & \\
\hline PASCUAL HERMANOS & & & & & & & & \\
\hline PEPSICO MANUFACTURING & & & & & & & & \\
\hline PIERRE GUERIN IBERICA & 1 & & & & & & & 1 \\
\hline PLANIFICACION Y CONTROL LOGISTICC & 1 & & & & & & & \\
\hline PROSIDER IBERICA & 1 & & & & & 1 & & \\
\hline ROTTNEROS MIRANDA & 1 & & & & & & 1 & 1 \\
\hline SAINT GOBAIN VICASA & 1 & & & & & & 1 & \\
\hline SCHINDLER & 1 & & & & & & & \\
\hline SERUNION & & & & & & & & \\
\hline SERVICIOS SEMAT & 1 & & & & & 1 & & \\
\hline SIRO BRIVIESCA & & & & & & & & \\
\hline SNACK VENTURES MANUFACTURING & 1 & & & & & 1 & & \\
\hline STORK INTERIBERICA & 1 & & & & 1 & & & 1 \\
\hline TECNICAS MEDIOAMBIENTALES TECMED & 1 & & & & & & & \\
\hline THYSSEN KRUPP ELEVADORES & 1 & & & & 1 & & & \\
\hline TRANS UNION GAS TUGASA & & 1 & & & & 1 & & \\
\hline TRW AUTOMOTIVE & & & & & & & & \\
\hline URBASER & 1 & & & & & & & \\
\hline VB AUTOBATERIAS & 1 & & & & & & 1 & \\
\hline ZAMORANO LIMPIEZAS MIRANDI & & & & & & & & \\
\hline ZF ANSA LEMFORDER & 1 & & & & & & & \\
\hline
\end{tabular}




\begin{tabular}{|c|c|c|c|c|c|c|c|c|}
\hline EMPRESAS AÑO 2008 & $\begin{array}{l}\text { REVISION } \\
\text { IPC }\end{array}$ & $\begin{array}{l}\text { REVISION } \\
\text { FIJA }\end{array}$ & $\begin{array}{l}\text { REVISION } \\
\text { VARIABLE }\end{array}$ & $\begin{array}{l}\text { NO } \\
\text { REVISION }\end{array}$ & PART. B ${ }^{\circ}$ & \begin{tabular}{|c|} 
PAGA \\
EXTRA \\
\end{tabular} & $\begin{array}{c}\text { OTRAS } \\
\text { REM. }\end{array}$ & INF. CONT. \\
\hline ADISSEO & 1 & & & & & 1 & 1 & 1 \\
\hline ALPHACAN & 1 & & & & & & 1 & \\
\hline AMVISA & 1 & & & & 1 & & 1 & \\
\hline AQUAGEST & 1 & & & & & 1 & & \\
\hline \multicolumn{9}{|l|}{ ARDASA } \\
\hline ARTEPREF & 1 & & & & & & & 1 \\
\hline AVENTIS & 1 & & & & & & & \\
\hline CALFERMAN & 1 & & & & & & & \\
\hline \multicolumn{9}{|l|}{ CENTRO GERONTOLOGICO } \\
\hline CERAMICAS GALA & 1 & & & & & & & \\
\hline CESPA & 1 & & & & & 1 & & \\
\hline CLAU 2000 & 1 & & & & & & & \\
\hline COMPAÑÍA MINERA RIO TIRON & 1 & & & & & 1 & & \\
\hline CONFECCIONES ORY & 1 & & & & & 1 & & \\
\hline DEXMUSA & 1 & & & & & 1 & & \\
\hline DIARIO DE BURGOS & 1 & & & & & 1 & & \\
\hline DUO FAST & 1 & & & & & & & 1 \\
\hline EDB & 1 & & & & & & & 1 \\
\hline \multicolumn{9}{|l|}{ EDSCHA } \\
\hline ESTACIONAMIENTOS Y SERVICIOS & 1 & & & & & 1 & & 1 \\
\hline \multicolumn{9}{|l|}{ EXPAL } \\
\hline EXPLOSIVOS COMPAÑÍA INDUSTRIA ALAVES/ & 1 & & & & 1 & & & 1 \\
\hline FABISA & 1 & & & & & & & \\
\hline GALLETAS CORAL & 1 & & & & & 1 & & \\
\hline \multicolumn{9}{|l|}{ GALLETAS JESUS ANGULO } \\
\hline GONVARRI INDUSTRIAL & 1 & & & & & 1 & 1 & \\
\hline GRUPO ANTOLIN ARA & 1 & & & & & 1 & 1 & \\
\hline GRUPO ANTOLIN ARDASF & 1 & & & & & & 1 & \\
\hline GRUPO ANTOLIN DAPSA & 1 & & & & & & 1 & \\
\hline GRUPO ANTOLIN EUROTRIN & 1 & & & & & & & \\
\hline GRUPO GARCIA CAMARERC & 1 & & & & & 1 & & 1 \\
\hline GRUPO GERARDO DE LA CALLE & 1 & & & & & & & 1 \\
\hline GRUPO ITEVELESA & 1 & & & & & & & \\
\hline HEIMBACH IBERICA & 1 & & & & & & & \\
\hline HELADOS MIKO & 1 & & & & & & 1 & \\
\hline \multicolumn{9}{|l|}{ HIPERBARIC } \\
\hline HORMIGONES Y EXC GERARDO DE LA CALLE & 1 & & & & & & & 1 \\
\hline HOSTAL TRES CONDES & 1 & & & & & 1 & & \\
\hline \multicolumn{9}{|l|}{ JOHNSON CONTROL AUTOBATERIAS } \\
\hline \multicolumn{9}{|l|}{ KRONOSPAN } \\
\hline \multicolumn{9}{|l|}{ LA FLOR BURGALESA } \\
\hline LENNOX REFAC & 1 & & & & & & & 1 \\
\hline MANUFACTURAS ORIVE & 1 & & & & & 1 & 1 & \\
\hline \begin{tabular}{|l} 
MINAS DE RIO TIRON CRIMIDESA \\
\end{tabular} & 1 & & & & & & & \\
\hline \multicolumn{9}{|l|}{ MONCOR 2000} \\
\hline MONTEFIBRE HISPANIA & 1 & & & & & 1 & 1 & \\
\hline MUEBLES MARIA LUISA & 1 & & & & & & & \\
\hline NICOLAS CORREA & & & 1 & & & & & \\
\hline PASCUAL HERMANOS & & & & & & & & \\
\hline PEPSICO MANUFACTURING & & & & & & & & \\
\hline PIERRE GUERIN IBERICA & 1 & & & & & & & 1 \\
\hline PLANIFICACION Y CONTROL LOGISTICC & 1 & & & & & & & \\
\hline PROSIDER IBERICA & 1 & & & & & 1 & & \\
\hline ROTTNEROS MIRANDA & 1 & & & & & & 1 & 1 \\
\hline SAINT GOBAIN VICASA & 1 & & & & & & 1 & \\
\hline SCHINDLER & 1 & & & & & & & \\
\hline SERUNION & & & & & & & & \\
\hline SERVICIOS SEMAT & 1 & & & & & 1 & & \\
\hline SIRO BRIVIESCA & & & & & & & & \\
\hline SNACK VENTURES MANUFACTURING & 1 & & & & & 1 & & \\
\hline STORK INTERIBERICA & 1 & & & & 1 & & & 1 \\
\hline TECNICAS MEDIOAMBIENTALES TECMED & 1 & & & & & & & \\
\hline THYSSEN KRUPP ELEVADORES & 1 & & & & 1 & & & \\
\hline TRANS UNION GAS TUGASA & & 1 & & & & 1 & & \\
\hline TRW AUTOMOTIVE & & & & & & & & \\
\hline URBASER & 1 & & & & & & & \\
\hline VB AUTOBATERIAS & 1 & & & & & & 1 & \\
\hline ZAMORANO LIMPIEZAS MIRAND/ & & & & & & & & \\
\hline \begin{tabular}{|l} 
ZF ANSA LEMFORDER \\
\end{tabular} & & 1 & & & & & & \\
\hline
\end{tabular}




\begin{tabular}{|c|c|c|c|c|c|c|c|c|}
\hline EMPRESAS AÑO 2009 & $\begin{array}{l}\text { REVISION } \\
\text { IPC }\end{array}$ & $\begin{array}{l}\text { REVISION } \\
\text { FIJA }\end{array}$ & $\begin{array}{l}\text { REVISION } \\
\text { VARIABLE }\end{array}$ & $\begin{array}{l}\text { NO } \\
\text { REVISION }\end{array}$ & PART. B ${ }^{\circ}$ & \begin{tabular}{|c|} 
PAGA \\
EXTRA \\
\end{tabular} & $\begin{array}{c}\text { OTRAS } \\
\text { REM. }\end{array}$ & INF. CONT. \\
\hline ADISSEO & 1 & & & & & 1 & 1 & 1 \\
\hline ALPHACAN & 1 & & & & & & 1 & \\
\hline AMVISA & 1 & & & & 1 & & 1 & \\
\hline AQUAGEST & 1 & & & & & 1 & & \\
\hline \multicolumn{9}{|l|}{ ARDASA } \\
\hline ARTEPREF & 1 & & & & & & & 1 \\
\hline AVENTIS & 1 & & & & & & & \\
\hline CALFERMAN & 1 & & & & & & & \\
\hline \multicolumn{9}{|l|}{ CENTRO GERONTOLOGICO } \\
\hline CERAMICAS GALA & 1 & & & & & & & \\
\hline CESPA & 1 & & & & & 1 & & \\
\hline CLAU 2000 & 1 & & & & & & & \\
\hline COMPAÑÍA MINERA RIO TIRON & 1 & & & & & 1 & & \\
\hline CONFECCIONES ORY & 1 & & & & & 1 & & \\
\hline DEXMUSA & 1 & & & & & 1 & & \\
\hline DIARIO DE BURGOS & 1 & & & & & 1 & & \\
\hline DUO FAST & 1 & & & & & & & 1 \\
\hline EDB & 1 & & & & & & & 1 \\
\hline \multicolumn{9}{|l|}{ EDSCHA } \\
\hline ESTACIONAMIENTOS Y SERVICIOS & 1 & & & & & 1 & & 1 \\
\hline \multicolumn{9}{|l|}{ EXPAL } \\
\hline EXPLOSIVOS COMPAÑÍA INDUSTRIA ALAVES/ & 1 & & & & 1 & & & 1 \\
\hline FABISA & 1 & & & & & & & \\
\hline GALLETAS CORAL & 1 & & & & & 1 & & \\
\hline \multicolumn{9}{|l|}{ GALLETAS JESUS ANGULO } \\
\hline GONVARRI INDUSTRIAL & 1 & & & & & 1 & 1 & \\
\hline GRUPO ANTOLIN ARA & 1 & & & & & 1 & 1 & \\
\hline GRUPO ANTOLIN ARDASF & 1 & & & & & & 1 & \\
\hline GRUPO ANTOLIN DAPSA & 1 & & & & & & 1 & \\
\hline GRUPO ANTOLIN EUROTRIN & 1 & & & & & & & \\
\hline GRUPO GARCIA CAMARERC & 1 & & & & & 1 & & 1 \\
\hline GRUPO GERARDO DE LA CALLE & 1 & & & & & & & 1 \\
\hline GRUPO ITEVELESA & 1 & & & & & & & \\
\hline HEIMBACH IBERICA & 1 & & & & & & & \\
\hline HELADOS MIKO & 1 & & & & & & 1 & \\
\hline \multicolumn{9}{|l|}{ HIPERBARIC } \\
\hline HORMIGONES Y EXC GERARDO DE LA CALLE & 1 & & & & & & & 1 \\
\hline HOSTAL TRES CONDES & 1 & & & & & 1 & & \\
\hline \multicolumn{9}{|l|}{ JOHNSON CONTROL AUTOBATERIAS } \\
\hline \multicolumn{9}{|l|}{ KRONOSPAN } \\
\hline \multicolumn{9}{|l|}{ LA FLOR BURGALESA } \\
\hline LENNOX REFAC & 1 & & & & & & & 1 \\
\hline MANUFACTURAS ORIVE & 1 & & & & & 1 & 1 & \\
\hline \begin{tabular}{|l} 
MINAS DE RIO TIRON CRIMIDESA \\
\end{tabular} & 1 & & & & & & & \\
\hline \multicolumn{9}{|l|}{ MONCOR 2000} \\
\hline MONTEFIBRE HISPANIA & 1 & & & & & 1 & 1 & \\
\hline MUEBLES MARIA LUISA & 1 & & & & & & & \\
\hline NICOLAS CORREA & & & 1 & & & & & \\
\hline PASCUAL HERMANOS & & & & & & & & \\
\hline PEPSICO MANUFACTURINC & & & & & & & & \\
\hline PIERRE GUERIN IBERICA & 1 & & & & & & & 1 \\
\hline PLANIFICACION Y CONTROL LOGISTICC & 1 & & & & & & & \\
\hline PROSIDER IBERICA & 1 & & & & & 1 & & \\
\hline ROTTNEROS MIRANDA & 1 & & & & & & 1 & 1 \\
\hline SAINT GOBAIN VICASA & 1 & & & & & & 1 & \\
\hline SCHINDLER & 1 & & & & & & & \\
\hline SERUNION & & & & & & & & \\
\hline SERVICIOS SEMAT & 1 & & & & & 1 & & \\
\hline SIRO BRIVIESCA & & & & & & & & \\
\hline SNACK VENTURES MANUFACTURING & 1 & & & & & 1 & & \\
\hline STORK INTERIBERICA & 1 & & & & 1 & & & 1 \\
\hline TECNICAS MEDIOAMBIENTALES TECMED & 1 & & & & & & & \\
\hline THYSSEN KRUPP ELEVADORES & 1 & & & & 1 & & & \\
\hline TRANS UNION GAS TUGASA & & 1 & & & & 1 & & \\
\hline TRW AUTOMOTIVE & & & & & & & & \\
\hline URBASER & 1 & & & & & & & \\
\hline VB AUTOBATERIAS & 1 & & & & & & 1 & \\
\hline ZAMORANO LIMPIEZAS MIRAND/ & & & & & & & & \\
\hline ZF ANSA LEMFORDER & & & & & & & & \\
\hline
\end{tabular}




\begin{tabular}{|c|c|c|c|c|c|c|c|c|}
\hline EMPRESAS AÑO 2010 & $\begin{array}{l}\text { REVISION } \\
\text { IPC }\end{array}$ & $\begin{array}{l}\text { REVISION } \\
\text { FIJA }\end{array}$ & $\begin{array}{l}\text { REVISION } \\
\text { VARIABLE }\end{array}$ & $\begin{array}{l}\text { NO } \\
\text { REVISION }\end{array}$ & PART. B ${ }^{\circ}$ & \begin{tabular}{|c|} 
PAGA \\
EXTRA \\
\end{tabular} & $\begin{array}{c}\text { OTRAS } \\
\text { REM. }\end{array}$ & INF. CONT. \\
\hline ADISSEO & 1 & & & & & 1 & 1 & 1 \\
\hline ALPHACAN & 1 & & & & & & 1 & \\
\hline AMVISA & 1 & & & & 1 & & 1 & \\
\hline AQUAGEST & 1 & & & & & 1 & & \\
\hline \multicolumn{9}{|l|}{ ARDASA } \\
\hline ARTEPREF & 1 & & & & & & & 1 \\
\hline AVENTIS & 1 & & & & & & & \\
\hline CALFERMAN & 1 & & & & & & & \\
\hline \multicolumn{9}{|l|}{ CENTRO GERONTOLOGICO } \\
\hline CERAMICAS GALA & 1 & & & & & & & \\
\hline CESPA & 1 & & & & & 1 & & \\
\hline CLAU 2000 & 1 & & & & & & & \\
\hline COMPAÑÍA MINERA RIO TIRON & 1 & & & & & 1 & & \\
\hline CONFECCIONES ORY & & 1 & & & & 1 & & \\
\hline DEXMUSA & 1 & & & & & 1 & & \\
\hline DIARIO DE BURGOS & 1 & & & & & 1 & & \\
\hline DUO FAST & 1 & & & & & & & 1 \\
\hline EDB & 1 & & & & & & & 1 \\
\hline \multicolumn{9}{|l|}{ EDSCHA } \\
\hline ESTACIONAMIENTOS Y SERVICIOS & 1 & & & & & 1 & & 1 \\
\hline \multicolumn{9}{|l|}{ EXPAL } \\
\hline EXPLOSIVOS COMPAÑÍA INDUSTRIA ALAVES/ & 1 & & & & 1 & & & 1 \\
\hline FABISA & 1 & & & & & & & \\
\hline GALLETAS CORAL & & 1 & & & & 1 & & \\
\hline \multicolumn{9}{|l|}{ GALLETAS JESUS ANGULO } \\
\hline GONVARRI INDUSTRIAL & 1 & & & & & 1 & 1 & \\
\hline GRUPO ANTOLIN ARA & 1 & & & & & 1 & 1 & \\
\hline GRUPO ANTOLIN ARDASF & 1 & & & & & & 1 & \\
\hline GRUPO ANTOLIN DAPSA & 1 & & & & & & 1 & \\
\hline GRUPO ANTOLIN EUROTRIN & 1 & & & & & & & \\
\hline GRUPO GARCIA CAMARERC & 1 & & & & & 1 & & 1 \\
\hline GRUPO GERARDO DE LA CALLE & 1 & & & & & & & 1 \\
\hline GRUPO ITEVELESA & 1 & & & & & & & \\
\hline HEIMBACH IBERICA & 1 & & & & & & & \\
\hline HELADOS MIKO & 1 & & & & & & 1 & \\
\hline \multicolumn{9}{|l|}{ HIPERBARIC } \\
\hline HORMIGONES Y EXC GERARDO DE LA CALLE & 1 & & & & & & & 1 \\
\hline HOSTAL TRES CONDES & 1 & & & & & 1 & & \\
\hline \multicolumn{9}{|l|}{ JOHNSON CONTROL AUTOBATERIAS } \\
\hline \multicolumn{9}{|l|}{ KRONOSPAN } \\
\hline LA FLOR BURGALESA & 1 & & & & & 1 & & \\
\hline LENNOX REFAC & 1 & & & & & & & 1 \\
\hline MANUFACTURAS ORIVE & 1 & & & & & 1 & 1 & \\
\hline \begin{tabular}{|l} 
MINAS DE RIO TIRON CRIMIDESA \\
\end{tabular} & 1 & & & & & & & \\
\hline \multicolumn{9}{|l|}{ MONCOR 2000} \\
\hline MONTEFIBRE HISPANIA & 1 & & & & & 1 & 1 & \\
\hline MUEBLES MARIA LUISA & 1 & & & & & & & \\
\hline NICOLAS CORREA & & 1 & & & & & & \\
\hline \multicolumn{9}{|l|}{ PASCUAL HERMANOS } \\
\hline PEPSICO MANUFACTURING & & & & & & & & \\
\hline PIERRE GUERIN IBERICA & 1 & & & & & & & 1 \\
\hline PLANIFICACION Y CONTROL LOGISTICC & 1 & & & & & & & \\
\hline PROSIDER IBERICA & 1 & & & & & 1 & & \\
\hline ROTTNEROS MIRANDA & 1 & & & & & & 1 & 1 \\
\hline SAINT GOBAIN VICASA & 1 & & & & & & 1 & \\
\hline SCHINDLER & 1 & & & & & & & \\
\hline SERUNION & & & & & & & & \\
\hline SERVICIOS SEMAT & 1 & & & & & 1 & & \\
\hline SIRO BRIVIESCA & & & & & & & & \\
\hline SNACK VENTURES MANUFACTURING & 1 & & & & & 1 & & \\
\hline STORK INTERIBERICA & 1 & & & & 1 & & & 1 \\
\hline TECNICAS MEDIOAMBIENTALES TECMED & 1 & & & & & & & \\
\hline THYSSEN KRUPP ELEVADORES & 1 & & & & 1 & & & \\
\hline TRANS UNION GAS TUGASA & & 1 & & & & 1 & & \\
\hline TRW AUTOMOTIVE & & & & & & & & \\
\hline URBASER & 1 & & & & & & & \\
\hline VB AUTOBATERIAS & 1 & & & & & & 1 & \\
\hline ZAMORANO LIMPIEZAS MIRAND/ & & & & & & & & \\
\hline ZF ANSA LEMFORDER & & & & & & & & \\
\hline
\end{tabular}




\begin{tabular}{|c|c|c|c|c|c|c|c|c|}
\hline EMPRESAS AÑO 2011 & \begin{tabular}{|l|} 
REVISION \\
IPC
\end{tabular} & \begin{tabular}{|l|} 
REVISION \\
FIJA
\end{tabular} & \begin{tabular}{|l|} 
REVISION \\
VARIABLE
\end{tabular} & \begin{tabular}{|l|} 
NO \\
REVISION
\end{tabular} & PART. B ${ }^{\circ}$ & \begin{tabular}{|l|} 
PAGA \\
EXTRA
\end{tabular} & \begin{tabular}{|c|} 
OTRAS \\
REM.
\end{tabular} & INF. CONT. \\
\hline ADISSEO & 1 & & & & & 1 & 1 & 1 \\
\hline ALPHACAN & 1 & & & & & & 1 & \\
\hline AMVISA & 1 & & & & 1 & & 1 & \\
\hline AQUAGEST & 1 & & & & & 1 & & \\
\hline \multicolumn{9}{|l|}{ ARDASA } \\
\hline ARTEPREF & 1 & & & & & & & 1 \\
\hline AVENTIS & 1 & & & & & & & \\
\hline CALFERMAN & 1 & & & & & & & \\
\hline \multicolumn{9}{|l|}{ CENTRO GERONTOLOGICO } \\
\hline CERAMICAS GALA & 1 & & & & & & & \\
\hline CESPA & 1 & & & & & 1 & & \\
\hline CLAU 2000 & 1 & & & & & & & \\
\hline COMPAÑÍA MINERA RIO TIRON & 1 & & & & & 1 & & \\
\hline CONFECCIONES ORY & & 1 & & & & 1 & & \\
\hline DEXMUSA & 1 & & & & & 1 & & \\
\hline DIARIO DE BURGOS & 1 & & & & & 1 & & \\
\hline DUO FAST & 1 & & & & & & & 1 \\
\hline EDB & 1 & & & & & & & 1 \\
\hline \multicolumn{9}{|l|}{ EDSCHA } \\
\hline ESTACIONAMIENTOS Y SERVICIOS & 1 & & & & & 1 & & 1 \\
\hline \multicolumn{9}{|l|}{ EXPAL } \\
\hline EXPLOSIVOS COMPAÑÍA INDUSTRIA ALAVES/ & 1 & & & & 1 & & & 1 \\
\hline FABISA & 1 & & & & & & & \\
\hline GALLETAS CORAL & & 1 & & & & 1 & & \\
\hline GALLETAS JESUS ANGULO & 1 & & & & & 1 & & \\
\hline GONVARRI INDUSTRIAL & 1 & & & & & 1 & 1 & \\
\hline GRUPO ANTOLIN ARA & 1 & & & & & 1 & 1 & \\
\hline GRUPO ANTOLIN ARDAS $f$ & 1 & & & & & & 1 & \\
\hline GRUPO ANTOLIN DAPSA & 1 & & & & & & 1 & \\
\hline GRUPO ANTOLIN EUROTRIN & 1 & & & & & & 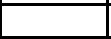 & \\
\hline GRUPO GARCIA CAMARERC & & & & 1 & & 1 & & 1 \\
\hline GRUPO GERARDO DE LA CALLE & 1 & & & & & & & 1 \\
\hline GRUPO ITEVELESA & 1 & & & & & & & \\
\hline HEIMBACH IBERICA & 1 & & & & & & & \\
\hline HELADOS MIKO & 1 & & & & & & 1 & \\
\hline \multicolumn{9}{|l|}{ HIPERBARIC } \\
\hline HORMIGONES Y EXC GERARDO DE LA CALLE & 1 & & & & & & & 1 \\
\hline HOSTAL TRES CONDES & 1 & & & & & 1 & & \\
\hline JOHNSON CONTROL AUTOBATERIAS & 1 & & & & 1 & & & \\
\hline \multicolumn{9}{|l|}{ KRONOSPAN } \\
\hline LA FLOR BURGALESA & 1 & & & & & 1 & & \\
\hline LENNOX REFAC & 1 & & & & & & & 1 \\
\hline MANUFACTURAS ORIVE & 1 & & & & & 1 & 1 & \\
\hline MINAS DE RIO TIRON CRIMIDES & 1 & & & & & & & \\
\hline \multicolumn{9}{|l|}{ MONCOR 2000} \\
\hline MONTEFIBRE HISPANIA & & & 1 & & & 1 & 1 & 1 \\
\hline MUEBLES MARIA LUISA & 1 & & & & & & & \\
\hline NICOLAS CORREA & & 1 & & & & & & \\
\hline \multicolumn{9}{|l|}{ PASCUAL HERMANOS } \\
\hline \multicolumn{9}{|l|}{ PEPSICO MANUFACTURING } \\
\hline PIERRE GUERIN IBERICA & 1 & & & & & & & 1 \\
\hline PLANIFICACION Y CONTROL LOGISTICC & 1 & & & & & & & \\
\hline PROSIDER IBERICA & 1 & & & & & 1 & & \\
\hline ROTTNEROS MIRANDA & 1 & & & & & & 1 & 1 \\
\hline SAINT GOBAIN VICASA & & 1 & & & & & 1 & \\
\hline SCHINDLER & 1 & & & & & & & \\
\hline \multicolumn{9}{|l|}{ SERUNION } \\
\hline SERVICIOS SEMAT & 1 & & & & & 1 & & \\
\hline SIRO BRIVIESCA & & 1 & & & & & 1 & \\
\hline SNACK VENTURES MANUFACTURING & 1 & & & & & 1 & & \\
\hline STORK INTERIBERICA & 1 & & & & 1 & & & 1 \\
\hline TECNICAS MEDIOAMBIENTALES TECMED & 1 & & & & & & & \\
\hline THYSSEN KRUPP ELEVADORES & 1 & & & & 1 & & & \\
\hline TRANS UNION GAS TUGASA & & 1 & & & & 1 & & \\
\hline TRW AUTOMOTIVE & & & & & & & & \\
\hline URBASER & 1 & & & & & & & \\
\hline VB AUTOBATERIAS & & & & & & & & \\
\hline ZAMORANO LIMPIEZAS MIRANDI & & & & & & & & \\
\hline ZF ANSA LEMFORDER & & & & & & & & \\
\hline
\end{tabular}




\begin{tabular}{|c|c|c|c|c|c|c|c|c|}
\hline EMPRESAS AÑO 2012 & \begin{tabular}{|l|} 
REVISION \\
IPC \\
\end{tabular} & \begin{tabular}{|l|} 
REVISION \\
FIJA
\end{tabular} & \begin{tabular}{|l|} 
REVISION \\
VARIABLE \\
\end{tabular} & \begin{tabular}{|l|} 
NO \\
REVISION \\
\end{tabular} & PART. Bo & \begin{tabular}{|c|} 
PAGA \\
EXTRA \\
\end{tabular} & \begin{tabular}{|c|} 
OTRAS \\
REM. \\
\end{tabular} & INF. CONT. \\
\hline ADISSEO & 1 & & & & & 1 & 1 & 1 \\
\hline ALPHACAN & 1 & & & & & & 1 & \\
\hline AMVISA & 1 & & & & 1 & & 1 & \\
\hline AQUAGEST & 1 & & & & & 1 & & \\
\hline \multicolumn{9}{|l|}{ ARDASA } \\
\hline ARTEPREF & 1 & & & & & & & 1 \\
\hline AVENTIS & 1 & & & & & & & \\
\hline CALFERMAN & 1 & & & & & & & \\
\hline CENTRO GERONTOLOGICO & 1 & & & & & & & \\
\hline CERAMICAS GALA & 1 & & & & & & & \\
\hline CESPA & 1 & & & & & 1 & & \\
\hline CLAU 2000 & 1 & & & & & & & \\
\hline COMPAÑÍA MINERA RIO TIROI & 1 & & & & & 1 & & \\
\hline CONFECCIONES ORY & & 1 & & & & 1 & & \\
\hline DEXMUSA & 1 & & & & & 1 & & \\
\hline DIARIO DE BURGOS & 1 & & & & & & & \\
\hline DUO FAST & & & & 1 & & & & 1 \\
\hline EDB & 1 & & & & & & & 1 \\
\hline EDSCHA & & & & 1 & & & 1 & \\
\hline ESTACIONAMIENTOS Y SERVICIOS & & 1 & & & & 1 & & 1 \\
\hline \multicolumn{9}{|l|}{ EXPAL } \\
\hline EXPLOSIVOS COMPAÑÍA INDUSTRIA ALAVES $/$ & 1 & & & & 1 & & & 1 \\
\hline FABISA & 1 & & & & & & & \\
\hline GALLETAS CORAL & & 1 & & & & 1 & & \\
\hline GALLETAS JESUS ANGULO & 1 & & & & & 1 & & \\
\hline GONVARRI INDUSTRIAL & & & & 1 & & 1 & 1 & \\
\hline GRUPO ANTOLIN ARA & 1 & & & & & 1 & 1 & \\
\hline GRUPO ANTOLIN ARDASF & 1 & & & & & & 1 & \\
\hline GRUPO ANTOLIN DAPSA & 1 & & & & & & 1 & \\
\hline GRUPO ANTOLIN EUROTRIN & 1 & & & & & & & \\
\hline GRUPO GARCIA CAMARERC & & 1 & & & & 1 & & 1 \\
\hline GRUPO GERARDO DE LA CALLE & 1 & & & & & & & 1 \\
\hline GRUPO ITEVELESA & 1 & & & & & & & \\
\hline HEIMBACH IBERICA & & 1 & & & & & & \\
\hline HELADOS MIKO & 1 & & & & & & 1 & \\
\hline \multicolumn{9}{|l|}{ HIPERBARIC } \\
\hline HORMIGONES Y EXC GERARDO DE LA CALLE & 1 & & & & & & & 1 \\
\hline HOSTAL TRES CONDES & 1 & & & & & 1 & & \\
\hline JOHNSON CONTROL AUTOBATERIAS & 1 & & & & 1 & & & \\
\hline \multicolumn{9}{|l|}{ KRONOSPAN } \\
\hline LA FLOR BURGALESA & 1 & & & & & 1 & & \\
\hline LENNOX REFAC & 1 & & & & & & & 1 \\
\hline MANUFACTURAS ORIVE & 1 & & & & & 1 & 1 & \\
\hline MINAS DE RIO TIRON CRIMIDES $f$ & 1 & & & & & & & \\
\hline \multicolumn{9}{|l|}{ MONCOR 2000} \\
\hline MONTEFIBRE HISPANIA & & & 1 & & & 1 & 1 & 1 \\
\hline MUEBLES MARIA LUISA & 1 & & & & & & & \\
\hline NICOLAS CORREA & & & & 1 & & & & \\
\hline \multicolumn{9}{|l|}{ PASCUAL HERMANOS } \\
\hline PEPSICO MANUFACTURING & & & & 1 & & 1 & & \\
\hline PIERRE GUERIN IBERICA & & & & 1 & & & & 1 \\
\hline PLANIFICACION Y CONTROL LOGISTICC & 1 & & & & & & & \\
\hline PROSIDER IBERICA & 1 & & & & & 1 & & \\
\hline ROTTNEROS MIRANDA & 1 & & & & & & 1 & 1 \\
\hline SAINT GOBAIN VICASA & & 1 & & & & & 1 & \\
\hline SCHINDLER & 1 & & & & & & & \\
\hline \multicolumn{9}{|l|}{ SERUNION } \\
\hline SERVICIOS SEMAT & 1 & & & & & 1 & & \\
\hline SIRO BRIVIESCA & & 1 & & & & & 1 & \\
\hline \multicolumn{9}{|l|}{ SNACK VENTURES MANUFACTURING } \\
\hline STORK INTERIBERICA & & & & 1 & 1 & & & 1 \\
\hline TECNICAS MEDIOAMBIENTALES TECMED & 1 & & & & & & & \\
\hline THYSSEN KRUPP ELEVADORES & 1 & & & & 1 & & & \\
\hline TRANS UNION GAS TUGASA & & 1 & & & & 1 & & \\
\hline \multicolumn{9}{|l|}{ TRW AUTOMOTIVE } \\
\hline URBASER & 1 & & & & & & & \\
\hline \multicolumn{9}{|l|}{ VB AUTOBATERIAS } \\
\hline ZAMORANO LIMPIEZAS MIRANDI & 1 & & & & & & & \\
\hline ZF ANSA LEMFORDER & & & & & & & & \\
\hline
\end{tabular}




\begin{tabular}{|c|c|c|c|c|c|c|c|c|}
\hline EMPRESAS AÑO 2013 & \begin{tabular}{|l|} 
REVISION \\
IPC
\end{tabular} & $\begin{array}{l}\text { REVISION } \\
\text { FIJA }\end{array}$ & $\begin{array}{l}\text { REVISION } \\
\text { VARIABLE } \\
\end{array}$ & $\begin{array}{l}\text { NO } \\
\text { REVISION }\end{array}$ & PART. B ${ }^{\circ}$ & \begin{tabular}{|l|} 
PAGA \\
EXTRA \\
\end{tabular} & \begin{tabular}{|c|} 
OTRAS \\
REM.
\end{tabular} & INF. CONT. \\
\hline ADISSEO & 1 & & & & & 1 & 1 & 1 \\
\hline ALPHACAN & 1 & & & & & & 1 & \\
\hline AMVISA & 1 & & & & 1 & & 1 & \\
\hline AQUAGEST & 1 & & & & & 1 & & \\
\hline \multicolumn{9}{|l|}{ ARDASA } \\
\hline ARTEPREF & 1 & & & & & & & 1 \\
\hline AVENTIS & 1 & & & & & & & \\
\hline CALFERMAN & 1 & & & & & & & \\
\hline CENTRO GERONTOLOGICO & 1 & & & & & & & \\
\hline \multicolumn{9}{|l|}{ CERAMICAS GALA } \\
\hline CESPA & 1 & & & & & 1 & & \\
\hline CLAU 2000 & 1 & & & & & & & \\
\hline COMPAN̂IIA MINERA RIO TIROI & 1 & & & & & 1 & & \\
\hline CONFECCIONES ORY & & 1 & & & & 1 & & \\
\hline DEXMUSA & 1 & & & & & 1 & & \\
\hline DIARIO DE BURGOS & 1 & & & & & & & \\
\hline DUO FAST & & & & 1 & & & & 1 \\
\hline EDB & 1 & & & & & & & 1 \\
\hline EDSCHA & & & & 1 & & & 1 & \\
\hline ESTACIONAMIENTOS Y SERVICIOS & & 1 & & & & 1 & & 1 \\
\hline EXPAL & & 1 & & & & & & 1 \\
\hline EXPLOSIVOS COMPAÑÍA INDUSTRIA ALAVES & 1 & & & & 1 & & & 1 \\
\hline FABISA & 1 & & & & & & & \\
\hline GALLETAS CORAL & & 1 & & & & 1 & & \\
\hline GALLETAS JESUS ANGULO & 1 & & & & & 1 & & \\
\hline GONVARRI INDUSTRIAL & & & & 1 & & 1 & 1 & \\
\hline GRUPO ANTOLIN ARA & & & & 1 & & 1 & 1 & \\
\hline GRUPO ANTOLIN ARDASF & & & & 1 & & & 1 & \\
\hline GRUPO ANTOLIN DAPSA & & 1 & & & & & 1 & \\
\hline GRUPO ANTOLIN EUROTRIN & 1 & & & & & & & \\
\hline GRUPO GARCIA CAMARERC & & 1 & & & & 1 & & 1 \\
\hline GRUPO GERARDO DE LA CALLE & 1 & & & & & & & 1 \\
\hline GRUPO ITEVELESA & 1 & & & & & & & \\
\hline \multicolumn{9}{|l|}{ HEIMBACH IBERICA } \\
\hline HELADOS MIKO & 1 & & & & & & 1 & \\
\hline \multicolumn{9}{|l|}{ HIPERBARIC } \\
\hline HORMIGONES Y EXC GERARDO DE LA CALLE & 1 & & & & & & & 1 \\
\hline HOSTAL TRES CONDES & 1 & & & & & 1 & & \\
\hline JOHNSON CONTROL AUTOBATERIAS & 1 & & & & 1 & & & \\
\hline \multicolumn{9}{|l|}{ KRONOSPAN } \\
\hline LA FLOR BURGALESA & 1 & & & & & 1 & & \\
\hline LENNOX REFAC & & 1 & & & & & & 1 \\
\hline MANUFACTURAS ORIVE & 1 & & & & & 1 & 1 & \\
\hline MINAS DE RIO TIRON CRIMIDES & 1 & & & & & & & \\
\hline MONCOR 2000 & & & & 1 & & & & \\
\hline MONTEFIBRE HISPANIA & & & 1 & & & 1 & 1 & 1 \\
\hline MUEBLES MARIA LUISA & 1 & & & & & & & \\
\hline NICOLAS CORREA & & & & 1 & & & & \\
\hline \multicolumn{9}{|l|}{ PASCUAL HERMANOS } \\
\hline PEPSICO MANUFACTURING & & & & 1 & & 1 & & \\
\hline PIERRE GUERIN IBERICA & & 1 & & & & & & 1 \\
\hline PLANIFICACION Y CONTROL LOGISTICC & 1 & & & & & & & \\
\hline PROSIDER IBERICA & 1 & & & & & 1 & & \\
\hline ROTTNEROS MIRANDA & 1 & & & & & & 1 & 1 \\
\hline SAINT GOBAIN VICASA & & 1 & & & & & 1 & \\
\hline SCHINDLER & 1 & & & & & & & \\
\hline \multicolumn{9}{|l|}{ SERUNION } \\
\hline SERVICIOS SEMAT & 1 & & & & & 1 & & \\
\hline SIRO BRIVIESCA & & 1 & & & & & 1 & \\
\hline \multicolumn{9}{|l|}{ SNACK VENTURES MANUFACTURING } \\
\hline STORK INTERIBERICA & & & & 1 & 1 & & & 1 \\
\hline TECNICAS MEDIOAMBIENTALES TECMED & 1 & & & & & & & \\
\hline THYSSEN KRUPP ELEVADORES & 1 & & & & 1 & & & \\
\hline TRANS UNION GAS TUGASA & & 1 & & & & 1 & & \\
\hline \multicolumn{9}{|l|}{ TRW AUTOMOTIVE } \\
\hline URBASER & & & & 1 & & 1 & & \\
\hline \multicolumn{9}{|l|}{ VB AUTOBATERIAS } \\
\hline ZAMORANO LIMPIEZAS MIRANDI & 1 & & & & & & & \\
\hline ZF ANSA LEMFORDER & & & & & & & & \\
\hline
\end{tabular}




\begin{tabular}{|c|c|c|c|c|c|c|c|c|}
\hline EMPRESAS AÑO 2014 & \begin{tabular}{|l|} 
REVISION \\
IPC
\end{tabular} & \begin{tabular}{|l|} 
REVISION \\
FIJA
\end{tabular} & \begin{tabular}{|l|} 
REVISION \\
VARIABLE
\end{tabular} & \begin{tabular}{|l|} 
NO \\
REVISION
\end{tabular} & PART. B ${ }^{\circ}$ & \begin{tabular}{|l|} 
PAGA \\
EXTRA
\end{tabular} & $\begin{array}{l}\text { OTRAS } \\
\text { REM. }\end{array}$ & $\begin{array}{c}\text { INF. } \\
\text { CONT. }\end{array}$ \\
\hline ADISSEO & 1 & & & & & 1 & 1 & 1 \\
\hline ALPHACAN & 1 & & & & & & 1 & \\
\hline AMVISA & 1 & & & & 1 & & 1 & \\
\hline AQUAGEST & 1 & & & & & 1 & & \\
\hline \multicolumn{9}{|l|}{ ARDASA } \\
\hline ARTEPREF & 1 & & & & & & & 1 \\
\hline AVENTIS & 1 & & & & & & & \\
\hline CALFERMAN & 1 & & & & & & & \\
\hline CENTRO GERONTOLOGICO & 1 & & & & & & & \\
\hline CERAMICAS GALA & & & & 1 & & & & \\
\hline CESPA & 1 & & & & & 1 & & \\
\hline CLAU 2000 & 1 & & & & & & & \\
\hline COMPAN̂ÍA MINERA RIO TIROI & 1 & & & & & 1 & & \\
\hline CONFECCIONES ORY & & 1 & & & & 1 & & \\
\hline DEXMUSA & 1 & & & & & 1 & & \\
\hline DIARIO DE BURGOS & 1 & & & & & & & \\
\hline DUO FAST & & 1 & & & & & & 1 \\
\hline EDB & 1 & & & & & & & 1 \\
\hline EDSCHA & 1 & & & & & & 1 & \\
\hline ESTACIONAMIENTOS Y SERVICIOS & & 1 & & & & 1 & & 1 \\
\hline EXPAL & & 1 & & & & & & 1 \\
\hline EXPLOSIVOS COMPAÑÍA INDUSTRIA ALAVES/ & 1 & & & & 1 & & & 1 \\
\hline FABISA & 1 & & & & & & & \\
\hline GALLETAS CORAL & 1 & & & & & 1 & & \\
\hline GALLETAS JESUS ANGULO & 1 & & & & & 1 & & \\
\hline GONVARRI INDUSTRIAL & & & & 1 & & 1 & 1 & \\
\hline GRUPO ANTOLIN ARA & & 1 & & & & 1 & 1 & \\
\hline GRUPO ANTOLIN ARDAS $F$ & & & & 1 & & & 1 & \\
\hline GRUPO ANTOLIN DAPSA & & & & 1 & & & 1 & \\
\hline GRUPO ANTOLIN EUROTRIN & & & & 1 & & & & \\
\hline GRUPO GARCIA CAMARERC & & 1 & & & & 1 & & 1 \\
\hline GRUPO GERARDO DE LA CALLE & 1 & & & & & & & 1 \\
\hline GRUPO ITEVELESA & 1 & & & & & & & \\
\hline HEIMBACH IBERIC $A$ & & 1 & & & & & & \\
\hline HELADOS MIKO & 1 & & & & & & 1 & \\
\hline HIPERBARIC & & 1 & & & 1 & & & \\
\hline HORMIGONES Y EXC GERARDO DE LA CALLE & 1 & & & & & & & 1 \\
\hline HOSTAL TRES CONDES & 1 & & & & & 1 & & \\
\hline JOHNSON CONTROL AUTOBATERIAS & & & & 1 & 1 & & & \\
\hline KRONOSPAN & & & & 1 & & & & \\
\hline LA FLOR BURGALESA & 1 & & & & & 1 & & \\
\hline LENNOX REFAC & & 1 & & & & 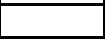 & & 1 \\
\hline MANUFACTURAS ORIVE & 1 & & & & & 1 & 1 & \\
\hline MINAS DE RIO TIRON CRIMIDESA & 1 & & & & & & & \\
\hline MONCOR 2000 & 1 & & & & & & & \\
\hline MONTEFIBRE HISPANIA & & & 1 & & & 1 & 1 & 1 \\
\hline MUEBLES MARIA LUISA & 1 & & & & & & & \\
\hline NICOLAS CORREA & & & & 1 & & & & \\
\hline \multicolumn{9}{|l|}{ PASCUAL HERMANOS } \\
\hline PEPSICO MANUFACTURINC & & 1 & & & & 1 & & \\
\hline PIERRE GUERIN IBERICA & & 1 & & & & & & 1 \\
\hline PLANIFICACION Y CONTROL LOGISTICC & 1 & & & & & & & \\
\hline PROSIDER IBERICA & 1 & & & & & 1 & & \\
\hline ROTTNEROS MIRANDA & 1 & & & & & & 1 & 1 \\
\hline SAINT GOBAIN VICASA & & 1 & & & & & 1 & \\
\hline SCHINDLER & 1 & & & & & & & \\
\hline \multicolumn{9}{|l|}{ SERUNION } \\
\hline SERVICIOS SEMAT & 1 & & & & & 1 & & \\
\hline SIRO BRIVIESCA & & 1 & & & & & 1 & \\
\hline \multicolumn{9}{|l|}{ SNACK VENTURES MANUFACTURING } \\
\hline STORK INTERIBERICA & & & & 1 & 1 & & & 1 \\
\hline TECNICAS MEDIOAMBIENTALES TECMED & 1 & & & & & & & \\
\hline THYSSEN KRUPP ELEVADORES & 1 & & & & 1 & & & \\
\hline TRANS UNION GAS TUGASA & & 1 & & & & 1 & & \\
\hline \multicolumn{9}{|l|}{ TRW AUTOMOTIVE } \\
\hline URBASER & & & & 1 & & 1 & & \\
\hline \multicolumn{9}{|l|}{ VB AUTOBATERIAS } \\
\hline ZAMORANO LIMPIEZAS MIRANDI & 1 & & & & & & & \\
\hline ZF ANSA LEMFORDER & & & & & & & & \\
\hline
\end{tabular}




\begin{tabular}{|c|c|c|c|c|c|c|c|c|}
\hline EMPRESAS AÑO 2015 & $\begin{array}{l}\text { REVISION } \\
\text { IPC }\end{array}$ & \begin{tabular}{|l|} 
REVISION \\
FIJA
\end{tabular} & \begin{tabular}{|l|} 
REVISION \\
VARIABLE
\end{tabular} & \begin{tabular}{|l|} 
NO \\
REVISION
\end{tabular} & PART. B & \begin{tabular}{|c|} 
PAGA \\
EXTRA
\end{tabular} & \begin{tabular}{|l|} 
OTRAS \\
REM.
\end{tabular} & INF. CONT. \\
\hline \multicolumn{9}{|l|}{\begin{tabular}{|l} 
ADISSEO \\
\end{tabular}} \\
\hline \multicolumn{9}{|l|}{ ALPHACAN } \\
\hline \multicolumn{9}{|l|}{ AMVISA } \\
\hline \multicolumn{9}{|l|}{ AQUAGEST } \\
\hline \multicolumn{9}{|l|}{ ARDASA } \\
\hline \multicolumn{9}{|l|}{\begin{tabular}{|l|} 
ARTEPREF \\
\end{tabular}} \\
\hline \multicolumn{9}{|l|}{ AVENTIS } \\
\hline \multicolumn{9}{|l|}{ CALFERMAN } \\
\hline \multicolumn{9}{|l|}{ CENTRO GERONTOLOGICO } \\
\hline \multicolumn{9}{|l|}{ CERAMICAS GALA } \\
\hline CESPA & & & & & & & & \\
\hline CLAU 2000 & & & & & & & & \\
\hline COMPAÑIÍA MINERA RIO TIROI & & & & & & & & \\
\hline CONFECCIONES ORY & & & & & & & & \\
\hline DEXMUSA & & & & & & & & \\
\hline DIARIO DE BURGOS & & & & & & & & \\
\hline DUO FAST & & & & & & & & \\
\hline EDB & & & & & & & & \\
\hline EDSCHA & 1 & & & & & & 1 & \\
\hline ESTACIONAMIENTOS Y SERVICIOS & & & & & & & & \\
\hline EXPAL & & 1 & & & & & & 1 \\
\hline EXPLOSIVOS COMPANIÍA INDUSTR & & & & & & & & \\
\hline FABISA & & & & & & & & \\
\hline GALLETAS CORAL & 1 & & & & & 1 & & \\
\hline GALLETAS JESUS ANGULO & & & & & & & & \\
\hline GONVARRI INDUSTRIAL & & 1 & & & & 1 & 1 & \\
\hline GRUPO ANTOLIN ARA & & 1 & & & & 1 & 1 & \\
\hline GRUPO ANTOLIN ARDAS $F$ & & & & 1 & & & 1 & \\
\hline GRUPO ANTOLIN DAPSA & & 1 & & & & & 1 & \\
\hline GRUPO ANTOLIN EUROTRIN & & 1 & & & & & & \\
\hline GRUPO GARCIA CAMARERC & & & & & & & & \\
\hline GRUPO GERARDO DE LA CALLE & & & & & & & & \\
\hline GRUPO ITEVELESA & & & & & & & & \\
\hline HEIMBACH IBERIC $f$ & & 1 & & & & & & \\
\hline HELADOS MIKO & & & & & & & & \\
\hline HIPERBARIC & & 1 & & & 1 & & & \\
\hline HORMIGONES Y EXC GERARDO DE & & & & & & & & \\
\hline HOSTAL TRES CONDES & & & & & & & & \\
\hline JOHNSON CONTROL AUTOBATER & & & & 1 & 1 & & & \\
\hline KRONOSPAN & & & & & & & & \\
\hline LA FLOR BURGALESA & & & & & & & & \\
\hline LENNOX REFAC & & 1 & & & & & & 1 \\
\hline MANUFACTURAS ORIVE & & & & & & & & \\
\hline MINAS DE RIO TIRON CRIMIDES $F$ & & & & & & & & \\
\hline MONCOR 2000 & 1 & & & & & & & \\
\hline MONTEFIBRE HISPANIA & & & & & & & & \\
\hline MUEBLES MARIA LUIS $A$ & & & & & & & & \\
\hline NICOLAS CORREA & & & & & & & & \\
\hline PASCUAL HERMANOS & & & & & & & & \\
\hline PEPSICO MANUFACTURINC & & 1 & & & & 1 & & \\
\hline PIERRE GUERIN IBERICA & & & & & & & & \\
\hline PLANIFICACION Y CONTROL LOGI & & & & & & & & \\
\hline PROSIDER IBERIC $A$ & & & & & & & & \\
\hline ROTTNEROS MIRANDA & & & & & & & & \\
\hline SAINT GOBAIN VICAS $\boldsymbol{A}$ & & & & & & & & \\
\hline SCHINDLER & & & & & & & & \\
\hline SERUNION & & & & & & & & \\
\hline SERVICIOS SEMAT & & & & & & & & \\
\hline SIRO BRIVIESCA & & 1 & & & & & 1 & \\
\hline SNACK VENTURES MANUFACTUR & & & & & & & & \\
\hline STORK INTERIBERICA & & & & & & & & \\
\hline TECNICAS MEDIOAMBIENTALES T & & & & & & & & \\
\hline THYSSEN KRUPP ELEVADORES & 1 & & & & 1 & & & \\
\hline TRANS UNION GAS TUGASA & & & & & & & & \\
\hline TRW AUTOMOTIVE & & & & & & & & \\
\hline URBASER & & & & 1 & & 1 & & \\
\hline VB AUTOBATERIAS & & & & & & & & \\
\hline ZAMORANO LIMPIEZAS MIRANDI & 1 & & & & & & & \\
\hline ZF ANSA LEMFORDER & & & & & & & & \\
\hline
\end{tabular}




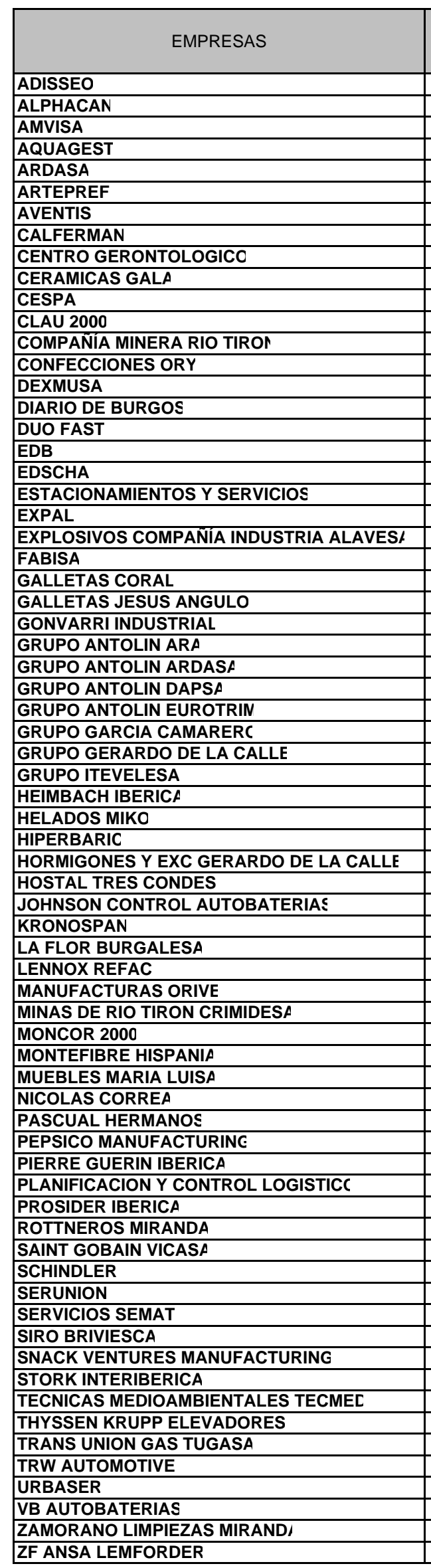

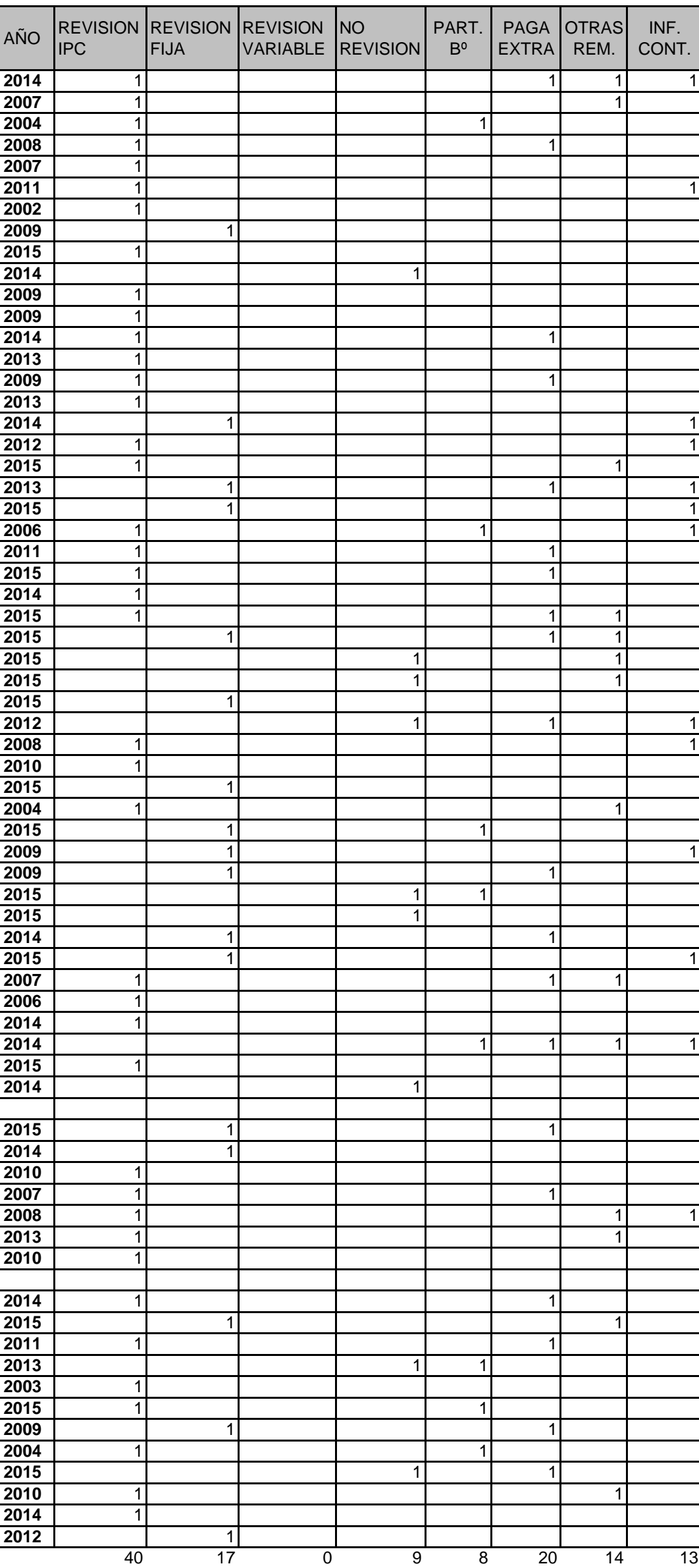

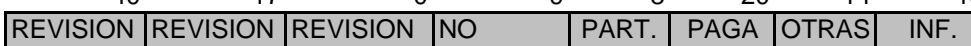
\begin{tabular}{|l|l|l|l|l|l|l|l}
\hline IPC & FIJA & VARIABLE & REVISION & $B^{\circ}$ & EXTRA & REM. & CONT. \\
\hline
\end{tabular} 


\begin{tabular}{|c|c|c|c|}
\hline EMPRESAS & AÑO & PART. B ${ }^{\circ}$ & $\begin{array}{l}\text { OTRAS } \\
\text { REM. }\end{array}$ \\
\hline ADISSEO & 2014 & & 1 \\
\hline ALPHACAN & 2007 & & 1 \\
\hline AMVISA & 2004 & 1 & \\
\hline EDSCHA & 2015 & & 1 \\
\hline EXPLOSIVOS COMPAÑÍA INDUSTRIA ALAVESA & 2006 & 1 & \\
\hline$\overline{\text { GONVARRI INDUSTRIAL }}$ & 2015 & & 1 \\
\hline GRUPO ANTOLIN ARA & 2015 & & 1 \\
\hline GRUPO ANTOLIN ARDASA & 2015 & & 1 \\
\hline GRUPO ANTOLIN DAPSA & 2015 & & 1 \\
\hline HELADOS MIKO & 2004 & & 1 \\
\hline HIPERBARIC & 2015 & 1 & \\
\hline JOHNSON CONTROL AUTOBATERIAS & 2015 & 1 & \\
\hline MANUFACTURAS ORIVE & 2007 & & 1 \\
\hline MONTEFIBRE HISPANIA & 2014 & 1 & 1 \\
\hline ROTTNEROS MIRANDA & 2008 & & 1 \\
\hline SAINT GOBAIN VICASA & 2013 & & 1 \\
\hline SIRO BRIVIESCA & 2015 & & 1 \\
\hline STORK INTERIBERICA & 2013 & 1 & \\
\hline THYSSEN KRUPP ELEVADORES & 2015 & 1 & \\
\hline TRW AUTOMOTIVE & 2004 & 1 & \\
\hline VB AUTOBATERIAS & 2010 & & 1 \\
\hline & & \multicolumn{2}{|r|}{14} \\
\hline & & PART. B ${ }^{\circ}$ & $\begin{array}{c}\text { OTRAS } \\
\text { REM. }\end{array}$ \\
\hline
\end{tabular}




\begin{tabular}{|c|c|c|c|}
\hline EMPRESAS & AÑO & PART. B ${ }^{\circ}$ & $\begin{array}{l}\text { OTRAS } \\
\text { REM. }\end{array}$ \\
\hline ADISSEO & 2014 & & 1 \\
\hline ALPHACAN & 2007 & & 1 \\
\hline AMVISA & 2004 & 1 & \\
\hline EDSCHA & 2015 & & 1 \\
\hline EXPLOSIVOS COMPAÑÍA INDUSTRIA ALAVESA & 2006 & 1 & \\
\hline GONVARRI INDUSTRIAL & 2015 & & 1 \\
\hline GRUPO ANTOLIN ARA & 2015 & & 1 \\
\hline GRUPO ANTOLIN ARDASA & 2015 & & 1 \\
\hline GRUPO ANTOLIN DAPSA & 2015 & & 1 \\
\hline HELADOS MIKO & 2004 & & 1 \\
\hline HIPERBARIC & 2015 & 1 & \\
\hline JOHNSON CONTROL AUTOBATERIAS & 2015 & 1 & \\
\hline MANUFACTURAS ORIVE & 2007 & & 1 \\
\hline MONTEFIBRE HISPANIA & 2014 & 1 & 1 \\
\hline ROTTNEROS MIRANDA & 2008 & & 1 \\
\hline SAINT GOBAIN VICASA & 2013 & & 1 \\
\hline SIRO BRIVIESCA & 2015 & & 1 \\
\hline STORK INTERIBERICA & 2013 & 1 & \\
\hline THYSSEN KRUPP ELEVADORES & 2015 & 1 & \\
\hline TRW AUTOMOTIVE & 2004 & 1 & \\
\hline VB AUTOBATERIAS & 2010 & & 1 \\
\hline
\end{tabular}




\begin{tabular}{|l|r|r|r|}
\hline \multicolumn{1}{|c|}{ EMPRESAS SOLO INFORMACION EXTERNA } & AÑO & PART. B & $\begin{array}{c}\text { OTRAS } \\
\text { REM. }\end{array}$ \\
\hline AMVISA & $\mathbf{2 0 0 4}$ & 1 & \\
\hline EXPLOSIVOS COMPAÑÍA INDUSTRIA ALAVESA & $\mathbf{2 0 0 6}$ & 1 & \\
\hline HIPERBARIC & $\mathbf{2 0 1 5}$ & 1 & \\
\hline JOHNSON CONTROL AUTOBATERIAS & $\mathbf{2 0 1 5}$ & 1 & \\
\hline STORK INTERIBERICA & $\mathbf{2 0 1 3}$ & 1 & \\
\hline THYSSEN KRUPP ELEVADORES & $\mathbf{2 0 1 5}$ & 1 & \\
\hline TRW AUTOMOTIVE & $\mathbf{2 0 0 4}$ & 1 & \\
\hline
\end{tabular}

\begin{tabular}{|l|r|r|r|}
\hline \multicolumn{1}{|c|}{ EMPRESAS SOLO INFORMACION INTERNA } & \multicolumn{1}{|c|}{ AÑO } & PART. B & $\begin{array}{r}\text { OTRAS } \\
\text { REM. }\end{array}$ \\
\hline ADISSEO & $\mathbf{2 0 1 4}$ & & 1 \\
\hline ALPHACAN & $\mathbf{2 0 0 7}$ & & 1 \\
\hline EDSCHA & $\mathbf{2 0 1 5}$ & & 1 \\
\hline GONVARRI INDUSTRIAL & $\mathbf{2 0 1 5}$ & & 1 \\
\hline GRUPO ANTOLIN ARA & $\mathbf{2 0 1 5}$ & & 1 \\
\hline GRUPO ANTOLIN ARDASA & $\mathbf{2 0 1 5}$ & & 1 \\
\hline GRUPO ANTOLIN DAPSA & $\mathbf{2 0 1 5}$ & & 1 \\
\hline HELADOS MIKO & $\mathbf{2 0 0 4}$ & & 1 \\
\hline MANUFACTURAS ORIVE & $\mathbf{2 0 0 7}$ & & 1 \\
\hline ROTTNEROS MIRANDA & $\mathbf{2 0 0 8}$ & & 1 \\
\hline SAINT GOBAIN VICASA & $\mathbf{2 0 1 3}$ & & 1 \\
\hline SIRO BRIVIESCA & $\mathbf{2 0 1 5}$ & & 1 \\
\hline VB AUTOBATERIAS & $\mathbf{2 0 1 0}$ & 1 \\
\hline
\end{tabular}

\begin{tabular}{|l|r|r|r|}
\hline EMPRESAS AMBAS INFORM. EXTERNA E INTERNA & AÑO & PART. B & $\begin{array}{r}\text { OTRAS } \\
\text { REM. }\end{array}$ \\
\hline MONTEFIBRE HISPANIA & $\mathbf{2 0 1 4}$ & 1 & 1 \\
\hline
\end{tabular}




\begin{tabular}{|c|c|c|c|}
\hline EMPRESAS NI INFORMACIÓN EXTERNA NI INTERNA & AÑO & PART. B & $\begin{array}{l}\text { OTRAS } \\
\text { REM. }\end{array}$ \\
\hline AQUAGEST & 2008 & & \\
\hline ARDASA & 2007 & & \\
\hline ARTEPREF & 2011 & & \\
\hline AVENTIS & 2002 & & \\
\hline CALFERMAN & 2009 & & \\
\hline CENTRO GERONTOLOGICO & 2015 & & \\
\hline CERAMICAS GALA & 2014 & & \\
\hline CESPA & 2009 & & \\
\hline CLAU 2000 & 2009 & & \\
\hline COMPAÑIÍA MINERA RIO TIRON & 2014 & & \\
\hline CONFECCIONES ORY & 2013 & & \\
\hline DEXMUSA & 2009 & & \\
\hline DIARIO DE BURGOS & 2013 & & \\
\hline DUO FAST & 2014 & & \\
\hline EDB & 2012 & & \\
\hline ESTACIONAMIENTOS Y SERVICIOS & 2013 & & \\
\hline EXPAL & 2015 & & \\
\hline FABISA & 2011 & & \\
\hline GALLETAS CORAL & 2015 & & \\
\hline GALLETAS JESUS ANGULO & 2014 & & \\
\hline GRUPO ANTOLIN EUROTRIM & 2015 & & \\
\hline GRUPO GARCIA CAMARERO & 2012 & & \\
\hline GRUPO GERARDO DE LA CALLE & 2008 & & \\
\hline GRUPO ITEVELESA & 2010 & & \\
\hline HEIMBACH IBERICA & 2015 & & \\
\hline HORMIGONES Y EXC GERARDO DE LA CALLE & 2009 & & \\
\hline HOSTAL TRES CONDES & 2009 & & \\
\hline KRONOSPAN & 2015 & & \\
\hline LA FLOR BURGALESA & 2014 & & \\
\hline LENNOX REFAC & 2015 & & \\
\hline MINAS DE RIO TIRON CRIMIDESA & 2006 & & \\
\hline MONCOR 2000 & 2014 & & \\
\hline MUEBLES MARIA LUISA & 2015 & & \\
\hline NICOLAS CORREA & 2014 & & \\
\hline \multicolumn{4}{|l|}{ PASCUAL HERMANOS } \\
\hline PEPSICO MANUFACTURING & 2015 & & \\
\hline PIERRE GUERIN IBERICA & 2014 & & \\
\hline PLANIFICACION Y CONTROL LOGISTICO & 2010 & & \\
\hline PROSIDER IBERICA & 2007 & & \\
\hline SCHINDLER & 2010 & & \\
\hline \multicolumn{4}{|l|}{ SERUNION } \\
\hline SERVICIOS SEMAT & 2014 & & \\
\hline SNACK VENTURES MANUFACTURING & 2011 & & \\
\hline TECNICAS MEDIOAMBIENTALES TECMED & 2003 & & \\
\hline TRANS UNION GAS TUGASA & 2009 & & \\
\hline URBASER & 2015 & & \\
\hline ZAMORANO LIMPIEZAS MIRANDA & 2014 & & \\
\hline ZF ANSA LEMFORDER & 2012 & & \\
\hline
\end{tabular}


PÁGINA 430 
ANEXO 14

\section{RESULTADOS ENCUESTA NOVIEMBRE 2000}


PÁGINA 432 


\begin{tabular}{|c|c|c|c|c|c|c|c|c|c|c|c|c|c|c|c|c|c|c|c|c|}
\hline EMPRESA & \begin{tabular}{|l|l|}
1 & $2 \mathrm{a}$ \\
\end{tabular} & $2 \mathrm{~b}$ & $3 a$ & $3 \mathrm{~b}$ & $4 \mathrm{a}$ & $4 \mathrm{~b}$ & $4 \mathrm{C}$ & $5 \mathrm{a}$ & $5 \mathrm{~b}$ & $5 \mathrm{c}$ & $6 \mathrm{a}$ & $6 \mathrm{~b}$ & $6 \mathrm{c}$ & $7 a$ & $7 \mathrm{~b}$ & $8 \mathrm{a}$ & $8 \mathrm{~b}$ & $8 \mathrm{c}$ & $8 \mathrm{~d}$ & 9 \\
\hline ANSA LEMFORDER S.A. & 1 & 0 & 1 & 0 & 1 & 0 & 0 & 1 & 0 & 0 & 7.378 & 7.822 & 431 & 1 & 0 & 0 & 0 & 0 & 1 & DIR. RRHH \\
\hline AMVISA & 1 & 0 & 1 & 0 & 1 & 0 & 0 & 1 & 0 & 0 & 1.487 & 2.331 & 98 & 1 & 0 & 0 & 1 & 0 & & DEP.RRHH \\
\hline ARTEPREF GERARDO DE LA CALLE S.A. & 1 & 0 & 1 & 0 & 1 & 0 & 0 & 0 & 0 & 1 & 803 & 653 & 47 & 1 & 0 & 0 & 1 & 0 & 0 & DEP.ADMON \\
\hline CERAMICAS GALA S.A & 1 & 0 & 1 & 0 & 0 & 0 & 1 & 0 & 0 & 1 & 8.584 & 7.792 & 481 & 1 & 0 & 0 & 0 & 0 & & JEFE PERS. \\
\hline CISER S.L. & 0 & 1 & 0 & 1 & 1 & 0 & 0 & 0 & 0 & 1 & 158 & 435 & 81 & 1 & 0 & 0 & 1 & 0 & 1 & DEP.ADMON \\
\hline COFRALIM & 0 & 1 & 1 & 0 & 0 & 0 & 1 & 0 & 0 & 0 & \begin{tabular}{|l|}
41.585 \\
\end{tabular} & 15.344 & 876 & 1 & 0 & 0 & 0 & 0 & 1 & DEP.ADMON \\
\hline CONFECCIONES ORY S.A. & 1 & 0 & 1 & 0 & 1 & 0 & 0 & 0 & 0 & 1 & 1.313 & 2.761 & 236 & 1 & 0 & 0 & 0 & 0 & & DEP.RRHH \\
\hline CRIMIDESA & 0 & 1 & 1 & 0 & 1 & 0 & 0 & 0 & 1 & 0 & 9.984 & 6.435 & 137 & 1 & 0 & 0 & 0 & 1 & 0 & DEP.RRHH \\
\hline DIARIO DE BURGOS S.L. & 1 & 0 & 1 & 0 & 1 & 0 & 0 & 0 & 0 & 1 & 1.578 & 990 & 59 & 1 & 0 & 0 & 0 & 0 & 1 & GERENTE \\
\hline DAPSA & 1 & 0 & 1 & 0 & 1 & 0 & 0 & 0 & 1 & 0 & 3.855 & 6.086 & 198 & 1 & 0 & 0 & 0 & 1 & & DEP.RRHH \\
\hline DORLYL IBERICA S.L. & 1 & 0 & 1 & 0 & 1 & 0 & 0 & 0 & 1 & 0 & 987 & 1.779 & 21 & 1 & 0 & 0 & 0 & 1 & 0 & DEP.ADMON \\
\hline DUOFAST DE ESPAÑA S.A. & 1 & 0 & 1 & 0 & 1 & 0 & 0 & 1 & 0 & 0 & 4.426 & 3.821 & 214 & 1 & 0 & 0 & 0 & 1 & & DEP.RRHH \\
\hline EDB S.A. & 0 & 1 & 1 & 0 & 0 & 0 & 1 & 1 & 0 & 0 & 2.767 & 1.594 & 100 & 1 & 0 & 0 & 0 & 0 & & JEFE PERS. \\
\hline ELF ATOCHEM ESPAÑA S.A. & 0 & 1 & 1 & 0 & 0 & 0 & 1 & 1 & 0 & 0 & \begin{tabular}{|l|}
29.294 \\
\end{tabular} & 60.565 & 523 & 1 & 0 & 0 & 0 & 0 & 1 & DEP.RRHH \\
\hline FABISA & 1 & 0 & 1 & 0 & 1 & 0 & 0 & 1 & 0 & 0 & 3.394 & 5.336 & 242 & 1 & 0 & 0 & 0 & 1 & 0 & DEP.RRHH \\
\hline FALUNORSA & & & & & & & & & & & & & & & & & & & & \\
\hline GALLETAS CORAL S.A. & 1 & 0 & 1 & 0 & 1 & 0 & 0 & 0 & 0 & 0 & 545 & 770 & 53 & 1 & 0 & 0 & 0 & 0 & 1 & DEP.ADMON \\
\hline GONVARRI INDUSTRIAL S.A. & 0 & 1 & 1 & 0 & 0 & 0 & 1 & 0 & 1 & 0 & 121.157 & 141.904 & 1.597 & 1 & 0 & 0 & 1 & 0 & 0 & DEP.RRHH \\
\hline HELADOS MIKO S.A. & 0 & 1 & 1 & 0 & 0 & 0 & 1 & 0 & 0 & 0 & \begin{tabular}{|l|}
41.585 \\
\end{tabular} & 15.344 & 876 & 1 & 0 & 0 & 0 & 0 & & DEP.ADMON \\
\hline HORMIGONES Y EXCAVACIONES G.C & 1 & 0 & 1 & 0 & 1 & 0 & 0 & 0 & 0 & 1 & 1.018 & 1.151 & 77 & 1 & 0 & 0 & 1 & 0 & 0 & DEP.ADMON \\
\hline HOSTAL TRES CONDES & 1 & 0 & 0 & 1 & 1 & 0 & 0 & 0 & 0 & 1 & 63 & 109 & 17 & 1 & 0 & 0 & 1 & 0 & 0 & DEP.ADMON \\
\hline JJ BIS 95 S.L. & 1 & 0 & 0 & 1 & 1 & 0 & 0 & 0 & 0 & 1 & 52 & 72 & 24 & 1 & 0 & 0 & 0 & 0 & & DEP.ADMON \\
\hline KIMBERLY CLARK MIRANDA S.A & 1 & 0 & 1 & 0 & 1 & 0 & 0 & 1 & 0 & 0 & 7.285 & 9.919 & 171 & 1 & 0 & 0 & 0 & 0 & 1 & DEP.RRHH \\
\hline LA CELLOPHANE ESPAÑOLA S.A & 1 & 0 & 1 & 0 & 0 & 0 & 1 & 1 & 0 & 0 & 3.619 & 6.795 & 351 & 1 & 0 & 0 & 0 & 0 & & JEFE PERS. \\
\hline LENNOX REFAC S.A. & 1 & 0 & 1 & 0 & 1 & 0 & 0 & 1 & 0 & 0 & 1.932 & 2.656 & 131 & 1 & 0 & 0 & 0 & 0 & 1 & DEP.RRHH \\
\hline MANUFACTURAS ORIVE S.A & 1 & 0 & 1 & 0 & 1 & 0 & 0 & 0 & 0 & 1 & 245 & 471 & 66 & 1 & 0 & 0 & 0 & 0 & 1 & DEP.ADMON \\
\hline MONTEFIBRE HISPANIA S.A & 0 & 1 & 1 & 0 & 0 & 0 & 1 & 1 & 0 & 0 & 12.933 & 16.847 & 454 & 1 & 0 & 0 & 0 & 0 & & DIR.RRLL \\
\hline NICOLAS CORREA S.A & 1 & 0 & 1 & 0 & 1 & 0 & 0 & 0 & 1 & 0 & 7.651 & 9.001 & 275 & 1 & 0 & 0 & 0 & 0 & 1 & DEP.RRHH \\
\hline ONNYX RSU & 1 & 0 & 1 & 0 & 1 & 0 & 0 & 0 & 1 & 0 & 4.438 & 3.364 & 523 & 1 & 0 & 0 & 0 & 0 & & DELEGADO \\
\hline PIERRE GUERIN IBERICA S.A & 1 & 0 & 1 & 0 & 0 & 0 & 1 & 1 & 0 & 0 & 942 & 2.071 & 111 & 1 & 0 & 0 & 1 & 0 & & DEP.RRHH \\
\hline PROSIDER IBERICA S.A & 1 & 0 & 1 & 0 & 1 & 0 & 0 & 0 & 1 & 0 & 611 & 801 & 28 & 1 & 0 & 0 & 0 & 0 & 1 & DEP.RRHH \\
\hline REPOSTERIA MARTINEZ S.A. & 1 & 0 & 1 & 0 & 0 & 0 & 1 & 1 & 0 & 0 & 8.000 & 3.253 & 903 & 1 & 0 & 0 & 0 & 0 & & DEP.RRHH \\
\hline RHONE POULENC S.A. & 1 & 0 & 1 & 0 & 1 & 0 & 0 & 1 & 0 & 0 & 10.924 & 11.231 & 108 & 1 & 0 & 0 & 0 & 1 & & DEP.RRHH \\
\hline ROTTNEROS MIRANDA S.A. & 1 & 0 & 1 & 0 & 1 & 0 & 0 & 1 & 0 & 0 & 7.285 & 9.919 & 171 & 1 & 0 & 0 & 0 & 0 & 1 & DEP.RRHH \\
\hline SAN MIGUEL S.A. & 0 & 1 & 1 & 0 & 0 & 0 & 1 & 1 & 0 & 0 & 35.138 & 42.141 & 978 & 1 & 0 & 0 & 0 & 1 & & DEP.ADMON \\
\hline SCHINDLER S.A. & 0 & 1 & 1 & 0 & 0 & 0 & 1 & 1 & 0 & 0 & 19.738 & 39.124 & 2.241 & 1 & 0 & 0 & 0 & 0 & 1 & DEP.RRHH \\
\hline SNACK VENTURES S.A. & 1 & 0 & 1 & 0 & 0 & 0 & 1 & 1 & 0 & 0 & 30.418 & 39.404 & 2.067 & 1 & 0 & 0 & 0 & 0 & & TEC.RRHH \\
\hline SOMA S.L. & 1 & 0 & 0 & 1 & 1 & 0 & 0 & 0 & 0 & 1 & 11 & 6 & 0 & 1 & 0 & 0 & 0 & 1 & 0 & DEP.ADMON \\
\hline STORK INTERIBERICA S.A. & 1 & 0 & 1 & 0 & 1 & 0 & 0 & 1 & 0 & 0 & 1.861 & 1.638 & 60 & 1 & 0 & 0 & 0 & 0 & 1 & DEP.RRHH \\
\hline STORK SISTEMAS ALIMENTARIOS S.A. & 1 & 0 & 1 & 0 & 0 & 0 & 1 & 1 & 0 & 0 & 942 & 2.071 & 111 & 1 & 0 & 0 & 1 & 0 & 0 & DEP.RRHH \\
\hline TALLERES ARA S.L. & 1 & 0 & 1 & 0 & 1 & 0 & 0 & 0 & 1 & 0 & 4.285 & 5.115 & 185 & 1 & 0 & 0 & 0 & 1 & & DEP.RRHH \\
\hline TUGASA & 1 & 0 & 0 & 1 & 1 & 0 & 0 & 0 & 0 & 1 & 60 & 69 & 10 & 1 & 0 & 0 & 0 & 1 & 0 & DEP.ADMON \\
\hline TRW S.A. & 0 & 1 & 1 & 0 & 0 & 0 & 1 & 1 & 0 & 0 & 3.300 & 13.100 & 330 & 1 & 0 & 0 & 0 & 0 & & DIR.FINANC. \\
\hline UNION ESPAÑOLA DE EXPLOSIVOS S.A & 0 & 1 & 1 & 0 & 0 & 0 & 1 & 1 & 0 & 0 & 34.685 & 19.210 & 621 & 1 & 0 & 0 & 0 & 0 & 1 & DEP.RRHH \\
\hline VB AUTOBATERIAS S.A. & 0 & 1 & 1 & 0 & 0 & 0 & 1 & 1 & 0 & 0 & 11.414 & 18.245 & 587 & 1 & 0 & 0 & 1 & 0 & 0 & DEP.RRHH \\
\hline VICASA S.A. & 0 & 1 & 1 & 0 & 0 & 0 & 1 & 1 & 0 & 0 & \begin{tabular}{|l|}
56.211 \\
\end{tabular} & 32.375 & 1.355 & 1 & 0 & 0 & 0 & 0 & & DEP.RRHH \\
\hline
\end{tabular}




\begin{tabular}{|c|c|c|c|c|c|c|c|c|c|c|c|}
\hline EMPRESA & $10 \mathrm{a}$ & $10 \mathrm{~b}$ & $11 \mathrm{a}$ & $11 \mathrm{~b}$ & $11 \mathrm{c}$ & $12 \mathrm{a}$ & $12 \mathrm{~b}$ & $13 \mathrm{a}$ & $13 \mathrm{~b}$ & $14 \mathrm{a}$ & $14 \mathrm{~b}$ \\
\hline ANSA LEMFORDER S.A. & 1 & 0 & 1 & 0 & 0 & 1 & 0 & 1 & 0 & 1 & 0 \\
\hline AMVISA & 1 & 0 & 1 & 0 & 0 & 1 & 0 & 1 & 0 & 1 & 0 \\
\hline ARTEPREF GERARDO DE LA CALLE S.A. & 1 & 0 & 1 & 0 & 0 & 1 & 0 & 1 & 0 & 1 & 0 \\
\hline CERAMICAS GALA S.A & 1 & 0 & 0 & 0 & 1 & 1 & 0 & 1 & 0 & 1 & 0 \\
\hline CISER S.L. & 1 & 0 & 1 & 0 & 0 & 1 & 0 & 1 & 0 & 1 & 0 \\
\hline COFRALIM & 1 & 0 & 1 & 0 & 0 & 1 & 0 & 1 & 0 & 1 & 0 \\
\hline CONFECCIONES ORY S.A. & 1 & 0 & 1 & 0 & 0 & 1 & 0 & 1 & 0 & 1 & 0 \\
\hline CRIMIDESA & 1 & 0 & 1 & 0 & 0 & 1 & 0 & 1 & 0 & 1 & 0 \\
\hline DIARIO DE BURGOS S.L. & 1 & 0 & 1 & 0 & 0 & 1 & 0 & 1 & 0 & 1 & 0 \\
\hline DAPSA & 1 & 0 & 1 & 0 & 0 & 1 & 0 & 1 & 0 & 1 & 0 \\
\hline DORLYL IBERICA S.L. & 1 & 0 & 1 & 0 & 0 & 1 & 0 & 1 & 0 & 1 & 0 \\
\hline DUOFAST DE ESPAÑA S.A. & 1 & 0 & 1 & 0 & 0 & 1 & 0 & 1 & 0 & 1 & 0 \\
\hline EDB S.A. & 1 & 0 & 0 & 1 & 0 & 0 & 1 & 0 & 1 & 0 & 1 \\
\hline ELF ATOCHEM ESPAÑA S.A. & 1 & 0 & 1 & 0 & 0 & 1 & 0 & 1 & 0 & 1 & 0 \\
\hline FABISA & 1 & 0 & 1 & 0 & 0 & 1 & 0 & 1 & 0 & 1 & 0 \\
\hline \multicolumn{12}{|l|}{ FALUNORSA } \\
\hline GALLETAS CORAL S.A. & 1 & 0 & 1 & 0 & 0 & 1 & 0 & 1 & 0 & 1 & 0 \\
\hline GONVARRI INDUSTRIAL S.A. & 1 & 0 & 1 & 0 & 0 & 1 & 0 & 1 & 0 & 1 & 0 \\
\hline COFRALIM & 1 & 0 & 1 & 0 & 0 & 1 & 0 & 1 & 0 & 1 & 0 \\
\hline HORMIGONES Y EXCAVACIONES G.C & 1 & 0 & 1 & 0 & 0 & 1 & 0 & 1 & 0 & 1 & 0 \\
\hline HOSTAL TRES CONDES & 1 & 0 & 1 & 0 & 0 & 1 & 0 & 1 & 0 & 1 & 0 \\
\hline JJ BIS 95 S.L. & 1 & 0 & 1 & 0 & 0 & 1 & 0 & 1 & 0 & 1 & 0 \\
\hline KIMBERLY CLARK MIRANDA S.A & 1 & 0 & 1 & 0 & 0 & 1 & 0 & 1 & 0 & 1 & 0 \\
\hline LA CELLOPHANE ESPAÑOLA S.A & 1 & 0 & 1 & 0 & 0 & 0 & 1 & 1 & 0 & 1 & 0 \\
\hline LENNOX REFAC S.A. & 1 & 0 & 1 & 0 & 0 & 1 & 0 & 1 & 0 & 1 & 0 \\
\hline MANUFACTURAS ORIVE S.A & 1 & 0 & 1 & 0 & 0 & 1 & 0 & 1 & 0 & 1 & 0 \\
\hline MONTEFIBRE HISPANIA S.A & 1 & 0 & 0 & 0 & 1 & 1 & 0 & 1 & 0 & 1 & 0 \\
\hline NICOLAS CORREA S.A & 0 & 1 & 1 & 0 & 0 & 1 & 0 & 1 & 0 & 1 & 0 \\
\hline ONNYX RSU & 1 & 0 & 1 & 0 & 0 & 0 & 1 & 0 & 1 & 0 & 1 \\
\hline PIERRE GUERIN IBERICA S.A & 1 & 0 & 1 & 0 & 0 & 1 & 0 & 1 & 0 & 1 & 0 \\
\hline PROSIDER IBERICA S.A & 1 & 0 & 1 & 0 & 0 & 1 & 0 & 1 & 0 & 1 & 0 \\
\hline REPOSTERIA MARTINEZ S.A. & 1 & 0 & 1 & 0 & 0 & 1 & 0 & 1 & 0 & 1 & 0 \\
\hline RHONE POULENC S.A. & 1 & 0 & 1 & 0 & 0 & 1 & 0 & 1 & 0 & 1 & 0 \\
\hline KIMBERLY CLARK MIRANDA S.A & 1 & 0 & 1 & 0 & 0 & 1 & 0 & 1 & 0 & 1 & 0 \\
\hline SAN MIGUEL S.A. & 1 & 0 & 1 & 0 & 0 & 1 & 0 & 1 & 0 & 1 & 0 \\
\hline SCHINDLER S.A. & 1 & 0 & 1 & 0 & 0 & 1 & 0 & 1 & 0 & 1 & 0 \\
\hline SNACK VENTURES S.A. & 1 & 0 & 1 & 0 & 0 & 1 & 0 & 1 & 0 & 1 & 0 \\
\hline SOMA S.L. & 1 & 0 & 1 & 0 & 0 & 1 & 0 & 1 & 0 & 1 & 0 \\
\hline STORK INTERIBERICA S.A. & 1 & 0 & 1 & 0 & 0 & 1 & 0 & 1 & 0 & 1 & 0 \\
\hline PIERRE GUERIN IBERICA S.A & 1 & 0 & 1 & 0 & 0 & 1 & 0 & 1 & 0 & 1 & 0 \\
\hline TALLERES ARA S.L. & 1 & 0 & 1 & 0 & 0 & 1 & 0 & 1 & 0 & 1 & 0 \\
\hline TUGASA & 1 & 0 & 1 & 0 & 0 & 1 & 0 & 1 & 0 & 1 & 0 \\
\hline TRW S.A. & 1 & 0 & 0 & 0 & 1 & 1 & 0 & 1 & 0 & 1 & 0 \\
\hline UNION ESPAÑOLA DE EXPLOSIVOS S.A & 1 & 0 & 1 & 0 & 0 & 1 & 0 & 1 & 0 & 1 & 0 \\
\hline VB AUTOBATERIAS S.A. & 1 & 0 & 1 & 0 & 0 & 1 & 0 & 1 & 0 & 1 & 0 \\
\hline VICASA S.A. & 1 & 0 & 1 & 0 & 0 & 1 & 0 & 1 & 0 & 1 & 0 \\
\hline
\end{tabular}




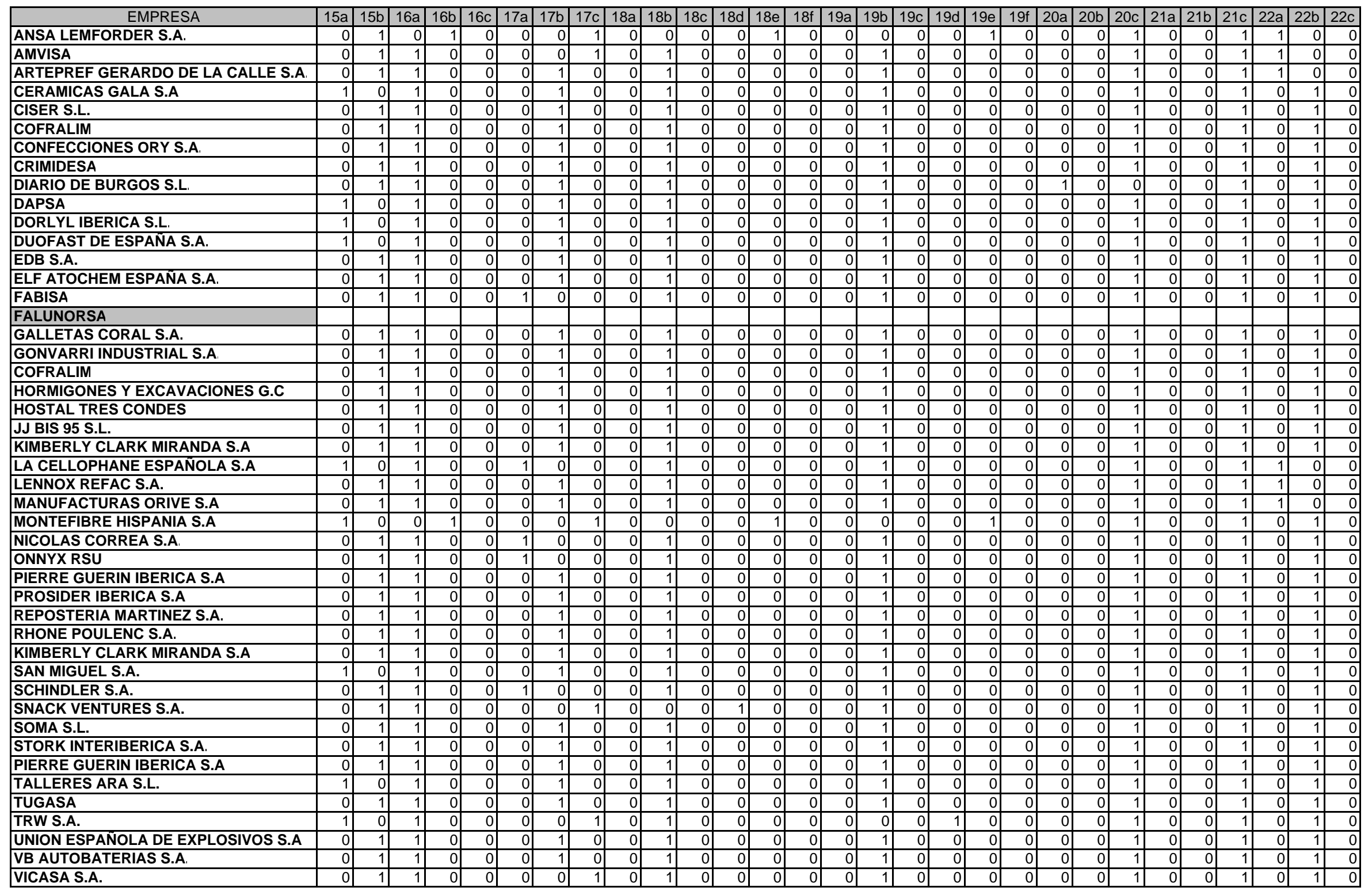


\begin{tabular}{|r|}
\hline EMPRESA \\
\hline ANSA LEMFORDER SA.
\end{tabular}

AMVISA

AMVISA

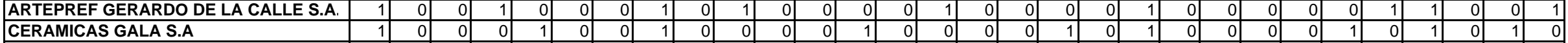

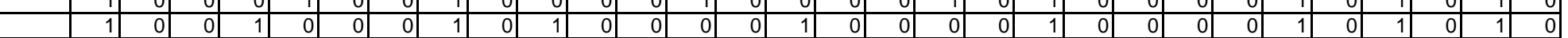

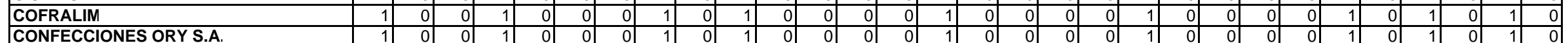

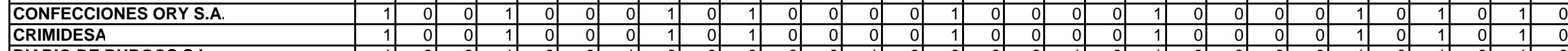

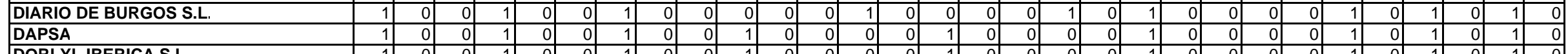

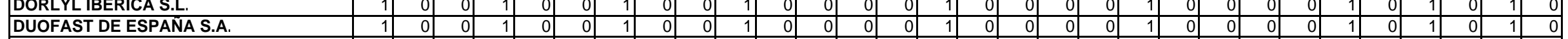

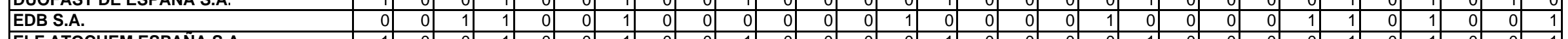

\begin{tabular}{|l|l|l|l|l|l|l|l|l|l|l|l|l|l|l|l|l|l|l|l|l|l|l|l|l|l|l|l|l|l|l|}
\hline ELF ATOCHEM ESPAÑA S.A. & 1 & 0 & 0 & 1 & 0 & 0 & 1 & 0 & 0 & 1 & 0 & 0 & 0 & 0 & 1 & 0 & 0 & 0 & 0 & 1 & 0 & 0 & 0 & 0 & 1 & 0 & 1 & 0 & 0 & 1 \\
\hline FABISA & 1 & 0 & 0 & 1 & 0 & 0 & 1 & 0 & 0 & 1 & 0 & 0 & 0 & 0 & 1 & 0 & 0 & 0 & 0 & 1 & 0 & 0 & 0 & 0 & 1 & 0 & 1 & 0 & 0 & 1 \\
\hline
\end{tabular}

GALLETAS CORAL S.A.

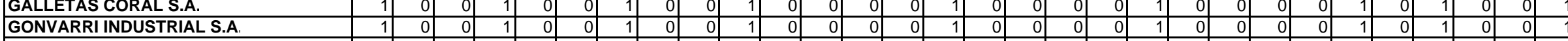

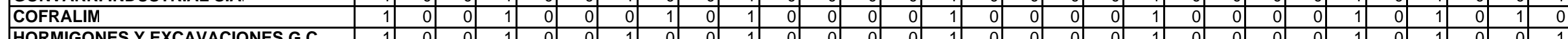

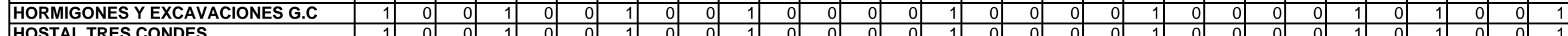

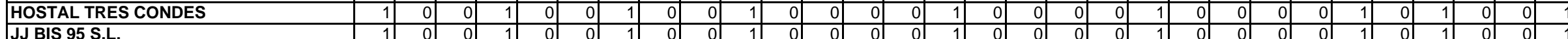

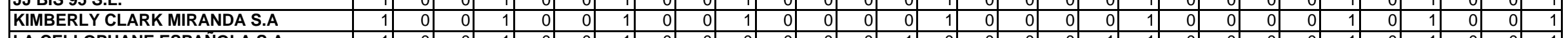

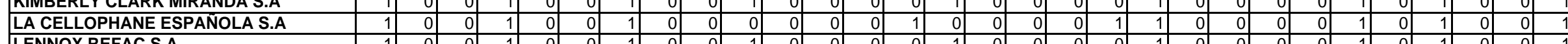

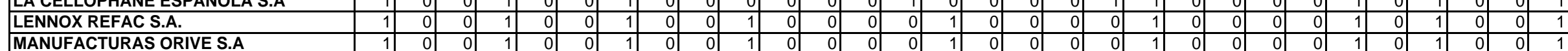

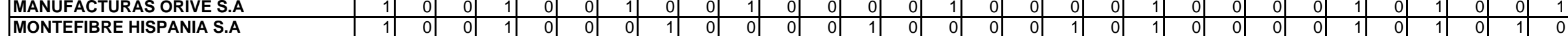

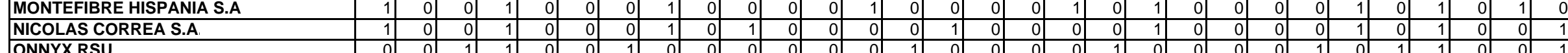

ONNYX RSU

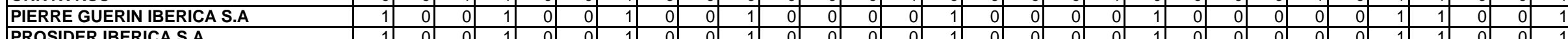

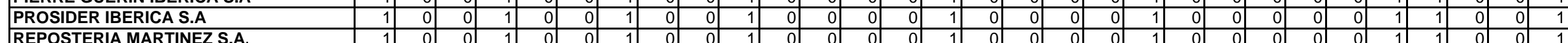

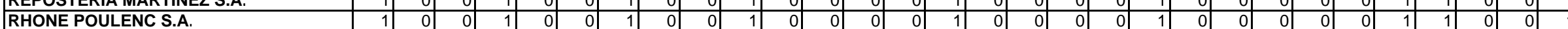

RHONE POULENC SA

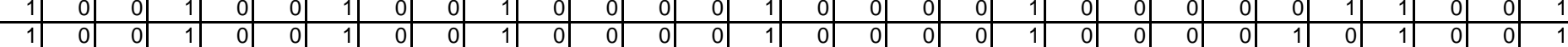

KIMBERLY CLARK MIRANDA S.A

SAN MIGUEL S.A.

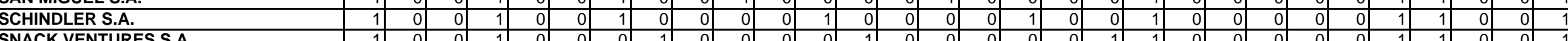

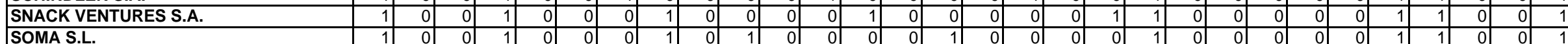

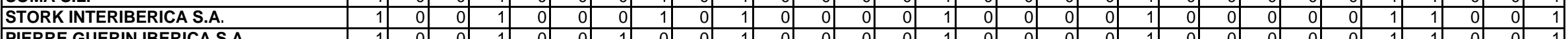

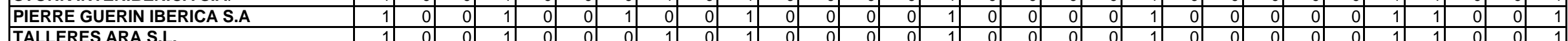

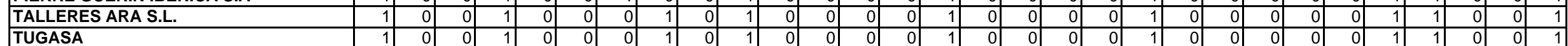

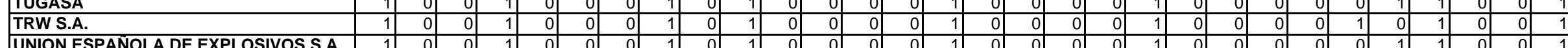

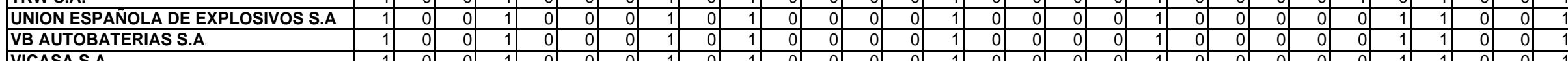

VICASA S.A. 
ANEXO 15

\section{RESULTADOS ENCUESTA MAYO 2015}


PÁGINA 438 


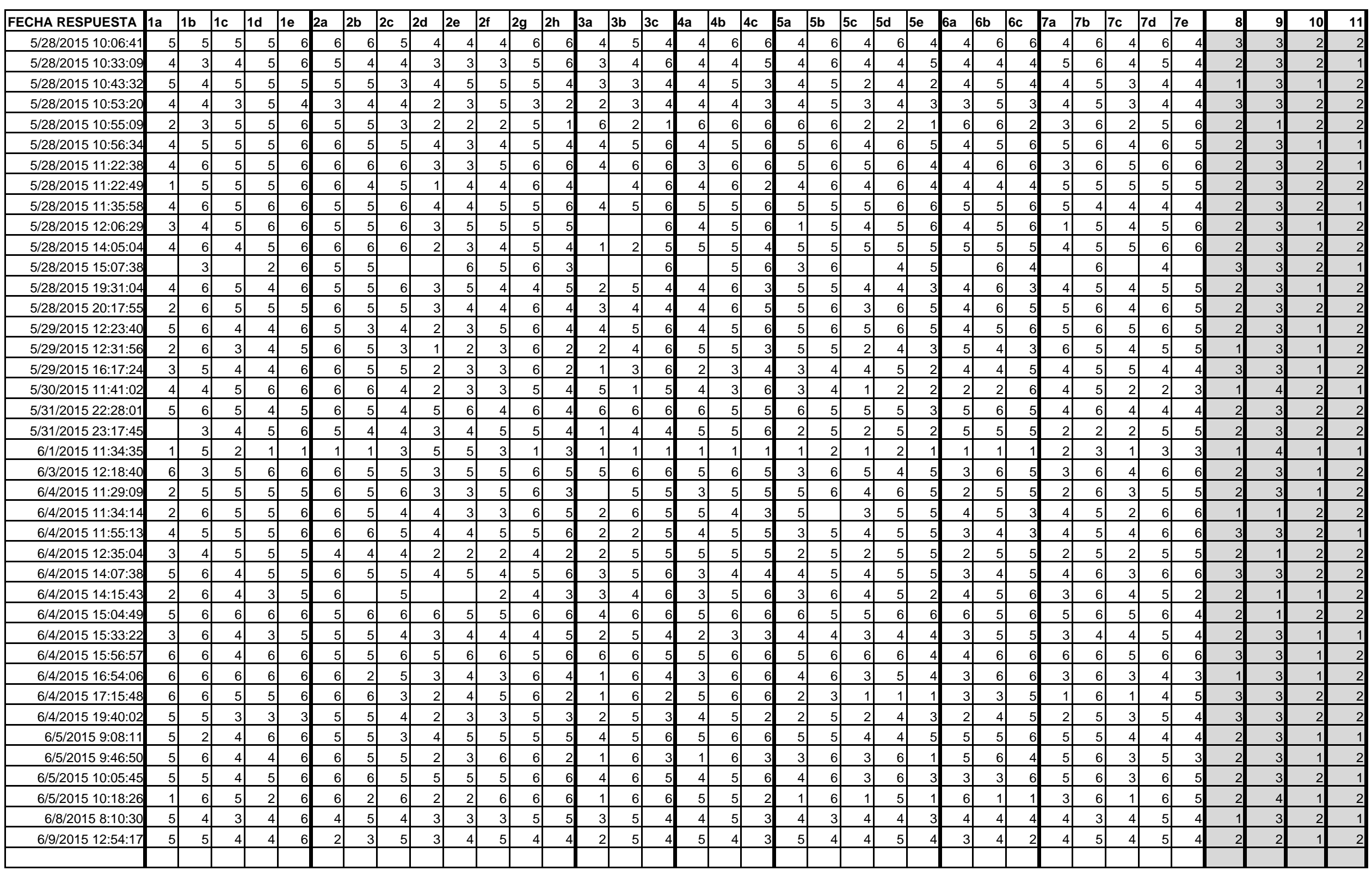


PÁGINA 440 
ANEXO 16

\section{RESUMEN RESPUESTAS ENCUESTA MAYO 2015}


PÁGINA 442 


\section{NEGOCIACIÓN COLECTIVA}

\section{Pregunta 1}

a) Convenio sectorial [1) De la siguiente relación, valore de 1 a 6 (siendo 1 menos importante y 6 más importante), los factores que considere más determinantes en la negociación del convenio colectivo de empresa]

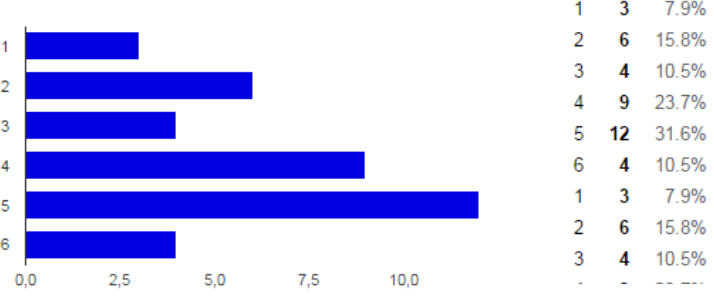

b) Poder de los sindicatos y calidad de las relaciones representan valore de 1 a 6 (siendo 1 menos importante y 6 más importante), Ic negociación del convenio colectivo de empresa]

esa [1) De la siguiente relación, dere más determinantes en la

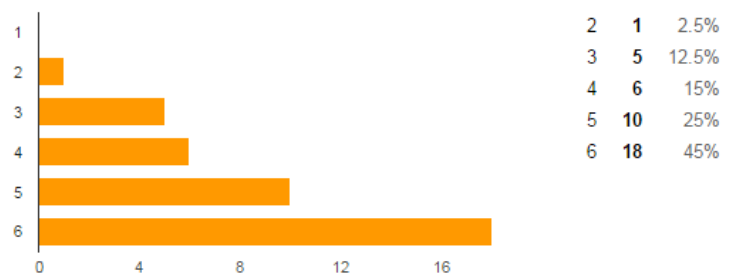

c) Coyuntura económica general [1) De la siguiente relación, valore de 1 a 6 (siendo 1 menos importante y 6 más importante), los factores que considere más determinantes en la negociación del convenio colectivo de empresa]
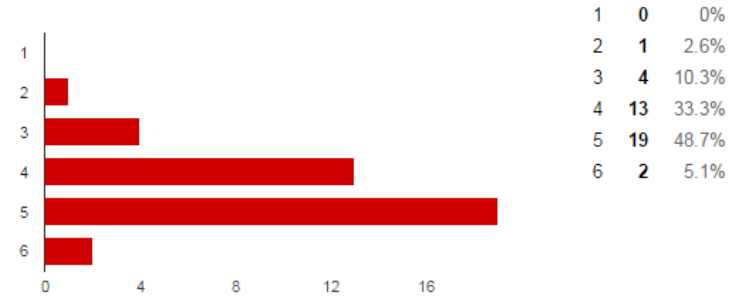

d) Coyuntura y situación económica del sector al que pertenece la empresa [1) De la siguiente relación, valore de 1 a 6 (siendo 1 menos importante y 6 más importante), los factores que considere más determinantes en la negociación del convenio colectivo de empresa]

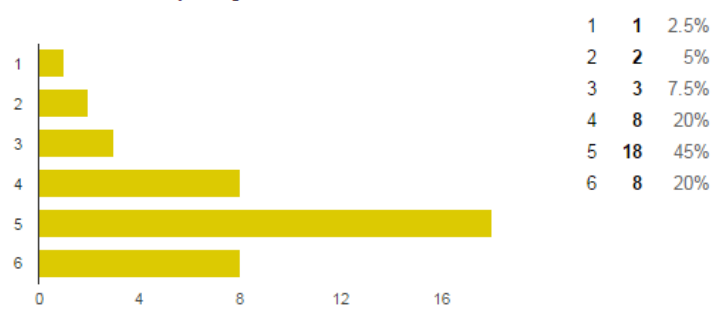

e) Situación económica de la empresa $\quad$ [1) De la siguiente relación, valore de 1 a 6 (siendo 1 menos importante y 6 más importante), los factores que considere más determinantes en la negociación del convenio colectivo de empresa]

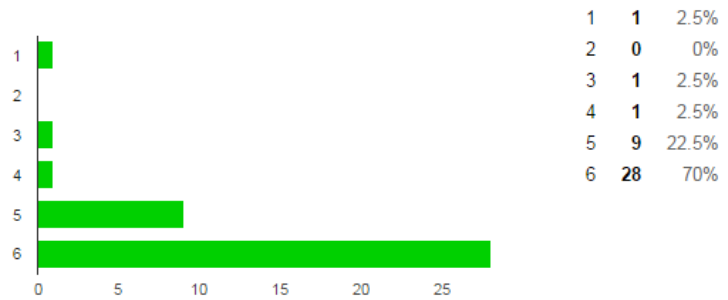




\section{Pregunta 2}

a) Condiciones económicas: retribución fija [2) De la siguiente relación, valore de 1 a 6 (siendo 1 menos importante y 6 más importante), las materias que considere más determinantes para la firma del convenio colectivo de empresa]

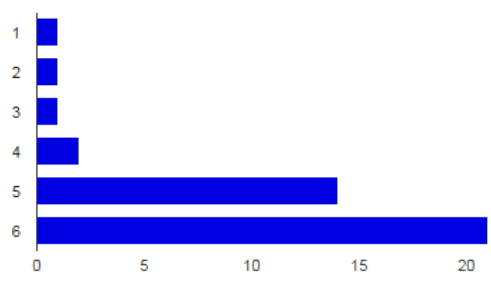

$$
\begin{array}{rrr}
1 & \mathbf{1} & 2.5 \% \\
2 & \mathbf{1} & 2.5 \% \\
3 & \mathbf{1} & 2.5 \% \\
4 & \mathbf{2} & 5 \% \\
5 & \mathbf{1 4} & 35 \% \\
6 & \mathbf{2 1} & 52.5 \%
\end{array}
$$

b) Jornada laboral [2) De la siguiente relación, valore de 1 a 6 (siendo 1 menos importante y 6 más importante), las materias que considere más determinantes para la firma del convenio colectivo de empresa]

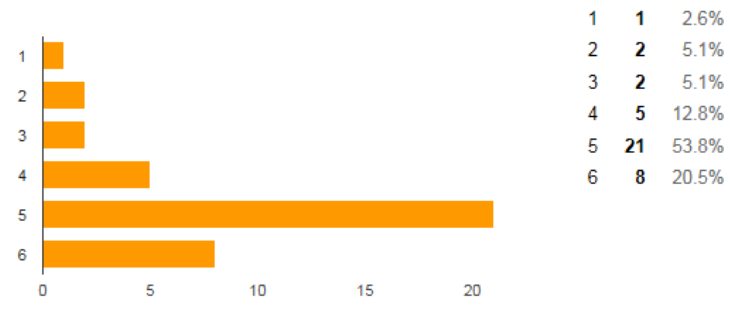

c) Flexibilidad tanto de jornada como funcional [2) De la siguiente relación, valore de 1 a 6 (siendo 1 menos importante y 6 más importante), las materias que considere más determinantes para la firma del convenio colectivo de empresa]

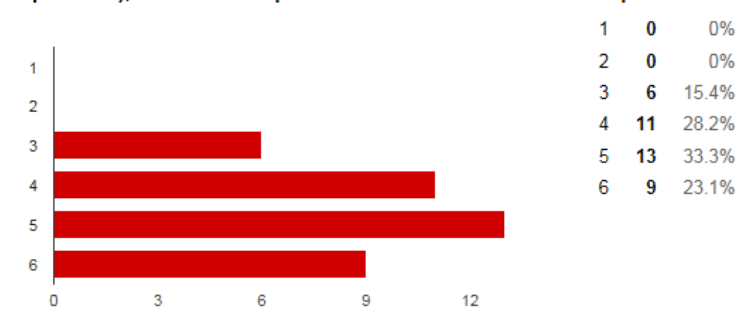

d) Derechos sindicales [2) De la siguiente relación, valore de 1 a 6 (siendo 1 menos importante y 6 más importante), las materias que considere más determinantes para la firma del convenio colectivo de empresa]

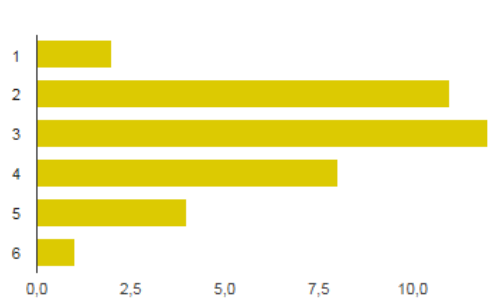

$$
\begin{array}{rrr}
1 & \mathbf{2} & 5.3 \% \\
2 & \mathbf{1 1} & 28.9 \% \\
3 & \mathbf{1 2} & 31.6 \% \\
4 & \mathbf{8} & 21.1 \% \\
5 & \mathbf{4} & 10.5 \% \\
6 & \mathbf{1} & 2.6 \%
\end{array}
$$

e) Derechos sociales, permisos, etc. [2) De la siguiente relación, valore de 1 a 6 (siendo 1 menos importante y 6 más importante), las materias que considere más determinantes para la firma del convenio colectivo de empresa]

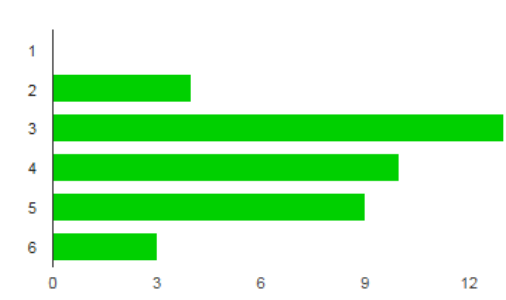


f) Condiciones de trabajo y productividad: retribución variable [2) De la siguiente relación, valore de 1 a 6 (siendo 1 menos importante y 6 más importante), las materias que considere más determinantes para la firma del convenio colectivo de empresa]

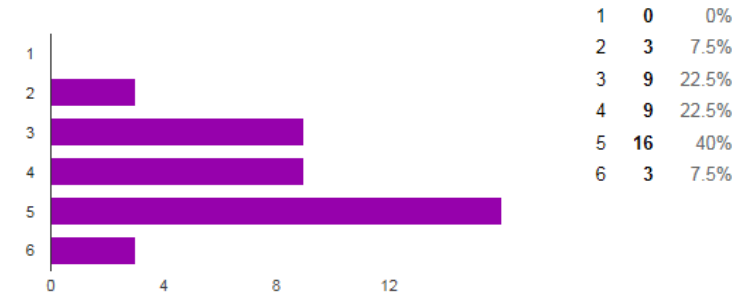

g) Incrementos salariales [2) De la siguiente relación, valore de 1 a 6 (siendo 1 menos importante y 6 más importante), las materias que considere más determinantes para la firma del convenio colectivo de empresa]

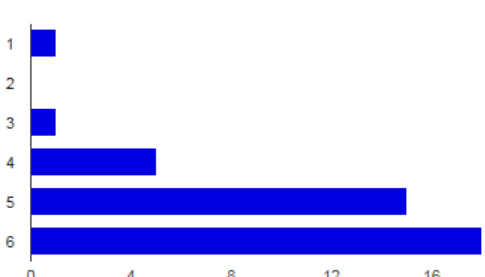

h) Mantenimiento-creación de empleo [2) De la siguiente relación, valore de 1 a 6 (siendo 1 menos importante y 6 más importante), las materias que considere más determinantes para la firma del convenio colectivo de empresa]

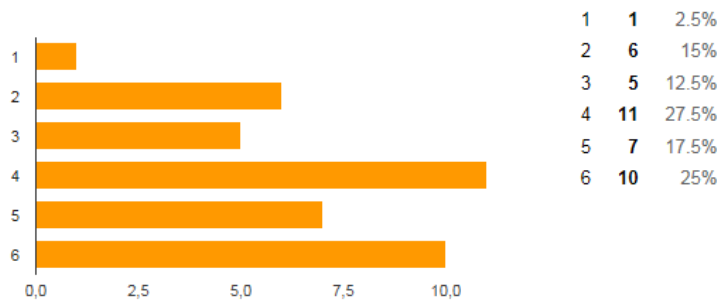




\section{Pregunta 3}

a) PIB [3) De la siguiente relación, valore de 1 a 6 (siendo 1 menos importante y 6 más importante), las referencias que considere mejor aceptadas por ambas partes en la firma del convenio colectivo de empresa, en lo que se refiere a la revisión salarial]

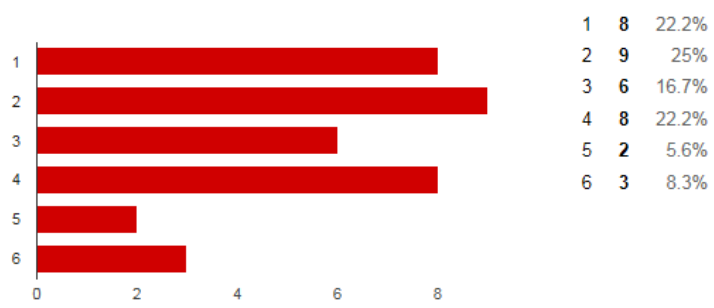

b) IPC [3) De la siguiente relación, valore de 1 a 6 (siendo 1 menos importante y 6 más importante), las referencias que considere mejor aceptadas por ambas partes en la firma del convenio colectivo de empresa, en lo que se refiere a la revisión salarial]

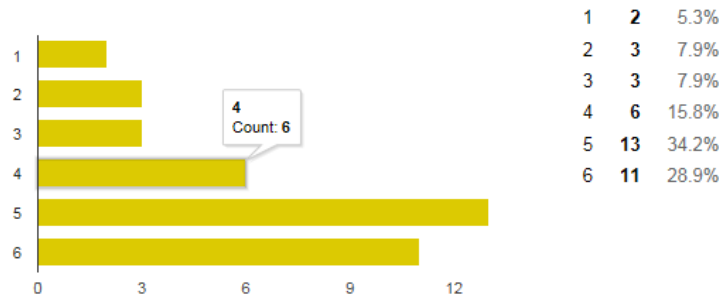

c) Información económica propia de la empresa (tanto estrictamente financiera como de productividad/calidad) [3) De la siguiente relación, valore de 1 a 6 (siendo 1 menos importante y 6 más importante), las referencias que considere mejor siguiente relación, valore de 1 a 6 (siendo 1 menos importante y 6 más importante), las referencias que considere mejor
aceptadas por ambas partes en la firma del convenio colectivo de empresa, en lo que se refiere a la revisión salarial]

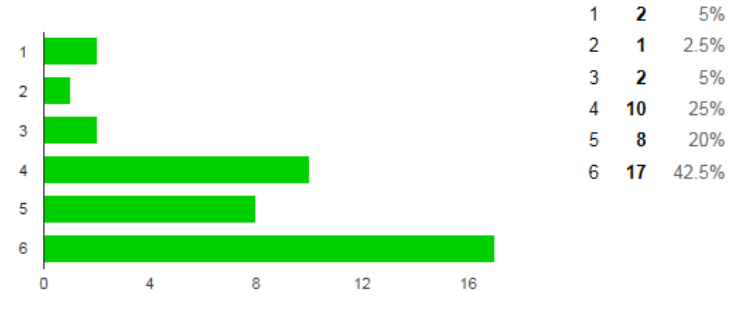




\section{INFORMACIÓN ECONÓMICA}

\section{Pregunta 4}

a) Información económica de años anteriores [4) De la información económica de la empresa, valore de 1 a 6 (siendo menos importante y 6 más importante), la que podría aceptarse por ambas partes para referenciar el incremento salarial]
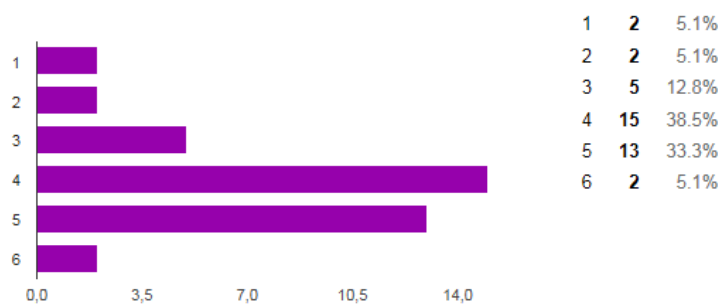

b) Información económica del momento de la negociación [4) De la información económica de la empresa, valore de 1 a 6 (siendo 1 menos importante y 6 más importante), la que podria aceptarse por ambas partes para referenciar el incremento salarial]
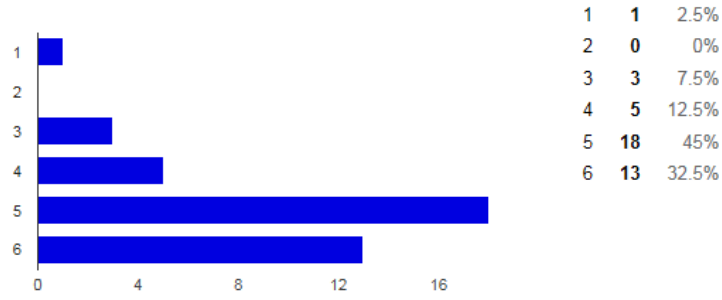

c) Información económica prevista para futuros ejercicios [4) De la información económica de la empresa, valore de 1 a 6 (siendo 1 menos importante y 6 más importante), la que podria aceptarse por ambas partes para referenciar el incremento salarial]

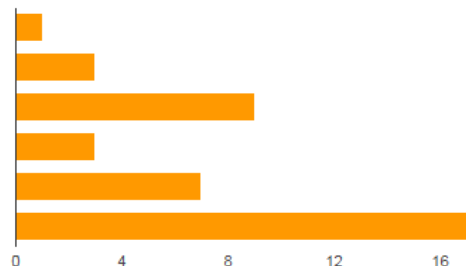




\section{Pregunta 5}

a) Facturación [5) De la información económica de la empresa, valore de 1 a 6 (siendo 1 menos importante y 6 más importante), la que podría aceptarse por ambas partes para referenciar el incremento salarial]

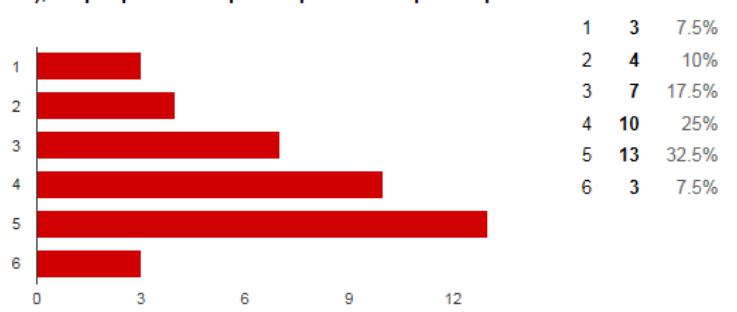

b) Resultados [5) De la información económica de la empresa, valore de 1 a 6 (siendo 1 menos importante y 6 más importante), la que podría aceptarse por ambas partes para referenciar el incremento salarial]

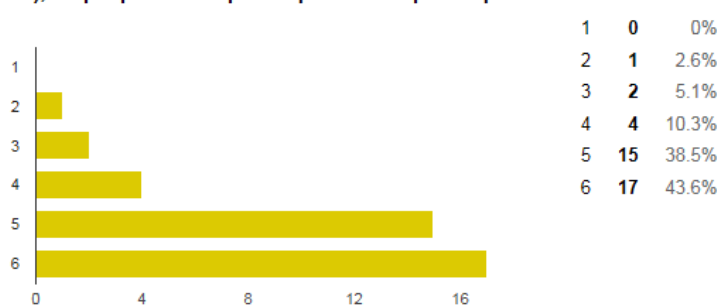

c) Cash flow [5) De la información económica de la empresa, valore de 1 a 6 (siendo 1 menos importante y 6 más importante), la que podría aceptarse por ambas partes para referenciar el incremento salarial]

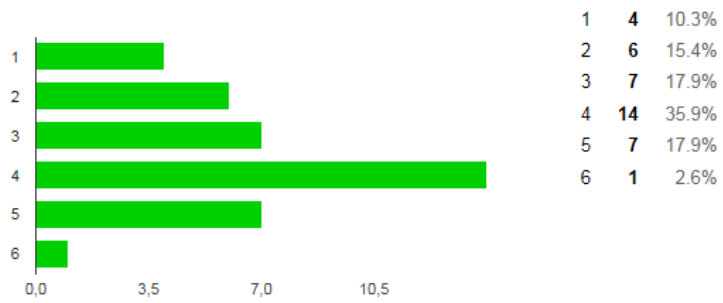

d) Productividad [5) De la información económica de la empresa, valore de 1 a 6 (siendo 1 menos importante y 6 más importante), la que podría aceptarse por ambas partes para referenciar el incremento salarial]

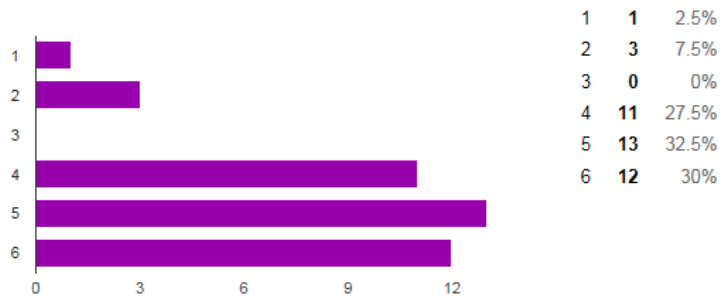

e) Inversión [5) De la información económica de la empresa, valore de 1 a 6 (siendo 1 menos importante y 6 más importante), la que podría aceptarse por ambas partes para referenciar el incremento salarial]

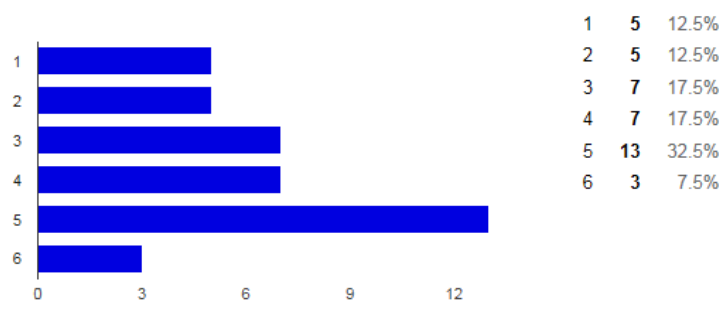




\section{Pregunta 6}

a) Información económica de años anteriores [6) De la información económica de la empresa, valore de 1 a 6 (siendo 1 menos importante y 6 más importante), la que podria aceptarse por ambas partes para establecer complementos variables]

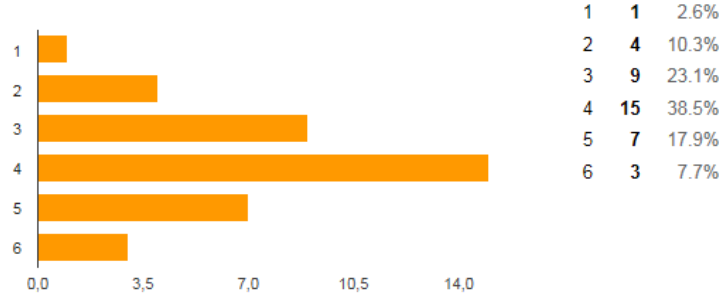

b) Información económica del momento de la negociación [6) De la información económica de la empresa, valore de 1 a 6 (siendo 1 menos importante y 6 más importante), la que podria aceptarse por ambas partes para establecer complementos variables]
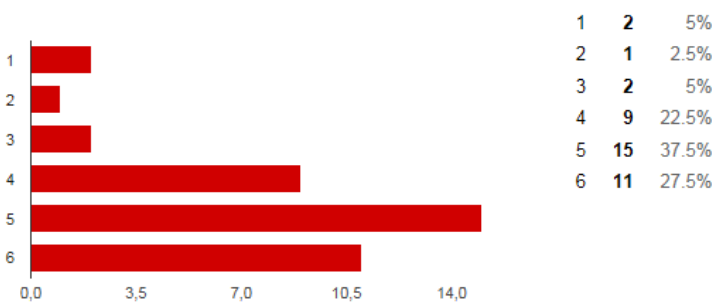

c) Información económica prevista para futuros ejercicios [6) De la información económica de la empresa, valore de 1 a 6 (siendo 1 menos importante y 6 más importante), la que podría aceptarse por ambas partes para establecer complementos variables]

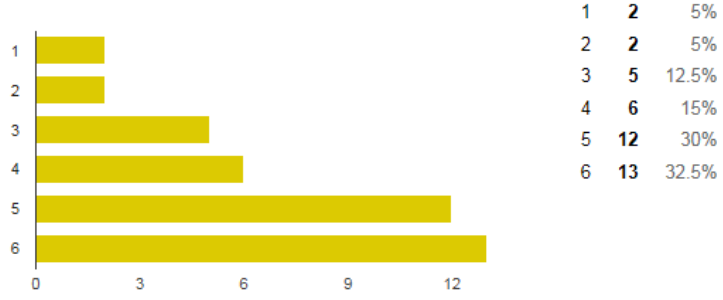




\section{Pregunta 7}

a) Facturación [7) De la información económica de la empresa, valore de 1 a 6 (siendo 1 menos importante y 6 más importante), la que podría aceptarse por ambas partes para establecer complementos variables]
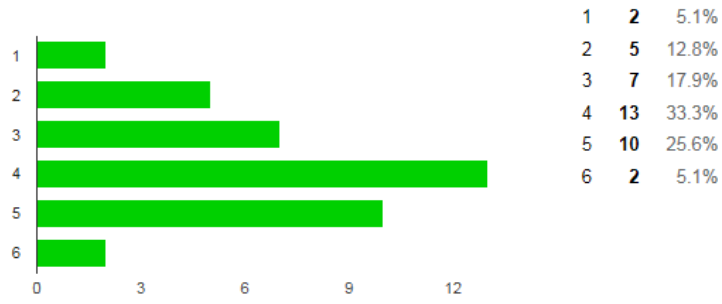

b) Resultados [7) De la información económica de la empresa, valore de 1 a 6 (siendo 1 menos importante y 6 más importante), la que podría aceptarse por ambas partes para establecer complementos variables]

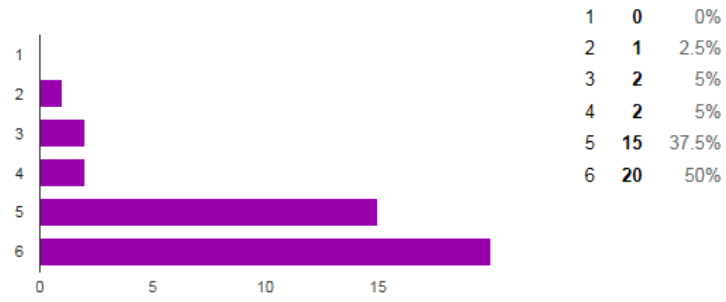

c) Cash flow [7) De la información económica de la empresa, valore de 1 a 6 (siendo 1 menos importante y 6 más importante), la que podria aceptarse por ambas partes para establecer complementos variables]

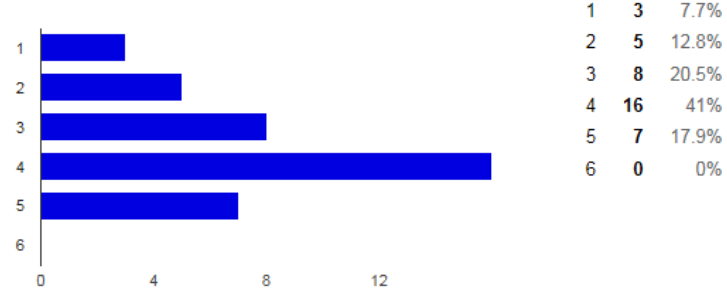

d) Productividad [7) De la información económica de la empresa, valore de 1 a 6 (siendo 1 menos importante y 6 más importante), la que podría aceptarse por ambas partes para establecer complementos variables]

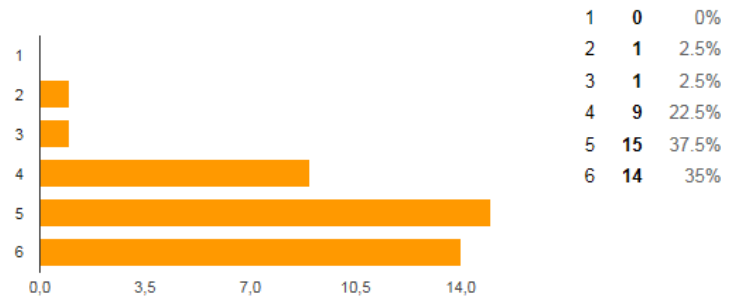

e) Calidad [7) De la información económica de la empresa, valore de 1 a 6 (siendo 1 menos importante y 6 más importante), la que podría aceptarse por ambas partes para establecer complementos variables]

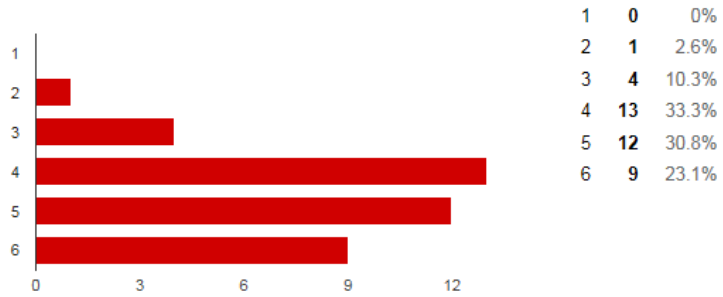




\section{INFORMACIÓN ECONÓMICA Y NEGOCIACIÓN COLECTIVA}

\section{Pregunta 8}

8) Indique si en su opinión, los representantes de los trabajadores consideran la información económica que se les suministra, como factor determinante a la hora de negociar y modular sus posiciones en la negociación:

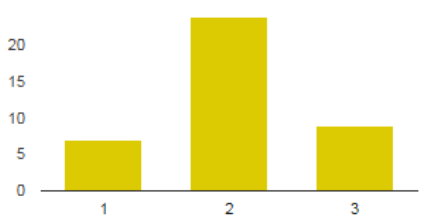

\section{Pregunta 9}

9) Indique si en su opinión si la situación y resultados de la empresa, sería aceptado por los representantes de los trabajadores para establecer

$$
\begin{array}{rrr}
\text { a) La subida salarial } & 5 & 12.5 \% \\
\text { b) Las remuneraciones variables } & 1 & 2.5 \% \\
\text { c) La subida salarial y las remuneraciones variables } & 31 & 77.5 \% \\
\text { d) Ninguna de las anteriores } & 3 & 7.5 \%
\end{array}
$$

\section{Pregunta 10}

10) En la legislación laboral podemos encontrar como la situación económica negativa puede llevar, entre otros casos, a la inaplicación del convenio colectivo. Considera que sería positivo que la legislación laboral incluyera que en el caso de situación económica positiva, los trabajadores también tienen que ser partícipes (económicamente) de esa situación

Si: $1 \quad 18 \quad 45 \%$

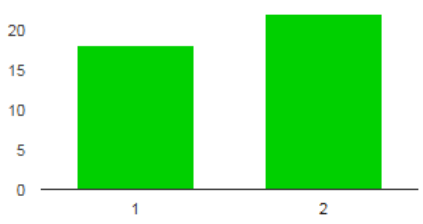

No: $22255 \%$ 
PÁGINA 452 


\section{ANEXO 17}

\section{RESUMEN RATIOS AGRUPADOS $2003-2013$}


PÁGINA 454 


\begin{tabular}{|l|r|r|r|r|r|r|r|}
\hline Nombre & \multicolumn{1}{|c|}{$\begin{array}{c}\text { Current } \\
\text { Ratio } \\
\%\end{array}$} & $\begin{array}{c}\text { Liquidity } \\
\text { Ratio } \\
\%\end{array}$ & $\begin{array}{c}\text { Solvency } \\
\text { Ratio } \\
\%\end{array}$ & $\begin{array}{c}\text { Return on } \\
\text { Shareholders } \\
\text { Funds } \\
\%\end{array}$ & $\begin{array}{c}\text { Return on } \\
\text { Total Assets } \\
\%\end{array}$ & $\begin{array}{c}\text { Profit Margin } \\
\%\end{array}$ & $\begin{array}{c}\text { Net Assets } \\
\text { Turnover } \\
\%\end{array}$ \\
\hline GRUPO 1 & 1,17 & 0,82 & 29,26 & 48,84 & 7,69 & 4,94 & 1,71 \\
\hline GRUPO 2 & 1,27 & 1,03 & 34,20 & 7,25 & 0,19 & 25,36 & 2,43 \\
\hline GRUPO 3 & 1,08 & 0,81 & 35,31 & $-49,77$ & $-4,84$ & $-3,06$ & 1,71 \\
\hline GRUPO 4 & 1,93 & 1,55 & 41,84 & 7,42 & 3,65 & 2,43 & 3,64 \\
\hline
\end{tabular}

\begin{tabular}{|l|r|r|r|r|r|r|r|}
\hline Nombre & $\begin{array}{c}\text { VENTAS } \\
\text { MEDIAS } \\
\text { POR } \\
\text { EMPLEADO }\end{array}$ & $\begin{array}{c}\text { GASTOS } \\
\text { PERSONAL } \\
\text { POR } \\
\text { EMPLEADO }\end{array}$ & $\begin{array}{c}\text { EMPLEADOS } \\
\text { MEDIA }\end{array}$ & $\begin{array}{c}\text { RTDO EXPLOT } \\
\text { POR } \\
\text { EMPLEADO }\end{array}$ & $\begin{array}{c}\text { RTDO } \\
\text { EJ ERCI CIO } \\
\text { POR } \\
\text { EMPLEADO }\end{array}$ & $\begin{array}{c}\text { CASH FLOW } \\
\text { POR } \\
\text { EMPLEADO }\end{array}$ & $\begin{array}{c}\text { VALOR } \\
\text { AGREADO } \\
\text { POR } \\
\text { EMPLEADO }\end{array}$ \\
\hline GRUPO 1 & 221,43 & 48,03 & 737,01 & 10,01 & 7,66 & 14,00 & 66,05 \\
\hline GRUPO 2 & 349,87 & 41,26 & 230,78 & 6,79 & 6,77 & $-8,72$ & 70,60 \\
\hline GRUPO 3 & 456,76 & 51,41 & 335,73 & $-8,11$ & $-9,72$ & 1,47 & 57,94 \\
\hline GRUPO 4 & 149,00 & 38,35 & 342,05 & 10,13 & 5,99 & 13,56 & 57,58 \\
\hline
\end{tabular}


PÁGINA 456 


\section{BIBLIOGRAFÍA}


AGUILAR CONDE, P. Y SANTIDRIÁN ARROYO, A. (1998) "La información contable en las relaciones laborales". Revista de Contaduría. Universidad de Antioquia. Medellín (Colombia). Septiembre 1998. No 33. Pp 133-153.

ALCHIAN, A. Y DEMSETZ, H. (1972) "Production, information costs, and economic organization". The American Economic Review. Diciembre. Pp 777-795.

AMERNIC, J. (1983) "Accounting for collective bargaining". CGA Magazine. Enero 1983. Pp 28-30.

AMERNIC, J. (1985) "The roles of accounting in collective bargaining". Accounting, Organizations and Society. Vol 10. $\mathrm{n}^{0}$ 2. 1985. Pp 227-253.

AMERNIC, J. Y CRAIG, R. (1992). "Employer equivocality and union heterogeneity as determinants of the role of accounting in collective bargaining". Accounting, Auditing \& Accountability Journal. Vol 5. $\mathrm{n}^{\circ} 1$. 1992. Pp 60-79.

ANTLE,R. Y SMITH, A. (1986). "An empìrical investigation of the relative performance evaluation of corporate executives". Journal of Accounting Research. Vol 24. no 1. Primavera 1986. Pp 1-39.

ARAUJO, J. A. (1994) "Un nuevo paradigma contable para Colombia: la utilidad de la información - el Decreto 2649 de 1993- "Revista de Contaduría. Universidad de Antioquia. núm 24-25. Pp 129-147. 
ARNOLD, P. Y HAMMOND, T. (1994) "The role of accounting in ideological conflict: lessons from the South African divestment movement". Accounting, Organizations and Society. Vol 19. n². Pp 111-126.

ARRAIZ, J. I. (1999) "Retribuir el futuros: guía práctica de la retribución en España". Ediciones Santillana Profesional.

ARRAZOLA VACAS, M. (1997) "Situación financiera y negociación salarial: un análisis empírico basado en la política de dividendos". Moneda y crédito. № 205. Pp 135-163.

ARRUÑADA, B. "La empresa como nexo contractual". Libro de Economía de la empresa: un enfoque contractual. Capítulo 3.pp 65-84.

ARRUÑADA, B. (1990) "La regulación de la información contable". Libro: Control y regulación de la Sociedad Anónima. Alianza Editorial. Madrid.

ARRUÑADA, B. (1990) "La regulación de la información empresarial". Boletín del Círculo de Empresarios. № 51. 3 Trimestre. Pp 11-42.

ARRUÑADA,B. (1999) "Limitaciones institucionales al desarrollo de la empresa". Papeles de Economía Española. № 78-79.pp 17-32.

AZOFRA PALENZUELA, V. Y MIGUEL HIDALGO, A. DE (1992) "Teoría financiera de la agencia, endeudamiento y estructura de propiedad". Revista Europea de Dirección y Economía de la Empresa. Vol 1. n² 2. Pp 135-146. 
AZORIN ESCOLANO, A. Y VARELA GONZÁLEZ, J.A. (1996) "Planes de compensación para la fuerza de ventas: un contraste empírico de un modelo de teoría de agencia". Revista Europea de Dirección y Economía de la empresa. Vol.5. n.2. Pp 137-148.

BAIMAN,S. Y DEMSKI, J. (1980) "Economically optimal performance evaluation and control systems". Journal of Accounting Research. Vol 18. Suplemento. Pp 184-220.

BAKER, G.P.; JENSEN, M.C. Y MURPHY, K. J.(1988) "Compensation and incentives: practice vs. theory". The journal of finance. Vol XLIII. Julio 1988. Pp 593-616.

BALL, R. Y FOSTER, G. (1982) "Corporate financial reporting: a methodological review of empirical research". Journal of Accounting Research. Vol. 20. Suplemento 1982. Pp 161-234.

BAREFIELD, R. Y COMISKEY, E. (1972) "The smoothing hypothesis: an alternative test". The Accounting Review. Abril 1972. Pp 291-298.

BARKEMA, H. Y GOMEZ MEJÍA, L. R. (1998) "Mangerial compensation and firm performance: a general research". Academy of Management Journal. Vol. 41. No2. Pp 135-145.

BARRENECHEA SUSO, J. Y FERRER LOPEZ, M. A.(1996) "El Estatuto de los Trabajadores". Deusto. $2^{\circ}$ edición. Bilbao. 1996. 
BASU, A. K.; LAL, R.; SRINIVASAN V. Y STAELIN R. (1985) "Salesforce compensation plans: an agency theoretic perspective". Marketing Science. Vol 4. n4. 1985. Pp 267-291.

BEAVER, W. H. Y DEMSKI, J. (1979) "The nature of income measurement". The Accounting Review. Vol LIV. nº 1. Enero. Pp 38-46.

BEIDLEMAN, C. (1973) "Income smoothing: the role of management". The Accounting Review. Vol XLVIII.Octubre 1973. n 4. Pp 653-667.

BERCHE MORENO, E. Y BARBERO, J.L. (1998) "Retribución del directivo propietario: el dilema entre los dividendos o el salario". Harvard Deusto Finanzas \& Contabilidad. Enero- Febrero 1998. Pp 78-80.

BERNE MANERO, C.; PEDRAJA IGLESIAS, M.; RIVERA TORRES, P. (1997) "Sistemas de retribución en el departamento comercial: un análisis del caso español: 1988-1995". Alta Dirección. 1997. Pp 79-89.

BLACKABY, F.T. (1978) "The reform of the wage bargaining system". National Institute Economic Review. Agosto. Pp 49-54.

BLANCHFLOWER, D. Y OSWALD, A. (1987). "Profit sharing- can it work?“. Oxford Economic Papers. 39. 1987. Pp 1-19.

BLOOM,M. Y MILKOVICH, G. (1998) "Relationships among risk, incentive pay, and organizational performance". Academy of Management Journal. Vol. 41. N03. Pp 283-297. 
BOUGEN, P. (1989) "The emergence, roles and consequences of an accounting-industrial relations interaction". Accounting, Organizations and Society. Vol 14. $n^{\circ}$ 3. 1989. Pp 203-234.

BOUGEN, P.; OGDEN, S.G. Y OUTRAM (1990). "The appearance and disappearance of accounting: wage determination in The U.K. coal industry". Accounting, Organizations and Society. Vol 15. no 3. Pp 149170.

BOWLES, S. (1985) "The production process in a competitive economy: Walrasian, Neo-Hobbesian and Marxian Models". The American Economic Review, 75. Pp 16-36.

BRICKLEY, J.; SMITH, C. Y ZIMMERMAN, J. (1995) "The economics of organizational architecture". Journal of Applied Corporate Finance. Vol 8. no 2. Verano 1995. Pp 19-31.

BRICKLEY, J.; SMITH, C. Y ZIMMERMAN, J. (1996) "Organizational architecture: a managerial economics approach". Editorial: Richard D. Irwin.

BRICKLEY, J.; SMITH C. Y ZIMMERMAN, J. (1997) "Managements fads and organizational architecture". Bank of America. Journal of Applied Corporate Finance. Volume 10. № 2. Summer. 1997

BRIO GONZALEZ, E. DEL (1995). "La responsabilidad social de la contabilidad". Técnica Contable. Pp 801-818. 
BROUSSEAU, E. (1993). "Les theories des contrats: une revue". Revue d'ecomie politique. Vol.103.n 1. Pp 1-82.

BROUSSEAU, E. Y GLACHANT, J.M. (2000) "Economie des contrats el renouvellements de l' analyse economique". Revue d' Economie Industrielle $n^{\circ} 92,2^{\circ}$ et 3 trimestre 2000. Pp 23-50.

BROWN, J. (1989) "Why do wages increase with tenure? On the job training and life-cycle wage growth observed within firms". The American Economic Review. Diciembre 1989. Vol 79. no 5. Pp 971-991.

BROWNELL, P. (1982) "The role of accounting data in performance evaluation, budgetary participation, and organizational effects". Journal of Accounting Research. Vol 20 no 1. Primavera 1982. Pp 12-27.

BURCHELL, S.; CLUBB, C.; HOPWOOD, A. Y NAPHAPIET, J. (1980) "The roles of accounting in organizations and society". Accounting, Organizations and Society. vol 5. n¹. 1980. Pp 5-27.

BURCHELL, S.; CLUBB, C. Y HOPWOOD, A. (1985) "Accounting in its social context: towards a history of value added in the United kingdom". Accounting, Organizations and Society. vol 10. $n^{\circ} 4$. 1985. Pp 381-413.

BURDA, M. (1997) "Corporatism, labor unions and the safety net". European Economic Review. Vol 41. Abril. Pp 635-646. 
BUSHMAN, R. Y INDJEJIKIAN, R. (1993) "Accounting income, stock price and managerial compensation". Journal of Accounting and Economics. 16. 1993. Pp 3-23.

CAMPBELL R. Y STANLEY L. "Economía laboral". McGrawHill.

CAMPBELL, C. (1993). "Do firms pay efficiency wages? Evidence with data al the firm level". Journal of Labor Economics. Vol 11. $\mathrm{n}^{\circ}$ 3. 1993. Pp 442-470.

CAÑIBANO CALVO, L. Y GONZALO ANGULO, J.A. (1996) "Los programas de investigación en contabilidad". Revista de Contaduría. Universidad de Antioquia. núm 29. Pp 15-61.

CAÑIBANO CALVO, L. Y GONZALO ANGULO, J. A. (1997) "Los programas de investigación en contabilidad". Revista de Contabilidad. Vol 0. $n^{\circ} 0$. Pp 57-95.

CARMONA MORENO, S. Y CARRASCO, F. (1988) "Información de contenido social y estados contables: una aproximación empírica y algunas consideraciones teóricas". Actualidad financiera. $n^{\circ} 41$. Semana 7. Noviembre 1988. Pp 2175-2192.

CARMONA MORENO, S. (1989) "La contabilidad como proceso de legitimación". Técnica Contable. Volumen 487. Junio 1989. Pp 351-358.

CARTA COMUNITARIA DE LOS DERECHOS SOCIALES FUNDAMENTALES DE LOS TRABAJADORES. 
CASTAÑO JARAMILLO, O. Y PRIETO SOTO, E. (1997) "La información contable frente a las necesidades del usuario". Revista de Contaduría. Universidad de Antioquia. $\mathrm{n}^{\circ}$ 30. Pp 125-138.

CHALOS,P.; CHERIAN, J. Y HARRIS, D. (1991) "Financial disclosure effects on labor contracts: a Nash Analysis". Contemporary Accounting Research. Vol 7. n². Pp 431-448.

CHARREAUX , G. (2000) "La theorie positive de l' agence: positionnemet et apports". Revue d' Economie Industrielle n' 92, $2^{\circ}$ et 3 trimestre 2000. Pp 193-214.

CHENHALL, R. H. y LANGFIELD-SMITH, K. (2000) "The role of employee incentive pay in sustaining strategic change". Paper presented in the second conference on new directions in management accounting ... (Brussels, Belgium).

CHOW, C. (1983) "The effects of job standard tightness and compensation scheme on performance: an exploration of linkages". The Accounting Review. Vol LVIII. nº 4. Octubre 1983. Pp 667-685.

CHOW, C.; COOPER, J. C. Y WALLER, W.S. (1988) "Participative budgeting: effects of a truth-inducing pay scheme and information asymmetry on slack and performace". The Accounting Review. Vol LXIII. $n^{\circ}$ 1. Enero 1988. Pp 111-122. 
CHOW, C.; HADDAD, K. Y WILLIAMSON, J. (1997) "Aplying the balanced scorecard to small companies". Management Acccounting. Agosto 1997. Pp 21-27.

CHRISTENSEN, J. (1981) "Communication in agencies". The Bell Journal of Economics. Pp 661-674.

CHRISTENSON, C. (1983). "The methodology of positive accounting". The Accounting Review. Vol LVIII. nº 1 . Enero 1983. Pp 1-22.

CLARKE, F.; CRAIG, R. Y AMERNIC, J. (1990) "Misplaced trust in reliance on published accounting data for wage negotiation: an international perspective". The International Journal of Accounting. 1990. 25. Pp 184-201.

CLARKE, F. Y CRAIG, R. (1991) "Juridical perceptions of the relevance of accounting data in wages fixation". British Journal of Industrial relations. Vol 29. n³. Septiembre 1991.pp 463-483.

CLEGG, H. (1976) "Trade unionism under collective bargaining: a theory based on comparisons of six countries". Basil Blackwell Publisher Limited, Oxford.

COASE, R. (1937) "The nature of the firm". Economica,4 . Pp 386-405. 
COMISIÓN CONSULTIVA NACIONAL DE CONVENIOS COLECTIVOS (1999) "La negociación colectiva en el escenario del año 2000: XII jornadas de estudio sobre negociación colectiva". Ministerio de Trabajo y asuntos sociales.

CONSTITUCIÓN ESPAÑOLA de 27 de Diciembre de 1978.

COOPER, D. Y ESSEX, S. (1977) "Accounting information and employee decision making". Accounting, Organizations and Society. Vol 2 no 3. 1977. Pp 201-217.

COOPER, D. Y SHERER, M. (1984) "The value of corporate accounting reports: arguments for a political economy of accounting". Accounting, Organizations and Society. Vol 9. no 3/4. 1984. Pp 207-232.

CORREA CARRASCO, M. "Convenios y Acuerdos Colectivos de Trabajo". Aranzadi.

CRAFT, J. (1981). "Information disclosure and the role of the accountant in collective bargaining". Accounting, Organizations and Society. Vol 6. $\mathrm{n}^{\mathrm{o}}$ 1. 1981. Pp 97-107.

CRUZ VILLALON, J. "Los derechos de información y consulta de los representantes de los trabajadores en la normativa comunitaria".

CUERVO GARCIA, A. "Análisis y planificación financiera de la empresa". Civitas. 
CUERVO GARCíA, A. (1999) "La dirección estratégica de la empresa: reflexiones desde la economía de la empresa". Papeles de Economía Española. № 78-79. Pp 34-55.

CULLIMAN, CHARLES P, Y KNOBLETT, J. (1994) "Unionization and accounting policy choices: an empirical examination". Journal of Accounting and Public Policy. 13. 1994. Pp 49-78.

CULLIMAN,C.; CLARK, M. Y KNIBLETT, J. (1994) "Accounting information and collective bargaining: a literature review and research framework". Journal of Accounting Literature. Vol 13. 1994. Pp 44-80.

CUTHBERT, N.H. Y WHITAKER, A. (1977) "Disclosure of information and collective bargaining: a re-examination". Journal of Business Finance \& Accounting. 4,3. Pp 373-378.

DAVIS, K.Y NEWSTROM, J. "Comportamiento humano en el trabajo. Comportamiento organizacional". Capítulo 18.

DEANGELO, L. (1988) "Managerial competition, information costs, and corporate governance: the use of accounting performance measures in proxy contests". Journal of Accounting and Economics. Vol. 10. Pp 3-36.

DEANGELO, H. Y DEANGELO, L. (1991) "Union negotiations and corporate policy. A study of labor concessions in the domestic steel industry during the 1980s". Journal of Financial Economics. 30. Pp 3-43. 
DEMSKI, J. Y FELTHAM, G. (1978) "Economic incentives in budgetary control systems". The Accounting Review. vol LIII. no 2. Abril 1978. Pp 336-359.

DEWE, P.; DUNNT, S. Y RICHARDSON, R. (1988) "Employee share option schemes, why sorkers are attracted to them". British Journal of Industrial Relations. 26. 1. Marzo 1988. Pp 1-21.

DIERKS, P. A. (1997). "What is EVA and how can it help your company?". Management accounting. Noviembre 1997. Pp 52-58.

DILLARD, J. Y BECKER, D'ARCY A. (1997) "Organizational sociology and accounting research or understanding accounting in organizations using sociology". American Accounting Association.

DIRECTIVA 94/45/CE DEL CONSEJO, DE 22 DE SEPTIEMBRE DE 1994, sobre la Constitución de un Comité de Empresa Europeo o de un procedimiento de información y consulta a los trabajadores en las empresas y grupos de empresas de dimensión comunitaria.

DOUMA, S. Y SCHREUDER, H. (1992) "Economic approaches to organizations". Prentice Hall. Londres.

DRIVER, M. Y MOCK, T. (1975). "Human information processing, decision style theory, and accounting information systems". The Accounting Review. Julio 1975. Pp 490-508.

DUNCAN, C. (1988) "Why profit pay will fail". Industrial Relations Journal. Vol 19. $n^{0}$ 3. 1988. Pp 186-200. 
DYE, R. (1985) "Disclosure of nonpropietary information". Journal of Accounting Research. Vol 23. n 1. Primavera 1985. Pp 123-145.

EBIMOBOWEI, A. Y YADIRICHUKWU, E. (2012) "Employees reporting and collective bargaining in organisations: a need for disclosure". Kuwait Chapter of Arabian Journal of Business and Management Review. Vol.1 $\mathrm{n}^{\mathrm{o}}$ 8, pp 23-36.

Revista Española de Financiación y Contabilidad. Volumen XXXIV, $\mathrm{n}^{\circ}$ 126, pp 787-790.

EHRENBERG, R. Y BOGNANO, M. (1990). "The incentive effects of tournaments revisited: evidence from the European PGA Tour". Industrial and Labor Relations Review. Vol. 45. Febrero 1990. Pp 74-S a 88-S.

EHRENBERG, R. (1990) "Introduction: Do compensation policies matter?". Industrial and Labor Relations Review. Vol 43. Febrero 1990. Pp 3-S 12-S.

EHRENBERG, R. Y SMITH, R. (1994) "Modern Labor Economics". 6a edición. Nueva York. Harper Collins.

EISENHARDT, K. (1988) "Agency-and institutional-theory explanations: the case of retail sales compensation". Academy of Management Journal. vol 31. $n^{\circ}$ 3. 1988. Pp 488-511.

ELIAS, N. (1990) "The effects of financial information symmetry on conflict of labor negotiations". The Accounting Review. Vol 65. $\mathrm{n}^{\circ}$ 3. Julio 1990. Pp 606-623. 
ELIAS, N. (1993) "Discussion of strategic financial disclosure: evidence from labor negotations". Contemporary Accounting Research. vol 9. n 2. 1993. Pp 551-558.

ELLIG, B. (1984) "Total compensation design: elements and issues". Personnel. Vol 61. Enero-Febrero. Pp 22-30.

ESTEBAN, A. "La reforma laboral en relación a la negociación colectiva". Harvard-Deusto.Finanzas \& Contabilidad.

FAMA, E. (1980) "Agency problems and the theory of the firm". Journal of Political Economy, 88. Pp 288-307.

FELTHAM,G. (1968) "The value of information". The Accounting Review. Octubre. Pp 684-696.

FERNANDEZ, Z. (1999) "El estudio de las organizaciones". Papeles de Economía Española. N078-79. Pp 56-77.

FERNANDEZ SEVILLANO (1998) "Contabilidad de gestión y empresa: el mito de la caverna". Partida doble. n 87. Marzo 1998. Pp 62-67.

FERRIS, K. (1977) "A test of the expectancy theory of motivation in an accounting environment". The Accounting Review. Vol LII. $\mathrm{n}^{\circ}$ 3. Julio 1977. Рp 605-615. 
FIRTH,M. (1990) "The incremental information content of employee reports for stock market investment decisions". Journal of Accounting and Public Policy. 9. Winter. Pp 293-305.

FOLEY,B.J. y MAUNDERS, K.T. (1977) "Accounting information disclosure and collective bargaining". New York; Holmer and Meier Publishers.

FREEMAN,R. (1976) "Individual movility and union voice in the labor market". The American Economic Review (papers and proceedings), 66 .pp 361-8.

FUENTELSAZ, L.; GÓMEZ, J.; MARTíNEZ, E.; Y POLO, Y. (1999) "Políticas de remuneración en el área de marketing: comportamiento vs resultados". IX Congreso Nacional de ACEDE.

GALLEN ORTIZ, M. L. "La relación accionistas-directivos: problemas de agencia y mecanismos de control". Análisis Financiero. Pp 34-45.

GARCIA OSMA, B.; MORA, ARACELI; SABATER, ANA M. (2010) "Strategic accounting choice around firm level labor negotiations". WP Serie EC, Ivie.

GARRIDO PEREZ, E. "La concreción normativa de las potestades de información" 
GARRIDO SAMANIEGO, M.J.; PEREZ SANTANA, M.P.; ROBLES PARAMIO, M.P. Y SANTOS ALVAREZ, M.V. (1997) "Relación de agencia: ¿es diferente en la empresa pública?". Alta Dirección. año XXXI. no 192. Marzo-Abril. Pp 79-88.

GEORGE,G. (1994) "The usefulness of accounting information in the Australian industrial relations environment". Paper 15-11-94. Melbourne, Australia.

GERHART,B. Y MILKOVICH, GEORGE T. (1990) "Organizational differences in managerial compensation and financial performance". Academy of Management Journal. Vol. 33. Nº4. Pp 663-691.

GIL SUAREZ, L. (1997) "La extinción del contrato de trabajo. El despido objetivo". Dirección y progreso nº 152. Pp 67-91.

GINER INCHAUSTI, B. (1990) "Información contable y toma de decisiones". Revista Española de Financiación y Contabilidad. Vol. XIX. $\mathrm{n}^{\circ}$ 62. Enero-marzo . Pp 141-161.

GJESDAL, F. (1981) "Accounting for stewarship". Journal of Accounting Research. Vol 19.n¹. Spring. Pp 208-231.

GJESDAL, F. (1982) "Information and incentives: The Agency Information Problem". Review of Economic Studies . XLIX pp 373-390.

GOGGANS, T. (1964) "The accountant's role in wage negotiations". The Accounting Review. Julio 1964. Pp 627-630. 
GOMEZ- MEJIA, L.; TOSI, H. Y HINKIN, T. (1987) "Managerial control, performance, and executive compensation". Academy of Management Journal. Vol 30. n 1. Marzo 1987. Pp 51-70.

GOSPEL, H. (1978) "The disclosure of information to trade unions: approaches and problems". Industrial Relations Journal. Vol 9.n³. Pp 1826.

GRÖJER, J. Y STARK, A. (1976) "Social accounting: a swedish attempt". Accounting, Organizations and Society. Vol 2. $n^{\circ} 4$. Pp 349-386.

GROSSMAN, S. Y HART, O. (1983) "An analysis of the principal-agent problem".Econometrica. Vol 51. n 1. Pp 7-45.

GURDON, M. (1985) "Equity participation by employees: the growing debate in West Germany". Industrial Relations. Vol 24. no 1. Winter. Pp 113-129.

HAGGERTY, M. Y LEIGH, D. (1993) "The impact of union wage concessions on union premiums". Industrial Relations. Vol 32. n¹. 1993. Pp 111-123.

HARRIES, M. Y RAVIV, A. (1979) "Optimal incentive contracts with imperfect information". Journal of Economic Theory. 20. 1979. Pp 231259.

HART, O. (1983) "Optimal labour contracts under asymmetric information: an introduction". Review of Economics Studies. Vol 50. Pp 3-35. 
HASSINK, H. (1995) "An empirical exploration of the role of financial accounting information and of auditors in collective bargaining". Paper presented at the $18^{\text {th }}$ annual congress of the European Accounting Asociation. Birmingham. Reino Unido. Mayo 1995.

HASSINK,H. (1998) "On the usefulness of corporate annual reports to trade union bargainers". Paper presented al the EAA Congress. Abril 1998. Antwerp. Bélgica.

HAWKINS, K. (1979) "The future of collective bargaining". Industrial Relations Journal. Vol 10. $\mathrm{n}^{\circ}$ 4. Pp 10-21.

HEALY,P.; KANG, S. (1986) "The effect of accounting procedure changes on CEOs 'cash salary and bonus compensations". Journal of Accounting and Economics. $\mathrm{n}^{\circ}$ 9. Pp 7-34.

HERMALIN, B. Y WEISBACH, M. (1991) "The effects of board composition and direct incentives on firm performance". Financial Management. Invierno 1991 pp 101-112.

HERRERA GOMEZ, J. Y FERNANDEZ GUERRERO, R. (1997) "Análisis de los procesos de concertación social y papel de los sindicatos desde la perspectiva de la dirección de recursos humanos". Estudios Financieros. No 172. 36/1997. Pp 87-120.

HICKS,, J.R. (1963) "The theory of wages". New York. St Martin Press. 
HOLMLUND, B. (1990) "Profit sharing, wage bargaining, and unemployment". Economic inquiry. Vol XXVII. Abril 1990. Pp 257-268.

HOPWOOD, A. (1978) "Towards an organizational perspective for the study of accounting and information systems". Accounting, Organizations and Society. Vol 3. $\mathrm{n}^{\circ}$ 1. 1978. Pp 3-13.

HOPWOOD, A. (1985) "The tale of a committee that never reported: disagreements on interwining accounting with the social". Accounting, Organizations and Society. Vol 10. no 3. 1985. Pp 361-377.

HORWITZ, B.Y SHABAHANG, R. (1971) "Published corporate accounting data and general wage increases of the firm". The Accounting Review. Vol XLVI. no 2. Abril 1971. Pp 243-252.

HULME, R. Y BEVAN, R. (1975) "The blue-collar worker goes on salary". Harvard Business Review. Vol 53. Marzo-Abril. Pp 104-112.

HUNT III, H. Y HOGLER, R. (1990) "Agency theory as ideology: a comparative analysis on critical legal theory and radical accounting". Accounting, Organizations and Society. Vol 15. nº 5. Pp 437-454.

HUTCHENS, R. (1987) "A test of Lazear's Theory of delayed payment contracts". Journal of Labor Economics. Vol 5. n 4. 1987 pp s155 - s170.

HUTCHENS, R. (1989) "Seniority, wages and productivity: a turbulent decade". Journal of Economic Perspecrives. vol 3. no 4. Otoño 1989. Pp 49-64. 
IGLESIAS CABERO, M. (1997) "Negociación colectiva”. Colex. Madrid. 1997.

JACKSON-COX,J.; THIRKELL, J. Y MC QUEENEY, J. (1984)."The disclosure of company information to trade unions: the relevance of the acas code of practice on disclosure". Accounting, Organizations and Society. Vol 9. no 3/4. 1984. Pp 253-273.

JAIN, H. (1981) "Disclosure of corporate information to trade unions in North America". Relations Industrielles. Vol. 36. n 4. Pp 748-771.

JENNERGREN, P. (1980) "On the design of incentives in business firmsa survey or some research". Management Science. Vol 26. $\mathrm{n}^{\circ} 2$. Febrero 1980. Pp 180-201.

JENSEN, M. Y MECKLING, W. (1976) "Theory of the firm: managerial behavior, agency costs, and ownership structure". The Journal of Financial Economics, 3. Pp 305-360.

JENSEN, M. Y MURPHY, K. (1980) "CEO incentives- it's not how much pay, but how". Harvard Business Review. Mayo-Junio . Pp 138-153.

JENSEN, M. Y MURPHY, K. (1990). "Performance pay and topmanagement incentives". Journal of Political Economy. Vol 98. 1990. Pp 225-264. 
JENSEN, M. Y MECKLING, W. (1995). "Specific and general knowledge, and organizational estructure". Journal of Applied Corporate Finance. Vol 8. $\mathrm{n}^{\circ}$ 2. 1995. Pp 4-18.

JIAMBALVO, J, (1979) "Performance evaluation and directed job effort: model development in a cpa firm setting". Journal of Accounting Research. Vol 17. $n^{\circ}$ 2. 1979. Pp 436-455.

JORDAN, J.S. (1989) "The economics of accounting information systems". Economic Theory and Economic Policy. Vol. 79. № 2. Pp 140-145.

KAPLAN, R. (1983) "Measuring manufacturing performance: a new challenge for managerial accounting research". The Accounting Review. vol LVIII. no 4. octubre. Pp 686-705.

KAPLAN, R. (1984) "The evolution of management accounting". The Accounting Review. Vol LIX. $\mathrm{n}^{\circ}$ 3. Julio 1984. Pp 390-418.

KAPLAN, R. (1985) "Comments on Pal Healey: evidence on the effect schemes on accounting procedure and accrual decisions". Journal of Accounting and Economics. 7. 1985. Pp 109-113.

KISSAN, J. Y THEVARANJAN, A. (1998) "Monitoring and incentives in sales organizations: an agency theoretic perspective". Marketing Science. Vol.17. n². Pp107-123. 
KLEIN, B. (1983) "Contracting costs and residual claims: the separation of ownership and control". The journal of law and economics. Vol. 26. №2. Pp-367-374.

KLEINER, M. (1984) "Public policy implications of financial information requirements under the National Labor Relations Act". Journal of Acounting and Public Policy. Vol 3. Winter. Pp 253-257.

KNIGHTS,D. Y COLLINSON, D. (1987) "Disciplining the shopfloor. A comparison of the disciplinary effects of managerial psychology and financial accounting". Acounting. Organizations and society. 12(5) pp 457477.

$\mathrm{KOCH}$, B. (1981) "Income smoothing: an experiment". The accounting review. Vol LVI. nº 3. Julio 1981. Pp 574-586.

KRAFFT,M. (1995) "Salesforce compensation systems: cross-sectional test of the relative explanatory power of transaction cost, analysis and agency theory implications". EMAC. PP 1809-1814.

LAFFARGA BRIONES, J. (1993) "Información contable y negociación colectiva". Trabajo de Investigación. Universidad de Cádiz.

LANG, K. Y KAHN, S. (1990). "Efficiency wage models of unemployment: a second view". Economic Inquiry. Vol XXVIII. Abril 1990. Pp 296-306. 
LAU,C.T. y NELSON, M. (1981) "Accounting implications of collective bargaining". Hamilton, Ontario (Canada). The society of management accountants of Canada

LAZEAR, E. (1981). "Agency, earnings profiles, productivity, and hours restrictions". The American Economic Review. Vol 71. no 4. Septiembre 1981. Pp 606-620.

LAZEAR, E. Y ROSEN, S. (1981) "Rank-order tournaments as optimum labor contracts". Journal of Political Economy. Vol 89. n 5. 1981. Pp 341380.

LEFEBVRE, C.; LIN. L. Y VAN NUFFEL, L. (1995) "Financial and economic information for industrial relations councils. The case of Belgium“. The European Accounting Review. Vol 4. no 3. Pp 555-569.

LEIBENSTEIN, H. (1966) "Allocative efficiency and X-Efficiency". The American Economic Review, 56. Pp 392-415.

LEIBENSTEIN, H. (1982) "The prisoners' dilemma in the invisible hand: an analysis of intrafirm productivity". The American Economic Review (Papers and Proceedings), 72.pp 92-7.

LEWIS, N.R.; PARKER, L.D. Y SUTCLIFFE, P.(1984) "Financial reporting to employees: the pattern of development 1919 to 1979". Accounting, Organizations and Society. Vol 9. no 3/4. 1984. Pp 275-289. 
LEY 10/1997, de 24 de Abril, sobre Derechos de Información y Consulta de los trabajadores en las empresas y grupos de empresas de dimensión comunitaria".

LIAO, S. (1979) "The effect of separation of owner ship from control on accounting policy decisions: a comment". The Accounting Review. Vol LIV. $n^{\circ}$ 2. Abril 1979. Pp 414-416.

LIBERTY, S. Y ZIMMERMAN, J. (1986) "Labor union contract negotiations and accounting choices". The Accounting Review. Vol LXI. n 4. 1986. Pp 692-712.

LORNE CARMICHAEL, H. (1990) "Efficiency wage models of unemployment- one view". Economic Inquiry. Vol XXVIII. Abril 1990. Pp 269-295.

MANZONI,J.F. Y BARSOUX, J.L. (1998) "The set-up-to fail syndrome". Harvard Business Review. Vol 76. n². Pp 101-113.

MARTÍNEZ SALDAÑA, E.; NARANJO CRUCES, I. Y POLO REDONDO, Y. (1997) "Remuneración de la fuerza de ventas: un análisis empírico desde una perspectiva de agencia". Revista Española de investigación de marketing, ESIC. №1. Pp 73-92.

MAUNDERS, K. (1981) "Accounting information and industrial relations: towards a managerial evaluation of the disclosure policy decision". Managerial Finance. Vol 7. $n^{\circ} 2$. Pp 2-5. 
MAUNDERS, K. (1984) "Employment reporting. An investigation of user needs, measurement and reporting issues and practice". The Institute of Chartered Accountants in England and Wales. Londres. 1984

MAUNDERS, K. Y FOLEY, B. (1984) "Information disclosure and the role of the accountant in collective bargaining-some comments". Accounting, Organizations and Society. Vol 9. n¹. 1984. Pp 99-106.

MAUTZ, R.K. (1963) "Accounting as a social science". The Accounting Review. April 1963. Pp 317-325

MAUTZ, D. JR. (1990)“Inflation adjusted disclosures and the determination of ability to pay in collective bargaining". Accounting, Organizations and Society. Vol 15. n 4. 1990.pp 273-295.

MCBARNET, D.; WESTON, S. Y WHELAN, C. (1993). "Adversary accounting: strategic uses of financial information by capital and labour". Accounting, Organizations and Society. Vol 18. $\mathrm{n}^{0}$ 1. 1993. Pp 81-100.

MCCUNE, J. (1998) "Aprender de los fracasos". Harvard Deusto Business Review. $\mathrm{n}^{\circ}$ 82. 1998. Pp 70-75.

MEDAWAR, C. (1976) "The social audit: a political view". Accounting, Organizations and Society. Vol 1. n 4. Pp 389-394.

MEEKS, G. Y WHITTINGTON, G. (1975) "Directors'pay, growth and profitability". The journal of Industrial Economics. Vol XXIV. no 1. Septiembre. Pp 1-14 
MENÉNDEZ ALONSO, E. J. (1999) "Influencia de la diversificación sobre la estructura de capital de las empresas, efecto coaseguro, costes de agencia y costes de transacción". IX Congreso Nacional de ACEDE.

MILGROM, P. Y ROBERTS, J. "Economía, organización y gestión de la empresa". Ariel Economía.

MINISTERIO DE ECONOMÍA Y HACIENDA (1997) "La negociación colectiva en las grandes empresas en 1995".

MITCHELL, F.; SAMS, K.; TWEEDIE, D. Y WHITE, P. (1980) "Disclosure of information: some evidence from case studies". Industrial Relations Journal. Vol 11. n 5. Pp 53-62.

MOLINA NAVARRETE, C. (1998) "La regulación del comité europeo de empresa". Centro de Estudios Financieros n 188. Pp 47- 100.

MONTERREY MAYORAL (1998) "Un recorrido por la contabilidad positiva". Revista española de Financiación y contabilidad. Vol. XXVII. № 95. Abril-junio 1998. Pp 427-467.

MONTOYA MELGAR, A. (1997). "Derecho del Trabajo". Tecnos. 18 edición. Madrid. 1997.

MORA ENGUIDANOS, A. (1995) "Los incentivos de la gerencia para influir en la calidad de la información contable". ESIC-MARKET. EneroMarzo 1995. Pp 103-117. 
MORISHIMA, M. (1991) "Information sharing and collective bargaining in Japan: effects on wage negotiations". Industrial and Labor Relations Review. Vol 44. no 3. Abril. Pp 469-485.

MORISHIMA, M. (1991) "Information sharing and firm performance in Japan". Industrial Relations. Vol 30.n 1. Winter 1991. Pp 37-61.

MURNIGHAN, K. Y BAZERMAN, M. (1990) "A perspective on negotiation research in accounting and auditing". The Accounting Review. Vol 65. $\mathrm{n}^{\circ}$ 3. Julio 1990. Pp 642-657.

NAMAZI, M. (1985) "Theoretical developments of principal-agent employment contract in accounting: the state of the art". Journal of Accounting Literature. Vol. 4. Pp 113-163.

NASH, J. (1950) "The bargaining problem". Econometrica. Pp 152-162.

NELSON,R. Y WINTER, S. (1982) "An Evolutionary theory of economic change". Cambridge, Massachusetts: The Belknap Press of Harvard University Press. Capítulo 5.

OAKES, L. Y COVALESKI, M. (1994) "A historical examination of the use of accounting- based incentive plans in the structuring of labormanagement relations". Accounting, Organizations and Society. Vol 19. $\mathrm{n}^{\circ}$ 7. 1994. Pp 579-599. 
OGDEN, S. Y BOUGEN, P. ( 1985) "A radical perspective on the disclosure of accounting information to trade unions". Accounting, Organizations and Society. Vol 10. n². 1985. Pp 211-224.

OGDEN, S. (1992) "The limits to employee involvement: profit sharing and disclosure of information". Journal of Management Studies. 29.2 Marzo 1992. Pp 229-248.

ORTÍN-ANGEL, P. Y SALAS-FUMAS, V. (1998) "Agency theory and internal labor market explanations of bonus payments: empirical evidence from spanish firms". Journal of Economics \& Management Strategy. Vol.7. no4. Pp573-613.

OWEN, D.L. Y HARTE, G.F. (1984) "Reporting on corporate accountability to the workforce". The Accountant's magazine. Mayo 1984. Pp 184-187.

OWEN, D.L. Y LLOYD, A. (1985) "The use of financial information by trade union negotiators in plant level collective bargaining". Accounting, Organizations and Society. Vol 10. $\mathrm{n}^{\circ}$ 3. 1985. Pp 329-350.

PACITTI, A. (1990) "Financial information for employees". Paper presented at the European Accounting Association Annual Congress. Budapest. Abril 1990.

PALMER, J. (1977) "The use of accounting information in labor negotiations". National Association of Accountants. Nueva York. 1977. 
PASCARELLA, P. (1998) "Cómo recompensar a los equipos". Harvard Deusto Business Review. no 82. Pp 62-69.

PEARCE, J.; STEVENSON, W. Y PERRY, J. (1985) "Academy of Management Journal “. Vol 28. n². 1985. Pp 261-278.

PEEL, D.A. Y POPE, P.F. (1984) "Corporate accounting data, capital market information and wage increases of the firm". Journal of Business Finance \& Accounting. 11. 2. Verano 1984. Pp 177-188.

PÉREZ SANTANA, M.P. (1999) "Retribución de altos directivos en empresas españolas: un enfoque de agencia". Universidad de Valladolid.

PFEFFER, J. (1998) "Six dangerous myths about pay". Harvard Business Review. Mayo-Junio . Pp 109-119.

PETTERSON, R. Y TRACY, L. (1977) "Testing a behavioral theory model of labor negotiations". Industrial Relations. Vol 16. no 1. Febrero 1977. Pp 35-50.

PILLSBURY, W.F. (1958) "Organized labor's view of corporate financial information". Journal of Accountancy. June. Pp-46-56.

PONS FELIX, A. (1996) "Información y relaciones laborales". Técnica contable. Pp 59-68. 
POOLE, M. (1988) "Factors affecting the development of employee financial participation in contemporary Britain: evidence from a national survey". British Journal of Industrial Relations. 26.1. Marzo 1988. Pp 2136.

POPE, P.F. Y PEEL, D. (1981) "The optimal use of information, collective bargaining, and the disclosure debate". Managerial Finance. Vol 7. $\mathrm{n}^{\circ} 2$. Pp 14-21.

POPE, P.F. Y PEEL D. A.(1981) "Information disclosure to employees and rational expectations". Journal of Business fiance \& Accounting. 8.1. 1981. Pp 139-146.

POPE, P. F. (1984). "Information asymmetries in participative budgeting: a bargaining approach". Journal of Business Finance \& Accounting. 11 (1). 1984 pp 41-59.

PORRET GELABERT, M. (1999) "Reflexión sobre los actuales sistemas de retribución". Revista de Recursos Humanos del CEF. Núm. 196. Julio 1999. Pp 169-184.

PRIESTLEY, T. "Empleo, justicia social y competitividad en la nueva sociedad". Harvard Deusto Business Review. Pp 88-96.

PRIETO MORENO, M.B Y PEREZ ARNAIZ, M.J. (1992) "La teoría positiva de la contabilidad en el transcurso de una década". Actualidad financiera vol. 47. 
PROPUESTA MODIFICADA DE DIRECTIVA 91/C 138/08 DEL CONSEJO, de 6 de Abril de 1991, por la que se completa el Estatuto de la Sociedad Europea relativo a la posición de los trabajadores.

PURDY, D. (1981) "The provision of financial information to employees: a study of the reporting practices of some large public companies in the United Kingdom". Accounting, Organizations and Society. Vol 6. $\mathrm{n}^{\circ} 4$. 1981 pp 327-338.

PUTTERMAN, L. (1984) "On some recent explantions of why capital hires labor". Economic Enquiry, 22. Pp 171-87.

RAHMAN, M.Y MCCOSH, A. (1976). "The influence of organisational and personal factors on the use of accounting information: an empirical study". Accounting, Organizations and Society.Vol 1. n 4. Pp 339-355.

REAL DECRETO 43/1996, de 19 de Enero, por el que se aprueba el Reglamento de los procedimientos de regulación de empleo y de actuación administrativa en materia de traslados colectivos.

REAL DECRETO LEGISLATIVO 1/1995, de 24 de Marzo, por el que se aprueba el Texto Refundido de la Ley del Estatuto de los Trabajadores.

REYNAUD, J.D. (1981) "Problemas y perspectivas de la negociación colectiva en los países miembros de la comunidad". Instituto de Estudios Sociales. Ministerio de Trabajo y Seguridad Social, Madrid.

RICART I COSTA, J. E. (1987) "Una introducción a los modelos de agencia". Revista Española de Economía. Vol 4. nº 1. Pp 43-61. 
RICHARDSON, A. J. (1987) "Accounting as a legitimating institution". Accounting, Organizations and Society. Vol 12. n 4. Pp 341-355.

RICHARDSON, R. Y NEJAD, A. (1986). "Employee share ownership schemes in The U.K. an evaluation". British Journal of Industrial Relations. 24.2. Julio 1986. Pp 233-250.

RIEGLER, C. (2000) "Aspects of Value Based Management in a hierarchical agency setting", paper presentado en el Workshop on Accounting and Economics IV, celebrado en Copenhague (Dinamarca) en Junio de 2000.

RIVERA UNGSON, G. Y STEERS, R. (1984) "Motivation and politics in executive compensation". Academy of management review. Vol 9. $\mathrm{n}^{\circ} 2$. Pp 313-323.

RODRIGUEZ PIÑERO, M. "El lugar de los trabajadores en la sociedad anónima europea".

RODRIGUEZ PIÑERO, M. "Los derechos de información y consulta de los trabajadores y la dimensión comunitaria de la empresa".

ROSS, S. A. (1973) "The economic theory of agency: the principal's problem". American Economic Review. Vol 63 nº 2. 1973. Pp 134-139.

ROTH, A. Y MURNIGHAN, J. K. (1982) "The role of information in bargaining: an experimental study". Econometrica. Vol 50. $\mathrm{n}^{\circ} 5$. Septiembre 1982. Pp 1123-1142. 
ROTH, A.; MURNIGHAN, J. K. Y SCHOUMAKER, F. (1988) "The deadline effect in bargaining: some experimental evidence". The American Economic Review. Vol 78. no 4. 1988. Pp 806-823.

SAA PÉREZ, P. Y GARCíA FALCÓN, J. M. (1999) "La influencia del sistema de recursos humanos en los resultados organizativos: una aplicación empírica de la teoría de la empresa basada en los recursos". IX Congreso Nacional de ACEDE.

SABATER MARCOS, ANA M. (2005) "Efecto de la negociación colectiva en el mercado continuo español: un análisis empírico". Revista Española de Financiación y Contabilidad. Volumen XXXIV, nº 126. Pp 787-790.

SABATER MARCOS, ANA M. Y LAFFARGA BRIONES, J. (2006) "¿Observa el mercado español las relaciones laborales ente empresarios y sindicatos? Un análisis empírico para el mercado continuo". Revista española de financiación y contabilidad, Vol. XXXV, nº 128. Pp 57-86.

SABATER MARCOS, ANA M. Y LAFFARGA BRIONES, J. (2008) "Información estratégica en la negociación colectiva: evidencia empírica para el mercado continuo español". Revista española de financiación y contabilidad, Vol. XXXVII, no 138. Pp 315-352.

SABATER MARCOS, ANA M. Y LAFFARGA BRIONES, J. (2008) "Spillover effect upon a labor event: an empirical analysis for the Spanish continuous market". Revista española de financiación y contabilidad, Vol. XXXVII, no 140. Pp 633-664 
SABATER MARCOS, ANA M. Y LAFFARGA BRIONES, J. (2011) "An empirical analysis of labor agreements on Spanish Stock Market". Investment Management and Financial Innovations, Volume 8, Issue 2. Pp 26-38.

SAENG KIM, W. Y LYN, E. (1991) "Going private: corporate restructuring under information asymmetry and agency problems". Journal of Business Finance \& Accounting. 18 (5). Septiembre 1991. Pp 637-649.

SAEZ OCEJO, J. L. (1998) "Contabilidad creativa y factores determinantes". Técnica Contable no 596-597. Pp 629-636. AgostoSeptiembre 1998.

SALA FRANCO Y OTROS.(1997) "Guía práctica de la negociación colectiva". Tirant la Blanch. 2a Edición. Valencia. 1997.

SALAS FUMAS, V. (1996) "Economía de la empresa: decisiones y organización". 2a edición. Barcelona. Ariel.

SALAS FUMAS, V. (1999) "Poder, relaciones y complementariedades en la teoría de la empresa". Papeles de Economía Española. № 78-79. Pp 215.

SALINAS MOLINA, F. (1998) "El despido objetivo". Ponencia presentada en la Jornada Técnica sobre la Reforma Laboral, celebrada en Barcelona en Abril de 1998. 
SAN MIGUEL, J. (1976) "Human information processing and its relevance to accounting: a laboratory study". Accounting, Organizations and Society. Vol 1. n 4. Pp 353-373.

SANZ VALLE, R. Y SABATER SÁNCHEZ, R. (1999) "Perspectiva universalista en la gestión de recursos humanos y sus efectos sobre los resultados de la empresa, una aplicación empírica". IX Congreso Nacional de ACEDE.

SCHAPPE, R. "Matrimonio entre sindicatos y dirección: cómo comprender y evitar el fracaso". Harvard Deusto Business Review. Pp 50-57.

SCHWAN, E. (1976) "The effects of human resource accounting data on financial decisions: an empirical test". Accounting, Organizations and Society. Vol 1. n²/3. Pp 219-237.

SEILER, E. (1984) "Piece rate vs. time rate: the effect of incentives on earnings". The Review of Economics and Statistics. Vol LXVI. $\mathrm{n}^{\circ} 3$. Agosto 1984. Рp 363-376.

SHERER, M.; SOUTWORTH, A. Y TURLEY, S. (1981) "An empirical investigation of disclosure usage and usefulness of corporate accounting information". Managerial Finance. Vol 7. n² 2. Pp 6-11.

SIMON, H. (1951) "A formal theory of the employments relationship". Econometrica. Vol 19. Pp 293-305. 
SLOAN, R. (1993) "Accounting earnings and top executive compensation". Journal of Accounting and Economics. 16. Pp 55-100.

SMITH, D. (1976) "The effect of the separation of ownershipo from control on accounting policy decsions". The Accounting Review. Vol LI. $\mathrm{n}^{\circ} 4$. 1976. Pp 707-723.

SOLOMONS, D. (1991) "Accounting and social change: a neutralist view". Accounting, Organizations and Society. Vol 16. n 3. Pp 287-295.

SPARKS, G. Y WILTON, D. (1971) "Determinants of negotiated wage increases. An empirical analysis". Econometrica. Vol 39. $\mathrm{n}^{\circ} 5$. Septiembre. Pp 739-750.

STROTH, L.; BRETT,J.; BAUMANN, J. Y REILLY, ANNE H. (1996) "Agency theory and variable pay compensation strategies". Academy of Management Journal. Vol.39.n³. Pp 751-767.

SUMMERS, L. (1989) "What can economics contribute to social policy? Some simple economics of mandated benefits. American Economic Review (AEA) Papers and Proceedings. Vol 79. $n^{\circ} 2$. Mayo 1989. Pp 177183.

SWIERINGA, R. Y WEICK, K. (1982). "An assesment of laboratory experiments in acoounting". Journal of Accounting Research. vol 20. Suplemento 1982. Pp 56-101. 
TINKER, A.; MERINO, B. Y NEIMARK, M. (1982) "The normative origins of positive theories: ideology and accounting thought". Accounting, Organizations and Society. Vol 7. n 2. Pp 167-200.

TOMCZYK, S.H. (1975) "Financial ratios and the ability to pay wage increases". DBA dissertation. University of Kentucky.

TOMKINS,C.; ROSENBERG, D. Y COLVILLE, I. (1980) "The social process of research: Some reflections on developing a multidisciplinary accounting project.". Accounting, Organizations and Society. Vol 5. n². Pp 247-262.

TRACY, L. Y PETERSON, R. (1986) "A behavioral theory of labor negotiations- how well has it aged". Negotiation Journal. Enero 1986. Pp 93-108.

TRUEMAN, B. Y TITMAN, S. (1988) "An explanation for accounting income smoothing". Journal of Accounting Research. Vol 26. Septiembre 1988. Pp 127-139.

TUA PEREDA, J. (1983) Libro: Principios y Normas de Contabilidad. Instituto de Planificación Contable. Madrid. 1983.

TUA PEREDA, J. (1988) "Evolución del concepto de contabilidad a través de sus definiciones". Revista de Contaduría. Universidad de Antioquia. Septiembre 1988. Pp 11-74. 
TUA PEREDA, J. (1990) "Algunas implicaciones del paradigma de utilidad contable". Revista de Contaduría. Universidad de Antioquia. Marzo 1990. Pp 19-48.

VAN REENEN, J. (1996) "The creation and capture of rents: wages and innovation in a panel of U.K. companies". The quaterly Journal of Economics. Vol.111.n¹.pp 195-226.

WALTON, R. Y MCKERSIE, R. (1974) "Teoría de las negociaciones laborales". Labor, Barcelona.

WANG, C. (1994) "Essays on Information Economics". Julio 1994. Canadá. Tésis.

WATERHOUSE, J.; GIBBINS, M. Y RICHARDSON, A. (1993) "Strategic financial disclosure: evidence from labor negotiations". Conmtemporary Accounting Research. Vol 9. $\mathrm{n}^{\circ}$ 2. Pp 526-550.

WATTS, R. Y ZIMMERMAN, J. (1978) "Towards a positive theory of the determination of accounting standards". The accounting Review. Vol LIII $n^{\circ}$ 1. Enero 1978. Pp 112-134.

WATTS, R. Y ZIMMERMAN, J. (1979) "The demand for and supply of accounting theories: the market for excuses". The Accounting Review. Vol LIV. no 2. Abril 1979. Pp 273-305. 
WATTS, R. Y ZIMMERMAN, J. (1983) "Agency problems, auditing, and the theory of the firm: some evidence". Journal of Law and Economics. Vol XXVI. Octubre 1983. Pp 613-633.

WATTS, R. Y ZIMMERMAN, J. (1990). "Positive acounting theory: a ten year perspective". The Accounting Review. Vol 65. n¹. 1990. Pp 131-156.

WILLIAMSON O.; WACHTER, M. Y HARRIS, J. (1975) "Understanding the employment relation: the analysis of idiosincratic exchange". The Bell Journal of Economics, 6. Pp 250-78.

WILLIANSON, O. (1980) "The organizational of work: a comparative institutional assessment". Journal of Economic Behavior and Organization, 1. Pp 5-38.

WILSON, D.; BUTLER, R.; CRAY, D.; HICKSON,D. J Y MALLORY, G.(1982) "The limits of trade union power in organisational decision making". British journal of Industrial Relations. Vol 20. n 3. 1982. Pp 322341.

WILSON, R. (1968) "The theory of syndicates". Econometrica. Vol. 36. $\mathrm{n}^{\circ}$ 1. Enero 1968. Pp 119-132.

WINDMULLER, J. (1989) "Nueva consideración de la negociación colectiva de los países industrializados". Informes OIT. Ministerio de Trabajo y Seguridad Social. 
WHITTINGTON, G. (1987) "Positive accounting: a review article". Accounting, Business Research. Vol 17. n 68. Pp 327-336.

WOODBURY, S. (1983) "Substitution between wage and nonwage benefits". The American Economic Review. Marzo 1983. Vol 73. no 1 pp 166-182.

YAMAJI, H. (1986) "Collective bargaining and accounting disclosure: an inquiry into the changes in accounting policy". International Journal of Accounting. Vol 22. Pp 11-23.

ZEFF, S. (1985) "Evolución de la teoría contable. La investigación empírica.". Revista de Contaduría. Universidad de Antioquía. Marzo 1985. Pp 25-51. 